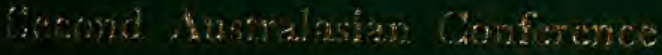

$$
\begin{aligned}
& \text { as }
\end{aligned}
$$

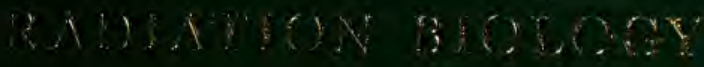

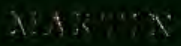

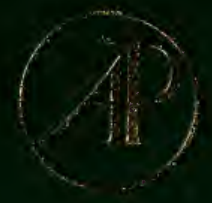




RADIATION BIOLOGY 



\section{RADIATION BIOLOGY}

Proceedings of the Second Australasian

Conference on Radiation Biology held at the University, Melbourne, 15-18 December, 1958

by

THE AUSTRALIAN RADIATION SOCIETY

Editor: J. H. MARTIN

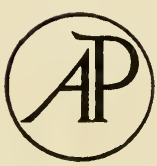

NEW YORK

ACADEMIG PRESS ING., PUBLISHERS LONDON

BUTTERWORTHS SGIENTIFIC PUBLICATIONS 
BL"IERWORTHS PLBIICATIONS LTD,

88 KINGSW.Y, LONDON, W.C.2

U.S.A. Edition published by

ACDENHC PRESS ING. PLBLISHERS

III FIFTH AVENL

NEW YORK 3 , NEW YORK

(C)

The several contributors named on pages ix to $\mathrm{xi}$ 1959

Set in Monotype Baskerville type

Printed in Great Britain by Spottiswoode, Ballantyne $\mathcal{E}^{\circ}$ Co. Ltd. London and Colchester 


\title{
FOREWORD
}

\author{
Sir F. MacFarlane Burnet, O.M., F.R.S.
}

Opening remarks to the Conference, December 15, 1958

\section{INTRODUCTION}

THIs Conference is concerned with the action of ionizing radiation on living cells. Its objectives are purely scientific and, in one sense, it is only indirectly concerned with the human implications of radiobiology.

But in my position, I feel that it is necessary that I should underline those implications. Radiation of the sort we are interested in is perhaps the most two-edged of all weapons. We all know the medical and industrial benefits of the use of X-rays and natural and artificial radio-active substances. And equally we are aware of the dangers that, in one way or another, are associated with atomic radiation.

I shall say nothing about the value and the problems of radio-therapy for cancer and other diseases, though much of the programme will, of course, be relevant to this field.

But I should like to speak for a few minutes on the problem of assessing the dangers of radiation to human beings.

At the present time we are all only too conscious of the dangers of radiationand if there is one practical task for radiobiology it is to provide a realistic understanding of the extent of the danger-and to express this in terms that can be clearly understood by anyone.

It is becoming a common practice in scientific publication to put a summary of conclusions at the beginning of the paper and I think that it will make my position clearer if I start with two simple statements which I believe do express the practical essence of current thought on radiobiological hazards.

1. That a major war fought with nuclear weapons would be an unimaginable calamity, resulting in the complete destruction of Western civilization and the death, directly or indirectly, of probably more than half the human population of the world and a tremendous increase in the burden of genetic damage carried by the survivors. The prevention of such a war is the overriding political and social necessity of our time.

2. That the danger associated with limited exposure to ionizing radiation, whether from cosmic rays and other natural sources, fall-out from test explosions, the medical uses of X-rays, or from work in laboratories and industrial establishments concerned with atomic power, is unimportant in comparison with the ordinary hazards of life.

I should like to elaborate the second of those statements because it is within its field that most of the work to be discussed at this conference will have its human relevance. 
It is the cluty of any medical officer of health to do his utmost to ensure that $n 0$ unnecessary illnesses or deaths should occur within the community for which he is responsible. If he has the final responsibility of a whole nation of 10 million people, he will still regard it as very serious if even five individuals die from bubonic plague, or hydrophobia, from explosion of industrial boilers, or from massive exposure to a source of atomic radiation. These are all things which should never cause death in a country like Australia. If they do, something is wrong which must be righted immediately. But in that same nation approximately 120,000 persons covering every age will die each year from causes distributed over all ages and showing a fairly uniform pattern, so many from cancer, so many from accident, and so on. The vast majority of these are not in any realistic sense of the word preventable.

Death is inevitable and in any community likelihood of death has a characteristic pattern in relation to age. This can be simply expressed for any age as the chance of dying within the next 12 months. At birth, in Australia it is of the order of $1: 40$ but once the first year is past falls steadily till it reaches a minimum at the age of 12 , when it is $1: 2500$. Thereafter it climbs slowly to about 1 per cent, i.e. $1: 100$ at the age of 50 and then progressively more steeply to the end of life.

People of my age know that there is a chance lying between 1 and 2 per cent that they will be dead a year from now. They also know that to drive a car 5000 miles in the year involves a risk of dying by road accident of the order of $1: 1000$ and that if one flies 20,000 miles there is a further risk of the order of $1: 10,000$ of death in an air crash. Neither adds significantly to the ordinary hazards of life and in neither case does the knowledge of the risk modify our behaviour. The product of the risk, multiplied by the number of people in the country, however, is quite large enough to justify plenty of thought and action to maintain and improve road and air safety.

In the radiation field, we have a reasonably accurate knowledge of the dose of radiation that will kill a man within a week or two and we know that to a fair approximation a very large dose of $\mathrm{X}$-rays given for the treatment of ankylosing spondylitis may induce fatal leukaemia in about 1:1000 of the patients treated, the actual likelihood being directly related to the size of the dose. Virtually all the rest is inference. But at least we know that all the changes we talk about, medical diagnostic X-rays, fall-out from bomb tests, etc., involve vastly smaller amounts of radiation than those I have mentioned.

It is a curious situation that one of the major political controversies of the twentieth century, the danger to mankind of radio-active fall-out from bomb tests, cannot be resolved in scientifically acceptable terms-and that in an attempt to clarify the fall-out situation people have been made seriously afraid of undergoing medically necessary X-ray examinations-again without any adequate scientific basis for their fear.

There are many things to be found out about the interactions of ionizing radiation and living cells and $I$ hope that contributions made at this conference will provide much of interest and value. But I am certain that most of us will listen particularly for anything that is relevant to the half-dozen major questions which must be answered if we are ever to resolve our current practical perplexities. At the risk of restating the obvious, I shall put these questions in abbreviated form. 


\section{FOREWORD}

1. Does the genetic effect of radiation show a linear dose-effect relationship down to the levels of natural background and below?

2. If not, how does the genetic effect of relatively small amounts of ionizing radiation on a standard human being vary with the total dosage, its physical quality and the time course of its administration?

3. What is the relative susceptibility to genetic damage of the foetus, the child and the adult?

4. Are the carcinogenic and leukaemogenic effects of radiation due essentially to the same mutagenic processes as are responsible for genetic damage? If so, are secondary 'promoting' factors also concerned in allowing the emergence of overt disease? Or, as Kaplan has suggested, is the whole effect unrelated to mutagenic action of radiation?

5. Whatever the process of carcinogenesis, knowledge on the influence of dose, quality and rate of administration, and of the relative susceptibility at different ages will be needed.

Until these questions can be answered, I believe we are justified in accepting some empirical rules for action:

1. All ionizing radiation is potentially harmful and the degree of exposure should be reduced to the lowest possible level that is consistent with the fulfilment of acceptable medical, industrial or military needs.

2. Exposure to artificial radiation not greater than the dosage always being received from natural sources is of no significance in comparison with normal hazards of life.

3. The potential benefit of any intelligent medical use of X-rays will far outweigh any risk of radiation damage.

4. The accepted international levels of permitted exposure in nuclear laboratories, etc., form a reasonable basis for action.

It is the task of conferences such as this to provide the background of quantitative knowledge that will allow us eventually to replace these empirical rules with scientifically valid recommendations. Only then are we likely to escape from the emotionally charged atmosphere of suspicion, controversy and misunderstanding that seems to rise in a stifling cloud whenever radiation hazards become a topic of political discussion.

I look forward very much to hearing the papers and discussions of this Conference. I am confident that it will help to stimulate research in Australia and aid understanding of the impact of radiobiology on human affairs.

I have much pleasure in declaring the Conference open. 



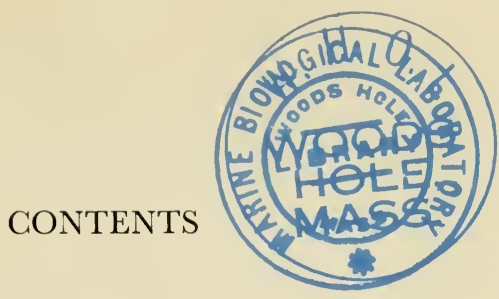

Foreword

1. Radiation Dose. Macroscopic, Microscopic and Sub-Micro-

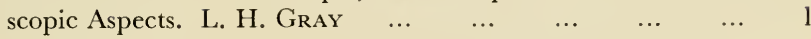

$\begin{array}{llllllllll}\text { Discussion } & \ldots & \ldots & \ldots & \ldots & \ldots & \ldots & \ldots & \ldots & 13\end{array}$

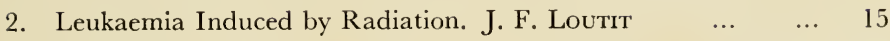

$\begin{array}{llllllllll}\text { Discussion } & \ldots & \ldots & \ldots & \ldots & \ldots & \ldots & \ldots & \ldots & 23\end{array}$

3. Effect of Whole-Body Irradiation on Thymus Function and Lymphocyte Homeostasis. Donald Metcalf $\quad \ldots \quad$.. 26

$\begin{array}{lllllllllll}\text { Discussion } & \ldots & \ldots & \ldots & \ldots & \ldots & \ldots & \ldots & \ldots & 29\end{array}$

4. Radiation Quality and Bone-Marrow Dose in Radiology.

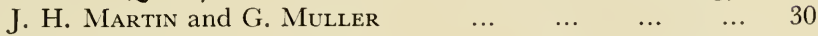

5. Some effects on Lymphoid Cells of Occupational and Accidental

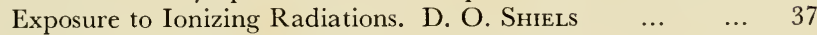

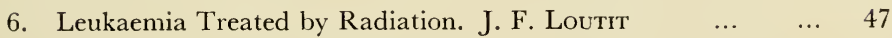

$\begin{array}{llllllllll}\text { Discussion } & \ldots & \ldots & \ldots & \ldots & \ldots & \ldots & \ldots & \ldots & 54\end{array}$

7. Selective Irradiation and Attempted Replacement of Bone Marrow in the Rabbit, Using ${ }^{198} \mathrm{Au}$. J. M. Garvan, E. P.

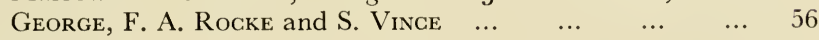

$\begin{array}{lllllllllll}\text { Discussion } & \ldots & \ldots & \ldots & \ldots & \ldots & \ldots & \ldots & \ldots & 66\end{array}$

8. Experiments in Homograft Survival. M. Kent $\quad \ldots \quad \ldots \quad \ldots \quad \ldots \quad 68$

$\begin{array}{lllllllllll}\text { Discussion } & \ldots & \ldots & \ldots & \ldots & \ldots & \ldots & \ldots & \ldots & 71\end{array}$

9. Secondary Radiation Disease Following Heterografting. Peter $\begin{array}{lllllllllll}\text { ILBERY } & \ldots & \ldots & \ldots & \ldots & \ldots & \ldots & \ldots & \ldots & 73\end{array}$

10. An Experimental Study of the Influence of Oxygen on the RadioSensitivity of the Ehrlich Ascites Tumour Cell. L. H. Gray 76

$\begin{array}{lllllllllll}\text { Discussion } & \ldots & \ldots & \ldots & \ldots & \ldots & \ldots & \ldots & \ldots & 84\end{array}$

11. The Action of Ionizing Radiation on Simple Organic Compounds.

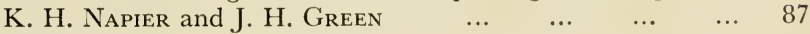

$\begin{array}{lllllllllll}\text { Discussion } & \ldots & \ldots & \ldots & \ldots & \ldots & \ldots & \ldots & \ldots & 93\end{array}$ 
12. The Effect of Beta Radiation on Porphyrin Compounds in

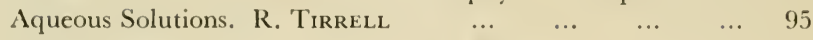
$\begin{array}{lllllllllll}\text { Discussion } & \ldots & \ldots & \ldots & \ldots & \ldots & \ldots & \ldots & \ldots & 102\end{array}$

13. Synthesis of Organic Compounds by Ionizing Radiation. S. Dilli $\begin{array}{lllllllll}\text { and J. H. GreEN } & \ldots & \ldots & \ldots & \ldots & \ldots & \ldots & 103\end{array}$

$\begin{array}{lllllllllll}\text { Discussion } & \ldots & \ldots & \ldots & \ldots & \ldots & \ldots & \ldots & \ldots & 115\end{array}$

14. Strontium in Man and Beast. J. F. Loutri $\quad \ldots \quad \ldots \quad \ldots \quad \ldots \quad 117$

$\begin{array}{lllllllllll}\text { Discussion } & \ldots & \ldots & \ldots & \ldots & \ldots & \ldots & \ldots & \ldots & 125\end{array}$

15. Studies in Detecting Radio-Active Fall-Out. E. C. Winkler $\ldots 127$ $\begin{array}{lllllllllll}\text { Discussion } & \ldots & \ldots & \ldots & \ldots & \ldots & \ldots & \ldots & \ldots & 137\end{array}$

16. Fall-Out Measurements in Australia. L. J. Dwyer, J. H. Martin

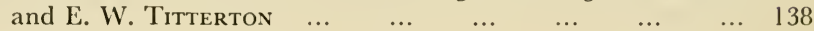
$\begin{array}{lllllllllll}\text { Discussion } & \ldots & \ldots & \ldots & \ldots & \ldots & \ldots & \ldots & \ldots & 145\end{array}$

17. Activity Levels in Relation to Laboratory Design and Practice.

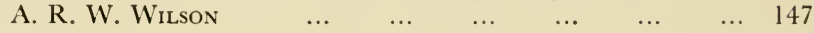
$\begin{array}{llllllllll}\text { Discussion } & \ldots & \ldots & \ldots & \ldots & \ldots & \ldots & \ldots & \ldots & 151\end{array}$

18. The Influence of Oxygen on the Radio-Sensitivity of Cells and $\begin{array}{llllllll}\text { Tissues. L. H. Gray } & \ldots & \ldots & \ldots & \ldots & \ldots & \ldots & 152\end{array}$

19. Radio-Protective Action of 5-Hydroxytryptamine. H. A. S. VAN $\begin{array}{llllllllll}\text { DEN BRENK } & \ldots & \ldots & \ldots & \ldots & \ldots & \ldots & \ldots & 169\end{array}$

$\begin{array}{lllllllllll}\text { Discussion } & \ldots & \ldots & \ldots & \ldots & \ldots & \ldots & \ldots & \ldots & 177\end{array}$

20. Effects of Respired Oxygen on Radio-Protective Action of Certain Amines:

(a) Lethality Studies. H. A. S. van den Brenk and Ruth Moore 179

(b) Rat Lymphocytes (in vivo). Ruth Moore and H. A. S. van DEN BRENK

21. The Life-Span of Mutagens Produced in Cells by Irradiation. $\begin{array}{llllllllll}\text { W. D. JacksoN } & \ldots & \ldots & \ldots & \ldots & \ldots & \ldots & \ldots & 190\end{array}$

22. Radio-Active Fission-Products in The Human Food Chain.

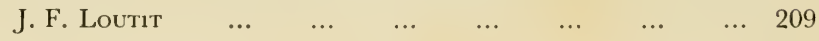
$\begin{array}{lllllllllll}\text { Discussion } & \ldots & \ldots & \ldots & \ldots & \ldots & \ldots & \ldots & \ldots & 218\end{array}$

23. Injury and Recovery in Neutron-Irradiated Animals. HowARD H. Vogel, Jr., Donn L. Jordan and Samuel Lesher ... $\quad \ldots 221$ $\begin{array}{lllllllllll}\text { Discussion } & \ldots & \ldots & \ldots & \ldots & \ldots & \ldots & \ldots & \ldots & 234\end{array}$ 


\section{CONTENTS}

Page

24. Immunological Studies on Lethally and Sub-Lethally Irradiated Animals. G. J. V. Nossal and Lois Larkin $\quad \ldots \quad \ldots \quad \ldots \quad \ldots 236$

$\begin{array}{lllllllllll}\text { Discussion } & \ldots & \ldots & \ldots & \ldots & \ldots & \ldots & \ldots & \ldots & 243\end{array}$

25. Short-Term Studies of the Effect of Radioiodine Therapy for Thyrotoxicosis on the Thyroidal Iodide Clearance Rate. I. D. Thomas, T. H. Oddie and F. F. Rundle $\quad \ldots \quad$. $\quad 244$

$\begin{array}{lllllllllll}\text { Discussion } & \ldots & \ldots & \ldots & \ldots & \ldots & \ldots & \ldots & \ldots & 245\end{array}$

26. Effect of X Irradiation on the Mouse Foetus. A. S. Fraser and $\begin{array}{lllllllll}\text { R. J. Hall } & \ldots & \ldots & \ldots & \ldots & \ldots & \ldots & \ldots & 248\end{array}$ $\begin{array}{lllllllllll}\text { Discussion } & \ldots & \ldots & \ldots & \ldots & \ldots & \ldots & \ldots & \ldots & 251\end{array}$

27. The Spectrum of Sensitivity of Drosophila Germ Cell Stages to X

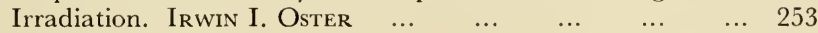
$\begin{array}{lllllllllll}\text { Discussion } & \ldots & \ldots & \ldots & \ldots & \ldots & \ldots & \ldots & \ldots & 266\end{array}$

The Genetic Basis of X-Ray Induced Somatic Damage. IRwIN I. $\begin{array}{llllllllll}\text { OStER } & \ldots & \ldots & \ldots & \ldots & \ldots & \ldots & \ldots & \ldots & 268\end{array}$

28. Imperfections Induced in Solids by Fast-Particle Irradiation. $\begin{array}{lllllllll}\text { P. G. Klemens } & \ldots & \ldots & \ldots & \ldots & \ldots & \ldots & \ldots & 272\end{array}$ $\begin{array}{llllllllll}\text { Discussion } & \ldots & \ldots & \ldots & \ldots & \ldots & \ldots & \ldots & \ldots & 281\end{array}$

29. Radiobiological Mechanisms at the Cellular Level:

Lines of investigation which have been opened up by recent

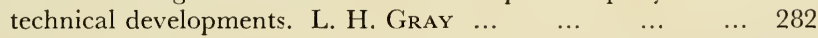

$\begin{array}{lllllllllll}\text { Discussion } & \ldots & \ldots & \ldots & \ldots & \ldots & \ldots & \ldots & \ldots & 298\end{array}$ 



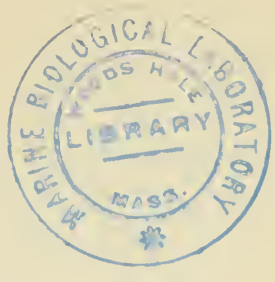

\title{
RADIATION DOSE-MAGROSCOPIC, MICROSGOPIC AND SUB-MICROSCOPIC ASPEGTS
}

\author{
L. H. Gray \\ British Empire Cancer Campaign Research Unit in Radiobiology, \\ Mount Vernon Hospital, Northwood, England
}

For the purpose of evaluating the physical, chemical, and biological effects of the interaction of radiation with matter, it is necessary to have some measure of the radiation, or its interaction, in physical terms.

The effects of radiation on a cell, or a tissue, are, of course, due to the radiation which is absorbed by the cell and independent of the radiation which happens to pass through the cell. It follows that for biological purposes the most suitable physical quantity can be defined in terms of energy imparted by ionizing particles to matter at the place of interest. It is in terms of this quantity that absorbed dose has been defined internationally ${ }^{1}$.

'Report of the International Commission on Radiological Units and Measurements (I.C.R.U.) 1956. Handbook 62.

1.1. Absorbed dose of any ionizing radiation is the energy imparted to matter by ionizing particles per unit mass of irradiated material at the place of interest.

1.2. The unit of absorbed dose is the rad. $1 \mathrm{rad}$ is $100 \mathrm{ergs} / \mathrm{g}$.'

There is another physical quantity which is useful for the description of radiological phenomena, namely the photon or neutron energy which would, through interaction with matter, become transformed into the energy of ionizing particles originating in a given quantity of matter, divided by its mass. This quantity has not hitherto been explicitly defined or named by the International Commission. There might be certain advantages in introducing such a definition to describe the interaction between radiation and matter quite generally, in terms of energy and mass, in some such manner as that suggested above. As this is at present under consideration by the Commission, it would be inappropriate to discuss it further here. It will readily be seen that in the restricted case of the interaction of photon radiation with air, this quantity is essentially that which has been defined by the Commission as 'exposure dose'. It is the quantity of which the roentgen is a unit. The relation between absorbed dose and exposure dose, as at present defined, has been discussed elsewhere ${ }^{2}$.

The energy defined by the absorbed dose is imparted to matter in the form of energy transfers between the moving charged particle and orbital electrons. These transfers result, in the first instance, in molecular excitation and ionization, and secondarily, in chemical change and heat. 
The absorbed energy is usually about equally divided between ionization and excitation, but we have as yet no precise information concerning the relative magnitudes of these two forms of energy transfer in condensed systems. In certain gases, rather accurate information is available, and it is the fact that the average energy, $W$, expended by ionizing particles per ion-pair formed in gases is nearly independent of the speed of the particles, within very wide limits, which has made ionization a useful measure of absorbed energy.

By the application of the cavity theory of ionization, and the use of appropriate physical constants ${ }^{1}$, the absorbed dose in a solid or liquid may be inferred from a measurement of gas ionization in a small cavity with an uncertainty which only slightly exceeds the uncertainty in our knowledge of I1. The value of $W$ for air which is recommended by the International Commission, is $34 \mathrm{eV}$ for $\mathrm{X}$ - and $\gamma$-ray dosimetry, and $35 \mathrm{eV}$ for neutron dosimetry. Table 1, compiled by Boag ${ }^{3}$, shows the considerable measure of agreement between the recent determinations of $W$.

Table 1. The average energy expended by electrons per ion-pair formed in air

\begin{tabular}{|c|c|c|c|}
\hline Author & Radiation & $\begin{array}{l}\mathrm{I} \text { air } \\
\mathrm{eV}\end{array}$ & $\begin{array}{c}\text { Standard error } \\
\mathrm{eV}\end{array}$ \\
\hline Emerya & & $33 \cdot 5$ & Not given \\
\hline Gross et al.b & ${ }^{35} \mathrm{~S} \beta$ & $33 \cdot 6$ & 0.3 \\
\hline Bay et al.c & ${ }^{35} \mathrm{~S} \beta$ & $33 \cdot 7$ & $0 \cdot 3$ \\
\hline Barberd & $\begin{array}{l}\text { I to } 35 \mathrm{MeV} \\
\text { electrons }\end{array}$ & $33 \cdot 8$ & $1 \cdot 2$ \\
\hline Jesse and Sadauskise & ${ }^{3} \mathrm{H} \beta$ & $33 \cdot 9$ & Not given \\
\hline,,,$\quad$, & ${ }^{63} \mathrm{Ni} \beta$ & $34 \cdot 0$ & Not given \\
\hline Weiss and Bernsteinf & $2 \mathrm{MeV}$ X-rays & $33 \cdot 9$ & $0 \cdot 8$ \\
\hline Bernier et al.g & ${ }^{60} \mathrm{Co} \gamma$-rays & $33 \cdot 0$ & $0 \cdot 3$ \\
\hline Skarsgard et al.h & $22 \mathrm{MeV}$ X-rays & $32 \cdot 8$ & $0 \cdot 6$ \\
\hline
\end{tabular}

a. Emery, E. W. Brit. J. Radiol. N.S. 29 (1956) 370

b. Gross, W., Wingate, C. and Failla, G. Radiation Res. 7 (1957) 570

c. Bay, Z., Mann, W. B. Seliger, H. H. and Wyckoff, H. O. Radiation Res. 7 (1957) 558

d. Barber, W. C. Phys. Rev. 97 (1955) 1071

e. Jesse, W. P. and Sadauskis, J. Phys. Rev. 97 (1955) 1668

f. Weiss, J. and Bernstein, W. Phys. Rev. 103 (1956) 1253

g. Bernier, J. P., Skarsgard, L. D., Cormack, D. V. and Johns, H. E. Radiation Res. 5 (1956) 613

h. Skarsgard, L. D., Bernier, J P., Cormack, D. V. and Johns, H. E. Radiation Res. 7 (1957) 217

Since the difference between the mean of these experimental values and $34 \mathrm{eV}$ is still doubtfully significant, and the precise evaluation of $\mathrm{W}$ for particles of different speed is still under investigation in a number of laboratories, the International Commission recommends that the value for $I W$ of $34 \mathrm{eV}$ should still be used in the interests of uniformity.

When we attempt to analyse dose response relationships in biological materials account has to be taken of the fact that energy is not delivered uniformly to matter, but discontinuously along the tracks of individual ionizing particles. Nearly 50 years ago C. T. R. Wilson ${ }^{4}$, who celebrates his 90th birthday this year, made his first cloud chamber expansion in the presence of X-rays, and wrote, 'with little expectation of success, and in making an expansion of the proper magnitude for condensation on the ions while the 


\section{H. GRAY}

air was exposed to the rays, I was delighted to see the cloud chamber filled with little wisps and threads of clouds-the tracks of electrons, ejected by the action of the rays'. Photographs of these tracks, scaled down in the ratio of the electron stopping powers of gas and tissue, still provide us with the best available information as to the approximate distribution of ionizing events in matter exposed to all types of ionizing radiation. We are still not too sure of the precise value of the scaling factor because we do not know the exact value of the average energy expended per ion-pair produced in condensed systems. Moreover, these photographs tell us nothing about the location of the excited molecules which occur along the tracks with greater frequency than the ions. Nevertheless, photographs of the type reproduced in Figures 1 and 2

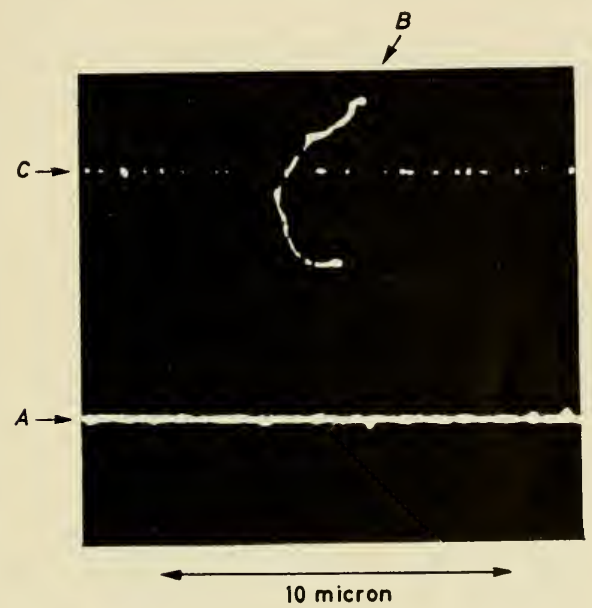

Figure 1. A, proton projected by a neutron; B, slow electron (20 kV) $\mathrm{X}$-ray; C, fast electron $(200 \mathrm{kV}) \gamma$-ray

suffice as a basis for the discussion of the physical factors to which differences between biological response to equal doses delivered by fast and by slow ionizing particles must be related. They provide us with a picture of the dose distribution within the living cell at the level of resolution of the electron-microscope.

The most obvious features of such pictures are the large amounts of empty space and the comparatively small number of particles which contribute to the energy deposited within a cell exposed to moderate doses of radiation. It is also important to note that the slower the particle, the higher the rate of loss of energy along the track, and the smaller the total number of tracks which contribute to a given dose. This has important biological consequences.

Consider, for example, the nucleus of a cell about 10 microns in diameter exposed to $25 \mathrm{rad}$ of soft $\mathrm{X}$ radiation $\left(\mathrm{Ag}_{\mathrm{K}}\right)$. The ionizing particles in this case will be photo-electrons having an energy of $21 \mathrm{kV}$ and range slightly 


\section{R.IDI ITION DOSE}

smaller than the diameter of the nucleus. The dissipation of $21 \mathrm{KeV}(3 \cdot 4$ $\left.10^{-8} \mathrm{ergs}\right)$ in a sphere 10 microns in diameter represents an energy dissipation of 67 ergs per g, or 0.67 rad. It therefore requires $\frac{25}{0.67}$, or approximately

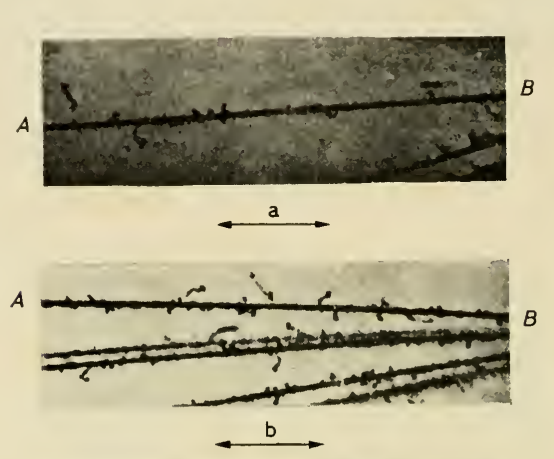

$\mathrm{MeV}$

7. 68

7.68
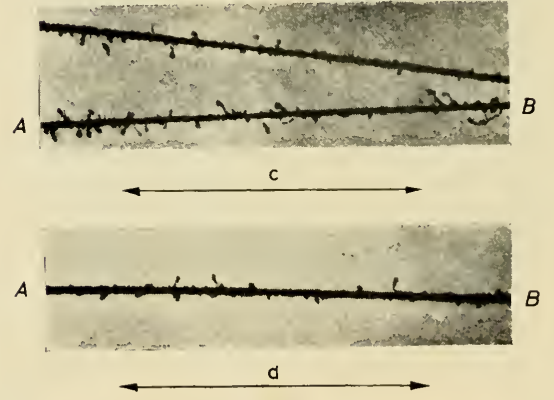

$2 \cdot 63$

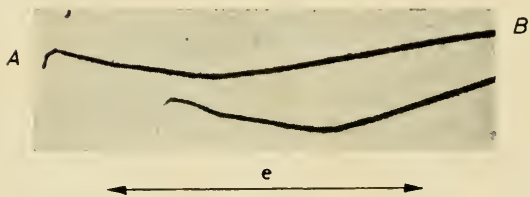

$B$

0.17

Figure 2. Wilson cloud chamber photographs of $\alpha$ particles showing $\delta$-rays

(Reproduced by kind permission of T. Alper from Z. Phys. 76 (1932) 172)

36 particles, to produce a dose of $25 \mathrm{rad}$. If we consider a large number of nuclei exposed to this dose, the number of photo-electrons crossing individual nuclei will be distributed about the mean, in accordance with the Poisson formula, and the standard deviation in the number of particles per nucleus 


\section{H. GRAY}

will be $\sqrt{ } 36-(6)$. There will thus be appreciable and possibly important differences between the quantities of energy dissipated in each nucleus, but the chance that any given nucleus altogether escapes ionization is $\mathrm{e}^{-36}$, which is quite negligible. Suppose, on the other hand, that the total dose were that corresponding to the maximum permissible weekly exposure, namely $0 \cdot 3$ rad, the mean number of particles will then be $\frac{0.3}{0.67}=0.45$ and no energy at all will be deposited in a fraction $\mathrm{e}^{-\mathbf{0 . 4 5}}$, or 64 per cent of the nuclei. Again, if the total dose were $25 \mathrm{rad}$ but the radiation were $\alpha$ radiation instead of $\mathrm{X}$ radiation, the nuclei would be traversed by an average of one particle and $e^{-1}$, or 37 per cent of the nuclei would be unaffected. Thus, whether or not the statistical aspects of dose are important in any given case would be dependent on:

(1) the size of the element of the tissue under consideration,

(2) the magnitude of the dose, and

(3) the type of radiation.

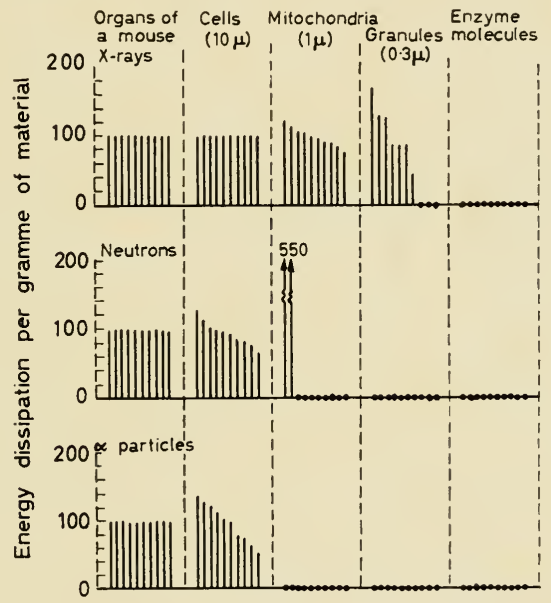

Figure 3

Figure 3 shows the actual estimated amount of energy deposited in each of 10 elements of tissue of the same size when exposed to $100 \mathrm{rad}$ of X-rays, neutrons, or $\alpha$-particles respectively. It is evident that in general 10 mitochondria or smaller particles could be selected at random from a group exposed to $100 \mathrm{rad}$ of $\alpha$-particles, and none would have been ionized. In the case of objects exposed to neutrons, a similar situation obtains for particles of $0.3 \mu$ in diameter and less. In the case of $\mathrm{X}$-rays, the critical size in relation to the dose of $100 \mathrm{rad}$ occurs at the level of macromolecular dimensions.

The above statements all refer to the direct deposition of energy by ionizing particles within the objects under consideration. Some of the energy 
transfers between the ionizing particle and orbital electrons give rise to the production of free radicals and to new stable molecular configurations. A proportion of these may be able to diffuse away from the track to distances determined by their lifetime and chemical reactivity. They can, in principle, react selectively with certain types of biological molecule, thus affecting a much larger proportion of these particular kinds of molecule than can be directly ionized by the moving particle. It is known that such indirect inactivations take place in dilute aqueous solutions of enzymes, desoxyribose nucleic acid (DNA) and other molecules of biological importance. We have only meagre evidence as to the extent in which such indirect inactivations take place in the living cell. Hutchinson and his colleagues ${ }^{5,6}$ have concluded that in the living yeast cell the effective diffusion range of products formed by ionizing particles is of the order of $30 \mathrm{~A}$. Thus, a dehydrogenase molecule which has a radius of $36 \mathrm{~A}$ is inactivated by energy deposited within a region about twice its own volume, and Co-enzyme $A$, of radius $6 \AA$, by energy deposited within 60 times its own volume. Such allowances for indirect inactivation do not significantly alter the statistical aspects of dose for any structure larger than an enzyme molecule.

Biological response may be influenced by dose rate as well as by dose. On a macroscopic scale, a cell irradiated at constant dose rate is being continuously exposed to injurious agents and a level of damage is reached which is a balance between the rate of injury and the rate of recovery. There is, however, a statistical aspect of dose rate as well as dose. In terms of particles, a volume element of the cell is discontinuously affected by events which are randomly distributed in time as well as in space. A dose-rate dependence may thus arise from interactions between successive particles which pass through the same volume element. These interactions may be at the chemical level, in which case the time constant which describes the dose-rate dependence will be related to the lifetime of intermediate species, as discussed by Lea ${ }^{7}$, and exemplified by the experiments of Chapiro ${ }^{8}$, Ghormley ${ }^{9}$, Sutton and Rotblat ${ }^{10}$, and others.

Alternatively, the time constant may be related to cell metabolism, as is thought to be the case when aberrant chromosome configurations are produced by the union of two or more tracks produced by different ionizing particles ${ }^{11,12,13}$. Clearly, in the case of any form of biological damage which arises in a uniform population of cells from the action of a single ionizing particle, biological response cannot be dose-rate dependent. Doserate dependence may, however, be observed even when injuries are induced by single particles if the population itself is heterogenous and changing with time in such a way that the distribution in sensitivity among the individual cells depends on the duration of exposure.

One example of the influence of dose rate on biological response is given in Figure $4(a)$ which reproduces the experimentally observed growth inhibition in Vicia roots exposed to $\gamma$ radiation at different dose rates. Each member of the family of curves corresponds to a constant exposure time. It is seen that a given dose was most effective when delivered in $8 \mathrm{~min}$. Longer exposures were less effective, but prolongation of the duration of exposure from 12 to 24 hours resulted in no further decrease in biological effectiveness. It will also be seen that there is an interdependence between dose and dose 


\section{H. GRAY}

rate in that the duration of exposure has no influence on the degree of biological damage sustained by roots exposed to less than about $50 \mathrm{rad}$. The dose required to produce three different levels of biological damage is shown as a function of duration of exposure in curves $A, B$, and $C$, of Figure $4(b)$. A logarithmic plot of minimum growth rate relative to that of control roots (Figure 5) shows that the dose-response relationship is exponential in the case of 12- and 24-hour exposures, but sigmoidal for shorter exposures. The shapes of the sigmoidal curves for both $\mathrm{X}$ and $\gamma$ radiation are dose-rate dependent, but the exponential curve is dose-rate independent, as would be expected for an injury induced by a single particle.

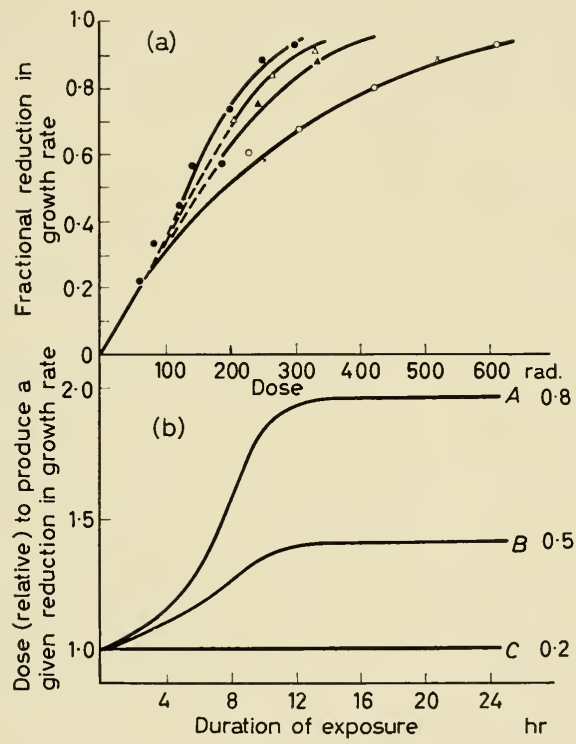

Figure 4. Influence of duration of exposure on $\gamma$-ray damage to roots

The range in duration of exposure studied in biological experiments has generally not been large enough to reveal the transition from dose-rate dependence to dose-rate independence illustrated in Figure $4(b)$. In view of the particle nature of ionizing radiation, dose-rate independence is, however, to be expected on physical grounds for the reasons given earlier whenever cells are exposed to sufficiently small doses at low dose rates. The doses and dose rates to which living organisms are exposed on the count of background radiation $(0.1 \mathrm{rad}$ in a year) would be likely to fall within the dose-rate independent range.

When two different qualities of radiation, given at the same dose rate, are compared, it is frequently found that the doses required to bring about the 


\section{R.IDIATION DOSE:}

same biological response are unequal. If the dose-response curves are of the same shape, i.e. if they may be superimposed by a simple change in the dose scale for one of the radiations, the inverse ratio of the doses which produce identical effects is defined as the relative biological efficiency (R.B.E.) of the two radiations (I.C.R.U. 1956, p. 7). Some seventy-five determinations of R.B.E. of supervoltage $\mathrm{X}$ radiation relative to ordinary deep-therapy $\mathrm{X}$ radiation have recently been reviewed by Kohn ${ }^{14}$. Plotted as a histogram, these observations show a Gaussian distribution with a mean at 0.85 and standard deviation of about $0 \cdot 15$. The difference from unity is small, and it is unfortunately the case that no inconsiderable fraction of the 300 scientific man-years of labour, represented by this histogram, is wasted through inadequate dosimetric precision. After doubtful results have been discarded, there nevertheless remains a substantial body of data indicating an R.B.E. of megavoltage relative to $200 \mathrm{kV} \mathrm{X}$ radiation of about $0 \cdot 8$. This is indicated

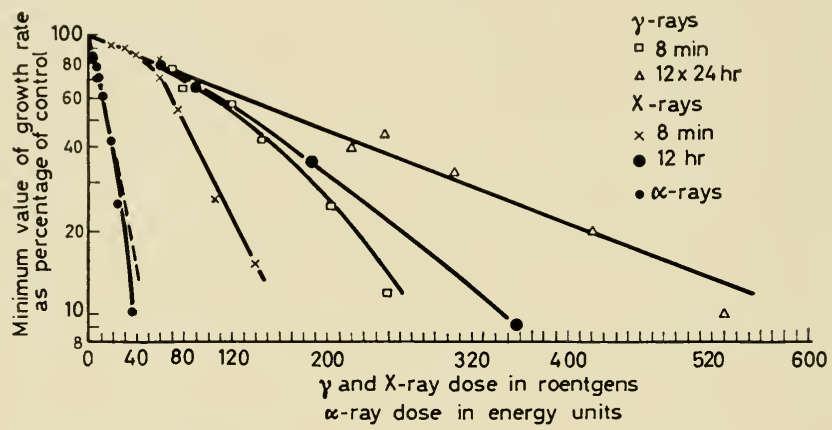

Figure 5. Inhibition of growth produced by $\delta, \mathrm{X}$ and $\alpha$ radiation

by the very careful work of Kohn himself, and his colleagues in San Francisco ${ }^{15}, 16$, and of a group of investigators at the Christie Hospital, Manchester ${ }^{17}$.

Large differences in R.B.E. are only found when radiations of very different quality are compared, e.g. when $\mathrm{X}$ and $\gamma$ radiation on the one hand is compared with neutron or $\alpha$ radiation on the other. Figure 5 shows a family of experimental curves for growth inhibition by $\alpha$-rays, $\mathrm{X}$-rays, and $\gamma$-rays ${ }^{18}$. The $\alpha$-ray curve is dose-rate independent over the range investigated. The X-and $\gamma$-ray curves have already been discussed in connection with dose-rate dependence. It is evident that in this case R.B.E. of any two radiations cannot be represented by a single parameter. A horizontal line, representing the growth rate ratio of irradiated to control roots of $0 \cdot 8$, intersects the curves in a series of doses which have quite different ratios from the intersections with a horizontal line at the $0 \cdot 15$ level. R.B.E. is thus seen to be a function of dose and dose rate. It is also a function of the physiological condition of the cells and the oxygen tension in their environment at the time of irradiation. Since the effects of densely ionizing particles are much less influenced by oxygen tension than those produced by $\mathrm{X}$ or $\gamma$ radiation, 


\section{H. GRAY}

larger values of R.B.E. are observed under anaerobic than under aerobic conditions. This is exemplified by Table 2 which shows the influence of oxygen tension on the $\mathrm{R}$. B.E. of $\alpha$ radiation relative to $\mathrm{X}$ radiation with respect to growth inhibition in Vicia roots.

Table 2

Influence of oxygen tension on R.B.E. of $\alpha$ radiation and $\mathrm{X}$ radiationa, $\mathrm{b}$

\begin{tabular}{lrrlllll}
\hline Oxygen tension mm Hg & 0 & 0.5 & 1 & 2 & 5 & 20 & 150 \\
R.B.E. & 11.8 & $8 \cdot 6$ & $7 \cdot 7$ & 6.9 & 5.8 & 4.9 & 4.5
\end{tabular}

Iicia growth inhibition: $\alpha$ radiation relative to $\mathrm{X}$ radiationa, $\mathrm{c}$

\begin{tabular}{|c|c|c|c|c|c|}
\hline \multirow{3}{*}{$\begin{array}{c}\text { X-ray } \\
\text { dose } \\
(\mathrm{r})\end{array}$} & \multirow{3}{*}{$\begin{array}{l}\text { Level } \\
\text { of } \\
\text { damage }\end{array}$} & \multicolumn{4}{|c|}{ R.B.E. } \\
\hline & & Aer & & Anae & \\
\hline & & High dose rate & Low dose rate & High dose rate & Low dose rate \\
\hline $\begin{array}{r}30 \\
150\end{array}$ & $\begin{array}{l}10 \% \\
70 \%\end{array}$ & $\begin{array}{r}12 \cdot 5 \\
4 \cdot 5\end{array}$ & $\begin{array}{c}12 \cdot 5 \\
\text { up to } 12 \cdot 5\end{array}$ & $\begin{array}{l}33 \\
12\end{array}$ & $\begin{array}{c}33 \\
12-33\end{array}$ \\
\hline
\end{tabular}

Tradescantia chromosome damage: $\mathrm{D}-\mathrm{D}$ neutrons relative to $\mathrm{X}$ radiationd

\begin{tabular}{cccc}
\hline $\begin{array}{c}\text { X-ray } \\
\text { dose } \\
(\mathbf{r})\end{array}$ & $\begin{array}{c}\text { Level } \\
\text { of } \\
\text { damage }\end{array}$ & R.B.E. (High dose rate) \\
50 & $10 \%$ & $8 \cdot 9$ & Anaerobic* \\
180 & $50 \%$ & $4 \cdot 2$ & 19 \\
\hline
\end{tabular}

* Assuming maximum aerobic to anaerobic sensitivity for neutrons $=1 \cdot 4$.

a. Gray, L. H. and Scholes, M. E. Brit. J. Radiol. N.S. 24 (1951) 82

b. Kihlman, B. A. Exp. Cell Res. 14 (1958) 639

c. Thoday, J. II. and Read, J. Nature, Lond. 160 (1947) 608

d. Conger, A. D., Randolph, iI. L., Sheppard, C. W. and Luippold, H. J. Radiation Res. 9 (1958) 525

Table 2 also presents published data for growth inhibition of Vicia roots and chromosome damage in Tradescantia microspores, from which it may be seen that according to the level of radiation damage, the dose rate, and the oxygen tension, the R.B.E. of a densely ionizing radiation relative to $\mathrm{X}$ radiation for a single type of biological response may have any value between 4.5 and 33 in the case of roots exposed to $\alpha$ and $\mathrm{X}$ radiation, or between $4 \cdot 2$ and 19 in the case of Tradescantia microspores exposed to neutrons and $\mathrm{X}$ radiation.

On a purely empirical basis, the R.B.E. of all types of ionizing radiation may be correlated with the rate of loss of energy (LET) along the tracks of the individual ionizing particles. This ratio varies in the extreme by a factor of a little over 1000 from 0.2 to $250 \mathrm{ekV} / \mu$, as between the fastest and the slowest particles commonly employed in radiobiological experiments. In practice, biological materials cannot readily be exposed to a dose of radiation 


\section{RADIATION DOSE}

contributed solely by particles of either extreme of LET. Even monochromatic sources of $X, \gamma$, and neutron radiation give rise to spectra of secondary particles, and each of these particles loses energy at a continuously varying rate before coming to rest. The particles, therefore, contribute to the dose at a continuously varying LET. Typical LET spectra resulting from the exposure of biological material to ${ }^{60} \mathrm{Co} \gamma$-rays, $200 \mathrm{kV}$ X-rays, $2 \mathrm{MeV}$ neutrons, and polonium $\alpha$-particles, are shown in Figure 6. Even these spectra fail to give the full picture of energy loss in one important respect, since they take no account of the secondary ionizing particles of low energy ( $\delta$-rays) which are set in motion along the tracks of the primary particles. These $\delta$-rays are seen very clearly as little spurs in all the cloud chamber photographs of Figure 2, except the lowest one, which depicts energy loss along the last micron of an $\alpha$-particle track where the $\delta$-rays have so little energy that their ionization merges with that of the primary particle at the level of resolution

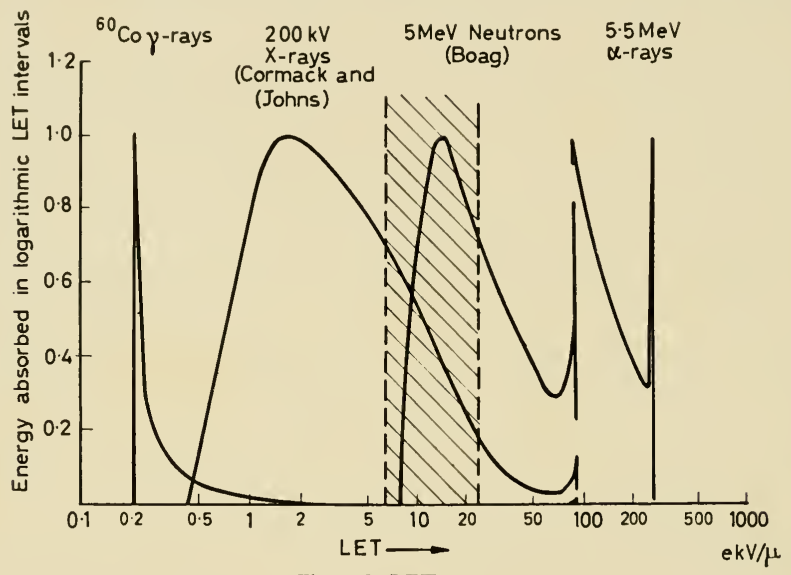

Figure 6. LET spectra

(Reproduced by kind permission of P. Howard-Flanders)

of the photograph. In the case of $\alpha$-rays, the accompanying $\delta$-rays represent a small contribution of the dose from particles of much lower LET than that of the main column of ionization. In the case of $\mathrm{X}$ and $\gamma$ radiation the reverse is the case. The $\delta$-rays represent a contribution of some 10 per cent to the total dose from particles of very much higher LET - a contribution which, though small, is in many cases of very great importance since it falls in a range of LET which has an extremely high R.B.E. Lea ${ }^{19}$ in fact concluded that chromosome structural changes induced in Tradescantia microspores by $\mathrm{X}$ and $\gamma$ radiation can be ascribed almost entirely by such very slow electrons. The range of LET values covered by $\delta$-rays is roughly that of the band between the broken vertical lines in Figure 6 .

Attempts have been made ${ }^{20}$ to compute LET spectra which take account of the $\delta$-rays, i.e. to derive distributions of dose in LET for material exposed to some of the more common sources of $\mathrm{X}$ and $\gamma$ radiation. These show the 
extent to which the differences in biological effectiveness, which might have been expected on the basis of spectra such as those of Figure 6, become blurred when the $\delta$-rays are taken into account, but they are unsatisfactory on account of an unavoidable arbitrariness in the definition of a $\delta$-ray. Burch $^{20}$, for example, includes as $\delta$-rays all particles which have an initial energy greater than $100 \mathrm{eV}$, which implies that clusters of three or more ionpairs are classified as high LET particles. It would seem to me that the close association of more than three ion-pairs are needed to give rise to chemical or biological effects which are characteristically different from those produced by more widely spaced ion-pairs.

Lea, from a study of the R.B.E. of different radiations with respect to the production of chromosome structural damage in Tradescantia microspores concluded that in order to produce a chromatid break a particle must satisfy two criteria; it must have a LET at least as great as $6 \mathrm{ekV} / \mu$, and a range of at least $0 \cdot 1 \mu$. These criteria ensure that a particle can cross a chromatid thread and will leave at least $0.6 \mathrm{ekV}$ of energy in the material of the chromosome in the course of its transit. In terms of Lea's estimates of the range and rate of loss of energy by slow electrons, these criteria imply that the effective electrons are those with an energy between about 1.5 and $2 \cdot 8 \mathrm{ekV}$. These conditions are satisfied by the 'tail' of the track of every electron of energy greater than $1.5 \mathrm{ekV}$, and in addition by a proportion of the $\delta$-rays generated along the entire length of a fast electron track. A few years ago I thought it might be of interest to calculate, for monochromatic photon beams of different energy, the proportion of the total dose which satisfies criteria of this kind. Details of such calculations are laborious and only approximate. They have been published elsewhere ${ }^{21,22}$. Figure 7 shows the results obtained in one such calculation. The ordinate $\eta$ is the proportion of the dose contributed by energy losses which satisfy the condition $0.5<Q$ $<3.0 \mathrm{ekV}$, and is shown as a function of the primary photon energy. The curves for hexane, water, and chloroform, differ on account of the increasing proportion of the total energy which is contributed by photo-electrons from the heavier elements oxygen and chlorine. The very pronounced hump in the curves for water and hexane is an unexpected finding. In terms of the extreme assumption that energy loss of the kind considered has unit efficiency for a particular kind of chemical or biological damage (e.g. chromosome breakage) and all radiations of lower LET have zero efficiency, the quantity $\eta$ represents the apparent mean efficiency of monochromatic $\mathrm{X}$ radiation as a function of photon energy. Most practical sources of $\mathrm{X}$ radiation have a fairly broad spectrum, as shown at the foot of Figure 7. It will be seen, however, that the peak of emission from a tube operated at $200 \mathrm{kV}$ with an 0.5 $\mathrm{mm} \mathrm{Cu}$ filter, approximately coincides with the peak of the hump for water and hexane. It might happen, therefore, that both lightly filtered and very heavily filtered $200 \mathrm{kV}$ radiation were less effective biologically than moderately filtered radiation. These calculations were, in fact, prompted by a report from Kirby-Smith and Daniels ${ }^{23}$ that $250 \mathrm{kVp}$ X radiation filtered through $3 \mathrm{~mm} \mathrm{Al}$ was 1.33 times as effective as radiation generated at the same kilovoltage but filtered through $4 \mathrm{~mm} \mathrm{Cu}$, in breaking Tradescantia chromosomes.

In conclusion I must add that all I have said regarding the distribution in 


\section{RADIATION DOSE}

space of the energy deposited within biological materials exposed to ionizing radiation, refers only to an initial state. New species are formed locally along the track in high concentrations and will move radially outwards and mingle with one another, in accordance with the laws of diffusion, in times which have been estimated to be $\sim 10^{-7} \sec ^{24}$. Large electric ficlds are suddenly brought into existence by the separation of positive and negative charges ${ }^{25}$. These fields will, at first, influence the movement of electrons and all ionic species, and in a polar medium may break secondary hydrogen bonds and thus lead to disorder in micromolecules and possibly to denaturization of proteins ${ }^{26,27}$. The rapidity of the changes which we believe to be occurring along the path traversed by an ionizing particle is one added difficulty in the

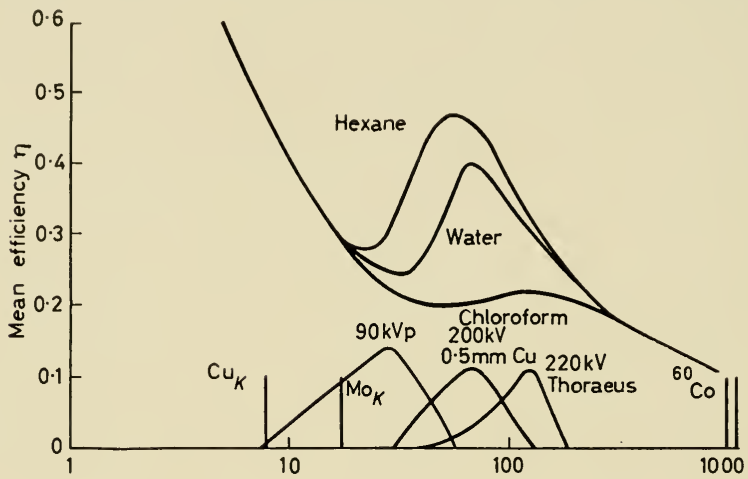

Figure 7. Efficiency $\eta$ as a function of photon energy for a process requiring an energy transfer of amount, $0.5<Q<3.0 \mathrm{ekV}$

already complex task of providing a physical basis for the interpretation of the chemical and biological changes which the irradiation provokes.

\section{REFERENCES}

${ }^{1}$ Report of the International Commission on Radiobiological Units and Measurements (I. C.R.U.), Handbook 62: U.S. Department of Commerce, National Bureau of Standards, Washington, 1956

${ }^{2}$ Gray, L. H. Brit. J. Radiol. N.S. 29 (1956) 355

${ }^{3}$ BoAG, J. W. Communication to the International Symposium on Quantities, Units and Measuring Methods of Ionising Radiations, Rome, 1958-in the press

${ }^{4}$ Wilson, C. T. R. Nobel Lecture, Les Prix Nobel en 1927, p. 6

${ }^{5}$ Hutchinson, F. Radiation Res. 7 (1957) 473

${ }^{6}$ Hutchinson, F., Preston, A. and Vogel, B. Radiation Res. 7 (1957) 465

${ }^{7}$ LEA, D. E. Actions of Radiations on Lizing Cells, 2nd edn: Cambridge University Press, London, 1955, p. 51

${ }^{8}$ Chaptro, A. Radiation Res. 6 (1957) 11

${ }^{9}$ Ghormley, J. A. Radiation Res. 5 (1956) 247

${ }^{10}$ Sutton, H. C. and Rotblat, J. Nature, Lond. 180 (1957) 1332 


\section{H. GRAY}

${ }^{11}$ LeA, D. E. Actions of Radiations on Living Cells, 2nd edn: Cambridge University Press, London, 1955, p. 225

${ }^{12}$ Wolff, S. and Luippold, H. E. Progress in Radiobiology (ed. J. S. Mitchell, B. E.

Holmes and C. L. Smith): Oliver and Boyd, Edinburgh, 1955, p. 217

${ }^{13}$ Beatty, A. V., Beatty, J. W. and Collins, C. Amer. F. Bot. 43 (1956) 328

${ }^{14}$ Kohn, H. I. Progress in Radiation Therapy (ed. F. Buschke): Grune and Stratton, New York, 1958 p. 62

${ }^{15}$ Kohn, H. I. and Gunter, S. E. Radiation Res. 5 (1956) 674

${ }^{16} \mathrm{Kohn}$, H. I. and Kallman, R. F. Radiation Res. 5 (1956) 693

${ }^{17}$ Christie Hospital and Holt Radium Institute Medical Research Council Unit, Symposium on the Relative Biological Efficiency of $4 \mathrm{MeV}$ and $300 \mathrm{kV}$ Radiations: published in Brit. F. Radiol. N.S. 30 (1957) 337

${ }^{18}$ Gray, L. H. and Scholes, M. E. Brit. 7. Radiol. N.S. 24 (1951) 82

${ }^{19}$ LEA, D. E. Actions of Radiations on Lizing Cells, 2nd edn: Cambridge University Press, London, 1955, p. 269

${ }^{20}$ Burch, P. J. R. Radiation Res. 6 (1957) 289

${ }^{21}$ Gray, L. H. Actions Chimiques et Biologiques des Radiation, vol. 1, (ed. M. Haissinsky): Masson et Cie, Paris, 1955, p. 76

${ }^{22}$ Gray, L. H. 7. Chim. phys. 52 (1955) 519

${ }^{23}$ Kirby-Smith, J. S. and Daniels, G. S. Genetics 38 (1953) 375

${ }^{24}$ LeA, D. E. Brit. F. Radiol. N.S. Supplement 1 (1947) 59

${ }^{25}$ Read, J. Brit. F. Radiol. N.S. 22 (1949) 366

${ }^{26}$ Franck, J. and Platzman, R. Radiation Biology, vol. 1 (ed. A. Hollaender): McGraw Hill, New York, 1954, p. 191

${ }^{27}$ Platzman, R. and Franck, J. Symposium of Information Theory in Biology (ed. H. P. Yockey): Pergamon Press, London, 1958, p. 262

\section{DISGUSSION}

Dr. George: Just to clear up one point of my ignorance-In Lea's figure ${ }^{1} T=0$. I do not see why $T=0$ if the negative and positive ions do not have the same distribution.

Dr. Gray: The diagram to which you refer was drawn by Lea to show the diffusion of the hydroxyl radicals and hydrogen atoms which he presumed to be formed from the positive and negative ions respectively. In that diagram time was measured from the moment of formation of these radicals.

DR. MARTIN: Would I be correct in assuming that the hump in your efficiency curve would depend upon the effective target size? It must bear some relationship to the range of $\delta$-rays.

Dr. Gray: Yes, the magnitude of the hump depends on the manner in which you define the quantity $Q$, i.e. on the kinds of energy transfer which are assumed to have unit efficiency. The definition will involve implicitly one assumption about target size and one about the amount of energy which must be deposited in the target to produce the particular biological effect under consideration. I have carried through a calculation for two different definitions of $Q$, and obtained humps of two different sizes, but located at approximately the same value of photon energy. I do not think this was accidental. The hump occurs in the range of photon energies for which the contribution of photo-electrons of the total dose is rapidly diminishing in size relative to that of recoil electrons, and is relatively independent of the particular way in which we define $Q$.

Mr. Green: Dr. Gray, in Figure 7 you showed the differing effects of hexane, water, and chloroform. Did those calculations involve mean atomic numbers for hexane? 


\section{RADIATION DOSE}

Dr. GraY: The approximate values of $\eta$ were calculated separately for photoelectrons and recoil electrons. The values shown in Figure 7 are weighted means which allow for the proportion of energy absorbed by each process in the atoms of hydrogen, oxygen, and chlorine, contained in the molecules liexane, water, and chloroform.

Dr. JAckson: Dr. Gray, having in mind Alexander's idea of direct action in dry tissue, I am wondering whether you think, from the physical standpoint, that the presence or absence of water in the medium can have any influence on $\delta$-ray production.

Dr. GraY: I do not think that the presence or absence of water in the medium is likely to have any great influence on the frequency with which $\delta$-rays of any given energy occur along the track of the primary particle. It may well, however, have an important influence on the distance from the axis of the track at which negative ions are formed by electron attachment, and at which the charge neutralization occurs. These factors will in turn influence the initial distribution of radicals relative to one another, and the chances of recombination as opposed to other forms of interaction. The water may thus, indirectly, have a considerable influence on the limits between which $Q$ must lie in order to achieve a given type of chemical or biological reaction.

DR. Vogel: Is there any place on the LET spectrum where the dose-rate independence is lost, and is it, in your opinion, specifically related to the number of ion-pairs per micron of tissue?

DR. GRAY: It seems that most biological effects which are initiated by the combined action of more than one ionizing particle are dose-rate dependent. If this is so, then the answer to your question depends on three things: (I) the dose, (2) the LET of the jonizing particles, and (3) the size of the structure initially damaged. The higher the LET, the larger the dose at which the transition from dose-rate dependence to doserate independence would be expected to occur. Figure 3 gives information for structures of different size exposed to X-rays, neutrons, and $\alpha$-particles, when in each case the dose is $100 \mathrm{rad}$. By application of the Poisson formula corresponding figures may be derived for any other dose. More accurately, you may use the Poisson formula and Lea's Table $18^{1}$ to calculate the probability that at any given dose level there will be one particle or more than one particle incident on the structure which you have in mind.

Dr. Segal: In the experiments where a plateau of radio-sensitivity was attained at 12 to 24 hours, I take it that the roots were irradiated continuously. How is this experiment affected if the total time were the same, but the dose were delivered in, say, 12 separate periods at hourly intervals?

Dr. Gray: In our experiments the roots were, as you say, irradiated continuously. Twelve separate fractions at hourly intervals should approximate to a 12-hour continuous irradiation, irrespective of the dose rate during each irradiation, since each of the separate doses will be only one twelfth of the total dose, which in the case of growth inhibition in roots is small enough to be in the dose-rate independent region. I would, however, not like to hazard a guess as to the closeness of the identity between highly fractionated and continuous irradiation of other materials. I believe such experiments have been carried out, but I cannot recall a literature reference to quote to you for this information.

\section{REFERENCE}

${ }^{1}$ LEA, D. E. Actions of Radiations on Living Cells: Cambridge University Press, London, 1946, p. 32 


\title{
LEUKAEMIA INDUCED BY RADIATION
}

\author{
J. F. Loutit
}

Medical Research Council Radiobiological Research Unit, Atomic Energy Research Establishment, Harwell, England

DURING the last generation the incidence of leukaemia in the populations of Western Europe and the United States of America has been increasing at a steady rate to more than double its former value. There are many who will incriminate radiation as the cause of this.

Certainly there has been a very steady and great increase in the use of $\mathrm{X}$-rays for medical purposes. However, it is not the increased number of $\mathrm{X}$-ray pictures taken which is important, but the average dose to the population due to the fact. Undoubtedly, over the same period of time there have been considerable technological improvements and the dose delivered to the patient during each exposure must undoubtedly have lessened with time. Only in the last few years have estimates been made for the average population dose. In 1956 the Medical Research Council in its report: The Hazards to Man of Nuclear and Allied Radiations, gave their appreciation of the average dose to the gonads. This was relevant to the understanding of the genetic hazards of radiation, but when we consider leukaemia it is the dose to the haemopoietic tissues in which we are interested. In Table 11 of Appendix $\mathrm{G}$ of the more recent report of the United Nations Scientific Committee on the Effects of Atomic Radiation an estimate has been made of the annual mean dose to the marrow from diagnostic X-ray exposure. In Australia, Martin ${ }^{1}$ had estimated this dose to be about $100 \mathrm{mREM}$. The figure given by the United Nations Scientific Committee was rather lower than that of Martin, but certainly of the same order. However, as we have fewer data on which to calculate restrospectively doses of a generation ago, we cannot yet compare the present state of affairs with the past.

Furthermore, we must always remember that it is not only radiological practice which has changed during the last generation. The statistical data are sufficiently good only for those countries with a high degree of civilization and the conditions of life there have altered markedly during this generation. We must remember that changes in the smoking habits of the population and the change from coal to oil as a source of fuel have been incriminated, rightly or wrongly, for the coincident rise in cancer of the lung. In medical circles one must not forget that in this period we have seen the rise of the sulphonamides, the anti-histamines, the antibiotics and a host of other widely used chemical therapeutic agents. Today life in general is just different from thirty years ago.

However, let us return to radiation. There is now abundant evidence that 
exposure to ionizing radiation does cause an increased incidence of leukaemia. This has been known in the field of animal experimentation for a very long time, but validation now comes from human clinical experience. The following list of evidence is not in historical chronological order.

According to the reports of the Atomic Bomb Casualty Commission, the surviving populations of Hiroshima and Nagasaki, who were exposed to the radiations of the atomic bombs exploded there in 1945, now have a high incidence of leukaemia which started a few years after 1945. There is a correlation between the incidence of leukaemia and the distance of the respective subjects from the weapon. The latter parameter is presumably correlated with the dose each subject received. It is notable that all must have received a single substantial dose of radiation at a very high intensity.

Secondly, in Great Britain over the last 20 years, most cases of ankylosing spondylitis were treated by radiotherapy. These cases also showed an increased incidence of leukaemia ${ }^{2}$. They received a variable number of courses of radiation each consisting of a number of exposures, but each exposure was a substantial dose given at a high dose rate. In this group, radiation was not given to the whole body but to a large fraction of the body which must have included most of the active haemopoietic bone marrow.

Thirdly, in the United States of America not a few children have been given localized radiotherapy of the neck or upper chest for treatment of a so-called enlargement of the thymus. Again, since this is radiotherapy, doses will have been given at a high dose rate, in most cases fractionated. It now transpires that some of these children have developed leukaemia or carcinoma of the thyroid and the incidence of both diseases is significantly higher than in control groups ${ }^{3}$.

Fourthly, in the U.S.A. it is claimed that there is an increased incidence of leukaemia among radiologists ${ }^{4}$. In round figures the incidence is said to be ten times higher in radiologists than in other medically qualified men. It is not practicable to go back over the history of these radiologists and their exposure to X-rays. The total doses they have received can be guessed at but in no way accurately assessed. However, whatever the total dose may have been, it will have been received in fractions at a high dose rate. In parenthesis one should note that in the small group of British radiologists leukaemia is not significantly increased ${ }^{5}$.

Lastly, from Stewart and her colleagues in Oxford ${ }^{6}$ we have the claim that exposure of the pregnant woman to X-rays for diagnostic purposes increases the liability of her offspring exposed in utero to develop leukaemia and other malignant diseases in the first ten years of life. The incidence of such diseases in these irradiated subjects was about twice that in the nonirradiated. On the other hand less than 10 per cent of malignancy in childhood can be attributed to this cause. Thus only a small proportion of pregnant mothers receive diagnostic $\mathrm{X}$ radiation during pregnancy. However, once again we should note that this is irradiation at a high dose rate.

A number of people are trying to forecast what the future holds for us. In an atomic age, no matter how careful we are now and in the future, with reactors and their ancillary plant, and with the processes now possible involving the use of radio-active materials en masse, there is bound to be a certain escape of radio-activity and therefore an increase in the natural 
background of radiation. A still greater source of emotional speculation is the practice of the major powers to explode nuclear weapons for trial purposes. Inevitably this releases radio-active fission-products and causes the induction of radio-activity by neutrons in normally stable atoms. Thus we can expect that there will be a gradual rise in the levels of external radiation to which we are exposed. The released radio-active materials will gain access to the body in various degrees depending on the chemical nature of the materials and there will be an increased exposure to internal radiation.

One can predict the future state of affairs only if there are reliable laws on which to base the predictions. Frankly there are not. But there is a certain amount of information concerning dose and effect. For instance, in their analysis of cases of leukaemia following irradiation for ankylosing spondylitis, Court Brown and Doll found that if they plotted incidence of leukaemia against the estimated mean dose to the marrow, the plotted points fell roughly on a straight line. On the other hand, while the incidence of leukaemia plotted against integral dose of radiation was linear at the lower doses, there was a marked departure from the linear relation at the higher doses. It is still arguable of course which is the better form in which to assess dose for this purpose.

In a theoretical appreciation of the problem Lewis ${ }^{7}$ used the data of Court Brown and Doll together with such data as are available of the American radiologists and the population of Hiroshima and Nagasaki. Given a few assumptions, he arrived at the conclusion that in each case the information is compatible with an incidence of leukaemia of about one in a million per year per roentgen received. This is tantamount to accepting a linear relationship between the incidence of leukaemia and the integrated dose of radiation irrespective of dose rate. In fact this presumes that the situation is analogous with that which is generally supposed to hold for gene-mutation. True-point mutation of genes, as distinct from the chromosomal structural mutations, is held to be strictly proportional to total dose. Thus the analogy leads to the conclusion that the induction of leukaemia is a similar process to the induction of gene-mutation, or going further, induction of leukaemia is due to somatic mutation. The concept of somatic mutation has been raised a number of times in the past in attempts to explain carcinogenesis. Hitherto the theory has always been found wanting as far as the explanation of the facts is concerned. Today it still seems to me naive to hope that such a simple relationship can be expected to hold even for one type of malignant disease and it does not help me to understand the natural history of leukaemia.

According to certain published statistics, when all classes of leukaemia are lumped together, there is an uneven distribution of incidence with age. An early mode occurs in childhood, from 20 to 40 years incidence is minimal; after which it increases with each decade. This sort of relationship holds also for the acute leukaemias. Chronic myelocytic leukaemia increases progressively with age. The incidence of chronic lymphatic leukaemia also rises progressively with age but not in linear fashion. On the hypothesis of somatic mutation induced by natural background radiation one would expect a linear increase, perhaps after some sort of incubation period to allow for 
manifestation of the condition. Broadly speaking the pattern for chronic myelocytic leukacmia is of this form, but that of acute leukaemia is not and both these types are represented in the radiation-induced cases.

Thus to me it is disappointing that the United Nations Committee, which in general produced an admirable scientific report, gave so much weight to the hypothesis of a possible linear relationship between the incidence of leukaemia and total accumulated dose of radiation. Certainly in the present state of knowledge it cannot be ruled out, but the accredited cases of radiation-induced leukaemia are so far limited to those induced by radiation given at high dose rates.

It behoves us now to see what help we can derive from animal experiments. As I have mentioned ionizing radiation has been recognized as an inducing agent of leukaemia and other malignant diseases in experimental animals. As far as leukaemia is concerned the mouse has been used to a far greater extent than any of the other routinely kept animals of the laboratory. Mice and fowls in particular, but other experimental animals also, suffer naturally from varieties of leukaemia. In birds these have long been attributed to viruses. There seems to be good evidence of separate viruses for avian lymphomatosis, myeloblastomatosis and erythroblastomatosis. In mice leukaemia is not uncommon and certain strains have been selectively bred for this disease. Strains such as $\mathrm{AK}$ and C58 have an incidence up to 80 per cent. Most of these selected natural leukaemias are apparently lymphoid in type. Myeloid leukaemia is found much more rarely in the mouse. True leukaemia, with an increased number of primitive cells in the peripheral blood, is not common except in the terminal stages. However, a widespread infiltration of the tissues is a necessary feature. The thymus, being part of the lymphatic system and being late to regress in the mouse compared with man, is commonly involved. In fact in some of the high-leukaemia strains and frequently in the varieties induced by radiation or by chemical agents, the thymus is involved earlier and to a greater extent than the other lymphoid tissues. Some workers therefore speak of thymic and non-thymic leukaemias. On the other hand, in many aged mice, a more localized type of malignant disease occurs which may be called reticulosarcoma or local lymphosarcoma. Thus, as in man so in the mouse there is a fair spread of clinical and pathological types of disease all of which can be fitted into a classification of malignant reticuloendotheliosis. The types are not identical with those recognized in human disease but there is a sufficient closeness for there to be a general recognition of an analogy between the diseases of mouse and man. Given therefore that the mouse is a fair model of man, it is fair for us to look at the data available from mice.

The work with which I am most familiar is that of my colleague, R. H. $\mathrm{Mole}^{8}$. He has chosen to use for most of this work the inbred strain of mouse, CBA. This is one of the standard strains introduced over 30 years ago by Strong who originally selected for longevity. The mice of our sub-strains still possess this characteristic. This means that they do not normally die prematurely of malignant disease as do most inbred strains which were selected for susceptibility to one or other form of malignant disease.

The control mice thus have a very low natural incidence of all forms of leukaemia certainly for the first two years of their life span of approximately 


\section{J. F, LOUTIT}

two and a half years. It is against this low background that the leukaemias experimentally induced by radiation are scored.

Mice aged from eight to ten weeks have been irradiated with X-rays either in single doses or by courses. The irradiation is applied to the whole body; for it has long been known that if part of the mouse is shielded, particularly a part containing active bone marrow which in the mouse is pretty well universally distributed throughout the skeleton, the shielding exerts a protective effect against the induction of leukaemia. The mice were irradiated to predetermined total doses up to $1500 \mathrm{r}$. Figure 1 in Mole's paper shows cumulative incidence of thymic leukaemia in the groups of female CBA mice that ultimately received $1500,1000,750$ and $500 \mathrm{r}$. The overall exposure time was from two to thirty weeks. There is a striking 'threshold effect'. Thymic leukaemia was only induced by a total of $750 \mathrm{r}$ and more. Figure 2 which gives the data for non-thymic leukaemia shows a completely different effect. In each group the incidence of non-thymic leukaemia increased and doses of $500 \mathrm{r}$ apparently had a greater effect later in life than the higher doses. However the numbers at risk were smaller in the groups given the larger dose. Mole admits that for this and other reasons much more analysis is needed to see whether the best basis for classification is clinical picture, morbid anatomy or cytological character.

If one takes from Mole's work, some of it unpublished, the data for the one dose of $750 \mathrm{r}$, this given in a single exposure causes about a five per cent mortality due to the radiation syndrome. Survivors which live for another 18 months or so all show the signs of residual radiation effects - the greying of hair, failure to attain normal weight and formation of cataract-but the death rate from leukaemia is only very slightly raised. However, as one may see from Figure 2, if the dose of $750 \mathrm{r}$ is given in fractions over a few weeks the total incidence of leukaemia may be 50 per cent or thereabouts. This result was obtained in spite of the fact that the sequelae of greying of the hair, diminished weight and formation of cataract were not prominent. Such results as these are not at first sight in accord with the hypothesis for linear relationship between total dose and incidence of leukaemia.

Mole and his colleagues have also been irradiating CBA mice chronically, either with fast neutrons in one of the Harwell piles or with $\gamma$-rays from ${ }^{60} \mathrm{Co}$. Some of these results have been published by Neary et al. ${ }^{9}$, but much still remains unpublished. Anyway, the incidence of leukaemia in these mice chronically irradiated either by fast neutrons or by $\boldsymbol{\gamma}$-rays, is again remarkably small, even though the integrated dose which they have received is substantial. This is further evidence against a directly proportional relationship between dose and effect.

Results of this sort have led Mole to set up an experiment whereby mice are irradiated with ${ }^{60} \mathrm{Co} \gamma$-rays at differing dose rates. This experiment has not yet been running for a sufficient length of time for anything like a comprehensive picture to have been obtained. Nevertheless the early results were so striking that it was felt justifiable to report them at the recent conference on the Peaceful Uses of Atomic Energy at Geneva ${ }^{10}$. The daily dose, the total dose and the overall exposure period were the same for each of these groups of mice. Mice of two strains were used and the results at 10 months after the start of the irradiation are given in Table 1. 
Table I* $^{*}$ liffects of dose-intensity on the incidence of leukarmia in female mice given whole-body gamma irradiation over a four-week exposure period

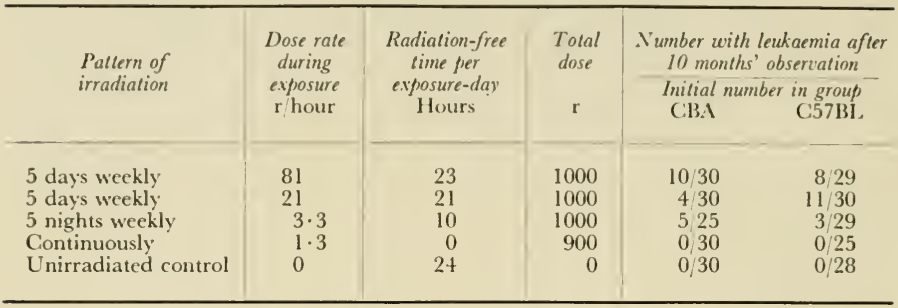

Leukaemia has occurred in substantial or significant numbers in both groups of mice-CBA and $\mathrm{C} 57 \mathrm{BL}$ - when the dose rates during exposure were 81 , 21 or $3.3 \mathrm{r}$ per hour. There has been no leukaemia in the two varieties of mice exposed at $1 \cdot 3 \mathrm{r}$ per hour or in the unirradiated controls. It might at this stage be worth while to quote from this paper of Mole*:

'If leukaemia in the mouse can be taken as a model for leukaemia in man, it seems clear (i) that there is no evidence to support the hypothesis that the chief determinant of the incidence of radiation-induced leukaemia is dose, and (ii) that there is some evidence which denies the validity of extrapolation from existing human data on the relation between dose and leukaemia to situations where the dose intensity is very much less. It must be conceded however that these conclusions are demonstrably true only of leukaemia incidences of 10 per cent or higher. It is not possible to refute experimentally a claim that the relation of dose to leukaemia incidence has a different form at lower incidences of leukaemia, i.e., that the experimentally observed relation cannot be extrapolated beyond the observed limits. Observations can never bridge this logical gap which can only be filled by a generally acceptable hypothesis of the mechanism of leukaemogenesis by radiation. Even though no such hypothesis exists at present, one firm conclusion at least can be reached. The experimental facts cannot be accounted for by the theory of somatic mutation without assuming the existence of an additional factor of overriding importance for the clinical expression of leukaemia. And if this factor is so important of itself, it seems logically unnecessary to postulate an additional mechanism, such as somatic mutation, to account for the facts.'

But this is a negative sort of conclusion. Let us keep the word mutation, but instead of somatic 'gene-mutation' let us consider somatic 'chromosomal-mutation'. Ford in our laboratory has been studying cytologically the cases of murine leukaemia provided by Mole. Most of these are radiation-induced leukaemias but a few of them have been spontaneous. Their results were also reported at Geneva ${ }^{11}$ and again I quote directly*:

'(i) The large majority of the leukaemias examined consist of mixed cell populations in which some, many, or even all of the cells contain chromosomes which differ from the basic diploid set of the species either in number

* Reproduced from the Proceedings of the L'nited Nations Organization Second Conference on the Peaceful Uses of Atomic Energy. 


\section{J. F. LOUTIT}

or form (of one or more individual chromosomes), or both. This is in marked contrast to normal reticular tissue, the cells of which show little or no variation of chromosome number and no change of chromosome form.

(ii) Usually the chromosomal variation in a leukaemic cell population is distributed about a single central, or modal type which can be regarded as characterizing the leukaemia. The modal types of different leukaemias show marked individuality, and are sometimes unique.

(iii) The characteristic modal cell-type, and the range of variation about the modal type, are normally maintained through a series of transplant generations. Occasionally, however, a new modal type, closely related to the old, arises.

(iv) New chromosomal variation attributable to non-disjunction and primary structural change is continuously appearing. The structural changes observed are relatively gross, and reasons were given for supposing that they represent only a part of a continuous series of changes of decreasing magnitude terminating in duplication or deletion of single gene-loci.'

This is firm evidence that in the established leukaemias there are usually to be found chromosomal changes which can literally be translated chromosomal-mutations. However, it has yet to be established whether these changes are related to the cause of the leukaemic state or whether they result from it. If they are related to cause, then they should have been present at the earliest time at which the leukaemia could be recognized in the animal. This has not yet been established in our laboratory. Moreover, as Ford and Mole point out, "There would appear to be two ways in which a distinctive chromosome-set of a primary leukaemia might arise: by progressive, small step by small step, evolution from an original normal cell through the operation of selection on variant types; or by a sudden catastrophic rearrangement and reassortment of the chromosomes and subsequent minor variation about the new mode. If the latter should be true, carcinogenesis would be the initiation of the catastrophic change and we would still be faced with the problem of discovering what the factors are which determine the change. If, on the other hand, the process should be a slow and progressive one, it would seem to be impossible to define at what stage abnormal but not necessarily pathological cells become frankly neoplastic.'

Certainly major structural lesions of the chromosomes are produced by radiation. Breakage of chromosomes with cross-union translocation has long been recognized as a radiation-induced lesion. Ford et al. ${ }^{12}$ have identified cytologically such a translocation in one of our laboratory stocks (T6) raised by Carter et al. ${ }^{13}$ from irradiated male mice. These mice contain the translocation in their somatic as well as their germ cells. Nevertheless, the translocation as such is not a determinant of malignancy. We (Barnes et al. unpublished) have maintained myeloid cells of this type as it were in culture in vivo, in successive mice irradiated to destroy their native haemopoietic tissues and recolonized with myeloid tissue which came originally from a T6 mouse. No leukaemia has been observed in the numerous mice under observation for a period of three years. Furthermore, we have had under observation other lethally irradiated mice, which have been resuscitated with foreign myeloid tissue, homologous or heterologous, and which some months later have regenerated their haemopoictic tissues from their 
own cells which were damaged by radiation. Ford ${ }^{14}$ has been able to identify a number of clones of cells with characteristic chromosomal lesions but we have yet to see such a clone exhibiting signs of malignancy. Chromosomal lesions by themselves do not seem to account for the malignant change.

One ought, therefore, to consider the other postulate- evolution by small steps from an original normal cell. Kaplan et al. ${ }^{15}$ may have produced examples of this. From their previous work they have found that thymectomy abolishes the liability of C57BL mice, irradiated with set courses of X-rays, to develop thymic leukaemia. They found that reimplantation of a normal thymus into such thymectomized irradiated animals restored to a certain extent the tendency to develop leukaemia, and, what was more remarkable, that the leukaemia frequently arose from the cells of the normal implant. This observation has been confirmed with other stocks by Law and Potter ${ }^{16}$ and ourselves ${ }^{17}$. To explain this phenomenon Kaplan ${ }^{18}$ is now considering how radiation could act through indirect mechanisms. He postulates that the disturbance of the internal environment may favour the selection of chance mutants, or may encourage abnormal repair. In the latter case step by step changes could be envisaged particularly if growth were cyclical. A further suggestion by Kaplan was that the radiation might activate a provirus.

Certainly as far as murine leukaemia is concerned a viral aetiology is now a fashionable concept. Gross ${ }^{19}$ has for years been arguing the case and reporting his experimental evidence for it. In his hands a cell-free extract from leukaemic tissue of $\mathrm{AK}$ mice has been able to induce lymphoid leukaemia in the Bittner sub-line of $\mathrm{C} 3 \mathrm{H}$ mice which normally develop leukaemia most rarely. In the early stages of this work Gross found it necessary to inject the cell-free extract into the mice when newborn. Our interpretation ${ }^{17}$ was that it was necessary for him to induce immunological tolerance of the host for the 'agent'. More recently Gross has been able, by serial passage of agent through a number of newborn hosts, to produce a still more potent extract which will induce leukaemia even in his adult $\mathrm{C} 3 \mathrm{H}$ mice. If this is confirmed, my first reaction would be that a hypothesis involving immunological paralysis would explain the effect. However, after injection of both the newborn with weakly active and the adult with strongly active material there is an appreciable interval of months before the leukaemia is manifest. A similar latent period is seen between application of 'inducing' agents such as X-rays, carcinogenic chemicals, etc., and the manifestation, but in this case no particularly receptive host (such as the $\mathrm{C} 3 \mathrm{HBi}$ ) need be chosen: mice of all strains will develop leukaemia if suitably irradiated. And, indeed, Gross now has obtained active extracts from irradiated mice, though we ${ }^{17}$, certainly less experienced in this field of 'extraction', have not been successful. If, therefore, the virus theory is to be extended by Gross to account for most if not all mouse leukaemia, the virus must be universally present in mouse stocks. It does not seem to me necessary to invoke an 'activation' and to compare the process with activation of lysogenic bacteria, as Gross has certainly done and I presume Kaplan to have done also. The conditions under which Gross induces his leukaemias and other tumours are similar to those whereby Stewart and Eddy 20 have recently produced 


\section{J. F. LOUTIT}

tumours in animals inoculated with cell-free extracts of tissue cultures stemming from foreign tumorous mice. They are also similar to the conditions reported by Hays et al. ${ }^{21}$ and Latarjet ${ }^{22}$ who have apparently induced tumours with foreign desoxyribose nucleic acid (DNA). In all cases the foreign DNA or viral 'agent' is injected into animals whose normal immunological mechanisms could be defeated owing to their own prematurity, by supersaturation or by inactivation.

Be that as it may there is still the incubation period and during this period some progressive step-wise process could be operating and, to me, this seers a probable explanation of the delay no matter whether the initial act was viral infection, genetic transformation or physico-chemical damage.

\section{REFERENCES}

${ }^{1}$ Martin, J. H. Med. J. Aust. 2 (1958) 158

${ }^{2}$ Brown, W. M. Court and Doln, R. Medical Research Council Special Report, Serial No. 295, 1957

${ }^{3}$ Simpson, C. L. and Hempelmann, L. H. Cancer, N.Y. 10 (1957) 42

${ }^{4}$ March, H. C. Amer. J. med. Sci. 220 (1950) 282

${ }^{5}$ Brown, W. M. Court and Doll, R. Brit. med. J. ii (1958) 181

${ }^{6}$ Stewart, A., Webi, J. and Hewrtt, D. Brit. med. J. $i$ (1958) 1494

${ }^{7}$ Lewis, E. B. Science, 123 (1957) 965

${ }^{8}$ Mole, R. H. Brit. med. Bull. 14, No. 2 (1958) 174

${ }^{9}$ Neary, G. L., Munson, R. J. and Mole, R. H. Chronic Radiation Hazards-An experimental study with fast neutrons: Pergamon Press, London, 1957

${ }^{10}$ Mole, R. H. Second Conference on the Peaceful Uses of Atomic Energy Paper A/CONF. 15/P/96 Geneva, 1958

${ }^{11}$ Ford, C. E. and Mole, R. H. Second Conference on the Peaceful Uses of Atomic Energy Paper A/CONF. 15/P/98 Geneva, 1958

${ }^{12}$ Ford, C. E , Hamerton, J. L., Barnes, D. W. H. and Loutit, J. F. Nature, Lond. 177 (1956) 452

${ }^{13}$ Carter, T. C., Lyon, M. F. and Phillips, R. J. S. J. Genet. 53 (1955) 154

${ }^{14}$ Barnes, D. W. H., Ford, C. E., Gray, S. M. and Loutit, J. F. Second Conference on the Peaceful Uses of Atomic Energy Paper A/CONF. 15/P/97 Geneva, 1958

${ }^{15}$ Kaplan, H. S., Hirsh, B. B. and Brown, M. B. Cancer Res. 16 (1956) 434

${ }^{16}$ Law, L. W. and Potter, M. Proc. nat. Acad. Sci., Wash. 42 (1956) 160

${ }^{17}$ Barnes, D. W. H., Ford, C. E., Ilbery, P. L. T., Jones, K. W. and Loutit, J. F. Communication to the Seventh International Cancer Conference London, 1958

${ }^{18}$ Kaplan, H. S. Communication to the Seventh International Cancer Conference London, 1958

${ }^{19}$ Gross, L. Cancer Res. 18 (1958) 371

${ }^{20}$ Stewart, S., Eddy, B. E. and Borges, N. J. nat. Cancer Inst. 20 (1958) 1225

${ }^{21}$ Hays, E. F., Simmons, N. S. and BECK, W. S. Nature, Lond. 180 (1957) 1419

${ }^{22}$ Latarjet, R. C.R. Acad. Sci., Paris 248 (1958) 853

\section{DISCUSSION}

Dr. Hoffman: With regard to the tumour viruses and the virus-like particle aspects of neoplasia, Bernhardt makes two points of interest. In an increasing number of instances of tumours, in increasing numbers of animals or species there are particles resembling viruses, which can be demonstrated microscopically. In a smaller number of these cases it can actively be filtered and used to transmit neoplasia. The point Bernhardt makes - that in the case of the fowl, in 12 per cent of apparently normal 
animals such particles could nevertheless be demonstrated and in certain instances of non-malignant tumours, no particles can be demonstrated-rather relates to a point which you made. Irradiation can bring forth a burst of what Bernhardt calls 'virus-like particles'.

Dr. Loutit: Thank you. I should like to keep quite an open mind about viruses and their relationship to tumours, but I would not, with no experience of viruses, exclude that viruses are universally present in animal tissue and that normally they are kept under control by the normal immunological mechanisms of the body. As I say by either utilizing the newborn animal and adding so much extra-virus in a short burst that the system is flooded, or by playing around with substantial doses of radiation which certainly inactivate, pro tem., at any rate, the immunological mechanism, you could bring about the spread of the virus, the consequent changes initiating a process, or being one of the factors in a process, which ultimately results in leukaemia. Moreover, I think leukaemia and most malignant diseases, are mediated by several different factors and these temporary disturbances of the post-virus relationship might well be one of the intermediary factors.

Dr. Sheldon: You gave the case of the American radiologists as being in the class which received a high dose rate. I should expect it would be rather a small dose rate over a long period like that in one of the other experimental classes mentioned later. DR. Loutit: I am not a radiologist, but there must be a number in the audience here. I would guess that most radiologists get their exposure from screening operations with a patient between them and the X-rays. During the time of exposure, it may be only a few minutes, they are exposed to radiation at a high dose rate. There may be an interval of a few minutes, a few hours, perhaps a few days, before they do another series of screenings, but during the time of exposure the tube is activated and they are exposed to the high rate. Would a radiologist confirm?

DR. DEANs: The figures concerning deaths from leukaemia amongst radiologists referred to by Dr. Loutit were compiled from obituary notices by March, Ulrich and others. These figures refer to an earlier generation of radiologists including pioneers of radiology, many of whom were probably exposed to what could be called a heavy dose of radiation at a high rate. As Martin and others have pointed out the output of fluoroscopic installations in use even to the present day may, in exceptional instances, be as high as $100 \mathrm{r}$ per minute.

DR. LoutrT: It seems likely that the protective measures which have been applied in the last 30 to 40 years have altered the situation. Kaplan states that he knows of absolutely no evidence that exposure to maximal permissible dose over a working lifetime of some 40 years can induce leukaemia. A recent analysis of average age at death from a variety of causes of radiologists, as compared with physicians not exposed to radiation, has been made by Shields Warren. Lewis applied an age correction to Warren's data and came to the conclusion that radiologists in fact live slightly longer than physicians in general.

Sir MacFarlane Burnet: May I make one minor protest against the idea that all mammals are all the time saturated with a large number of unrecognizable viruses? I just cannot believe that. With regard to virus and cancer, I think one point that was implicit in Dr. Loutit's discussion was that if somatic mutation or sequential somatic mutation is concerned in leukaemia, then the emergence of leukaemia into the overt disease may well require additional physiological or other factors. There exists, I think, the possibility that rather casual viruses, with the appropriate material, might push and act as a promoting factor, essentially to push the disease into overt manifestation. But I have a very deeply ingrained suspicion of electro-microscopic appearances which are not verificd by the appropriate transfer, and I think it is a dangerous concept to feel that you can at will postulate any unrecognizable virus in the tissues that is required to support the hypothesis. 


\section{DISCUSSION}

Dr. Fowler: Mr. Chairman, in his opening remarks, Dr. Loutit made the statement that the Western world is seeing an increase in leukaemia at a steadily increasing rate. I am sure that Dr. Loutit will agrce with me that to an audience such as this, which contains a good many non-medical members, that statement should be qualified to read that-recorded incidence of leukaemia shows a rise in Western nations. The statement depends upon vital statistics which are subject to certain errors-death certificates often show the error of incorrect certification from diagnostic difficulties, and an error is introduced by the fact that the statisticians make no difference between lymphatic leukaemia and myeloid leukaemia, which appear to be two distinct diseases. Dr. Loutit's implication, of course, was that life is changing, as he puts it, and we are being subjected probably to more radiation as a population. But radiations appear to cause myeloid leukaemia rather than lymphatic leukaemia in man, and lymphatic leukaemia is characteristic of old age, so that if you use the age incidence as indicative of lengthy exposure to rays, you seem to me to have a contradiction on pathology. I had hoped that perhaps Dr. Keogh would be present today to tell you that a study of his on the population in Victoria shows distinctly that over the last ten years there has not been an increase in the incidence of leukaemia.

DR. LoutiT: I am glad that this point has been brought up because when I was preparing the material I was unable to find any Australian statistics, and therefore I noted in the script, at any rate, that my rise referred only to conditions in Western Europe and the United States of America. It is heartening to learn that there is one part of the Western world where in the last ten years there has apparently been no rise. 


\title{
EFFECT OF WHOLE-BODY IRRADIATION ON THYMUS FUNGTION AND LYMPHOGYTE HOMEOSTASIS*
}

\author{
Donald Metcalf \\ IV alter and Eliza Hall Institute, Royal Melbourne Hospital, \\ Melbourne, Victoria

\section{INTRODUCTION}

THE occurrence of leukaemia in man following exposure to ionizing irradiation was first documented by Aubertin ${ }^{1}$. Subsequently, Krebs et al. ${ }^{2}$ and Furth and Furth ${ }^{3}$ described the induction of leukaemia in mice by whole-body irradiation. These observations have since been amply confirmed.

Whilst it is likely that ionizing irradiation may induce leukaemia in a small number of cases by direct mutagenic effects, the elegant experiments of Kaplan ${ }^{4,5}$ have shown that, in mice, in the majority of cases, the induction of leukaemia is by an indirect mechanism.

The thymus plays a major role in this indirect process. Thymectomy, performed either before or after irradiation substantially reduces the subsequent incidence of leukaemia. Stimuli, arising from the irradiated tissues, appear capable of affecting the degeneration-regeneration cycle in the thymus following irradiation and determine whether or not neoplasia occurs in this organ. In addition, following irradiation, the thymus has been shown to influence the appearance of leukaemia in the other lymphoid tissues by means of a non-cellular influence produced by the thymus ${ }^{6}$.

Metcalf ${ }^{7}$ has shown that the thymus produces a lymphocytosis stimulating factor (L.S.F.) and that in lymphoid leukaemia, both in humans and mice, excessive levels of L.S.F. are present.

\section{EFFECT OF WHOLE-BODY IRRADIATION ON LYMPHOCYTE LEVELS}

When young adult C57BL mice are exposed to a single dose of $250 \mathrm{r}$ wholebody irradiation, there occurs the well-known post-irradiation depression of circulating lymphocyte levels (Figure 1). Gradual recovery to pre-irradiation levels occurs in 20 to 30 days. If such mice are observed for the duration of their subsequent life, they are found to develop a permanent lymphocytosis - this lymphocytosis first becomes apparent 2 to 3 months after irradiation.

Thus the response to irradiation, in the mouse, is a biphasic one. Studies made on mice in the acute, lymphopenic, phase have shown ${ }^{8}$ that if such mice are grafted with normal, unirradiated, isologous thymic tissue, the lymphopenia is lessened and such mice achieve normal lymphocyte levels

* This work was jointly sponsored by the Anti-Cancer Council of Victoria and the National Institutes of Health, Washington, Grant No. C-2547. 
faster than irradiated control mice. Cell-free thymus extracts, when injected into irradiated mice, produce similar effects. Lymph-node grafts or injections of lymph-node extracts do not alter the acute lymphopenic phase following irradiation. Thymectomy increases the degree and the duration of post-irradiation lymphopenia.

These findings suggest that with this dosage of whole-body irradiation,

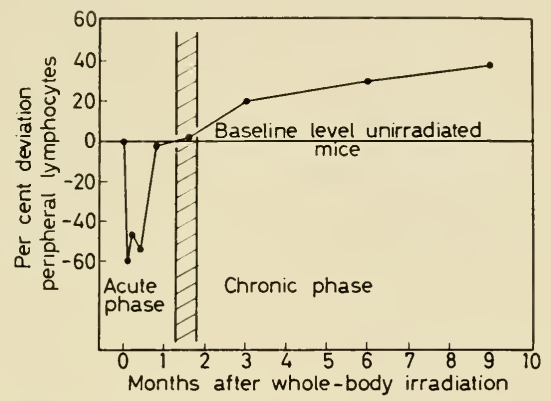

Figure 1. Biphasic response in peripheral lymphocyte levels in the mouse following whole-body irradiation

part at least of the observed lymphopenia is due to depression of some noncellular factor produced by the thymus. This thymic factor is probably thymic L.S.F.

\section{EFFECT OF WHOLE-BODY IRRADIATION ON THYMUS FUNCTION}

The indirect evidence described above suggests that in the initial phase following irradiation, thymic L.S.F. is depressed parallel with the depression in circulating lymphocyte levels.

In sharp distinction to these initial changes is the situation found in mice showing a lymphocytosis in the second phase following irradiation ${ }^{9}$.

L.S.F. assays on mice, 3, 6, 9 and 15 months after whole-body irradiation (250-450 r) have shown that virtually all mice have elevated L.S.F. levels. Such mice also show the apparent development of unresponsiveness to stimulation by L.S.F. similar to that previously described in pre-leukaemic and leukaemic AKR and C58 mice ${ }^{10}$. However, this apparent unresponsiveness to L.S.F. in irradiated mice has been shown to be a secondary effect of elevated endogenously-produced L.S.F. levels. After thymectomy, irradiated mice show unimpaired responsiveness to stimulation by L.S.F. ${ }^{9}$

\section{THYMIC L.S.F. AND LYMPHOID LEUKAEMIA}

The evidence to date ${ }^{10}$ suggests that the normal function of L.S.F. is to stimulate the maturation and/or division of primitive lymphoid cells into mature small lymphocytes. A study of pre-leukaemia arising spontaneously in the high-leukaemia mouse strains AKR and C58 has indicated that such mice invariably show elevated L.S.F. levels and an associated unresponsiveness to stimulation by L.S.F. It has been suggested ${ }^{10}$ that this abnormal stimulus 


\section{THYMUS FUNC"ION ANI) LYMPHOCY"IE HOMEOSTASIS}

to multiplication if present for long enough, might eventually induce neoplasia in the target cells, i.e., the lymphoid tissues.

The present cridence of elevated L.S.F. levels developing in mice subjected to whole-body irradiation is of considerable interest in view of the leukacmogenic effect of whole-body irradiation in mice.

It suggests that, in mice, irradiation-induced lymphoid leukaemia may share a common pathogenesis with the spontaneous disease. This would fit
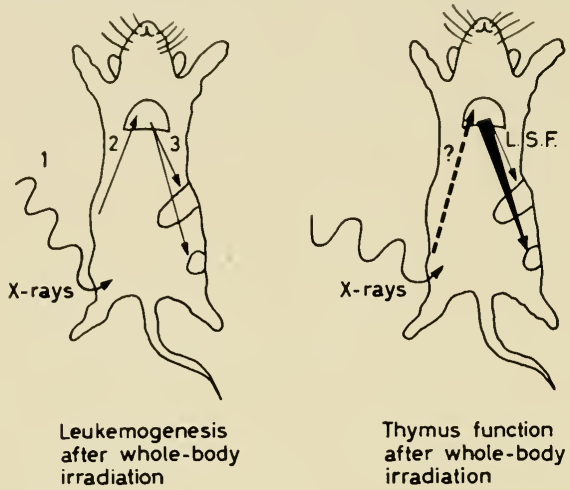

Figure 2. Comparison between the indirect mechanism of leukaemogenesis following irradiation proposed by Kaplan ${ }^{5}$ and the effect of irradiation on thymic L.S.F. production

well the indirect mechanism by which Kaplan ${ }^{5}$ has conceived irradiation induces lymphoid leukaemia in mice (Figure 2) and the paramount role played by the thymus in this process.

\section{REFERENCES}

${ }^{1}$ Aubertin, C. Bull. Soc. Radiol. méd. Paris 40 (1931) 218

${ }^{2}$ Krebs, C., Wagner, A. and Rask-Nielsen, H. C. Acta. radiol., Stockh. Supplement $10(1930) 1$

${ }^{3}$ Furth, J. and Furth, O. B. Amer. J. Cancer 28 (1936) 54

${ }^{4}$ Kaplan, H. S. J. nat. Cancer Inst. 11 (1950) 83

${ }^{5}$ Kaplan, H. S. Cancer Res. 14 (1954) 535

${ }^{6}$ Law, L. W. and Potter, M. Proc. nat. Acad. Sci., Wash. 42 (1956) 160

${ }^{7}$ Metcalf, D. Brit. J. Cancer 10 (1956) 442

${ }^{8}$ Metcalf, D. and Buffett, R. F. Communication to the Seventh International Cancer Conference London, 1958

${ }^{9}$ Metcalf, D. Radiation Res. 1958-in the press

${ }^{10}$ Metcalf, D. Proceedings of the Third Canadian Cancer Research Conference: Academic Press Inc., New York, 1959 -in the press 


\section{DISGUSSION}

DR. Vogel: If your hypothesis is correct, how do you account for the lack of leukaemia production that Dr. Loutit just reported in Dr. Mole's experiments-that is, when the radiation dose level was low, he reported that in ten months there were no leukaemias; also in Dr. Kaplan's work, I believe fractionating four times increased the leukaemia rate. How does your theory account for these marked changes in leukaemia appearing in mice?

Dr. Metcalf: We do not really know, since the only type of irradiated mouse we worked with has either received a single dose or three fractionated doses. Both spreading the irradiation out over a long period and giving intense doses of some thousands of roentgens locally to the thymus failed to induce leukaemia and we wondered whether, since this L.S.F. production was radio-sensitive, we were either wiping it out completely in the case of the very large doses, or keeping it suppressed by a continuous small dose. However, we have not checked up on thymus function in mice of that type. 


\title{
RADIATION QUALITY AND BONE-MARROW DOSE IN RADIOLOGY
}

\author{
J. H. Martin and G. Muller
}

Physics Department, Peter MacCallum Clinic, Melbourne

IT has been realized for many years that ionizing radiations can induce leukaemia, but it is only in recent years that its induction in man at low doses has become apparent. This realization arises from evidence of leukaemia among radiologists, that in the survivors of the atomic bomb explosions in Japan, that given in the work of Court-Brown and Doll on the incidence in persons treated for ankylosing spondylitis, the investigation in children treated by X-rays for enlargment of the thymus gland and the much publicized studies of Alice Stewart and her colleagues relating incidence of leukaemia in children to exposure to diagnostic X-rays in utero.

These studies have shown the possibility of a linear relationship between incidence of leukaemia and dose of radiation, but the information at low doses is scanty, and it is also possible to assume a threshold. Bone-marrow doses resulting from radiation procedures are, therefore, under study to clarify the situation.

Some preliminary assessments in various countries of bone-marrow dose due to diagnostic radiology have been made and are referred to in the recent report of the United Nations Scientific Committee on Atomic Radiations ${ }^{1}$.

In this paper an endeavour will be made to give a more detailed assessment of the bone-marrow dose taking into account the changes in quality of the radiation as it penetrates a scattering medium such as the body.

A study has been made of the radiation conditions with regard to quality and quantity within the field of radiation, and outside it in regions to which radiation can be scattered. The corrections to be made for the absorption of radiation by the bony shell surrounding the bone marrow, vary very much with the energy of the radiation in the range of energies of interest and a knowledge of the radiation quality within the body is thus necessary.

An assessment of bone-marrow dose has been made first, for the conditions of kilovoltage and filtration considered to be average for diagnostic practice at present. These factors have been determined from a survey of the factors in use by a number of $\mathrm{X}$-ray departments. In addition, an assessment has been made for conditions used with high kilovoltage techniques, a charge of about $30 \mathrm{kV}$ being usual. Radiation quality within the radiation field has been studied using a system whose response is markedly dependent upon energy and comparing the results with those obtained from a non-quality dependent system. The system has been calibrated to yield effective H.V.L. in aluminium as a measure of the quality of the radiation of interest. The result of the quality study is shown in Figure 1 . 


\section{J. H. MARTIN AND G. MULLER}

Radiation scattered outside the defined field has been studied ${ }^{2}$ at the two depths of approximately $5 \mathrm{~cm}$ and $10 \mathrm{~cm}$. The result of a similar study is shown in Figure 2 and it will be seen that the amount of radiation falls off approximately logarithmically with distance from the edge of the field.

In Figure 3 is plotted the amount of scatter at a given point against radiation quality from which it will be seen that the scatter increases with radiation quality reaching, however, a maximum about a half value layer of $2.5 \mathrm{~mm}$ of copper, that is, in the deep therapy range. Thus, as far as the diagnostic

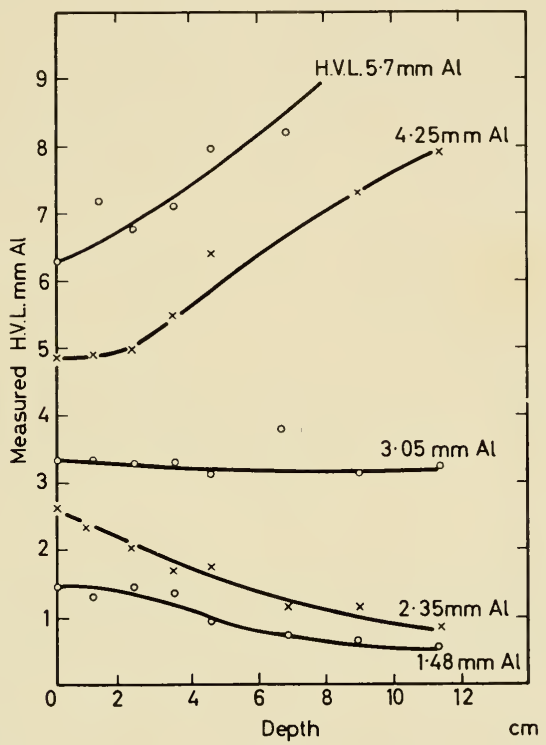

Figure 1

$\mathrm{X}$-ray region is concerned, higher kilovoltage techniques involve more scattered radiation.

The skin doses appropriate to each type of examination which have been used are those listed in Table 1. These are taken mainly from the work of one of us (J.H.M.) and are listed together with those given by the International Commission on Radiological Protection? ${ }^{7}$. The percentage of the surface dose reaching the region of interest has been determined from the data of Trout, Kelley and Cathey ${ }^{3}$. The dose thus reaching the bone is corrected for absorption by the hard shell. The appropriate absorption coefficient is obtained from the work of Spiers ${ }^{4}$ using the radiation quality data of Figure 1. The bone-marrow dose is then obtained by correcting this figure for the emission of electrons from the hard bony surface after the method developed by Spiers ${ }^{5}$. This latter correction does not exceed 10 per cent. The bone-marrow distribution used is derived from the work of 


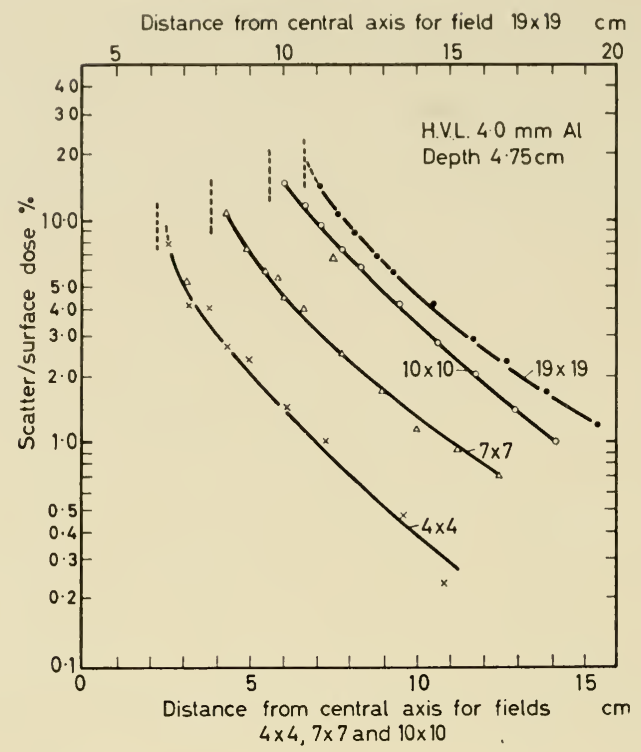

Figure 2

Mechanik ${ }^{6}$ but the mass of bone marrow taken is that given for the standard man by the International Commission on Radiological Protection ${ }^{8}$.

The number of X-ray examinations carried out in Australia annually has been determined by obtaining the consumption of X-ray film annually and

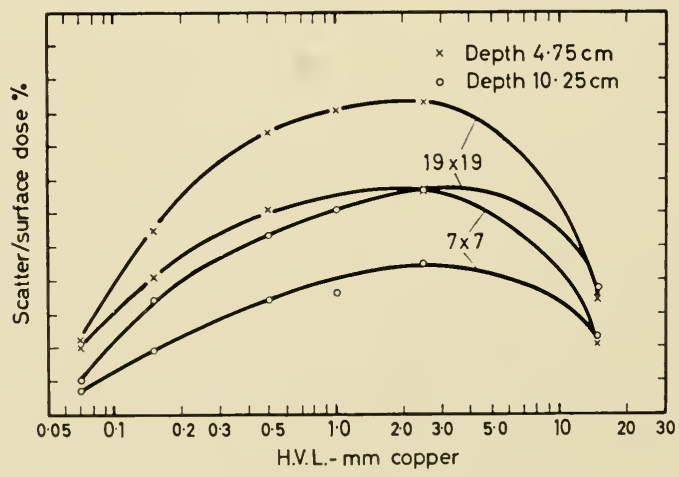

Figure 3 


\section{J. H. MARTIN AND G. MULLER}

Table 1. Skin doses-roentgens per exposure

\begin{tabular}{|c|c|c|c|c|c|}
\hline \multirow{2}{*}{ Examination } & \multicolumn{4}{|c|}{ Collected } & \multirow{2}{*}{$\begin{array}{l}\text { I.C.R.P. } \\
1955\end{array}$} \\
\hline & Range & $\begin{array}{c}\text { Estimated } \\
\text { average }\end{array}$ & $\underset{\mathrm{kV}}{\mathrm{High}}$ & $\begin{array}{c}\text { Heavy } \\
\text { filtration }\end{array}$ & \\
\hline Sinuses & $1 \cdot 3-13$ & 4 & $0 \cdot 2$ & $0 \cdot 8$ & - \\
\hline Skulls & $0 \cdot 7-2 \cdot 8$ & $1 \cdot 5$ & - & $0 \cdot 3$ & $\begin{array}{l}\text { A.P. } 1 \cdot 2-1 \cdot 6 \\
\text { L. } \quad 0 \cdot 8-1 \cdot 2\end{array}$ \\
\hline Dental & $1-15$ & 4 & 一 & $0 \cdot 3$ & $3-5$ \\
\hline $\begin{aligned} & \text { Chest: } \text { A.P. } \\
& \text { L. } \\
& \text { M.M. } \\
& \text { Tomo }\end{aligned}$ & $\begin{array}{c}0 \cdot 04-1 \cdot 0 \\
0 \cdot 1-0 \cdot 4 \\
0 \cdot 2-1 \cdot 5 \\
-\end{array}$ & $\begin{array}{l}0 \cdot 1 \\
0 \cdot 2 \\
0 \cdot 7 \\
-\end{array}$ & $\begin{array}{l}0 \cdot 03 \\
- \\
-\end{array}$ & $\begin{array}{l}0 \cdot 007 \\
\overline{0} \\
0 \cdot 04\end{array}$ & $\begin{array}{c}0 \cdot 04-0 \cdot 2 \\
\overline{0} \\
0 \cdot 2-0 \cdot 5 \\
0 \cdot 5\end{array}$ \\
\hline $\begin{array}{l}\text { Pelvis: A.P. } \\
\text { Lat. } \\
\end{array}$ & $\begin{array}{l}1-5 \cdot 3 \\
6 \cdot 5-22 \\
\end{array}$ & $20^{2 \cdot 5}$ & $\begin{array}{l}0 \cdot 8 \\
11\end{array}$ & $\begin{array}{l}0 \cdot 8 \\
3\end{array}$ & $\overline{2-2} \cdot 5$ \\
\hline $\begin{array}{l}\text { Pregnancy: A.P. } \\
\text { Obl. A.P. } \\
\text { L. } \\
\text { Inlet } \\
\text { Outlet }\end{array}$ & $\begin{array}{c}3 \cdot 6-9 \cdot 2 \\
16-50 \\
7-120 \\
14-65 \\
4 \cdot 7-18 \cdot 5 \\
\end{array}$ & $\frac{5}{20}$ & $\begin{array}{l}0 \cdot 5 \\
\text { E } \\
=\end{array}$ & $\begin{array}{l}\bar{Z} \\
\bar{z} \\
\end{array}$ & $\begin{array}{l}3-6 \\
\text { - } \\
\text { - }\end{array}$ \\
\hline $\begin{array}{l}\text { General intestine } \\
\text { (including barium } \\
\text { meal) }\end{array}$ & $0 \cdot 7-8 \cdot 2$ & 3 & - & $0 \cdot 15$ & - \\
\hline $\begin{array}{c}\text { Spine: A.P. } \\
\text { L. }\end{array}$ & $\begin{array}{r}2-14 \\
2 \cdot 5-34 \\
\end{array}$ & 5 & - & 二 & $\begin{array}{l}1 \cdot 6-2 \cdot 5 \\
1 \cdot 8-3 \cdot 5\end{array}$ \\
\hline $\begin{array}{r}\text { Cervical spine: A.P. } \\
\text { Lat. }\end{array}$ & $0 \cdot 4 \cdot \frac{2}{4} \cdot 6$ & $\overline{1 \cdot 0}$ & 二 & $\overline{0 \cdot 025}$ & - \\
\hline $\begin{array}{r}\text { Dorsal spine: A.P. } \\
\text { Lat. }\end{array}$ & $\begin{array}{l}2 \cdot 7-4 \cdot 5 \\
1 \cdot 8-6 \cdot 0\end{array}$ & - & - & - & - \\
\hline $\begin{array}{c}\text { Lumbo-sacral joint and } \\
\text { Lower spine: A.P. } \\
\text { Lat. }\end{array}$ & $\begin{array}{l}1 \cdot 2-8 \\
2 \cdot 5-26 \\
\end{array}$ & $\begin{array}{r}2 \\
10\end{array}$ & $\begin{array}{c}0 \cdot 15 \\
0 \cdot 9-6 \cdot 5\end{array}$ & $\begin{array}{l}0 \cdot 38 \\
0 \cdot 8\end{array}$ & 二 \\
\hline Gall-bladder & $0 \cdot 6-3 \cdot 1$ & 2 & - & - & - \\
\hline $\begin{array}{l}\text { I.V.P., Ureta, } \\
\text { Kidney, etc. }\end{array}$ & $1 \cdot 3-6$ & $1 \cdot 5$ & - & - & $\begin{array}{l}1 \cdot 4-2 \cdot 5 \\
1 \cdot 5-1 \cdot 9\end{array}$ \\
\hline Limbs & $0 \cdot 2-2 \cdot 8$ & 1 & 一 & 一 & - \\
\hline Extremities & $0 \cdot 25-1 \cdot 7$ & $0 \cdot 6$ & - & - & $0 \cdot 06$ \\
\hline Screening & $\begin{array}{l}4-127 \\
\mathrm{r} / \mathrm{min}\end{array}$ & $20 \mathrm{r} / \mathrm{min}$ & - & $6 \mathrm{r} / \mathrm{min}$ & $7-20 \mathrm{r} / \mathrm{min}$ \\
\hline Abdomen: A.P. & - & - & - & - & $1 \cdot 5-3$ \\
\hline Shoulders: A.P. & - & - & - & - & $0 \cdot 7-1 \cdot 0$ \\
\hline Heart kymography & - & $2 \cdot 0$ & - & - & $2-4$ \\
\hline
\end{tabular}


clividing this by the average size of an X-ray film used. Since most of the X-ray film used in this country is locally manufactured, the former quantity can be determined with a fairly high degree of accuracy. The latter quantity has been assessed from a knowledge of the number and size of X-ray film used in three large diagnostic departments, as well as from the entire consumption of one importer of X-ray film. This leads to the figure of $4 \times 10^{6}$ examinations annually of which some 3.5 million are on adults and some five hundred thousand on children. The number of examinations per capita is, therefore, greater than in other countries. ${ }^{1}$ It is, however, relevant that while the number of doctors in Australia per head of population is rather less than that in the United States ${ }^{9}$ the number of radiologists per capita is some 15 per cent greater ${ }^{10}$. The number of $\mathrm{X}$-ray examinations of a particular type carried out has been determined by surveying the records of five Australian hospitals and the result of the survey is given in Table 2.

Table 2. Percentage distribution of $\mathrm{X}$-ray examinations in a number of Australian hospitals

\begin{tabular}{|c|c|c|c|c|c|c|c|c|c|}
\hline \multirow{2}{*}{ Examination } & \multicolumn{2}{|c|}{$A$} & \multicolumn{2}{|c|}{$B$} & \multirow{2}{*}{$\begin{array}{c}C \\
\text { Total }\end{array}$} & \multirow{2}{*}{$\begin{array}{c}D \\
\text { Total }\end{array}$} & \multicolumn{2}{|c|}{$E$} & \multirow{2}{*}{$\begin{array}{c}F \\
(\mathbf{F})\end{array}$} \\
\hline & $(\mathrm{Ml})$ & $(\mathrm{F})$ & $(\mathrm{M})$ & $(\mathrm{F})$ & & & $(\mathrm{M})$ & $(\mathrm{F})$ & \\
\hline Extremities & $26 \cdot 8$ & $17 \cdot 5$ & $30 \cdot 6$ & $15 \cdot 9$ & $17 \cdot 9$ & $33 \cdot 0$ & $26 \cdot 9$ & $20 \cdot 3$ & $4 \cdot 2$ \\
\hline Skull, etc. & $12 \cdot 6$ & $12 \cdot 4$ & $7 \cdot 8$ & $6 \cdot 9$ & $5 \cdot 3$ & $9 \cdot 0$ & $7 \cdot 9$ & $5 \cdot 7$ & $2 \cdot 6$ \\
\hline Chest & $20 \cdot 8$ & $29 \cdot 1$ & $29 \cdot 6$ & $36 \cdot 8$ & $55 \cdot 4$ & $25 \cdot 8$ & $44 \cdot 0$ & $42 \cdot 6$ & $70 \cdot 0$ \\
\hline $\begin{array}{l}\text { Pelvis including } \\
\text { pregnancies }\end{array}$ & $2 \cdot 6$ & $2 \cdot 8$ & $2 \cdot 4$ & $1 \cdot 4$ & $6 \cdot 4$ & $5 \cdot 6$ & & & $5 \cdot 1$ \\
\hline Hips & $2 \cdot 7$ & $3 \cdot 2$ & $1 \cdot 9$ & $3 \cdot 3$ & & & $=2$ & $6 \cdot 6$ & \\
\hline $\begin{array}{l}\text { Lumbo-sacral } \\
\text { joint }\end{array}$ & $4 \cdot 5$ & $3 \cdot 4$ & $5 \cdot 5$ & $5 \cdot 2$ & & & & & $2 \cdot 6$ \\
\hline Dorsal vertebrae & $2 \cdot 4$ & $2 \cdot 1$ & $0 \cdot 8$ & $0 \cdot 6$ & $2 \cdot 6$ & 10.7 & & & $0 \cdot 7$ \\
\hline Cervical vertebrae & $\overline{1} \cdot 5$ & $1 \cdot 7$ & $2 \cdot 2$ & $3 \cdot 5$ & & & $=5 \cdot 1$ & $4 \cdot 9$ & $0 \cdot 5$ \\
\hline Ribs & $0 \cdot 5$ & $0 \cdot 8$ & $1 \cdot 5$ & $0 \cdot 6$ & - & - & & & $0 \cdot 3$ \\
\hline Shoulders & $2 \cdot 4$ & $1 \cdot 5$ & $2 \cdot 8$ & $2 \cdot 1$ & $2 \cdot 5$ & 一 & 一 & - & - \\
\hline Urinary tract & $5 \cdot 5$ & $4 \cdot 9$ & $0 \cdot 3$ & $0 \cdot 5$ & - & $3 \cdot 3$ & $2 \cdot 1$ & $3 \cdot 1$ & $0 \cdot 7$ \\
\hline Cholecystography & $1 \cdot 4$ & $4 \cdot 6$ & - & $0 \cdot 5$ & $1 \cdot 2$ & $2 \cdot 3$ & $0 \cdot 8$ & $2 \cdot 8$ & $1 \cdot 4$ \\
\hline Abdomen & $8 \cdot 3$ & $5 \cdot 4$ & $1 \cdot 0$ & $3 \cdot 7$ & $4 \cdot 0$ & - & $1 \cdot 4$ & $2 \cdot 3$ & $1 \cdot 3$ \\
\hline $\begin{array}{c}\text { Barium meals } \\
\text { and enema }\end{array}$ & $2 \cdot 5$ & $2 \cdot 4$ & $9 \cdot 9$ & $8 \cdot 2$ & $3 \cdot 0$ & $7 \cdot 4$ & $7 \cdot 1$ & $7 \cdot 6$ & $4 \cdot 6$ \\
\hline I.V.P. & $2 \cdot 3$ & $2 \cdot 3$ & $1 \cdot 1$ & $3 \cdot 0$ & $1 \cdot 0$ & $2 \cdot 0$ & - & $\ldots$ & $2 \cdot 8$ \\
\hline Pyelography & $0 \cdot 4$ & $0 \cdot 5$ & - & $0 \cdot 1$ & $0 \cdot 6$ & $0 \cdot 3$ & 一 & - & $0 \cdot 4$ \\
\hline Gall-bladder area & $1 \cdot 9$ & $4 \cdot 6$ & $2 \cdot 5$ & $7 \cdot 1$ & - & - & 一 & - & $2 \cdot 0$ \\
\hline Bladder & $0 \cdot 6$ & $0 \cdot 3$ & $0 \cdot 1$ & - & - & - & - & 一 & 一 \\
\hline Kidney & $0 \cdot 2$ & $0 \cdot 2$ & $0 \cdot 2$ & $0 \cdot 1$ & - & 一 & 一 & - & - \\
\hline Liver & $0 \cdot 1$ & $0 \cdot 1$ & - & $0 \cdot 1$ & - & - & - & - & - \\
\hline Dental & 一 & - & - & - & $0 \cdot 3$ & 一 & $2 \cdot 3$ & $4 \cdot 1$ & $0 \cdot 1$ \\
\hline Salpingography & 一 & $0 \cdot 2$ & - & $0 \cdot 1$ & 一 & $\overline{0}$ & 一 & - & $0 \cdot 6$ \\
\hline Oihers & & - & - & - & - & $0 \cdot 4$ & - & 一 & 一 \\
\hline
\end{tabular}

Based on the foregoing information, it is possible to calculate the bonemarrow dose from each type of examination and the results are in Tables 3 and 4. In Table 3 are listed the values appropriate to normal techniques (N.V.) and also those appropriate to the use of high voltage (H.V.) techniques. It will be seen that the difference in the bone-marrow dose between 


\section{J. H. MARTIN AND G. MULLER}

normal and high $\mathrm{kV}$ conditions, is about 20 per cent. Although high kilovoltages result in lower skin doses, by a factor of the order of three, the greater penetration of high $\mathrm{kV}$ beams mean that more radiation penetrates to the bone marrow. As compared with a previous assessment ${ }^{11}$ in which no allowance was made for radiation quality, the value now obtained is some 18 per cent higher, a difference which is within the order of accuracy of the determination.

Table 3. Adults

\begin{tabular}{|c|c|c|c|c|c|}
\hline \multirow{2}{*}{ Examination } & \multirow{2}{*}{$\begin{array}{l}\text { Percentage } \\
\text { of cases } \\
\text { per annum }\end{array}$} & \multicolumn{2}{|c|}{$\begin{array}{c}\text { Marrow dose } \\
\left(\text { gram-rad } \div 10^{5}\right)\end{array}$} & \multicolumn{2}{|c|}{$\begin{array}{c}\text { Percentage of total } \\
\text { marrow dose }\end{array}$} \\
\hline & & N.V. & H.V. & N.V. & H.V. \\
\hline $\begin{array}{l}\text { Extremities } \\
\text { Skull } \\
\text { Chest } \\
\text { Ribs } \\
\text { Pelvis } \\
\text { Cervical vertebrae } \\
\text { Shoulders } \\
\text { Hips } \\
\text { Urinary tract } \\
\text { Cholecystography } \\
\text { Lumbo-sacral joint } \\
\text { Abdomen } \\
\text { Barium meal and enema } \\
\text { Pyelography } \\
\text { Bladder } \\
\text { Kidney } \\
\text { Liver } \\
\text { Salpingography } \\
\text { Dorsal vertebrae } \\
\text { Gall-bladder }\end{array}$ & $\begin{array}{r}22 \cdot 5 \\
12 \cdot 5 \\
24 \cdot 7 \\
0 \cdot 6 \\
2 \cdot 7 \\
1 \cdot 6 \\
1 \cdot 9 \\
2 \cdot 9 \\
5 \cdot 2 \\
2 \cdot 0 \\
4 \cdot 0 \\
7 \cdot 0 \\
2 \cdot 5 \\
2 \cdot 7 \\
0 \cdot 5 \\
0 \cdot 2 \\
0 \cdot 1 \\
0 \cdot 1 \\
2 \cdot 2 \\
3 \cdot 2\end{array}$ & $\begin{array}{c}334 \\
282 \\
7 \cdot 6 \\
1240 \\
12 \\
8 \\
259 \\
570 \\
202 \\
950 \\
1630 \\
192 \\
358 \\
4 \cdot 5 \\
3 \cdot 3 \\
1 \cdot 3 \\
82 \\
656 \\
71\end{array}$ & $\begin{array}{c}228 \\
158 \\
4 \\
1000 \\
6 \cdot 4 \\
3 \cdot 8 \\
323 \\
228 \\
80 \\
1130 \\
1480 \\
235 \\
143 \\
2 \cdot 1 \\
1 \cdot 3 \\
0 \cdot 4 \\
135 \\
500 \\
30\end{array}$ & $\begin{array}{r}\overline{5 \cdot 1} \\
4 \cdot 2 \\
0 \cdot 1 \\
18 \cdot 7 \\
0 \cdot 2 \\
0 \cdot 1 \\
3 \cdot 7 \\
7 \cdot 9 \\
2 \cdot 9 \\
14 \cdot 2 \\
22 \cdot 6 \\
2 \cdot 9 \\
5 \cdot 0 \\
0 \cdot 1 \\
0 \cdot 1 \\
- \\
1 \cdot 2 \\
9 \cdot 9 \\
1 \cdot 0\end{array}$ & $\begin{array}{r}\overline{-}- \\
3 \cdot 7 \\
2 \cdot 7 \\
0 \cdot 1 \\
16 \cdot 2 \\
0 \cdot 1 \\
0 \cdot 1 \\
5 \cdot 7 \\
3 \cdot 4 \\
1 \cdot 3 \\
21 \cdot 0 \\
27 \cdot 4 \\
4 \cdot 2 \\
2 \cdot 1 \\
- \\
- \\
- \\
2 \cdot 4 \\
9 \cdot 3 \\
0 \cdot 5\end{array}$ \\
\hline Gall-bladder & & 6862 & 5688 & & \\
\hline
\end{tabular}

To the values in Tables 3 and 4 must be added allowances for screening procedures and mass miniature radiography. The final bone-marrow dose becomes about 140 gram-rads or 95 millirads per head of population.

These figures make it possible to assess the incidence of leukaemia which can be attributed to the use of diagnostic X-rays. Broadly speaking, from a survey of some X-ray diagnostic departments, it can be said that the age distribution of the cases presented does not differ radically from that of the population, and the average number of years at risk is thus 34. Assuming that there is no threshold for the effect, that the integrated dose rather than the dose at any given point is significant, and that the dose administered is cumulative, and these assumptions should be stressed, one finds that the incidence of leukaemia which could possibly be attributed to the use of diagnostic X-rays is some 10 per cent of the 50 per million cases occurring annually, i.e. a total of 50 cases per year in Australia.

Between 1936 and 1956 the consumption of X-ray film for medical use in 
Table 4. Cihildren

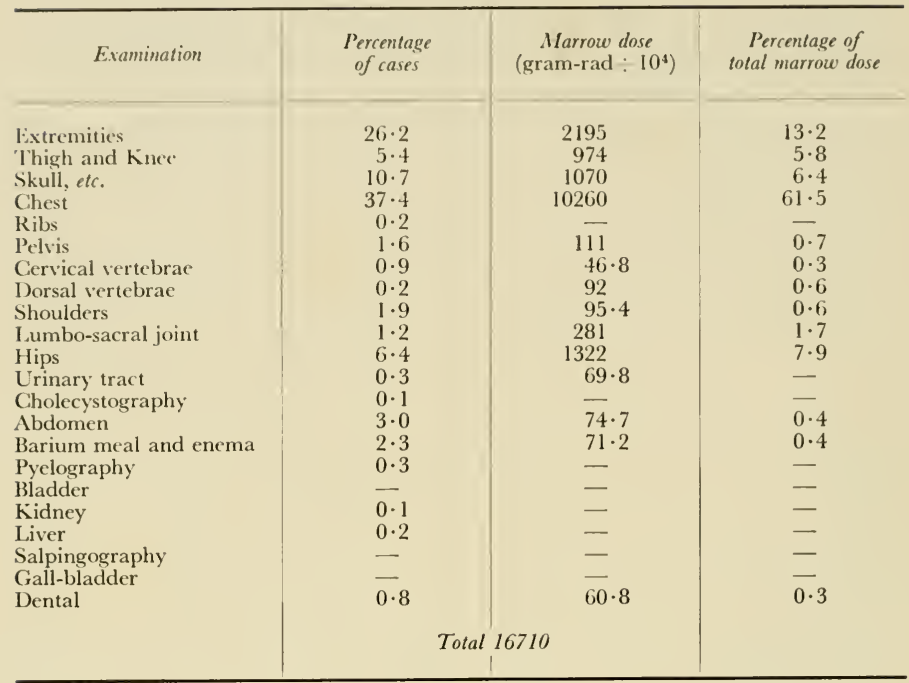

Australia increased by a factor of about nine, while in the same period, the combined sensitivity of film and screens increased by about five and the population by about 50 per cent. It follows that the amount of radiation fed into the bone marrow of the population has not changed in that period.

\section{REFERENCES}

${ }^{1}$ United Nations Scientific Committee on the Effects of Atomic Radiation Report to the General Assembly, 1958

${ }^{2}$ Martin, J. H. and Evans, E. A. Brit. J. Radiol. N.S. 32 (1959) 7

${ }^{3}$ Trout, E. D., Kelley, J. P. and Cathey, G. A. Amer. J. Roentgenol. 67 (1952) 946

${ }^{4}$ Spiers, F. W. Brit. J. Radiol. N.S. 24 (1951) 365

${ }^{5}$ Spiers, F. W. in the Medical Research Council Special Report Series No. 295: H.M. Stationery Office, London, 1957

${ }^{6}$ Mechanik, N. Z. ges. Anat. 1. Z. Anat. EntwGesch. 58 (1926) 79.

${ }^{7}$ International Commission on Radiological Protection Brit. 7. Radiol, N.S. Supplement 6 (1955) 86, Table DX.

8 ibid. Supplement 6 (1955) 25, Table II.

${ }^{9}$ Health: Journal of the Commonwealth Department of Health 8 (1958) 17

${ }^{10}$ Donaldson, S. W. Amer. F. Roetgenol. 66 (1951) 929

${ }^{1}$ Martin, J. H. Med.J. Aust. ii (1958) I57 


\title{
SOME EFFEGTS ON LYMPHOID GELLS OF OCGUPATIONAL AND AGGIDENTAL EXPOSURE TO IONIZING RADIATIONS
}

\author{
D. O. ShiEls
}

\section{Melbourne}

INTRODUCTION

ACGORDING to numerous authorities the earliest sign of the effects of ionizing radiation on the blood is a reduction in white cell count or in the lymphocyte count. The object of this paper is to show that certain other changes are more sensitive and consistent indications than either of these, of the effects of minor degrees of ionizing radiation.

Evidence has previously been adduced ${ }^{1,2,3,4}$ that when comparison was made between a group of persons occupationally exposed to ionizing radiations and a group of persons not so exposed, there were in the former group the following changes from the normal: an increase in the ratio of large lymphocytes plus monocytes to small lymphocytes; an increase in the ratio of large lymphocytes to small lymphocytes; a decrease in the percentage of lymphocytes which show granules in the cytoplasm, and an increase in the percentage of the monocytes which were of a particular type, and certain indices derived from these. Evidence was also produced ${ }^{2}$ that the tests for these factors are more sensitive and consistent than are the usual blood counts, in indicating effects of ionizing radiation.

Any criticism to the effect that the deviations from the normal blood picture were due to factors other than radiation, such as overwork, fatigue, bad ventilation, sub-clinical infection, worry, etc., never had much weight since the controls were also subject to similar influences. Comment has been made by Russ $^{5}$ in reference to the ratios that other factors not yet recognized might be at work, such as apprehension over dangers or reaction to a new environment. Such factors could not apply in the case of persons exposed to ionizing radiation of which they had no knowledge. Such were the circumstances in the accidental exposures dealt with in this paper. Neither the adults nor the children had any apprehension of danger, nor were they aware of being exposed to any new environment.

It is reasonably certain, therefore that the effects on the blood which were found in these accidental exposure cases were due to ionizing radiation even though the exposures in most of the cases were not great. A short description of the occurrences is given below.

\section{ACCIDENTAL EXPOSURES}

\section{The Caesium Incident}

A man aged about 28 years $(\mathrm{Mr} . \mathrm{X}$ ) carried about at work for a week, in the front thigh pocket of his overalls, a capsule containing 2.5 curies of 


\section{()C:LPATIONIL AND AC:C:II)ENTAL EXPOSLRE}

${ }^{137}$ Cs. His overalls were worn while at work and on at least four and possibly fwe crenings while he was at home doing work about the house. On these occasions he wore the overalls while at the evening meal during which his family consisting of his wife and three young female children $\left(1 \frac{1}{2}, 3 \frac{1}{2}\right.$ and $5 \frac{1}{2}$ years of age) were seated at the dining table in close proximity to him.

During the night the overalls either hung on a wall in the living-room or were draped over a chair in it, at a distance possibly of 10 to 12 feet from the bunks in which the children slept. The positions are shown by the asterisks in Figure 1.

Five other workmen were associated with Mr. X while he was at work
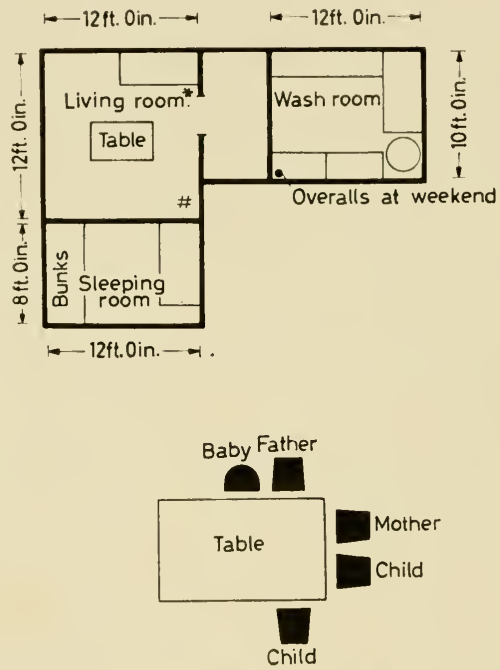

Figure 1. Plan of the house of Mr. X

and two of these were more closely associated with him than the others, working with him all the time.

Shortly after admission of Mr. X to hospital tests were performed on him and the five other workmen. They were carried out by the hospital staff. With the exception of those of $\mathrm{Mr}$. X the only striking abnormality in the other workmen were low platelet counts $(148,100,150,160,138,000$, Mr. X's being 80,000 . Serial examinations of the peripheral blood of Mr. $\mathrm{X}$ were carried out by the hospital staff during a period of some months and also several bone-marrow biopsies. Subsequently the right leg of Mr. X was amputated at the hip joint, because of extensive tissue damage. The tests referred to in the Introduction to this paper were performed on Mr. X and four of his fellow workmen, on his wife and three children. Those on Mr. X were continued at intervals for some months. 


\section{O. SHIELS}

\section{The Cobalt Incident}

A capsule containing 0.5 curies of ${ }^{60} \mathrm{Co}$ was being used for the testing of gas pipes. A small boy aged four years handled it for about 10 minutes, a small playmate aged six years probably handled it for a short time, as did the boy's mother for perhaps 3 minutes.

\section{Dosages}

Approximate estimates of the dosages received are shown later, together with the corresponding values of Index 1 .

\section{Clinical Effects}

Except in the case of $\mathrm{Mr}$. X there were no recognizable clinical effects attributable to exposure to ionizing radiation.

Experience prior to these incidents had shown that clearer separation of the results for exposed and unexposed groups could be obtained by combining two or more of the factors above mentioned in the Introduction into three indices. Index 1 is equal to the percentage of the lymphocytes with granules in the cytoplasm divided by the ratio $\frac{L+M}{S}$. Index la is the percentage of the lymphocytes with granules in the cytoplasm divided by the ratio $\frac{L}{S}$. Index 2 is Index 1 divided by the percentage of monocytes which are of a particular type described elsewhere 4 . This has not been a matter merely of expediency in separation of classes of persons, since it has been shown that there is a close inverse correlation between the percentage of lymphocytes with granules and the ratio of monocytes and large lymphocytes to small lymphocytes and also between the percentage of lymphocytes with granules and the percentage of monocytes which are of the particular type above referred to.

\section{Effects on $\mathrm{Mr} . \mathrm{X}$}

Total body dose was estimated at 150 to 200 r. Neutrophils showed a rise to about 9700 in the second day after cessation of exposure and then an irregular fall to normal range at 20 to 30 days.

Lymphocytes were originally very low being only 250 on the first day after cessation of exposure-rising irregularly to over 1500 at 14 days.

Monocytes were 270 on the first day after cessation of exposure and rose rapidly to 1400 on the eighth day. Eosinophils showed irregularly high values for about 15 days then a period of low values for 30 days and again high values for 60 days. Platelets were at first very low rising to normal range at 7 to 8 days with a second irregular fall to very low values $(<100,000)$ at 16 to 18 days - followed by a fairly steady rise to normal values at about 55 days.

Table 1 shows a comparison of the effects on the usual test factors of irradiation and on the newer test factors. This indicates on the whole a much slower recovery to normal values for the newer tests than in the case of the usual tests. 
Table 1

\begin{tabular}{|c|c|}
\hline Factor & Relation to normal values \\
\hline $\begin{array}{l}\text { Waemoglobin } \\
\text { White cell count } \\
\text { Absolute counts } \\
\text { Neutrophils } \\
\text { Lymphocytes } \\
\text { Eosinophils } \\
\text { Monocytes } \\
\text { Platelets }\end{array}$ & $\begin{array}{l}\text { Within } 81-90 \% \text { of normal throughout } 80 \text { day's } \\
\text { Within normal for first } 45 \text { days } \\
\text { Returned to normal range in } 20-30 \text { days } \\
\text { Abnormal', throughout, , } 32 \text { days } \\
\text { Returned to normal range in } 20 \text { days } \\
\text {,", ,", , , } 50 \text { days }\end{array}$ \\
\hline $\begin{array}{l}\frac{L+M}{S} \\
\frac{L}{S} \\
\% \text { Lymphocytes } \\
\text { with granules } \\
\text { Index } 1 \\
\text { Index } 2 \\
\text { Ratio } \frac{\text { Monocytes }}{\text { Lymphocytes }}\end{array}$ & 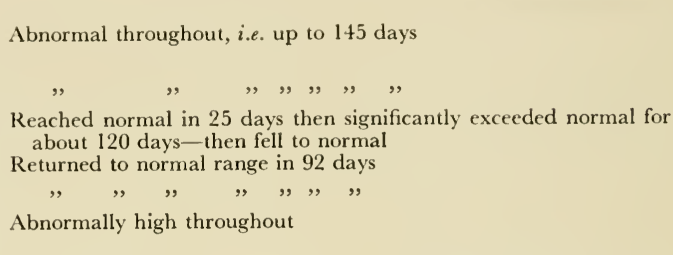 \\
\hline
\end{tabular}

\section{Effects on all subjects}

It was not possible to estimate accurately the doses received but approximate calculations have been made by the staff of the Cancer InstituteDr. Martin and Miss McRae and by the late Dr. C. E. Eddy. These with the corresponding values for Index 1 are shown in Table 2. These results suggest a rough inverse relationship between dosages and the values of Index 1 .

Table 2

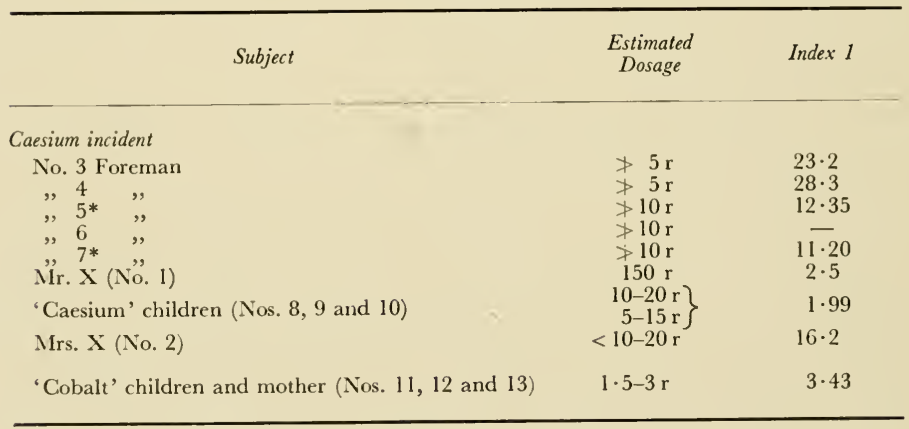

- Nos. 5 and 7 worked with No. 1 the whole time on the job but were not with him at home.

Figures 2 and 3 show the curves for Index 1 for Mr. X (No. 1 of the ${ }^{137} \mathrm{Cs}$ cases), No. 1 of the ${ }^{60} \mathrm{Co}$ cases (small boy of four years) i.e., No. 11 in Table 3, and the mean curve for the ${ }^{60} \mathrm{Co}$ cases. 


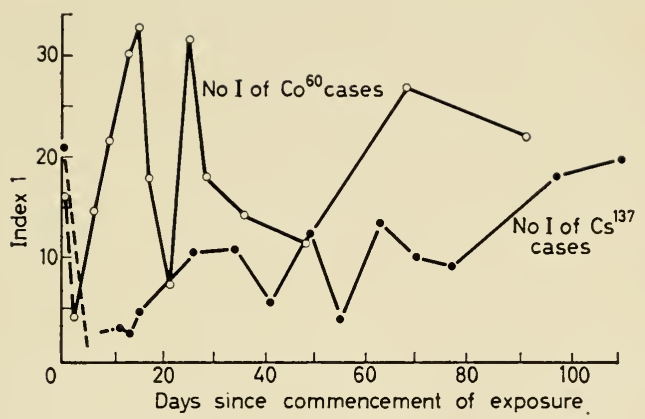

Figure 2. Index 1 of Mr. X (No. 1 of the ${ }^{137} \mathrm{Cs}$ cases) and No. 1 of the ${ }^{60} \mathrm{Co}$ cases (small boy of four years)

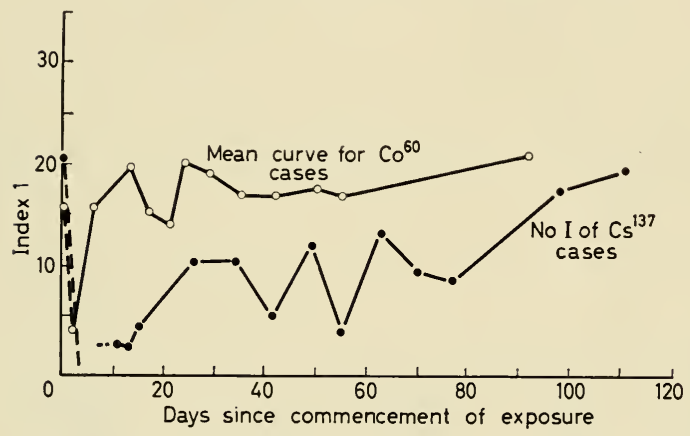

Figure 3. Mean curve of Index 1 for all ${ }^{60} \mathrm{Co}$ cases and No. 1 of the ${ }^{137} \mathrm{Cs}$ cases

Comparison of accidentally exposed persons with unexposed persons

The values of the various newer tests for accidentally exposed persons have been compared with those for unexposed persons. The group of exposed persons was made up of $\mathrm{Mr}$. $\mathrm{X}$ and his wife, the two fellow workmen who worked with him most closely, his three children, the boy who handled the cobalt ampoule, his little companion and his mother. The unexposed group consisted of clerical and other staff of the Victorian Health Department and 20 small healthy children. The results for exposed children (five) are shown in Table 3 and illustrated in Figure 4. There was a very significant difference between the mean for each of these factors for exposed and unexposed children the $P$ values being for $\frac{L+M}{S} \quad 0.05>P>0.01$; $\frac{L}{S} \quad 0.01>P>0.001$; per cent lymphocytes with granules $P<0.001$, Index $1 P<0 \cdot 001$, Index $2 P<0 \cdot 001$. 
OCCLP.IIIONAL, ANI) ACCIIDENTAL IXPOSLRI:

Table 3. Results marked $a$ are the first; those marked $b$ are the results a month later

\begin{tabular}{|c|c|c|c|c|c|c|c|c|}
\hline \multirow{2}{*}{ Factor } & & \multicolumn{3}{|c|}{${ }^{137}$ Cacsium subjects } & \multicolumn{2}{|c|}{ B"Cio subjects } & \multirow{2}{*}{$\begin{array}{l}\text { Mean } \\
\text { for } \\
\text { exposed } \\
\text { children }\end{array}$} & \multirow{2}{*}{$\begin{array}{l}\text { Mean } \\
\text { for } \\
\text { controls } \\
(20)\end{array}$} \\
\hline & & No. 8 & No. 9 & No. 10 & No. 11 & No. 12 & & \\
\hline$\frac{I+. M}{S}$ & $a$ & $3 \cdot 7$ & $2 \cdot 75$ & $2 \cdot 26$ & $6 \cdot 25$ & $3 \cdot 43$ & $3 \cdot 68$ & - \\
\hline & $b$ & $2 \cdot 58$ & $1 \cdot 96$ & $1 \cdot 73$ & $2 \cdot 37$ & $2 \cdot 03$ & $2 \cdot 13$ & $2 \cdot 73$ \\
\hline$\frac{L}{S}$ & $a$ & $2 \cdot 74$ & $2 \cdot 22$ & $1 \cdot 75$ & $4 \cdot 0$ & $2 \cdot 23$ & $2 \cdot 59$ & - \\
\hline & $b$ & $2 \cdot 0$ & $1 \cdot 52$ & $\mathrm{I} \cdot 30$ & $1 \cdot+5$ & $1 \cdot 32$ & $1 \cdot 58$ & $1 \cdot 89$ \\
\hline $\begin{array}{l}\% \text { of lymphocytes } \\
\text { with granules }\end{array}$ & $\vec{a}$ & $\begin{array}{l}7 \cdot 54 \\
15 \cdot 4\end{array}$ & $\begin{array}{c}0 \cdot 0 \\
13 \cdot 56\end{array}$ & $\begin{array}{r}8 \cdot 86 \\
20 \cdot 75\end{array}$ & $\begin{array}{l}25 \cdot 0 \\
33 \cdot 33\end{array}$ & $\begin{array}{r}9 \cdot 52 \\
+5 \cdot 45\end{array}$ & $\begin{array}{l}10 \cdot 18 \\
25 \cdot 70\end{array}$ & $42 \cdot 35$ \\
\hline $\begin{array}{l}\% \text { of Monocytes of } \\
\text { "B' type }\end{array}$ & $\begin{array}{l}a \\
b\end{array}$ & $\begin{array}{l}42 \cdot 4 \\
30 \cdot 0\end{array}$ & $\begin{array}{l}54 \cdot 54 \\
30 \cdot 0\end{array}$ & $\begin{array}{l}41 \cdot 75 \\
11 \cdot 11\end{array}$ & $\begin{array}{l}48 \cdot 15 \\
26 \cdot 66\end{array}$ & $\begin{array}{l}33 \cdot 33 \\
27 \cdot 27\end{array}$ & $\begin{array}{l}44 \cdot 03 \\
23.0\end{array}$ & 4 \\
\hline Index 1 & $a$ & $2 \cdot 04$ & $\begin{array}{l}0 \cdot 0 \\
6 \cdot 93\end{array}$ & $\begin{array}{r}3 \cdot 92 \\
11 \cdot 99\end{array}$ & $\begin{array}{c}4 \cdot 0 \\
14 \cdot 06\end{array}$ & $\begin{array}{r}2 \cdot 86 \\
22 \cdot 23\end{array}$ & $\begin{array}{r}2 \cdot 58 \\
12 \cdot 26\end{array}$ & - \\
\hline Index 2 & $a$ & $\begin{array}{l}0 \cdot 05 \\
0 \cdot 20\end{array}$ & $\begin{array}{l}0 \cdot 0 \\
0 \cdot 23\end{array}$ & $\begin{array}{l}0.095 \\
1 \cdot 08\end{array}$ & $\begin{array}{l}0 \cdot 08 \\
0 \cdot 52\end{array}$ & $\begin{array}{l}0.083 \\
0.81\end{array}$ & $\begin{array}{l}0.06 \\
0.57\end{array}$ & $0 \cdot 70$ \\
\hline
\end{tabular}

The results for Index 1 for mixed groups of adults and children are shown in Table t. They show very significant differences between the mean values for the exposed and unexposed groups.

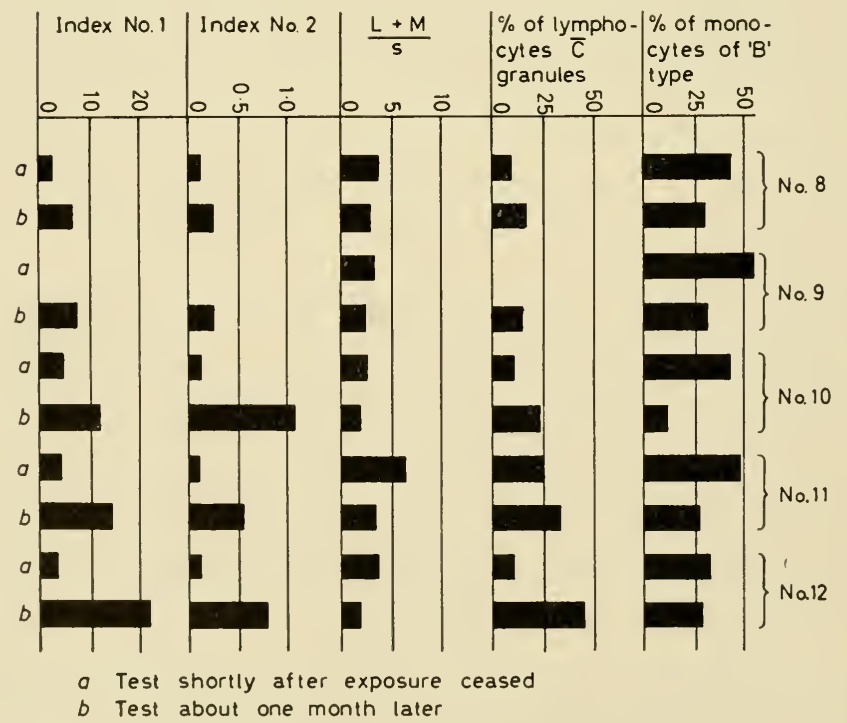

Figure 4. Results of tests on accidentally exposed children 
D. O. SHIELS

Table 4. Index 1-Comparison of means

\begin{tabular}{|c|c|c|c|c|c|c|}
\hline \multicolumn{2}{|c|}{ Groups compared } & \multicolumn{5}{|c|}{ Mean values } \\
\hline Unexposed & Exposed & Unexposed & Exposed & $n$ & ' $t$ ' & $P$ \\
\hline $56\left\{\begin{array}{l}36 \text { adults } \\
20 \text { children }\end{array}\right.$ & $12\left\{\begin{array}{l}7 \text { adults } * \\
5 \text { children }\end{array}\right.$ & $19 \cdot 3$ & $10 \cdot 0$ & 66 & $3 \cdot 629$ & $<0.001$ \\
\hline do. & $10\left\{\begin{array}{l}5 \text { adults } \\
5 \text { children }\end{array}\right.$ & $19 \cdot 3$ & $6 \cdot 07$ & 64 & $5 \cdot 07$ & $<0 \cdot 001$ \\
\hline $48\left\{\begin{array}{l}28 \text { adults } \\
20 \text { children }\end{array}\right.$ & $12\left\{\begin{array}{l}7 \text { adults } * \\
5 \text { children }\end{array}\right.$ & $16 \cdot 88$ & $10 \cdot 00$ & 58 & $3 \cdot 52$ & $<0.001$ \\
\hline $40\left\{\begin{array}{l}20 \text { adults } \dagger \\
20 \text { children }\end{array}\right.$ & $10\left\{\begin{array}{l}5 \text { adults } \\
5 \text { children }\end{array}\right.$ & $15 \cdot 5$ & $6 \cdot 07$ & 48 & $5 \cdot 74$ & $<0.001$ \\
\hline
\end{tabular}

* Includes values for 2 adults who had very little exposure.

+ The 20 values for adults were the lowest of the 36 giving the most unfavourable values for comparison of the means.

\section{EFFECTS IN OCCUPATIONALLY EXPOSED PERSONS}

Evidence additional to that previously produced $1,2,3,4$ will now be presented that quite marked changes in the values found for these newer tests occur as a result of a few months' work in occupations involving exposure to ionizing radiation.

Fourteen persons working as nursing sisters or radiographers in mass

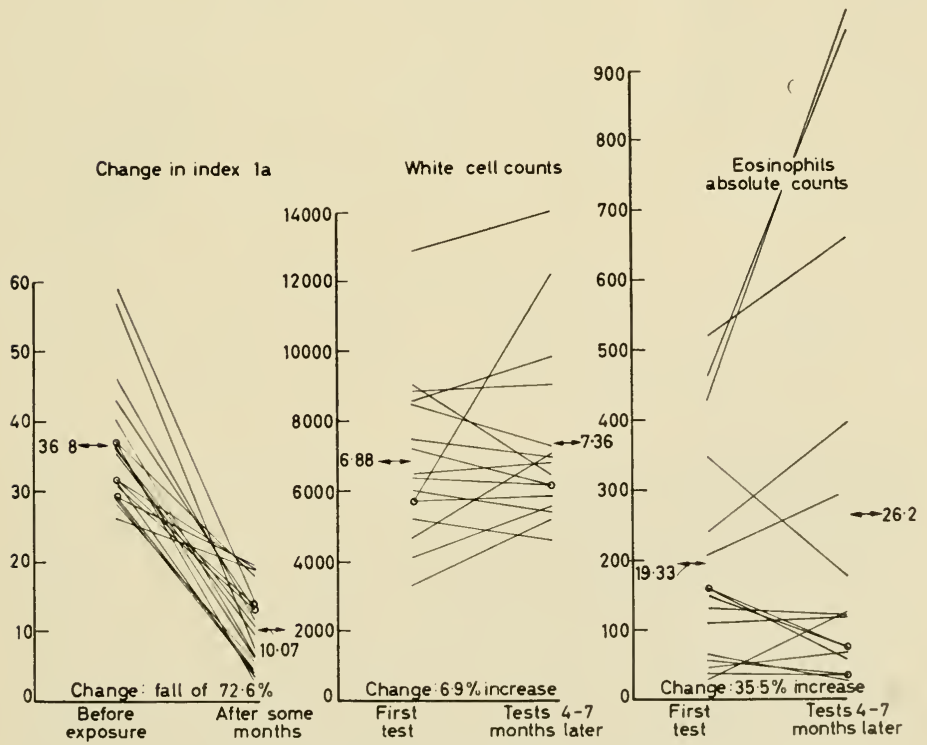

Figure 5. Results of tests on occupationally exposed persons 
$\mathrm{X}$-ray surveys or on $\mathrm{X}$-ray work in Tuberculosis Bureaux, were examined before conmencing in their work and again after a period of four to seven months. Two others who had worked in this type of activity for some considerable time were examined during the period during which they were engaged in this work and again after being for some months on work in which there was no exposure to ionizing radiation. The changes in the latter two cases were just the opposite to those found for the fourteen. The usual blood tests were done by a technical assistant at the same time as the blood films were taken for these newer tests.

There were no significant changes in the counts of white cells, lymphocytes, nor in the lymphocyte/neutrophil ratios.

There appeared to be an increase in the eosinophil counts but this was not

Change in absolute lymphocyte counts
Change in percentage of lymphocytes with granules
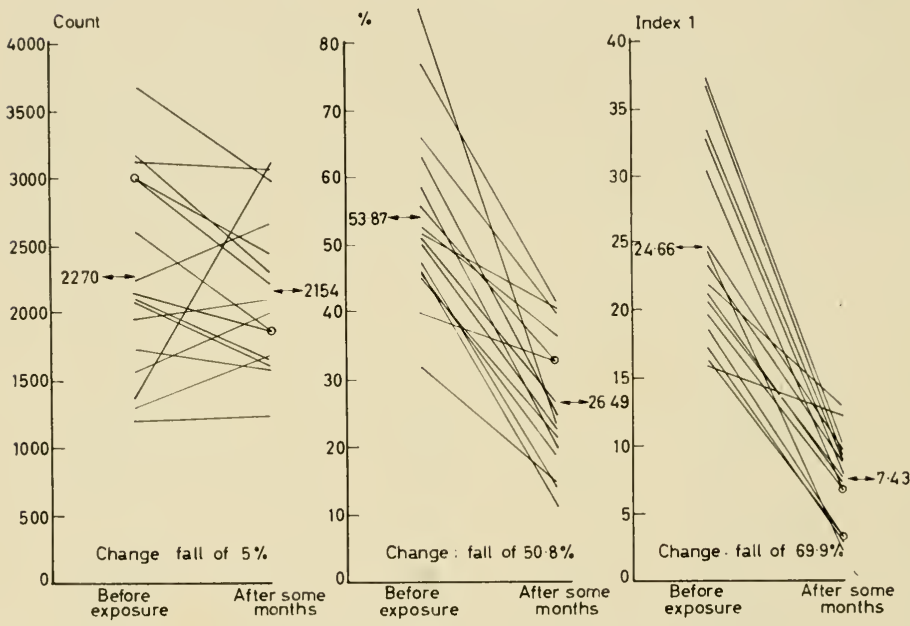

Figure 6. Results of tests on occupationally exposed persons

statistically significant. However, if the differences between the two values for each person were expressed as a percentage of the first pre-exposure value, the mean of such percentage differences was significant, $P<0 \cdot 001$.

The values are shown in Figures 5, 6 and 7. The lines joining the points are meant merely to indicate the corresponding points for each different individual. The results of statistical analysis of the values are as shown in Table 5 .

The results shown above indicate the value of paying attention to structural characteristics rather than to mere numbers. For instance, although the absolute lymphocyte counts remained significantly unaltered after some months' exposure, the absolute count of small lymphocytes showed a marked 


\section{O. SHIELS}

decrease. The counts of small lymphocytes were done as the result of suggestions made by Dr. O. A. Trowell of Harwell.

The clinical significance of the changes which were observed in these newer tests is not known at present, beyond the fact that abnormal values persisting for some time were associated in other individuals with lassitude and fatigue.

If it is a fact that the smaller lymphocytes are the older, more mature ones, then the considerable reduction in their numbers, the total numbers of all

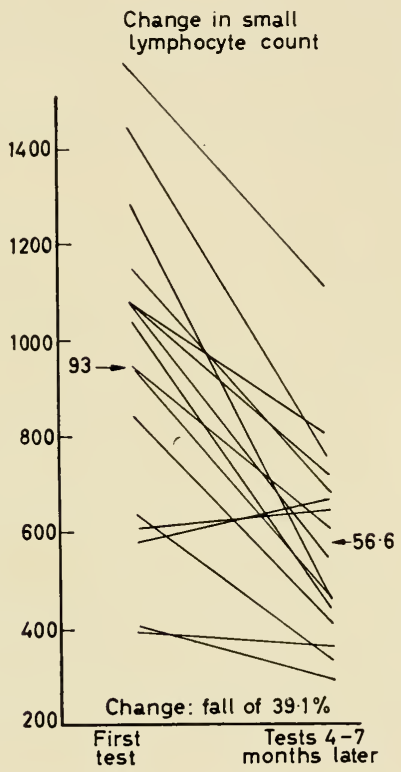

Figure 7. Results of tests on occupationally exposed persons

lymphocytes showing no significant reduction, would probably indicate a more rapid turnover of the lymphocytes. This increase in turnover might amount to 30 per cent so that the lymphopoietic system would be working at increased capacity. If this condition should continue for 20 to 30 years, as it may well do in those whose livelihood is in radiation work, the effects might be significant with regard to the expectation of life.

The dosages for those occupationally exposed were not known but they were working in conditions considered satisfactory by those in authority in their organizations. At the time these tests were made monitoring was unsatisfactory. In those instances for which monitoring records were available the exposures were less than $0.3 \mathrm{r}$ free air dose per week. 
Table 5. Mean values

\begin{tabular}{|c|c|c|c|c|}
\hline Factor & $\begin{array}{c}\text { Before } \\
\text { exposure }(16)\end{array}$ & $\begin{array}{l}\text { ifter } 4.7 \\
\text { months (16) }\end{array}$ & ' $t$ ' & $P$ \\
\hline White cell count & 6880 & 7360 & $0 \cdot 50$ & $\left.\begin{array}{r}<0.7 \\
0.6\end{array}\right\}$ \\
\hline 1.ymphocyte count & 2270 & 2100 & $0 \cdot 7.45$ & $\left.\begin{array}{r}<0.5 \\
<0.4\end{array}\right\}$ \\
\hline I arge lymphocyte count & 1339 & 1533 & $1 \cdot 296$ & $\left.\begin{array}{l}<0.3 \\
>0.2\end{array}\right\}$ \\
\hline Ratio $\begin{array}{l}\text { Iymphocyte } \\
\text { neutrophils }\end{array}$ & $0 \cdot 75$ & $0 \cdot 58$ & $1 \cdot 90$ & $\left.\begin{array}{l}<0.1 \\
0.05\end{array}\right\}$ \\
\hline Eosinophil count & 193 & 262 & $0 \cdot 78$ & $\left.\begin{array}{r}<0.5 \\
>0.4\end{array}\right\}$ \\
\hline Small lymphocyte count & 930 & 566 & $3 \cdot 55$ & $\left.\begin{array}{c}<0.01 \\
>0.001\end{array}\right\}$ \\
\hline$\%$ lymphocytes with granules & $5+$ & 26 & $6 \cdot 59$ & $<0.001$ \\
\hline Index 1 & $24 \cdot 4$ & $7 \cdot 4$ & $9 \cdot 81$ & $<0.001$ \\
\hline Index la & $36 \cdot 8$ & $10 \cdot 1$ & $9 \cdot 91$ & $<0 \cdot 001$ \\
\hline
\end{tabular}

Whatever the dosages the fact remains that these newer tests showed marked changes whereas the usual tests did not.

Acknowledgements are gratefully rendered to the following: Dr. K. D. Fairley, Consulting Physician, Royal Melbourne Hospital, Dr. P. O'Donnell, Medical Superintendent of the same Hospital, for access to the patient Mr. X and the hospital records of the case; Dr. D. C. Cowling, Clinical Pathologist at the Royal Melbourne Hospital for results of the usual blood tests; Dr. Alan Bell, Director of the Industrial Hygiene Division, New South IVales Department of Health for loan of blood films of the ${ }^{60} \mathrm{Co}$ cases; the late Dr. C. E. Eddy, Director of the Commonwealth X-ray and Radium Laboratory and Dr.J.H. Martin, Physicist and Miss E. C. McRae, B.Sc., of the Physics Department of the Cancer Institute for estimates of dosages; Mrs. van den Berg of the Industrial Hygiene Division, Department of Health, Iictoria, for the preparation of blood films. Special thanks are given to the Hon. E. Cameron, Minister of Health, Tictoria, for approval of a grant for the continuation of this work.

\section{REFERENCES}

${ }^{1}$ Shiet.s, D. O. Med. J. Aust. (195t) 583

${ }^{2}$ Shitels, D. O. Australasian Annals of Medicine 4 (1955) 145

${ }^{3}$ Shitels, D. O. Med. J. Aust. (1955) 91

${ }^{4}$ Shinels, D. O. Med. J. Aust. (1955) 235

${ }^{5}$ Russ, S. Bull. Hyg., Lond. 30 (1955) 1087 


\title{
LEUKAEMIA TREATED BY RADIATION
}

\author{
J. F. Loutit \\ Medical Research Council Radiobiological Research Unit, \\ Atomic Energy Research Establishment, Harwell, England
}

THE discussion of this subject will be confined to work on leukaemia in the mouse. It is true that in the last year or so similar studies have been made on the leukaemia in man but in this field our laboratory has played as yet no part.

The work on mice stemmed from the observations by Jacobson and his group $^{1}$ that mice which had received a lethal dose of X-rays might recover following suitable treatment. The treatment consisted of implanting, under anaesthesia, into the peritoneal cavities of the mice, spleens from normal animals. Lorenz et al. ${ }^{2}$ carried the observations further, demonstrating that suspensions of cells from bone marrow administered by injection after the irradiation were also effective as therapy. In Lorenz's hands injections by the intravenous route gave better results than those given intraperitoneally; and successful results were obtained in mice, not only when homologous bone marrow from mice of different strains but also when heterologous bone marrow from animals of a different species, guinea-pigs, was injected intravenously. It was later shown by Congdon and Lorenz ${ }^{3}$ that rat bone marrow, as well as guinea-pig marrow, was effective.

Naturally, these very striking results led to the conclusion that the normal bone marrow or spleen, given as therapy, contained a humoral agent which caused an accelerated recovery of the irradiated mouse's own haemopoietic tissue. It was inconceivable, on the basis of the laws of tissue transplantation, that foreign material which had been injected could be a viable graft, which would multiply and function and thereby save the irradiated animal's life. However, when we entered the field sometime after Jacobson and Lorenz, we set out to see whether, under the very special circumstances following a lethal dose of $\mathrm{X}$ radiation, the normal laws of tissue transplantation did in fact hold.

After accumulating a certain amount of more or less indirect evidence which would support an hypothesis involving the uptake of the injected cells as a graft, and their subsequent function, we were able to show, as did others at about the same time, that in fact the massive dose of X-raysnormally the lethal dose-had destroyed the animal's capacity to reject foreign cells, which in fact flourished and continued to keep the animal alive.

The evidence from our laboratory ${ }^{4,5}$ indicated that not only was the bone marrow of the irradiated animal recolonized by the injected cells but so were the lymphoid tissues. Given that the recovery was due to the recolonization of the host's depopulated haemopoictic tissues with cells from a normal 
donor, it was obvious to many that here was a potential treatment for leukaemia of the mouse.

This, like the analogous human condition, is a generalized disease involving the normal haemopoietic and lymphopoietic tissues but infiltrating other tissues as well. The characteristic leukaemia of the mouse is lymphoblastic and the murine leukacmias with which we shall be concerned are of this standard form. If the malignant lymphoid cells are as radio-sensitive as the normal cells of the haemopoietic tissues, then in theory it should be possible to destroy these malignant cells and replace them with a normal culture from another animal. In point of fact, even before the cellular repopulation hypothesis had been substantiated, Hollcroft and her colleagues from the National Cancer Institute at Bethesda ${ }^{6}$ had tried this sort of treatment in the case of a mouse lymphosarcoma and in generalized lymphomatosis of the guinea-pig. Their results, however, had not been dramatic and their report which appeared in a journal not widely read had escaped us.

Our earliest results in attempting this form of treatment were also a therapeutic failure, in that all the treated animals died. Nevertheless, there was enough material to give us some encouragement. These results which have been reported ${ }^{7}$ can be summarized as follows: we had available to us a radiation-induced lymphoblastic leukaemia (151/1) of the CBA strain of mouse given to us by Dr. R. H. Mole. This was maintained by serial passage of the leukaemic cells in CBA mice. The leukaemia in the early generations of passage was strictly strain-specific. These mice of the CBA strain were injected, either intravenously or intraperitoneally, with $10^{6}$ cells and a period of seven days was allowed to elapse during which it was presumed that the leukaemic cells would proliferate. In fact, it took about two to three weeks, depending on the route of inoculation, for the mice to succumb to the transmitted leukaemia. After seven days the injected mice were irradiated at $43 \mathrm{rad} / \mathrm{min}$ with $950 \mathrm{rad}$ of $\mathrm{X}$-rays to the whole body. They were then injected intravenously with normal bone marrow from adult mice, or spleen from infant mice.

In the first experiments, the normal cells injected came from mice of the same inbred strain. This isologous material was adequate in reconstituting the depopulated tissues, but after a lapse of about a month the mice died with a recrudescence of the leukaemia. Therefore the dose of $950 \mathrm{rad}$ given at high dose rate had been insufficient to cause the complete elimination of all the leukaemic cells.

However, the other CBA mice, to which the leukaemia had been transmitted in the same dose, were treated after irradiation, not with isologous myeloid tissue, but with homologous material from mice of strains C57BL, $\mathrm{A}$ or $\mathrm{C} 3 \mathrm{H}$. In some cases the homologous material came from normal mice, in other cases from mice which had previously been immunized by two injections of the CBA leukaemic cells. Some of these mice treated with homologous material lived for several months and then died with a condition of generalized wasting and loss of condition, a syndrome which is not uncommon when homologous or heterologous material has been administered. It is often called 'secondary disease', because it is secondary in time; and it is generally agreed that it is a consequence of an immunological reaction between the elements of donor and host in the chimaerical animals. 


\section{J. F. LOUTIT}

Congdon $^{8}$ and Makinodan ${ }^{9}$, from Oak Ridge, have in the past expressed their opinion that this 'secondary disease' is caused by the host recovering its immunological capacity and reacting against the graft. However, our published views ${ }^{10}$ on the other hand are that it is due to the donor material maturing as lymphoid tissue and setting up an immunological reaction against the host's antigens. The fact that some of these 'leukaemic' CBA mice, recolonized with foreign homologous bone marrow, did in fact not die of the recurrence of their leukaemia but of 'secondary disease' is, we think, one of the pieces of evidence which favours our hypothesis and we have further evidence from a number of different angles ${ }^{11}$.

For the moment we accept that the donor tissue does react against the host on normal tissue and malignant alike. It may be possible ultimately to use this reaction in therapy, but the approach will have to be more refined than in our original exercise, and certainly, even today, we are unable to use the reaction against the unwanted malignant cells with the fine control that would be necessary.

Whatever may be the possibilities arising from the use of homologous material after lethal doses of radiation, our next approach was to see if we could get a more efficient extinction of the leukaemic cells by means of the radiation alone, followed, of course, by injections of isologous myeloid tissue. It happened that in the laboratory, at the same time, other mice were being irradiated continuously over 25 hours. As one would predict the dose-response relationships for this irradiation at low intensity were different from those at the higher intensity: $1450 \mathrm{rad}$, given in the 25 hours, was the $\mathrm{LD}_{98}$ corresponding to the 950 rad given in 20 minutes or so.

Therefore, CBA mice, to which the leukaemia had been transmitted seven days earlier, were introduced into this experiment and given a dose of $1620 \mathrm{rad}$ in 25 hours. The original leukaemia 151/1 was used for the first of several experiments; it was then in its fifth to seventh generation of passage. For the irradiation, the mice were placed in groups of five, in aluminium cages having a floor area of $25 \times 10 \mathrm{~cm}^{2}$ and a height of $12 \mathrm{~cm}$. Food and water were available throughout the irradiation. The Siemens Stabilipan X-ray-therapy set was operated at $250 \mathrm{kV}$ constant potential and at 4 or $6 \mathrm{~mA}$, the half-value layer being $1 \cdot 2 \mathrm{~mm}$ copper. The beam was directed horizontally through the sides of the cages and the distance of the tube was such that the movement of mice within their cages would not alter their dose by more than a few per cent.

After the mice were removed from the radiation field, they were injected with normal isologous CBA bone marrow. The preliminary results of the first three runs have already been reported ${ }^{12}$ and are shown in Table 1 . In these experiments some of the mice had originally been injected with leukaemic cells subcutaneously; three months after the therapy 17 out of 20 were still alive. Five mice had received the leukaemic cells intravenously and three out of these five were also alive.

The later results and further experiments using this array were presented this year at the Third Canadian Cancer Conference and will be reported in due course in the volume of the Proceedings. The following data are therefore a recapitulation of this report ${ }^{13}$.

Firstly, several additional leukaemias have been included in the series. 
Table 1. Animals surviving (A) and dying ( $\dagger$ ) after treatment with subacute whole-body X-irradiation and intravenous bone marrow

\begin{tabular}{|c|c|c|c|c|}
\hline Experiment & 1 & \multicolumn{2}{|c|}{2} & 3 \\
\hline $\begin{array}{l}10^{6} \text { leukacmic cells given } \\
\text { (date) }\end{array}$ & $\begin{array}{l}\text { S.C. } \\
(1+356)\end{array}$ & \multicolumn{2}{|c|}{ S.C. I.V. } & $\begin{array}{c}\text { S.C. } \\
(24 / 5 / 56)\end{array}$ \\
\hline Unirradiated controls & $t+t+t$ & $\dagger+\mathrm{AA}$ & $t+t+$ & $\dagger+t \dagger \dagger$ \\
\hline Experimental (date) & $(21-22 / 3 / 56)$ & $(3-4$ & $5 / 56)$ & $(31 / 5-1 / 6 / 56)$ \\
\hline $\mathrm{CB}: \mathrm{IH}$ & $A A A A A$ & $A A A A A$ & A A A $†+*$ & A A $A \dagger \dagger$ \\
\hline$\Lambda / H$ & A A A & - & - & A A $\dagger^{*} \dagger^{*} \dagger^{*}$ \\
\hline $\mathrm{T}_{6} /+$ & - & - & - & A A A $\dagger^{*}+*$ \\
\hline
\end{tabular}

S.C. = Subcutaneously. I.V. = Intravenously

* Deaths not attributable to leukaemia.

One of them has been nominated 151/2 and, although its origins are a little obscure, in our opinion it was a spontaneous leukaemia occurring in a CBA mouse; $137 / 1$ was another leukaemia of the CBA strain but was induced by radiation; 251 rose in an isologous chimaera, an irradiated CBA mouse restored by our colleague, Miss C. L. Miller, with liver from a normal CBA foetus; 138/2, on the other hand, was induced by X-rays in a C57BL mouse.

Secondly, observations of the mice in the first three experiments, of which you have seen the preliminary results, over long periods of time until their death, has confirmed that three months is a sufficiently long time for one to be able to assess the success or failure of the therapy as far as cure of the leukaemia is concerned. There was no recurrence of leukaemia after this time. Most of the mice in these groups lived for between one and two years after treatment and died apparently of old age, perhaps rather accelerated by the irradiation.

Thirdly, few of the subsequent repetitions were as successful as the first three. Table 2 summarizes the results of those experiments in which CBA mice had originally been injected subcutaneously with $10^{6}$ cells of leukaemia 151 1: it inclicates that long-term survivors were obtained following the irradiation with 1620 rad over 25 hours and restoration with both isologous and homologous bone marrow. During this period between Experiments I and VII, the generation of passage of $151 / 1$ extended from the sixth to the 13th. Table 3 shows that the final results were less successful when the leukaemia $151 / 1$ had been injected intravenously. A variable number of successes were obtained up to Experiment $V$, where the leukaemia was in its ninth passage; but in Experiment VIII, with the leukaemia in its 13th passage, and in subsequent trials, no successes were 


\section{J. F. LOUTIT}

Table 2. Survivors of CBA mice, injected subcutaneously with $10^{6}$ cells leukaemia $151 \mathrm{l}$, treated after seven days with $1620 \mathrm{rad} \mathrm{X}$-rays, and restored with normal bone marrow injected intravenously

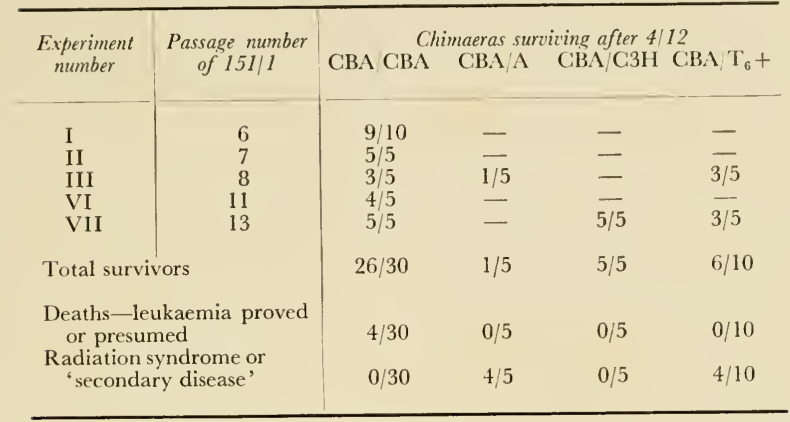

scored, and the majority of the deaths were due to leukaemia either proven or presumed.

Table 4 shows the results from the second leukaemia, 151/2. Here our experiences are more limited than with the former leukaemia, 151/1, and all the results are included in the one table, whether the original route of passage of the leukaemic cells was intravenous or subcutaneous. Successes were

Table 3. Survivors of CBA mice, injected intravenously with $10^{6}$ cells leukaemia $151 / 1$, treated after seven days with $1620 \mathrm{rad}$ of X-rays and restored with normal bone marrow injected intravenously

\begin{tabular}{l|c|cc}
\hline $\begin{array}{c}\text { Experiment } \\
\text { number }\end{array}$ & $\begin{array}{c}\text { Passage number } \\
\text { of } 151 / 1\end{array}$ & $\begin{array}{c}\text { Chimaeras surviving after 4/12 } \\
\text { CBA/CBA }\end{array}$ & CBA/C3H \\
\hline II & 7 & $3 / 5$ & - \\
IV & 9 & $1 / 5$ & - \\
V & 9 & $7 / 15$ & - \\
VIII & 13 & $0 / 5$ & - \\
XI & 18 & $0 / 5$ & $0 / 10$ \\
XII & 24 & $0 / 15$ & - \\
Total survivors & $11 / 50$ & $0 / 10$ \\
Deaths-leukaemia proved & $38 / 50$ & $10 / 10$ \\
or presumed & & \\
\hline
\end{tabular}

scored up to the eighth generation of passage of the leukaemia (Experiment VIII). This leukaemia was not uscd subsequently for about a year, when it was in its 59 th generation of passage. Its rate of growth had then accelerated so that most animals injected and kept as controls died within 7 to 10 days.

Experiment IX was an attempt to extend the period of delay between the intravenous injection of the leukaemic cells and the radiotherapy from 7 to 11 days. Leukaemia $151 / 1$ was used and was then in its 14 th generation. 


\section{ILUKALMIA TREATIDD BY RADIATION}

Table t. Survivors of C13.I mice, injected subcutaneously (S.C.) or intravenously (I.V.) with $10^{6}$ cells leukaemia 1512 , treated alter seven days with 1620 rad X-rays and restored with normal isologous bone marrow

\begin{tabular}{l|c|c|c}
\hline $\begin{array}{c}\text { Experiment } \\
\text { number }\end{array}$ & $\begin{array}{c}\text { Passage number } \\
\text { of } 1512\end{array}$ & $\begin{array}{c}\text { Route of } \\
\text { passage }\end{array}$ & $\begin{array}{c}\text { Isologous chimaeras } \\
\text { survizing after 4/12 }\end{array}$ \\
\hline IV & 4 & I.V. & $0 / 10$ \\
VI & 6 & S.C. & $9 / 10$ \\
VIII & 8 & I.V. & $7 / 10$ \\
XV & 59 & I.V. & $0 / 10$ \\
Total survivors & & $16 / 40$ \\
Deaths-leukaemia proven & & \\
or presumed & & $24 / 40$ \\
\hline
\end{tabular}

Even in this relatively carly generation it, too, was showing some acceleration of growth; and at the time the mice were irradiated after 11 days, they were clinically ill, and one had already died of leukaemia. There were no longterm survivors of this experiment.

In Experiment X, leukaemia 138/2 of the C57BL strain was used and was in its third generation of passage. Out of the 20 animals fully treated with $\mathrm{X}$ radiation and subsequent injection of bone marrow, three given $1310 \mathrm{rad}$ and isologous bone marrow, two given 1125 rad and isologous bone marrow, and one given $1125 \mathrm{rad}$ and homologous bone marrow lived for well over a year. The doses given to $\mathrm{C} 57 \mathrm{BL}$ mice were smaller than for CBA, as with our substrains the $\mathrm{C} 57 \mathrm{BL}$ mice are in general more radio-sensitive.

Experiment XII was another attempt, after a couple of previous failures, to treat leukaemia $151 / 1$, then in its 24 th generation. In one group the radiotherapy was given after five days and in another after the standard seven days. Some mice were given $1620 \mathrm{rad}$; for others, the dose was raised to $1750 \mathrm{rad}$. Neither of these variations ensured a cure, and all the animals died of leukaemia.

In Experiment XIII, since leukaemia 151/1 seemed to have become more malignant with the increasing number of generations, leukaemia 137/1, which was in its second passage, was used. Animals were treated seven days after the intravenous injection of the leukaemic cells with 1620 or 1750 rad. Nevertheless, in spite of this being a recently isolated leukaemia, all the treated animals died.

Experiment XIV was similar in plan. The other newly arisen leukaemia 251 , which was in its fifth passage, was used. Treatment was given after seven days to three groups of 10 animals; the doses of X-rays were 1620 , 1750 or 2000 rad. There was but one survivor which had received $2000 \mathrm{rad}$ of X-rays and, of course, was injected with isologous bone marrow.

This record of success and failure merely points to some of the complexities of the problem. There are a large number of variables, only some of which can be controlled.

Thus we have kept the size of the original inoculum of leukaemic cells in each case to $10^{6}$. In the early stages we did vary the route of transmission 


\section{J. F. I.OUTIT}

of the leukaemia; in some cases the leukaemia was given subcutaneously, in others intravenously. In the later experiments we settled for the intravenous route, because this was the severer test, resulting in a shorter time between inoculation and death from leukaemia of untreated animals, $(17 \pm 0.7$ days (I.V. series) and $28 \pm 1 \cdot 9$ days (S.C. series) for $151 / 1$, between the sixth and 13th passages); also, in the treated animals, the clinical results were less good when the leukaemic cells had been given intravenously.

It was not possible to ensure that the leukaemias did not alter with the passage of time. There was a strong clinical impression, supported by observations on the time taken to kill control animals, that after periods of relative stability the two leukaemias $151 / 1$ and $151 / 2$ became more 'malignant'. We attribute our earlier therapeutic successes and later failures to this cause. However, from our very limited experience with a mere handful of transmissible leukaemias it does seem that not all leukaemias of recent origin, and in their early generations of passage, are necessarily amenable to this form of treatment. It is perhaps to be expected that in the mouse, as in man, a leukaemia may be acute, sub-acute or chronic, reflecting the intrinsic 'malignancy' of that individual line. Furthermore, mere age and high numbers of generations of passage need not necessarily make for increased 'malignancy'. In other studies of this type, Hewitt and Wilson ${ }^{14}$ have, it is true, failed to treat successfully a CBA leukaemia of some considerable age in terms of generations of passage, but Trentin ${ }^{15}$ has had some successes in treating the Gardner lymphosarcoma, which is a leukaemia of considerable age.

In the earlier stages of the work we kept the time of treatment constantseven days after inoculation. However, this does not ensure that the leukaemia is at the same stage of dissemination if there is variation between generations of passage of an individual leukaemia, or if there is variation between leukaemias. Presumably, the greater the spread of the disease, and the greater the number of leukaemic cells present, the more difficult it would be to effect elimination of all the malignant cells.

Variations of the total dose given, and of the dose rate, are possibilities, and our experiences are extremely limited. The malignant cells may be killed by the effects of the radiation interfering with the mechanisms of mitosis, or by direct cytotoxic effect, as is characteristic in small lymphocytes. Neither mechanism is more than vaguely understood, so that until these fundamentals are worked out, particular schedules of irradiation are based on empiricism.

As a general conclusion we might say that the material presented above does suggest that, under some conditions which cannot be defined, some transmitted leukaemias are radio-curable. Preliminary studies by Simonsen et al. ${ }^{16}$ suggest that the same may be true of some leukaemias indigenous to the treated animal, and induced by chemical carcinogens. The possibility of using adjuvants, such as chemical cell-toxins or immunological reactions, to supplement the effect of the irradiation might well be explored.

REFERENCES

${ }^{1}$ Jacobson, L. O., Simmons, E. L., Marks, E. K., Gaston, E. O., Robson, M. J. and Eldredge, J. H. J. Lab. clin. Med. 37 (1951) 683 
2Lorenz, E., Conginon, C. C. and Uprioff, I). Radiology 58 (1952) 863

${ }^{3}$ Congdon, C. C. and Lorenz, L. Amer. J. Physiol. 176 (1954) 297

${ }^{+}$Mitciuson, N. A. Brit. J.exp. Path. 37 (1956) 239

${ }^{5}$ Ford, C. F., Hamerton, J. L., Barnes, D. W. H. and Loutit, J. I. Nature, Lond. $177(1956) 452$

${ }^{6}$ Holi.croft, J., Lorenz, E., Congidon, C. C. and Jacobson, L. O. Rer. mex. Radiol. 7 (1953) 115

${ }^{7}$ Barnes, D. W. H. and Loutit, J. F. Brit. J. Haematol. 3 (1957) $2+1$

${ }^{8}$ Congdon, C. C. J. cell. comp. Physiol. 50 Supplement 1 (1957) 103

${ }^{9}$ Makinodan, T. J. cell. comp. Physiol. 50 Supplcment 1 (1957) 327

${ }^{10}$ Barnes, D. W. H., Ford, C. E., Ilbery, P. L. T., Koller, P. C. and Loutit, J. F. J. cell. comp. Physiol. 50 Supplement 1 (1957) 123

${ }^{11}$ Barnes, D. W. H., Ford, C. E., Ilbery, P. L. T. and Loutit, J. F. Transpl. Bull. 5 (1958) 101

${ }^{12}$ Barnes, D. IV. H., Corp, M. J., Loutit, J. F. and Neal, F. E. Brit. med. J. ii (1956) 626

${ }^{13}$ Barnes, D. W. H., Corp, M. J., Ilbery, P. L. T., Loutit, J. F. and Neal, F. E. Proceedings of the Third Canadian Cancer Conference; Acadcmic Press Inc., New York, 1959 - in the press.

${ }^{14}$ Hewitt, H. B. and Wilson, C. W. Brit. J. Radiol. N.S. 31 (1958) 304

15 Trentin, J. J. Proc. Amer. Ass. Cancer Res. 2 (1957) 256

${ }^{16}$ Simonsen, M., Engelbreth-Holm, J., Jensen, E. and Poulsen, H. Communication to the Seventh International Cancer Conference London, 1958

\section{DISGUSSION}

Dr. Nossal: As regards this extraordinarily important question of whether 'secondary disease' is due to reaction of the graft against the host, or of the host against graft -we have been performing what I think are extremely simple experiments which may have some bearing on this question, and I should like your views on it. The design follows those of Lorenz and Jacobson, and we use an outbred randomly mated strain of rats, which are given a large sub-lethal dose of irradiation of the order of $500 \mathrm{r}$ delivered at a rapid dose rate. In the course of certain immunological experiments we have transplanted tiny fragments of spleen to the peritoneal cavities of these rats. Now we find that, as early as three days after such homografts, a large proportion of the cells of the graft take on basophilic staining, eccentricity of the nucleus and all the characteristics that Fagreus has described for the immature plasma cells. After some three or four more days these cells, which now form the majority of the live cells left in the graft, are typical marschalk-type plasma cells. Similarly, when a single-cell suspension of such spleen cells is injected into the peritoneal cavity, a very similar sequence of events is obtained in the draining mesenteric lymph-nodes, and to a lesser extent in the lymph-nodes in distant parts of the body. I was wondering, Sir, whether you have observed this phenomenon with spleen cells, and whether you would agree that it is at least consistent with the vicw that the grafted cells are making antibodies to the host.

DR. LoutiT: This secms to me to be a very admirable approach, and I think that the conditions are not quite the same, but perhaps you will correct me. $500 \mathrm{r}$ to the outbred rat, I would gucss, is not the $\mathrm{LD}_{98}$, but perhaps an $\mathrm{LD}_{5}$ or $\mathrm{LD}_{10}$, so that in the first place you have not, presumably, completely eliminated the host's capacity to regenerate its own tissue, but you have shown that the grafted tissues do grow initially at any rate and do produce this deviation towards plasma cell-type. Our experience is that if we take the $\mathrm{LD}_{100}$ mouse and give it restorative treatment, not bone marrow but bone marrow plus splcen, adult spleen, or bone marrow plus 


\section{DISCUSSION}

adult lymph-node, in each case there being a considerable contribution of mature lymphoid tissue, then the animals do not survive for more than a few wceks, and usually they die in the first ten days or so and the death therefore is contemporary with the radiation syndrome. Your type of experiment obviously is better designed to elucidate this particular point, because the radiation dose is not sufficient to cause the death of the animal by itself and any delayed death is therefore probably largely contributed to by this reaction of the grafted spleen against the host. Certainly, if we give bone marrow to restore lethally irradiated mouse and homologous lymphoid tissue, adult lymphoid tissue which has been made immune against the host-type material, then we do get death within about five or six days; that is even before the irradiation syndrome manifests itself in complete form, and in those cases the lymphoid tissues of the chimaera are stuffed with large basophilic cells which could be these antibody producing type cells, although we have not made any formal tests for the type of antibodies they are producing. I think the important thing is, with all these things, that we can produce a reaction of the graft against the host, but we have not yet found a means of turning it off at will.

DR. Vogel: I wonder, Dr. Loutit, if you have tried any experiments of a similar nature following neutron irradiation. The reason $\mathrm{I}$ ask is that there is just a tendency of an indication in some works that we have done, that although we got secondary homologous deaths after $\gamma$-rays, after neutrons we do not seem to.

DR. Loutit: We ourselves have not done any work, but I am aware that work has been published, both from Oak Ridge and San Francisco on this point, but off-hand I cannot recall that this was on homologously treated neutron-irradiated animals, and therefore I cannot recall in those reports, whether there was evidence of this 'secondary disease' or not. Can you remember?

DR. Vogen: Yes, I believe they were all isologous.

DR. LoutrT: That is my impression, yes. In which case one would not expect to see this delayed death, and I am very interested to hear your observation on this point and would like to discuss it afterwards. 


\title{
SELEGTIVE IRRADIATION AND ATTEMPTED REPLACEMENT OF BONE MARROW IN THE RABBIT, USING ${ }^{198} \mathrm{Au}$
}

\author{
J. M. Garvan, E. P. George, F. A. Rocke and S. Vince*
}

St. Vincent's Hospital, Darlinghurst, N.S.W.

\section{INTRODUCTION}

Following the success achieved ${ }^{1}$ in the replacement of bone marrow in mice receiving whole-body irradiation, it seemed natural to attempt the same replacement in larger animals, such as the rabbit. Since, however, whole-body irradiation at the dose levels required to destroy the rabbit's own bone marrow produces in the rabbit fatal radiation damage to other organs $^{2}$, it becomes necessary to find some more selective way of irradiating the haemopoietic tissue. Radio-active isotopes appeared to offer a possible solution to this problem and it was therefore decided to investigate their suitability as a means of producing selective irradiation to the bone marrow and other haemopoietic organs.

Ionic radio-phosphorus, ${ }^{32} \mathrm{P}$, and colloidal radio-gold, ${ }^{198} \mathrm{Au}$, were chosen for preliminary investigation, for reasons which we now discuss briefly. Both are readily available. Apart from some Brehmsstrahlung $\gamma$ radiation from the pure $\beta$ emitter ${ }^{32} \mathrm{P}$ and the relatively weakly ionizing $\gamma$ radiation from the $\beta, \gamma$ emitter ${ }^{198} \mathrm{Au}$, both these isotopes irradiate tissue only within a range of one or two $\mathrm{mm}$ of the site of their deposition. Hence, if selective distribution of isotope can be achieved, corresponding selective irradiation of tissue can also be achieved. As regards selective distribution of isotope, ${ }^{32} \mathrm{P}$ was considered because it is a bone-seeking element and it has already been used in the control of polycythaemia vera and leukaemia ${ }^{3}$. Intravenously injected colloidal ${ }^{198} \mathrm{Au}$ was considered because it is known to be selectively taken up in the liver, spleen and bone marrow ${ }^{4}$.

Preliminary experiments were undertaken on a series of guinea-pigs in order to get some estimate of the order of magnitude of the specific curie dosef level required to produce aplasia of the bone marrow. The isotopic material was injected via the intracardiac route and it was found that specific dose levels of the order of $2 \mathrm{mC} / \mathrm{kg}$ for ${ }^{32} \mathrm{P}$ or ${ }^{198} \mathrm{Au}$ produced complete aplasia. The animals died, presumably of anaemia, in two to three weeks. Autopsy revealed gross petechial haemorrhage in all cases. The liver and other organs of the animals were examined for changes that could be attributed to the direct effects of radiation and in no case was any such change observed.

In the main investigation with rabbits, we chose colloidal ${ }^{198} \mathrm{Au}$ as the

* Institute of Child Health, Royal Alexandra Hospital for Children, Camperdown, N.S.W.

$\dagger$ By 'specific curie dose', or simply 'specific dose', we refer to the quantity of radioactivity administered per unit body-weight. 
source of irradiation in preference to ${ }^{32} \mathrm{P}$ for the following reasons. Firstly, presumably the selective incorporation of the colloid into the recticuloendothelial elements of the bone marrow should, in view of the short range of the principal ionizing component of radiation emitted by ${ }^{198} \mathrm{Au}$, give maximum discrimination in favour of irradiation of marrow rather than bone. Secondly, subsequent transfusion of bone marrow with minimum damage to the transfusion from residual radio-activity can be made earlier in the case of ${ }^{198} \mathrm{Au}$ because of its shorter physical half-life, $2 \cdot 7$ days as against 14 days for ${ }^{32} \mathrm{P}$. And thirdly, problems of radiometric assay of specimens are simplified in the case of ${ }^{198} \mathrm{Au}$ because of the emitted $\gamma$ radiation.

We accordingly decided to investigate the possible role of ${ }^{198} \mathrm{Au}$ in the destruction of the bone marrow in the rabbit.

If this could be achieved we proposed to follow this up with bone-marrow transfusions in animals receiving this form of irradiation.

The results of this investigation are described in the following paper.

\section{METHOD}

Except for the first series, adult rabbits, hutch-bred and without regard to strain or sex, were used.

The colloidal ${ }^{198} \mathrm{Au} *$ was administered via the ear vein, being diluted if necessary with physiological saline. The Amersham catalogue states that the colloid as supplied contains some glucose and about $0 \cdot 05 \mathrm{~m}$ sodium chloride, and is stabilized with gelatin. The gold concentration was $10 \mathrm{mg} / \mathrm{ml}$. Those rabbits which received the dose on which we finally settled, each received of the order of $5 \mathrm{mg}$ of gold. This should be well below the minimum toxic level. The best information that we have to date regarding particle size is that most particles are from 20 to $25 \mathrm{~m} \mu$ in diameter with a few at $60 \mathrm{~m} \mu$ and a few $5 \mathrm{~m} \mu$.

Since the physical half-life of ${ }^{198} \mathrm{Au}$ is $2 \cdot 7$ days and the biological half-life of colloids is long compared with this period ${ }^{5}$, it is necessary to consider the minimum permissible time-lapse between dosing with ${ }^{198} \mathrm{Au}$ and transfusion of bone marrow. We have set this minimum at four days, at which time 36 per cent of the administered ${ }^{198} \mathrm{Au}$ remains.

Replacement of bone marrow was attempted with homologous long-bone marrow which had been passed through a succession of needles of decreasing bore and diluted about 10 times with physiological saline. Administration was by the ear vein and followed the sacrificing of the donor by not more than one hour. No anticoagulant was used, and no case of embolism was encountered in 36 transfusions. Nucleated cell counts of the transfusions have indicated that each transfused rabbit received of the order of $10^{9}$ nucleated cells per transfusion.

As a precaution against possible infections the last three of five series of rabbits were given intramuscular injections of streptomycin and penicillin.

Measurements were made of body-weight, total white cell count, haemoglobin concentration and total serum proteins. When any rabbit died, specimens were taken of various soft tissues, notably liver, bone marrow, spleen and whole-blood. These were weighed, digested in the cold with

* Supplied by the United Kingdom Atomic Energy Authority Radiochemical Centre, Amersham, England. 
chromic acid and subjected to radiometric assay by $\gamma$-counting with a scintillation counter. Figures for specific activity of ${ }^{198} \Lambda \mathrm{u}$ obtaincd from this assay were used to estimate roentgen doses to the respective tissues.

Biopsy sections were prepared from liver, sternum and spleen. All sections were of $5 \mu$ thickness, routine paraffin-embedded and stained with haematoxylin-cosin. Duplicates were prepared for detection of gold aggregates by a two-hour saturation in alcoholic picric acid. Sternum specimens were decalcified in 10 per cent versene.

The total number of rabbits used was 44 , grouped in five series: a, b, c, d, e. The rabbits of any one series were used simultaneously and numbered with the series letter as suffix.

In each series a number of rablits, referred to as controls, received doses of the isotope without receiving transfusions. Those which received both are referred to as 'treated'.

Series a and b were used to determine a suitable dose level, the range of specific dose for these series being 0.8 to $9.4 \mathrm{mC} / \mathrm{kg}$. In series $\mathrm{c}, \mathrm{d}$ and $\mathrm{e}$, a dose of $3 \cdot 0$ and, finally, $2 \cdot 5 \mathrm{mC} / \mathrm{kg}$ was settled on.

Series a, b, c, and d rabbits had intact spleens. Series e rabbits were splenectomized eight to ten days before irradiation.

\section{Distribution of ${ }^{198} \mathrm{Au}$}

\section{RESULTS}

While radiometric assays were made of liver, bone marrow and spleen from each rabbit which died, occasional specimens of other organs and of excreta were also assayed. In general, the uptake of ${ }^{198} \mathrm{Au}$ in lung, kidney, stomach, mesentery, brain, adipose tissue, the injected ear, faeces, urine and whole-blood was so low that we can assume that all but an amount of the order of 2 per cent of the administered dose of ${ }^{198} \mathrm{Au}$ was taken up and retained in liver, bone marrow and spleen. Thus, since the total uptake for liver, spleen and bone marrow was about 98 per cent and that for liver and spleen could be estimated from the known weights of these organs, the total uptake for bone marrow was readily estimated by subtraction.

Table 1 shows the range, mean and standard deviation for percentage

Table 1. Percentage uptake of ${ }^{198} \mathrm{Au}$ in liver, bone marrow and spleen

\begin{tabular}{|c|c|c|c|c|c|}
\hline \multirow{2}{*}{$\begin{array}{l}\text { Number } \\
\text { of } \\
\text { rabbits }\end{array}$} & \multirow{2}{*}{$\begin{array}{c}\text { Specific dose } \\
\text { range, } \\
\mathrm{mC} / \mathrm{kg}\end{array}$} & \multirow{2}{*}{ Tissue } & \multicolumn{3}{|c|}{ Percentage uptake } \\
\hline & & & Range & Mean & S.D. \\
\hline $\begin{array}{l}2 \\
2 \\
2\end{array}$ & $0 \cdot 4-2 \cdot 3$ & $\begin{array}{l}\text { Liver } \\
\text { Marrow } \\
\text { Spleen }\end{array}$ & $\begin{array}{c}51-88 \\
10-47 \\
0 \cdot 02-0 \cdot 10\end{array}$ & $\begin{array}{l}70 \\
28 \\
0 \cdot 06\end{array}$ & $\begin{array}{l} \pm 26 \\
\pm 26 \\
\pm 0.06\end{array}$ \\
\hline $\begin{array}{l}10 \\
10 \\
11\end{array}$ & $2 \cdot 5-3 \cdot 0$ & $\begin{array}{l}\text { Liver } \\
\text { Marrow } \\
\text { Spleen }\end{array}$ & $\begin{array}{c}37-89 \\
5-60 \\
0 \cdot 02-0 \cdot 70\end{array}$ & $\begin{array}{l}58 \\
39 \\
0 \cdot 16\end{array}$ & $\begin{array}{l} \pm 19 \\
\pm 20 \\
\pm 0 \cdot 18\end{array}$ \\
\hline $\begin{array}{l}3 \\
3 \\
3\end{array}$ & $5 \cdot 7-9 \cdot 4$ & $\begin{array}{l}\text { Liver } \\
\text { Marrow } \\
\text { Spleen }\end{array}$ & $\begin{array}{c}41-56 \\
40-57 \\
0 \cdot 0+-0 \cdot 08\end{array}$ & $\begin{array}{l}46 \\
51 \\
0 \cdot 06\end{array}$ & $\begin{array}{l} \pm 9 \\
\pm 10 \\
\pm 0.02\end{array}$ \\
\hline
\end{tabular}


J. M. GARVAN, E. P. GEORGE, F. A. ROCKE, AND S. VINCE

uptake in liver, bone marrow and spleen at various levels of specific dose. It should be noted that the instrumental errors involved in the individual assay figures which make up the means are negligible compared with the standard deviations quoted.

We have used as a measure of the concentration of ${ }^{198} \mathrm{Au}$ in a given tissue the ratio of the specific activity in the tissue to the specific dose administered. This ratio is referred to as the 'concentration' and is measured in $\mu \mathrm{C} / \mathrm{g}$ tissue per $\mathrm{mC} / \mathrm{kg}$ whole-body. It will be clear that the value of the concentration in a given tissue is the ratio of the specific activity in that tissue to the average specific activity over the whole body, and that the average concentration must always be unity over the whole body, regardless of the specific dose administered.

Table 2 shows the range, mean and standard deviation of the concentration for rabbits which died after receiving specific doses of $2 \cdot 5$ to $3 \cdot 0 \mathrm{mC} / \mathrm{kg}$.

Table 2. Concentration of ${ }^{198} \mathrm{Au}$ in liver, bone marrow and spleen

\begin{tabular}{|c|c|c|c|c|}
\hline \multirow{2}{*}{$\begin{array}{c}\text { Number } \\
\text { of } \\
\text { rabbits }\end{array}$} & \multirow{2}{*}{ Tissue } & \multicolumn{3}{|c|}{ Concentration $\mu \mathrm{C} / \mathrm{g}$ per $\mathrm{mC} / \mathrm{kg}$} \\
\hline & & Range & Mean & S.D. \\
\hline 10 & Liver & $11 \cdot 8-33 \cdot 8$ & $21 \cdot 7$ & $\pm 7 \cdot 8$ \\
\hline 10 & Marrow & $12 \cdot 7-52 \cdot 3$ & $33 \cdot 7$ & $\pm 11 \cdot 4$ \\
\hline 11 & Spleen & $0 \cdot 66-16 \cdot 9$ & $4 \cdot 0$ & $\pm 4 \cdot 8$ \\
\hline
\end{tabular}

The assay findings regarding relative concentration between rabbits were confirmed by microscopic examination of tissue slides for the presence of gold aggregates.

No concentration comparable in value with those shown for liver, bone marrow and spleen was observed in any other tissue.

Except in the cases of two rabbits, assay specimens of liver were made up by pooling several small pieces of mass of the order of $0 \cdot 2 \mathrm{~g}$. In the two cases mentioned, separate assays were made of pieces of mass of the order of $1 \mathrm{~g}$ from different parts of the liver. The observed standard deviations of the specific activity over these two sets were \pm 0.5 per cent and $\pm 8 \cdot 0$ per cent of the mean values.

Except in the cases of three rabbits, assay specimens of bone marrow were obtained from the shaft of one femur only and were of mass of the order of $0.5 \mathrm{~g}$. Table 3 shows, for the three exceptions mentioned, the sites of origin of multiple specimens and the corresponding concentrations of ${ }^{198} \mathrm{Au}$.

\section{Roentgen doses}

Roentgen doses in REP to tissues due to $\beta$ radiation have been computed from specific activity of ${ }^{198} \mathrm{Au}$, using the formula of Mayneord ${ }^{6}$, and on the assumption that the tissue dimensions are large compared to the range of $\beta$-particles, which is of the order of $1 \mathrm{~mm}$. Doses due to $\gamma$ radiation might be roughly estimated as of the order of 20 per cent of the corresponding 
IRRAIATION AND REPLACEMIENT OF BONE MARROW, USING; I9A

Table 3. Macroscopic variation of the concentration of ${ }^{198}$ Au in bone marrow

\begin{tabular}{clc}
$\begin{array}{c}\text { Rabbit } \\
\text { number }\end{array}$ & \multicolumn{1}{c}{ Siles of bone marrow } & $\begin{array}{c}\text { Respective concentrations } \\
\mu \mathrm{C} / \mathrm{g} \text { per m } \mathrm{kg}\end{array}$ \\
\hline IIc & Right femur, left femur & $2 \cdot 29,2 \cdot 21$ \\
$5 \mathrm{~d}$ & Femur, rib & 32,37 \\
$6 \mathrm{~d}$ & Femur middle, femur end, rib, skull & $28,27,48,28$ \\
\hline
\end{tabular}

$\beta$ doses. Table $t$ shows the range, mean and standard deviation of $\beta$ doses for rabbits which died after receiving $2 \cdot 5$ to $3 \cdot 0 \mathrm{mC} / \mathrm{kg}$. The dose is estimated as that delivered to the tissue up to the time of death, so that a part of the variation in the dose delivered could be attributed to variation in survival time. Since, however, the shortest survival time involved is $7 \cdot 5$ days, when 85 per cent of the activity present has decayed, this part of the

Table 4. Roentgen doses to liver, bone marrow and spleen

\begin{tabular}{|c|c|c|c|c|c|}
\hline \multirow{2}{*}{$\begin{array}{c}\text { Number } \\
\text { of } \\
\text { rabbits }\end{array}$} & \multirow{2}{*}{$\begin{array}{c}\text { Specific } \\
\text { dose } \\
\mathrm{mC} / \mathrm{kg}\end{array}$} & \multirow{2}{*}{ Tissue } & \multicolumn{3}{|c|}{$\beta$ dose REP } \\
\hline & & & Range & Mean & S.D. \\
\hline 3 & $3 \cdot 0$ & $\begin{array}{l}\text { Liver } \\
\text { Marrow } \\
\text { Spleen }\end{array}$ & $\begin{array}{c}2810-4170 \\
2740-9600 \\
200-640\end{array}$ & $\begin{array}{r}3460 \\
6000 \\
460\end{array}$ & $\begin{array}{l} \pm 680 \\
\pm 1100 \\
\pm \quad 230\end{array}$ \\
\hline $\begin{array}{l}7 \\
8 \\
8\end{array}$ & $2 \cdot 5$ & $\begin{array}{l}\text { Liver } \\
\text { Marrow } \\
\text { Spleen }\end{array}$ & $\begin{array}{r}2080-5580 \\
4230-8830 \\
120-3040\end{array}$ & $\begin{array}{r}4070 \\
6040 \\
910\end{array}$ & $\begin{array}{l} \pm 380 \\
\pm 430 \\
\pm 990\end{array}$ \\
\hline
\end{tabular}

variation would be small, and for the same reason the figures given could be taken as virtually those for complete decay of the radio-activity. Rabbits which received doses of ${ }^{198} \mathrm{Au}$ in excess of $3.0 \mathrm{mC} / \mathrm{kg}$ received correspondingly larger roentgen doses to tissues.

\section{Survizal}

For non-splenectomized rabbits which received specific doses of 2 to 3 $\mathrm{mC} / \mathrm{kg}$, out of 7 controls there are 2 or 29 per cent, surviving at the time of writing, and out of 14 treated there are 7 or 50 per cent surviving, the shortest time since the dosing being 56 days. It is too early yet to determine survival rates for splenectomized rabbits. None of these survivors are showing any outward signs of sickness, although No. $2 \mathrm{~b}$ did show such signs at 7 to 14 days.

Table 5 shows details of irradiation, transfusion, and survival time for the five series of rabbits used to the time of writing. Periods of time shown commence in each case on the day of dosing with ${ }^{198} \mathrm{Au}$. For rabbits still alive at the time of writing, the survival time shown is to 6th November, 1958. 
J. M. GARVAN, E. P. GEORGE, F. A. ROCKE AND S. VINCE

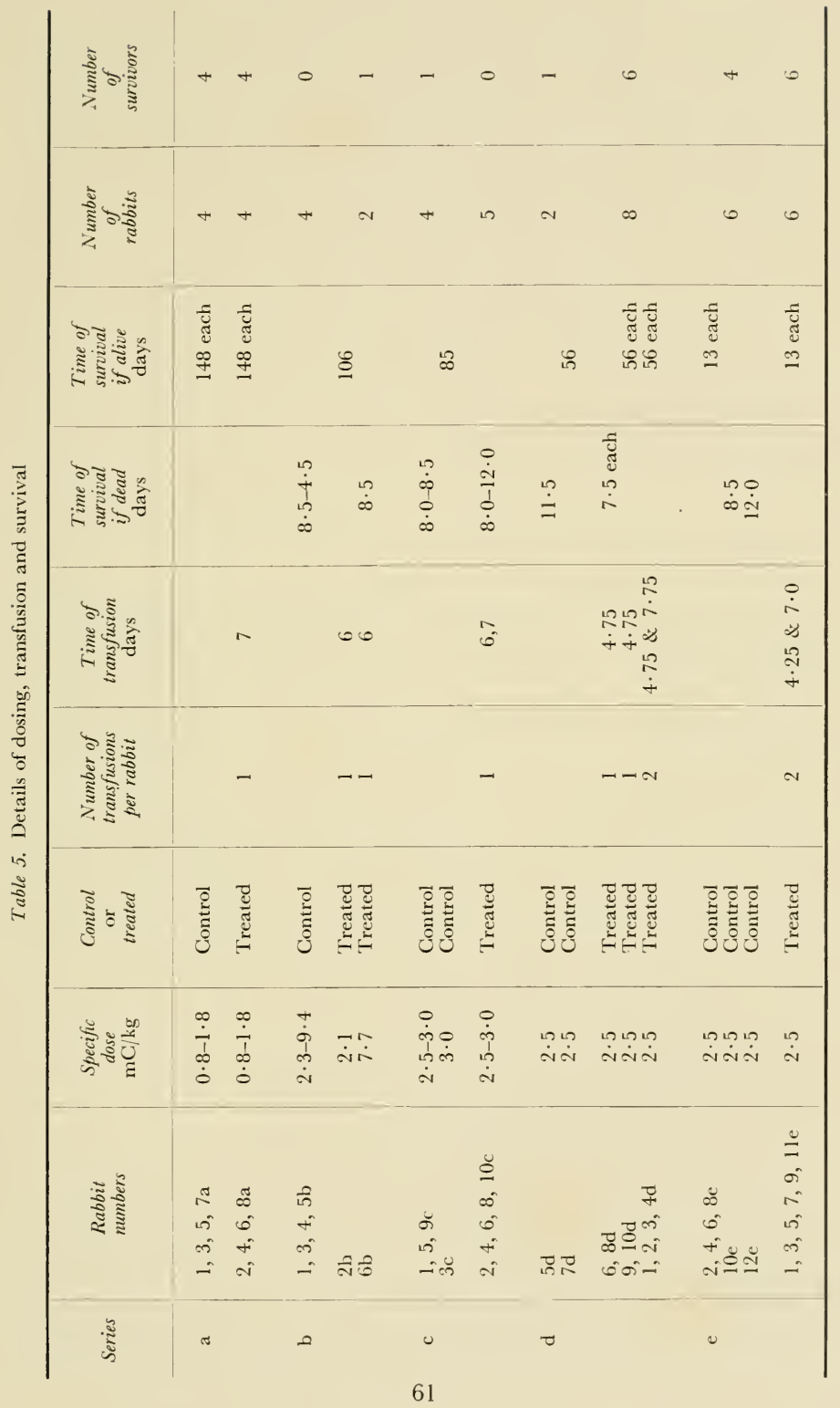




\section{Histo-pathology}

Findings reported under this heading are based on biopsies taken from two normal rabbits not irradiated or treated in any way, one rabbit which had been intravenously injected with of the order of $50 \mathrm{mg}$ of stable colloidal gold and 11 of the rabbits of series $b$ and $c$ which had succumbed. So far no survivors have been sacrificed.

While rabbits examined, including some receiving higher specific curie doses than those shown in Table $t$, have received $\beta$ doses to the liver of up to 13,000 REP and spleen doses of up to $5000 \mathrm{REP}$, no biopsy has revealed any damage to liver or spleen which could be attributed to radiation.

Examination of bone-marrow biopsies has shown severe hypoplasia or complete aplasia in all cases except Nos. 2c and 4c (treated rabbits which received 5700 and 2700 REP respectively to the bone marrow), which showed moderate to severe hypoplasia. No significant correlation was observed between the degree of hypoplasia and the roentgen dose received by the marrow, although one of the two rabbits with complete aplasia, No. 7b, a control, received the highest $\beta$ dose, that is 22,000 REP.

In some of these cases there were small foci in the bone marrow adipose tissue resembling necrosis. This could not be differentiated with confidence from post-mortem autolysis.

In some there were small foci of residual haemopoietic tissue. Whether this was associated with, or due to, severe hypoplasia, or to implantation from the transfused bone marrow, it is not possible to say at the present stage of the investigation.

\section{Gross appearance at autopsy}

Findings reported under this heading are based on examination of all 19 rabbits which have died.

These findings are characterized chiefly by petechial haemmorrhage, although in some cases, notably those surviving four or five days only, no petechial haemorrhage was observed. In only one non-splenectomized case, No. $5 \mathrm{~d}$, a control, was the degree of haemorrhage believed sufficient to have caused death. But in both splenectomized cases there was gross haemorrhage on heart, lungs and intestines and in skeletal muscle.

In some cases liver, lungs and bone marrow were pale, and in some the marrow was hyperaemic and sloppy. Gross effects did not appear to be related to presence or absence of treatment.

Weight loss to time of death in 11 rabbits which received $2 \cdot 5$ to $3 \cdot 0$ $\mathrm{mC} / \mathrm{kg}$ of ${ }^{198} \mathrm{Au}$ ranged from $1 \cdot 5$ to $14 \cdot 8$ per cent, with mean $8 \cdot 5$ per cent and standard deviation $\pm 4 \cdot 6$ per cent.

\section{Haematology}

In general, the picture for the total leukocyte count was characterized by an initial sharp fall to a minimum in from two to six days, followed by a gradual recovery to near normal in about three weeks for survivors, or a plateau at the minimum value for non-survivors. For rabbits which received only the single bone-marrow transfusion at seven or eight days there was no significant difference, during the life-time of the non-survivors, between the counts for controls and treated rabbits. But for rabbits which received 
J. M. GARVAN, E. P. GEORGE, F. A. ROCKE AND S. VINCE

the earlier transfusion, i.e., before five clays, there was, on the average, a definite post-transfusion rise which could be distinguished from the slow rise experienced with the later single transfusion.

There was evidence that a decrease in specific curie dosage lengthens the time taken to reach the leukocyte count minimum, and that for dose levels below $2 \mathrm{mC} / \mathrm{kg}$ this leukopenia is not as severe as for higher dose levels.

Figures 1, 2 and 3 show the total leukocyte count for rabbits receiving

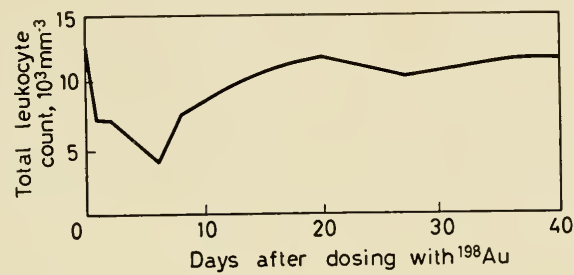

Figure 1. Total leukocyte count for 8 rabbits receiving 0.8 to $1.8 \mathrm{mC} / \mathrm{kg}$ dosage of ${ }^{198} \mathrm{Au}$, including 4 rabbits receiving single bone marrow transfusions at 7 days and 4 controls

specific curie doses in the ranges 0.8 to $1.8 \mathrm{mC} / \mathrm{kg}, 2 \cdot 1$ to $3.0 \mathrm{mC} / \mathrm{kg}$ and $3 \cdot 0$ to $9.4 \mathrm{mG} / \mathrm{kg}$. Survivors, non-survivors, controls and treated rabbits are lumped together except in Figure 2 where those receiving transfusions before five days are represented by a separate graph.

In general for rabbits receiving specific doses of 2.5 and $3.0 \mathrm{mC} / \mathrm{kg}$, there

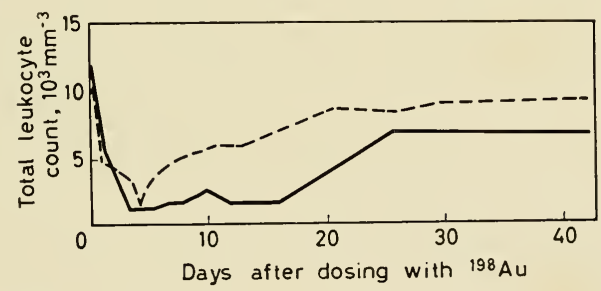

Figure 2. Total leukocyte count for 31 rabbits receiving $2 \cdot 1$ to $3.0 \mathrm{mC} / \mathrm{kg}$ dosage of ${ }^{198} \mathrm{Au}$ - full line represents 19 rabbits, including 6 receiving single bone-marrow transfusions at 7 or 8 days, and 13 controls-broken line represents 12 rabbits receiving double transfusions at 4 to 5 days, and at 7 to 8 days

was a steady fall in haemoglobin concentration after dosing, from a value of the order of $15 \mathrm{~g}$ per $100 \mathrm{ml}$. to a value of the order of $10 \mathrm{~g}$ per $100 \mathrm{ml}$. at about 18 days. This was followed by a very slow rise. As yet there are insufficient data to state definitely whether transfusion of bone marrow has any effect on haemoglobin concentration, or whether anaemia has been a significant factor in radiation deaths which have occurred. 
Findings on total serum proteins and serum protein fractions are not sufficiently conclusive to be reported at this stage.

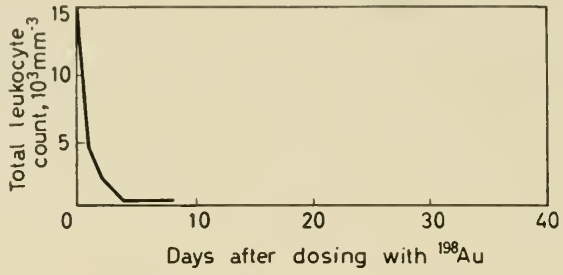

Figure 3. Total leukocyte count for 5 rabbits receiving 3.0 to $9 \cdot 4 \mathrm{mC} / \mathrm{kg}$ dosage of ${ }^{198} \mathrm{Au}$, including onc rabbit receiving single bone-marrow transfusion at 6 days and 4 untreated rabbits

Insufficient time has elapsed to determine what effect, if any, the splenectomizing of rabbits has had on the haematological situation.

\section{DISCUSSION OF RESULTS}

The results have shown that, using colloidal ${ }^{198} \mathrm{Au}$ under the conditions of this investigation, it is possible to selectively irradiate the bone marrow of the rabbit to a degree which produces severe or even complete aplasia, and that this can be readily achieved without producing any detectable radiation damage to other organs. This is made possible by the relatively high uptake of the colloid in the marrow, it being roughly half of the administered dose; also by the fact that almost all the rest of the dose is taken up by the liver, a relatively radio-resistant organ. This distribution is in contrast to that observed for colloidal ${ }^{198} \mathrm{Au}$ of other manufacture, administered intravenously in dogs and humans by other workers $7,8,9$, who report uptakes by liver, bone marrow and spleen of the order of 90,5 and 5 per cent respectively. Whether we have here a species difference in distribution is not clear, but it is interesting to note that distribution in the rabbit has been observed to vary with variation in colloidal particle size for some materials other than gold $^{5}$, with higher uptake by the marrow for smaller particle sizes. Hence the distribution observed in the present investigation may be due to the particle size used.

It has been reported ${ }^{2}$ that homologous bone-marrow transplants have been achieved in the rabbit, using whole-body radiation doses of from 800 to $1000 \mathrm{r}$. The rate of success rose to a maximum of 62 per cent with increasing dose, but even for the successful cases $1000 \mathrm{r}$ proved to be $\mathrm{LD}_{100}$ at 30 days. It would seem from this that if consistent success in replacement of marrow were to be achieved, then it would be desirable to give doses of more than $1000 \mathrm{r}$ to the bone marrow. Since roentgen dosage measurements have not been made on the tissues of survivors in the present investigation it cannot be stated with certainty that they received bone-marrow doses comparable with rabbits which died. However, the haematological findings would suggest that they did and that doses around five and six times 
the whole-body $\mathrm{LD}_{100}$ can be given to the marrow, using colloidal ${ }^{198} \mathrm{Au}$, with a mortality significantly less than 100 per cent, and without the gastrointestinal ulceration produced by the whole-body dose. It is well known that on the microscopic scale the distribution of the colloid is patchy, and that the effective radiation dose may be somewhat lower than the mean tissue dosages we have used. Regarding the question of lethality of dose, it is also interesting to note that for, say, $2.5 \mathrm{~kg}$ rabbits with the regime using $1000 \mathrm{r}$ whole-body irradiation, integrated gram-roentgen doses of the order of $2.5 \times 10^{6}$ gram-roentgens are given. However, with the isotopic regime* the gram-roentgen dose, due to $\beta$ irradiation, is of the order of only 30 per cent of this figure.

The assays have demonstrated that spleen uptake was variable to such an extent that one cannot predict whether a given rabbit will receive an haematologically significant dose to the spleen or will be left with a virtually protected spleen. Since protection of the rabbit spleen without bone-marrow transfusion does appear to have an enhancing effect on survival, haemopoietic recovery ${ }^{10}$ and on antibody production ${ }^{11}$, it seemed advisable at length to control this factor, so that the last series was splenectomized. As yet, insufficient data on this series are available for any definite conclusions to be drawn.

For rabbits with intact spleens, at specific dosage levels of 2 to $3 \mathrm{mC} / \mathrm{kg}$, there is a higher survival rate in the case of those treated, but above and below this range there was failure to differentiate between treated and control rabbits. The findings on survival are consistent with those of other workers on the effects of bone-marrow transfusions following whole-body irradiation $^{12,13}$.

It is interesting to note that increased survival rate ( 75 per cent) and an enhancement of the average rate of recovery of the leukocyte count were achieved in the cases of double transfusion when one was made before the fifth day. If the earlier transfusion was responsible for this result, then we are faced with the problem of whether the chances of success could be further enhanced by using some isotope with shorter half-life, for a transfusion given on the fourth day may receive from residual radio-activity at these specific dosage levels with ${ }^{198} \mathrm{Au}$, a roentgen dose shown to produce severe aplasia of bone marrow in some cases. However, it is clear that, since survival or non-survival may not necessarily correspond to success or failure in transplantation, it may be possible to lower the administered dosage level itself without necessarily impairing the chances of success in transplantation.

It is not as yet established that a transplantation has taken place. With a view to establishing positive identification of any such transplant which may have occurred, we have now initiated investigations along the lines of those employed by Porter ${ }^{2}$ for identification by haematological sex determination.

We would like to thank Professor Lorimer Dodds for his stimulation and interest in the problem, and Dr. R. J. Walsh for many discussions. Mr. W. A. Sollich made many useful suggestions concerning chemical problems and Mr. R. A. Nyman gave much willing assistance in the manugement of the animals.

* Using a specific dose of $2 \cdot 5 \mathrm{mC} / \mathrm{kg}$. 
IRRADIATION ANI) REPIACENIENT OF BONL MARROW, LSING ${ }^{198} A U$

The work was supported by a grant from The Australian Atomic Energy Commission and one of us $(F, R$.) would like to acknowledge a maintenance grant also from the Commission.

W'e would like to thank the Boards of St. Vincent's Hospital and the Royal Alexandra Hospital for Children, particularly Dr. D. Reye, for providing facilities for carrying out the investigation.

Whe are grateful to the Commoneealth X-Ray and Radium Laboratory for obtaining all the radio-active materials used in the investigation.

\section{REFERENCES}

'Barnes, D. W. H., Corp, M. J., Loutit, J. F. and Neal, F. E. Brit. med. J. ii (1956) 626

${ }^{2}$ Porter, K. A. Brit. J. exp. Path. 38 (1957) 401

${ }^{3}$ Osgoon, E. F. Therapeutic Use of Artificial Radio-isotopes (Ed. P. F. Hahn): John Wiley and Sons, New York, 1956

${ }^{4}$ Sheppard, C. W., Wells, E. B., Hahn, P. F., and Goodell, J. P. B. F. Lab. clin. Med. 32 (1947) 274

${ }^{5}$ Dobson, E. L., Gofman, J. W., Jones, H. B., Kelly, L. S. and Walker, L. A. J. Lab. clin. Med. 34 (1949) 305

${ }^{6}$ Mayneord, W. V. Brit. J. Radiol. N.S. Supplement 2 (1950) 142

${ }^{7}$ Root, S. W., Andrews, G. A., Kniseley, R. M. and Tyor, M. P. Cancer, N.Y. 7 (1954) 856

${ }^{8}$ Zilversmit, D. B., Boy'd, G. A. and Brucer, M. J. Lab. clin. Med. 40 (1952) 255

${ }^{9}$ Hahn, P. F., Corothers, E. L., Hilliard, G. W., Bernard, L. and Jackson, M.

Therapeutic Use of Artificial Radio-isotopes (Ed. P. F. Hahn): John Wiley and Sons, New York, 1956

${ }^{10}$ Jacobson, L. O., Marks, E. K. and Gaston, E. O. Rev. Hémat. 8 (1953) 515

${ }^{11}$ Jacobson, L. O., Robson, M. J. and Marks, E. K. Proc. Soc. exp. Biol., N.Y. 75 (1950) 145

${ }^{12}$ Hilfinger, M. F., Ferguson, J. H. and Riemenschneider, P. A. J. Lab. clin. Med. 42 (1953) 581

${ }^{13}$ Jacobson, L. O., Marks, E. K. and Gaston, E. O. Proc. Soc. exp. Biol., N.Y. 91 (1956) 135

\section{DISCUSSION}

Mr. van DEN BRENK: Could I ask how long after the last graft was given, the marker was identified, and also could you give us an idea of the relative dosage with regard to the biotin of the animals and whether they were grafted or not grafted? How long did they live after irradiation, and what was the dosage given?

Dr. GEorge: First of all, as to the time of identification of the marker-that was three weeks following bone transplantation. The figures you are asking for (concerning the survival or otherwise of the rabbits that had different dosages), are all in the table.

Dr. Hofrman: Two points I should like to raise Dr. George-firstly, do you have any evidence as to whether, although the spleen has taken up so little isotope, it in fact, offers any protective effect?

DR. GEORGE: Only indirectly, in that we were puzzled by the fact that animals that had been receiving 6,000 $\mathrm{r}$ to the marrow (and we took slides of the marrow and it really was fairly aplastic), still recovered, and only indirectly did we infer that spleen protection was operating. We just have not had time to do everything, but we noticed that the spleens were given very low dosages and therefore, we cut a corner by not proving the point, but in future, splenectomizing all rabbits. 


\section{DISCUSSION}

Dr. Hoffman: I am a little puzzled about this because although spleen is packed with myeloid element in the mouse, I think these are absent in most other laboratory animals. I think they are absent in the rabbit, I do not think there are any myeloid elements in the rabbit's spleen?

Dr. George: I do not know.

Dr. Hoffman: The second point is with regard to the aspect you mentioned very briefly - that you have not yet gone into the problem of secondary disease. I again wonder, rather than assert, are there any sufficiently inbred strains of rabbits available to permit isologous transplantation?

Dr. GEORGE: Oh yes, thank you ! I did not mention that these were ordinary laboratory bred rabbits, they were not of any particular strain. There were no isologous transfusions, these were all homologous. 


\title{
EXPERIMENTS IN HOMOGRAFT SURVIVAL
}

\author{
M. KENT \\ The Department of Surgery, University of Melbourne, Melbourne
}

TiIS PAPER is presented to introduce the subject of homotransplantation and, in particular, to discuss the influence of total body irradiation on the mechanisms of the homograft reaction. It contains an interim report on work being carried out within the Department of Surgery of the University of Melbourne.

THE NATURE OF THE HOMOGRAFT REACTION

With the exception of the cornea, cartilage and blood vessels, all homografts undergo complete disintegration at varying time intervals. This process can be observed in its simplest form in the case of whole-thickness skin grafts in rabbits. An adequate capillary blood supply develops in four days. The epithelium, in the case of autotransplants, shows a gradual thickening over the first two weeks, reducing slowly to normal in four weeks. By contrast, homografts show a less marked thickening of the epithelium, with rejection of the graft at about ten days. The process of graft disintegration is accompanied by neighbouring infiltration of small round cells, mainly polymorphs of the inflammatory reaction.

Many hypotheses have been put forward to explain the mechanism of homograft rejection ${ }^{1}$. The theory of actively acquired immunity, implying an antigen-antibody reaction, has considerable experimental backing. Accelerated disintegration follows re-exposure of the host to homografts from the same donor; antibodies to certain homotransplants (particularly tumours) have been demonstrated; the homograft reaction is not seen in grafts in the anterior chamber until contact with the host's circulation occurs; and finally, methods which suppress the activity of the reticuloendothelial system (the presumed site of antibody production) have the effect of prolonging homotransplant survival. The grafts, however, are rejected shortly after recovery of the reticulo-endothelial system.

Some rejected theories worth mentioning are:-

(1) The theory of natural immunity on the analogy of blood group incompatibility. There is no sound evidence that natural antibodies play a part in homograft rejection; the time lag between contact and rejection of the homotransplant is not in keeping with this theory.

(2) The theory of lack of vascular supply is not borne out by the histological evidence, by the time of rejection of the graft in relation to its vascularization, nor by the fact that destruction of anterior chamber implants follow on this vascularization.

(3) The theory of local cellular reaction. That tissue cells have no toxic 


\section{KENT}

effects on their homologous neighbours has been demonstrated by in vitro tissue cultures.

METHODS OF PROLONGING HOMOGRAFT SURVIVAL

Using the theory of actively acquired immunity as a working hypothesis, attempts at homograft prolongation have followed these lines:-

(1) 'Desensitization' of the proteins of the homograft before application. The limitations of this approach are apparent.

(2) Isolation of the graft from contact with the host's antibody-producing mechanisms-the success of anterior chamber grafts is an example of this approach.

(3) Modification of the activity of the reticulo-endothelial system of the host. Methods used include mechanical blockage by intravenous injections of trypan blue, nitrogen mustards, total body irradiation and steroid administration.

(4) The phenomenon of 'actively acquired tolerance'2. Tissue inoculation before, or at birth, from another animal of the same species, will allow a host to accept, later in life, grafts from the original donor. This effect seems to depend on some kind of 'training' of the cells which undertake immunological reactions, while the cells are still immature.

Much interest has centred on the effects of total body irradiation on graft survival, and many workers, both in Britain and the U.S.A., are engaged in this field. Dempster et al. ${ }^{3}$ reported prolongation of skin graft survival to 16 to 20 days, using sub-lethal doses of irradiation, but after this period there was rapid rejection of the graft. The effect was increased with higher $\mathrm{X}$-ray dosage, but lethal levels were reached before prolongation of the acceptance of the graft was apparent.

Methods have been sought to allow survival of animals while X-ray dosage is increased to still higher levels. Blood transfusions have a transient effect. A more prolonged effect (offering protection of one to three months) is afforded by injection of homologous bone-marrow extracts ${ }^{4}$, whilst if isologous marrow (i.e., transplantation within an inbred strain) is used, the effect appears to be permanent ${ }^{5}$. Splenic-pulp injections have a similar effect ${ }^{6}$.

Jacobson ${ }^{7}$ was able to protect mice, following whole-body lethal irradiation, by this means, and many have confirmed this experiment. Workers at Harwell ${ }^{8}$ have demonstrated that this protection is due to colonization of the host's bone marrow and lymphoid tissue by marrow cells of the donor, the identification of the donor's cells being made possible by altering their chromosome pattern. Similar success in protection against the lethal effects of irradiation by bone-marrow injection has been demonstrated in the rabbit ${ }^{9}$ and the $\operatorname{dog}^{10}$, whilst there are some reports of success with heterologous marrow ${ }^{11}$.

Under these circumstances, before recovery of the reticulo-endothelial system of the host occurs, homografts from genetically related mice have been shown to survive ${ }^{12}$. Trentin ${ }^{13}$ demonstrated tolerance of homografts from the donors of the bone marrow, in mice, both with isologous (genetically related) and homologous mice, but found no prolongation of the homograft reaction if the bone marrow and the skin were taken from different animals. 
The aim of the present investigation has been to clarify the position with regard to the effect of irradiation on homograft survival, using marrow infusion (and any other therapeutic measures which may be indicated) as a means of prolonging animal survival at lethal dosages. Thus we are endeavouring:-

(1) to establish a control value for homograft survival in the animal chosen, i.e., in the rabbit.

(2) to observe the effect of various dosage levcls of irradiation on homograft survival.

(3) to establish a lethal dosage, against which it will be possible to judge the effects of therapy.

(4) to observe the effects of bone-marrow infusion on survival following lethal irradiation (using homologous marrow).

(5) to determine the effect on homograft survival in lethally-irradiated rabbits of marrow infusions from the skin donors and from unrelated rabbits.

\section{Experimental Technique}

Rabbits of different skin colours (mostly black and white) have been used. Under general anaesthesia pieces of whole-thickness skin, one-inch square, have been removed from each ear and attached to similar defects. A series of autografts has been completed to act as controls. This has been followed by a series of homografts, initially without radiation dosage. The rabbits have been used in pairs, one black and one white-each homograft has had its own autograft 'control'.

Irradiation has been carried out three days prior to skin-grafting; the rabbits were enclosed in Perspex boxes for the purpose. The technique was under the care of Dr. H. A. S. van den Brenk of the Peter MacCallum Clinic. Details are as follows:-Half-value of $1 \mathrm{~mm}$ copper, $250 \mathrm{kV}, 15 \mathrm{~mA}$, an added filter of $0.25 \mathrm{~mm}$ copper and $1 \mathrm{~mm}$ aluminium. $15 \mathrm{~cm}$ focal surface dose and a $30 \mathrm{~cm}$ diameter open-port field. The free-air dose was $110 \mathrm{r}$ per minute.

\section{Interim Results}

Survival of the grafts has been estimated by frequent inspection, a definite behaviour pattern becoming recognized. An autograft becomes slightly swollen in the first three or four days, but remains quite soft. In the second week there is desquamation of the superficial layers of the graft and in the third week regrowth of hair commences. The graft remains soft and pliable throughout. The first sign of rejection of a homograft is a loss of this softness - the graft becomes dry and gradually hardens over a period of two or three days. Separation then slowly occurs, the skin defect being covered by epithelialization from the edges and fibrous tissue contracture. Until rejection commences, the behaviour of homografts has been indistinguishable from that of their autograft controls.

A graft is recorded as rejected at the first sign of hardness, which is the first difference noted between the homograft and its autograft control. Table 1 shows the results so far obtained.

All deaths occurred within 30 days of irradiation, the majority in the first 


\section{KENT}

Table 1. Length of homograft survival in rabbits irradiated prior to skin grafting

\begin{tabular}{|c|c|c|c|c|}
\hline \multirow{2}{*}{ Group } & \multirow{2}{*}{$\begin{array}{c}\text { Number of } \\
\text { rabbits }\end{array}$} & \multirow{2}{*}{ Deaths } & \multicolumn{2}{|c|}{ Graft survival in days } \\
\hline & & & Average & Range \\
\hline Homografts & 22 & 0 & $9 \cdot 5$ & $6-16$ \\
\hline $\begin{array}{c}\text { Homografts } \\
600 \mathrm{r}\end{array}$ & 12 & 1 & $16 \cdot 5$ & $7-46$ \\
\hline $\begin{array}{c}\text { Homografts } \\
700 \mathrm{r}\end{array}$ & 18 & 2 & $19 \cdot 5$ & $7-56$ \\
\hline Homografts & 72 & 24 & $19 \cdot 5$ & $11-42$ \\
\hline $\begin{array}{c}\text { Homografts } \\
900 \mathrm{r}\end{array}$ & 24 & 16 & Ince & plete \\
\hline
\end{tabular}

14 days. It will be seen that $900 \mathrm{r}$ has been established as a lethal X-ray dosage with the techniques being used. A control value of 9.5 days has been reached for homograft survival. The increasing X-ray dosages have been accompanied by a lengthening of homograft survival. The wide range of variation in homograft survival in the irradiated groups is indicated.

\section{REFERENCES}

${ }^{1}$ Dempster, W. J. Brit. med. J. ii (1951) 1041

${ }^{2}$ Billingham, R. E., Brent, L. and Medawar, P. B. Phil. Trans. B 239 (1956) 357

${ }^{3}$ Dempster, W. J., Lennox, B. and Boag, J. W. Brit. J. exp. Path. 31 (1950) 670

${ }^{4}$ Congdon, C. C. and Urso, I. S. Amer. J. Path. 33 (1957) 749

${ }^{5}$ Congdon, C. C. and Urso, I. S. Radiation Res. 5 (1956) 474

${ }^{6}$ Loutit, J. F. J. Nuclear Energy 1 (1954) 87

${ }^{7}$ Jacobson, L. O. Cancer Res. 12 (1952) 315

${ }^{8}$ Ford, C. E., Hamerton, J. L., Barnes, D. W. H. and Loutit, J. F. Nature, Lond. 177 (1956) 452

${ }^{9}$ Helfinger, M. F., Ferguson, J. H. and Reemenschneider, P. A. J. Lab. clin. Med. 42 (1953) 581

${ }^{10}$ Ferrebee, J. W., Lochte, H. L., Jaretzki, A., Sahler, O. P. and Thomas, E. D. Surgery 43 (1958) 516

${ }^{1}$ Makindon, T. Proc. Soc. exp. Biol., N.Y. 92 (1956) 174

${ }^{12}$ Main, J. M. and Prenn, R. T. J. nat. Cancer Inst. 15 (1955) 1023

${ }^{13}$ Trentin, J. Proc. Soc. exp. Biol., N.Y. 92 (1956) 688

\section{DISGUSSION}

Dr. Loutit : Mr. Kent has asked for guidance, and I suggest that the last line of the table does imply that in his group where 33 per cent survived from $900 \mathrm{r}$, the immune response has only been temporarily inactivated by this dose. But if he then proceeds to give bone marrow for restoration to a comparable group, it is liable that the bone-marrow graft will only last 29 to 51 days or thereabouts and will then be rejected. I think he should go on with the table to see what is 100 per cent death, and probably, although he will not be able to score the survival of homografts of skin, he should, by means of the technique of marked leukocytes of Vince, George, Rocke and Garvan, be able to score the length of survival of his marrow grafts.

MR. Rocke: Do you have any information on the possible effect of irradiation of the donor before taking the graft on this homograft technique?

Mr. Kent: I am sorry, there is no information on that. 


\section{EXPERIMENTS IN HOMOGRAFT SURVIVAL}

Dr. GEORgE: I should like to ask if you did any autopsies on the animals which died? Did you find any cause of death?

Mr. KENT: We followed quite a few of the animals with leukocyte counts on alternate day's before they died, and marked depression of the leukocyte count is the only real observation I have to make on the cause of death.

DR. PEARCE: I should be interested to know whether you consider it to be worth while irradiating just the ears of the rabbits so transplanted to see whether there would be any effect on the local tissues that could be included in the possible effect of the graft?

Mr. Kent: I should be interested to do this, Dr. Pearce, but I doubt whether it would have any effect on the prolongation of the homograft.

DR. Clarke: Why is the rabbit used in this work? The genetic variability is obviously an obstacle in the interpretation of experiments of this kind. If you use inbred lines of rats, or better still, mice, then the genetic variability can at least be minimized to some extent.

Mr. KENT: I think that the choice of animal is a very vexed question because one always has in mind the clinical applications of these things in the long run, and I think that the choice of inbred animals is obviously going to lead to more success in the experiments.

Mr. JACKson: Is the black-eared rabbit a Himalayan?

Mr. Kent: Not so far as I know.

Mr. JACKson: If it was, it would be very interesting to see the change in the expression of the gene. I think it should be checked to see whether it is a Himalayan rabbit. 


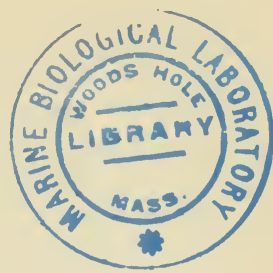

\title{
SECONDARY RADIATION DISEASE FOLLOWING HETEROGRAFTING
}

\author{
Peter Ilbery \\ Radiobiology Research Unit, Department of Preventive Medicine, \\ University of Sydney
}

Mice can be made to survive thirty days following lethal whole-body irradiation (the conventional time taken to assess radiation recovery as control irradiated untreated animals are all dead by this time), by haemopoietic grafting. However, at about six weeks post-irradiation and treatment mice receiving haemopoietic homografts commence to suffer from secondary radiation disease, the severity, extent and mortality of which being dependent upon their degree of genetic disparity ${ }^{1}$. Barnes et al. ${ }^{2}$ showed that secondary radiation disease could be avoided in the hitherto invariably lethal chimaerical combination CBA/C57 in mice by the use of spleen cells from donors less than twelve hours old. In this work an exploratory probe has been made into the possibility of using this technique for across-species grafting, heterografting, notoriously unpredictable and largely unsuccessful.

\section{Materials}

Pure strain CBA, C57 and DBA mice maintained by this unit and Wistar rats, at least eight generations inbred by the McMaster Laboratory, were used. The radiation source was the Theratron ${ }^{60} \mathrm{Co}$ Unit at the Royal Prince Alfred Hospital which gave a dosage rate of $40 \mathrm{rad} / \mathrm{min} \gamma$-rays $(1.3$ $\mathrm{MeV}$ ), having a 2 per cent isodose fall off from centre to edge of the $10 \mathrm{~cm}$ diameter irradiation cage.

\section{Experimental}

Thirty-four DBA mice received $950 \mathrm{rad}{ }^{60} \mathrm{Co}$ lethal whole-body $\gamma$ irradiation. An eighth generation inbred pregnant Wistar rat was the source of the donor material. Ten DBA mice received $8 \times 10^{6}$ each of its bone-marrow cells. Nine mice received $8 \times 10^{6}$ each of foetal spleen cells and five, $8 \times 10^{6}$ each of foetal liver cells (five and an half foetal spleens were required to give this dosage; the embryos were of greater than two weeks gestation, six embryos weighing $37 \cdot 8 \mathrm{~g}$ ). Ten irradiated control DBA mice were all dead within twelve days.

Thirty-two CBA mice received $1050 \mathrm{rad}{ }^{60} \mathrm{Co}$ lethal whole-body $\gamma$ irradiation. A ninth inbred generation Wistar rat which had littered less than fifteen hours previously was the source of donor material. Nine mice received $12 \times 10^{6}$ each of adult bone-marrow cells. Fourteen mice received 
between $3 \cdot 2$ and $4 \cdot 2 \times 10^{6}$ each of less than fifteen-hours-old balby rat spleen cells. Nine irradiated control mice were all dead within thirteen days.

Twenty C57 mice received $900 \mathrm{rad}{ }^{60} \mathrm{Co}$ lethal whole-body $\gamma$ irradiation. A DBA mouse which had littered not more than nineteen hours previously was the source of the donor material. Six mice received $1.2 \times 10^{6}$ each of adult bone-marrow cells, whilst five received $1 \cdot 1 \times 10^{6}$ each of less than

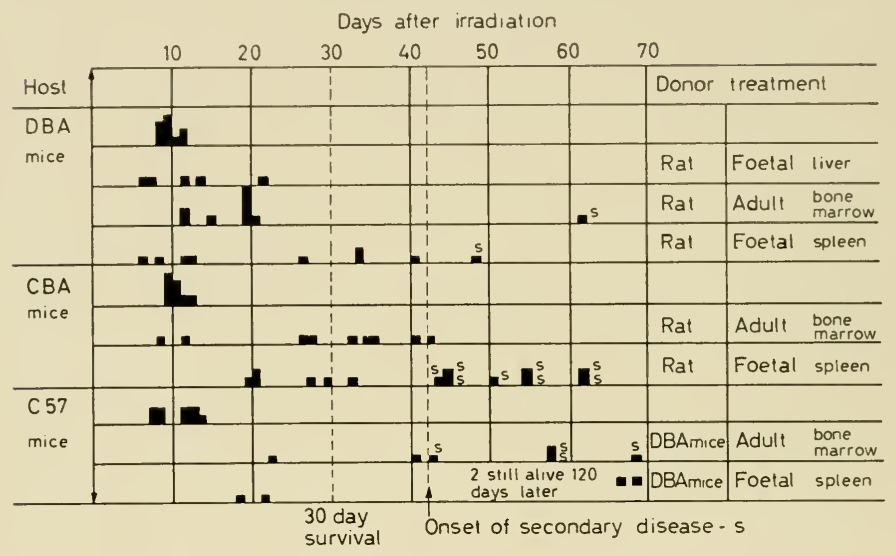

Figure 1. Length of survival of mice after irradiation and grafting

nineteen-hours-old DBA baby spleen cells. Nine irradiated control mice were all dead within 14 days. The results are represented graphically in Figure 1.

\section{DISCUSSION OF RESULTS}

The University College Hospital Group ${ }^{3}$ has described a state of actively acquired tolerance which follows intravenous injection of splecn cells of one strain into newborn or foetal mice of another strain. The host and donor cells continue to live harmoniously together in favourable combinations and skin can be grafted from mice of the donor strain to the chimaera. The abrogation of host immune mechanisms by lethal whole-body irradiation results in 'radiation tolerance' for an haemopoietic graft comparable to the use of a newborn host by Billingham and Brent ${ }^{3}$. In one the immune mechanism has not developed and in the other it is suppressed so that for a time at least a graft may be acceptable. But because the mechanism of secondary radiation disease is believed to be a chronic antigen-antibody reaction of donor cells at a later date against the host, which is characterized by wasting, diarrhoea and specific time of onset, the use of immunologically 'null' donor material (itself of foetal origin) might result in a non-reactive situation. In practice it is seen that intravenous injection of foetal haemopoietic homografts into lethally irradiated hosts results in their 


\section{PETER ILBERY}

prolonged survival without signs of secondary disease whereas the use of adult haemopoietic homografts invariably results in the syndromes qualified by the degree of genetic divergence of host and donor.

Although foetal donor heterograft cells gave enhanced survival compared with adult cells, nine out of ten DBA mice given adult haemopoietic tissue and four out of nine DBA mice given 'null' haemopoietic tissue were dead before 30 days when the 30 -day survival period was the criterion; by the end of the six-week post-irradiation period and heterografting, nine out of nine CBA mice given adult haemopoietic tissue and six out of fourteen CBA mice given 'null' haemopoietic tissue were dead i.e., those given 'null' cells were alive.

Although a capacity for enhanced survival using foetal donor material in heterografting is shown it does not prevent the occurrence of secondary radiation disease in those surviving longer than six weeks which can be obtained with homografting with 'null' material.

\section{REFERENCES}

${ }^{1}$ Ilbery, P. L. T., Koller, P. C. and Loutit, J. F. J. nat. Cancer Inst. 20 (1958) 1051 ${ }^{2}$ Barnes, D. W. H., Ilbery, P. L. T. and Loutit, J. F. Nature, Lond. 181 (1958) 488

${ }^{3}$ Billingham, R. E. and Brent, L. Transplantation Bull. 4 (1957) 67 


\title{
AN EXPERIMENTAL STUDY OF THE INFLUENGE OF OXYGEN ON THE RADIO-SENSITIVITY OF THE EHRLICH ASCITES TUMOUR GELL
}

\author{
L. H. Gray \\ British Empire Cancer Campaign Research Unit in Radiobiology, \\ Mount I'ernon Hospital, . Northwood, England
}

I PROPOSE in this paper to give an account of an experimental investigation which Dr. Eleanor Deschner and I have carried out ${ }^{1}$ with the object of comparing the radio-sensitivity of mammalian tumour cells in vivo and in vitro under controlled conditions of oxygen tension. It was known that the radio-sensitivity of many mammalian tissues was positively correlated with the availability of oxygen to the tissues, but the form of the relation between radio-sensitivity and the concentration of dissolved molecular oxygen in the immediate environment of the cell had not been investigated in the living animal. The control and measurement of the oxygen tension in an organized tissue seemed to present insuperable difficulties, and we considered that a better chance of success lay in an attempt to measure the concentration of dissolved oxygen in the peritoneal fluid at the time of irradiation in an animal bearing an Ehrlich ascites tumour. This tumour grows as a single cell suspension in the peritoneal cavity which contains nutrients, and generally a certain amount of blood. An inoculum of $10^{7}$ cells gives rise in the course of 5 days to about $2 \mathrm{ml}$. of fluid containing $\sim 10^{8}$ cells $/ \mathrm{ml}$. This fluid, diluted with plasma obtained by centrifuging the peritoneal fluid from other tumourbearing animals, with blood added to a mean concentration of $5 \times 10^{8}$ red blood cells (r.b.c.)/ml., was the fluid used for in vitro irradiations. After irradiation in the manner described below, alequots were inoculated into fresh host mice for a period of about 15 hours, during which tumour cells begin to enter their first division. The mice were killed, the peritoneal fluid withdrawn, and the cells fixed and stained. Anaphase figures which showed either chromosome bridge or a fragment were scored as abnormal. In control material, the proportion of abnormal cells was around 5 per cent. In irradiated material the log percentage normal cells was linearly related to dose provided the irradiation was not too heavy. The coefficient of aberration production $\alpha$, is:

$$
\frac{\log _{\mathrm{e}} F_{C}-\log _{\mathrm{e}} F_{R}}{D}
$$

where $F_{C}$ is the fraction of normal cells in control material, $F_{R}$ that in irradiated material, and $D$ is the dose in rads. This coefficient was used as a measure of radio-sensitivity. In the interests of accuracy, the dose $D$, was adjusted so as to give rise to about 65 per cent abnormal cells in all irradiated 


\section{H. GRAY}

samples, irrespective of the conditions of irradiation. Subsequent to irradiation, cells were treated in precisely the same way, whether they had been irradiated in vitro or in vivo.

A careful preliminary investigation established that, provided the dose was adjusted to give roughly equal amounts of damage, the presence or absence of oxygen at the time of irradiation had no influence on the percentage of abnormal anaphases seen at different times after irradiation. This was true whether the irradiation was at $18^{\circ} \mathrm{C}$ or at $37^{\circ} \mathrm{C}$. When the inoculum was $0.2 \mathrm{ml}$. containing roughly $2 \times 10^{7}$ cells, the percentage of abnormal anaphases rose slowly with increasing interval between irradiation and fixation to a flat maximum at 14 to 15 hours, and then fell. As a standard procedure, cells were therefore fixed at 14 hours after inoculation. Since the problem of ascertaining the precise oxygen tension of the cells at the time of irradiation was approached somewhat differently in the case of in vitro and in vivo irradiations, these two aspects of the investigation will be described separately.

\section{IN VITRO IRRADIATIONS}

In the case of in vitro irradiation, the difficulty hinges essentially about the fact that radio-sensitivity is varying most rapidly with oxygen tension at very low oxygen tensions, namely those corresponding to concentration of dissolved oxygen of about $5 \mu \mathrm{M} / 1$. Fluid containing this amount of dissolved oxygen is in equilibrium with a gas phase which contains about $0 \cdot 3$ per cent of oxygen at room temperature, and about 0.5 per cent at $37^{\circ} \mathrm{C}$. Those familiar with Warburg manometric techniques will appreciate the difficulty of maintaining an adequate oxygen concentration in a fluid phase containing respiring tissue, even when the gas phases consist of almost pure oxygen. The difficulties are obviously increased several hundred-fold in the present experiments on account of the very low oxygen tensions which are of interest. These were satisfactorily overcome in the case of irradiations at room temperature by the use of low tumour cell concentrations, and an irradiation vessel which allowed gas to be blown at high speed obliquely and eccentrically on to the surface of a small depth of fluid contained in a gas-tight enclosure, (see Figure 1). The gas inflow at about 60 c.c. $/$ sec agitated and vigorously stirred the fluid. The all-glass syringe at the base of the irradiation vessel was used once a minute for 15 min before irradiation to withdraw the fluid and reintroduce it into the irradiation vessel as a small fountain. This counteracted any tendency to sedimentation of cells and broke up small clumps into individual cells. In order that oxygen shall pass from the gas into the fluid phase at a rate which keeps pace with cellular respiration, there must inevitably be a pressure differential. Our objective was to keep this differential small compared with that corresponding to a concentration of $5 \mu \mathrm{M} / 1$. in the fluid phase. A calculation based on $Q_{\mathrm{O}_{2}} \sim 2 \mu \mathrm{l}$. of oxygen per minute per $10^{8}$ cells at $18 \mathrm{C}$, kindly measured for us by Dr. D. L. Dewey, and a measured rate of exchange of oxygen between the gas phase and a fluid which did not contain cells, indicated that the concentration of dissolved oxygen in the irradiation experiments, at room temperature, would be known with the desired accuracy if we worked with concentrations not exceeding $4 \times 10^{6}$ tumour cells per $\mathrm{ml}$. The margin of uncertainty in 
these calculations, however, was such that we felt it important to try to measure the pressure differential between the two phases directly. Ordinary polarographic methods were judged to be unsuitable because of the turbulence of the fluid, the nature of the fluid, and the presence of blood. The following procedure was found to give the desired information:

To the end of a micro gas pipette ${ }^{2}$ a small Perspex sleeve was attached in such a way as to retain a bubble of about $1.5 \mathrm{~mm}$ diameter formed below the surface of the fluid when the pipette was introduced at an angle of about $45^{\circ}$ to the vertical. The bubble was formed from whatever gas constituted the gas phase in the irradiation vessel. During a period of $5 \mathrm{~min}$ below the surface of the tumour suspension, the oxygen content of the bubble changed

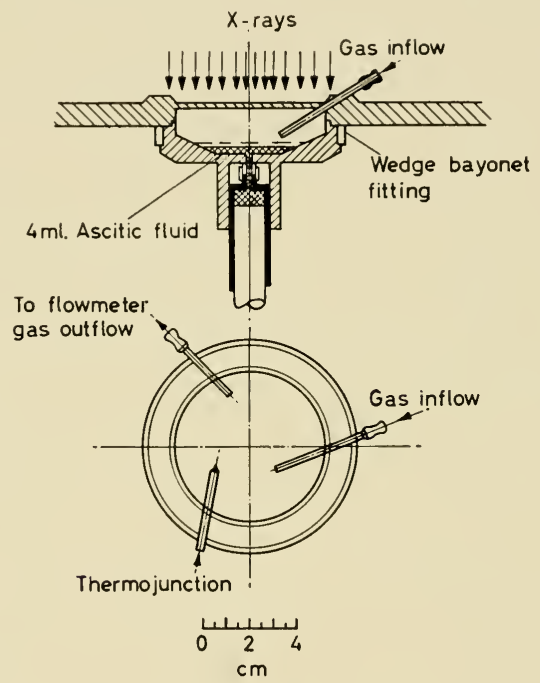

Figure 1. Perspex irradiation vesseI

to a new equilibrium value corresponding to the actual partial pressure of oxygen in the fluid bathing the tumour cells. The bubble was then withdrawn into the gas pipette and transferred to the analysing compartment of the apparatus shown as a block diagram in Figure 2. This apparatus employs the oxygen analyser described by Hersch ${ }^{3}$. Hydrogen from a cylinder passes through a flowmeter, a catalyst to remove traces of oxygen, an electrolysis cell introduced for calibration purposes, a compartment into which the fluid can be introduced for analysis, and an electro-chemical cell which responds at constant flow rate to the presence of trace amounts of oxygen by giving a current proportional to the concentration of oxygen in the gas phase. In the instrument we have employed, l part per million (p.p.m.) of oxygen gives a current of the order of $7 \mu \mathrm{A}$ when the hydrogen 


\section{H. GRAY}

flow is $130 \mathrm{ml} . / \mathrm{min}$. The zero is constant over short periods of time to about $\pm 0.01 \mu \mathrm{A}$. This apparatus is adapted to the measurement of quantities of oxygen in the manner previously outlined ${ }^{4}$ by the inclusion of the fluxmeter, $F$, in series with the galvanometer in the balancing arm of the potentiometer (Figure 2). The oxygen content of the sample introduced into the analysing compartment is collected during a period of $2 \mathrm{~min}$ and the amount, if small, is proportional to the fluxmeter reading. The absolute amount of oxygen in the sample is obtained by reference to the fluxmeter reading which results from the introduction by electrolysis of a known amount of oxygen into the system. Replicate observations showed that the oxygen content of a $5 \mu \mathrm{l}$. bubble at a partial pressure of up to $10 \mathrm{~mm}$ mercury could be measured in this way to $\pm 10^{-9} \mathrm{~g}$ corresponding to $\pm 0 \cdot 1 \mathrm{~mm}$ mercury in partial pressure. The overall errors with which differences in partial pressure between gas and fluid phase could be measured by the formation and

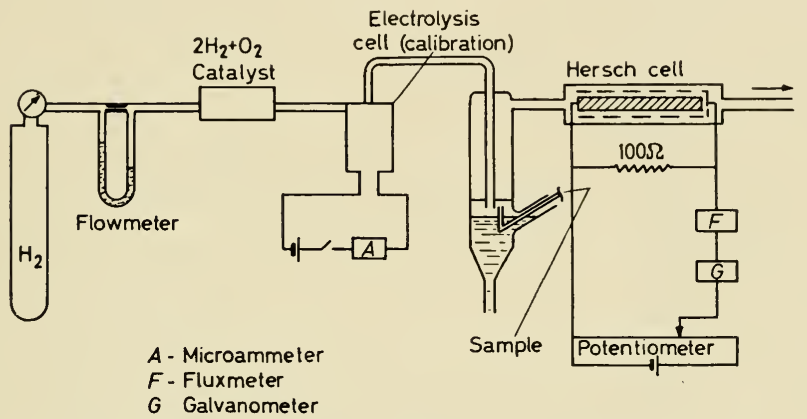

Figure 2. Apparatus for the micro-assay of oxygen

retraction of a bubble under fluid which contained tumour cells in the manner described above, were about twice those stated above. Check measurements with tumour-bearing fluid at different temperatures and different cell concentrations showed approximately: (a) zero differences in partial pressure between gas and fluid when cellular respiration was poisoned by calcium cyanide, $(b)$ proportionality between the pressure differential and the concentration of tumour cells, and $(c)$ that the pressure differential at different temperatures was roughly in proportion to the measured $Q_{\mathrm{O}_{2}}$ of the cells at these temperatures. On the basis of all these measurements, it was possible to conclude that when $4 \mathrm{ml}$. of tumour-bearing fluid was equilibrated with gas in the apparatus shown in Figure 1, and in the manner described, the pressure differential at $18 \mathrm{C}$ was $0.4 \mathrm{~mm}$ mercury at a tumour cell concentration of $4 \times 10^{6} \mathrm{cells} / \mathrm{ml}$. It was, therefore, estimated that in the irradiation experiments the concentration of dissolved oxygen in the fluid phase was $0.7 \mu \mathrm{M} /$. less than that which would correspond with true equilibrium between gas and fluid phases in the absence of cellular respiration. This small difference was allowed for. 
At room tempcrature our observations of the relation between radiosensitivity and concentration of dissolved oxygen (Figure 3) may be represented by the formula:

$$
\frac{\alpha-\alpha_{\mathrm{N}}}{\alpha_{\mathrm{N}}}=(m-1) \frac{\left[\mathrm{O}_{2}\right]}{\left[\mathrm{O}_{2}\right]+K}
$$

when $m$ is 2.8 and $K$ is $5 \pm 2 \mu \mathrm{M}$ l. In this formula $\alpha_{N}$ is the aberration coefficient under strictly anoxic conditions, and $\left[\mathrm{O}_{2}\right]$ is the concentration of dissolved oxygen. At $37^{\circ} \mathrm{C}$ the $Q_{\mathrm{O}_{2}}$ of the cells is about five times as high as at $18^{\circ} \mathrm{C}$. To obtain the same degree of accuracy in the control of dissolved oxygen in the irradiated fluid as in the room temperature experiments already described, it would therefore be necessary to work with a concentration of tumour cells slightly less than $10^{6}$ per $\mathrm{ml}$. This was not practicable

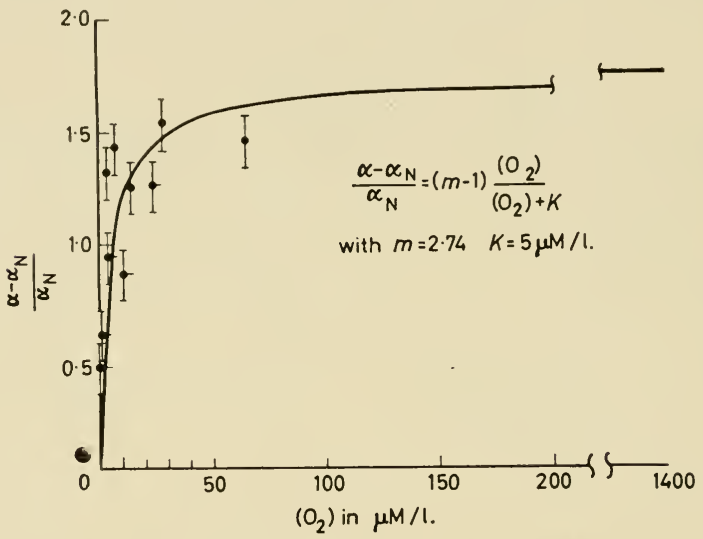

Figure 3. Ehrlich ascites tumour cells irradiated at $18 \mathrm{C}$ in vitro

at the time*. Observations made at $37^{\circ} \mathrm{C}$ with higher cell concentrations, with an estimated correction for the pressure differential between gas and fluid phases conformed, within the limits of experimental error, with equation (1) without any change in the constants. Even though the calculated allowance for the pressure differential is based on the measurements which were made at $18^{\circ} \mathrm{C}$, it is subject to some uncertainty, and a substantial difference between the value of $K$ at $37^{\circ} \mathrm{C}$ and at room temperature cannot positively be ruled out. It is very unlikely that $K$ is greater than $10 \mu \mathrm{M} / 1$. at $37^{\circ} \mathrm{C}$.

The extremes of radio-sensitivity corresponding to complete anoxia and to full oxygenation were measured at $3{ }^{\circ} \mathrm{C}, 18^{\circ} \mathrm{C}$, and $36^{\circ} \mathrm{C}$, with results given in Table $I$. The extreme sensitivity ratio $m$ shows no systematic variation over this large range of temperatures.

* A means of working with concentrations as low as $10^{6}$ per $\mathrm{ml}$. has since been devised and further work is in progress by the author in collaboration with Dr. Alma Howard and Miss Christine Hawes. 
Table 1. Dependence of aberration coefficients on temperature

\begin{tabular}{lccc}
\hline \multicolumn{1}{c}{ Temperature } & $3 \mathrm{C}$ & $18 \mathrm{C}$ & $36 \mathrm{C}$ \\
\hline Minimum (anaerobic) value of $\alpha$ & $1 \cdot 68 \pm 0 \cdot 11$ & $1 \cdot 70 \pm 0 \cdot 11$ & $2 \cdot 03 \pm 0 \cdot 13$ \\
Maximum (oxygen) value of $\alpha$ & $4 \cdot 54 \pm 0 \cdot 28$ & $5 \cdot 25 \pm 0 \cdot 33$ & $5 \cdot 87 \pm 0 \cdot 37$ \\
$\alpha_{\mathrm{O}_{2} / \boldsymbol{N}_{2}}$ & $2 \cdot 70 \pm 0 \cdot 25$ & $3 \cdot 10 \pm 0 \cdot 27$ & $2 \cdot 90 \pm 0 \cdot 27$ \\
\hline
\end{tabular}

\section{IN VIVO IRRADIATIONS}

The in vivo measurements posed problems different from those which we encountered in our attempt to measure the relation between radio-sensitivity and oxygen tension in vitro, since the only control which we could exert over the oxygen tension in the peritoneal cavity was through the composition of the gas respired by the animal, and it was necessary to try to measure the oxygen tension in the fluid in the peritoneal cavity of the living animal. The bubble technique was applied again, but in the following way:

Typically, a five-day old tumour in our animals consisted of 1 to $2 \mathrm{ml}$. of fluid containing about $10^{8}$ tumour cells $/ \mathrm{ml}$, some inflammatory cells, and a variable amount of blood. A small bubble of gas was introduced by hypodermic needle into the peritoneal cavity $30 \mathrm{~min}$ before irradiation, and equilibration was assisted by massage of the abdomen. The size of this bubble, which consisted of $0.1 \mathrm{ml}$. of either nitrogen or a 5 per cent oxygen in nitrogen mixture, was chosen to be small enough to come into equilibrium with the fluid during the $30 \mathrm{~min}$ before irradiation but large enough not to follow the rapidly falling oxygen tension of the fluid which results from continued cellular respiration after the death of the animal. Sampling the bubble was a delicate operation which was carried out as quickly as possible. The spinal cord was severed immediately after irradiation, the muscular wall of the abdomen was exposed, and the animal suspended ventral side upwards by clamping the abdominal wall. The bubble rose and became located near the clamp. A gas pipette having a sharp glass tip was made to pierce the abdominal wall below the level of the fluid, and the tip was moved up into the bubble. A small sample of gas was drawn into the pipette. Before withdrawing the pipette the tip was once again brought into a position below the fluid into the peritoneal cavity, and some fluid was taken in to seal the gas sample. The volume of the sample was noted and its oxygen content assayed by means of the Hersch analyser, as already described. A second sample of gas was taken in another pipette about 1.5 min later. Comparing the second sample with the first, it was evident that oxygen tension in the bubble was falling at about $3 \mathrm{~mm}$ mercury per min. Extrapolation back to zero time gave an estimate of the oxygen tension in the bubble at the moment when the animal was killed, i.e. at the end of irradiation. The range of values observed and their mean is given in Table 2 for animals breathing gas which contained $8 \cdot 5,10,21$ (air), and 100 per cent oxygen.

The table shows the corresponding mean values of the aberration coefficient $\alpha$ and of the ratio $\alpha / \alpha_{N}$.

Two additional measurements of radio-sensitivity were made shortly after the introduction of $10^{-2}$ or $10^{-1}$ moles hydrogen peroxide into the peritoneal cavity of tumour-bearing animals which were respiring air. When such 
Table 2. Composition of gas in equilibrium with fluid in the Peritoneal cavity of mice and related aberration cocflicients

\begin{tabular}{|c|c|c|c|c|c|c|}
\hline \multirow[b]{2}{*}{ Per eent $\mathrm{O}_{2}$ in respired gas } & \multicolumn{4}{|c|}{$\begin{array}{l}\text { No supplementary } \\
\text { treatment }\end{array}$} & \multicolumn{2}{|c|}{$\begin{array}{c}\mathrm{H}_{2} \mathrm{O}_{2} \text { introduced } \\
\text { into peritoneal } \\
\text { cavity } \\
10^{2} \mathrm{M} 10^{-1} \mathrm{M}\end{array}$} \\
\hline & $8 \cdot 5^{\circ} \%$ & $10 \%$ & $\begin{array}{l}21^{\circ} \% \\
(\Lambda i r)\end{array}$ & $100^{\circ}$ & $\Lambda \mathrm{ir}$ & Air \\
\hline $\begin{array}{l}\text { Number of animals } \\
\mathrm{pO}_{2} \text { at time of irradiation in } \mathrm{mm} \\
\text { mercury }\end{array}$ & 4 & 6 & 18 & 16 & 8 & 10 \\
\hline Range of values & $9-11$ & $8-17$ & $7 \cdot 3-26 \cdot 4$ & $11-58$ & - & - \\
\hline Mean values $\left\{\begin{array}{l}\mathrm{N}_{2} \text { injected } \\
5^{\circ}{ }_{0} \mathrm{O}_{2} \text { injected } \\
\text { All observations }\end{array}\right.$ & $\begin{array}{l}8 \cdot 8 \\
9 \cdot 0 \\
8 \cdot 9\end{array}$ & $\begin{array}{l}10 \cdot 5 \\
11 \cdot 5 \\
11 \cdot 0\end{array}$ & $\begin{array}{l}13 \cdot 9 \\
15 \cdot 3 \\
1+\cdot 6\end{array}$ & $\begin{array}{l}39 \cdot 9 \\
36 \cdot 9 \\
38 \cdot 4\end{array}$ & - & - \\
\hline $\begin{array}{l}\text { Rate of decrease of bubble } p_{2} \\
\text { with time mm mercury } / \text { min }\end{array}$ & $3 \cdot 3$ & $2 \cdot 6$ & $2 \cdot 3$ & $6 \cdot 6$ & 一 & - \\
\hline Aberration coefficient $\alpha \times 10^{3}$ & $\begin{array}{l}2 \cdot 07 \\
+0.08\end{array}$ & $\begin{array}{l}2 \cdot 12 \\
\pm 0 \cdot 10\end{array}$ & $\begin{array}{c}2 \cdot 42 \\
\pm 0.08\end{array}$ & $\begin{array}{c}3 \cdot 20 \\
\pm 0 \cdot 23\end{array}$ & $3 \cdot 6 \pm 0 \cdot 6$ & $5 \cdot 0 \pm 0 \cdot 5$ \\
\hline$\alpha, \alpha N$ & $\begin{array}{l}1 \cdot 02 \\
\pm 0 \cdot 04\end{array}$ & $\begin{array}{l}1 \cdot 05 \\
\pm 0.05\end{array}$ & $\begin{array}{l}1 \cdot 19 \\
\pm 0 \cdot 04\end{array}$ & $\begin{array}{l}1 \cdot 58 \\
\pm 0 \cdot 11\end{array}$ & $1 \cdot 8 \pm 0 \cdot 3$ & $2 \cdot 5 \pm 0 \cdot 3$ \\
\hline
\end{tabular}

quantities of hydrogen peroxide are introduced into the peritoneal cavity the fluid becomes a mass of small bubbles of oxygen, resulting mainly from a decomposition of the hydrogen peroxide by the catalase present in the red blood cells. This was found to be a very effective way of raising the oxygen tension throughout the cavity, but was obviously incompatible with a measurement of the actual oxygen tension in the cavity by our bubble technique. The treatment did not raise the spontaneous aberration frequency appreciably above the usual 5 per cent level. The radio-sensitivity of tumour cells irradiated in the peritoneal cavity in the presence of hydrogen peroxide are shown in Table 2. The value of the anaerobic aberration coefficient $\alpha_{\mathrm{N}}$ is that observed in vitro. It is seen that the average sensitivity of tumour cells in the peritoneal cavity of an animal breathing 8.5 per cent oxygen barely exceeds the completely anaerobic value, and is only 20 per cent greater than the anaerobic value in an animal breathing air. Administration of oxygen increases the average sensitivity to 60 per cent above the anaerobic value. By the administration of hydrogen peroxide, the average sensitivity may be raised to a level only slightly below that of cells irradiated in vitro in the fully oxygenated condition.

When values of radio-sensitivity and of the bubble oxygen tension in the peritoneal cavity in each of the 44 irradiated animals are compared individually, however (Figure 4), a very wide scatter is revealed. In only a few animals did the radio-sensitivity approach the value, shown by the upper broken line, which would have been observed in vitro for cells at the oxygen tension recorded by the bubble. In most animals, radio-sensitivity is much lower than that corresponding to the bubble oxygen tension, but in none is it significantly below the in vitro anaerobic level. Since most, and in some cases all the fluid in the peritoneal cavity of an irradiated animal was injected into new hosts and scored for chromosome abnormality, the mean of all such scores must relate to the average condition of the whole fluid. We have noted 
that the lowest values of the aberration coefficient observed in vivo agree closely with the anaerobic in vitro value, and that the highest value observed in vivo, in animals injected with hydrogen peroxide, are close to the maximum fully oxygenated in vitro value. We think it probable that in vivo and in vitro sensitivities are also equal at all intermediate oxygen tensions, and that the scatter of the points in Figure 4 represents the extent to which the average oxygen tension in the fluid of the cavity lies below that measured by the bubble, which will inevitably be located adjacent to one of the vascularized membranes.

If there are $n \times 10^{8}$ cells $/ \mathrm{ml}$. in the peritoneal cavity, the oxygen consumption of the fluid will be $11 n \mu l . \mathrm{O}_{2} / \mathrm{g} / \mathrm{min}^{*}$, or $0.66 n \mu \mathrm{l} . / \mathrm{mg}$ wet weight $/ \mathrm{hour}$. If this fluid were stationary and in contact with a plain vascular membrane which was at a $p_{\mathrm{O}_{2}}$ of $40 \mathrm{~mm}$ mercury, the $p_{\mathrm{O}_{2}}$ would fall to zero at a distance

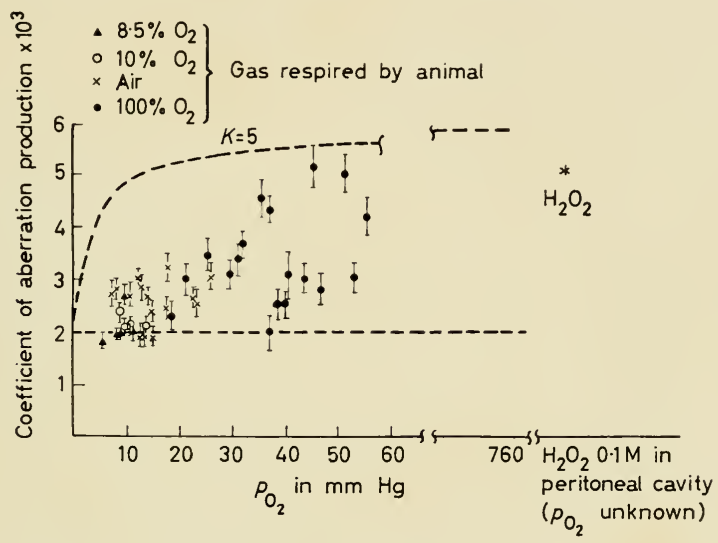

Figure 4. Radio-sensitivity of Ehrlich ascites tumour cells irradiated in vivo

of $145 / \sqrt{ } n$ microns from the membrane. Since, in a five-day tumour, the concentration of cells is usually about $10^{8} / \mathrm{ml}$., $n \sim 1$, so that the only cells which, in the absence of stirring, would have a sensitivity appreciably above the anoxic level, would be those within $145 \mu$ of a vascularized membrane at $p_{\mathrm{O}_{2}}$ of $40 \mathrm{~mm}$ mercury. If the oxygen tension of the membrane were $P \mathrm{~mm}$ mercury, the distance would be $145 \checkmark^{\prime}(P / 40)$ microns. The volume of a five-day tumour is $\sim 2 \mathrm{ml}$. If, to consider the worst case from the point of view of oxygen supply, the tumour corresponded to a spherical mass of fluid confined within a membrane which is maintained at $40 \mathrm{~mm}$ mercury, the outermost $145 \mu$ of fluid would contain 7 per cent of the fluid. The expected ratio of $\alpha / \alpha_{\mathrm{N}}$ would therefore be that of a mixture of 7 per cent of aerated cells $\left(\left[\mathrm{O}_{2}\right] \sim 50 \mu \mathrm{M} / \mathrm{I}\right.$. $)$ and 93 per cent of anoxic cells, i.e. $\sim 1 \cdot 10$. Owing to the convoluted surface of the viscera, a somewhat higher value would be expected in practice in the absence of stirring. The observed value (Table 2) was $1 \cdot 19$.

* Measurements by Dr. D. L. Dewey at $37^{\circ} \mathrm{C}$. 
In the case of each animal irradiated while breathing air, we have calculated from the olserved aberration coefficient the percentage of acrobic cells. Individual values range from zero to 36 per cent with a mean of 13 per cent. Allowing that the convolutions of the viscera may double the effective area of a given volume of fluid, this figure is about that which might be expected in the absence of stirring. Since our animals were immobilized during irradiation, there may well have been very little stirring action at this period - though, as explained above, the abdomen was deliberately massaged while the bubble of gas was being brought into equilibrium before irradiation. Stirring would have to be rather rapid to be effective. If the oxygen storage capacity of the blood, which was present in variable amounts, is excluded, an element of fluid containing $10^{8}$ tumour cells $/ \mathrm{ml}$. which had been raised to a $p_{\mathrm{O}_{2}}$ of $40 \mathrm{~mm}$ mercury by contact with a membrane, would, through tumour cell respiration, become anoxic in $7 \mathrm{sec}$. Thus, aerobic sensitivity could only be maintained if every element of fluid were brought into contact with a membrane at least once every $7 \mathrm{sec}$.

Except when an animal was being turned over, the gas bubble would always have lain against a membrane. In the light of the figures given above, it is evident that the dimensions of a $0.1 \mathrm{ml}$. bubble are such that some parts of the bubble surface are likely to have been in contact with virtually anoxic fluid. The recorded $p_{\mathrm{O}_{2}}$ in the bubble is thus probably slightly lower than that of the membrane. The more uniform the oxygen tension throughout the fluid, the closer would the bubble indicate the correct value. This accords with the fact that the observed aberration coefficients were occasionally up to the level of the broken line in Figure 4, but never above it. Thus, in all respects, our in vivo observations accord with what might be expected from a knowledge of the structure, size, cell concentration, and $Q_{\mathrm{O}_{2}}$ of a five-day tumour.

Increasing the concentration of oxygen in the gas breathed by the animal increases the mean sensitivity of the tumour cells; injection of hydrogen peroxide increases it still more. Only an exceptionally vigorous massage of the abdomen, continuing throughout the period of irradiation, would be expected to increase substantially the mean sensitivity of the tumour cells in an animal breathing any of the gas mixtures tested.

\section{REFERENCES}

${ }^{1}$ Deschner, E. E. and Gray, L. H. Radiation Res. (1959)-in the press.

${ }^{2}$ Kırk, P. L. Quantitative Ultramicroanalysis: John Wiley, Inc., New York, 1950, p. 224, figure 90

${ }^{3}$ Herscil, P. Instrum. Pract. (1957) 937

${ }^{4}$ Gray, L. H. Progress in Radiobiology (Ed. J. S. Mitchell, B. E. Holmes and C. L. Smith): Oliver and Boyd, Edinburgh, 1955, p. 267

\section{DISGUSSION}

DR. Duncan: Perhaps I might start the ball rolling on a chemical question. It seems to me that this problem is very similar to the tuberculous problem which Professor Rubold studied, and in this, one of the things which of course is interesting, is the effect of X-rays on the fluid. Now, we know perfectly well that irradiation can produce hydroxy-radicals and other oxidizing agents, and it therefore would appear 


\section{H. GRAY}

that some effect could be produced by introducing into the cells some oxidizing agent, like hydrogen peroxide, and things of this kind. I wondered, in the first place, whether anything had been done on those lines, and in this connection, too, could you tell us something about the relation between the respiration in this case and the oxygen? Is it that all these cells are respiring whether or not they are present with oxygen? Does the respiration have any effect on them or not?

DR. GRAY: The first part of your question, I think, concerns the production of peroxides in the fluid. It is most likely that organic peroxides are produced when you irradiate the ascitic fluid in which these cells are in suspension. If this were so, and if the peroxides were contributing to the observed chromosome damage by their effects on cells during the short period of irradiation, it would be expected that an increased amount of damage would be seen if the cells were allowed to stand in the presence of the fluid after the end of irradiation. This was checked by leaving the cells in the presence of the irradiated plasma for periods of up to three-quarters of an hour, but no increased damage was seen. I suspect that this is because the cells contain catalase. Such after-effects were observed long ago by Alper ${ }^{1}$ when irradiated virus was allowed to stand in the presence of the irradiated medium, and has been observed quite recently by Adler ${ }^{2}$ and Adler and Stapleton ${ }^{3}$ with bacteria which contained no catalase. In each case the effect of the irradiated fluid could be reproduced by exposing irradiated organisms to other fluid which contained a known amount of hydrogen peroxide. Adler and Stapleton worked with a haemin-deficient mutant strain of Escherichia coli, in which they could control the amount of catalase present in the cells by the composition of the culture medium. They were thus able to show that an after-effect was observed only with the bacteria which contained no catalase. It is interesting also to note that both with the viruses and the bacteria the interaction after the end of irradiation was between peroxides and irradiated organisms. Interaction with unirradiated organisms was negligible by comparison. In a paper presented at the recent Atoms for Peace Conference, Kunkel and Schubert ${ }^{4}$ have reported some rather striking protection effects observed with cysteamine administered after the end of irradiation. Perhaps the most striking were those observed with a hibernating dormouse. Cysteamine administered to the active dormouse before irradiation has a protective effect similar to that observed with mice. When the hibernating dormouse is irradiated, the damaging effects of the radiation only begin to become evident when the dormouse comes out of hibernation. Kunkel and Schubert report that protection against this damage may be obtained by the administration of cysteamine up to 3 weeks after irradiation, provided it is given while the dormouse is still in the hibernating condition. In the same paper they report a very interesting verbal communication from Dittrich. Working with the same tumour cells as those with which Dr. Deschner and I have worked, namely the Ehrlich ascites tumour, Dittrich reports that 'increased chromosomal damage is seen in cells which have been irradiated either in the presence of air or oxygen near $0^{\circ} \mathrm{C}$ if they are allowed to warm up to $37^{\circ} \mathrm{C}$ in the presence of $2 \mathrm{~atm}$ oxygen'. In the course of some studies which Dr. Howard, Miss Hawes, and I were carrying out at $2{ }^{\circ} \mathrm{C}$, we compared the proportion of abnormal anaphases in cells which had been irradiated anaerobically or in the presence of low concentrations of oxygen, and allowed on the one hand to warm up to $37^{\circ} \mathrm{C}$ over a period of $20 \mathrm{~min}$ in the presence of the gas in which they had been irradiated, or, on the other hand, in the presence of oxygen at $1 \mathrm{~atm}$. In a few preiiminary experiments of this kind, we have observed no influence of the post-treatment with oxygen at 1 atm pressure. We hope to extend our observations to $2 \mathrm{~atm}$ pressure for comparison with the reported observations of Dittrich.

My colleague, Dr. Dewey, measured the respiration of Ehrlich ascites tumour cells down to partial pressures of about $7 \mathrm{~mm}$ mercury without observing any dependence of $Q_{\mathrm{O}_{2}}$ on the partial pressures of oxygen. In some cells, notably muscle cells, this independence is known to extend to $1 \mathrm{~mm}$ mercury, and in bacteria to much lower 
values still. If the cells have no oxygen available to them, they obviously cannot respire.

1)R. McCAllum: If we are studying oxygen in equilibrium, are we studying the actual oxidation-reduction potentials of the system? Could it be that Redox potentials of enzyme systems rather than the dissolved oxygen control the radio-sensitivity of the cells which you have been observing?

DR. GraY: I doubt if one can exclude such an interpretation in the most general sense that radio-sensitivity is related to the Redox potential of some unspecified enzyme system. I shall have more to say about this tomorrow. In certain cells I think the evidence is strongly against the influence of oxygen on radio-sensitivity being mediated through the Redox condition of the cytochrome enzymes. This has been specifically tested in the cases of two bacteria and one yeast, by comparing the influence of oxygen on wild type cells and haemin-deficient mutants. In the experiments of Moustacchi ${ }^{5}$ it was estimated that the amount of respiratory enzyme present in the haemin-deficient mutant strain was less than three parts per thousand of that in the wild type. The two strains, however, show some influence of oxygen on radiosensitivity.

Mr. van den Brenk: May I ask Dr. Gray if he thinks that in experiments with $E$. coli which Hollaender reported, a protection by cysteamine over and above that evident by simple anoxia was due to the fact that the nominally anoxic cells still contained a small amount of residual oxygen?

DR. GRAY: If I am thinking of the same experiment as you $\operatorname{are}^{6}$, then there would appear to be some doubt concerning the experimental facts of the situation. Marcovich $^{7}$ has made many experiments with cysteamine and a strain of bacteria, which were nominally those used by Hollaender, but was never able to obtain a better degree of protection than by simple anoxia. I am afraid I have no suggestion as to how this apparent discrepancy is to be resolved.

Mr. VAN DEN BRENK: Do you suspect that in the transfer of oxygen from the intercellular fluid to the inside of the cell, that it is just a question of physical diffusion gradient, or that there might be energy involved as a transfer process?

DR. GraY: I wish that a biochemist could tell us the answer to that question. For my part, I do not know the answer. In bacteria the question has been fairly carefully examined by Longmuir ${ }^{8}$ who measured the $Q_{\mathrm{O}_{2}}$ of extracted cytochrome oxidase and of the same enzyme in the intact bacterial cell as a function of oxygen concentration. In most cases these were the same, but he did find a $Q_{\mathrm{O}_{2}}$ which was lower for the intact bacillus in the case of Megaterium. This he provisionally ascribed to a diffusion barrier offered by the cell membrane. I am not sure whether he still holds to this interpretation. He found no evidence of a similar diffusion barrier offered by the cell wall of liver cells. It would be very desirable to have accurate data for a wide variety of cells, since we are now concerned, from the radiobiological standpoint, with extremely low concentrations of oxygen, and barriers which might hitherto have been regarded as unimportant may in reality be significant.

\section{REFERENCES}

${ }^{1}$ Alper, Tikvah Brit. J. Radiol. N.S. 27 (1954) 50

${ }^{2}$ Adler, H. I. Radiation Res. 9 (1958) 451

${ }^{3}$ Adler, H. I. and Stapleton, G. E. Radiation Res. 9 (1958) 84 Abstr.

${ }^{4}$ Kunkel, H. A. and Schubert, G. Proceedings of the Second International Conference on the Peaceful Uses of Atomic Energy, Geneva, 1958-in the press

${ }^{5}$ Moustacchi, E. Ann. Inst. Pasteur 94 (1958) 89

${ }^{6}$ Hollaender, $\Lambda$. and Stapleton, G. E. Proceedings of the First International Conference on the Peaceful Uses of Atomic Energy, 11, Geneva, 1955, p. 311

${ }^{7}$ Marcovich, H. Ann. Inst. Pasteur 93 (1957) 456

${ }^{8}$ Longmuir, I. S. Biochem. J. 57 (1954) 81 


\title{
THE AGTION OF IONIZING RADIATION ON SIMPLE ORGANIC GOMPOUNDS
}

\author{
K. H. Napier and J. H. Green \\ The Department of Radiochemistry, University of New South Wales, \\ Kensington, N.S.W.
}

\section{INTRODUCTION}

INTEREST has been taken in the action of ionizing radiation on organic compounds ever since radio-active materials have been used. Lind $^{1}$, in a series of papers in 1926, reports experiments on the reactions of various hydrocarbons in the presence of radon which is decomposing to give off $\alpha$ particles. Various degradative and polymeric compounds were found.

Interest has been revived in this study as radiation sources have become readily available over the past ten years. The accent of these studies has however changed. Whereas Lind was satisfied in reporting that he found polymeric compounds, now we want to know what these polymeric compounds are and how they are formed.

But the simple irradiation of pure organic compounds gives results that are difficult to interpret, as many compounds are formed and their analysis is difficult. Dewhurst ${ }^{2}$ has found 16 products from the radiolysis of $n$-hexane, with analysis by gas chromatography, which is the most useful technique to date. Hydrocarbons from $\mathrm{C}_{1}$ to $\mathrm{C}_{12}$, both straight and branched chain, were formed. Other products could have been present, but they were not identified. Mechanisms can be put forward to explain these products, but, when it is possible for any bond in the original compound to be broken and when secondary reactions and radical combinations can occur, a quantitative approach is difficult.

A study of the primary processes involved in the radiolysis is more informative, and enables predictions to be made. This is important when synthesis by ionizing radiation is contemplated because this is the field in which radiation will prove useful in the future, especially as larger and larger sources become available.

When radiation acts on organic compounds, and the radiation is absorbed, the molecules are activated or ionized. Pentane has been chosen as an example in these studies as it represents the simple hydrocarbons which are the simplest of organic compounds.

The primary process can be represented as:

$$
\mathrm{C}_{5} \mathrm{H}_{12} \longrightarrow \mathrm{C}_{5} \mathrm{H}_{12}^{*} \text { or } \mathrm{C}_{5} \mathrm{H}_{12}^{+}
$$

The next step is for the activated molecule or molecule-ion to lose the excess energy, in coming to a relaxed state, as heat or some other form of 
energy. However, at this stage the activated or charged molecule tends to decompose into smaller fragments, both charged and uncharged.

or

$$
\begin{aligned}
\mathrm{C}_{5} \mathrm{H}_{12}^{*} \longrightarrow \mathrm{CH}_{3}^{-}+\mathrm{C}_{4} \mathrm{H}_{9} \\
\\
\mathrm{C}_{2} \mathrm{H}_{5}^{*}+\mathrm{C}_{3} \mathrm{H}_{7} \\
\mathrm{C}_{5} \mathrm{H}_{11}+\mathrm{H}^{\cdot} \\
\mathrm{C}_{5} \mathrm{H}_{12}^{+} \longrightarrow \mathrm{C}_{5} \mathrm{H}_{11}^{+}+\mathrm{H}^{\cdot} \\
\mathrm{C}_{4} \mathrm{H}_{9}^{+}+\mathrm{CH}_{3}^{\cdot} \\
\mathrm{C}_{3} \mathrm{H}_{7}^{+}+\mathrm{C}_{2} \mathrm{H}_{5}
\end{aligned}
$$

Both the above mechanisms probably occur, but it is seen that if these processes do occur, every bond in the pentane molecule is capable of being broken. The individual contribution of the above reactions has still to be determined and although equations (2) to (7) are formally similar, it must be remembered that bond dissociation energies are not the same in charged and uncharged molecules.

A further complicating factor in these primary studies is that pure compounds must be irradiated, and as soon as some of the compound has been decomposed the compound is no longer pure. The effects of these impurities on the radiolysis can be considerable and they will appear as secondary effects. Before any of the products are present in detectable amounts, considerable doses are required and this means that secondary effects could be considerable with sources of high intensity.

A technique that can give direct information about the primary processes is that using scavengers. A scavenger is a compound which will react with molecular fragments to produce recognizable compounds or to remove selected fragments from the system. It is assumed, in some cases without proof, that the scavenger is not itself decomposed in the radiolysis and does not interfere to a marked extent with the radiolysis (for example, by electron capture). Iodine has been used as the scavenger ${ }^{3,4}$ in this study, as by the use of gas chromatography the resulting alkyl iodides may be analysed ${ }^{5,6,7}$. This gives the relative proportions of the free radicals formed.

The essential process in the use of iodine is the quantitative reaction of iodine with all free radicals present:

$$
\mathrm{R}^{\cdot}+\mathrm{I}_{2} \longrightarrow \mathrm{RI}+\mathrm{I}^{\cdot}
$$

It is assumed that this reaction has zero activation energy ${ }^{8}$ and also that the iodine free radical is incapable of initiating further reaction, combining only with another iodine atom.

The analysis of the products after the irradiation of an iodine-hydrocarbon mixture is performed by gas chromatography. The sensitivity of the technique is very greatly increased by using iodine labelled with ${ }^{131} \mathrm{I}$ at a specific activity of about $100 \mu \mathrm{C}$ per ml. of hydrocarbon liquid. The eluted alkyl iodides are detected by a Geiger-Müller counter. Most analyses are 
performed with a total of $10 \mu \mathrm{g}$ of iodonated products. Any non-iodonated products are not detected, which simplifies the analysis.

\section{EXPERIMENTAL}

The experimental technique consisted of preparing a solution of iodine containing ${ }^{131} \mathrm{I}$ in the hydrocarbon ${ }^{6,7}$. This solution was then transferred to a glass ampoule, and was de-gassed under high vacuum and finally sealed off under vacuum. Samples were then irradiated either by $\beta$-rays from a $500 \mathrm{mC}{ }^{90} \mathrm{Sr}-{ }^{90} \mathrm{Y}$ source, or $\gamma$-rays from a $5 \mathrm{C}{ }^{137} \mathrm{Cs}$ source.

The resulting mixture was analysed for iodonated products by gas chromatography, using as a detector a Geiger-Müller tube which detected only these products. Any products that did not contain iodine were neither detected, nor determined. Chromatographic columns were, in general, about $50 \mathrm{~cm}$ long and were packed with Celite containing silicone oil. A special counter-current flushing device ${ }^{7}$ was used to overcome the problems caused by condensation and adsorption of alkyl iodides in the detector.

\section{RESULTS AND DISCUSSION}

Table 1 shows the results of iodine scavenging in hydrocarbons from several sources. The figures given in the analyses are not complete and the percentages are calculated only on the products determined. Since the products determined shown in the table can result from the direct splitting of the hydrocarbon, followed by scavenging with iodine, these should be the only primary products. Higher iodides and polyiodides cannot result from

Table 1. Results of iodine scavenging in hydrocarbons

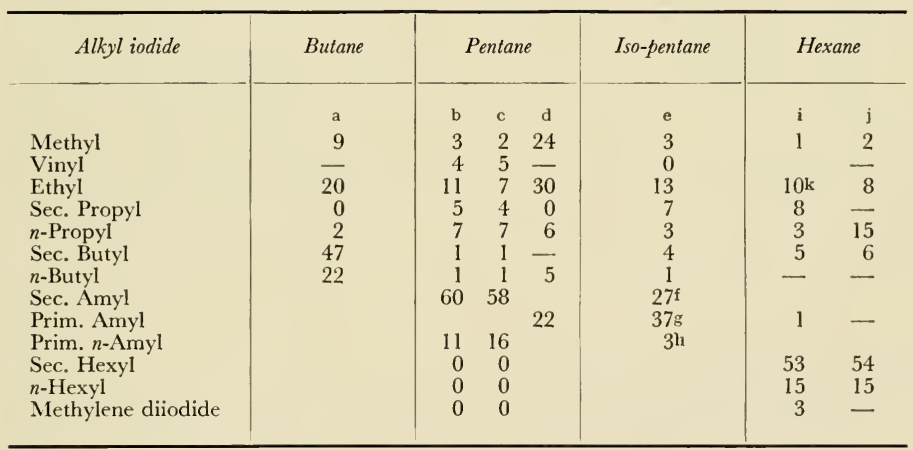

a. C. E. McCanley and R. H. Schuler J. Amer. chem. Soc. 79 (1957) 4008

b. Present work- ${ }^{90} \mathrm{Sr} \beta$-rays

c. Present work- ${ }^{137} \mathrm{Cs} \gamma$-rays

d. L. Gevantman and R. R. Williams J. phys. Chem. 56 (1952) 569 Vapour phase work

e. Present work- ${ }^{90} \mathrm{Sr} \beta$-ravs

f. This product is probably 2 -iodo-3-methyl butane whereas other sec. iodides are 2 - or 3-iodo-pentane

$\mathrm{g}$. This product is probably both 1-iodo-2-methyl-butane and 1-iodo-3-methyl-butane, whereas for pentane it is 1-iodo-pentane

h. 1-iodo-pentane

i. Present work- ${ }^{137} \mathrm{Cs} \gamma$-rays

j. H. A. Dewhurst $J$. phys. Chem. 62 (1958) 15

k. Vinyl iodide present but not resolved completely 
possible primary processes and so must be at least secondary products. As the present interest is in the primary products, the proportions of these secondary products would have no bearing on the primary product yield. These higher iodides are known to be present, although exactly in what form they are present is not known.

Another product not mentioned in Table 1 is hydrogen iodide. This compound has been identified in the gas chromatography as a peak that is cluted at different times, depending on the history of the column in use. If the column is new and still contains small amounts of absorbed water, the hydrogen iodide is eluted slightly later than $n$-amyl iodide. However, if the column has been used for several hours, at an elevated temperature, the water present has been slowly eluted from the column, and the hydrogen iodide appears with the methyl iodide. Final proof of the presence of hydrogen iodide is that when the activity giving this peak was collected, by trapping in liquid oxygen, the material was preferentially soluble in an aqueous phase rather than an organic phase-(chloroform or hexane). This can only be hydrogen iodide as both iodine and organic iodides are more soluble in the organic solvent. To avoid the complication of the hydrogen iodide, small amounts of soda lime were included in the columns, preventing the hydrogen iodide from being eluted. No complete analyses for hydrogen iodide have been made, due to the difficulty in determining hydrogen iodide with any accuracy. Rough analyses have shown that the hydrogen iodide can be as high as 20 per cent of the total iodine at some stages in the irradiation.

If the irradiation mixture is distributed between an organic solvent such as chloroform or petrol and an aqueous sodium sulphite solution, an estimate of the organic and inorganic iodine can be obtained by counting each fraction. By counting the activity eluted from the column an estimate of the activity appearing as volatile organic iodides can be determined.

Experiments have shown that if the radiolysis is continued for long periods, the inorganic iodine is less than 1 per cent, showing that hydrogen iodide is only a temporary product. There are other products which appear as organic iodides but which are not eluted from the columns. These products could be polyiodides, and it is hoped that these will be identified.

The detection of hydrogen iodide, indicates that hydrogen atoms must be present in the decomposition, formed by the reactions:

and

$$
\mathrm{C}_{5} \mathrm{H}_{12} \longrightarrow \mathrm{C}_{5} \mathrm{H}_{11}+\mathrm{H}^{\cdot}
$$

$\mathrm{H}+\mathrm{I}_{2} \longrightarrow \mathrm{HI}+\mathrm{I}^{\circ}$

$\mathrm{I}^{*}$ is considered to be incapable of reacting as follows:

$$
\mathrm{I}^{\cdot}+\mathrm{C}_{5} \mathrm{H}_{12} \longrightarrow \mathrm{HI}+\mathrm{C}_{5} \mathrm{H}_{\mathrm{in}}
$$

The absence of such hydrogen abstraction processes means that hydrogen atoms must be formed as primary fragments, in order that hydrogen iodide should be found. A similar reaction to (11) occurs in the chlorination and bromination of hydrocarbons, when a chain reaction is known to occur. The $G$-values (i.e. molecules transformed per $100 \mathrm{eV}$ absorbed), are high for chlorination, but here are low (about four) suggesting that a chain process 
is unlikely with iodination. However, the fact that there are hydrogen atoms present in the irradiation mixture does not mean that all molecular hydrogen comes from hydrogen atoms reacting as follows:

$$
\mathrm{H}^{*}+\mathrm{C}_{5} \mathrm{H}_{12} \longrightarrow \mathrm{H}_{2}+\mathrm{C}_{5} \mathrm{H}_{\mathrm{i1}}
$$

Experiments by Dewhurst ${ }^{9}$ and Dorfman ${ }^{10}$ on the effect of scavengers on the hydrogen yield, have shown that small amounts of scavengers cause the hydrogen yield to drop to about 65 per cent of that from irradiations without scavengers, and then to remain constant at this level with increased scavenger concentration. These results are interpreted to mean that 65 per cent of the hydrogen is from a molecular detachment process, and that the remaining 35 per cent is from hydrogen atoms.

As the total dose increases, the proportion of products eluted through the columns becomes at first higher until most of the iodine has become organically combined, but then this proportion decreases slowly. This indicates that for the investigation of primary products, the experimental results should be extrapolated to zero dose.

A further complicating factor is the scavenging for free radicals by the alkyl iodides themselves. The smaller alkyl iodides seem to be more efficient in this respect than the larger iodides. If a solution of labelled ethyl iodide in pentane is irradiated and then put through the chromatographic column, products corresponding to secondary and primary amyl iodides are formed. The ratio of the concentrations of these is the same as in the original iodine scavenging irradiations. This is a secondary effect, but complicates the primary effects, as irradiation must be sufficient to cause reaction of at least 50 per cent of the total iodine, to give convenient solutions for analysis.

Of the products formed by the iodine scavenging reactions, most may be explained by the scavenging of free radicals formed by simple, bond scission. However, the presence of secondary propyl, butyl and amyl iodides is difficult to explain. One idea ${ }^{7}$ is that, when charged $\mathrm{C}_{5} \mathrm{H}_{12}^{+}$decomposes, it does so according to equations $(5),(6)$ and (7). The charged ions have all the excess energy left after splitting, and the methyl and ethyl free radicals have only thermal energies. It seems that the ions rearrange, and it may be calculated that the secondary structure is more stable than the primary structure $^{11}$. When these ions are neutralized and lose their energy by collision with other molecules, they then may combine with iodine. The presence of these iodides in the products indicates that a process of this kind is likely.

Organic iodides, that are not eluted through the chromatographic columns, are either iodides higher than $\mathrm{C}_{5}$ or, more probably, polyiodides. The polyiodides could be formed by addition of iodine to the double bond left by molecular abstraction of hydrogen. Dewhurst ${ }^{5}$ has quoted results that the amount of double bonding formed by the irradiation of hexane decreases from a $G$-value of 1.3 in pure hexane to 0.6 when there is iodine in the solution. This agrees with the theory that iodine adds to these double bonds. Neither Dewhurst nor ourselves have found any alkyl iodides with carbon chains longer than the parent hydrocarbon.

In interpreting results from scavenging techniques one is faced with the question of the efficiency of these scavengers. It is realized that iodine as a 
scavenger may not capture all the available free radicals. Some of the results (the product distributions) are valid if all free radicals are captured with the same efficiency, but there is no evidence to confirm or deny this proposition. The $G$-values determined will depend strongly on the efficiencies of radical capture.

The exact lifetime of a free radical in solution is not known, but it seems sufficiently long to give reaction with iodine. The activated free radicals would have even longer lifetimes than the non-activated.

Efficiencies of free radical capture by iodine should be of the order of 90 per cent.

It should also be remembered that the free radicals detected are only those which diffuse from the radiation track and have become thermalized. Recombinations within the spur cannot be followed in this way.

The presence of foreign compounds during the radiolysis of hydrocarbons, is responsible for changed effects. There are two types of change, an enhanced decomposition and a protective action, but both effects are due to energy exchanges in the mixture.

Enhanced reaction has been found when pentane was irradiated in the presence of silica gel ${ }^{12}$. The products formed were not increased proportionally to the simple irradiation, and this indicates that the exchange of the energy absorbed in the silica, and then transferred, is not a simple exchange. It is quite possible that reactions of this type could occur with the glass walls of the reaction vessels.

The second effect of the protective action is shown in the irradiation of benzene-cyclohexane mixtures ${ }^{13}$. It has been shown that the mixture acts more like benzene than a mixture. The suggestion is that benzene has a greater capacity for absorbing energy without decomposition, due to the resonating structure of the benzene. There is energy exchange from the cyclohexane to the benzene, where the energy finally appears as heat rather than energy of bond fission. These conclusions have been drawn from the study of gas yields and gas analysis from the radiolysis of mixtures of benzene and cyclohexane.

From these examples where energy exchange is known to take place with changed effects, it is logical to conclude that in irradiation of simple compounds, exchange also occurs between the molecules. During the irradiation, molecules, activated to differing extents are present. Possibly, the different products result from the decomposition of molecules of differing degrees of activation.

There are other scavengers that have been used $^{8}$ but none have been found to be as convenient as iodine, as iodine is the only scavenger with which the products from different free radicals may be detected. Other scavengers give the total free radicals only.

From the study of the action of radiation on pentane it is hoped that the different techniques, especially those in which iodine is a scavenger and those with irradiations of the pure liquid, may be combined to give an overall picture. Furthermore, when we see the diversity of products formed from such a simple compound as pentane, we can imagine the multitude of products produced when more complex compounds are irradiated. Indications that every bond in pentane is capable of breakage have been found. 
This probably applies to more complex compounds with correspondingly more bonds to break.

Thus by studying the effects of radiation on simple organic compounds, it is possible to observe their behaviour. From these results it should be possible to estimate the breakdown products from more complex compounds, especially when we wish to look at biologically active compounds, which could have as breakdown products, products that are active in a different way from the original.

One of us (K. H. N.) wishes to acknowledge the grant of a Research Studentship from the Australian Atomic Energy Commission, which made it possible for him to undertake this work.

\section{REFERENCES}

${ }^{1}$ Lind, S. C. and Bardwell, D. C. J. Amer. chem. Soc. 48 (1926) 1575

${ }^{2}$ Dewhurst, H. A. J. chem. Phys. 24 (1956) 1254

${ }^{3}$ Durham, R., Martin, G. and Sutton, H. Nature, Lond. 164 (1949) 1052

${ }^{4}$ Williams, R. R. and Gevantman, L. H. J. phys. Chem. 56 (1952) 569

${ }^{5}$ Dewhurst, H. A. J. phys. Chem. 62 (1958) 15

${ }^{6}$ Napier, K. H. and Green, J. H. Proceedings of the Symposium on Atomic Energy in Austraiia Sydney, 1958

${ }^{7}$ Green, J. H. and Napier, K. H.-in the press

${ }^{8}$ Schuler, R. H. J. phys. Chem. 62 (1958) 37

${ }^{9}$ Dewhurst, H. A. J. phys. Chem. 61 (1957) 1466

${ }^{10}$ Dorfman, L. M. J. phys. Chem. 62 (1958) 29

${ }^{11}$ Stevenson, D. P. Trans. Faraday Soc. 49 (1953) 867

${ }^{12}$ Caffrey, J. M., Jr., and Allen, A. D. J. phys. Chem. 63 (1958) 33

${ }^{13}$ Burton, N., Chang, J., Lipsky, S. and Reddy, M. P. Radiation Res. 8 (1958) 203

\section{DISGUSSION}

Dr. GRAY: I was wondering whether out of your observations you can reach any idea of the relative probability of breaking a carbon-carbon bond thus liberating one of the hydrogens? That is one question. The second is whether by any chance you have tried the two radical scavengers, namely oxygen or nitric oxide?

Mr. NAPIER: I will answer the second question first. I have not tried oxygen or nitric oxide; as a matter of fact I am not too sure what effect oxygen has, but I have been removing it by de-gassing under high vacuum, to reduce complications. The other question regarding the breakage of carbon-carbon bonds to carbon-hydrogen bondI do not know of any mathematical calculations here, but I think it must be pointed out that it is usually considered that the carbon-hydrogen bond is the stronger. Yet from these results one appears to get a lot more breakage of the carbon-hydrogen bond.

DR. GRAY: There is a great deal of energy to spare if one ionizes it, so that the fact is that it is a stronger bond. It is interesting to know whether it breaks or does not break.

Mr. NAPIER: There is so much excess energy that the difference of a few calories in the bond energy should not make any difference.

DR. Duncan: What you are really saying is that the bond energy in the excited state is making the different order. 
DR. GRAY: I am interested to know experimentally whether it does or does not and which breaks most frequently.

DR. DUNCAN: It seems to me that one very important consequence of this is that there are five carbon atoms and, on statistical grounds of course, one expects to be ahead in the ratio of two to one. Now, the effects which they give, of course, are not in this ratio at all, partly because one might very well get transfer of energy along this chain, which is known to occur, and of which this might be evidence, and also of course, because the subsequent chemical reactions which take place are not actions which are purely chemical but are concerned with excited species between radicals. Therefore, this kind of thing could happen in biological systems, and because of it, care must be exercised in interpreting the results. 


\title{
THE EFFECT OF BETA RADIATION ON PORPHYRIN COMPOUNDS IN AQUEOUS SOLUTIONS
}

\author{
R. Tirrell \\ School of Biological Sciences, University of. New South W'ales \\ INTRODUCTION
}

DURING the past few years there has been a marked interest in porphyrins as biological and chemical compounds. This is reflected in the large number of investigations carried out on the biosynthesis of porphyrins ${ }^{1 \mathbf{a}, b} \mathbf{b}, \mathbf{c}, 2$.

Irradiation of porphyrin compounds has also received increased attention. It is generally agreed that the product of irradiation of a porphyrin or haem is an intact cyclical tetrapyrrole ${ }^{3}$. However, a precise knowledge of the change occurring in porphyrin compounds on irradiation is lacking, and the work herein deals with two aspects of this.

The investigations are part of a programme concerned with the effects of radiation on the synthesis of porphyrins by the erythrocytes of the domestic fowl. Thus the first section describes the effect of $\beta$ radiation on protoporphyrin when it is dissolved in plasma from fowl's blood; the effect of dose rate, as well as the general effect of the radiation on the protoporphyrin, is considered. The second section deals with changes in the molecular structure of protoporphyrin and ferriprotoporphyrin when these are irradiated in alkaline solution.

\section{EXPERIMENTAL}

\section{Materials}

Plasma

The plasma was from blood collected during routine commercial killing of adult fowls (Gallus domesticus). Age, sex and strain were neglected.

The blood contained $15 \mathrm{mg}$ penicillin G, $15 \mathrm{mg}$ streptomycin and $20 \mathrm{mg}$ heparin (dissolved in $5 \mathrm{ml} .0 .9$ per cent $\mathrm{NaCl}$ ) per $500 \mathrm{ml}$. blood.

\section{Radiation}

The ${ }^{90} \mathrm{Sr}-{ }^{90} \mathrm{Y} \beta$ radiation (500 millicurie) source at the Radiochemistry Laboratory, University of N.S.W., was used throughout.

Details of procedure, dosimetry, etc., have been given previously".

All radiation doses given are stated in rads, and each is an 'average' dose (i.e., energy absorption $/ \mathrm{ml}$. solution). This also applies to the dose rates which are given, (i.e., $\operatorname{rad} \mathrm{ml}^{-1} \mathrm{~min}^{-1}$ ).

\section{Protoporphyrin in plasma}

\section{Methods}

(a) General effect

Preparation of solution $-3.6 \mathrm{mg}$ protoporphyrin were dissolved in $10 \mathrm{ml}$. $\mathrm{N} \mathrm{NaHCO}_{3}$ and volume made up to $100 \mathrm{ml}$. with plasma. 


\section{THE EFFECT OF BETA RADIATION ON PORPHYRIN COMPOUNDS}

Irradiation-(i) $13 \mathrm{ml}$. portions of solution were irradiated with average (i.e., per millilitre) doses of 210 to $2500 \mathrm{rad}$. Dose rate (average) was $41 \cdot 7$ $\mathrm{rad} \mathrm{min}$.

(ii) $7 \mathrm{ml}$. portions of solution were irradiated with average doses of 1000 to $8000 \mathrm{rad}$. The average dose rate was $72.4 \mathrm{rad} / \mathrm{min}$.

Estimation of porphyrins-The solution was prepared by diluting 1 in 10 with water and was then read in the spectrophotometer at the wavelength of maximum Soret absorption (40l-404 $\mathrm{m} \mu$ ).

Irradiations and estimations were in duplicate.

(b) Effect of dose rate

Preparation of solution- $-2.5 \mathrm{mg}$ protoporphyrin were dissolved in $7 \mathrm{ml}$. $\mathrm{N} \mathrm{NaHCO}_{3}$ and the volume made up to $80 \mathrm{ml}$. with plasma.

Irradiation-Two batches of solution were irradiated with doses of 2000 and 750 rad respectively. Within each batch, the dose rate was varied by adjusting the volume of solution. Dose rates of 36 to $108 \mathrm{rad} / \mathrm{min}$ were used.

Estimation of porphyrins - As the position of the Soret bands in the previous experiment had shown some tendency to fluctuate, the full extraction method as described by Dresel and Falk ${ }^{1 \mathrm{a}}$ was used. In this method, the porphyrins are finally extracted with, and read in, 15 per cent $w / v ~ H C l$. This has the advantage of stabilizing the position of the absorption bands to a greater extent than with the aqueous solution.

Optical densities were measured at the wavelength of maximum Soret absorption (410-411 $\mathrm{m} \mu)$; the extinction coefficient was that given by Dresel and Falk ${ }^{1 a}$.

\section{Changes in the porphyrin molecule}

(a) Protoporphyrin-1.6 mg protoporphyrin were dissolved in $4 \mathrm{ml} . \mathrm{N}$ $\mathrm{NaHCO}_{3}$ and the volume made up to $40 \mathrm{ml}$. with water. $7.5 \mathrm{ml}$. of this solution were irradiated with a dose of $3000 \mathrm{rad}$, the dose rate being 72.4 $\mathrm{rad} / \mathrm{min}$.

Solutions for spectrophotometric examination were prepared as follows:

$\begin{array}{lr}\text { Protoporphyrin soln. } \begin{array}{r}3.5 \mathrm{ml} \\ 4.1 \mathrm{ml}\end{array} \text {. } \\ \text { Water } & \text { to } 10.0 \mathrm{ml} \text {. }\end{array}$

Irradiated and non-irradiated solutions, prepared as above, were examined in a Cary Recording Spectrophotometer. The position and strength of the bands were measured from the tracing.

(b) Ferriprotoporphyrin-4.8 $\mathrm{mg}$ ferriprotoporphyrin chloride (synonym haemin) were dissolved in $2 \cdot 5 \mathrm{ml} .0 \cdot 1 \mathrm{~N} \mathrm{NaOH}$ and the volume made up to $25 \mathrm{ml}$. with water. $7.5 \mathrm{ml}$. of this solution were irradiated with $3000 \mathrm{rad}$, the dose rate being $72 \cdot 4 \mathrm{rad} / \mathrm{min}$.

Solutions for spectrophotometric examination were prepared as follows:

$\begin{array}{ll}\text { Ferriprotoporphyrin soln. } & 0.5 \mathrm{ml} \text {. } \\ \text { Water } & 5.5 \mathrm{ml} \text {. } \\ \text { Pyridine } & 4.0 \mathrm{ml} .\end{array}$

A 'pinch' of sodium dithionite was added to each tube immediately prior to spectrophotometric examination. 


\section{R. TIRRELL.}

Irradiated and non-irradiated solutions, prepared as above*, were examined in a Cary Recording Spectrophotometer and the position and strength of the absorption bands measured from the tracing.

\section{RESULTS}

\section{(a) General effect}

Protoporphyrin in Plasma

During the initial period of irradiation, there was a drop in Soret band strength, as indicated in Figure 1 (I and II). The drop was much sharper in the second experiment than in the first and this is discussed in relation to dose rate, in the next section.

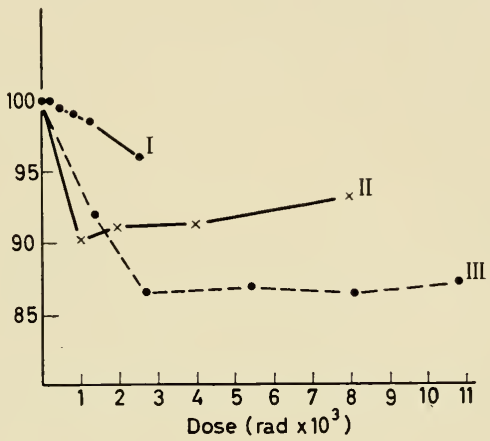

Figure 1. Irradiation of protoporphyrin under various conditions. Ordinate: Soret band readings expressed as percentage of non-irradiated controls. I and II : irradiated in plasma. III : irradiated in alkaline solution. Dose rates: I: $41 \cdot 7 \mathrm{rad} / \mathrm{min}$. II : $72 \cdot 4 \mathrm{rad} / \mathrm{min}$. III : $41 \cdot 7 \mathrm{rad} / \mathrm{min}$.

In the second experiment (II, Figure 1), the decrease continued until the Soret band strength was 90 per cent that of the non-irradiated control. After this there was no further decrease. It will be seen that this curve is similar to that obtained by irradiating protoporphyrin in alkaline solution. This is shown in III (Figure 1), which is from an earlier investigation ${ }^{4}$ and is included for comparison.

Comparing now I and III (Figure 1) which have the same dose rate, it may be seen that the effect of irradiation on protoporphyrin in alkaline solution is greater than in plasma. This, of course, is a percentage decrease. But as the concentration of protoporphyrin in III was greater than in I, the absolute rate of decrease (as well as the percentage decrease) is greater for alkaline solution than for plasma.

* The name pyridine ferroprotoporphyrin will be used for this particular solution: the name hemochrome will be used to describe the general type of solution (as tabulated by Lemberg and Legge, reference 5, p. 164). 
(b) E:ffect of dose rate

The result of using a dose of $2000 \mathrm{rad}$ with varying dose rates, is seen in II Figure 2). A complete conversion to the product substance occurred at the higher dose rates and the effect was essentially the same as in Figure 1 (II and III). No relationship between dose rate and effect on protoporphyrin could be obtained.

In the next irradiation, a dose of $750 \mathrm{rad}$ was used and complete conversion to the product substance did not occur. The degree of conversion, as measured by Soret band strength, thus appears to be a function of dose rate (I, Figure 2). The fluctuation of the points about the straight line was

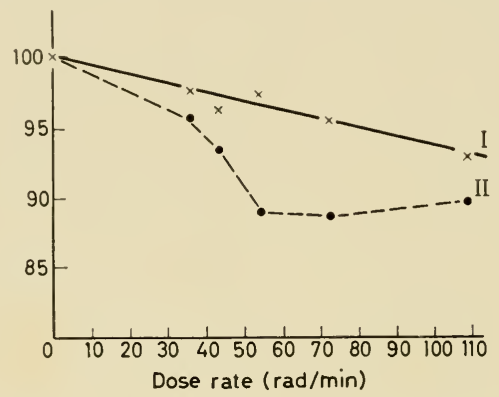

Figure 2. Effect of dose rate. Ordinate: Porphyrin concentration, calculated as protoporphyrin and expressed as percentage of non-irradiated controls. I: $750 \mathrm{rad}$ dose. II : $2000 \mathrm{rad}$ dose

probably due to the fact that a period of four days elapsed between the irradiation of plasma and estimation of porphyrins. A line of best fit was therefore calculated statistically.

\section{(a) Protoporphyrin}

\section{Changes in the Porphyrin Molecule}

The position and strength of the absorption bands of the irradiated and non-irradiated solutions are given in Table 1 .

Table 1. Effect of irradiation on absorption bands of protoporphyrin

\begin{tabular}{|c|c|c|c|c|}
\hline \multicolumn{2}{|c|}{ Control (non-irradiated) } & \multicolumn{2}{|c|}{ Test (irradiated) } & \multirow{2}{*}{$\begin{array}{l}\text { Ratio: } \\
\text { O.D. test } / O . D \text {. control } \\
\text { (per cent) }\end{array}$} \\
\hline $\begin{array}{l}\text { Position } \\
(\mathrm{m} \mu)\end{array}$ & O.D. & $\begin{array}{l}\text { Position } \\
\quad(\mathrm{m} \mu)\end{array}$ & $O . D$ & \\
\hline $\begin{array}{l}410 \\
560 \\
600 \\
675\end{array}$ & $\begin{array}{l}1.535 \\
0.115 \\
0.050 \\
? 0.005\end{array}$ & $\begin{array}{l}410 \\
560 \\
600 \\
675\end{array}$ & $\begin{array}{l}1 \cdot 390 \\
0 \cdot 100 \\
0 \cdot 045 \\
? 0 \cdot 005\end{array}$ & $\begin{array}{l}90 \cdot 6 \\
87 \cdot 2 \\
90 \cdot 0\end{array}$ \\
\hline
\end{tabular}




\section{R. TIRRELL.}

The effect of irradiation may be stated as follows: (i) There is no shift in the position of any band. (ii) The strength of bands after irradiation is approximately 90 per cent of that of bands for the non-irradiated solution. This is of the same order as previously found when the Soret band only was examined.

\section{(b) Ferriprotoporphyrin}

The irradiation of ferriprotoporphyrin produced no shift in the position of the absorption bands of the spectrum (Table 2). It did, however, produce a reduction in strength of the three bands, comparable with that found for protoporphyrin.

Table 2. Effect of irradiation on absorption bands of ferriprotoporphyrin examined as the pyridine hemochrome

\begin{tabular}{|c|c|c|c|c|}
\hline \multicolumn{2}{|c|}{ Control (non-irradiated) } & \multicolumn{2}{|c|}{ Test (irradiated) } & \multirow{2}{*}{$\begin{array}{l}\text { Ratio: } \\
\text { O.D. test/O.D. control } \\
\text { (per cent) }\end{array}$} \\
\hline $\begin{array}{l}\text { Position } \\
\quad(\mathrm{m} \mu)\end{array}$ & $O . D$. & $\begin{array}{l}\text { Position } \\
\quad(\mathrm{m} \mu)\end{array}$ & $O . D$ & \\
\hline $\begin{array}{l}418 \\
526 \\
557\end{array}$ & $\begin{array}{l}1 \cdot 525 \\
0 \cdot 155 \\
0 \cdot 290\end{array}$ & $\begin{array}{l}418 \\
526 \\
557\end{array}$ & $\begin{array}{l}1 \cdot 420 \\
0 \cdot 140 \\
0 \cdot 265\end{array}$ & $\begin{array}{l}93 \cdot 2 \\
90 \cdot 5 \\
91 \cdot 5\end{array}$ \\
\hline
\end{tabular}

\section{DISGUSSION OF RESULTS}

The experiments on the effect of dose rate indicate a positive correlation between the rate at which radiation is given and the rate at which the protoporphyrin is converted to the product tetrapyrrole. This was not unexpected, for two reasons, the first being the protective effect of the plasma proteins. There is evidence that serum albumin can react with $\mathrm{OH}$ radicals ${ }^{6}$. It has also been found that, to some extent, added protein can protect haemocyanin from the action of $\mathrm{X}$-rays ${ }^{7}$. Therefore, with the irradiation of protoporphyrin in plasma, the number of free radicals available for reaction with the protoporphyrin would depend on the number reacting with the proteins. The number of such available free radicals would probably increase with increasing dose rate.

Secondly, the molecular structure of protoporphyrin suggests that some of the energy absorbed by, say, the methene bridges, may be transferred to, and taken up by, the aromatic pyrrole rings. A similar effect has been found with the synthetic copolymer of isobutylene and styrene ${ }^{8}$, in which the energy which is absorbed by the isobutylene part of the chain is transferred to the styrene part of the chain, where it is dissipated by the aromatic ring system, resulting in a comparatively small amount of chemical change. If this is so, for the protoporphyrin molecule, the amount of energy available for reaction with the methene bridges (i.e., left over after transfer to the pyrrole rings) could be dependent on the amount of energy available to the protoporphyrin molecule in unit time, i.e., dose rate. In this case, the effect should be found when protoporphyrin is irradiated in alkaline solution. This aspect will be investigated further. 
Considering now the general effect of $\beta$ radiation on the porphyrin molecule, it may be seen, firstly, that there is no essential difference between the effect of irradiating protoporphyrin in plasma and irradiating it in aqueous solution (Figure 1, I, II and III). That is, there is a rapid conversion to a cyclical tetrapyrrole (i.e., a porphyrin) having a Soret band with an extinction coefficient which is approximately 90 per cent that of protoporphyrin. The product porphyrin, moreover, is not affected by radiation at the strength used.

This is consistent with the phenomenon reported by Rothschild, Cosi and Meyers ${ }^{9}$, who worked with ferriprotoporphyrin, and by Hamilton, Okada and Morrison ${ }^{3}$, who worked with lactoperoxidase. Thus the conversion to the product porphyrin takes place, irrespective of whether the porphyrin is free, part of a haem or part of a haemoprotein.

There are general reasons for considering that the product porphyrin (or porphyrin moiety) is of the oxyporphyrin type, i.e., that it is formed by replacement of the $\mathrm{CH}$ group of one of the methene bridges with a $\mathrm{C}-\mathrm{OH}$ or a $\mathrm{C}=\mathrm{O}$ group (reference 5, p. 91) and these reasons have been previously given ${ }^{4}$.

However, as a result of their work with ferriprotoporphyrin, Rothschild, Cosi and Meyers conclude that the vinyl groups of the porphyrin side chains are responsible for the change. They base this on two main considerations.

(1) Ferrideuteroporphyrin, which lacks the vinyl groups of the ferriprotoporphyrin does not exhibit a similar behaviour on irradiation.

(2) On irradiation, the absorption band of the ferriprotoporphyrin which is centred at $612 \mathrm{~m} \mu$, shifts to $600 \mathrm{~m} \mu$. One would infer from this a change in the structure of the porphyrin side chains.

The present investigation, being primarily concerned with protoporphyrin compounds, did not include investigation of deuteroporphyrin compounds, hence no comment can be made on this aspect.

With regard to (2), however, it may be seen from Tables 1 and 2, that in the present investigation there was no band shift on irradiation, either with protoporphyrin or with ferriprotoporphyrin. This suggests that there was no alteration in the side chains. Lemberg and Falk ${ }^{10}$ found that any alteration in side chain structure caused a definite band shift. Furthermore, the decrease in strength of all bands in both compounds suggests a saturation of the methene bridge bonds. Also, Rothschild, Cosi and Meyers obtained their band shift when the spectra were examined in $\mathrm{NaOH}$ solution. The general instability of the band positions of ferriprotoporphyrin in $\mathrm{NaOH}$ solution is well known; Lemberg and Falk ${ }^{10}$, for instance, quote only the hemochrome band positions when referring to haems.

Further, if the figures given by Rothschild, Cosi and Meyers for the pyridine hemochromes of their solutions are examined, the band position changes following irradiation are very small and do not suggest a definite alteration of the side chains. These figures are given in Table 3 in which the band positions for the pyridine hemochromes of ferriprotoporphyrin, as quoted by Lemberg and Legge ${ }^{5}$, Rothschild, Cosi and Meyers ${ }^{9}$, and the present investigator, are given. The band positions for the pyridine hemochromes of the product substances of Rothschild, Cosi and Meyers, and of the present investigator, are also given. 


\section{R. TIRRIILI}

This does not, of course, invalidate the statement by Rothschild, Cosi and Meyers on the 'importance of the vinyl groups of ferriprotoporphyrin in the production of the new compound'. 'This has been emphasized elsewhere. 'Addition of two vinyl groups to give protoporphyrin . . . increased tremendously the sensitivity of the molecule to irradiation' 11 . But this does not

Table 3. The absorption bands of the pyridine hemochromes of ferriprotoporphyrin and irradiation products

\begin{tabular}{|c|c|c|c|c|}
\hline Author & Substance & Wavel & $\begin{array}{l}\text { ngth o } \\
(\mathrm{m} \mu)\end{array}$ & bands \\
\hline Lemberg and Legge & Ferriprotoporphyrin & 558 & 525 & \\
\hline Rothschild, Cosi and Meyers & $\begin{array}{l}\text { Ferriprotoporphyrin } \\
\text { Irradiation product }\end{array}$ & $\begin{array}{l}556 \\
554\end{array}$ & $\begin{array}{l}525 \\
522\end{array}$ & $\begin{array}{l}420 \\
417\end{array}$ \\
\hline This investigation & $\begin{array}{l}\text { Ferriprotoporphyrin } \\
\text { Irradiation product }\end{array}$ & $\begin{array}{l}557 \\
557\end{array}$ & $\begin{array}{l}526 \\
526\end{array}$ & $\begin{array}{l}418 \\
418\end{array}$ \\
\hline
\end{tabular}

negate the conclusion that the figures in Table 3, as well as those on the irradiation of protoporphyrin, suggest a conversion to an oxyporphyrin type of compound, without alteration of the side chains.

I wish to thank Dr. J. E. Falk for his interest in these investigations.

My thanks also go to those members of the Radiochemical Laboratory, University of N.S.W., who have helped me on numerous occasions.

\section{REFERENCES}

${ }^{1}$ Dresel, E. I. B. and FAlK, J. E. (a) Biochem. J. 63 (1956) 72

(b) ibid. p. 80

(c) ibid. p. 388

${ }^{2}$ Shemin, D. in Currents in Biochemical Research: Interscience Publishers, Inc., New York, 1956

${ }^{3}$ Hamilton, H. B., Okada, S. and Morrison, M. Biochim. biophys. acta, 23 (1957) 540

${ }^{4}$ Tirrell, R. Proceedings of the Symposium on the Peaceful L'ses of Atomic Energy in Australia 1958 -in press

${ }^{5}$ Lemberg, R. and Legge, J. W. Hematin Compounds and Bile Pigments: Interscience Publishers, Inc., New York, 1949

${ }^{6}$ Brohult, G. Nova Acta Soc. Sci. upsal 12, No. 4 (1940). Quoted by Bacq and Alexander ${ }^{12}$

${ }^{7}$ Pickles, E. G. and Anderson, R. S. J. gen. Physiol. 30 (1947) 83

${ }^{8}$ Alexander, P. and Charlesby, A. Nature, Lond. 173 (1954) 578

${ }^{9}$ Rothschild, Mary-Louise, Cosi, Laura and Meyers, L. S. Nature, Lond., 182 (1958) 316

${ }^{10}$ Lemberg, R. and Falk, J. E. Biochem. J. 49 (1951) 675

${ }^{11}$ Barron, E. S. G. and Johnson, Phyllis, Radiation Res. 5 (1956) 290

${ }^{12} \mathrm{BAcQ}, \mathrm{Z}$. M. and Alexander, P. Fundamentals of Radiobiology: Butterworths Scientific Publications, London, 1955 


\section{DISCUSSION}

DR. Duncan: From a theoretical point of view I should be very interested, Mr. Tirrell, in whether you have a comparison between the spectra of the hacm and the porphyrin, particularly of the $300 \mathrm{~m} \mu$. downwards region, because one would have expected the spectrum to show some of the iron bands in this region. I noticed you used ferrous rather than ferric. I do not know whether there is a reason for this. but the ferric would have been better from a theoretical point of view.

Mr. Tirrell: Yes, at ultra-violet range it probably would. However, for work with the pyridine hacmochrome, the ferric haenochrome bands are not particularly well defined-and it is usual to reduce the haemochrome immediately before examination with sodium dithionite, in which case the solution changes colour and the bands sharpen quite markedly.

DR. DUncan: Is there any difference between the haem (even in the ferrous state) and the porplyyrin?

Mr. Tirrell: Yes, but it is difficult to compare the two, because normally you work with pyridine for a haem and you look at protoporphyrin, for example, in strong acid solution. When you look at them in, say, $0 \cdot 1 \mathrm{~N} \mathrm{NaOH}$ in both cases, the bands are diffuse and they tend to wander over a range of a few millimicrons.

Dr. Gray: In regard to the dose-rate effect, these irradiations, as far as I could sce from your figures, were probably running for ten minutes up to sixty minutes.

Mr. Tirrell: Yes, approximately.

DR. GRAY: This seems to imply rather long-lived species, and I wondered if there could be any more stable species, and radicals which could produce your effect. For instance, if you irradiate the water or the medium and add the porphyrin, what, if any, effect do you get?

Mr. TiRrell: I have not tried that.

DR. GRAY: Something could be produced in the solution which then reacted with the porphyrin and this reaction rate was affecting your results.

Mr. Tirrell: Yes, it is possible. I thought, of course, for some time of the possibility of peroxide formation because this seems to come up in the literature. However, both the work on lacto-peroxidase and also the work of Forssberg on catalase rather discredited the idea because in both cases the enzyme which was irradiated could react with any hydrogen peroxide formed. I had not thought of any other compound of a long-lived nature developing in the solution at all; intuitively, I thought of the idea of resonance and the higher energy orbitals. I should imagine it could be quite easily checked by putting the porphyrin into the solution, after it had been irradiated. 


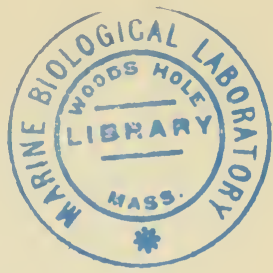

\title{
SYNTHESIS OF ORGANIC COMPOUNDS BY IONIZING RADIATION
}

\author{
S. Dilli and J. H. Green \\ Department of Radiochemistry, University of New South Wales, \\ Kensington, N.S.IW.

\section{INTRODUCTION}

THE radiation synthesis of chemical compounds has begun to engage the serious attention of scientists for two main reasons. Firstly, it is likely that the commercial production of certain classes of compounds by radiation synthesis will be economically feasible. Secondly, the synthesis of primitive forms of life-from a number of amino acids, ammonia and acetic (or formic) acid which could lead to a nucleoprotein-has recently become more than a remote possibility. Experimental data in this field are scanty and the results have not been collected together. Several accounts are available in which the possibilities of radiation synthesis are mentioned in passing, for example the extensive review of Collinson and Swallow ${ }^{1}$ on the radiation decomposition of organic compounds and in certain bibliographies, ${ }^{2,33}$. Brief comments are given in the books by Oparin ${ }^{3}$, Urey ${ }^{4}$ and Bernal ${ }^{23}$.

There is no clear definition of the meaning of 'radiation synthesis'. The term is used to refer generally to the formation of identifiable compounds in a system which is absorbing energy from nuclear or high-energy radiation sources, from sources of ultra-violet (u.v.) radiation and spark and silent electric discharges. In this sense no distinction is made, on the basis of physical mechanisms, between the various types of radiation and their effects. If we remember, however, that several types of fragments can be formed in chemical systems which are in a radiation flux, some clarification is possible.

Broadly speaking the primary reactive species in irradiated systems are excited molecules and radicals and charged molecule- and radical-ions. The general field of photochemistry provides information on the behaviour of excited species only, because no ionization occurs in a system irradiated with u.v. and visible light. The field of radiation chemistry refers to systems which contain both ionized and excited species. It is in this connection that we define radiation synthesis as 'the formation of radiation products, which are chemically and physically different from their parents, by the combined effects of ionization and molecular excitation'. This definition excludes all photochemical systems and leaves surprisingly few cases which can be called unambiguously 'radiation syntheses'.

In earlier work in radiation chemistry, probably because the greatest emphasis was put on gas-phase reactions, it was felt that the ultimate behaviour of the system could be explained in terms of ion formation in clusters along the radiation tracks ${ }^{5}$. It was a relatively easy matter to 
measure or calculate the total number of ions formed in the system and the experimental results were expressed in ion-pair yields either for the destruction or for the formation of molecules. It was recognized later, particularly in comection with the enormous amount of work on water and aqueous systems, that excited molecules and free radicals were perhaps predominant factors. Experimental results are therefore now expressed in terms of the amounts of material destroyed or formed in the absorption from the radiation field of a fixed, measurable amount of energy. These are ' $G$-values'. $G_{\mathrm{H}_{2} \mathrm{O}}$ is the number of molecules of water destroyed for each $100 \mathrm{eV}$ of energy absorbed, and $G_{11}$, would be the comparable yield of hydrogen in the same system. However, it is now believed that the formation of charged ions is responsible, at least in the primary events, for much of the final state of an irradiated system ${ }^{6,7,8}$.

It is clear that the types and interactions of species formed in the primary radiation interactions will determine the overall behaviour of the system. The problems involved are divisible into three sections: $(a)$ the nature and energies of primary fragments must be established, $(b)$ the kinetics and energetics of reactions of the primary fragments with other constituents of the system must be known and $(c)$ the exact nature and amounts of final products of the irradiation must be determined. In general we have been concerned with reactions in the gas and liquid phases and seldom with the solid phase, although the latter aspect will increase in importance.

Information on the problems of section $(a)$ is available from electron impact data ${ }^{9}$ using mass spectrometers to determine the types and energies of primary charged fragments. There are two deficiencies in the data available with this technique. In general, positively charged species only have been measured and there is an appreciable time, up to $10^{-7} \mathrm{sec}$, in which reactions of primary fragments can occur in the source before fragments pass to the analyser. There is an increasing amount of work now being done on negative ion formation, metastable transitions and rearrangements and secondary reactions, which will soon be extremely valuable in radiation chemistry. Another approach, which should provide similar data in the gas phase, is the use of scavengers for reactive species. Several scavengers have been proposed but the most useful so far is radio-active iodine, because the organic iodides produced with reactive radicals can now be identified and measured with some confidence ${ }^{10,8}$. In addition, in simple systems at least, an attempt is being made to study the theoretical basis of the disruption of molecules and reactions between fragments and molecules ${ }^{11}$.

An equally complex problem is found in the nature of the secondary reactions which occur (section $(b)$ above). In this case, it is essential to distinguish clearly between the reactions which can occur in different phases. The nature of the environment and the average times required for reactive species to form and react are the basic considerations which determine the ultimate behaviour of the system. A good picture of the time scale is given in the review by Magee $^{12}$, and a modified chronological table is shown in Table 1. The physical picture of the primary processes is usually as follows: along the paths of the radiation through matter secondary ionization and excitation occur with great intensity in isolated 'spurs'; primary fragments are formed within the spurs and it may be taken that any reactions of the 
Table 1. Chronology of events in radiolysis

\begin{tabular}{|c|c|}
\hline Time (sec) & Events \\
\hline$<10^{-14}$ & Primary particles and secondary electrons traverse a molecule \\
\hline $10^{-14}$ & Molecular vibration and fast molecular dissociations \\
\hline $10^{-13}$ & Electron capture in molecules in the liquid phase \\
\hline $10^{-12}$ & Radical moves one space in diffusion in a liquid \\
\hline $10^{-11}-10^{-9}$ & $\begin{array}{l}\text { Dielectric relaxation in a liquid-Collision time for thermal electrons } \\
\text { in a gas at } 1 \mathrm{~atm} \text { - Gas molecule collision time at } 1 \mathrm{~atm}\end{array}$ \\
\hline $10^{-8}$ & $\begin{array}{l}\text { Lifetime for radiation de-excitation of an excited singlet state (allowed } \\
\text { transition)- } \\
\text { *Forward reaction complete in a } \gamma \text {-ray spur in water }\end{array}$ \\
\hline $10^{-7}$ & $\begin{array}{l}\text { Thermal electron }(0.025 \mathrm{eV}) \text { captured in a gas (assuming capture } \\
\text { probability per collision is } 1 \text { in } 1000 \text { ) } \\
\text { *Forward reaction complete in an } \alpha \text {-track in water }\end{array}$ \\
\hline $10^{-5}-10^{-4}$ & Reaction of radical with a solute in molar concentration \\
\hline $10^{-3}-10^{-2}$ & Lifetime for radiation of triplet state (forbidden transition) \\
\hline
\end{tabular}

* The 'forward' reaction in water is: $\mathrm{H}_{2} \mathrm{O} \longrightarrow \frac{1}{2} \mathrm{H}_{2}+\frac{1}{2} \mathrm{H}_{2} \mathrm{O}_{2}$.

fragments with their environment inside spurs will be over in perhaps $10^{-8}$ sec; any fragments which have reacted will diffuse away from the spurs and react mainly with free electrons and molecules in the medium; interaction between tracks will occur by reaction between diffusing species; such interactions may occur in about $10^{-5} \mathrm{sec}$ in liquids.

An important point to notice is that, in liquids, charged fragments will be neutralized very quickly by electron capture before any structural changes or reactions can occur. This is not the case in the gas phase, where electron capture may take as long as $10^{-7} \mathrm{sec}$ and charged fragments are therefore capable of undergoing many reactive collisions before neutralization. For this reason, ion-molecule reactions, which have recently been found able to explain certain gas-phase radiolyses ${ }^{7}$, do not seem likely to play a part in the liquid phase. Again, the chance of reformation of the parent molecule by recombination of initial fragments is much higher in the liquid (a 'cage' effect) than it is in the gas phase and radical-radical two-centre reactions are generally more likely in the liquid.

\section{SYNTHESIS WITH INDUSTRIAL POSSIBILITIES}

Although the range of products, which can be produced on the laboratory scale, is large, serious consideration has been given to a few general processes only. The economic feasibility of a given radiation synthesis is decided by all the complex considerations of the chemical industry. The basic factors, which determine the attractiveness of a proposal for an industrial chemical process, are the capital cost of the plant, the operating cost and the return on capital. When these factors are assessed in detail there are four conditions under which radiation may be economically used for chemical syntheses:

(a) Where the product obtained is of high value and cannot be obtained readily by orthodox methods - A good example on the pilot-plant scale of this category is the recently developed radiation synthesis of complex molecules labelled with tritium ${ }^{13}$. The soft $\beta$ radiation from ${ }^{3} \mathrm{H}$ itself is used to cause a primary fragmentation of molecules in the gas phase with subse- 
quent introduction of the active nucleide into the complex molecule. Such labelled products are, in general, very difficult to synthesize by orthodox methods and the products are expensive and in high demand in the biological sciences.

The irradiation of an air-saturated solution of cholesterol in acctic acid gives a very interesting example of specificity of a radiation synthesis ${ }^{14}$. Although there are many possible sites of attack in the sterol molccule, acetylation occurs at a specific site with about 34 per cent yield of the cholesteryl acetate:
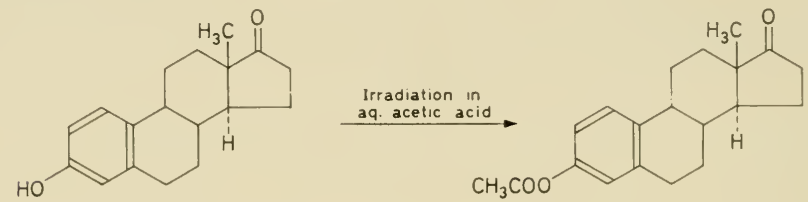

Certain polymerizations are uniquely caused by ionizing radiations. The $\gamma$ irradiation of perfluoropropylene, perfluorobutadiene, perfluoroacrylonitrile, perfluoroisobutylene and perfluoroamylpropylene gave liquid or solid polymers of low chain length, while 1,1-dihydroperfluorobutylacrylate gave a rubbery polymer which is highly cross-linked ${ }^{15}$. It seems that polymerization at very low temperatures or in the solid state is specific to ionizing radiation. An example is the polymerization of tetraethylene glycol dimethacrylate at $-55^{\circ} \mathrm{C}{ }^{16}$ or of isobutene in the liquid phase at $-80^{\circ} \mathrm{C}^{34}$.

The irraciation of oleic acid gives rise, among other polymerized acids, to the decarboxylation product 8-heptadecene. This compound can easily be separated in a very pure form ${ }^{17}$.

Although none of the examples given above refer to processes which are likely to be taken up by the chemical industry, it is clear that there are many reactions yet to be found which will be developed in time. The possibilities are enormous and so is the developmental research required.

(b) In cases where chain reactions occur with the conversion of a large mass of material after the initial ionizing event and where chain initiators are normally a more expensive catalyst or source of radiation (u.v. or electric discharge)-

There are many reactions which proceed by chain processes to yield products of commercial importance. Perhaps the most striking technical example is the halogenation of benzene. In the presence of u.v. or $\gamma$ radiation a rapid reaction occurs between chlorine and benzene to form an isomeric mixture of $1,2,3,4,5,6$,-hexachlorocyclohexane and the temperature cannot be controlled easily. Greater control is possible with the reaction of a solution of benzene ( 20 per cent) in carbon tetrachloride. (In this case, $G_{\gamma}\left(\mathrm{C}_{6} \mathrm{H}_{6} \mathrm{Cl}_{6}\right.$ ) $=85,000)$. In general, the yields of the $\gamma$-isomer are about 12 per cent for each type of initiation. This suggests that the primary process in each case is $\mathrm{Cl}_{2} \longrightarrow 2 \mathrm{Cl}$ and, apart from reasons of convenience, there is no advantage of one type of radiation over the other.

The chlorination of toluene ${ }^{18}$ is, however, quite a different reaction when it is initiated by $\gamma$ radiation from that initiated with $u . v$. In the latter case 


\section{S. DHLII ANI J. H. GREEN}

the primary process is again the formation of chlorine atoms and the final result is side-chain substitution exclusively. With ionizing radiation it is apparent that ionization and excitation of the toluene molecule is at least as important as attack on the chlorine molecule and ionization effectscharge transfer and electron capture-play an important part. The final products are mainly the result of nuclear sulstitution leading again to $1,2,3,4,5,6$,-hexachlorocyclohexane, as well as side-chain substitution leading to benzyl chloride and benzotrichloride.

(c) There are conditions in which the required chain reaction can be 'catalysed' by ionizing radiation at much lower pressures and temperatures than by orthodox catalysts. There is a real cost advantage here. The process which has attracted the greatest attention up to the present is the polymerization of ethylene to polyethylene. The normal process for the production of polyethylene requires pressures of the order of 1000 atmospheres and temperatures of $300-400^{\circ} \mathrm{C}$. There would be a reduction in operating costs, if the reaction were carried out under normal conditions of temperatures and pressure, but raw materials cost the same (about 80 per cent of total costs for the polymerization) and the economic advantage of using ionizing radiation is debatable. If the radiation source cost nothing, as it may in the future disposal of fission-products, there would probably be a slight advantage in using ionizing radiation.

Perhaps the real advantage in using $\gamma$ radiation for polymerization will be in the ease of control of the final properties of the polymer. For example, the chain length of polyacrylonitrile and polyvinylpyrrolidone can be varied readily by changing the dose rate and monomer concentration. In the latter polymer an additional advantage is that the radiation product has a much narrower range of molecular weights than the catalytic product ${ }^{19,20}$.

We have referred already to the formation of polymers in the solid state but it is worth while to add some further comments on this topic. A very interesting possibility is that, because the reaction occurs in an ordered lattice, it may be possible to alter the nature of addition products by changing the order. Such addition products would not normally be formed in the disordered liquid or gas phase. Some progress has already been made in the formation of controlled graft and block co-polymers by the effect of $\gamma$-rays on solid solutions of appropriate monomers. Irradiation at a later stage, i.e., after a solid polymer is formed, has been extensively studied and the technique is used industrially to modify polymers for special purposes. For example, where a higher heat resistance is required, extensive radiation produced cross-linking gives a polymer which is much less fusible than the parent polymer.

(d) In circumstances where an orthodox catalyst must be removed at great expense from the final product, the use of $\gamma$ radiation is attractive. It is not easy to find an industrial chemical process which might be quoted in this section, but an illustration of the possibilities is given by the oxidation of toluene to benzoic acid. Radiolytic oxidations offer some promise generally ${ }^{21}$. The orthodox process is to use a cobalt naphthenate catalyst which becomes mixed with the product in such a way that a laborious and costly purification procedure is required. Radiation catalysis offers advantages in such circumstances. 
We are concemed here not so much with radiation-induced modification of biologically active compounds as with the production of simple compounds, which could conceivably react together to form a nucleoprotein. For many years, scientists have been aware of the significance which attaches to the production of protein precursors in ionizing radiation fields. Perhaps the earliest discovery was Loeb's production in 1913 of glycine in a silent discharge reaction in a mixture of carbon monoxide, ammonia and water vapour ${ }^{22}$.

$\Lambda$ bricf summary of gas-phase reactions of carbon compounds, which occur in electric discharges is as follows:

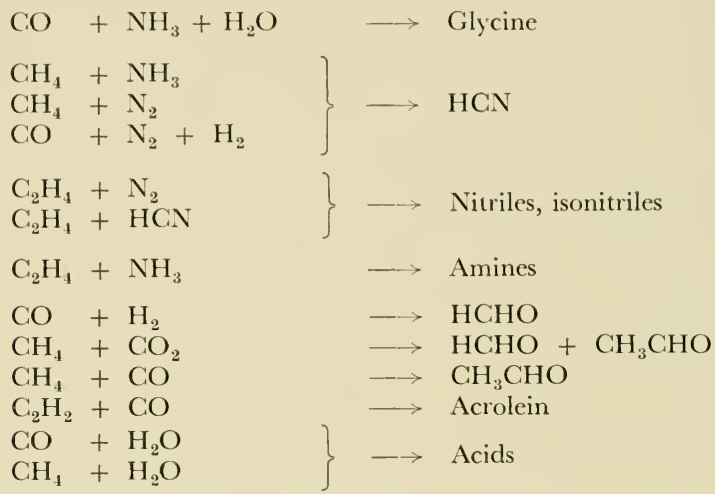

It is to be noted that unidentified 'polymers' have been found in each case and, furthermore, that it is doubtful that a complete analysis has been carried out in any case for the simpler products. Another important feature is that it is seldom clear whether the reported synthesis occurred as a primary reaction in the gas phase or as a secondary process in a condensed phase.

Such experiments would have had greater biological significance if they had been conducted always in a reducing atmosphere. The conclusions reached by Urey ${ }^{4}$ in his extension of Oparin's ${ }^{5}$ theory are that the planets were formed at low temperatures $\left(<300^{\circ} \mathrm{C}\right)$ and that the early forms of life were developed in a reducing atmosphere of hydrogen. Primary radiation chemical reactions to produce precursors of living material should therefore, presumably, always involve the participation of gaseous molecular or atomic hydrogen. It is a matter beyond the scope of this paper to discuss the next two stages in detail - the aggregation of the precursors into living matter and the maintenance of life in a highly reducing atmosphere. A matter requiring further argument is the formation of such precursors from oxygen-containing gases, which implies the existence of circumstances which could not be regarded as invariably reducing.

In a recent series of papers 24 , Miller has investigated the formation of a series of amino and hydroxy acids and miscellaneous compounds in a system 
chosen to resemble present concepts of primitive conditions on earth. $\mathrm{He}$ assumed a reducing atmosphere, that the surface of the earth was mainly ocean and that reactions occurred below $100^{\circ} \mathrm{C}$ as a result of excitation and ionization from lightning discharges. Miller subjected a mixture of ammonia (or nitrogen), methane, water vapour and hydrogen to a silent electrical discharge for periods of up to a week. The products were analysed chromatographically and sometimes the pure products were isolated and identified by standard methods. These procedures seem to have been adequate except for the purines and pyrimidines which were sought on paper chromatograms scanned with u.v. light. However, these compounds do not absorb in the u.v. region and, in any case, they might be expected in reduced forms ${ }^{25}$ for which Miller did not search.

The general conclusion which can be reached is that, if HCN and aldehydes are present, the Strecker cyanohydrin synthesis reaction provides a pathway to amino and hydroxy acids:

or

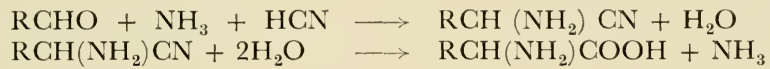

$$
\begin{array}{lll}
\mathrm{RCHO}+\mathrm{HCN} & \mathrm{RCH}(\mathrm{OH}) \mathrm{CN} \\
\mathrm{RCH}(\mathrm{OH}) \mathrm{CN}+2 \mathrm{H}_{2} \mathrm{O} \longrightarrow & \mathrm{RCH}(\mathrm{OH}) \mathrm{COOH}+\mathrm{NH}_{3}
\end{array}
$$

In his most recent work, Miller verified that these reactions do occur at $100^{\circ} \mathrm{C}$ under the conditions which have been taken to apply to primitive processes. He boiled for a week a mixture of the following compounds: Hydrogen at $30 \mathrm{~cm}$ pressure, $4.5 \mathrm{ml} .28$ per cent ammonia (corresponding to $25 \mathrm{~cm}$ pressure), 20 mmoles hydrogen cyanide, $6 \cdot 1$ mmoles formaldehyde, 3.64 mmoles acetaldehyde and 1.16 mmoles propionaldehyde in $325 \mathrm{ml}$. water. The following products were found in percentage yields, based on aldehyde added, which are in parenthesis-glycine (16), alanine (35), $\alpha$-aminobutyric acid (23), glycolic acid (12), lactic acid (12), $\alpha$-hydroxybutyric acid (13), iminodiacetic acid (18) and imino-acetic-propionic acid (?).

In the actual syntheses which Miller made, he found that the replacement of ammonia by nitrogen produced the same products but the yield (based on carbon in the original mixture) dropped from 15 to 7 per cent. (Another interesting point is that the presence of ferrous iron, which might be expected if there were much iron present at the formation of the planets, did not increase the yield.) The compounds which were formed in the greatest yield - quantities are quoted in the parentheses as moles $\times 10^{5}$-and which were definitely identified were as follows:

(a) Amino acids and derivatives-Glycine (63), d,l-alanine (34), sarcosine (5), $\beta$-alanine (15), $\alpha$-aminobutyric acid (5), $\mathrm{N}$-methylalanine (1), aspartic acid $(0 \cdot 4)$, glutamic acid $(0 \cdot 6)$, iminodiacetic acid $(5 \cdot 5)$ and imino-aceticpropionic acid (methyl ethylamine $\alpha, \alpha^{1}$-dicarboxylic acid) (1.5).

(b) Hydroxy acids-Glycolic acid (56), lactic acid (3I) and $\alpha$-hydroxybutyric acid (5).

(c) Aliphatic acids-Formic acid (233), acetic acid (15.2), propionic acid $(12 \cdot 6)$ and succinic acid $(3 \cdot 8)$.

(d) Ureas-Urea (2) and methylurea (1.5). 
(e) Unidentified polymers which did yield some glycine on drastic treatment. Some products were carried down with trichloracetic acid (as proteins are carried), but this behaviour is not specific for proteins.

It is interesting to notice at this stage that it has been claimed that the presence of an aromatic ring seems to be necessary for the radiation condensation of amino acids to polypeptides ${ }^{27}$. Phenylalanine, tryptophane and tyrosine are condensed to polypeptides but glycine, alanine, leucine, valine, lycine, glutamic acid and aspartic acid are not.

\section{SYNTHESIS OF UREA}

Loiseleur and Petit reported the synthesis of urea following the irradiation of an ammoniacal and methanolic solution of $m$-phenylenediamine and dichloromethane with X-rays in the presence of air ${ }^{26,27}$. They showed that the formation of urea depended upon the concentration of diamine and the irradiation dose falling off beyond certain values for both, and that, of the diamine isomers, only $m$-phenylenediamine was efficacious.

The urea present after irradiation was precipitated as the insoluble dixanthylurea by the addition of 10 per cent methanolic solution of xanthydrol. The nitrogen content of this derivative was reported as 6.665 per cent (theoretical $6 \cdot 66$ per cent).

The proposed mechanism for this reaction was as follows, the need for $m$-phenylenediamine suggesting an intermediate stage:

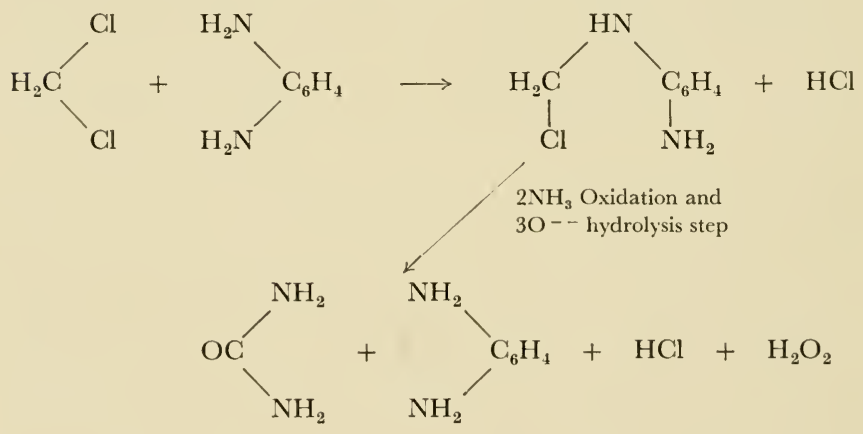

However, it is quite likely that the reaction actually proceeds by the initial formation of an aromatic phenol leading to a relatively stable peroxide, which takes part in coupling reactions with other molecules both during and after irradiation.

Our aim was to repeat this experiment using a $\gamma$-ray source, to verify, if possible, this reaction mechanism and then to synthesize substituted ureas.

\section{Irradiation Techniques}

The cell used consisted of a small round-bottomed glass tube $6 \cdot 5 \mathrm{~cm}$ long and $3.0 \mathrm{~cm}$ in diameter fitted with a stopper through the centre of which passed a smaller glass tube $7.0 \mathrm{~cm}$ long and $0.75 \mathrm{~cm}$ in diameter. This small tube 


\section{S. DILLI AND J. H. GREEN}

was sealed at the lower end and the source fitted neatly into it. The cell held 25 to $30 \mathrm{ml}$. solution and was supported in the vertical position in the centre of a paraffin-wax cube as shown in Figure 1 .

The $5 \mathrm{C}^{137} \mathrm{Cs}$ source was held in a cylindrical lead castle approximately $30 \mathrm{~cm}$ high and $30 \mathrm{~cm}$ diameter. Access to the castle was by means of a drawer fitted diametrically at its base, the inner compartment of which was approximately an $8 \mathrm{~cm}$ cube. The paraffin block was then put into the compartment, the cell positioned in the block and when the drawer was closed, the source was lowered into the inner cell tube.

To aerate the solution, a perforated coil of polythene capillary tubing passed through to the bottom of the cell. A second tube led the air from the cell compartment. A small electric blower supplied air at a controlled rate

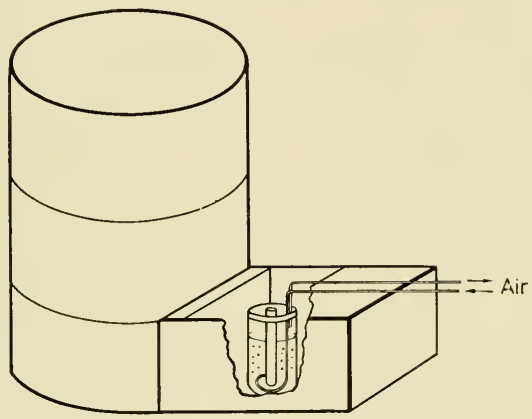

Figure 1. Apparatus used for irradiations with ${ }^{137} \mathrm{Cs}$

(25 to $30 \mathrm{ml}$. per $\mathrm{min}$ ) to the cell after passing first through a volume of solution of the same composition as that under irradiation.

The solution to be irradiated $\left(\mathrm{CH}_{3} \mathrm{OH} 32 \mathrm{ml}\right.$., $\mathrm{CH}_{2} \mathrm{Cl}_{2} 4 \mathrm{ml}$, $m$-phenylenediamine $250 \mathrm{mg}, 30$ per cent aq. ammonia $0.25 \mathrm{ml}$.) was freshly prepared for each irradiation. Methanol and dichloromethane were fractionated in $500 \mathrm{ml}$. aliquots and then used as required without further purification. The impure phenylenediamine was first purified by distilling in an atmosphere of nitrogen. Although this represented a considerable improvement, it was necessary to redistil the diamine each time, immediately before use, as decomposition obviously occurred in less than twenty-four hours. Ammonia (Sp. gr. 0.880) was diluted with distilled water. Reagent xanthydrol as a 10 per cent solution in methanol was used. Later, the xanthydrol was synthesized and used as a 10 per cent solution in ethanol 28,29 .

The absorbed irradiation dose was determined by measuring the oxidation of ferrous iron in $0.8 \mathrm{~N}$ sulphuric acid ${ }^{30}$. The value of $G_{\mathrm{Fe}^{+++}}$was taken as 15.5 and accordingly, the dose was $10^{16} \mathrm{eV} / \mathrm{ml} / \mathrm{min}$ or approximately $200 \mathrm{rad} / \mathrm{ml} . \mathrm{min}$. The irradiation cell described above was used for X-ray irradiation also. The cell was mounted in front of the window of an X-ray generator operated at $20 \mathrm{~mA}$ and $40 \mathrm{kV}^{\top}$ with a copper target. To determine 
the absorbed dose, the ferrous sulphate-sulphuric acid system was again used in the cell placed in exactly the same position. The same system of acration was used. In this case the absorbed dose rate $1.5 \times 10^{15} \mathrm{eV} / \mathrm{ml} / \mathrm{min}$ was rather less than had been anticipated.

\section{Analytical Techniques}

The detection of urea was found to be far from a simple matter because it was complicated always by the presence of the more reactive $m$-phenylenediamine. The method of Fosse using xanthydrol, which was detailed by Loiseleur was at first used. This reagent is not specific for urea although it does form a well-defined dixanthylurea derivative ${ }^{31}$. Further, the reaction was found to be erratic and even failed, when used as recommended, to react

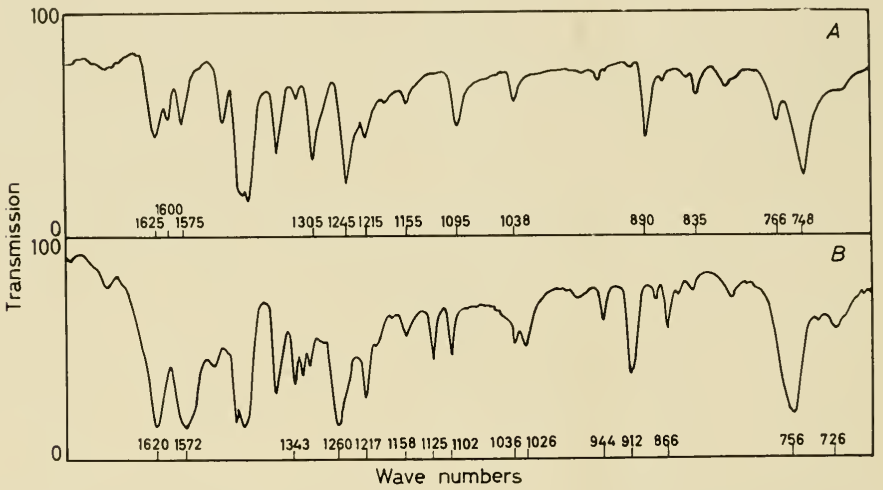

Figure 2. Infra-red spectra of dixanthylurea and unknown derivative $-A$, unknown $-B$, urea derivative

with rather large amounts of added urea. For example, $25 \mathrm{mg}$ urea dissolved in $10 \mathrm{ml}$. ethanol and $20 \mathrm{ml}$. glacial acetic acid failed to give the derivative after standing for several days. In another case, $100 \mathrm{mg}$ of urea produced the derivative only after standing for twenty-four hours during which time the mixture was shaken vigorously for several hours. On the other hand, $5 \mathrm{mg}$ urea dissolved in $5 \mathrm{ml}$. water and $20 \mathrm{ml}$. glacial acetic acid gave the derivative almost immediately following the addition of the xanthydrol.

In the early stages of these experiments, what was thought to be the derivative, dixanthylurea, obtained from the solution after irradiation, was shown to be identical with a crystalline deposit recovered from a control test with non-irradiated solution treated in the same way. This substance, as yet unidentified, appeared regularly in both the irradiated and non-irradiated solutions after standing for several days. The elemental analysis and infra-spectra (shown in Figure 2), showed clearly that the substance was not the same as the derivative obtained in the same way with a pure urea. 
Neither did it appear to be what was thought to be a xanthyl-derivative of the diamine. The analyses were as follows:

\section{Figures are expressed as percentages}

C $\quad \mathrm{H} \quad \mathrm{N} \quad \mathrm{O}$

1. Dixanthylurea

2. Mono-substitute Xanthyl $\begin{array}{lllll}\text { derivative of } m \text {-phenylene- } & 79 \cdot 3 & 5 \cdot 6 & 9 \cdot 7 & 5 \cdot 6\end{array}$ diamine (Hypothetical)

3. Di-substitute Xanthyl derivative of $m$-phenylenediamine (Hypothetical)

4. Derivative obtained

$\begin{array}{cccc}\text { - } & \text { - } & 6 \cdot 66 & \text { (by diff. } \\ 79 \cdot 3 & 5 \cdot 6 & 9 \cdot 7 & 5 \cdot 6 \\ 82 \cdot 0 & 5 \cdot 1 & 6 \cdot 0 & 6 \cdot 8 \\ 80 \cdot 5 & 4 \cdot 9 & 3 \cdot 6 & 11 \cdot 0\end{array}$

These results give an empirical formula for the derivative of $\mathrm{C}_{6 \cdot{ }_{7}} \mathrm{H}_{4 \cdot 9} \mathrm{~N}_{0 \cdot 26} \mathrm{O}_{0 \cdot 61}$ or approximately $\mathrm{C}_{61} \mathrm{H}_{45} \mathrm{~N}_{2} \mathrm{O}_{6}$.

The empirical formulae for the other three derivatives are:

1. $\mathrm{C}_{27} \mathrm{H}_{20} \mathrm{~N}_{2} \mathrm{O}_{3}$

2. $\mathrm{C}_{19} \mathrm{H}_{16} \mathrm{~N}_{2} \mathrm{O}$

3. $\mathrm{C}_{32} \mathrm{H}_{24} \mathrm{~N}_{2} \mathrm{O}_{2}$

In an endeavour to increase the limiting sensitivity of the urea detection, a method using paper chromatography was sought. It was not difficult to detect as little as $10 \gamma$ of urea by this approach, and methods are available for the quantitative estimation of urea by this means ${ }^{32}$. Numerous solvent systems were used but were found quite unsuitable for a number of reasons. In all the suggested solvent systems, the very reactive, polar $m$-phenylenediamine failed to migrate as a compact spot and in fact showed a marked, although varied, degree of 'tailing'. Coupled with greater reactivity of the diamine with the chromogenic reagent to produce a highly coloured (orangebrown) area, the tailing made the uni-dimensional technique less sensitive. By using the two-dimensional technique however, it was possible to detect as little as $50 \gamma$ urea with ease using as solvent, butanol-ethanol-water $(4: 1: 1)$. However, the effect of the diamine was still apparent in the form of a rectangular coloured area. Viewing with u.v. light helped to define the urea spot further, showing it as a black spot on a rather strong fluorescent (pink) area to $m$-phenylenediamine.

This solvent was used until it was found that aqueous pyridine (4:1) gave good separations using the uni-dimensional, ascending technique. The chromogenic reagent was dimethylaminobenzaldehyde as a one per cent solution in ethanol and containing one $\mathrm{ml}$. concentrated hydrochloric acid. After spraying, the chromatogram was heated in an oven at $100^{\circ} \mathrm{C}$ for five minutes to increase the intensity of the yellow urea spot.

\section{RESULTS AND CONCLUSION}

The results showed that no urea was obtained from the solution after irradiation under the conditions of the experiment described. The irradiation periods extended to twelve hours, at one hour intervals for the first six. In 
addition, half-hour irradiations were made using an X-ray machine, but the absorbed dose was rather low. However, the range was considered wide enough to test the claim of the synthesis with u.v. light and X-rays.

The method of precipitation given by Loiseleur gave negative results and the behaviour of the reagent was found unreliable. The chromatographic method of identifying urea was found to be more sensitive, and was linited however, by the final concentration of the diamine added to the paper. The 'tailing' effect increased with the concentration of diamine. Again, negative results were obtained.

It seems that the formation of a blue colour in the Loiseleur solution was considered by him to be a measure of irradiation beyond the optimum for maximum urea yield. Our observations showed that the colour was obtained shortly after the preparation of the solution and increased markedly during the course of several days. It is assumed that this is not a simple oxidative phenomenon because of its occurrence in various polar solvents. Complete oxidation of $m$-phenylenediamine produces yellow-brown quinoid substances. The intensity of this blue colour increased sharply after two hours irradiation with the $\gamma$-ray source. Although no attempt was made to identify the blue compound, from its chromatographic behaviour, separation and purification for this purpose appears feasible.

In postulating a reaction mechanism for this complex system, under the conditions of aeration, the action of $\mathrm{OH}$ radicals must be considerable, suggesting the formation of phenolic (or even polyhydric) intermediates. Reaction may then follow with $m$-phenylenediamine present or with latter and further oxidized phenolic bodies. The catalytic behaviour of the phenylenediamine would also need mass-balance studies. Unfortunately no energy absorption measurements were reported by Loiseleur, although a high X-ray flux at the liquid surface was used (200,000 roentgen per min). It is possible that this fact may be significant for successful synthesis.

\section{REFERENCES}

${ }^{1}$ Collinson, E. and Swallow, A. J. Chem. Rev. 56 (1956) 471

${ }^{2}$ United Kingdom Atomic Energy Authority Reports A.E.R.E. C/R 1575 (1), (2), (3) et seq.

${ }^{3}$ Oparin, A. I. The Origin of Life: Dover Publications, Inc., New York, 1953

${ }^{4}$ Urey, H. C. The Planets: Yale University Press, New Haven, 1952

${ }^{5}$ Lind, S. C. The Chemical Effects of Alpha Particles and Electrons: Chemical Catalog Company, New York, 1928

${ }^{6}$ Stevenson, D. P. J. phys. Chem. 61 (1957) 1453

${ }^{7}$ Meisels, G. G., Hamill, W. H. and Williams, R. R. J. Phys. Chem. 61 (1957) 1456

${ }^{8}$ Napier, K. H. and Green, J. H. unpublished work 1958; Proceedings of the Second Australasian Conference on Radiation Biology: Butterworths, London, 1959 p. 87; Proceedings of the Symposium on Atomic Energy in Australia Sydncy, 1958

${ }^{9}$ Field, F. H. and Franklin, J. L. Electron Impact Phenomena: Academic Press Inc., New York, 1957

${ }^{10}$ Śchuler, R. H. J. phys. Chem. 62 (1958) 37

${ }^{11}$ Magee, J. L. and Ganguly, A. K. J. phys. Chem. 25 (1956) 129

${ }^{12}$ Magee, J. L. Ann. Rer'. nucl. Sci. 3 (1953) 171

${ }^{13}$ Wilzbacil, K. \&. J. Amer. chem. Soc. 79 (1957) 1013

${ }^{14}$ Keller, M. and Werss, J. J. chem. Soc. (1951) 1247 


\section{DISGUSSION}

${ }^{5}$ Ballantine, D. S., Glines, A., Colombo, P. and Manowitz, B. U.S. Atomic Energy Commission Report BNL-294, 1954

${ }^{6}$ Schmitz, J. V. and Lawton, E. J. Science 113 (1951) 718

${ }^{7}$ Burton, V. L. and Breger, A. Science 116 (1952) 477

${ }^{8}$ Harmer, D. E., Anderson, L. C. and Martin, J. J. Chem. Engng. Progr., Series 50 $11(1954) 253$

${ }^{19}$ Collinson, E. and Dainton, F. S. Disc. Faraday Soc. 12 (1952) 212

Ballantine, D. S. and Manowitz, B. U.S. Atomic Energy Commission Report BNL-317, 1954

${ }^{1}$ Bach, N. Proceedings of the First Conference on the Peaceful Uses of Atomic Energy 7 Geneva, 1955

!2 Loeb, W. Ber. dtsch. chem. Gres. 46 (1913) 690

${ }^{3}$ Bernal, J. D. The Physical Basis of Life: Rutledge, London, 1951

${ }^{4}$ Miller, S. L. J. Amer. chem. Soc. 77 (1955) 2351; Science 117 (1953) 528; Biochim. biophys. Acta 23 (1957) 23; Communication to the 133rd Meeting of the American Chemical Society, 1958

${ }^{25}$ Shaw, G. J. Aust. chem. Inst. Series 1025 (1958) 505; and personal communication ${ }^{26}$ Loiseleur, J. and Petit, M. C.R. Acad. Sci. 240 (1955) 1026

${ }^{27}$ Loiseleur, J. J. Chim. phys. 52 (1955) 626

${ }^{28}$ Grlman, H. and Blatt, A. H. Organic Syntheses, Vol. I: John Wiley and Son, Inc., New York, 1941

${ }^{29}$ Kny-Jones, F. G. and WARd, A. M. Analyst 54 (1929) 574

${ }^{30}$ Haybittle, J. L., Saunders, R. D. and Swallow, A. J. J. chem. Phys. 25 (1956) 1215

${ }^{31}$ Elderfield, R. G. (Ed.) Heterocylic Compounds Vol. II: John Wiley and Son, Inc., New York, 1951

${ }^{32}$ Milks, J. E. and Janes, R. N. Analyt. Chem. 28 (1956) 846

${ }^{33}$ Tolbert, B. M. and Lemmon, R. M. Radiation Res. 3 (1955) 52

${ }^{34}$ Davison, W. H. T., Pinner, S. H. and Worrall, R. Chem. E Ind. (Rev.) (1957) 1274

\section{DISGUSSION}

Dr. Duncan: I remember a report by Sir John Cockcroft in $1954^{1}$ that cholesterol splits on $\mathrm{X}$ irradiation into two products only, with a 90 per cent yield. Now this, of course was done under different conditions from the work which Dr. Green reports, but could he comment on the differences between the two pieces of work?

DR. GREen: I cannot say anything as I do not know what happened-whether it was irradiated in a pure form, or what the conditions were. My information came from the review by Collinson and Swallow ${ }^{2}$. I think there are four pages of reactions which occur with sterols reported there. This example is of some specific interest to my paper. Understanding of radiation-induced reactions is obscured by the fact that one uses any radiation which is handy. One has no idea which component of it whether it is the ionization effect, or the molecular excitation, or the heat effect-is producing the reaction.

Professor RALPh: I think one interesting comment one might make on some of the results we have heard this afternoon is that very often the initial products of irradiation of some of these compounds of biological interest seem fairly closely parallel to those which often occur under biological conditions. I think this might be an approach which should perhaps be pushed a little further in the plotting out of biosynthetic and degradative sequences. I think some of Weiss's work, for example, on the irradiation of sterols under different conditions, does in fact support this. 
1) 1) 1 xcax: I remember two years ago being told of the preparation of radio-active material by the bombardment of solids with radio-active ions of very small energy (less than $1 \mathrm{kel}$ ). Could anyone tell me if there have been any developments in this type of radio-synthesis?

DR. GRAY: I do not know of that particular experiment. There were some experiments something like them done by Essex, who tried to distinguish the effect of ions and radicals produced by an electronic beam by sceing whether he got reactions when he drew the ions to the side. This was a good many years ago, and I have not seen any more of that work.

\section{REFERENCES}

${ }^{3}$ Cockcroft, SIR J. The Development of Radiation Chemistry and Radiochemistry: The Royal Institute of Chemistry, London, 1954

¿Collinson, E. and Swallow, A. J. Chem. Rev. 56 (1956) 471 


\title{
STRONTIUM IN MAN AND BEAST
}

\author{
J. F. Loutit
}

\section{Medical Research Council Radiobiological Research Unit, Atomic Energy Research Establishment, Harwell, England}

StrictLy SPEAKING the subject of this communication and of that on Radioactive Fission-Products in the Food Chain (p. 209) is not radiobiology. This branch of science might be defined as the study of the effects of radiations on living cells and organisms. Nevertheless, since in the present and future state of the world ionizing radiation will be liberated in tissue by artificially produced radio-active materials, a prerequisite of radiobiological investigation is an understanding of how each particular radio-active nucleide is dealt with by the organism and where it is ultimately most concentrated.

To most of us, medically qualified and lay, the most important consideration is for ourselves-man. However, from the investigator's point of view, man presents some difficulties which can be overcome with experimental animals. Consequently, it is also necessary to elucidate in any series of investigations how good a model the mouse, rat, rabbit, etc., is of man.

If we turn now to radio-active strontium produced in nuclear fission, two isotopes assume particular importance, firstly because of their long half-lives $\left(T_{\frac{1}{2}}\right)-{ }^{89} \mathrm{Sr} 50$ days and ${ }^{90} \mathrm{Sr} 28$ years-and secondly because, being emitters of $\beta$-particles only, any radiation from them will have an intensely localized effect. ${ }^{91} \mathrm{Sr}$ and isotopes of higher mass-number are also fission-products, but as their half-lives are only a few hours or less they present no particular biological hazard. The stable strontium in nature is a mixture of ${ }^{84} \mathrm{Sr}$, ${ }^{86} \mathrm{Sr},{ }^{87} \mathrm{Sr}$ and mainly ${ }^{88} \mathrm{Sr}$. This still leaves a number of other possible isotopes which can be produced in cyclotrons or reactors, and among them ${ }^{85} \mathrm{Sr}\left(T_{\frac{1}{2}}=65\right.$ days $)$ and a metastable state of ${ }^{87} \mathrm{Sr}\left(T_{\frac{1}{2}}=2 \cdot 8\right.$ hours $)$ have proved useful as tracers, both being emitters of $\gamma$-rays only.

Although the metabolism of strontium was studied sporadically before the advent of nuclear fission, a greatly increased effort has been exerted in the last fifteen years. Since the first publications after World War II by Hamilton ${ }^{1}$ and his colleagues from Berkeley who administered ${ }^{85} \mathrm{Sr}$ to rats, it has been confirmed in a variety of small laboratory animals that the behaviour of strontium in vivo is in general similar to that of calcium. More recently the observations have been extended to the larger animals, particularly ruminants which are so important in our nutritional economy.

Certain features are common to the various species investigated. For instance, the strontium retained is stored in bone where its biological turnover is extremely slow; and the uptake by the normal route from the gut is much greater in the infant and adolescent than in the adult. On the other hand, the different animals vary somewhat in their methods of excretion. In some animals the route is mainly from the gut, in others mainly in urine. In the case of the ruminant, we are particularly concerned with the excretion 
in milk which in Western civilizations is the main source of dietary calcium. Recent work in lingland at the Agricultural Research Council Field Station at Compton ${ }^{2}$ is in line with previously reported studies from the U.S.A. In six days dairy cows excreted into the milk $0 \cdot 17$ to $3 \cdot 8$ per cent (mean 0.67 per cent) of a single dose of ${ }^{89} \mathrm{Sr}$ administered with the feed : the excretion fell off rapidly thereafter. The amount excreted seemed to be related to the yield of milk and the time-course of excretion of ${ }^{89} \mathrm{Sr}$ was closely parallel to that of ${ }^{45} \mathrm{Ca}$ when the two nucleides were administered together.

With some of this background, experiments on man were started some years ago at the Medical Research Council Radiobiological Research Unit by Harrison. At that time it was not felt to be justifiable to administer the fission-products ${ }^{89} \mathrm{Sr}$ or ${ }^{90} \mathrm{Sr}$ to normal subjects, and it was our special aim to investigate these products in the physiological state of man. (In the U.S.A. ${ }^{89} \mathrm{Sr}$ has been given to human patients in the terminal stages of malignant disease. We felt, however, that the status of such individuals with regard to calcium and its chemical analogues might well be atypical because of wasting and confinement to bed.) Harrison et al. ${ }^{3}$ therefore adopted the policy of giving pharmacological doses of stable strontium to their volunteers and by comparing the intake and output of this stable strontium (assayed by neutron-activation-analysis), showed that the retention must have been comparable with that of most laboratory experimental animals. The route of excretion in man was identified as predominantly in urine for absorbed strontium, although naturally much unabsorbed strontium passed through the gut to appear in faeces.

More recently with the $\gamma$-ray emitting ${ }^{85} \mathrm{Sr}$ and the A.E.R.E.-whole-body$\gamma$-counter ${ }^{4}$ both available, Harrison (personal communication) has felt justified in giving two volunteers the small dose of $0.5 \mu \mathrm{C}$ intravenously. Thus the excretion could be followed for a period of some months and the retention calculated and compared with the observed retention as recorded by the whole-body-counter. The results of this exercise are not yet satisfactorily interpreted. Suffice it to say that they indicate the turnover of strontium in man to be considerably faster than the somewhat pessimistic value of some ten years as the biological half-life adopted by the International Commission on Radiological Protection.

Since in general the laboratory animal appears to be a not unrepresentative model for man, it is fair to consider the strontium-calcium relationships so far determined and to discuss them.

\section{The Absorption and Excretion of Calcium}

The mammal has remarkable powers for controlling its calcium metabolism to maintain either balance in the adult or regulated growth in infancy and adolescence. The complete understanding of this mechanism is far from being realized.

It is known, however, that the gut plays some part in the regulation. Balance of calcium can be maintained in the adult on a wide range of diets of varying composition. On diets with a marginal amount of calcium the percentage absorption of calcium is high. With increasing excess over this threshold the percentage absorption of calcium is reduced so that the absolute amount absorbed does not run pari passu with the amount in the diet. 


\section{J. F. LOUTIT}

Excretion is via the kidneys and to a certain extent the gut, the percentage contribution of the latter organ varying with the species of animal and with the calcium status of the individual. The renal excretion at least is influenced by humoral influences, notably by parathyroid and thyroid activity releasing calcium from the buffer state, the bone. Phosphate metabolism is closely connected with that of calcium and disturbance of the one is reflected in the other.

\section{Strontium and Calcium Differentiation by Tissues}

Strontium is chemically related to calcium and in general its metabolism in the animal is similar. There are certain differences, however, which indicate that certain tissues distinguish between the two. Calcium is preferentially absorbed from the gut by a factor of about two. Strontium is excreted by the kidney with greater facility by a similar factor ${ }^{3}$ and, in the experimental animal, the mammary gland ${ }^{5}$ and the placenta ${ }^{6}$ pass calcium preferentially to strontium. The storehouse tissue, bone, is said to treat the two elements at physiological levels without distinction?

\section{Central Differentiation of Strontium and Calcium}

The question needing answer is - does the body control strontium metabolism by a mechanism similar to but separate from that for calcium, or does the mechanism not distinguish between them at, for instance, some central governing locus for both, but only at the effector mechanisms? If there is a controlling master mechanism for strontium alone, one would expect that by markedly increasing the strontium intake one would, on analogy with calcium, markedly depress the percentage uptake from the gut. However, this has not been observed in man or the rat. Harrison et al. ${ }^{3}$ have shown that of a single oral dose of 100 or $250 \mathrm{mg}$ of stable strontium about a third was absorbed by man. This dose is about 50 to 100 times that of the normal daily intake of stable strontium. Nevertheless when a single tracer dose of ${ }^{89} \mathrm{Sr}$ was taken orally, the absorption was not notably different (personal communication from G. E. Harrison). This ${ }^{89} \mathrm{Sr}$ was taken in the carrier-free state, but before absorption it must have been mixed to some extent with carrier from the natural diet and body fluids. One-third absorbed, therefore, seems representative for strontium over a range of concentrations of at least 100 and possibly greater orders of magnitude. The same phenomenon has been observed in rats given ${ }^{89} \mathrm{Sr}$ as a single dose by stomach tube and followed at once by carrier strontium from 0 to $400 \mu \mathrm{g} / \mathrm{g}$ of body weight. The fraction absorbed was if anything increased at the higher levels of carrier $^{8}$ : the percentage retention by the skeleton after 24 hours was about the same in all groups, but the percentage excretion in urine was greater after the higher doses. The amount of strontium laid down in the skeleton during this period must in absolute terms have differed between the two extreme groups by a factor of over 400. These results do not suggest any homoeostatic mechanism operating specifically for strontium.

If, however, the master mechanism for homoeostatic control of calcium in the body cannot distinguish between strontium and calcium, then these phenomena are explicable in terms of atomic concentration. The normal concentration of calcium in, for instance, plasma is $100 \mathrm{mg}$ or 5 mequiv. 
per litre and of strontium is $40 \mu \mathrm{g}$ or barely 1 eequiv. per litre. Thus, raising the plasma level of strontium one hundredfold has an insignificant effect on the combined molar concentration of calcium and strontium.

Further evidence in support of this concept of central lack of discrimination at a control centre is obtained from the work of MacDonald et al. ${ }^{9}$, who showed that adding calcium carriers to diets reduced the absorption of strontium. If the control centre regulates the absorption of calcium from the gut to amounts necessary for maintaining balance or optimal growth, then by reducing the percentage of calcium absorbed from diets high in calcium, the percentage of strontium absorbed will be similarly limited if the strontium intake is kept constant (which is in practice practically impossible, as all natural sources of calcium contain strontium), or if the normal calcium to strontium ratio is not markedly disturbed, which is the condition likely to be found experimentally.

In addition, Wasserman et al. ${ }^{10}$ have equilibrated rats on diets of adequate calcium status, but varying by a factor of four in calcium (and therefore probably strontium also). When a state of equilibrium was attained, constant doses of radio-active calcium $\left(\mathrm{Ca}^{\star}\right)$ and strontium $\left(\mathrm{Sr}^{\star}\right)$ tracers were added to each diet. The active isotopes were deposited in bone in such a way that the radio-active strontium was deposited according to its concentration in terms of calcium in the diet, that is, the observed ratio of $\mathrm{Sr}^{\star} \mathrm{Ca}^{\star}$ bone to $\mathrm{Sr}^{\star} / \mathrm{Ca}^{\star}$ diet was the same in each group. In other words, as far as the master mechanism was concerned, strontium behaved as an analogue of calcium; but individual mechanisms within the body did discriminate between the two. That this result was obtained in virtue of the varying calcium contents of the diet and not of the unmeasured stable strontium contents was shown by a control experiment, in which varying the stable strontium by a factor of four made no difference to the percentage uptake of radio-active tracer strontium.

\section{The Mechanism of Peripheral Discrimination}

The discrimination that does occur within various tissues can perhaps be explained on purely physico-chemical grounds. The mechanism whereby ions are actively carried across cells or cell membranes is still uncertain, but it is possible to postulate that chelation plays some part. Nearly all chelating agents so far investigated are more efficient binders of calcium than strontium, the ratio of the appropriate constants for calcium and strontium being usually in the region of two. Such a mechanism if common to membranes in the gut, mammary gland and placenta would explain why each apparently discriminates in favour of calcium by a factor of about two. The apparently reverse phenomenon in the kidney is explicable in terms of renal physiology. The glomeruli of the kidney merely passively excrete an ultrafiltrate of plasma, 95 per cent or more of the volume of which is reabsorbed by the tubules. The discriminating powers of the kidney lie largely in the tubules and reabsorption of the so-called threshold substances almost certainly favours calcium to strontium as in the other active processes. Harrison's calculations suggest that the human kidney clears plasma of calcium at the rate of $2 \mathrm{ml} . / \mathrm{min}$, but of strontium at about $8 \mathrm{ml} . / \mathrm{min}$. The clearance of strontium is independent of the plasma levels of strontium within a range of 


\section{J. F. LOUTIT}

one hundredfold, as would be expected if it were not strontium levels which were important but combined calcium and strontium levels.

\section{Inertia of the System}

For what are probably good physiological reasons the mechanism of control for calcium metabolism has considerable inertia. Calcium is an essential element for neuromuscular co-ordination and for the structure of the skeleton. Calcium in the extracellular water amounts to just over $1 \mathrm{~g}$ and in the skeleton to just over $1000 \mathrm{~g}$ in the $70 \mathrm{~kg}$ man. While far from all the skeletal calcium is available it provides a very substantial bank on which the body can draw in time of need to maintain a constant level of plasma calcium. Minor changes in calcium balance evoke no rapid response. Substantial changes in the intake of calcium are reflected in the total economy of calcium only after long latent intervals. Thus, Walker et al. ${ }^{11}$ found that it took many weeks for subjects to come into calcium balance after being transferred from adequate to low calcium diets. On the other hand, and understandably, an animal made chronically deficient of calcium will adapt and take all available supplies with avidity and will continue to do so for a long time.

The growing animal is more responsive and labile than the adult. Nevertheless, even under these circumstances, there is a steady pattern of accumulation which is adhered to in spite of environmental irregularities, unless these are extreme.

\section{Interpretation of $\mathrm{Sr} / \mathrm{Ca}$ Ratios}

Analyses are available of human bones and various articles of diet for ${ }^{90} \mathrm{Sr}$ and stable strontium $\left({ }^{\mathrm{s} S}\right)$ in relation to calcium. The problem is how to evaluate the data and what to use for purposes of prediction. In this exercise it is important to bear in mind the physiological considerations discussed above and particularly to be wary of the use of the equation derived by Comar et al. ${ }^{12}$ :

$$
\text { Observed Ratio }=\frac{\mathrm{Sr} / \mathrm{Ca} \text { bone }}{\mathrm{Sr} / \mathrm{Ca} \text { precursor }}
$$

unless it can be established that a state of equilibrium exists. No one is more emphatic on this than Comar himself.

\section{Stillbirths}

Assays of the bones of stillbirths have been made for ${ }^{90} \mathrm{Sr}$ and ${ }^{\mathrm{s}} \mathrm{Sr}$ in relation to calcium. There is a much greater variation in the ratio ${ }^{90} \mathrm{Sr} / \mathrm{Ca}$ than in the ratio ${ }^{\mathrm{s}} \mathrm{Sr} / \mathrm{Ca}$. If a state of equilibrium is assumed between foetal bone and maternal plasma the data for ${ }^{\mathrm{s}} \mathrm{Sr} / \mathrm{Ca}$ can be compared with other observations on human plasma. Representative figures are $200 \mu \mathrm{g}{ }^{\mathrm{s}} \mathrm{Sr} / \mathrm{g} \mathrm{Ca}$ for bone of stillbirths (Bryant et al. ${ }^{13,14}$, Sowden and Stitch ${ }^{15}$ ) and $400 \mu \mathrm{g}$ ${ }^{\mathrm{s}} \mathrm{Sr} / \mathrm{g}$ Ca for human plasma (personal communication from G. E. Harrison), which would suggest a placental discrimination factor of two for man as well as rat.

Whereas it has been possible to assay the bones of individual stillbirths for ${ }^{90} \mathrm{Sr}$ no figure has been obtained for individual human plasmas. On an isotopic basis one could suggest that, if a median figure of about $0.5 \mathrm{~S} . \mathrm{U}$. 


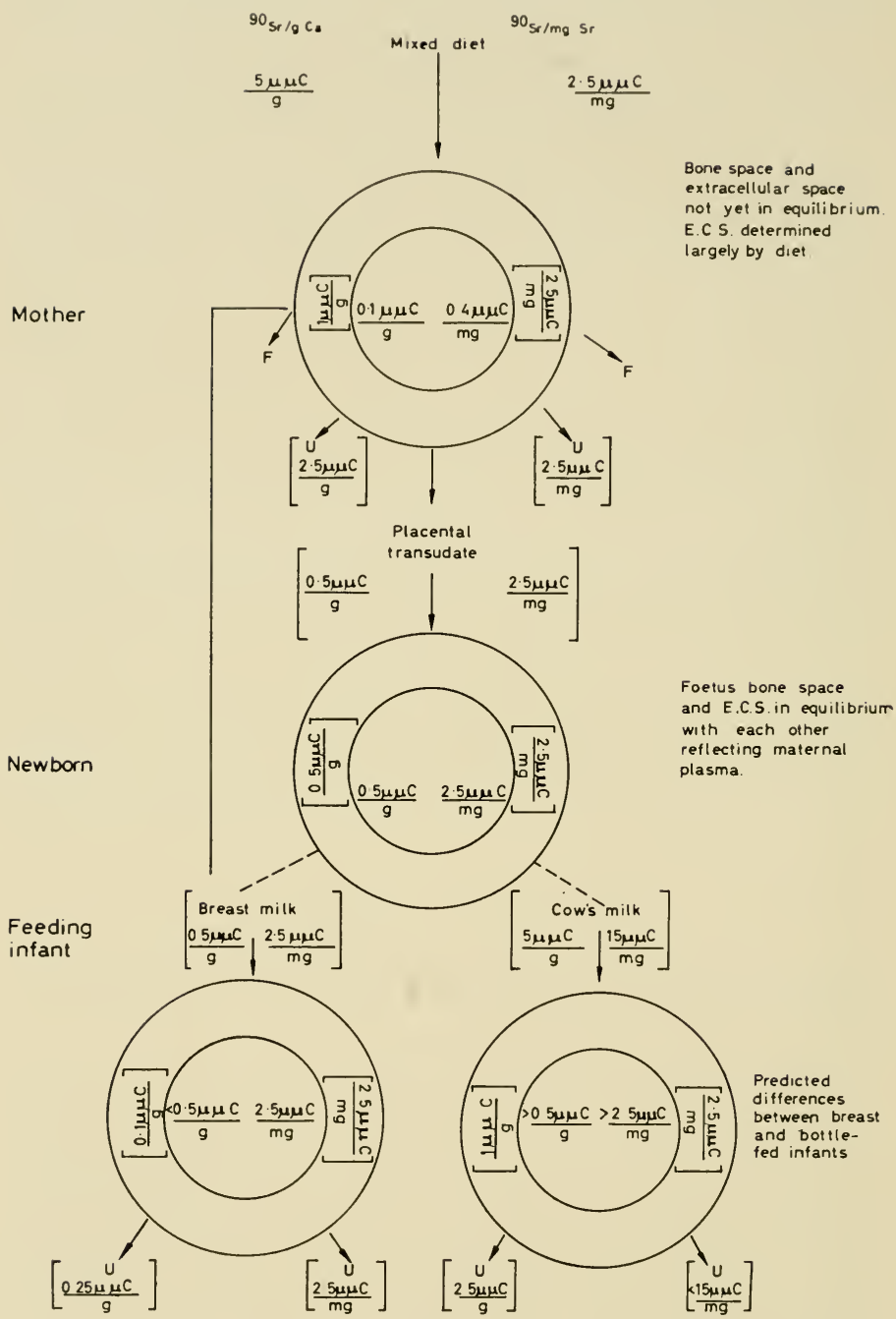

Figure 1. Representative observed and predicted values for ${ }^{90} \mathrm{Sr} / \mathrm{g} \mathrm{Ca}$ and ${ }^{90} \mathrm{Sr} / \mathrm{mg} \mathrm{Sr}$ ratios; predicted values in brackets-assuming infant discriminates as adult; observed values unbracketed. Outer circles-extracellular space. Inner circles-bone space 


\section{J. F. LOUTIT}

be the ${ }^{90} \mathrm{Sr} / \mathrm{Ca}$ value in bones of stillbirths, $1 \mathrm{~S}$.U. should be the corresponding figure for human plasma. (It would take about 20 litres of plasma to make this assay feasible!) However, according to Bryant et al., the ${ }^{90} \mathrm{Sr}$ in stillbirths varies by a factor of about five so that the ${ }^{90} \mathrm{Sr} / \mathrm{s} \mathrm{Sr}$ ratio will also vary widely in stillbirths, in the respective plasmas of the mothers and in the mothers' diets.

In summary, from stillbirths one learns more about the mother in the last stages of pregnancy than anything else. Infants probably start post-natal life with a variable ${ }^{90} \mathrm{Sr}$ specific activity in terms of both ${ }^{\mathrm{s}} \mathrm{Sr}$ and calcium.

\section{Infants}

At birth there is the abrupt change from nutrition by maternal plasma via the placenta to nutrition by maternal colostrum and milk. Infancy is a period of great accumulation of calcium. The child's birth weight is doubled in about six months and trebled in a year. Mitchell et al. ${ }^{16}$ give the increase in calcium as from $28 \mathrm{~g}$ at birth to $100 \mathrm{~g}$ in the first year of life. The increase is accomplished in the face of numerous qualitative changes in diet-weaning from breast milk to cow's milk, and the gradual introduction of mixed feeding. Representative figures for cow's milk and mixed diets might be $300 \mu \mathrm{g}$ and $1500 \mu \mathrm{g} * \mathrm{Sr} / \mathrm{g}$ Ca. Very preliminary figures for human milk suggest a value of about $200 \mu \mathrm{g}{ }^{\mathrm{s}} \mathrm{Sr} / \mathrm{g} \mathrm{Ca}$ (personal communication from G. E. Harrison). If this is confirmed an infant fed solely on breast milk should have been supplied with $\mathrm{s} \mathrm{Sr}$ and calcium in constant ratio from early times to the institution of mixed feeding, but in post-natal life it has potentialities for discriminating between strontium and calcium denied to it in pre-natal life. It has a functioning gut and kidney. If, in fact, these organs discriminate as in the adult, the $\mathrm{Sr} / \mathrm{Ca}$ ratio in bone for both ${ }^{\mathrm{s}} \mathrm{Sr}$ and ${ }^{90} \mathrm{Sr}$ could fall in the first few months of life. We cannot confirm this from available analysis because of lack of clinical history. Infants fed on cow's milk will have a rather higher intake of $\mathrm{sr}$ and, if the milk is fresh or recently dried, a much higher intake of ${ }^{90} \mathrm{Sr}$. (Much dried milk for infants in England has been on the shelf for years and much comes from overseas.) Depending on whether discrimination is yet established one would predict a smaller or greater increase in the $\mathrm{Sr} / \mathrm{Ca}$ ratios in bone.

Since the diet in infancy varies, and since discrimination at this age is still uncertain, it is inappropriate to derive an Observed Ratio (bone/diet) certainly for ${ }^{\mathrm{S}} \mathrm{Sr} / \mathrm{Ca}$. However, if the infant's daily diet is relatively constant in so far as ${ }^{90} \mathrm{Sr} / \mathrm{Ca}$ is concerned-and this may be not far from the truth once weaning from breast milk has occurred-one may speculate. Many diets, either of cow's milk only or mixed, seem to contain at present about $5 \mu \mu \mathrm{C}{ }^{90} \mathrm{Sr} / \mathrm{g} \mathrm{Ca}$ and most infant bones contain about $1 \mu \mu \mathrm{C} / \mathrm{g} \mathrm{Ca}$. From this one may hazard the guess that the body's capacity to differentiate between strontium and calcium does develop comparatively early.

\section{The growing child and adult}

The growing child eats substantially the same sort of diet as the adult. He differs according to age on the quantity eaten. Whereas, the adult is merely reforming bone at a slow rate of turnover, the adolescent is accumulating calcium and its analogues for formation of new bone. Langham and 


\section{SIRONTIUM IN MAN AND BIAST}

Anderson ${ }^{17}$ have calculated the ${ }^{90} \mathrm{Sr}$ Ca equilibrium in the bones of adolescents taking both accretion and remodelling into account. They derive figures which are in close agreement with those observed by Kulp et al. ${ }^{18}$. This may be fortuitous as both sets of authors made some rather shaky assumptions. However, if the procedure is valid it provides support for the concept that the behaviour of ${ }^{90} \mathrm{Sr}$ in the body can be predicted from the intake of ${ }^{90} \mathrm{Sr}$ and calcium.

At these periods of life, because in mixed diets ${ }^{5} \mathrm{Sr}$ and calcium can be in fairly constant equilibrium, measurement of them can have some prognostic value in predicting ${ }^{90} \mathrm{Sr}$ values for bone.

\section{CONCLUSION}

If the above deductions and speculations are valid, the important factors to determine if we wish to predict the concentration in bone of ${ }^{90} \mathrm{Sr}$, are the average daily intakes of ${ }^{90} \mathrm{Sr}$ and calcium. Determinations of $\mathrm{sr}$ and the derivation of specific activity of ${ }^{90} \mathrm{Sr} / \mathrm{Sr}$ give indications merely of the degree to which ${ }^{90} \mathrm{Sr}$ and strontium have equilibrated. On the basis of present-day observations on food and bone, I have therefore attempted to predict some of the values on which there are so far no published data, (Figure l). I do this in the hope of stimulating those with clinical material to make the observations.

\section{REFERENCES}

${ }^{1}$ Hamilton, J. G. Radiology 49 (1947) 325

${ }^{2}$ Garner, J. Food Chain Conference, Harwell, 1958

${ }^{3}$ Harrison, G. E., Raymond, W. H. A. and Tretheway, H. C. Clin. Sci. 14 (1955) 681

${ }^{4}$ Rundo, J. Second Conference on the Peaceful Uses of Atomic Energy, Paper A CONF. 15/P/1467, Geneva, 1958

${ }^{5}$ Comar, C. L. and Wasserman, R. H. Progress in Nuclear Energy, Biological Sciences: Pergamon Press, London, 1956, p. 153

${ }^{6}$ Comar, C. L., Whitney, I. B. and Lengemann, F. W. Proc. Soc. exp. Biol., N.Y. 88 (1955) 232

${ }^{7}$ Comar, C. L., Wasserman, R. H., Ullberg, S. and Andrews, G. A. Proc. Soc. exp. Biol., N.Y. 95 (1957) 386

${ }^{8}$ Harrison, G. E., Jones, H. G. and Sutton, A. Brit. J. Pharmacol. 12 (1957) 236

${ }^{9}$ MacDonald, N. S., Spain, F., Ezmirlian, F. and Rounds, D. E. J. Nutr. Quoted by MacDonald, N. S. in U.S. Atomic Energy Commission Report ANL-5884

${ }^{10}$ Wasserman, R. H., Comar, C. L. and Papadopotlou, D. Science 126 (1957) 1180

${ }^{11}$ Walker, A. R. P., Fox, F. W. and Irving, J. T. Biochem. J. 42 (1948) 452

${ }^{12}$ Comar, C. L., Wasserman, R. H. and Nold, M. M. Proc. Soc. exp. Biol., N Y. 92 (1956) 859

${ }^{13}$ Bryant, F. J., Chamberlain, A. C., Morgan, A. and Spicer, G. S. A.E.R.E. HP/R 2353 (1957)

${ }^{14}$ Bryant, F. J., Henderson, E. H., Spicer, G. S. and Webb, M. S. W. A.E.R.E. $C / R 2583$ (1958)

${ }^{15}$ Sowden, E. M. and Stitch, S. R. A.E.R.E. MRC/R 2030 (1956)

${ }^{16}$ Mitchell, H. H., Hamilton, T. S., Steggerda, F. R. and Bean, H. W. J. biol. Chem. 158 (1945) 635

${ }^{17}$ Langham, W. H. and Anderson, E. C. Science 126 (1957) 205

${ }^{18}$ Kulp, J. L., Eckelman, W. R. and Schulert, A. R. Science 125 (1957) 219 


\section{DISGUSSION}

Professor Titterton: I wonder if you could tell us something of the distribution of strontium in bone, whether it is uniform throughout the bone or if not, how it varies.

Dr. LoutrT: We do not know anything at all of the distribution of ${ }^{\mathrm{s}} \mathrm{Sr}$ throughout the bone, but, since by and large, the human subject is in equilibrium with his intake and environment, we would imagine that the ${ }_{8} \mathrm{Sr}$ and calcium are uniformly distributed if the person is in a constant environment, but nowadays, with air travel and so forth, so few of us are in a constant environment. But if you take radio-active strontium and give a single dose, then this is distributed in bone inhomogenously, and this merely represents the calcification and bone growth during any particular short period of time. Thus, if one received in an accident, shall we say strontium by inhalation, by mouth, and so on, the deposition of this strontium would be focal, depending on which areas of bone were actually active at the time. But as far as, shall we say, world-wide fall-out is concerned, provided the ${ }^{90} \mathrm{Sr}$ in the diet is reasonably uniform over periods of time, then one would expect that these inhomogeneities would even out; the ${ }^{90} \mathrm{Sr}$ would become like ${ }^{\mathrm{s}} \mathrm{Sr}$, the strontium would be deposited with calcium and one would grow up with pretty well uniform deposition of strontium. This postulates of course, that the skeleton is being uniformly turned over. Now this is not necessarily true. Some parts of the skeleton may be laid down at birth and be almost fixed for the rest of life. Other parts of the skeleton may well be completely absorbed, remodelled, and reformed. So that the whole problem does become rather complex, and as a first approximation for constant intake, you can say that the distribution vis-à-vis calcium is constant, but this may be in error by a factor of two or three or so.

Professor Titterton: May I ask a supplementary question? These last remarks you have made would lead one to believe that there would be differences between bones, and I should therefore like to ask what ratios you would expect in, for example, ${ }^{90} \mathrm{Sr}$ take-up between ribs, vertebrae, femur and so on?

Dr. Loutit: Measurements are being made of these bones at the moment, and certainly our experience is that with yearling sheep, which have been on constant diets over the last year, the activity is uniform in bones, ribs, vertebrae and femurs, but there are data from the U.S.A. of human subjects given ${ }^{90} \mathrm{Sr}$ where the variation between bones is a factor of two or so. These are subjects with malignant disease and I do not feel that they represent a fair comparison. They are not in normal calcium metabolism and I think that this may just be an expression of their abnormal state as of calcium-strontium metabolism.

Dr. Poynton: I should like to ask Dr. Loutit whether any work has been done using subjects with disorders of calcium metabolism, such as calcium losing nephritis or parathyroid tumours or work using parathormone. It seems to me that possibly one could compare the uptakes of strontium and calcium, using such subjects; one can more or less clear a subject of calcium and then replace it with strontium, I suppose.

I am out of touch with central physiology but I am surprised that the placenta can distinguish between strontium and calcium when it lets through enormous molecules and antibodies and so forth.

DR. LoutrT: If we can take the second question first-I do not have to tell you of course that placentation varies enormously between species, and I do not think there are any direct experiments on the human transmission, this was only an inference. However, there are data on the rat mother and foetus and their calcium-strontium relationships, and in this case the placental discrimination certainly does seem to obtain, as far as the experimental results can be considered reliable. Of course, if 


\section{STRONTIUM IN MAN AND BEAST}

the material has to go through a cell or a membrane there is the capacity to discriminate across that barrier, but if the material goes through holes then presumably there is less or no means of discrimination. It may therefore be that this will be a tool for discriminating between methods of passage across the placenta if the data are confirmed. As far as investigations into abnormal calcium states are concerned, I think this, at the moment, is probably purely the exercise of a few people in clinical research departments, who are interested in bone pathology and abnormal bone physiology. There is no set programme that I know of. It depends on the interest of the individual, and at present with the free availability of radio-active calcium, many of these states are being investigated with radio-active calcium. The high specific activity material which one would require for clinical investigation is still extremely expensive.

Parathormone of course, has been used for the decontamination of subjects contaminated both with strontium and earlier with radium, but it is not a particularly effective agent because it takes a very long time to act and to produce any substantial elimination of calcium and the contaminate. However, you saw from the calculated graph, and it can be shown directly with radio-active isotopes, that the uptake into bone from plasma and extracellular fluid is extraordinarily rapid. There is no method of blocking this very rapid uptake that we know of. This is to be desired from the point of view of treatment of accidental contamination, that is, some method which would block only the uptake as and when required. But again, presumably this is a physico-chemical problem, the earliest uptake of calcium and strontium ions by the bone being, probably, a physico-chemical process and one would have to defeat this process.

MR. JACKson: I should like to ask Dr. Loutit if milk teeth in children have been used as an index, not merely of strontium but of deficiencies in calcium phosphate metabolism. Could children with the various known deficiencies be taken and their milk teeth examined as a method of estimation?

DR. Loutit: Well, I am sure that those who are interested in calcium metabolism and dental problems in general can answer part of your question, but I am not well versed in dental physiology. As far as the problem of monitoring is concerned-is the milk tooth an indicator in vivo, of the degree of contamination of the subject? The answer is, in theory-yes; the calcium and strontium will be laid down in the milk tooth during a well-defined period of time. The amount of ${ }^{90} \mathrm{Sr}$ in the milk tooth is, therefore, an indicator of the contamination in the extra cellular fluid of the foetus, or the newborn during that time. However, the mass of a milk tooth is so small that the concentration of ${ }^{90} \mathrm{Sr}$ at the present levels could not be physically determined in a milk tooth. It would be practicable, of course, to collect the central upper right incisors of all children born in certain months and to bulk them. This would give only a broad figure, and as you saw there is considerable individual variation in a population such as the British population. So it is practicable but, for use on a mass basis, it would be very difficult administratively. 


\title{
STUDIES IN DETECTING RADIO-AGTIVE FALL-OUT
}

\author{
E. C. Winkler
}

\section{Physics Department, Peter MacCallum Clinic, Melbourne}

WORLD-WIDE MEASUREMENT of radio-active fall-out has been in progress for some time now, and a steady increase in the number of stations can be observed. The commonest method in use is the sticky-paper method and our interest, since the Melbourne area is included in the network operated by the Australian Atomic Weapons Test Safety Committee, has been in other methods of detecting fall-out.

Large quantities of radio-active fission-products are released on the explosion of a nuclear weapon. These products can return to earth in three ways. Firstly, they can become attached to particles of matter thrown up in the explosion and fall out in the immediate vicinity. Secondly, they can be thrown up into the stratosphere and fall out within a few hundred miles of the test site. Thirdly, mainly with a thermo-nuclear weapon, they can be forced into the stratosphere where they circle the earth and fall out only gradually over a period of years. Since Melbourne is 1000 miles from the nearest testing site, and several thousand from most, we are primarily interested in this third section of the fission-products.

It was our aim to study methods of detection of the presence of fissionproducts in the atmosphere in Melbourne. This involved the investigation of any samples of unusual activity, to ascertain that they were actually bomb debris and also, if possible, to trace their origin.

MATERIALS

The apparatus used is shown in Figure 1.

Collection was made in four ways.

\section{(1) For the collection of airborne material}

Two screens of cheesecloth, gauge $30 \times 50$ threads per in. size 6 in. $\times$ 12 in., were mounted on wire supports attached to a horizontal rod which was turned by the wind against a Perspex vane so that the cheesecloth was always facing into the wind.

The cheesecloth was directly protected from rain by a $4 \mathrm{ft}$. square roof having very slender supports to give minimum obstruction. For 64 collections one piece of cheesecloth was earthed and the other was insulated from the ground.

\section{(2) For the collection of 'fall-out' material}

The term 'fall-out' is generally used to include all the fission-products produced in explosions which reach the earth, but in this paper, for want of a better term, it is used in a restricted sense, to refer to radio-active 


\section{STLDIES IN DETECTING RADIO-ACTIVE FALL-OUT}

particles which have fallen out of the stratosphere and also out of the atmosphere, as distinct from the particles which have fallen out of the stratosphere but have been collected as airborne particles or as present in rainwater.

The $16 \mathrm{ft}^{2}$ roof protecting the checsecloth was covered with a sheet of polyvinyl chloride. This presented a fairly smooth surface to collect dust which was subsequently washed by rain from the roof into a beaker. The

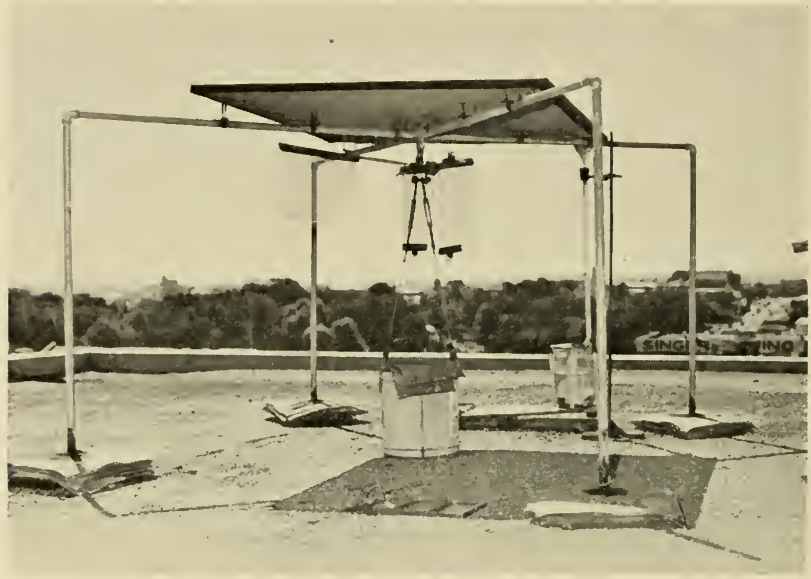

Figure 1. Photograph of apparatus

bottom of the beaker was covered with filter paper as it was found that without this, dust adhered to the bottom of the beaker and efficient collection was difficult.

\section{(3) For the collection of material brought down by rain}

The protective roof was sloped to one corner and had a retaining rim $1 \mathrm{in}$. high, around it, so that rain falling on to the roof was collected in a 5-l. beaker.

(4) For comparison of the gummed-paper method commonly used at monitoring stations

A strip of 6 in. wide commercial adhesive tape, exposed length 1 in., attached to a brass frame was placed beside the rest of the apparatus.

All of the apparatus was situated on the roof of the nurses' home of the Peter MacCallum Clinic-a site reasonably unobstructed by other buildings.

All counting was carried out with an EHM2S mica end-window GeigerMüller tube, with tube and sample shielded on all sides by $1 \frac{1}{2}$ in. of lead.

\section{PROCEDURE}

The cheesecloth was changed at weekly intervals. After cxposure, it was ashed over a Bunsen burner, the ash was weighed, transferred to an aluminium planchette and counted for $20 \mathrm{~min}$. This was the airborne material. 


\section{E. C. WINKLER}

The rainwater was collected at weekly intervals, the filter paper from the bottom of the beaker was removed and the water was filtered. The two pieces of filter paper were then ashed and the ash was weighed and counted for $20 \mathrm{~min}$. This was the 'fall-out' material.

One litre of the filtered rainwater was evaporated, the residue rubbed off the evaporating dish on to a piece of filter paper which was then ashed and counted for $50 \mathrm{~min}$. This was the 'rained out' material.

The gummed paper was changed daily except over weekends. A week's samples were then ashed together, weighed and counted for $20 \mathrm{~min}$. This was compared for only 5 weeks.

All samples were recounted 3 days after collection, as, according to Tajima and Doke ${ }^{1}$, the natural radio-activity due to radon and thorium would have become negligible by this time.

\section{RESULTS}

The results have been graphed as net counts per min for each week of collection, which gives a relative, if not an absolute, picture with the counting system used. The background count was approximately 8 counts per min.

In Figure 2 are plotted the activities of cheesecloth, 'fall-out' and rainwater samples.

Peaks of unusual activity were found as follows:

(i) For airborne particles, 10 counts per min was the activity of a normal week's collection.

On the 6th June, $1957 \quad 500$ counts $/ \mathrm{min}$ were recorded On the 24th October, $1957 \quad 300$ counts $/ \mathrm{min}$ were recorded And in July and August, $1958 \quad 100$ counts/min were recorded

(ii) For fall-out particles, 10 counts per min was again the activity of a normal week's collection of dust.

On the 24th October, 1957

On the 7 th November, 1957

1000 counts $/ \mathrm{min}$ were recorded

200 counts $/ \mathrm{min}$ were recorded And in August and September, 195840 counts $/ \mathrm{min}$ were recorded

(iii) For the rainwater the counting rates are harder to interpret and these are replotted on a larger scale in Figure 3. If we examine the activities plotted on a larger scale this will become more obvious. The counts per min per litre of rainwater have been graphed (continuous line). Since the collecting area is known and the total weekly rainfall can be obtained from the Bureau of Meteorology, the counting rate per total weekly rainfall can be calculated, assuming that the litre of water counted was of average activity for the week. These are plotted as the broken line.

As can be seen, certain peaks occur on one graph which have no corresponding peak on the other graph. When the rainfall is low, the counting rate per litre of water would tend to be high - a marked example of this being seen for 21 st January, 1958, when only $250 \mathrm{ml}$. of water were collected and the counting rate was extrapolated to give that for one litre. When the rainfall is high, the counting rate per weekly rainfall would tend to be high also.

For these reasons, it is probable that the significant peaks are those which 
STLDIFS IN DEILCTING RADIO-ACTIVE FALL-OUT

occur simultancously in both graphs (Figure 2). Actually, when viewed broadly, as on the graph with a smaller scale, these differences become far less important, and peaks can be seen with relative casc.

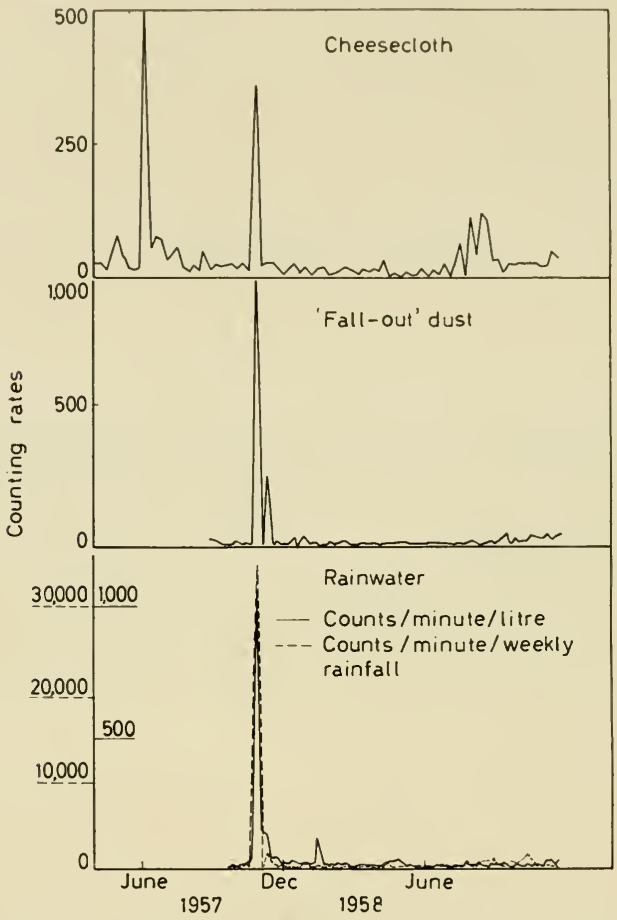

Figure 2. Activities of cheesecloth, 'fall-out' and rainwater samples in 1957 and 1958

The normal counting rate for 1 litre of water was 6 counts per min above background, and peaks regarded as significant occurred:

on the 24 th October, 1957-1000 counts/min were recorded, and in July and August, 1958-12 counts $/ \mathrm{min}$ were recorded.

In comparing the weekly activities collected with cheesecloth, dust collected from the roof, and rainwater, we find that there is a good agreement in the main peaks. Since the fall-out and water collections were not commenced until a couple of months after the cheesecloth collection, no comparison can be made for the 6 th June, 1957, but we see that on 24th October, 1957 a peak is recorded in each case and also a general increase in activity in July and August, 1958. 


\section{E. C. WINKLER}

Admittedly this is not a long period of time for comparison to be made, but there is no reason to believe that it is not a typical time interval.

The fall-out and airborne activities collected are to a certain extent complementary, but from this study it seems that, in general, if there is an

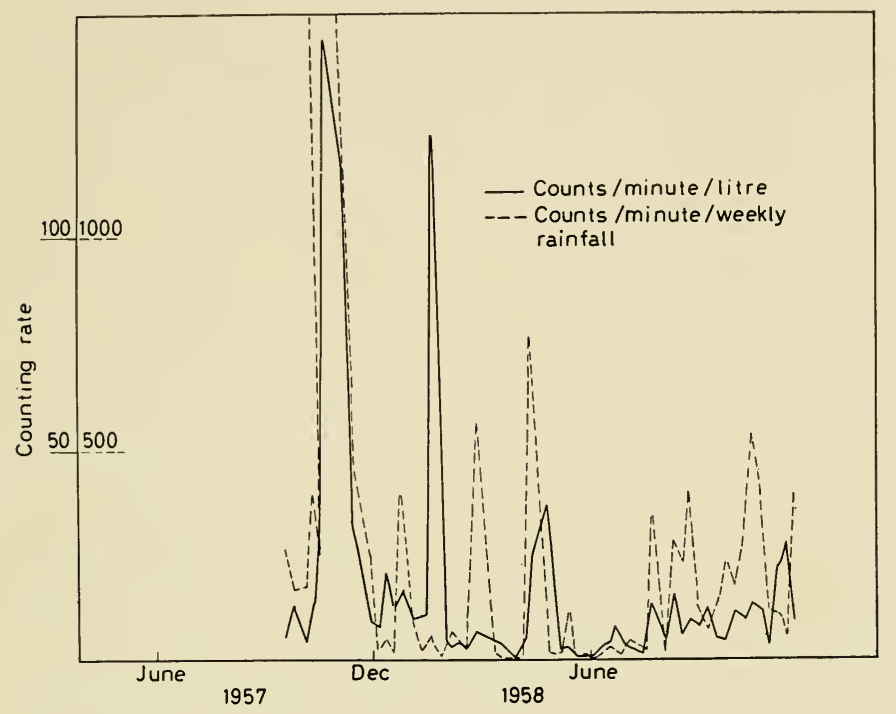

Figure 3. Activity of rainwater

increase in one there is a corresponding increase in the other. These increases may not be quantitatively the same but are of the same order of magnitude.

\section{Properties of Active Samples}

(i) Further investigations were carried out on most of the samples exhibiting unusually high activity.

Probably the best way of ascertaining that these activities are due to fission-products is to plot their decay curve. Several recounts were made on samples over a period of about twelve months after collection and the curves of their decay were compared with the curve of the $-1 \cdot 2$ power of time which is commonly held to be the rate of decay of fission-products.

A comparison of measured and theoretical decay is shown in Figure 4, plotted for two of our typical samples.

The close agreement shows that there is very good reason to believe the activities collected were due to fission-products. Since the slope of this curve is continually changing, the approximate time elapsed between the explosion and collection can be obtained from the comparison. 


\section{STUDIES IN DETECIING RADIO-ACTIVE FALL-OUT}

From Table 1 it can be seen that there is little doubt of the origin of the fall-out collected. It is interesting to note that the time elapsed between explosion and collection is approximately 10-20 days, even though some

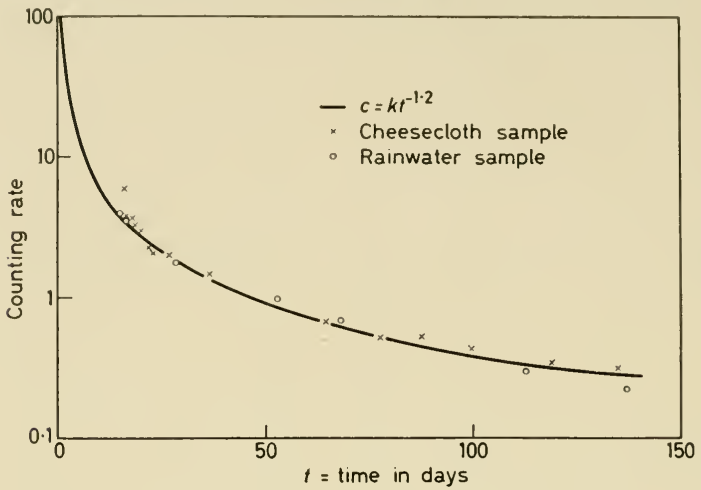

Figure 4. Comparison of measured and theoretical decay

explosions were actually in Australia and others were considerably further away. It must be remembered, however, that only weekly collections were made, so there is no way of telling whether, for instance, the activity had been collected 3 or 10 days after the explosion.

There are certain limitations in this estimation. The main one is that since such a large number of nuclear weapon tests have been carried out

Table 1. Estimated origins from graphs, compared with known dates of explosions

\begin{tabular}{|c|c|c|c|c|}
\hline Sample & $\begin{array}{l}\text { Date of } \\
\text { original } \\
\text { count }\end{array}$ & $\begin{array}{l}\text { Age from } \\
c=k t^{-1.2} \\
\text { graph }\end{array}$ & $\begin{array}{l}\text { Hence } \\
\text { date of } \\
\text { origin }\end{array}$ & $\begin{array}{l}\text { Kinown } \\
\text { dates of } \\
\text { explosions }\end{array}$ \\
\hline Earthed cheesecloth & 6.6 .57 & 8 days & 29.5 .57 & \multirow{2}{*}{$\begin{array}{cc}16.5 .57 & \text { (Christmas } \\
1.6 .57 & \text { lsland) } \\
5.6 .57 & \end{array}$} \\
\hline Insulated cheesecloth & 6.6 .57 & 15 days & 22.5 .57 & \\
\hline Earthed cheesecloth & 24.10 .57 & 9 days & 15.10 .57 & \multirow{3}{*}{9.10 .57 (Maralinga) } \\
\hline Rainwater & 24.10 .57 & 13 days & 11.10 .57 & \\
\hline 'Fall-out' dust & 24.10 .57 & 10 days & 14.10 .57 & \\
\hline Earthed cheesecloth & 15.7 .58 & 15 days & 1.7 .58 & \multirow{4}{*}{$\begin{array}{l}\text { A series of } \\
\sim 30 \text { explosions } \\
\text { at Marshall Island, } \\
\text { June-July, } \\
\text { 1958. }\end{array}$} \\
\hline Earthed cheesecloth & 5.8 .58 & 20 days & 16.7 .58 & \\
\hline Earthed cheesecloth & 12.8 .58 & 15 days & 28.7 .58 & \\
\hline Earthed cheesecloth & 19.8 .58 & 20 days & 30.7 .58 & \\
\hline
\end{tabular}




\section{E. C. WINKLER}

over the past few years, with a great increase over the past several months, the activity measured can never be attributed solely to one explosion.

(ii) The method of rapid dating of fission-products using the continuous change in $\beta$-ray energy distribution with ageing of the sample has been investigated. Assuming the dates deduced from comparison with the $t^{-1 \cdot 2}$ curve and subsequent correction from known dates of explosions are correct, the ratio of the intensity through $0.025 \mathrm{~mm}$ aluminium absorber to the intensity through $0 \cdot 125 \mathrm{~mm}$ aluminium has been plotted against age.

An endeavour was made to determine the age of the material using change in $\beta$-ray energy distribution.

A ${ }^{90} \mathrm{Sr}-{ }^{90} \mathrm{Y}$ source was measured for the same ratio to give an approximate

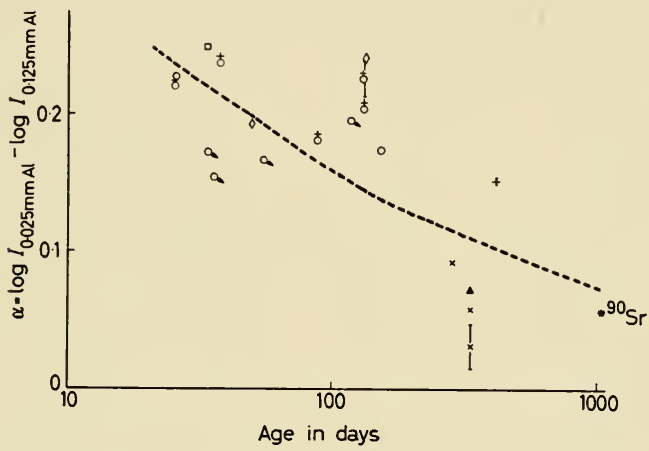

Figure 5. Determination of age using change in $\beta$-ray energy distribution

calibration figure, but as at no stage are these the only $\beta$-emitting isotopes present in the fission-products, the figure could only give the order of ratio to be expected (Figure 5).

The probable error due to randomness in counting is as shown for two points on the graph. This becomes important because the index of age is the ratio of two quantities of the same order. The only way for this error to be reduced for samples of this activity would be to greatly increase the counting time. The discrepancies between successive evaluations of the same sample can be explained by this probable error but the result is a very wide scatter of points. It could be postulated that there was a trend in ratio with age in the expected direction but, from this experience, it would seem that this method by itself would be of little use as a criterion of age but may possibly be of some use as a guide to confirmation.

(iii) To obtain some idea of the energy of the radiation, the absorption in aluminium was plotted for one sample. The thickness of aluminium needed to decrease the intensity from 100 per cent to 50 per cent was $0.1 \mathrm{~mm}$ and from 50 per cent to 25 per cent was $0.7 \mathrm{~mm}$.

From the graphs of relative activities of the nucleide products of simultaneous slow neutron fission of ${ }^{235} \mathrm{U}$ as given by Hunter and Ballou ${ }^{2}$, the isotopes present at the time after fission corresponding to the age of the 
sample (100 days in this case) can be found. By averaging the $\beta$-encrgies in the appropriate proportions it is found that the average $\beta$-ray energy is approximately $0.8 \mathrm{MeV}$. This has a range of approximately $1.3 \mathrm{~mm}$ aluminium, which is in good agreement with the order of half-value layer obtained.

\section{Comparisons of Coluction Methods}

\section{(1) Earthed and insulated screens}

In a single observation, some American workers ${ }^{3}$ noted that the dust collected on earthed and insulated screens was approximately equal in

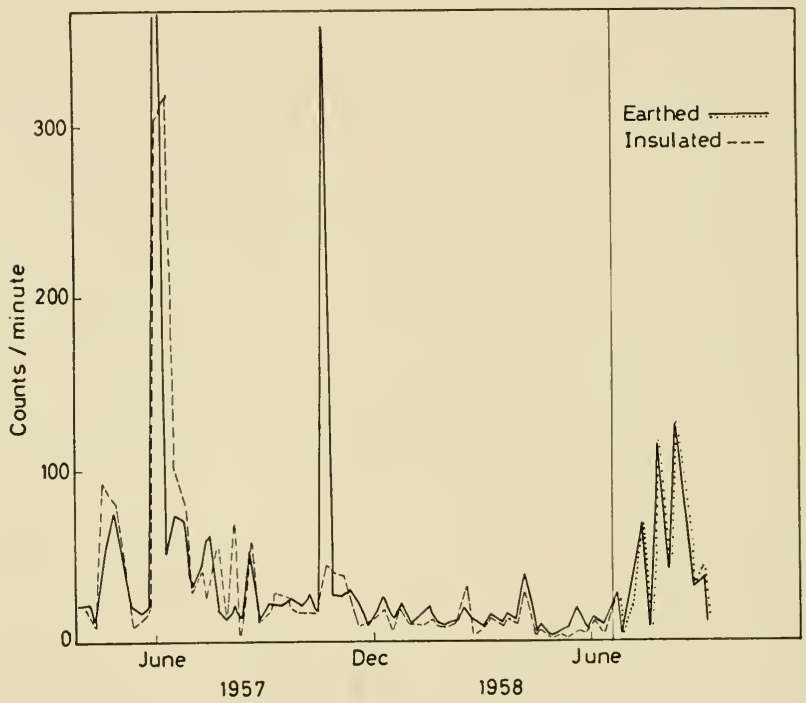

Figure 6. Comparison of earthed and insulated screens-sample activities

activity, but the mass of dust collected on the insulated screen was nearly double that on the earthed. This matter was further investigated here, as it would be interesting to know just how great a part electrostatic attraction plays in the settling out of airborne particles.

A series of measurements was carried out with one piece of cheesecloth on an earthed frame and the other piece on an insulated frame. The results were compared with those for a series when both frames were earthed (Figure 6).

From the graph, little significant difference can be seen between the continuous and broken lines except on one occasion (24.10.57) when the insulated cheesecloth fell off the frame before the week was up. However, when the results from two earthed screens are examined, it is seen that 


\section{E. C. WINKLER}

these graphs do follow each other more closely than previously. A very similar situation is seen in the graphs of the mass of dust collected (Figure 7).

A probable explanation of this is that the cheesecloth itself is insulating

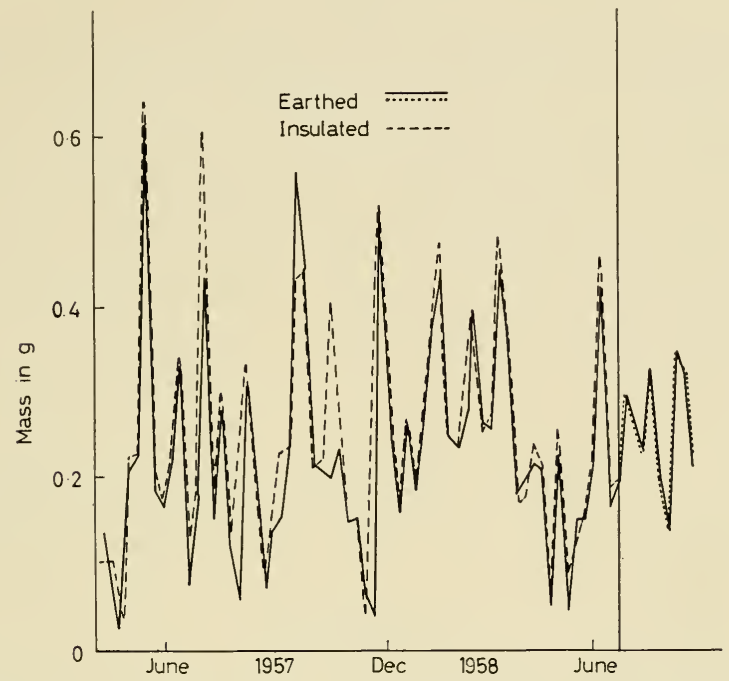

Figure 7. Comparison of earthed and insulated screens-sample masses

and only after a layer of conducting dust settled on it was there a noticeable difference in the screens. The screens used by the Americans were of stainless steel.

(2) Sticky-paper method of collection and deposition of dust on roof with subsequent collection

A series of five measurements was carried out using the sticky-paper method. The dust collected on the sticky paper should be comparable to the 'fall-out' dust collected, although it is claimed by some workers that the sticky paper also collects rainwater activity.

It was found that the activity of the 'fall-out' dust from the roof was approximately three times that of the week's sticky-paper samples but when the fact that the collecting areas were $16 \mathrm{ft} .{ }^{2}$ and $0.5 \mathrm{ft} .{ }^{2}$, respectively, was allowed for, the roof collection had 10 per cent of the efficiency of the sticky paper.

If we assume that the sticky paper also collects rainwater activity, we find that 'fall-out' dust plus rainwater efficiency varies from 14 per cent to 96 per cent of the gummed paper. Because of this large range of efficiency, obviously due to differences in weekly rainfall, it seems likely that the sticky paper has a near-zero efficiency for collection of rainwater activity. 


\section{STLIDES IN DETECTING RADIO-ACTIVI FALL-OUT}

From our figures, the sticky paper appears to be more efficient than the method of collection of dust deposited on the roof, but it is less sensitive because of the smaller exposed area.

\section{Efficiency}

The counting system has been calibrated by using a ${ }^{36} \mathrm{Cl}$ source supplied by the Commonwealth X-Ray and Radium Laboratory and calibrated by the Laboratory against a ${ }^{20} \mathrm{Tl}$ standard calibrated by the A.W.R.E.

The efficiency of collection using cheesecloth probably varics with the wind velocity. Blifford, Lockhart and Baus ${ }^{3}$, using stainless-steel screens, found that the activity collected did not vary regularly with the mesh of the screen. This could be due to the fact that increase in collecting area for smaller mesh size was compensated by the reduced air flow.

These workers determined the efficiency of 40 mesh stainless-steel screens, comparable with cheesecloth, by backing a screen with efficient filter paper and drawing air through this filter. Assuming the efficiency of the filter paper to be 100 per cent, the efficiency of the screen was found to be 11 per cent.

From this value, and an average wind velocity, the actual activity corresponding to the collections has been calculated: for example, for the week preceding the 24th October, 1957 there was a sharp rise in activity in all cases.

These correspond to:

an airborne activity of

a ground activity of

a rainwater activity of

$$
\begin{gathered}
1 \mu \mu \mathrm{C} / \mathrm{m}^{3} \\
16 \mathrm{mC} / \mathrm{km}^{2} \\
18 \mu \mu \mathrm{C} / \mathrm{ml}^{2}
\end{gathered}
$$

In general, the results obtained by us are in good agreement with the published results of the Safety Committee: hence a further assessment of hazards is unnecessary. As the Safety Committee have stated, the dose levels involved at the present time, are very small compared with naturally occurring radio-activity. This is partly due to the fact that there is very little mixing between the winds of the Northern and Southern Hemispheres, which, incidentally, makes it relatively easy in Australia to relate unusual activity to specific explosions, as most of the test sites are in the Northern Hemisphere. This made the Christmas Island tests particularly interesting as it has a latitude of $2^{\circ} \mathrm{N}$.

\section{Evaluation of Methods}

The standard methods of detection of fall-out used by the Safety Committee are gummed paper and, to a lesser extent, rainwater measurements, air-filter measurements, and measurements of the activity of sheep's thyroids.

This committee has found that gummed paper and air-filter activities do not show close correlation with each other. We have found that when an increase in activity has been obtained by one method each of the other methods has shown a corresponding increase.

The cheesecloth screen for the detection of airborne particles has the advantage that it is much less inclined to break down than an air pump, it requires no power, which is of some importance at outback stations, and it 


\section{E. C. WINKLER}

provides a means of continuous monitoring of the atmosphere. For this reason it would be particularly useful for inter-trial periods when it is not vitally important to know exactly on what day any increase in activity appears, but it is desirable to know whether any increase occurs. A weekly collection would certainly be preferable to a daily one in these cases. Cheesecloth has the additional advantage over gummed paper that it is much less likely to be affected by precipitation.

Although the counting system has a fairly low efficiency, the sensitivity is higher than that of some standard systems because of the low background counting rate and the longer period of collection. It has been the custom to carry out two assays of each sample but only the second of these is necessary.

In conclusion it is felt that the methods of detection reviewed here, and in particular that using the cheesecloth screen can be recommended as practical and meaningful techniques.

I would like to thank Dr. J. H. Martin of the Cancer Institute, for his guidance and encouragement throughout this work.

\section{REFERENCES}

${ }^{1}$ Tajima, E. and Doke, T. Science 123 (1956) 211

${ }^{2}$ Hunter, H. F. and Ballou, N. E. Nucleonics 9 (1951) C-3

${ }^{3}$ Blifford, I. H., Lockhart, L. B. and Baus, R. A. Science 123 (1956) 1120

\section{DISGUSSION}

Professor Titterton: I should like to ask whether your peak in June 1957 can be correlated with the Australian Atomic Weapons Test Safety Committee global fall-out results which appeared in Melbourne on 17 th June. Would your weekly change give us enough overlap for that?

Mrs. Winkler: No, it would not, because our high activity screen was collected on the 6 th, so the activity would be from the week preceding the 6 th.

Mr. JACKsON: How would you correct for the variation in wind velocity if you used a cheesecloth collector? The collection would depend on wind velocity enormously.

Mrs. WinkLer: Yes, that is very true, but from figures obtained from the Bureau of Meteorology, I found that the wind velocity over a period of a year-in units of monthly miles that the wind travels - varies from about 5500 to about 6300 . I was very surprised to find that it actually was as constant as that over the whole year. So it looks as though averaged over the week, variation in wind velocity would make little difference. 


\title{
FALL-OUT MEASUREMENTS IN AUSTRALIA
}

\author{
L. J. Diwyer,* J. H. Martin† and E. W. Titterton + \\ The Australian Atomic IVeapons Tests Safety Committee
}

It Has been the role of the Australian Atomic Weapons Tests Safety Committee to ensure that the testing of nuclear weapons in Australia does not lead to damage to life or property on this continent. To provide the Committee with the necessary data to carry out this task, a number of special projects have been instituted, of primary importance amongst which is the establishment of an extensive fall-out monitoring network and a scientific centre for the careful evaluation and prediction of meteorological conditions throughout Australia, and particularly at the test site, during a test series. This latter service has enabled the Committee to ascertain that conditions suitable for a safe firing have been chosen. It is not our intention in this paper, however, to discuss the meteorological aspects of weapon testing in Australia; the phenomonology of explosions and the meteorological problems peculiar to the testing range at Maralinga, in South Australia, have already been discussed ${ }^{1,2}$. We are here concerned with the measurements of fall-out from our own tests and from those conducted overseas.

The fall-out monitoring network has operated continuously since May 1956. Following a local test the information afforded by the network allows us to confirm that the radio-active material reaching the ground conforms to the predicted pattern, while in the periods between testing operations data are furnished on the fall-out from tests conducted elsewhere.

Other programmes, instituted to support these measurements of total fission-products, examine a number of materials for particular radio-isotopes occurring in fall-out and also arising from the fission of heavy nuclei. Due to a combination of properties such as biological and chemical behaviour, radio-active half-life and fission yield, these radio-isotopes could be considered to constitute a hazard under extreme circumstances. With a view to assessing these hazards as they are related to fall-out over Australia, the thyroids of sheep grazing close to test sites have been examined for radioiodine shortly after each test in Australia, and a wide-scale programme entailing the collection of a number of biological and geophysical materials and their analysis for ${ }^{90} \mathrm{Sr}$ is now in progress.

With the exception of the period of the most recent test series, Operation 'Antler', September to October, 1957, the results of fall-out measurements conducted by the network, from its inception prior to the Monte Bello Islands tests, May to June 1956, up to December 31, 1957, have been reported ${ }^{1,2,3,4}$. The details of the gummed film, air sampling, and

* Commonwealth Bureau of Meteorology, Melbourne.

† Department of Physics, Cancer Institute Board of Victoria, Cancer Institute, Melbourne.

† Department of Nuclear Physics, Australian National University, Canberra. 


\section{J. DWYER, J. H. MARTIN AND E. W. TITTERTON}

open-pot fall-out sampling methods have also been described previously, and some of the radio-iodine data have been discussed. It remains to consider the measurements from Operation 'Antler', and to outline the ${ }^{90} \mathrm{Sr}$ programme, the first stage of which is now nearing completion.

\section{OPERATION 'ANTLER'}

This test series, the second to be conducted at the Maralinga site, was held during September and October 1957. Three nuclear weapons were detonated, the first two from towers and the third suspended above the ground from balloons.

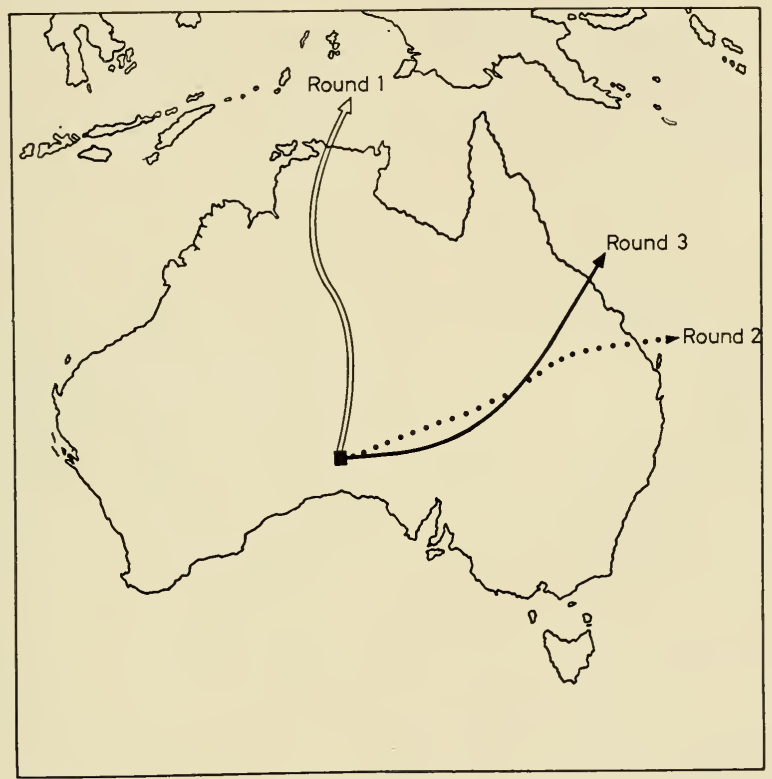

Figure 1. The cloud trajectories for the three nuclear weapons exploded at the Maralinga site (Operation 'Antler')

This balloon technique was used for the first time in Australia. The arrangement was designed to hold the weapon, complete with its instrumentation and cabling, much higher above the ground than conventional towers. It has been known for some time that fall-out levels would be greatly reduced with explosions under these circumstances but much difficulty has been experienced in the past in positioning the device with sufficient precision. Many of these difficulties have now been overcome and the whole exercise was carried out most successfully. It is noteworthy that the United States Atomic Energy Commission in its most recent test series at the Nevada site made extensive use of this technique. 


\section{FALL-OUT MEASUREMENTS IN AUSTRALIA}

The first weapon, Round 1, was mounted on a tower and fired on September 14, 1957. Marked directional variation with altitude of the upper level winds resulted in the radio-active material being dispersed very widely over the continent north of the test area. Rainfall during the period was restricted to the south-eastern coastal areas. It did not coincide with the fall-out material.

Round 2, also mounted on a tower, was fired on December 25, 1957. Both velocity and angular wind sheer caused the main cloud to be distributed widely to the north-east and the east of Maralinga.

The third and last weapon of the series was suspended above the desert

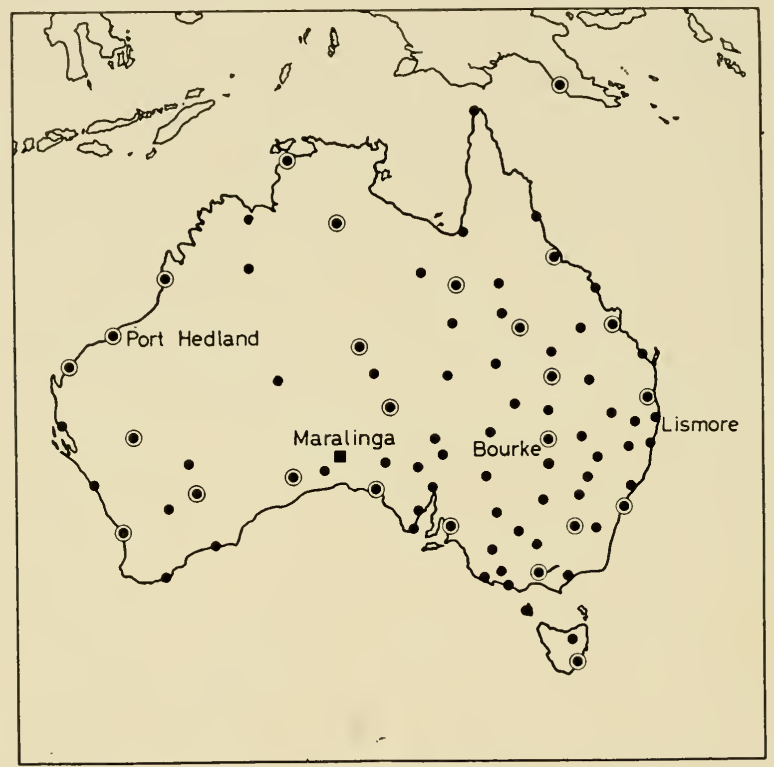

Figure 2. Fall-out sampling stations during a test series at Maralinga-stations marked with an additional circle are continuing in operation

by means of balloons. It was fired on October 9, 1957. As had been predicted, rain was restricted to southern New South Wales and Victoria, and the main cloud of radio-active material moved eastward and then northeastward in its passage to the Queensland coast. Again, the material was distributed very widely. The cloud trajectories for the three rounds are indicated in Figure 1.

Between September 10 and October 24, 85 stations continuously monitored fall-out, using gummed films. Each film was exposed for 24 hours before being forwarded to a central laboratory for analysis. Some of these stations also sampled air and rainwater. The distribution of the sampling stations is given in Figure 2. It will be noted that the network was chosen to have 


\section{J. DIVYER, J. H. MARTIN AND E. W. TITTERTON}

the highest density of stations in the more populous areas downwind from the test site.

The measured activity of each gummed-film sample collected during the series was converted to the activity at mid-collection time, using the $t^{-1.2}$ law known to apply to fission-products of this age. Whole-body $\gamma$-ray doses integrated to 50 years were calculated following Hallden and Harley ${ }^{6}$. Table 1 gives the accumulated whole-body $\gamma$-ray dose in milliroentgen for

Table 1. Whole-body $\gamma$-ray dose calculated to 50 years for stations in Australiano correction has been made for shielding

\begin{tabular}{|c|c|c|c|c|c|}
\hline Location & $\begin{array}{c}\text { Total } \\
\text { in milli- } \\
\text { roentgen }\end{array}$ & Location & $\begin{array}{l}\text { Total } \\
\text { in milli- } \\
\text { roentgen }\end{array}$ & Location & $\begin{array}{l}\text { Total } \\
\text { in milli- } \\
\text { oentgen }\end{array}$ \\
\hline Adelaide & $1 \cdot 0$ & Goondiwindi & $0 \cdot 4$ & Warrnambool & $0 \cdot 3$ \\
\hline Woomera & $0 \cdot 8$ & Longreach & 0.9 & Currie & $0 \cdot 1$ \\
\hline Hall's Creek & $0 \cdot 9$ & Mackay & $3 \cdot 7$ & Hobart & $0 \cdot 2$ \\
\hline Port Moresby & $0 \cdot 6$ & Normanton & 0.5 & Western Junction & $0 \cdot \overline{3}$ \\
\hline Broome & $0 \cdot 6$ & Richmond & $0 \cdot 1$ & Ceduna & $0 \cdot 4$ \\
\hline Kalgoorlie & - & Rockhampton & 0.9 & Leigh Creek & $0 \cdot 7$ \\
\hline Daly Waters & $0 \cdot 2$ & Roma & $0 \cdot 3$ & Maree & $1 \cdot 2$ \\
\hline Oodnadatta & $1 \cdot \overline{6}$ & Thargomindah & $3 \cdot 0$ & Mt. Gambier & $0 \cdot 2$ \\
\hline Onslow & $0 \cdot 5$ & Armidale & $1 \cdot 6$ & Port Augusta & $1 \cdot 6$ \\
\hline Thursday Island & 0.5 & Bourke & $4 \cdot 0$ & Port Lincoln & - \\
\hline Wyndham & 0.6 & Canberra & 0.4 & Tarcoola & - \\
\hline Melbourne & $1 \cdot 8$ & Cobar & 0.6 & Watson & - \\
\hline Port Hedland & $0 \cdot 3$ & Coff's Harbour & $0 \cdot 5$ & Albany & 一 \\
\hline Meekathara & $0 \cdot 1$ & Broken Hill & $2 \cdot 0$ & Esperance & - \\
\hline Geraldton & - & Coonabarabran & $1 \cdot 0$ & Forrest & $0 \cdot 1$ \\
\hline Alice Springs & $2 \cdot 0$ & Dubbo & $0 \cdot 3$ & Leonora & $0 \cdot 1$ \\
\hline Townsville & $2 \cdot 9$ & Hillston & 0.9 & Southern Cross & $0 \cdot 1$ \\
\hline Sydney & $0 \cdot 2$ & Lismore & $0 \cdot 2$ & Giles & $0 \cdot 7$ \\
\hline Charleville & 0.7 & Tenterfield & $0 \cdot 2$ & Boulia & 0.4 \\
\hline Cloncurry & $1 \cdot 0$ & Walgett & $0 \cdot 6$ & Windorah & $0 \cdot 4$ \\
\hline Cairns & $1 \cdot 7$ & Williamstown & $0 \cdot 2$ & Tambo & 0.5 \\
\hline Brisbane & $0 \cdot 4$ & Wagga & $0 . \overline{9}$ & Winton & 0.5 \\
\hline Perth & - & Sale & $1 \cdot 7$ & Forbes & $0 \cdot 1$ \\
\hline Carnarvon & $0 \cdot 1$ & Echuca & $1 \cdot 5$ & Cook & - \\
\hline Darwin & $1 \cdot 9$ & Hamilton & $0 \cdot 3$ & Cleve & 0.6 \\
\hline Bundaberg & $0 \cdot 5$ & Mildura & $1 \cdot 0$ & Tibooburra & $0 \cdot 4$ \\
\hline Camooweal & $1 \cdot 3$ & Nhill & 0.8 & Finke & $1 \cdot 6$ \\
\hline Cunnamulla & 0.8 & Swan Hill & $1 \cdot 1$ & Birdsville & 0.5 \\
\hline Emerald & $1 \cdot 0$ & & & & \\
\hline
\end{tabular}

the series. No correction has been made for the shielding afforded by the normal living habits of man, which can introduce a reduction by an order of magnitude as a correction factor.

The highest level for the series, $4 \mathrm{mr}$, was recorded at Bourke and, even with no allowance for shielding, this corresponds to less than 0.1 per cent of the natural background over the same period. This is by far the lowest of the maximum dose levels recorded for each of the three test series:-58 $\mathrm{mr}$ at Port Hedland from Operation 'Mosaic' (Monte Bello Islands, May to June 1956), $24 \mathrm{mr}$ at Lismore, Operation 'Buffalo' (Maralinga, September to October, 1956) and $4 \mathrm{mr}$ at Bourke, Operation 'Antler'.

As had been expected from past experience, the air sampling measurements 


\section{FALL-OUT MEASUREMIENTS IN AUSTRALIA}

could not be satisfactorily correlated with the gummed-film results. The maximum level of fission-product contamination detected by the air samplers was 0.01 per cent of that allowable under the recommendations of the International Commission on Radiological Protection.

Of the rainwater samples collected by the 12 stations using this monitoring technique, none exhibited an activity greater than $1 \mu \mu \mathrm{C} / \mathrm{m}^{3}$, corresponding to the background in the detector.

Of the other measurements of gross fission-product activity carried out during the series, the most interesting results were obtained from a comparison of gummed films exposed side by side $^{5}$. It is obvious that the sampling processes are strongly dependent on the particulate nature of the fall-out material; large activities, especially close to the trial site and shortly after firing, occasionally resulted from a single large particle and so did not truly represent the radiation levels in the locality.

\section{RADIO-IODINE MEASUREMENTS}

It is well known that animal thyroid tissue has an affinity for iodine, so that radioiodine, ingested by a grazing animal from fodder contaminated with fission-products, is quickly concentrated in the thyroid gland. It may be estimated in vivo or, more precisely, after thyroidectomy.

During 1956, an Australia-wide survey was made of radioiodine in the thyroid glands of grazing sheep and cattle. It was apparent that measurements close to the weapon test site would adequately monitor the maximum levels of radioiodine contamination likely to result in unrestricted areas from the testing of a low yield nuclear weapon. During Operation 'Antler' thyroids were collected from only those sheep grazing within 150 miles to 200 miles of Maralinga, in areas close to the trajectories of the radio-active clouds.

For about 10 days after each explosion and at intervals of about 3 days, three sheep were sacrificed in each of the chosen localities and the thyroid glands were forwarded to Maralinga for analysis. Eight out of the 68 glands examined contained activities less than the minimum detectable in the equipment. The remaining tissue contained low activities of ${ }^{131} \mathrm{I}$ but in a few cases ${ }^{133} \mathrm{I}$ and isomeric ${ }^{131} \mathrm{Xe}$ were also identified and estimated from their $\gamma$-ray spectra.

The highest individual level of ${ }^{131} \mathrm{I}$ detected was $42 \mathrm{~m} \mu \mathrm{C} / \mathrm{g}$ of thyroid, with a mean value of $24 \mathrm{~m} \mu \mathrm{C} / \mathrm{g}$ of thyroid for the group of three glands. This should be compared with calculated and measured radioiodine burdens, which can give rise to biological damage.

Maximum permissible levels of ${ }^{131} \mathrm{I}$ for short-term exposure of animals have been given by Scott Russell, Martin and Wortley ${ }^{7}$ of the British Agricultural Research Council. They calculate that no detectable biological damage would be caused to sheep from the daily ingestion of 26,000 $\mathrm{m} \mu \mathrm{C}$ of ${ }^{131} \mathrm{I}$ from pasture contaminated with fission-products. They assume that grazing on this pasture is limited to the period from the first to the fourteenth day after fission and the activity is referred to the first day. This ingestion would give a mean thyroid burden of about $3000 \mathrm{~m} \mu \mathrm{C}^{131} \mathrm{I} / \mathrm{g}$ thyroid for the period, and a total dose to the thyroid of $1000 \mathrm{rad}$. This group has also shown that the contribution to the dose to the thyroid gland 


\section{J. DWYER, J. H. MARTIN AND E. W. TITTERTON}

from ${ }^{133} \mathrm{I}$, ceases to be an appreciable fraction of that from ${ }^{131} \mathrm{I}$ in mixed fission-products after seven days. The contribution from isomeric ${ }^{131} \mathrm{Xe}$, although increasing for a short time, is not appreciable at any stage.

Experiments conducted by Bustad et al. ${ }^{8}$ entailed the continuous feeding of radioiodine to sheep over entire lifetimes. They observed no biological damage to sheep fed $150 \mathrm{~m} \mu \mathrm{C}$ daily for life, and only slight damage to those fed $5000 \mathrm{~m} \mu \mathrm{C}$ daily. On these results it would seem reasonable to assume that the maximum daily ingestion for no damage would be about $1000 \mathrm{~m} \mu \mathrm{C}$, which would lead to a mean lifetime concentration of radioiodine of some $600 \mathrm{~m} \mu \mathrm{C} / \mathrm{g}$ of thyroid.

The maximum integrated dose to sheep thyroid glands from the transient contamination resulting from Operation 'Antler' is very small compared with the dose required to produce biological damage.

\section{RADIO-STRONTIUM IN AUSTRALIA}

In May 1957 the Australian Atomic Weapons Tests Safety Committee, in co-operation with the United Kingdom Atomic Weapons Research Establishment, planned a continuing survey of Australian biological and geophysical materials for ${ }^{90} \mathrm{Sr}$. Since facilities are only now being developed in Australia to carry out these difficult measurements, the Committee at the outset of its survey accepted the offer of the Atomic Energy Research Establishment to perform the analyses in the United Kingdom.

The programme was designed to monitor various phases of the uptake of the radio-isotope - the surface contamination, the levels in a number of food materials and in human bone. Samples of soil, powdered milk, cabbage, and human bones have been collected from the locality of the five population centres, namely Perth, Adelaide, Melbourne, Sydney and Brisbarie. Some difficulty was anticipated in arranging for an adequate supply of human bone tissue, particularly from infants, so long bones from sheep grazing close to the five population centres, as well as from 11 other sites in central and eastern Australia, were included in the first stage of the programme. The levels of ${ }^{90} \mathrm{Sr}$ in animal bones are known to depend markedly on the chemistry of the pasture soil, and with the established wide variations of this property the results cannot be easily interpreted to throw light on human experience without much additional data. Since a supply of human bone tissue is now assured, the collection of sheep bones has been discontinued.

Soil, cabbages and powdered milk were sampled in September 1957 and 1958. Powdered milk was also obtained in March 1958 to give some idea of seasonal variation. Human bone tissue has been collected throughout 1958; 142 samples, of age from stillborn to 80 years, are now being analysed. Sheep bones were provided from the 16 sites in September 1957 and 1958.

The results so far to hand are too few to allow of an unequivocal evaluation of the situation. The available soil data, however, confirm the expectation that levels in the Southern Hemisphere are lower by a factor of three or four than those in the Northern Hemisphere. Table 2 shows Australian accumulated surface deposition for mid-1957 reported by the United Nations Scientific Committee ${ }^{9}$, as well as some United States Atomic Energy Commission data for early 1958 and our own results for September 1957. The agreement between the sets of data is within the estimated errors. These 
results should be compared with mean values of about $8 \mathrm{mC} / \mathrm{km}^{2}$ for the United Kingdom and U.S.A., from data reported by the United Nations Scientific Committec.

Table 2. ${ }^{90} \mathrm{Sr}, \mathrm{mC} / \mathrm{km}^{2}$ for Australia

\begin{tabular}{|c|c|c|c|}
\hline \multirow[b]{2}{*}{ Location } & \multicolumn{2}{|c|}{ Soil measurements } & \multirow{2}{*}{$\begin{array}{l}\text { Analysis of collected } \\
\text { fall-out to mid-1957 } \\
\text { (U.N. Scientific } \\
\text { Committee) }\end{array}$} \\
\hline & $\begin{array}{l}4 \text { in. deep } \\
\text { Aug.-Sept. 1957 } \\
\text { (Dwyer } \text { et al.) }\end{array}$ & $\begin{array}{l}6 \text { in. deep } \\
\text { Early } 1958 \text { (U.S.A.E.C.) }\end{array}$ & \\
\hline $\begin{array}{l}\text { Perth } \\
\text { Adelaide } \\
\text { Alice Springs } \\
\text { Katherine } \\
\text { Melbourne } \\
\text { Hobart } \\
\text { Sydney } \\
\text { Southport } \\
\text { Brisbane }\end{array}$ & $\begin{array}{l}2 \cdot 7 \\
1 \cdot 6 \\
- \\
\overline{3 \cdot 4} \\
\overline{2 \cdot 5} \\
2 \cdot 6 \\
2 \cdot 1\end{array}$ & $\begin{array}{c}2 \cdot 7,1 \cdot 8 \\
1 \cdot 0,1 \cdot 3 \\
1 \cdot 7,1 \cdot 9 \\
= \\
= \\
4 \cdot 6,4 \cdot 4\end{array}$ & $\begin{array}{l}2 \\
3 \\
= \\
2 \\
2 \\
2 \cdot 3 \\
2\end{array}$ \\
\hline
\end{tabular}

Another conclusion which may be drawn from the existing information and also one to be expected, is that only a small percentage of the surface accumulation of ${ }^{90} \mathrm{Sr}$ in Australia has arisen from local tests. The information in Table 2 indicates that the levels are sensibly uniform across southern Australia, and, since Perth does not receive fall-out from Maralinga, the contribution from local testing should be manifest as a difference between the levels in eastern and western Australia. In addition the levels of ${ }^{90} \mathrm{Sr}$ reported by the U.N. Scientific Committee for these latitudes in South Africa and South America are about the same as those for Australia.

Collection of material in this sampling programme is continuing and the results for the first stage will be reported in full as soon as the analyses are completed.

\section{REFERENCES}

${ }^{1}$ Butement, W. A. S., Dwyer, L. J., Eddy, C. E., Martin, L. H. and Titterton, E. W. Aust. J. Sci. 20 (1957) 125

${ }^{2}$ Butement, W. A S., Dwyer, L. J., Martin, L. H., Stevens, D. J. and Tittęrton, E. W. Aust. J. Sci. 21 (1958) 63

${ }^{3}$ Dwyer, L. J., Keam, D. W., Stevens, D. J. and Titterton, E. W. Aust. J. Sci. 20 (1957) 39

${ }^{4}$ Keam, D. W., Dwyer, L. J., Martin, J. H., Stevens, D. J. and Titterton, E. W. Aust. J. Sci. 21 (1958) 8

${ }^{5}$ Keam, D. W., Dwyer, L. J., Stevens, D. J. and Trtterton, E. W. Aust. J. Sci. 21 (1958) 99

${ }^{6}$ Hallden, N. A. and Harley, J. H. Laboratory Report 56-2 Health and Safety Laboratory, United States Atomic Energy Commission, 1956

${ }^{7}$ Russell, R. Scott, Martin, R. P. and Wortley, G. A.E.R.E. ARC/RBC 5 (1956)

${ }^{8}$ Bustad, L. K., George, L. A., Jr., Marks, S., Warner, D. E., Barnes, C. M., Herde, K. E. and Kornberg, H. A. Radiation Res. 6 (1957) 380

${ }^{9}$ United Nations Scientific Committec on the Effects of Atomic Radiation, Report to the General Assembly, 1958 


\section{DISCUSSION}

DR. GEORGE: There is one problem that I have had for some time and I should like to ask Professor Titterton if he could clear it up now-in reading references he has mentioned, and I noticed again this morning in his slides, he did give the radiation hazard to the population in terms of the dosage, in milliroentgens, which are quite small, due to the $\gamma$-rays-I was under the impression that a good proportion of the radiation burden to the population from fall-out arose from the $\beta$ activity. Firstly, is this so; secondly, if it is so, how did it compare with the $\gamma$-ray dose that he has mentioned?

Professor Titterton: I am unable to give you the precise numbers. The $\beta$ dose is actually very small, for the simple reason that the range of $\beta$-particles in anything is small, therefore it cannot constitute a whole-body dose; it cannot reach the gonads in either the male or the female.

Dr. GEORGE: What about ingestion?

Professor Titterton: Well, yes, but where does it go? We saw this morning (Paper 14), a very large fraction is excreted, and again the range of the particle concerned is very small. The only case to worry about is one where the activity is laid down in a very confined region and can selectively irradiate a very small volume of tissue, and that is the case with ${ }^{90} \mathrm{Sr}$. The other point is that even if there was a significant contribution to dose here, since we are in the region of a few mREM per 50 years, doubling this or trebling, or multiplying by 10 , would not result in anything to worry about.

Mr. Rocke: You stated that there is a suggestion that there is a threshold to the effects of ${ }^{90} \mathrm{Sr}$. Is that only for leukaemia or is it for all the radiobiological effects of ${ }^{9} \mathrm{Sr}$ ?

Professor TitTerton: I would rather this question be addressed to the biologists, but the situation is that there has always been an argument as to whether the doseeffect relationship is linear or shows a threshold, and the prudent thing to do, which is what we have always done, has been to assume that it is linear. There is now a very strong body of opinion in scientific circles swinging to the point of view that there is a threshold. From the discussions I had in the U.S.A. and in the U.K. recently, this applies to leukaemia and bone cancer-but if any biologist here could throw further light on it I would be very glad.

DR. LoutrT: I think the situation has been identified over the last few days. I did quote some of Dr. Mole's work on experimental leukaemia in the mouse, which stated that if one took the observable leukaemia after irradiation the points fell on a graph, which one can extrapolate to zero, and say that there is a threshold dose, given by the intercept, below which no effects can be observed. One cannot measure biologically with any precision in the low dose region, and this is definitely an extrapolation. A mathematical relationship indicating that there was a sigmoid curve would be equally possible. In this case, as an approximation one can draw a straight line through the lowest experimental point and the origin, and this is the part we are considering when the considerations are for populations rather than experimental groups. It may be that there is a very small contribution of effect, call it leukaemia or carcinoma of bones-which will be there, but which one cannot, in the present state of experimental work, measure.

Dr. Springell: There has been some concern about the ${ }^{14} \mathrm{C}$ fall-out in nuclear weapon tests; I wondered whether Professor Titterton would like to comment on this. 


\section{FALL-OUT MEASLREMILNTS IN AUSTRALIA}

Professor Titterton: This problem was looked into in detail many years ago. It is of course proportional to the neutron production and therefore is insignificant in terms of the weapon tests which are carried out in Australia; if there is a hazard, it will certainly arise from hydrogen bombs of one kind and another. Two very detailed analyses have been carried out, one in Britain and one in the U.S.A. and the conclusion is that there is not a problem here. That I think is a very reasonable conclusion in the light of the very low energy $\beta$-particle which results from the ${ }^{14} \mathrm{C}$ brcak up.

DR. Loutrit There is one other point I should like to clear up. You mentioned the presence of the ${ }^{137} \mathrm{Cs}$, but rejected it as a hazard because it was not selectively taken up into any specific tissue, such as thyroid and bone. However, it is absorbed extremely well through the gut and the respiratory mucous membrane, if that means anything, and it is retaincd in the human body for a half-period of 120 days. Therefore it is not entirely to be neglected, and if there is an internal hazard from weapons on the genctic basis, rather than the somatic basis, it is ${ }^{137} \mathrm{Cs}$ that is going to count.

Professor Titterton: Quite so, I completely agree with that, but this of course is measured in our whole-body dose measurements and then you get an upper limit for that. I should emphasize that all these figures which I am giving to you are all upper limits; they are the worst thing that could possibly happen. 


\title{
ACTIVITY LEVELS IN RELATION TO LABORATORY DESIGN AND PRAGTICE
}

\author{
A. R. W. Wilson \\ Australian Atomic Energy Commission Research Establishment, \\ Lucas Heights, N.S.W.
}

\section{INTRODUCTION}

IN PLANNING an experiment involving radio-active material, proper consideration must be given to the measures, appropriate to the amount and radio-toxicity of the nucleide involved, which should be adopted as protection against the hazards of ingestion and inhalation. Particular consideration must be paid to the type and finish of the laboratory building and the requisite degree of containment of the experiment, i.e., can it be carried out in the open laboratory, or should it be contained inside a fume hood or glove box? It must further be decided whether special measures are required to control the spread of radio-active contamination.

The question of laboratory design and standard has been considered in detail by various authors ${ }^{1-6}$. Dunster ${ }^{7}$, in particular, has classified laboratories into three general standards of finish, and has tabulated the amounts of activity which may reasonably be handled in each. Considerably less guidance is, however, available on the requisite degree of containment and the necessity for contamination control measures. It is, of course, not possible to lay down any rigid rules concerning these, since a number of parameters which determine the degree of hazard, cannot be evaluated except as a result of experience, and then only as lying within a relatively broad range. Typical of such parameters is, for instance, the mass fraction of a powder sample which might become airborne in the course of a weighing operation. This will depend, inter alia, on the density and particle size distribution of the powder, the draught across the sample, and most importantly, on the skill and care of the worker.

Despite these difficulties, and allowing for the probability that early estimates may prove to be a long way wide of the mark, it does appear useful, in setting up a laboratory for work with radio-active material, to attempt to form some guiding rules which can be amended in the light of subsequent experience. Whilst it is clearly important that any such rules should not under-estimate the control precautions required, it is also most desirable that over-elaborate precautions should not be adopted, since this would not only lead to a wasteful use of expensive facilities but, moreover, appreciably restrict the methods which can be used to carry out the experiment.

\section{HAZARD CLASSIFICATION OF AREAS}

The activity levels discussed in this paper have been calculated for initial application at the Lucas Heights Establishment of the Australian Atomic 


\section{ACTIVITY LEVELS IN LABORATORY DESIGN ANI) PRACTICE}

Energy Commission. It is therefore perhaps relevant to first describe the situation existing at that Establishment. All of the laboratories in the radiochemical building fall within the classification (I) of Dunster, being provided with readily decontaminable surfaces, adequate fume hoods and forced ventilation giving approximately 20 room changes an hour. Following British practice, areas within the radio-chemical building are classified as red, blue or white. A red contamination area is one in which the normal procedures in the area may sometimes give rise to hazardous levels of contamination of surfaces and of breathing air. A blue contamination area is one in which contamination is unlikely to reach hazardous levels, and a white area one in which the amounts of activity in use are not such as to necessitate any special restrictions. The blue and red contamination areas are located in the active section of the building and access to them is by way of a change room. Measures against the spread of contamination in these latter areas include regular monitoring of all laboratory surfaces, systematic cleaning procedures, clothing and shoe changes for persons entering and leaving the area, showering, prohibition of smoking and eating, and the monitoring of hands for contamination. In general, stricter measures apply in red areas than in blue. A decision on the necessity for contamination control measures then, amounts to deciding the maximum amounts of radio-activity which should be used in a white area. No consideration has been given here to the $\gamma$ radiation hazard associated with the radio-active material to be used in the laboratory, it being assumed that adequate shielding will be provided to reduce the $\gamma$ radiation dose rate to acceptable levels.

\section{ROUTES OF INGESTION AND INHALATION}

Three possible sets of circumstances leading to the ultimate ingestion or inhalation of radio-active material have been considered in these calculations, viz.:-

\section{(a) The day-to-day transfer of small amounts of radio-active material into the body}

Under this heading, has been considered the direct transfer of radio-active material into the body, either by ingestion or inhalation, resulting at the time of handling material, as distinct from transfer by contamination buildup. The daily ingestion and inhalation by this route must be limited to the maximum permissible daily intakes of the particular nucleide (m.p.d.i.) derived directly from the maximum permissible drinking water and air concentration figures which were suggested by the International Commission on Radiological Protection (I.C.R.P.).

\section{(b) A single accidental inhalation or ingestion of an appreciable fraction of the material being handled}

For the purposes of these calculations, the maximum amount of radioactive material, which it is considered may be tolerated as a single ingestion occurring only once in a lifetime, has been put equal to the amount which would produce an integrated dose to the critical organ of not more than $25 \mathrm{REMI}$ over a lifetime, except in the case of ${ }^{239} \mathrm{Pu}$ and ${ }^{232} \mathrm{Th}$. In these latter cases the long effective half-lives result in the dose being delivered at a 
relatively uniform rate throughout the lifetime of the individual. Accordingly, the quantities of these materials have been calculated to give a dose rate to the critical organ of not more than 0.3 REM per week, although over a lifetime this could amount to a total of some 750 REM.

(c) The build-up of radio-active material on laboratory surfaces to a level which is likely to lead to appreciable transfer into the bodies of persons working in the laboratory

Dunster $^{8}$ has derived permissible contamination levels for laboratory surfaces based on ${ }^{90} \mathrm{Sr}$ in the case of $\beta$ emitters and ${ }^{239} \mathrm{Pu}$ and ${ }^{226} \mathrm{Ra}$ in the

Table 1. Assumptions used in deriving tabulation of maximum amounts of activity recommended for use under specified conditions*

\section{White Area: Open Room}

(a) Day-to-day transfer:-Average daily transfer into the body assumed to be not greater than 0.1 per cent of total activity in use, on the basis that the laboratory practice and housekeeping are equal to the standards of a well-run chemical laboratory.

(b) Spill or explosion ingestion/inhalation:-Ingestion of 0.1 of total activity is not sufficient to cause a lifetime dose to the critical organ exceeding 25 REM or alternatively a weekly dose of 0.3 REM in the cases of plutonium and thorium. Activity inhaled following a spill or explosion is not sufficient to give a lifetime dose to the critical organ exceeding 25 REM or alternatively a weekly dose of $0.3 \mathrm{REM}$ in the cases of plutonium and thorium under following circumstances:-

(i) all activity is airborne.

(ii) active material is uniformly distributed by the spill or explosion in a sphere of radius equal to the distance between the explosion point and the head of the worker.

(iii) sphere of active material drifts past the worker with a velocity determined by the air change rate in the laboratory ( 20 changes $/ \mathrm{hr}$ ).

(c) Contamination build-up:-Daily spread of activity is assumed to be one per cent of the total in use and routine cleaning procedures result in the removal of 90 per cent of this 25 -year build-up in the case of all $\beta$ emitters is not to give levels exceeding $4 \times 10^{-4} \mu \mathrm{C} / \mathrm{cm}^{2}$ over a total floor area of $50 \mathrm{~m}^{2}$ and in the cases of ${ }^{239} \mathrm{Pu}$ and ${ }^{226} \mathrm{Ra}$ levels not exceeding $10^{-5} \mu \mathrm{C} / \mathrm{cm}^{2}$ over the same area. ${ }^{239} \mathrm{Pu}$ and ${ }^{226} \mathrm{Ra}$ level is modified for other $\alpha$ emitters in the ratio of the respective maximum permissible daily intakes.

2. Blue Area: Open Room

(a) Day-to-day transfer:-Special measures adopted in the handling of radio-active materials (e.g., the wearing of gloves and the monitoring of laboratory air) result in a reduction of the transfer to 10 per cent of the white area transfer.

(b) Spill or explosion ingestion/inhalation:-Ingestion of 0.01 of total activity is not sufficient to give a lifetime dose to the critical organ exceeding 25 REM or alternatively a weekly dose of 0.3 REM. Activity inhaled following spill or explosion is not sufficient to give a lifetime dose to the critical organ exceeding 25 REM or alternatively a weekly dose of 0.3 REM under the conditions of $1(b)$ except that only 0.1 of the material is assumed to become airborne.

(c) Contamination build-up:-No limit is applied since routine monitoring is carried out in all blue areas. However, the limits set by $2(a)$ and $(b)$ result in the contamination hazard being not more than $10^{2}$ times the white area contamination hazard.

\section{Blue Area: Fume Hood}

Fume hood containment is assumed to reduce both transfer and spill or explosion hazards to one per cent of the blue area open-room case. No contamination build-up limit applied.

4. Red Area: Open Room and Fume Hood

Definition of red area recognizes hazardous levels possible at times, hence all red area limits have been placed at 10 times the corresponding blue area limits.

5. Red Area: Glove Boxes or Sealed Cells

Upper limit is set by fire and explosion hazard and each case must be considered individually.

* It is here assumed that the radio-active material is in the form of a fine dry powder which is the form most likely to be transferred into the body by inhalation. 


\section{ACTIVITY LIVELS IN LABORATORY DI:SIG.N ANI) PRACITCI:}

case of $\alpha$ emitters. He points out that, due to the external radiation hazard associated with $\beta$ contamination, no relaxation of the ${ }^{90} \mathrm{Sr}$ limit can be allowed in applying it to other $\beta$ emitters. In the case of $\alpha$ radiation, however, since the hazard is entircly one of ingestion and inhalation, some relaxation can be allowed in considering less radio-toxic $\alpha$ emitters than ${ }^{239} \mathrm{Pu}$ and ${ }^{226} \mathrm{Ra}$. In the calculations of this paper 1)unster's figure of $4 \times 10^{-4} \mu \mathrm{C} / \mathrm{cm}^{2}$ for widespread $\beta$ contamination has been applied to all $\beta$ emitters and his figure of $10^{-5} \mu \mathrm{C} / \mathrm{cm}^{2}$ for ${ }^{239} \mathrm{Pu}$ and ${ }^{266} \mathrm{Ra}$ contamination has been modified for other $\alpha$ emitters in the ratio of the respective maximum permissible daily intakes. The total amounts of the various nucleides which may be distributed around the laboratory over a number of years, without exceeding the allowable contamination level, have then been calculated from these figures. The amount of activity which may be handled in the laboratory can then be obtained by integrating an assumed daily fractional spread, with due allowance for radio-active decay.

\section{DISCUSSION OF RESULTS}

Table 1 sets out the assumptions which have been used to relate the recommended maximum amounts of activity for use under specified conditions to the various hazards discussed as in the last section of this paper. The calculations have been carried out for a number of nucleides and the final gencralized expressions given in the Table 2 have been chosen to limit the

Table 2. Recommended maximum amounts of activity for use under specified conditions

White Area Operations involving radio-active material in any physical form:

- up to $10 \mu \mathrm{C}$ of any $\beta \gamma$ emitter except ${ }^{90} \mathrm{Sr}$ and ${ }^{228} \mathrm{Ra}$ which should be limited to $1 \mu \mathrm{C}$.

- up to $10^{-1} \mu \mathrm{C}$ of any $\alpha$ emitter except ${ }^{232} \mathrm{Th}$ and natural $\mathrm{U}$ of which amounts up to $6 \times 10^{-1} \mu \mathrm{C}$ shall be permitted.*

Blue Area Operations involving radio-active material in a dry dusty form:

Open room $-10^{3} \times$ m.p.d.i.

Fume hood $-10^{5} \times$ m.p.d.i.

Red Area Operations involving radio-active material in a dry dusty form:

Open room $-10^{4} \times$ m.p.d.i.

Fume hood $-10^{6} \times$ m.p.d.i.

All quantities above $10^{6} \times$ m.p.d.i. should be handled in a glove box or sealed cell.

\section{All Areas}

\section{Modifying Factors}

Storage in closed but suitably vented containers-increase limits by a factor of $10^{3}$.

\section{White Areas}

(In the case of ${ }^{232} \mathrm{Th}$ and natural $\mathrm{U}$ only)

General dry but non-dusty operation-increase by a factor of 10 .

Wet chemistry-increase by a factor of $10^{2}$.

Blue and Red Areas

General dry but non-dusty operations-increase by a factor of 10 .

Wet chemistry or more general operations on materials of low specific activity-increase by a factor of $10^{2}$.

* A special limit is allowed for ${ }^{232} \mathrm{Th}$ and natural $\mathrm{U}$ due to their low specific activity.

+ The maximum permissible daily intake is to be taken here as the daily water intake $\times$ I.C.R.P. occupational permissible drinking water concentration or the daily air intake $\times$ 1.C.R.P. occupational permissible air concentration, whichever is the smaller. 


\section{A. R. W. WILSON}

amount recommended for use under a particular circumstance at least to the smallest of the three maximum quantities of activity for each nucleide determined by the restrictions consequent on the hazards listed above.

In conclusion, it must again be emphasized that these figures have been developed only as a guide to assist in the initial operation of an establishment. They must necessarily be amended in the light of experience and may well prove to be far removed from the limits determined by practice.

My thanks are due to Mr. C. N. Watson-Munro, Chief Scientist, Australian Atomic Energy Commission, for permission to publish this paper and to Mr.J.A. D. Stockdale of the Health Physics Division of the Australian Atomic Energy Commission for assistance in carrying out some of the calculations.

\section{REFERENCES}

${ }^{1}$ Levy, H. A. Chem. Engng Newes 24 (1946) 3168

${ }^{2}$ Levy, H. A. Industr. Engng Chem. (Industr.) 41 (1949) 248

${ }^{3}$ Mackintosh, A. P. Nucleonics 5 (1949) 48

${ }^{*}$ Tomkins, P. C. Industr. Engng Chem. (Industr.) 41 (1949) 239

${ }^{5}$ Tomkins, P. C. and Levy, H. A. Industr. Engng Chem. (Industr.) 41 (1949) 228

${ }^{6}$ Spence, R. Proceedings of the First Conference on the Peaceful Uses of Atomic Energy 7, Geneva, 195539

${ }^{2}$ Dunster, H. J. Med. ill. 8 (1954) 731

${ }^{8}$ Dunster, H. J. Atomics 6 (1955) 233

\section{DISGUSSION}

Dr. Austin: Was the air which was extracted from the glove box filtered in any way? Dr. Wilson: Yes, the air coming up the tube is either filtered or, alternatively, discharged up a fairly high stack so that there is a very good dilution. 


\title{
THE INFLUENGE OF OXYGEN ON THE RADIO- SENSITIVITY OF CELLS AND TISSUES
}

\author{
L. H. Gray
}

\author{
British Empire Cancer Campaign Research Unit in Radiobiology, \\ Mount Vernon Hospital, Northwood, England
}

MANY cells and tissues are much more damaged by exposure to ionizing radiation if they are situated in an aerobic environment at the time of irradiation than if they are deprived of oxygen. One of the earliest clear-cut examples of this was seen in Ascaris eggs by Holthusen ${ }^{1}$ who observed that the dose of X-rays required to prevent the eggs hatching was three times as great when the eggs were anaerobic as when they were aerobic at the time of irradiation. Subsequently, many other kinds of response to radiation have been tested in a variety of cells. In the great majority, it has been found that sensitivity is positively correlated with the availability of oxygen to the cells at the time of irradiation (Table 1 , Section $A$ ). The entries and references in Section $A$ of Table 1 are only a selection from the very large number of investigations which have revealed a positive dependence of radio-sensitivity on oxygen tension.

Section $B$ of the Table 1 cites a number of instances in which little or no oxygen dependence has been reported, and two systems in which greater radiation damage in the absence of oxygen has been reported. These systems are phage and calf thymus DNA irradiated in dilute aqueous suspension and assayed immediately for plaque-forming ability or for loss of structural viscosity respectively. The reverse oxygen effect is very well established in the case of the phage ${ }^{2}$. Nevertheless, if either the phage or the DNA (desoxyribose nucleic acid) is allowed to stand for a period of time before assay the over-all damage is greater if oxygen has been present at the time of irradiation. On account of the comparative rarity and corresponding importance of exceptions, some examples are included in Section $B$ which are commonly reported as oxygen independent, though a careful scrutiny of the published data shows this not to be the case (reverse mutation to streptomycin independence in Escherichia coli $\left.\mathrm{B} / \mathrm{r}^{*}\right)$, and one example, namely dominant mutation induction in mouse sperm, in which the assignment rests on the observation that the effect was not diminished by hypoxia. Real oxygen independence could only be considered as established if, in addition, the administration of oxygen to the animals at the time of irradiation was

* The data presented by Anderson $^{3}$ show that anacrobiosis results in a dose reduction factor for reverse mutation to streptomycin independence of about 1.3. Dr. Gunther has pointed out to me that the scatter of points in Anderson's Figure 2, p. 343, is such that the dose reduction factor might be considerably larger, especially if observations at the lower dose levels are considered more rcliable for the estimation of mutation rates than those at higher dose levels where the interpretation may become complicated by cell death. 


\section{H. GRAY}

Table 1. The sensitivity of cells and tissues to $\mathrm{X}$ radiation classified in relation to dependence on oxygen tension

Biological

material

Damage

Reference

A. Sensitivity positively correlated with oxygen tension

Rat

Mouse

Guinea pig $\}$ Death from whole body exposure

$2,3,4,5$

6

7

8,9

$11,12,13,4,5$

14,15

16,17

9,18

19

Chromosome structural damage

Lens of eye

Tumours

$18,20,21,22,23$, $24,25,26$

27

28

29

Recessive lethal mutation (eg

Reduced hatchability of egg due to: $(a)$ nuclear, and

(b) cytoplasmic injury

30,31

Suppression of 'Erupt Eye'

32

33

Formation of 'melanotic tumour'

34

35

$\begin{array}{ll}\text { Grasshopper } & \text { Mitotic inhibition in the neuroblast } \\ \text { Sea urchin } & \text { Cleavage delay in the egg }\end{array}$

\begin{tabular}{llc}
\hline Roots & Mitotic arrest & 36 \\
& Growth and survival & 37 \\
Microspores & Chromosome structural damage & 38,40 \\
Seeds & Chromosome structural damage & 39,40 \\
& Germination, subsequent growth and chromosome & $41,42,43$ \\
Yeast & $\quad$ structural damage* & 44 \\
& Loss of colony forming ability & 45 \\
Paramecium & Nine reverse mutations to growth factor independence & 46 \\
Bacteria & Genetic damage leading to reduced viability & $47,48,49,50$ \\
& Loss of colony forming ability & 51 \\
Phage & Reverse mutation to purine independence in $E$. coli B/r & 52,53 \\
DNA & Indirect inactivation including 'after-effect' & ' \\
& Loss of structural viscosity when 'after-effect' is & 54
\end{tabular}

B. Correlation between sensitivity and oxygen tension either not evident or inverse

Mouse

Dominant léthal mutations induced by irradiation of sperm $\dagger$

Bacteria

Reverse mutation to streptomycin independence in E. coli $\mathrm{B} / \mathrm{r}_{+}^{+}$

Paramecium

Non-genetic damage

Phage

Direct inactivation

Indirect inactivation (immediate)

Transforming principle DNA

Indirect inactivation (immediate)

58

Loss of structural viscosity (immediate effect, irradiated in dilute aqueous solution)

54

59

Erythrocyte

Leakage of potassium

* The sensitivity of barley seeds may not be influenced by gaseous atmosphere at the time of irradiation. An influence of oxygen is, however, clearly evident from studies of post-irradiation treatments.

+ This entry is based on the absence of an effect of hypoxia, which could be due to the fact that the sperm which were tested are normally nearly anoxic. Dominant lethals due to irradiation of oocytes show an influence of hypoxia and are therefore oxygen positive $(60)$. Dominant lethals resulting from irradiation of Drosophila sperm show a small effect of hypoxia (see text) (61).

$\ddagger$ A small positive dependence on oxygen was observed (see text). 
Rifiences to Tabte 1

1. Dowely, A. 11., Bennett. M. D. and Chastain, Sarah M. Radiology 55 (1950) 879

2. Evans, T. C.. Cicoclrich, I. P'. and Slaughter, J. C. Kadiology 38 (1942) 201

3. Lacassague, A. C. R. Acad. Sici., Purns 215 (19+2) 231

4. Lavassagnc, A. aul Latarjıt, R. C. K. Soc. Biol., Paris 137 (1943) 413

5. Limperos, (i. J. Franklin Inst. 249 (1950) 513

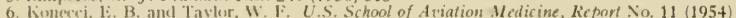

7. Stearner, S. 1'hvllis, Christian, limily J. 13. and 13rues, A. .1. Amer. J. Physiol. $176(1954) 455$

8. Rambach, W. A., Alt, 11. L. and Cooper, J. A. 1). Proc. Soc. I:xp. Biol., N.Y. 86 (1952) 159

9. Devik, F. Brit. J. Radiol. N.\$. 25 (1952) 481

10. Trowell, O. A. Brit. J. Railiol. N.S. 26 (1953) 302

11. Mottrim, J. C. Brit. J. Kadiol. (K'óntg. Soc. Sect.) 29 (1924) 174

12 . Nottram, J. C. Brit. J. Surg. 19 (1932) 481

13. Chase, H. B. Procedings of the Sccond International Conference on the Peaceful Uses of Atomic Energy, Geneva, 1958 in the press

14. Howard-Flanders, 1. and W'right, 1:. A. Nature, Lond. 175 (1955) 428

15. Howarl.Flanclers, P. and Wright, 1. A. Brit. J. Radiol. X.S. 30 (1957) 593

16. Russell, l iane 13. Radtation Biology, vol. 1 (ed. A. Hollaender): McGraw Hill, New York, 1954, p. 905

17. Russell, 1.iane 13. and Russell, W. L. J. ccll. comp. Physiol. 43 (1954) Supplement 1

18. Conger, A. D. Kadiology 66 (1956) 63

19. Howard-Flanders, P. and Jirie, A. Radiation Res. 7 (1957) 357

20. Crabtree, H. G, and Cramer, W. 11th Scicntific Report of the Imperial Cancer Research Fund (1934) 75, 90,104

21. Hall, B. V.. Hamilton, K. and Brues, A. M. Cancer Res. 12 (1952) 268

22. Hollcroft, J. W., Lorenz, E. and Matthews, M. J. nat. Cancer Inst. 12 (1952) 751

23. Gray, 1. H., Conger, A. D., Ebert, M., Hornsey, S. and Scott, O. C. A. Mrit. J. Radiol. X.S. 26 (1953) 638

24. Dittrich, W. and Stuhlmann, H. Naturteissenschaften 41 (1954) 122

25. Goldfeder, A. and Clarke, G. E. Proc. Ame'r. Ass. Cancer Res. 2 (1957) No. 3

26. 1)eschner, E. E. and Gray, L. H. Radiation Res. (1959) in the press

27. Baker, W. K. and Edington, C. W. Genetics 37 (1952) 665

28. Baker, W. K. and Sgourakis, E. I'roc. nat. Acad. Sri., H'ash. 36 (1950) 176

29. Ulrieh, H. Drosophila Inform. Serv. 30 (1956) 155

30. Vlrich, H. Radiation Res. 9 (1958) 196

31. Ulrich, H. Drosophila Inform. Serv. 31 (1957) 168

32. Glass, B, and Plaine, H. L. Proc. nat. Acad. Sci., Wash. 38 (1952) 697

33. Jlaine, H. L. and Glass, B. Canccr Res. 12 (1952) 829

34. Gaulden, Mary E., Nix, Marjorie and Moshman, J. J. cell. comp. Physiol. 41 (1953) 451

35. Anderson, R. S. Biol. Bull., H'ood's Hole 77 (1939) 325

36. Evans, H. J., Neary, G. J. and Tonkinson, S. M. Nature, Lond. 181 (1958) 1083

37. Read, J. Brit. J. Radiol. X.S. $25(1952) 89$

38. Thoday, J. M. and Read, J. Nature, Lond. 160 (1947) 608

39. Riley, H. P. Giles, N. H. Jr. and Beatty, A. V. Amer. J. Bot. 39 (1952) 592

40. Giles, N. H. Jr. Radialion Biology, vol. 1 (ed. A. Hollaender): McGraw Hill, New York, 1954. p. 744

41. Nilan, R. A. Genetics 39 (1954) 943

42. Caldecott, R. S., Johnson, Elizabeth B., North, D. T. and Konzak, C. F. Proc. nat. Acad. Sci., Hash. 43 (1957) 975

43. Curtis, H. J., Delihas, N., Caldecott, R. S. and Konzak, C. F. Radiation Res, 8 (1958) 526

44. Beam, C. A. Proc. nat. Acad. Sci., Wash. 41 (1955) 857

45. Gunther, R. L.-personal communication (1959)

46. Kimball, R. F. Ann. N.Y. Acad. Sci. 59 (1955) 638

47. Hollaender A Stapleton, G. E and Vlartin, F. L Vature, Lond 167 (1951) 103

48. Laser, H. Nature, Lond. 174 (1954) 753

49. Goucher, C. R., Kamei, I. and Kocholaty, W. Arch. Biochem. 65 (1956) 522

50. Howard-Flanders, P. and Alper, Tikvah. Radiation Res. 7 (1957) 518

51. Anderson, E. H. Proe, nat. Acad. Sci., Wash. 37 (1951) 340

52. Alper, Tikvah Brit. J. Radiol. N.S. 27 (1954) 50

53. Alper, Tikvah Disc. Faraday Soc. 12 (1952) 234

54. Conway, B. E. Brit. J. Radiol. N.S. 27 (1954) 42

55. Russell, W. L.., Kile, J. C. Jr. and Russell, Liane B. Gcneties 36 (1951) 574

56. Hewitt, H. B. and Read, J. Brit. Radiol. N.S. 23 (1950) 416

57. Alper, Tikvah Radiation Res. 2 (1955) 119

58. Latarjet, R. Ciba Foundation Symposium on Ionising Radiations and Cell Metabolism, (ed. G. E. W: Wolstenholme and C. N. O'(onnor): Churehill, London, 1956, p. 294

59. Sheppard, C. W. and Stewart, Marian. J. cell comp. Physiol. 39 Supplement 2 (1952) 189

60. Russell, Jiane B. and Major, Mary H. Genetics 38 (1953) 687

61. Baker, W. K. and von Halle, Elizabeth S. Proe. nat Acad. Sci., Wash. 39 (1953) 152

found not to alter the induced dominant mutation rate. The induction of dominant mutations in Drosophila sperm shows only a small oxygen dependence, but in this case there is independent evidence that mature Drosophila sperm normally exist at low oxygen tensions.

Both from the practical standpoint and in relation to the understanding of the role of oxygen in radiobiology, a knowledge of the quantitative dependence of radio-sensitivity on available oxygen is of great importance. Since we have no direct measure of oxygen tension within the cell, the best we can do is to correlate sensitivity with the concentration of oxygen in the immediate environment of the cell. Howard-Flanders and Alper ${ }^{4}$ were the first to obtain a precise evaluation of this relation between oxygen sensitivity and oxygen concentration. They worked with bacteria and yeast which 


\section{H. GRAY}

were irradiated in low concentrations in a vessel which permitted constant equilibration throughout the irradiation by bubbling the suspension in a gas of the required composition. I described in a previous lecture the manner in which Dr. Deschner and I have investigated this relation for Ehrlich ascites tumour cells - the only mammalian cells so far examined.

The results which Dr. Deschner and I obtained ${ }^{5}$ with ascites tumour cells conform well to the relation proposed by Howard-Flanders and Alper (Figure 1), namely:

$$
\frac{S-S_{\mathrm{a}}}{S_{\mathrm{a}}}=(m-1) \frac{\left[\mathrm{O}_{2}\right]}{\left[\mathrm{O}_{2}\right]+K}
$$

where $m=3 \pm 0 \cdot 2$ and $K=5 \pm 2 \mu \mathrm{M} / 1$. at room temperature.

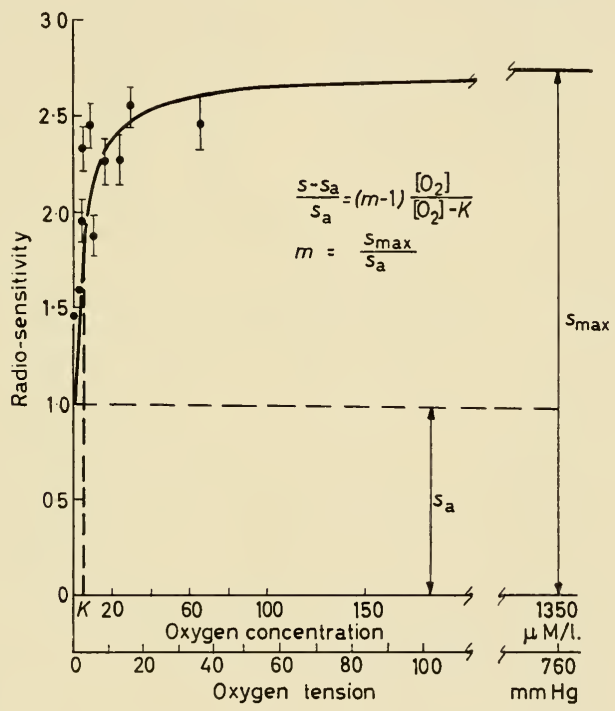

Figure 1. Influence of oxygen on radio-sensitivity (Erhlich ascites tumour cells)

Under conditions in which cellular respiration was poisoned by Cupferron (ammonium N-nitrosophenylhydroxylamine), Kihlman ${ }^{6}$ evaluated $m$ and $K$ for chromosome structural damage induced in Vicia faba roots by $\mathrm{X}$ radiation. The observed value of $m$ was significantly higher than the value for $m$ of 3 found by Kihlman and others ${ }^{7,8,9}$ in the absence of Cupferron. The value of $K$, on the other hand, was, within the limits of experimental error, the same as for bacteria, yeast, and tumour cells (see Table 2).

The cells composing most tissues exist at a variety of oxygen tensions, depending on their distance from the source of supply of oxygen and on the cellular respiration rate $\left(Q_{\mathrm{O}_{2}}\right)$ of the intervening cells. This is most evidently 
INFLLENCE OF OXYGEN ON RADIO-SENSITITIY OF CELLS ANI TISSULS

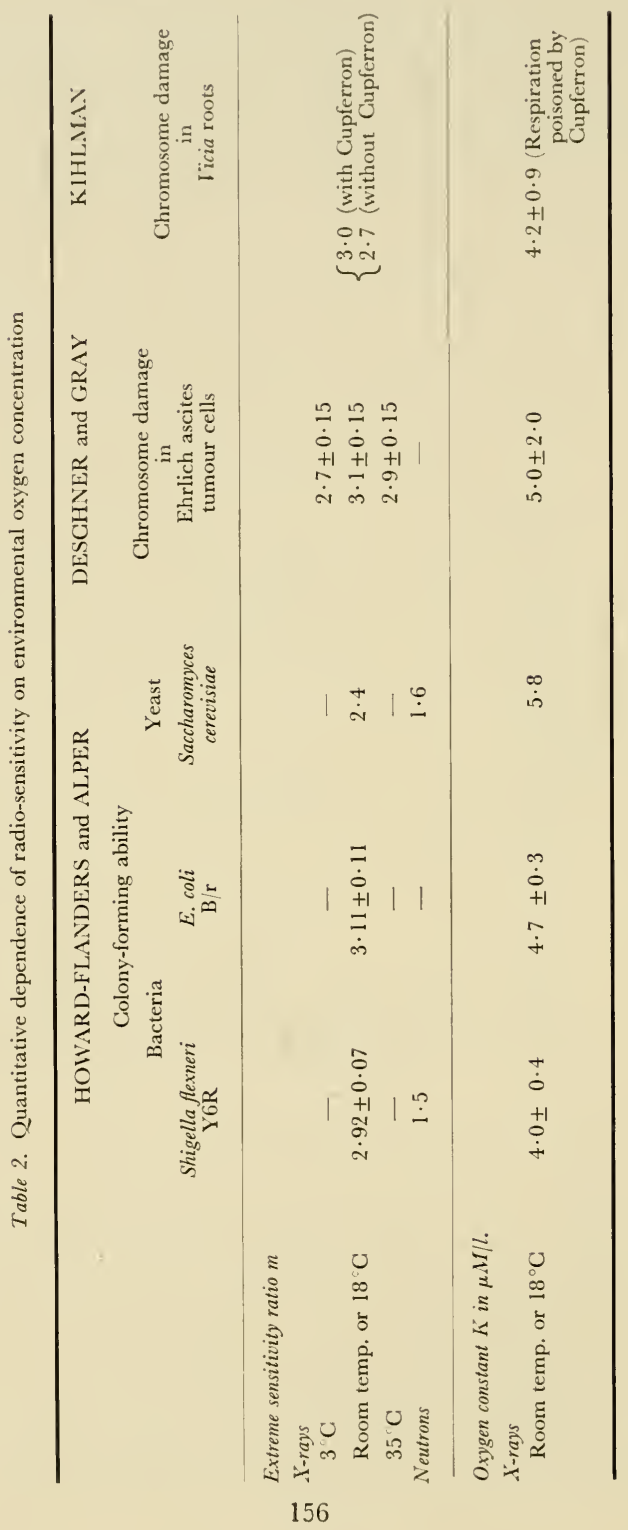




\section{H. GRAY}

the case in structures such as roots and anthers, and in organs and tissue fragments irradiated in vitro, which derive their oxygen from an ambient fluid. Figure 2 shows the manner in which the mean radio-sensitivity of the cells composing such tissues depends on the oxygen tension at the surface. As would be expected, the larger the structure and the higher the $Q_{\mathrm{O}_{2}}$, the greater the surface oxygen tension required to establish a given level of radiosensitivity. It had been noted as early as 1934 by Crabtree and Cramer ${ }^{10}$ that the sensitivity of tumour fragments irradiated in vitro was somewhat increased when respiration was reduced either by reducing the temperature or by the
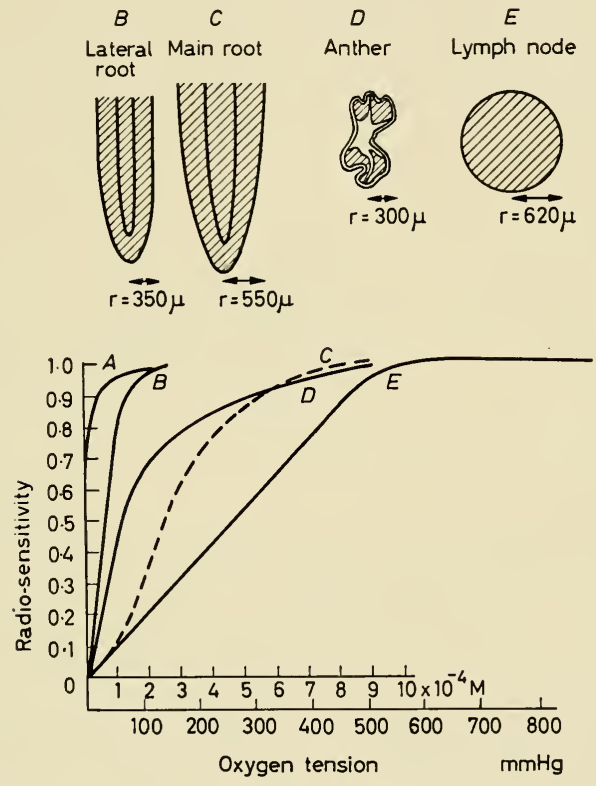

Figure 2. Effect of oxygen on sensitivity of tissues

use of cyanide as a respiratory poison. The fact was confirmed by Hall, Hamilton, and Brues ${ }^{11}$, who explained the observation in terms of a falling gradient of oxygen tension from the surface to the centre of the tumour fragment, and showed in support of this explanation that the effect disappeared if sufficiently small fragments were used. As mentioned above, Kihlman has shown that when respiration is totally suppressed in roots by Cupferron, the radio-sensitivity is related to oxygen tension by a curve indistinguishable from that for the cell suspensions so far examined (Curve $A$, Figure 2, instead of by Curve B, Figure 2).

Under conditions other than those of total anoxia, temperature may exercise a control over radio-sensitivity indirectly by controlling $Q_{\mathrm{O}_{2}}$, as in 
the experiments by Crabtrec and Cramer mentioned above. Figure 3 shows a very striking example of this. Giles' olservations ${ }^{12}$ of the influence of temperature on the production of chromosome structural damage resulting from the irradiation of Tradescantia microspores within the anther in an atmosphere containing 5 per cent oxygen in helium (Figure 2) are contrasted in Figure 3 with those of Deschner and myself for suspensions of ascites tumour cells in which $p_{\mathrm{O}_{2}}$ was held constant at all temperatures. It will be seen that the increasing $Q_{\mathrm{O}_{2}}$ of the microspores themselves, and of other tissues composing the anther, steadily reduces the oxygen tension throughout the anther, and hence the average sensitivity of the microspores, until at $40^{\circ} \mathrm{C}$ the anaerobic level of sensitivity is reached. In the case of the tumour cells in suspension, the sensitivity increases slightly with temperature under both aerobic and anaerobic conditions in such a way that the ratio remains constant within the limits of experimental error ${ }^{5}$. With these facts in mind, we may

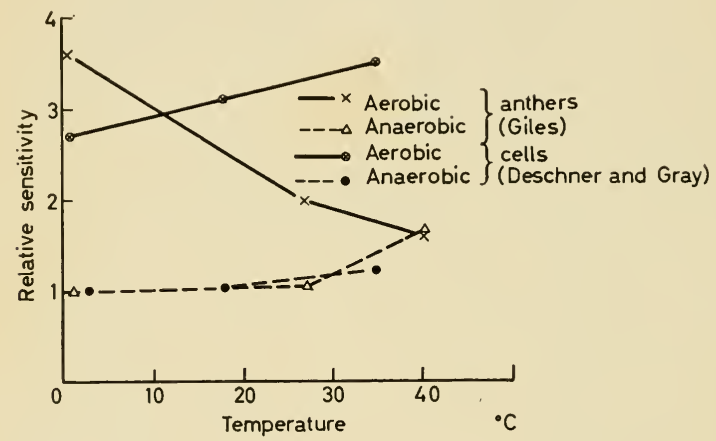

Figure 3. Temperature dependence of aerobic and anaerobic sensitivity

consider the influence of oxygen on the sensitivity of various tissues in the living animal. The relationship for individual tumour cells depicted in Figure 1 and the corresponding constants $(m=3$ and $K=5 \mu \mathrm{M} / 1$.), refer to irradiation at room temperature. In the living animal we are concerned with the values of these constants at $37^{\circ} \mathrm{C}$. The constant $m$ is practically independent of temperature over the range $3^{\circ}$ to $36^{\circ} \mathrm{C}^{5}$, but there are at present no reliable published data for the influence of temperature on $K$. Our own observations at $36^{\circ} \mathrm{C}$ were consistent with a value for $K$ of $5 \mu \mathrm{M}$., but a value as high as $10 \mu \mathrm{M} / 1$. could probably not have been excluded. Subsequent observations* indicate that $K$ is the same at $3{ }^{\circ} \mathrm{C}$ as at room temperature and we provisionally assume that at $37^{\circ} \mathrm{C}$ the value is the same as at room temperature. If this is so, then it is evident from Figure 1 that the ascites tumour cells would be almost fully sensitive at venous oxygen tension (taken as $40 \mathrm{~mm} \mathrm{Hg}$ ), and in as far as the sensitivity of other mammalian cells is similarly related to oxygen tension it might be thought that all

* Current investigations by the author and colleagues. 


\section{H. GRAY}

tissues of the living animal would normally be in the fully sensitive condition. In several instances, however, this has been shown not to be the case since the administration of oxygen to the animal at the time of irradiation has resulted in an increase in the radio-sensitivity of the tissue in question. Thus, for radiobiological damage to growing bone in the tails of young mice, Howard-Flanders and Wright ${ }^{13}$ observed that one unit of dose delivered to the animal breathing oxygen was equivalent to $1 \cdot 35$ units delivered to an animal breathing air. Expressing sensitivity by the reciprocal of the dose required to bring about a given degree of biological damage, then relative to the completely anoxic state the sensitivity of the tail bone in animals breathing $0 \cdot 1,0 \cdot 2$ (air), $0 \cdot 4,1$, and 3 atmospheres oxygen were found to be $1 \cdot 32$, $1 \cdot 97,2 \cdot 27,2 \cdot 56$ and $2 \cdot 67$. If for the individual cells from which the damage arises $K=5 \mu \mathrm{M} /$ l., these observations place the mean oxygen tension of the target cells at about $4 \mathrm{~mm} \mathrm{Hg}$ when the animal is breathing air.

Howard-Flanders and Pirie ${ }^{14}$ observed that with regard to the fall in glutathione content of rabbit lens-attributable to an initial damage to the lens epithelium - the effectiveness of a given dose was increased by a factor of 1.24 by oxygen administration. Since corresponding figures for total anoxia and for the maximum level of sensitivity are not known in this case, oxygen tension at the lens epithelium under normal conditions cannot be inferred with any certainty but is probably not far from the mean value inferred for growing bone in the mouse tail. In both these situations, the target cells are separated from their oxygen supply, and a calculation of the diffusion of oxygen from a capillary network at $40 \mathrm{~mm} \mathrm{Hg}$ on the basis of the observed dimensions of the structures concerned and approximate values of $Q_{\mathrm{O}_{2}}$, indicates that the inferred oxygen tensions are roughly in accordance with expectation.

The case of damage to pigment cells at the base of resting and growing hair follicles has been rather fully investigated by Chase and Hunt ${ }^{15}$. The observed ratio of maximum to minimum sensitivity was very close to three for both the resting and growing follicle. Interpreted in terms of a cellular response for which $m=3$ and $K=5 \mu \mathrm{M} / 1$., or $3.8 \mathrm{~mm} \mathrm{Hg}$ partial pressure of oxygen, these data indicate that under normal conditions the oxygen tension is about $6 \mathrm{~mm} \mathrm{Hg}$ at the pigment cells at the base of the resting follicles and about $9 \mathrm{~mm} \mathrm{Hg}$ at the base of the growing follicles. Application of a vascular clamp to stop blood supply to the area only reduced sensitivity to its lowest level if the skin was situated in an atmosphere devoid of oxygen. In normal conditions enough oxygen enters through the skin to provide a partial pressure of around $1 \mathrm{~mm} \mathrm{Hg}$ at the base of the follicles.

Scott ${ }^{16,17}$ observed that when small solid tumours in mice, grown from an inoculum of Ehrlich ascites tumour cells, were irradiated while the animal was breathing oxygen at 1 atm pressure, the effectiveness of the dose in causing tumour regression was increased by a factor of about 1.5. As discussed in my previous lecture (page 76), Deschner and I observed that the same cells growing in the peritoneal cavity had a sensitivity only about 20 per cent above that corresponding to the completely anoxic state.

From the standpoint of radio-therapy it is important to note that the mean oxygen tension of the tumour cells growing either in solid or ascites forms is lower than the figures inferred for any of the normal tissues so far investigated. 
In the five-day old ascites tumour, the cell density is about $10^{8} / \mathrm{ml}$, which may be much higher than cell concentration in human ascites. We believe, on the other hand, that the condition of low oxygen tension inferred for the solid mouse tumours is typical of many human tumours. This belief is based partly on indirect evidence derived from observed features of the histological structure and blood supply of some human tumours ${ }^{18}$, and partly on the fact that in seven test cases in which different portions of the same human tumour were exposed to the same dose, with or without oxygen administration, considerably greater histological damage was evident in the regions of the tumour which had been irradiated when the patient was breathing oxygen $^{19}$.

When suspensions of small numbers of tumour cells are inoculated into the mouse intradermally ${ }^{20}$, or are allowed to invade the liver (Hewitt-personal communication), so that the tumour cells take up the oxygen tension of the normal tissues, their radio-sensitivity is not increased to any significant degree by the administration of oxygen to the mouse at the time of irradiation. We conclude that in such cases the oxygen tension of the tumour cells is probably at least $30 \mathrm{~mm} \mathrm{Hg}$.

It is evident that if a tumour contains even a very small proportion of nearly anoxic cells, these rather than the bulk of the aerobic tumour cells will determine the success or otherwise of the treatment. This is illustrated in Table 3, which supposes that a total dose of $4500 \mathrm{r}$ is delivered to a mass of

Table 3. The influence of oxygen tension on the proportion of cells which survive $4500 \mathrm{r}$ calculated for cells having $\mathrm{D}_{1 / \mathrm{e}}$ (aerobic) of $150 \mathrm{r}$

\begin{tabular}{|c|c|c|c|c|c|c|}
\hline \multicolumn{2}{|c|}{ Partial pressure of oxygen in $\mathrm{mm} \mathrm{Hg}$} & 0 & $1 \cdot 5$ & 4 & 12 & 110 \\
\hline \multicolumn{2}{|l|}{ Relative radio-sensitivity } & 1 & $1 \cdot 5$ & 2 & $2 \cdot 5$ & 3 \\
\hline \multirow{2}{*}{$\begin{array}{l}\text { Number of cells and } \\
\text { volume effectively } \\
\text { treated }\left(90^{\circ} \% \text { chance }\right. \\
\text { that no cell survives) }\end{array}$} & Number of cells & $2 \cdot 10^{3}$ & $3 \cdot 10^{5}$ & $5 \cdot 10^{7}$ & $10^{10}$ & $10^{12}$ \\
\hline & of tissue (mm) & $1 / 6$ & 1 & 4 & 20 & 100 \\
\hline
\end{tabular}

tumour cells at different oxygen tensions. In line with the observations of Puck $^{21}$ for HeLa cells growing in culture, and the observations of Hewitt ${ }^{22}$ for mouse leukaemia cells growing in the living animal, it has been assumed that the proportion of cells which retain reproductive integrity is exponentially related to dose, and that under aerobic conditions 37 per cent of cells survive $150 \mathrm{r}$. In this hypothetical situation there would be a 90 per cent chance of sterilizing all of a population of $10^{12}$ aerobic cells, but only $2 \times 10^{3}$ anaerobic cells. Table 3 shows that while a minority of completely anaerobic cells could jeopardize success in therapy, a comparatively small increase in oxygen tension could have a very favourable influence on the chances of successful sterilization.

WAYS IN WHICH OXYGEN MAY AFFECT RADIO-SENSITIVITY

The oxygen molecule has an embarrassingly wide range of properties which might be relevant to a discussion of the manner in which it influences radiosensitivity. 


\section{H. GRAY}

By its presence within the cell oxygen may control regional Redox potentials, and in particular the Redox condition of the respiratory enzymes; it may, through the pathway of oxidative phosphorylation, provide an essential source of energy for the development of initial physical and chemical disturbances into manifest biological lesions; it may, by virtue of its own biradical character react with radiation induced radicals so as to convert reversible or innocuous chemical changes into forms incompatible with normal cellular activity; or again, operating at the chemical level, the oxygen molecule may, by virtue of its paramagnetic properties, alter the probability of transition in either direction between singlet and triplet states, or through its electron affinity alter the steps involved in charge neutralization following the ionization of the medium by charged particles.

We may refer briefly to a few of the experiments which have been stimulated by one or other of these considerations. It was natural that an answer should first have been sought biochemically in terms of a greater susceptibility of the aerobically metabolizing cell. This was the approach of Crabtree $^{10}$, whose results are summarized in Table 4. All these results were carefully checked with three different transplantable mouse tumours. The

Table 4. Radio-sensitivity

\begin{tabular}{lll}
\hline \multicolumn{1}{c}{ Increased } & \multicolumn{1}{c}{ Decreased } & \multicolumn{1}{c}{ Unaltered } \\
\hline HCN treatment & $\mathrm{N}_{2}$-anaerobiosis at $37 \cdot 5 \mathrm{C}$ & $\mathrm{ICH}_{2}$. COONa treatment \\
Aerobiosis at $0 \mathrm{C}$ & $\begin{array}{l}\mathrm{CO} \text {-anaerobiosis at } 37.5 \mathrm{C} \\
\mathrm{N}_{2} \text {-anaerobiosis at } 0 \mathrm{C}\end{array}$ & $\begin{array}{l}\mathrm{NaF}_{\text {treatment }} \\
\text { Variations in glucose concentration } \\
\text { Variations in pH }\end{array}$ \\
\hline
\end{tabular}

cyanide and iodoacetate were used at concentrations which greatly depressed respiration and glycolysis respectively in these particular tumours, without influencing the proportion of takes on re-inoculation. If it is correct to interpret the effect of cyanide and low temperature as due to the reduction or abolition of oxygen gradients through the tumour fragments, then Table 4 shows no effect of any of the enzyme poisons tested in these particular cells. All Crabtree's observations are compatible with the view that radiosensitivity is controlled by availability of oxygen to the tumour cells-i.e. by the presence or absence of dissolved molecular oxygen. Subsequent work, however, has revealed a number of cases in which enzyme poisons can influence sensitivity in the presence of dissolved oxygen (Table 5). No very consistent pattern is discernible. A $2 \cdot 5$-hour pre-treatment with carbon monoxide abolishes oxygen sensitivity in grasshopper embryos-in the dark but not in the light, suggesting a cytochrome mechanism-but a half-hour pre-treatment with carbon monoxide under pressure enhances the oxygen-dependent sensitivity of microspores and roots. Cyanide treatment during irradiation (with abundant oxygen present) has no effect on tumours, grasshopper embryos, and roots, but suppresses the oxygendependent sensitivity in Sarcina lutea.

In order to throw light on the possible role of the cytochrome system, Moustacchi ${ }^{23}$ has compared the aerobic and anaerobic sensitivities of three 
Table 5. Influence of molccular oxygen on radio-sensitivity in the presence of ('nzyme poisons

\begin{tabular}{|c|c|c|c|}
\hline Organism & Poison & $\begin{array}{l}\text { Influence on } \\
\text { oxygen dependent } \\
\text { sensitivity }\end{array}$ & Reference \\
\hline Mouse tumour & $\begin{array}{l}\text { Fluoride } \\
\text { Iodoacetate } \\
\text { Cyanide } \\
\text { Cyanide }\end{array}$ & $\left.\begin{array}{l}\text { No chauge } \\
\text { No change } \\
\text { Increased } \\
\text { No change }\end{array}\right\}$ & $\mathrm{a}$ \\
\hline Sarcina lutea & Cyanide & Abolished & c \\
\hline \multirow[t]{2}{*}{$\begin{array}{l}\text { Grasshopper } \\
\text { embryo }\end{array}$} & Cyanide & $\begin{array}{l}\text { No change } \\
\text { (summation of injuries) }\end{array}$ & d \\
\hline & $\begin{array}{l}\text { Carbon monoxide } 80 / 20 \mathrm{CO}_{2} \text { and } \\
\text { above (including } 2 \cdot 5 \text { hours pre- } \\
\text { treatment) }\end{array}$ & & \\
\hline $\begin{array}{l}\text { Tradescantia } \\
\text { microspores }\end{array}$ & $\begin{array}{l}\text { Carbon monoxide } 4 \text { atm (including } \\
0.5 \text { hour pre-treatment) }\end{array}$ & Increased & $\mathrm{e}$ \\
\hline \multirow[t]{3}{*}{ Vicia roots } & Cyanide & $\begin{array}{l}\text { Slight increase } \\
\text { No change } \\
\text { No change }\end{array}$ & $\begin{array}{l}f \\
g \\
h\end{array}$ \\
\hline & Azide & No change & $\mathrm{i}, \mathrm{j}$ \\
\hline & $\begin{array}{l}\text { Carbon monoxide high pressure (in- } \\
\text { cluding } 0.5 \text { hour pre-treatment) }\end{array}$ & Increased & $\mathrm{k}$ \\
\hline
\end{tabular}

a. Crabtree, H. G. and Cramer, W. 11th Scientific Report of the Imperial Cancer Research Fund (1934) 75, 90,104

b. Hall, B. V., Hamilton, K. and Brues, A. A. Cancer Res. 12 (1952) 268

c. Laser, H. Naturc, Lond. 174 (1954) 753

d. Tahmisian, T. N. and Devine, Rosemarie L. Radiation Res. 3 (1955) 182

e. King, E. D., Schneiderman, H. A. and Sax, K. Proc. nat. Acad. Sci., Hash. 38 (1952) 34

f. Mottram, J.C. Brit. J. Radiol. N.S. 8 (1935) 643

. Read, J 3oth Anmul Report of the British Empire Cancer Campaign (1952) 297

h. Kihlman, B. A. J. biophys. biochem. Cytol. 3 (1957) 363,381

i. Kihlman, B. A. Exp. Cell Res. 8 (1955) 404

j. Kihlman, B. A. Hereditas, Lund. 41 (1955) 384

k. Gray, L. H. Acta. radiol., Stockh. 41(1954) 61

normal organisms and their mutant forms which are deficient in the enzymes of aerobic respiration. The three organisms were E. coli B., E. coli M.L., and yeast. In the case of the two strains of $E$. coli it was estimated that the respiratory enzymes were either absent, or present at a concentration of less than $1 / 500$ th of that in the wild type. The X-ray sensitivities of mutant and wild types were, nevertheless, the same both when irradiated in nitrogen and in oxygen, i.e. the influence of oxygen was as marked in the mutant as in the wild typc. The 'petite' mutant of yeast was more sensitive than the wild type, but like the bacteria, showed the same ratio of aerobic to anaerobic sensitivity. Howard-Flanders ${ }^{24}$ has also observed that the ratio of aerobic to anaerobic sensitivity is the same in wild type yeast as in a cytochromedeficient mutant.

As mentioned earlier, the induction of chromosome structural damage by $\gamma$ and $\mathrm{X}$ radiation has almost always been found to be positively correlated with oxygen tension at the time of irradiation. The aberrant configurations which are actually observed, or are inferred from genetic analysis, are 


\section{H. GRAY}

usually visualized as having arisen in two steps, viz. by a breaking of individual chromatid threads and by the illegitimate fusion of broken ends. In attempts to interpret their observations, different authors have expressed views ranging between the extremes in which oxygen is considered only to increase the initial breakage or only to affect the probability of illegitimate reunion $12,25,26,27,28,29$. In a recent careful analysis of aberrations produced by a single exposure of Vicia roots to ${ }^{60} \mathrm{Co} \gamma$-rays, Neary and Evans ${ }^{9}$ find quantitatively the same influence of oxygen on chromatid breaks, isochromatid breaks, chromatid interchanges, and the formation of small achromatic regions on the chromatid thread, formerly confused with chromatid breaks. They conclude that while their results support the view that oxygen increases the initial or primary effect of radiation on the chromosomes, certain details indicate that the primary event may not be the actual breakage of chromatids. The low frequency of true chromatid breaks and the absence of isochromatid aberrations showing no reunion are more in accord with the exchange mechanism for aberration production, as proposed by Revell ${ }^{30}$.

Wolff and Atwood ${ }^{31}$ studied the influence of oxygen on chromatid aberrations produced in Vicia root tip cells by fractionated X-ray exposures. Interpreting the influence of fractionation on the yield of those types of aberrations which involve two chromosomes along the classical lines developed by Sax ${ }^{32,33}$ and by $\mathrm{Lea}^{34}$ and Catcheside ${ }^{35}$, they have concluded that the presence of oxygen at the time of irradiation increases damage to a mechanism involved in the healing of broken chromosome ends as well as to the primary breakage. From subsequent experiments in which soaked Vicia seeds were exposed to fractionated doses $75 \mathrm{~min}$ apart, Wolff and Luippold ${ }^{36}$ concluded that the rejoining of ends of chromosomes broken during the first part of the exposure was dependent not only on the presence of oxygen, but on continued oxidative phosphorylation, during the interval between the two irradiations, since oxygen was ineffective in seeds treated with dinitrophenol and in seeds kept in an atmosphere of 95 per cent carbon monoxide: 5 per cent oxygen in the dark, but not in the light. Whether the primary event in the production of chromosome aberrations is the chromatid break as postulated by Sax, or the chromatid interchange as postulated by Revell ${ }^{30}$, the evidence presented by Wolff, Atwood," and Luippold is most naturally interpreted, as the authors suggest, to indicate a metabolic requirement for chromosome aberration production which involves cellular respiration. Nevertheless, it would be very valuable if support could be obtained for this view from experiments with cells, rather than tissues, since with tissues there must always be some doubt concerning the effect of the supplementary treatments on the oxygen tension at the target cells. Thus, dinitrophenol is known to increase cellular respiration and is quoted ${ }^{37}$ as increasing basal metabolic rate as much as tenfold. This agent will, therefore, give rise to a corresponding increase in tissue oxygen gradients, and a fall in the oxygen tension at the target cells which might even become completely anoxic. Carbon monoxide has an opposite effect on cellular respiration, but treatment with carbon monoxide (under pressure) before and during a single aerobic irradiation, is known to increase radiation damage to Tradescantia microspores ${ }^{38}$ and Vicia meristem cells ${ }^{39}$. Beatty, Beatty and Collins ${ }^{40}$ have observed that when Tradescantia microspores are irradiated in 
the anther at very low dose rates, corresponding to exposure times of about 8 hours, more two-hit cluromosome aberrations are produced if the irradiation is given in the absence than in the presence of oxygen. The same result was obtained if the radiation was delivered at high dose rate, but preceded by 8 hours of anacrobiosis. The authors interpret their observations in terms of the postulate of Wolff and Luippold that oxidative phosphorylation speeds chromosome rejoining and thereby reduces the yield of interchanges resulting from exposure at very low dose rates.

$A$ period of anaerobic culture greatly increases the radio-resistance of $E$. coli $B / r$ and changes the dose response curve, but the cells still respond to changes in oxygen tension at the time of irradiation in the same manner as aerobically grown cells ${ }^{41}$. Prolonged anaerobiosis, likewise, does not apparently have any influence on the relation between sensitivity and the environmental oxygen concentration at the time of irradiation in the case of either root meristem cells or Ehrlich ascites tumour cells. Reference will be made in Paper 29 to the fact that for periods of up to half an hour after X irradiation 42,43 , and in some cases for much longer periods, oxygen can influence the level of damage sustained by barley seeds, as reflected in subsequent seedling growth and chromosome damage at the first root tip division. Much light may be thrown on these observations by the experiments of Jackson (Paper 21) with onion seed reported at this Conference. These effects have chiefly been observed when seeds are very dry at the time of irradiation. It seems that in biological materials such as seeds and spores ${ }^{44}$, which normally have a low water content, the influence of oxygen is most marked when the water content is reduced to the lowest possible level, and decreased or eliminated by small amounts of water.

Dittrich (quoted by Kunkel and Schubert ${ }^{45}$ and personal communication), has recently observed that if Ehrlich ascites tumour cells are irradiated at about $2{ }^{\circ} \mathrm{C}$ and allowed to warm up to room temperature in $2 \mathrm{~atm}$ pressure, more chromosome structural damage is produced than if the cells warm up in air. We have not observed a similar effect when Ehrlich ascites tumour cells are allowed to warm up to room temperature in oxygen at $1 \mathrm{~atm}$ pressure.

In assessing all these results, account must be taken of the fact that oxygen alone, without irradiation, produces chromosome structural damage in very dry Tradescantia pollen ${ }^{46}$, and may, in combination with cyanide ${ }^{47}$ or Cupferron 48,49 , produce chromosome structural damage in Vicia meristem cells. Moreover, irradiated medium is toxic to irradiated DNA and irradiated phage ( $c f$. Table 1), and to irradiated catalase-deficient bacteria ${ }^{50,51}$.

As a general rule, somatic cells, growing in normal physiological conditions, have been found to respond instantly to changes in oxygen tension before irradiation and to be uninfluenced by changes in oxygen tension immediately after irradiation. The time limits for Vicia root meristem cells were set at less than $30 \mathrm{sec}$ by $\operatorname{Read}^{7}$ and a similar figure was found by Giles $^{12}$ for Tradescantia microspores. It is less than $4 \mathrm{sec}$ for bone damage in the mouse tail ${ }^{13}$, less than 2 sec for Ehrlich ascites tumour cells (Deschner and Gray, unpublished) and less than $1 / 50 \mathrm{sec}$ for bacteria ${ }^{52}$. In each case the figure quoted is merely the shortest time in which the worker was able to change the oxygen tension before and after irradiation. In experiments 
recently conducted by Dewey and Boag ${ }^{53}$, which will be reported more fully in Paper 29, very large doses of electron radiation have been given to bacteria in a single $2 \mu$ sec pulse. Bacteria which were aerobic ( 1 per cent oxygen in the gas phase) and had the corresponding radio-sensitivity at the beginning of the pulse, responded as if they had been nearly anaerobic, owing, as we believe, to the radio-chemical utilization of all the oxygen initially present in the cell during the early part of the radiation pulse. These experiments open the way to an experimental evaluation of the maximum interval which may elapse between irradiation and the availability of the oxygen if the oxygen is to influence the overall radiation response. The extreme rapidity with which a cell can show a change from aerobic to anaerobic sensitivity, and conversely, would be consistent with the view that oxygen is interacting with short-lived chemical species produced by irradiation.

An event of decisive importance in the development of the theory that oxygen influences radiation damage by participating in the chemical changes initiated along the tracks of individual ionizing particles, was the observation of Thoday and Read 54,55 that while oxygen greatly influences the damage to root meristem cells when this is initiated by X-rays, it has little or no influence when the damage is initiated by $\alpha$-rays. It is now known that the ratio of the aerobic to the anaerobic sensitivity of many cells is a function of the LET of the ionizing particles, being greatest for the low LET radiations such as $\gamma$ and $\mathrm{X}$ radiation, intermediate for neutrons, and least for high LET radiations such as $\alpha$-particles. This situation has a rather complete counterpart in radiation chemistry, since a number of chemical reactions are known for which the ratio of aerobic to anaerobic yield is similarly dependent on LET. Among the earliest chemical reactions to be studied in detail in this connection were the oxidation of ferrous sulphate and the formation of hydrogen peroxide by the irradiation of pure water, and in each case it was postulated that the role of oxygen was to interact with the hydrogen atoms $\mathrm{H}$. which result from the radiolysis of water to form $\mathrm{HO}_{2} \cdot$, which is a powerful oxidizing agent. Accordingly it was suggested that oxygen might have a similar role in radiobiology ${ }^{56}$. It now appears doubtful whether $\mathrm{HO}_{2} \cdot$ is an important intermediate in chemical reactions induced in aqueous solution at neutral $\mathrm{pH}$ since the radical is believed to be largely dissociated into $\mathrm{H}^{+}$and $\mathrm{O}_{2}^{-}$above $\sim \mathrm{pH} 2^{57}$, but it is still generally accepted as an intermediate in the oxidation of ferrous to ferric in aerobic solutions at very acid $\mathrm{pH}$. Alper ${ }^{58}$ proposed that in radiobiology the oxygen molecule enhances damage by combining with the organic radical rather than the hydrogen atom. This still leaves open the question as to how far the primary radicals formed by the radiolysis of water contribute to biological damage, since the organic radical with which oxygen interacts may have been formed either as a result of ionization of the molecule itself, or, secondarily, by reaction with an $\mathrm{H}$. or $\mathrm{OH}$ - radical. Hutchinson's data 59,60 indicate that as regards the inactivation of two enzymes and a co-enzyme in the living yeast cell, the indirect process is the more important. The idea that the oxygen molecule reacts with an organic radical accords better not only with what has been said above about the dissociation of $\mathrm{HO}_{2} \cdot$ at neutral $\mathrm{pH}$, but also with the low concentration $(\sim 5 \mu \mathrm{M} / 1$.) at which oxygen is effective radiobiologically ${ }^{24}$. 
It will be seen that the species $\mathrm{O}_{2}$ can be formed by electron attachment to $\mathrm{O}_{2}$ as well as by the formation and dissociation of $\mathrm{HO}_{2} \cdot$. This species has been postulated ${ }^{61}$ as an intermediate in the inactivation of 'dry' trypsin, the yield of which is somewlat increased by oxygen under $\mathrm{X}$ irradiation but not under $\alpha$ radiation.

The readiness with which oxygen combines with other radicals is attributable to its own bi-radical character, i.e. to the fact that it has two unpaired electrons. These unpaired electrons also confer the property of paramagnetism. While almost all the common gases are diamagnetic, there are three which share with oxygen the property of being paramagnetic by virtue of possessing an unpaired valance elcctron. These are, nitric oxide, nitrogen dioxide and chlorine dioxide, and it occurred to Howard-Flanders to sce whether nitric oxide could play the role of oxygen in the initiation of radiobiological damage. As reported recently ${ }^{62}$, he was rewarded by finding that when Shigella flexneri are rendered completely anoxic and exposed to X-rays after equilibration with a mixture of nitric oxide and nitrogen containing less than 1 per cent nitric oxide, the bacteria are as sensitive as when fully aerobic. Kihlman has recently reported ${ }^{63}$ that nitric oxide similarly raises the sensitivity of anoxic roots (I icia faba), and we have found that the sensitivity of anaerobic Ehrlich ascites tumour cells is raised approximately to the aerobic level by equilibration with nitric oxide/nitrogen mixtures ${ }^{64}$. HowardFlanders ${ }^{24}$ has estimated that molecule for molecule nitric oxide and oxygen have about the same influence on radio-sensitivity, and Kihlman ${ }^{63}$ (personal communication) has reached a similar conclusion from his studies of chromosome damage in Vicia meristem cells. Although not a metabolite in the ordinary sense, nitric oxide is believed to be an intermediate in the metabolism of certain micro-organisms and it can combine reversibly with haemoglobin ${ }^{65}$ and reduced cytochrome oxidase. Biochemical as well as radio-chemical mechanisms, therefore, might be invoked to account for the observed phenomenon. If this were the case the relation between radiosensitivity and nitric oxide concentration would presumably reflect the proportion of some pigment molecules with which the nitric oxide is combined at a given nitric oxide concentration, but the apparent identity of the sensitivity-concentration relation for nitric oxide and oxygen would then be very remarkable since it would imply equal affinity of the pigment for these two molecules. The fact that temperature has little or no influence on the form of the sensitivity-concentration relation in the case of oxygen* is also against the view that this relation reflects the reversible dissociation of an organic complex with oxygen.

Nitric oxide is well known to chemists as a powerful scavenger of free radicals, but the reaction rates of nitric oxide with photo-initiated free radicals are known in some instances to be very different from those of oxygen (R. H. Pallen-personal communication). Moreover, nitric oxide having only one unpaired electron should react with only one free radical to form a stable product, whereas the combination of oxygen, which has two unpaired electrons, with a free radical yields a product which is still a free radical. The addition of oxygen to organic free radicals frequently leads to

* Current investigations by the author and colleagues with Ehrlich ascites tumour cells and with bacteria. The contrary statement by Howard-Flanders ${ }^{24}$ has been withdrawn. 


\section{H. GRAY}

the formation of peroxides which decompose thermally. Thus, when a 1 per cent solution of polystyrene in chloroform is irradiated, the presence of oxygen enormously enhances the number of breaks which are induced in the polymer chain compared with an anaerobic irradiation, but nitric oxide has no such effect (A. Chapiro-personal communication). Irradiated Perspex is not bleached by nitric oxide as it is by oxygen (Boag and Gray-unpublished).

Professor Porter has drawn my attention to the fact that the two gases, oxygen and nitric oxide, are equally efficient in producing spin forbidden transitions, such as between singlet and triplet states, as well as in transfer to and from metastable states. This possible role of oxygen and nitric oxide in radiobiology would appear to deserve very serious study.

Finally, reference should be made to the theoretical studies of Platzman and Franck ${ }^{66}$, who adduce cogent reasons for believing that the electric fields which arise through the separation of positive and negative charges at the instant of ionization may lead to an important measure of secondary hydrogen bond breakage in proteins and other polar macromolecules. It is conceivable that the readiness with which electrons become attached to oxygen and nitric oxide may influence the magnitude and duration of such electric fields.

It may well be that when the story of oxygen controlled radio-sensitivity is fully unfolded, each attribute of this remarkable molecule-physical, chemical and biochemical-will be seen to be critical to some aspect of the phenomenon which we have had under review.

\section{REFERENCES}

${ }^{1}$ Holtuusen, H. Pflüg. Arch ges Physiol. 187 (1921) 1

${ }^{2}$ Alper, Tikvah Brit. 7. Radiol. N.S. 27 (1954) 50

${ }^{3}$ Anderson, E. H. Proc. nat. Acad. Sci., Wash. 37 (1951) 340

${ }^{4}$ Howard-Flanders, P. and Alper, Tikvah Radiation Res. 7 (1957) 518

${ }^{5}$ Deschner, E. E. and Gray, L. H. Radiation Res. (1959)-in the press

${ }^{6}$ Kinlman, B. A. Nature, Lond. 182 (1958) 730

${ }^{7}$ ReAD, J. Brit. F. Radiol. N.S. 25 (1952) 89, 154

${ }^{8}$ Thoday, J. M. Brit. Sci. Newes 3 (1950) 66

${ }^{9}$ Neary, G. J. and Evans, H. J. Nature, Lond. 182 (1958) 890

${ }^{10}$ Crabtree, H. G. and Cramer, W. 11th Scientific Report of the Imperial Cancer Research Fund (1934) 75, 90, 104

${ }^{11}$ Hall, B. V., Hamilton, K. and Brues, A. M. Cancer Res. 12 (1952) 268

${ }^{12}$ Giles, N. H. Jr. Radiation Biology, vol. 1 (ed. H. Hollaender) : McGraw Hill, New York, 1954, Figure $10 \cdot 8$, p. 743

${ }^{13}$ Howard-Flanders, P. and Wright, E. Brit. F. Radiol. N.S. 30 (1957) 593

${ }^{14}$ Howard-Flanders, P. and Pirie, Antolnette Radiation Res. 7 (1957) 357

${ }^{15}$ Chase, H. B. and Hunt, J. W. Pigment Cell Biology: Academic Press, Inc., New York, 1959, Chapter 29

${ }^{16}$ Gray, L. H., Conger, A. D., Ebert, M., Hornsey, S. and Scott, O. C. A. Brit. 7. Radiol. N.S. 26 (1953) 638

${ }^{17}$ Gray, L. H., Chase, H. B., Deschner, E. E., Hunt, J. W. and Scott, O. C. A. Proceedings of the Second International Conference on the Peaceful Uses of Atomic Energy, Geneva, 1958-in the press

${ }^{18}$ Thomlinson, R. H. and Gray, L. H. Brit. F. Cancer 9 (1955) 539

${ }^{19}$ Churchill-Davidson, I., Sanger, C. and Thomlinson, R. H. Lancet (1955) 1091

${ }^{20}$ Scott, O. C. A. 35th Annual Report of the British Empire Cancer Campaign, covering the year 1958 - in the press. 
${ }^{21}$ Púck, T. T. Adtanc. biol. med. Phy's. 5 (1957) 75

${ }^{22}$ Hewtrt, H. B. Brit. 7. Cincer 12 (1958) 378

${ }^{23}$ Moustaccir, E. Ann. Inst. Pasteur 94 (1958) 89

${ }^{24}$ Howari)-Flanders, P. Adianc.biol.med.Phys.6 (1958) 553 ; personal conmunication

${ }^{25}$ Giles, N. H. 7. cell. comp. Physiol. 45 Supplement 2 (1955) 271

${ }^{26}$ Scimwartz, D. Proc. nat. Acad. Sci., W'ash. 38 (I952) 490

${ }^{27}$ Siwansox, C. P. J. cell. comp. Physiol. 45 Supplenent 2 (1955) 285

${ }^{28}$ Baker, W. K. and von Halie, Eilzabeth S. 7. cell comp. Physiol. 45 Supplement 2 (1955) 299

${ }^{29}$ Conger, A. D. 7. cell. comp. Physiol. 45 Supplement 2 (1955) 309

${ }^{30}$ ReVell, S. H. Ann. N.Y. Acad. Sci., 68 (1958) 802

${ }^{31}$ Wolff, S. and Atwood, K. C. Proc. nat. Acad. Sci., Wash. 40 (1954) 187

$32 \mathrm{SAx}, \mathrm{K}$. Genelics 23 (1938) 494

${ }^{33} \mathrm{SAx}, \mathrm{K}$. Genetics 25 (1940) 41

${ }^{34}$ LEA, D. E. Actions of Ionizing Radiations on Living Cells: Cambridge University Press, London, 1946

${ }^{35}$ Catcheside, D. G. Advanc. Genet. 2 (1948) 271

${ }^{36}$ WolfF, S. and Luippold, H. E. Science 122 (1955) 231

37 Harrow, B. Textbook of Biochemistry: W. B. Saunders, Philadelphia, 1946, p. 415

${ }^{38}$ King, E. D., Schneiderman, H. A. and Sax, K. Proc. nat. Acad. Sci., Wash. 38 (1952) 34

${ }^{39}$ Gray, L. H. Acta Radiol., Stockh. 41 (1954) 61

${ }^{40}$ Beatty, A. V., Beatty, Jeanne W. and Collins, Cynthia Amer. J. Bot. 43 (1956) 328

41 Hollaender, A., Stapleton, G. E. and Martin, F. L. Nalure, Lond. 167 (1951) 103

42 Caldecott, R. S., Johnson, Elizabeth B., North, D. I. and Konzak, C. F. Proc. nal. Acad. Sci., Wash. 43 (1957) 975

${ }^{43}$ Curtis, H. J., Delihas, N., Caldecott, R. S. and Konzak, C. F. Radiation Res. 8 (1958) 526

4T Tallentire, A. Nature, Lond. 182 (1958) 1024

${ }^{45}$ Kunkel, H. A. and Schubert, G. Proceedings of the Second International Conference on the Peaceful Uses of Atomic Energy, Geneva, 1958-in the press

${ }^{46}$ Conger, A. D. and Fairchild, Lucile M. Proc. nat. Acad. Sci., Wash. 38 (1952) 289

${ }^{4} 7$ Lilly, Lorna J. and Thoday, J. M. Nature, Lond. 177 (1956) 338

${ }^{48}$ Kihlman, B. A. J. biophys. biochem. Cytol. 3 (1957) 363

${ }^{49}$ Kihlman, B. A., Mertz, T. and Swanson, C. P. J.biophys. biochem. Cjtol. 3 (1957) 381

50 AdLer, H. I. Radiation Res. 9 (1958) 451

${ }^{51}$ Adler, H. I. and Stapleton, G. E. Radiation Res. 9 (1958) 84

52 Howard-Flanders, P. and Moore, D. Radiation Res. 9 (1958) 422

${ }^{53}$ Dewey, D. L. and BoAg, J. W. Nature, Lond. 183 (1959) 1450

${ }^{54}$ Thoday, J. M. and Read, J. Nature, Lond. 160 (1947) 608

${ }^{55}$ Thoday, J. M. and Read, J. Nature, Lond. 163 (1949) 133

${ }^{56}$ Gray, L. H. Radiation Res. 1 (1954) 189

${ }^{57}$ Dainton, F. S. Radiation Res. Supplement 1 (1959) 1

${ }^{58}$ Alper, Tikvahi Radiation Res. 5 (1956) 573

${ }^{59}$ Hutchinson, F. Radiation Res. 7 (1957) 473

${ }^{60}$ Hutchinson, F., Preston, A. and Vogel, B. Radiation Res. 7 (1957) 465

${ }^{61}$ Alexander, P. Radiation Res. 6 (1957) 653

${ }^{62}$ Howard-Flanders, P. Nature, Lond. 180 (1957) 1191

${ }^{83}$ Kihlman, B. A. Exp. Cell. Res. 14 (1958) 639

${ }^{64}$ Gray, L. H., Green, F. O. and Hawes, C. A. Nature, Lond. 182 (1958) 952

${ }^{65}$ Keilin, JoAn Biochem. J. 59 (1955) 571

${ }^{6}$ Platzman, R. and Franck, J. Information Theory in Biology, (ed. H. P. Yockey): Pergamon Press, London, 1958, p. 262 


\title{
RADIO-PROTEGTIVE AGTION OF 5-HYDROXYTRYPTAMINE
}

\author{
H. A. S. VAN DEN BRENK \\ Radiobiological Research Unit, Cancer Institute Board, \\ Melbourne
}

MANY chemicals are known, which protect animals against ionizing radiations $^{1}$. However, their exact mode of action remains in doubt. By analogy with polymer experiments in vitro, the mechanism appears dependent on an indirect competition for oxidizing radicals, particularly $\mathrm{HO}_{2}$ radicals, produced by irradiation in tissue fluids ${ }^{2}$. Other evidence is advanced to support this hypothesis. Protective action in vivo, is substantial only for radiations giving low ion densities along the track of the ionizing particles; for Escherichia coli, chemical protectors are active in the presence of anaerobiosis $^{3}$. Alexander et al. ${ }^{1}$ also state that whilst many chemical protectors, efficient in vivo, are vasoconstrictors, e.g. certain catechol amines and pitressin, and possibly give protection as a result of induced tissue anoxia, this factor does not apply to certain other protective substances.

More recently, $\mathrm{Bacq}^{4}$ has been more impressed with the views of L. H. Gray and others ${ }^{5}$, stressing the importance of cellular anoxia, induced by radioprotective chemicals, and has added evidence in support. However, Bacq remains convinced that an eclectic theory of cellular anoxia does not suffice, as an explanation of all aspects of radio-protection, and feels that some fundamental physico-chemical action must be accepted, based on the idea of competition for free radicals ${ }^{1}$ or perhaps that of a radio-resistant protectorenzyme complex, which is subsequently dissociated by irradiation, with restoration of normal activity ${ }^{6,7}$. The protective action in vivo of a non-SH substance such as tryptamine, is particularly stressed by Bacq, as not suitably explained by the last hypothesis, or by the anoxic theory.

In reviewing these deliberations and others, concerning radio-protective action in vivo, certain conclusions seem inevitable:

(i) intracellular and intercellular organization is such that complex concentration gradients of protective metabolites and pharmacological substances exist, which seem to preclude a close analogy with protection of simple chemical systems in vitro

(ii) for a chemical or metabolite to manifest substantial protection in vivo, toxic side effects invariably accompany this action. For 'less toxic' substances such as cysteine, compared on a molar basis with more toxic substances such as cysteamine, to achieve comparable radio-protective action in vivo, the dose must be increased, and results in comparable toxicity

(iii) the fundamental mechanisms which govern 'selective toxicity' of chemical agents on living matter, would seem cogent in relation to the effects of ionizing radiations. 


\section{Selective Toxicity}

A review of the subject is beyond the scope of this paper but has been given by Albert ${ }^{8,9}$. It is based on the original conception of Ehrlich of a relatively specific metabolite-receptor combination. Today, the receptor is considered a macromolecule (usually an enzyme), and the combination with a metabolite involves:

(i) the ability of a drug to reach its receptor-a quality at least partly dependent on physico-chemical characteristics (molecular size, lipoid water partition coefficients, ionization constant, etc.). Also, active transport mechanisms may be involved requiring expenditure of energy, obtained from the simultaneous oxidation of carbohydrates

(ii) a steric similarity of drug and its analogues, for specific receptor combination

(iii) a chemical bonding usually due to secondary valencies (hydrogen bonds, ionic bonds, multiple van der Waal's bonds). The bonding is rather readily severed (e.g. by washing in water)

(iv) competitive antagonism between a metabolite and sterically similar antimetabolite, expressed quantitatively as a 50 per cent inhibitory index of the molar ratio of metabolite and its analogue

(v) the receptor macromolecule, blocked by a metabolite, can no longer perform one of the metabolic duties within the cell, and pharmacological effect occurs. Whilst this constitutes the favoured hypothesis of action postulated by Woolley ${ }^{10}$ for naturally occurring metabolites, a more complex situation prevails in the case of metabolites and their analogues, which are normally not actively involved in basal metabolism but which cause pharmacological effects when endogenously released in the organism or exogenously administered (e.g. catechol amines, 5-hydroxy tryptamine, and their respective antimetabolites). However a quantitative competitive inhibition prevails in this three-cornered situation of receptor, metabolite and antimetabolite, similar to the more simple relationship already discussed.

\section{Relationship of Selective Toxicity to Radio-protective Effect of Metabolites in vivo}

If a metabolite e.g. 5-hydroxytryptamine (serotonin; 5-hydroxy-3-(betaaminoethyl) indole) is capable of entering the zone of influence in a cell, where vital macromolecules are vulnerable to ionizing radiations, and affords protection at this site, this protective action based on the physico-chemical hypothesis of competition for free radicals, should not be diminished by the presence of a specific analogue (antimetabolite) at this site.

On the other hand, if the inactivation of oxidizing radicals is determined by an alteration in basal metabolism due to a metabolite-receptor combination, which interferes with the normal metabolic cycle, Redox potentials, intracellular oxygen tension, etc., antimetabolites would be expected to modify (reduce) this specific radio-protective effect selectively in those cells which possess specific receptors. This condition should hold in vivo and in vitro for a particular tissue.

As a third alternative, generalized radio-protection as a result of anoxaemia, will result from selective toxicity, where the receptors are present in smooth muscle, but the radio-protective action of the metabolite for a non-muscular tissuc in viro, should be reduced when exposed in vitro under suitable conditions. 


\section{H. A. S. VAN DEN BRENK}

Selective Toxicity of Indole Amines and Their Radio-protective Action

The radio-protective action of tryptamine and 5-hydroxytryptamine (5-OHT) has been studied in vivo, and the effects of specific antimetabolites and antagonists of 5-OHT have been determined. A preliminary report has been made. ${ }^{11}$

\section{Radio-protectize action of 5-OHT}

Acute lethality-This substance is a powerful protective agent for radiationinduced acute lethality in rats and mice ${ }^{5,2}$. Our own results have confirmed this effect. In adult Canberra black stock rats a dose of $0.5 \times 10^{-5}$ moles

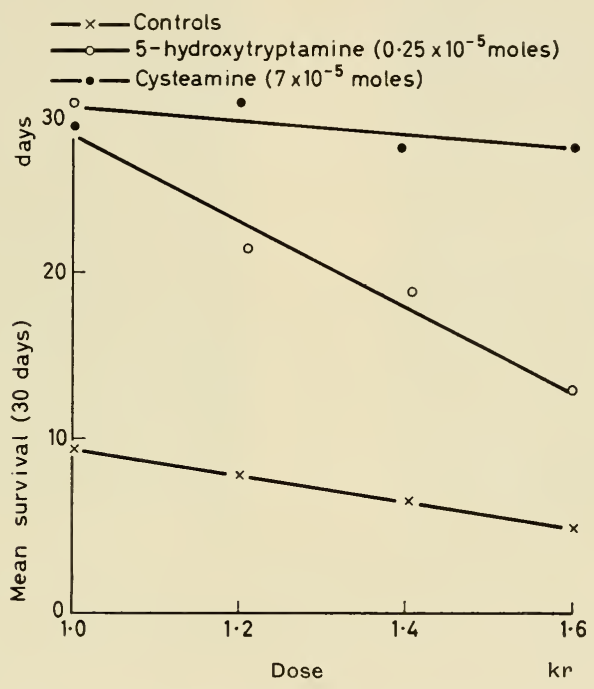

Figure 1. Protective action of 5-hydroxytryptamine and cysteamine administered 5 minutes preceding irradiation, compared for mortality in Swiss mice due to total body irradiation-Each point represents mean survival for 20 animals, at end of 30 days observation period

5-OHT, given five to seven minutes before whole-body irradiation with $1000 \mathrm{r} X$-rays $(250 \mathrm{kV})$ gives 50 to 90 per cent survivors at 30 days. In unprotected similar rats, this dose is uniformly lethal with a mean survival of about seven days. In mice similar results are recorded, and compared with cysteamine. These results are shown in Figure 1.

Weight loss-Both treated irradiated rats and untreated irradiated controls, lose weight for an initial five days after irradiation, after which controls progressively lose weight until death, whilst protected rats commence to regain weight, and within 20 days after irradiation the original weight has been attained.

Diarrhoea-There is a 100 per cent incidence of diarrhoea amongst irradiated 
surviving control rats, and an incidence of 0 to 15 per cent diarrhoea amongst protected animals, over the period during which most control animals die (i.e. two to ten days after irradiation).

Prolonged survival-Most protected rats surviving beyond 30 days, have survived in good health for prolonged periods of up to twelve months, although their body weight is reduced, greying of hair occurs with typical distribution, and in odd animals squamous cell carcinomata of skin have appeared.

Fertility - Whilst reduced fertility has resulted, inter-brecding of protected irradiated male and female survivors after $1000 \mathrm{r}$ total body irradiation, has resulted in a fair proportion of litters with offspring reduced in number but apparently normal. Most offspring are successfully suckled and gain weight at a normal rate. Bacq and Alexander ${ }^{2}$ state that female rats protected by cysteamine, are permanently sterilized by $700 \mathrm{r}$ X-rays.

Protective dose of 5 -OHT-Doses of less than $0.5 \times 10^{-5}$ moles afford considerably less protection against acute lethality, but doses as low as $0.5 \times 10^{-6}$ moles, reduce incidence of diarrhoea to 50 per cent, of the control value.

Protection of locally irradiated skin-Rats receiving the protective agent (5-OHT) parenterally in doses of $0.5 \times 10^{-5}$ moles before local irradiation of skin with soft X-rays $(30 \mathrm{kV}$, H.V.D. $2 \mathrm{~mm}$ in tissue, dose of $4000 \mathrm{r}$ at surface of skin, field size $2.5 \mathrm{~cm}$ round circle), show greatly diminished reactions and skin damage. Plate 1 shows the results of such an experiment. This protective action for 5-OHT, is considerably greater, than the local protection afforded by cysteamine in doses of $20 \times 10^{-5}$ moles, despite the greater protective action of the latter against acute lethality in rats from whole-body irradiation.

\section{Protective action of related indoles and histamine}

1-tryptophan-The parent amino acid, which gives 87 per cent protection of polymer in vitro in concentrations of $8 \times 10^{-4}$ moles $^{1}$ fails to protect in vivo in mice $\left(1 \times 10^{-5}\right.$ moles $)$ or in rats $(200 \mathrm{mg} / \mathrm{kg}$ given 10 to 30 minutes preceding irradiation). Bacq and Alexander attribute the failure of aromatic and heterocyclic amino acids to protect in vivo, as due to relative inability to penetrate membrane barriers, by virtue of their carboxyl groups.

Attempts to modify uptake of the amino acid 1-tryptophan, and 3,4dihydroxyphenyl alanine by pretreatment of rats with reserpine to release catechol amines and 5-OHT, and an amine oxidase inhibitor (iproniazid) to prevent destruction of any aromatic amines formed in tissues, have failed to yield significant protection attributable to amino acid incorporation in the cells; 3,4-dihydroxyphenyl alanine itself in doses of $200 \mathrm{mg} / \mathrm{kg}$ in rats causes pilierection and sympathetico-mimetic activity, but fails to afford substantial radio-protection, as distinct from results recorded by Alexander et al. ${ }^{1}$ for mice.

Tryptamine 3-(beta-aminoethyl) indole-This unhydroxylated substance, is the naturally occurring indole amine in invertebrate tissues ${ }^{12}$ and in equimolecular doses in mice gives substantial protection ${ }^{1}$. From our own results, it is a much weaker protective agent than 5-OHT in rats although its pharmacological behaviour is similar but also less intense. Contrary to the claim of Bacq and Alexander ${ }^{2}$ that tryptamine is not a vasoconstrictor, Reid ${ }^{13}$ and 
A

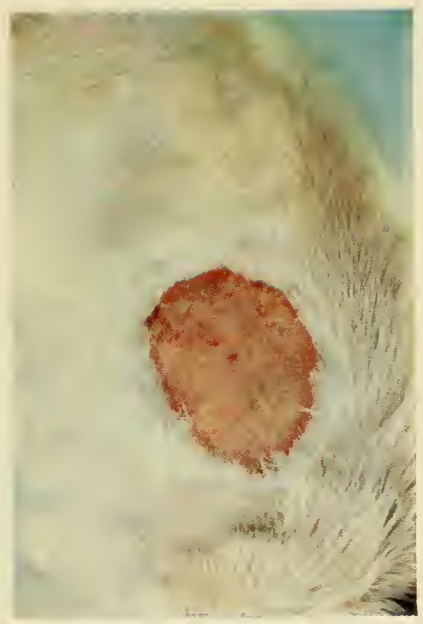

B

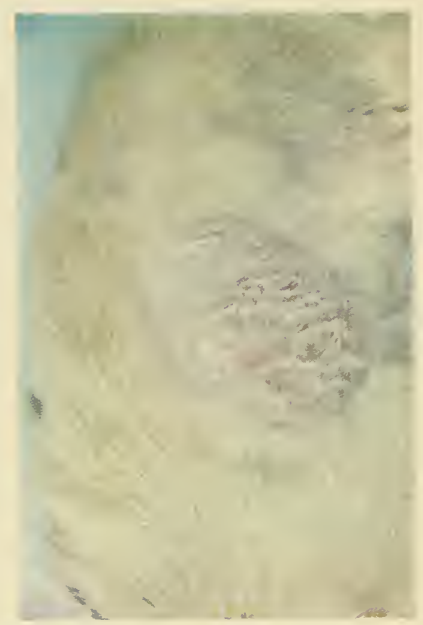

Plate 1. Effect of an intraperitoneal injection of 5 -hydroxytryptamine $\left(0.5 \times 10^{-5}\right.$ mole) administered 5 minutes preceding local irradiation of skin with soft $\mathrm{X}$-rays $(30 \mathrm{kV}, \mathrm{H} . \mathrm{V} . \mathrm{D}$. in tissue $2 \mathrm{~mm}$, field size $2 \cdot 5 \mathrm{~cm}$ diameter circle, dose $4000 \mathrm{r}$ at skin surface)

A. Right flank of animal 20 days after irradiation (without protective agent

B. Left flank of same animal 20 days after irradiation following 5-hydroxytryptamine treatment 



\section{H. A. S. VAN DEN BRENK}

Page $^{14}$ have shown it to cause intense smooth muscle contraction, similar to its hydroxyl derivative.

Auxin (3-indole acetic acid and 5-hydroxyindole acetic acid)-These substances fail to give significant protection in vivo, and are pharmacologically inactive in other respects. However indoles protect polymethacrylic acid in vitro ${ }^{1}$ and since auxin is the natural growth hormone of plants, an investigation of its protective properties in the latter, would seem indicated. It has been reported that the tryptophan-indole acetic acid enzyme system in plants is very sensitive to irradiation, $1 \mathrm{r}$ causing 10 per cent inhibition of the enzyme ${ }^{15}$.

Histamine-For rats, this substance is a much weaker protective agent than 5 -OHT, and only with huge doses $(60$ to $80 \mathrm{mg} / \mathrm{kg}$ ) is protection obtained with 20 to 30 per cent survivors at 30 days.

\section{Endogenous 5-OHT-Effects of release and depletion on radiation lethality in rats}

The mean body content of 5-OHT in the adult rat is approximately $125 \mathrm{\mu g} / \mathrm{kg}^{16}$ - i.e. approximately $2 \times 10^{-5}$ moles 5 -OHT in a $150 \mathrm{~g}$ rat. By comparison an exogenous dose of $0.5 \times 10^{-5}$ moles 5 -OHT is required for substantial radio-protection, i.e. about 25 per cent of the total body content. Also free $5-\mathrm{OHT}$ is rapidly destroyed by amine oxidase present in many tissues, an enzyme which is strongly inhibited by 1 -isopropyl-2-isonicotinylhydrazine (iproniazid).

Endogenous 5-OHT is bound to tissue proteins in an inactive state, and not available to 5-OHT receptors in this state. It can be released in a 'free' form together with catechol amines by reserpine, or together with histamine by certain diamines $(e . g$. Compound $48 / 80)$. If its breakdown is blocked by an amine oxidase inhibitor, a high concentration of the 'free' form in tissues can be induced. On the other hand reserpine alone maintains low levels of 'bound' and 'free' 5-OHT in the animal during the tranquillized state. However, reserpinized tissues have reduced sensitivity to the pharmacological action of $5-\mathrm{OHT}^{17}$ - a feature which is demonstrated by the accompanying kymograph recordings (Figure 2) of a rat stomach preparation, used for the bioassay of 5 -OHT ${ }^{18}$.

Radiation lethality in 5-OHT depleted rats-Rats reserpinized 16 hours before irradiation, show the same lethality to irradiation as untreated rats. If similar dosage of reserpine is given five minutes before irradiation, a slight but variable protection results, partly attributable to an increased free 5-OHT available to receptors, which are partially refractory to its action. If exogenous 5-OHT is given in the usual dosage to reserpinized rats, a substantial protection results (40 to 80 per cent survivors at 30 days, $1000 \mathrm{r}$ whole-body irradiation) comparable to similar doses of 5-OHT in unreserpinized animals. However, the reserpinized animal tolerates the 5-OHT much better than control rats. These findings suggest that radiation protection with 5-OHT does not depend per se on its effect on smooth muscle receptors, and vasoconstriction.

Protection due to release of endogenous 5-OHT-Iproniazid alone failed to build up 'free' 5-OHT in the intact animal, sufficient to give protection, but alternative metabolic pathways exist for the inactivation of 5-OHT, which do not involve amine oxidases. Reserpine alone gave slight protection 
if adıninistered five to ten minutes before irradiation (vide supra) and Compound $48 / 80(200 \mu \mathrm{g})$ administered seven minutes before irradiation, gave more substantial protection (20 to 30 per cent survivors at 30 days, $1000 \mathrm{r}$ whole-body irradiation - largely attributable to the large amounts of histamine liberated. Animals acutely depleted of histamine by Compound 4880 show a slight but not significant increase in lethality ${ }^{19}$. Animals pretreated with iproniazid and given reserpine 30 minutes preceding irradiation, show a slight but significant protection, with a doubling of the mean survival for $1000 \mathrm{r}$ whole-body dose.

To summarize the results obtained for endogenous 5-OHT in radiation protection, it would appear that the concentration of 'bound' 5 -OHT in

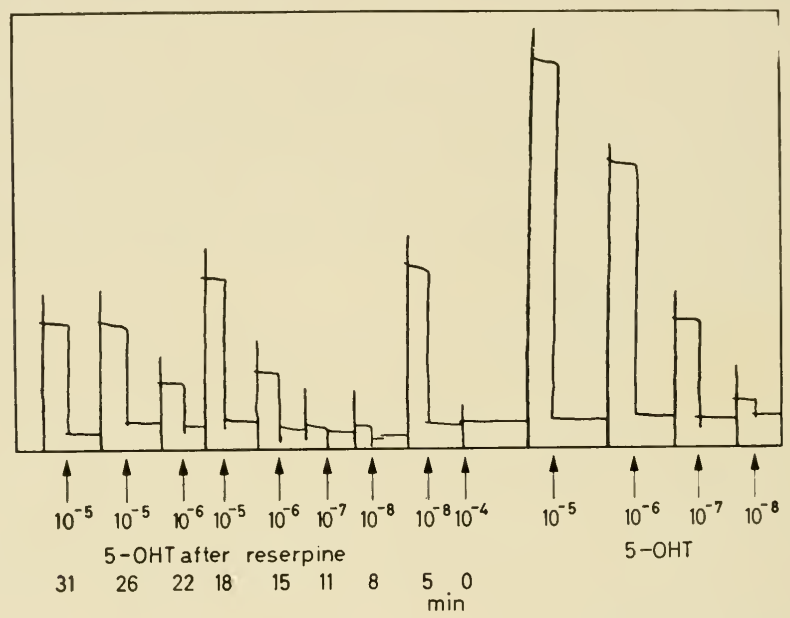

Figure 2. Showing reduction in sensitivity of rat stomach muscle preparation to 5-hydroxytryptamine, following reserpine

rat tissues plays no part in protection of the animal against $\mathrm{X}$ irradiation. A change to the 'free' form gives protection, even in the presence of refractory 5-OHT receptors on smooth muscle cells, but more critical experimentation is required and is being carried out to establish this point which is of crucial importance in the mechanism of 5 -OHT protection in vivo.

\section{Effect of 5-OHT antagonists and antimetabolites}

A range of 5-OHT analogues of proven specificity are available, largely owing to the researches of Woolley and Shaw.

Two types of tryptamine receptors are present, which can be selectively blocked $20,21-M$ receptors, probably present on nerve endings and selectively blocked by morphine and atropine, and $D$ receptors present on smooth muscle and selectively blocked by 5-OHT analogues and certain $\beta$-haloalkylamines (e.g. dibenzyline or phenoxybenzamine). Of these, the latter ( $D$ receptors) 


\section{H. A. S. VAN DEN BRENK}

are of much greater specificity and importance. These receptors are present on smooth muscle cells, and contraction of the actomyosin filaments in the cell is apparently induced by $\mathrm{Ca}^{++}$and $\mathrm{Mg}^{++}$ions in the presence of ATP, and not by the amine itself ${ }^{22}$, the latter being considered to combine with the receptor and lead to an increase in membrane permeability with passage of water and metallic ions into the cell ${ }^{23}$.

$D$ receptors-If these receptors are blocked by a specific antimetabolite such as lysergic acid diethylamide (LSD), its brominated derivative (BOL) or a highly specific serotonin derivative, l-benzyl-5-methoxy-2N, N-trimethyl tryptamine (BAS), prior to administration of 5-OHT in rats, the radioprotective effect of the indole can be almost completely annulled ${ }^{11}$. The relative molecular amounts of 5-OHT and the antimetabolite administered decide the degree of protection, but is difficult to determine with any accuracy in vivo. However, the approximate molar ratios which give maximal antagonism, for the three antimetabolites studied are given in Table 1 .

Table 1

\begin{tabular}{c|c}
\hline Antimetabolite & Molar ratio for 90 per cent inhibition of radio-protection of 5-OHT \\
\hline LSD & $1 / 100$ \\
BOL & $10 / 1$ \\
BAS & $1 / 1$ \\
\hline
\end{tabular}

The approximate 'inhibitory indices' given are subject to considerable error, owing to the nature of the experimental conditions, but seem to follow the more accurate pharmacological pattern, obtained in vitro. The antimetabolites administered alone, before or after irradiation, do not significantly influence radiation lethality, but tend to diminish diarrhoea-particularly LSD and BOL.

The result with BAS is particularly interesting in that this compound, is a substituted serotonin which Woolley has stated to be very specific in blocking $5-\mathrm{OHT}$, and even inactive against tryptamine itself ${ }^{24}$.

The $\beta$-haloalkylamines, are adrenergic blocking agents, and our work has been confined to the use of dibenzyline, which in doses of $0.25 \mathrm{mg}$ failed to reverse the protective effect of 5-OHT, but further experimental work is in progress with larger doses, given at various times before the challenge dose of 5-OHT.

$M$ receptors-Atropine failed to modify 5 -OHT protection in rats in doses of $0.25 \mathrm{mg}, 10$ minutes preceding irradiation. It would appear that these receptors are relatively unimportant in the radio-protective action under consideration.

\section{Specificity of Antimetabolites of 5-OHT and Histamine}

To compare the inhibition of these two radio-protective amines, the inhibitory effects of an antiserotonin and an antihistamine, were tested against histamine and 5-OHT respectively. It has been found that whilst Promezathine reverses 
the radio-protective effect of histamine in rats, it has no significant effect on 5-OHT protection. Conversely 5-OHT antimetabolites did not significantly reduce the rather weak protective action of histamine in rats.<smiles>NCCc1cnc[nH]1</smiles>

Histamıne

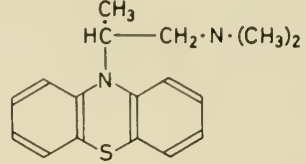

Promezathine

\section{Conclusions}

In summarizing the results of experiments presented here, it appears that radio-protection by $5-\mathrm{OHT}$ and histamine is intimately related to specific receptor-metabolite reactions in competent cells.

If the amine acted as a competitive free radical, one would suspect that (i) a sterically similar antimetabolite such as BAS, with similar physicochemical properties and chemical activity, should result in radio-protection in vivo and in vitro; (ii) the free presence in the cell, of an antimetabolite, should neither decrease the radio-protective effect of the respective metabolite nor an unrelated metabolite.

It is difficult to reconcile the findings presented, with this hypothesis of radio-protective mechanisms. Also it seems from our studies in animals depleted of histamine, 5-OHT and catechol amines, that the 'bound' endogenous entity in cells does not confer cellular radio-resistance. Its change to a 'free' form in vivo, is necessary, although decrease in sensitivity of specific vasoconstrictor receptors, allows for substantial protection to persist. However, apart from the latter finding, most of the results obtained are largely consistent with the theory, that radio-protection in vivo is due to anoxia of tissues - possibly secondary to bronchoconstriction and vasoconstriction, but more likely the result of a histotoxic anoxia. This decision will rest on the results in vitro with simpler systems, and other experiments to be detailed later.

It would seem that certain experiments are indicated. Particularly, the effect of metabolites, respective and unrelated antimetabolites, singly and in combination, should be examined for protective action in vitro using polymer solutions, for comparison with the results in the intact animal.

I am indebted to Miss M. Haas, for experimental results shown in Figure 2. Gifts of 5-hydroxytryptamine, LSD and BOL were kindly supplied by Sandoz Ltd., Marsilid (iproniazid phosphate) by Roche Products Pty. Ltd., and 1-benzyl-2,5-dimethyl serotonin $(B A S)$ by Merck \& Co. Ltd., New York. My colleague, Mrs. K. Elliott, assisted in the experimental procedures, and her invaluable help is gratefully acknowledged.

\section{REFERENCES}

${ }^{1}$ Alexander, P., Bace, Z. M., Cousens, S. F., Fox, M., Herve, A. and Lazar, J. Radiation Res. 2 (1955) 392

${ }^{2}$ Bace, Z. M. and Alexander, P. Fundamentals of Radiobiology: Butterworths, London, 1955 


\section{IISCIUSSION}

${ }^{3}$ Hollaender, A. and Doudney, C. O. Symposium of Radiobiology (Liège): Butterworths, London, 1955, p. 112

${ }^{4}$ BAcQ, Z. M. Adiances in Radiobiology (Ed. Hevesy, Forssberg and Abbot): Oliver and Boyd, Edinburgh, 1957

${ }^{5}$ Gray, J. L., Tew, J. T. and Jensen, H. Proc. Soc. exp. Biol., N.Y. 80 (1952) 604

${ }^{6}$ Bacq, Z. M. and Herve, A. Bull. Acad. Méd. Belg. 17 Series 6 (1952) 13

${ }^{7}$ Eldjarn, L. and Pihl, A. Progress in Radiobiology (Ed. Mitchell, Holmes and Smith): Oliver and Boyd, Edinburgh, 1956

${ }^{8}$ Albert, A. Selective Toxicity: Methuen, London, 1951

${ }^{9}$ Albert, A. Nature, Lond. 182 (1958) 421

${ }^{10}$ Woolley, D. W. A Study of Antimetabolites: John Wiley and Son, Inc., New York, 1952

${ }^{11}$ VAn den Brenk, H. A. S. and Elliott, K. Nature, Lond. 182 (1958) 1506

${ }^{12}$ Erspamer, V. and Vialli, M. Nature, Lond. 167 (1952) 1033

${ }^{13}$ Rein, G. Aust. J. exp. Biol. med. Sci. 29 (1951) 101

${ }^{14}$ Page, I. H. J. Pharmacol. 105 (1952) 58

${ }^{15}$ Gordon, S. A. Progress in Radiobiology (Ed. Mitchell, Holmes and Smith): Oliver and Boyd, Edinburgh, 1955

${ }^{16}$ Erspamer, V. Experientia 10 (1954) 471

${ }^{17}$ Gillis, C. N. and Lewis, J. J. Nature, Lond. 178 (1956) 859

${ }^{18}$ Vane, J. R. Brit. J. Pharmacol. 12 (1957) 344

${ }^{19}$ van den Brenk, H. A. S. Brit. J. exp. Path. 39 (1958) 300

${ }^{20}$ Gaddum, J. H. J. Physiol. 119 (1953) 363

${ }^{21}$ Gaddum, J. H. and Hameed, K. H. Brit. J. Pharmacol. 9 (1954) 240

${ }^{22}$ Csapo, A. Recent Progress in Hormone Research in the Proceedings of the Laurentian Hormone Conference, Vol. 12: Academic Press Inc., New York, 1956

${ }^{23}$ Woolley, D. W. Nature, Lond. 180 (1957) 630

${ }^{24}$ Shaw, E. and Woolley, D. W. Proc. Soc. exp. Biol., N.Y. 96 (1957) 439

\section{DISGUSSION}

DR. LoutiT: If we score our protective action versus the dose of 5-hydroxytryptamine employed, I understand that Dr. van den Brenk got a linear rise with molarity of 5-hydroxytryptamine, whereas Hope's data certainly goes through a maximum and then decreases with increasing molarity. On the other hand he did also score body temperature and found that body temperature fell with increasing dose. Thus there was this divorcement of protective action and body temperature. Have you any commentary on that sort of observation?

Mr. van DEN BREnK: With the doses of 5-hydroxytryptamine that we used we do get a linear relationship for a confined range of dosage. I have only increased the dose (this is in rats) up to $7.5 \mu$ moles after which I found that a lot of the animals died early as a result of the injection which was thus getting on towards the maximum tolerated dose of about $7 \cdot 5 \mu$ moles. Beyond this level of dosage I have no information. With regard to hypothermia-I doubt if that is an important factor in 5-hydroxytryptamine protection because reserpinized rats are definitely more hypothermic than rats treated with 5-hydroxytryptamine but fail to show significant radio-protective effect, despite being completely tranquillized, and their body temperature thus even lower.

Dr. Vogel: Several years ago I believe there was a report by von Sallmann at Columbia which stated that there was some protection in the epithelium of the lens, for cysteine as judged by mitotic counts and in the reduction in cataracts formed after whole-body irradiation with X-rays. I wondered if, with any of the agents that 


\section{RAIOAPOTICIIIE ACTION OF 5-HYDRONYTRYPTAMINE}

you used you saw any such protection against cataract formation in the rats that received 1000 to $1600 \mathrm{r}$ and lived?

Mr. VAN DEN BRENK: Yes, I saw that there were very few rats which had developed cataracts in the survivors. I should have mentioned that point. I suppose I have got 200 of these surviving rats now alive from six to twelve months and there are very few that have cataracts - the odd one we do see. I might mention with regard to the local effect of 5-hydroxytryptamine that Bacq reported that cystcamine I think he used cysteamine), given as an ointment and rubbed into the skin, gave substantial protection. He used this as an argument for it acting by competitive radical formation because there could be no vascular or anoxic effect. That, of course, is doubtful. I have repeated the experiments with cysteamine, 5-hydroxytryptamine, adrenalin and several other protective substances, using 10 per cent ointments rubbed into the skin and I could never obtain anything like the radio-protective action that I showed in skin when the animal received the substance parenterally before irradiation. There is a slight reduction in skin damage, but it is only slight. 


\title{
EFFEGTS OF RESPIRED OXYGEN-RADIO-PROTEGTIVE AGTION OF GERTAIN AMINES-(a) LETHALITY STUDIES
}

\author{
H. A. S. van den Brenk and Ruth Moore \\ Radiobiological Research Unit, Cancer Institute Board, \\ Melbourne
}

Considerable experimental evidence has been obtained associating chemical protection against ionizing radiations with alteration in oxygen tension. Particular attention has been given to sulphur-containing protective agents which exist as reducing $(-\mathrm{SH})$ and oxidizing (-SS-) entities. Loiseleur and Latarjet ${ }^{1}$ reported that cysteine, ascorbic acid and aldehydes increased the yield of $\mathrm{H}_{2} \mathrm{O}_{2}$ in $\mathrm{X}$-irradiated water, the reducing agents being considered to act as hydrogen donors, hydrogen peroxide being formed from combination with $\mathrm{HO}_{2}$ radicals as a detoxication product. Using the Hersch cell for oxygen assay, Gray ${ }^{2}$ has demonstrated the consumption of oxygen by cysteamine in vitro; Pihl and Eldjarn ${ }^{3}$ have correlated the degree of protective action with the ability to form mixed disulphides. Fischer ${ }^{4}$ showed that cysteamine, like anoxia, causes accumulation of organic acids (particularly pyruvic and lactic acids) in the plasma.

Injections of cysteamine, cysteine or glutathione cause marked falls of oxidation-reduction potentials in muscle and tumours ${ }^{5}$. Scott ${ }^{6}$ has reported that pure oxygen at 1 or 2 atmospheres protects mice against lethal doses of cysteamine, whilst mice given sub-lethal doses of cysteamine, show diminished tolerance to anoxia. Bacq et al. ${ }^{7}$ reported that cystamine decreases the oxygen saturation of venous blood, in rats, although histamine fails to do so.

The effects of reduced oxygen tensions on the radio-protective action of certain substances in vitro and in vivo have been studied for some time. Whilst 10 per cent oxygen does not protect mice against $\mathrm{X}$-rays an additive effect obtains if combined with cysteine ${ }^{8}$. Similar results were obtained for moderate hypoxia in mice with cysteamine and cystamine ${ }^{9}$.

However, Devik ${ }^{10}$ has reported that cysteamine fails to give significant protection for local tissue damage due to radiation, in perfused rabbit ears rendered severely anoxic.

One would expect the effectiveness of protective agents in the presence of raised oxygen tensions to be substantially decreased if the protective phenomenon depends on some physical interference with access of oxygen to the site of radiation damage within the cell as distinct from interaction with free radicals. Similarly, if the protective agent causes increased oxygen consumption by the tissue and local depletion of oxygen, provision of freely 
available oxygen should reduce the protective action. Four main ways in which this problem may be studied experimentally are:

(i) Alterations in calculated diffusion gradients of oxygen in relation to cell sizcs, and cell aggregates.

(ii) Artificial inhibition of oxidative metabolism by substances such as cyanide, which inactivate cytochrome, catalase, etc.; or dinitrophenol used to uncouple phosphorylation from respiratory processes.

(iii) Alteration of cellular oxygen consumption by changes in environmental temperature.

(iv) Direct alterations in partial pressures of oxygen to which cells are exposed.

Crabtrce and Cramer ${ }^{11}$ originally demonstrated that a reduction of oxidative metabolism in tumour tissue in vitro, by chilling, or cyanide and other enzyme poisons, increased radio-sensitivity in the presence of oxygen. The differences in 'oxygen effect' observed between small and large cells, single cell suspensions and cell aggregates are largely explained in relation to diffusion gradients of oxygen from the medium to the interior of the cell. In whole animals, most available evidence of the effect of increased available oxygen within the cell, on the action of protective agents, relates to the effect of cyanide.

We have investigated and compared the effects of pretreatment with cyanide, and pressurization of animals with pure oxygen during irradiation, on the effects of certain protective agents in vivo in mice and rats. Only preliminary results are available, conducted over the past five months, since an experimental apparatus was designed and constructed. This apparatus allows for the administration of pure gases or predetermined mixtures of gases to animals at pressures of up to $120 \mathrm{lb}$. per sq. in. The rate of compression and decompression of animals can be controlled and preset at desired levels. Preliminary flushing of the chamber atmosphere gives levels of purity of more than 95 per cent. Partial pressures of respired oxygen varying from 0.05 to 5.0 atmospheres have been used and the effects on the protective action of cysteamine, cystamine, 5-hydroxytryptamine (5-OHT), histamine and adrenalin, studied in both rats and mice. Preliminary studies and lethality findings, are described in this paper.

\section{Action of Cyanide on Radiochemical Protection}

Sodium cyanide itself was reported to give protection against irradiation in C57 Black strain mice ${ }^{12}$, but not in rats ${ }^{13}$. Mottram ${ }^{14}$ reported that cyanide enhanced radio-sensitivity of Vicia faba roots; Crabtree and Cramer ${ }^{11}$ found similar enhancement of radiation effects for tumour cells, whilst $\mathrm{Hall}^{15}$ found that cyanide did not alter tumour radio-sensitivity in vitro in the absence of oxygen. Cyanide does not influence the sensitivity of bacteria-a finding attributed to the free availability of intracellular oxygen by diffusion from the medium.

In view of the contradictory findings in rats and mice, we have repeated experiments using Swiss mice and both Wistar and Canberra black stock rats. The results show that a dose of $0.1 \mathrm{mg}$ of $\mathrm{NaCN}$ in $25-\mathrm{g}$ mice gives weak protection against $1000 \mathrm{r}$ whole-body irradiation. However, this protective 
effect is annulled by irradiation of cyanide pretreated mice in pure oxygen at 4 atmospheres absolute pressure. A dose of $0.2 \mathrm{mg} \mathrm{NaCN}$ in $150 \mathrm{~g}$ rats, failed to give significant protection against $1000 \mathrm{r}$ whole-body irradiation. These results are shown in Table 1.

Table 1. Effect of respired oxygen on radio-protective effect of sodium cyanide in mice (1000 r X-rays whole-body irradiation)

\begin{tabular}{|c|c|c|c|}
\hline Group & $\begin{array}{l}\text { Number of } \\
\text { Animals } \\
\text { (Mean weight) } \\
\text { in g) }\end{array}$ & $\begin{array}{l}\text { Number of } \\
\text { survivors } \\
\text { at } \\
30 \text { days }\end{array}$ & $\begin{array}{l}\text { Mean survival } \\
\text { over } 30 \text { days } \\
\text { (Days) }\end{array}$ \\
\hline Controls (Irradiated in air) & $10(25 \cdot 4)$ & 0 & $6 \cdot 70( \pm 2 \cdot 42)$ \\
\hline $\begin{array}{l}\text { Controls (Irradiated in pure oxygen at } 4 \\
\text { atmospheres absolute pressure) }\end{array}$ & $10(25 \cdot 1)$ & 0 & $4 \cdot 60( \pm 1 \cdot 76)$ \\
\hline $\mathrm{NaCN}(0.1 \mathrm{mg}) *$ (Irradiated in air) & $10(25 \cdot 2)$ & 2 & $13 \cdot 50( \pm 9 \cdot 52)$ \\
\hline $\begin{array}{l}\mathrm{NaCiN}(0 \cdot 1 \mathrm{mg}) * \text { (Irradiated in pure } \\
\text { oxygen at } 4 \text { atmospheres absolute } \\
\text { pressure) }\end{array}$ & $10(25 \cdot 9)$ & 0 & $6 \cdot 30( \pm 2 \cdot 73)$ \\
\hline
\end{tabular}

* $\mathrm{NaCN}$ administered intraperitoneally 5 minutes preceding irradiation

However, although cyanide is said to increase oxygen concentration in the blood, due to inhibition of oxygen utilization by tissues, the dose used in mice causes considerable shock and collapse of animals, and it is felt the latter may be sufficient to result in anoxic anoxaemia and slowing of the circulation. This effect in mice was clearly ameliorated when animals were observed in pure oxygen under pressure. In rats, shock and collapse following cyanide in the doses used was much less, although moderate increase in dosage resulted in toxicity and some deaths.

\section{Effect of Cyanide on Chemical Protection in Rats}

Smith et al. ${ }^{16}$ have reported that cyanide does not modify the protective action of cysteine in the rat. Our experience is limited to cystamine $(10 \times$ $10^{-5}$ moles) and 5-hydroxytryptamine $\left(0.50 \times 10^{-5}\right.$ moles $)$ in rats. The effects of a dose of $0.2 \mathrm{mg}$ of $\mathrm{NaCN}$ on the protective action of these substances, for $1000 \mathrm{r}$ whole-body irradiation, are shown in Figures 1 and 2. Whilst the protective action of 5-OHT was significantly decreased, no such significant decrease resulted for cystamine although, the difference in dosage of the two protective agents, and the relative degrees of protection afforded must be taken into account. It is quite likely that for lower doses of cystamine, a reduction in the radio-protection observed may be afforded by cyanide. Experiments to test this prediction, are to be conducted.

\section{Effect of Tension of Respired Oxygen on Chemical Protection in Rats and Mice}

Cystamine and 5-hydroxytryptamine - The effect of respired $\mathrm{pO}_{2}$ on lethality following $1000 \mathrm{r}$ X-rays to whole-body in rats and mice, protected with cystamine $\left(1 \times 10^{-4}\right.$ moles for rats, $3 \times 10^{-5}$ moles for mice) or 5-OHT 


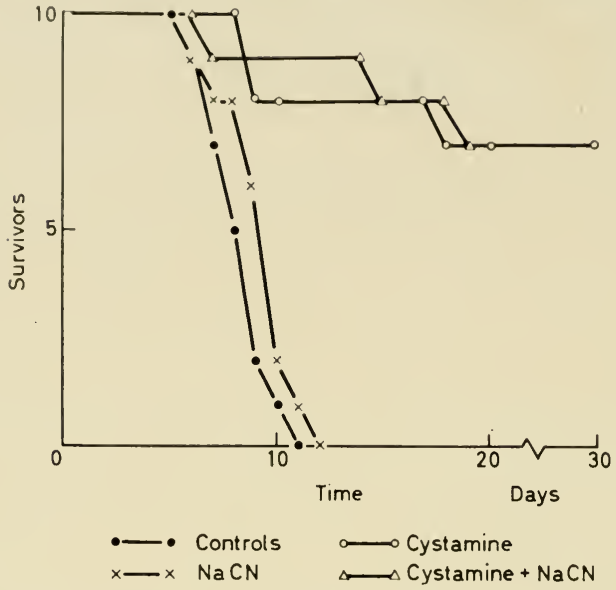

Figure 1. Effect of pretreatment with cyanide on the protective action of cystamine in rats, following $1000 \mathrm{r}$ whole-body $\mathrm{X}$ irradiation in air

$\left(0.5 \times 10^{-5}\right.$ moles for rats, $0.25 \times 10^{-5}$ moles for mice) are given in Figures 3 and 4 . For both species of animals, the protective action for both amines is

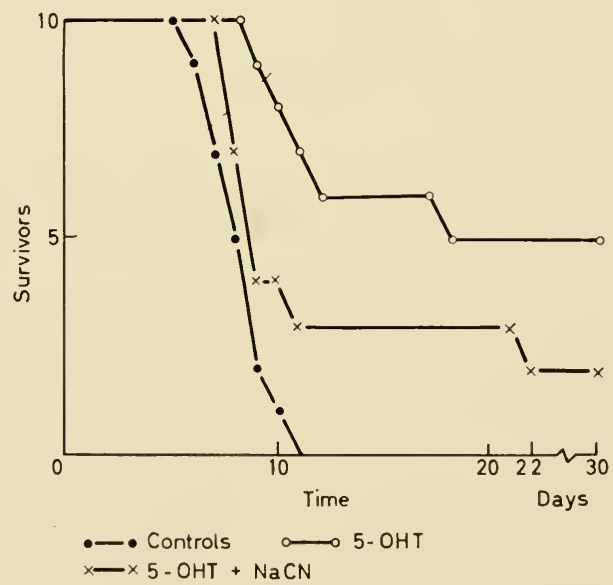

Figure 2. Effect of pretreatment with cyanide on the protective action of 5-hydroxytryptamine in rats following $1000 \mathrm{r}$ wholebody $\mathrm{X}$ irradiation in air 


\section{H. A. S. VAN DEN BRENK AND RUTH MOORE}

reduced by increasing the partial pressure of respired oxygen during irradiation, but even at 4 atmospheres pure oxygen (respired gases), substantial radio-protection exists for both rats and mice. In rats, oxygen reduces the

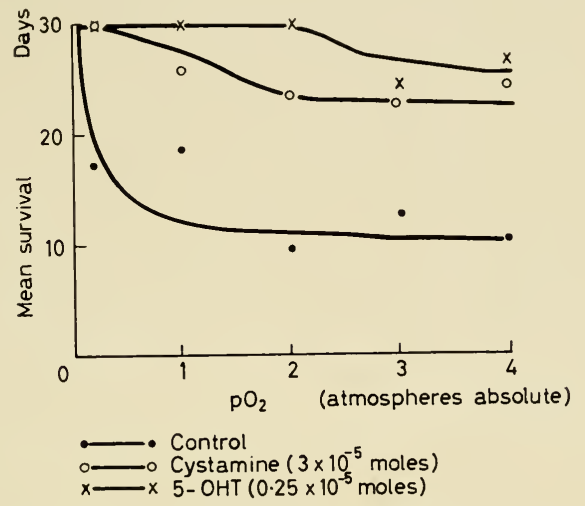

Figure 3. Effect of respired oxygen tension on the radioprotective actions of cystamine and 5-hydroxytryptamine against acute radiation-induced lethality in mice (830 r)

protective action of 5-OHT considerably more than that of cystamine, whilst the reverse holds for mice, although doses of the amines used must be taken

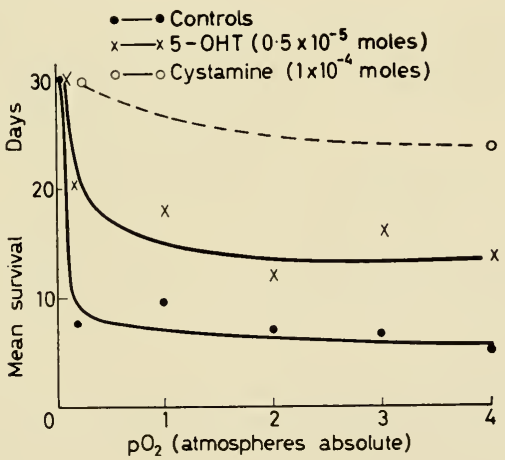

Figure 4. Effect of respired oxygen tension on the radio-protective actions of cystamine and 5 -hydroxytryptamine against acute radiationinduced lethality in rats $(1000 \mathrm{r})$

into consideration. Before any firm conclusions are reached, experiments being conducted using the amines in various doses for various partial pressures of respired oxygen will need to be evaluated. However, these preliminary 
results suggest that the protective action in wivo for rats and mice is oxygen dependent, but the results do not suggest that the protector acts solely by causing anoxic anoxacmia. For the oxidized substance cystamine (-S-S-), partial pressures of respired oxygen from $0 \cdot 2$ to 4 atmospheres absolute cause very little reduction in the radio-protection afforded in rats. This differs from the findings of Salerno et al. ${ }^{17}$ with the reduced substance cysteamine $(-\mathrm{SH})$. Direct measurements of vena caval blood oxygen concentrations for different partial pressures of respired oxygen after administration of protective agents is required, but this is difficult in practice. We hope to make some measurements of oxidation-reduction potentials and oxygen tensions using platinum electrodes after the technique of Cater et al. ${ }^{5}$ to obtain more direct information of the conditions which prevail, but inspection of the protected animals respiring 2 to 4 atmospheres pure oxygen, does not reveal the cyanosis, respiratory difficulty, or collapse, seen under similar circumstances in air at 1 atmosphere absolute.

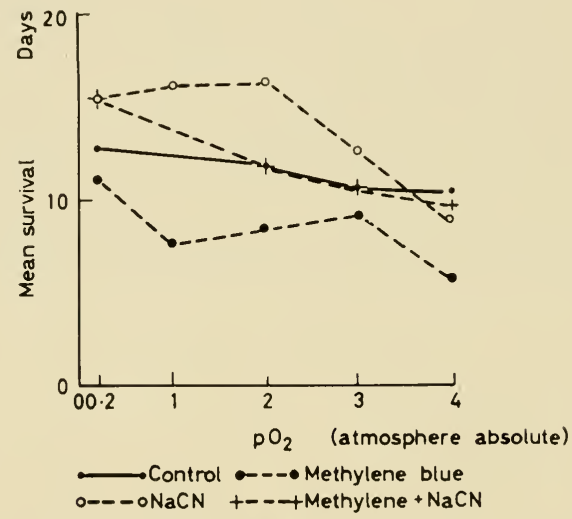

Figure 5. Effect of respired oxygen tension on acute radiation-induced lethality in mice (830 $\mathrm{r}$ X-rays), following pretreatment with sodium cyanide $(0.1 \mathrm{mg})$, methylene blue $(2 \cdot 0 \mathrm{mg})$, or combinations of these substances

Histamine and Adrenalin-A few experiments have been conducted with rats, using histamine phosphate $(10 \mathrm{mg})$ or adrenalin ( $n$-methyl-nor-adrenalin hydrochloride $0.01 \mathrm{mg}$ ) as protective agents. In our experience, these substances are very weak protective agents in the rat. Increasing the respired $\mathrm{pO}_{2}$ beyond $\mathrm{l}$ atmosphere absolute, annulled the protective action of these substances-one (histamine), a bronchoconstrictor and vasodilator, the other (adrenalin), a bronchodilator and vasoconstrictor. Again we have no direct knowledge of the various oxygen concentrations which prevailed under these circumstances, but an oxygen effect seems important in the protective action. 


\section{H. A. S. VAN DEN BRENK AND RUTH MOORE}

\section{Effect of Respired $\mathrm{pO}_{2}$ and Methylene Blue on Cyanide Protection in Mice}

It is known that methylene blue in vivo protects against cyanide poisoning of animals. Methylene blue injected into the intact animal, acts as a hydrogen acceptor and is rapidly reduced to a colourless form. It also combines with haemoglobin to form methaemoglobin. The latter substance complexes cyanide to form a biologically inert compound. As the result of its oxidizing properties, one might expect methylene blue to sensitize animals to irradiation and that such sensitization may be increased further by increasing the tissue oxygen tensions. Our preliminary results for mice support this conclusion and are shown in Figure 5. On the other hand poisoning of oxidative metabolism by cyanide, with a rise in tissue oxygen concentrations should give similar results, but for mice a protective action results, which is annulled by increasing the partial pressure of respired oxygen to 3 atmospheres absolute in mice. This latter finding suggests that for mice, cyanide may be exerting its protective effects largely due to respiratory inhibition, and anoxic anoxaemia. By combining methylene blue pretreatment with cyanide, raised respired $\mathrm{pO}_{2}$ more effectively diminishes the protective action of cyanide in mice. Again, further experiments along these lines are being conducted, incorporating competitive pharmacological actions, as with metabolite-antimetabolite inhibition, presented in the previous paper.

\section{CONCLUSIONS}

The analogy obtained for the respective effects of cyanide and artificially raised tissue oxygen tensions, on radio-chemical protection in vivo, is striking. The results point to the importance of an 'oxygen effect' in protective mechanisms.

If a substantial fraction of radiation damage is due to the production of oxidizing radicals in irradiated tissue fluids, the levels of oxygen concentration in cells is of paramount importance. A similar condition holds for the interpretation of the 'oxygen effect' as due to sensitization (by oxygen) of essential macromolecules to X-rays.

From the data provided by Lefort ${ }^{18}$ extrapolation of the curves for $\mathrm{H}_{2} \mathrm{O}_{2}$ production in water at $\mathrm{pH} 6$ to 8 by $\mathrm{X}$-rays, for different concentrations of dissolved oxygen suggest, that for the low doses of $\mathrm{X}$-rays used in mammalian biological experiments, the increase in yield of oxidizing radicals for oxygen concentrations beyond $358 \mu$ moles oxygen per litre of water (i.e. water saturated with air at atmospheric pressure) is small. The slope of the curve is greatest over initial hypoxic levels. The respiration of oxygen at 3 to 4 atmospheres $\mathrm{pO}_{2}$, would not be expected to give a quantitative increase in yield of such oxidizing radicals, accepting adequate oxygenation in the lungs and blood flow sufficient to inactivate available protective free radicals. On the other hand the oxygen effect in untreated animals is very steep over levels of 5 to 7 per cent respired oxygen ${ }^{13}$ (also see Figures 3 and 4), and most rats exposed to such levels of oxygen tension suffer extreme collapse and require resuscitation after irradiation exposures lasting 3 to 4 minutes. 'Chemically protected' animals respiring pure oxygen at 1 atmosphere and even air, do not exhibit these extreme symptoms of anoxia.

A more satisfactory explanation for the results obtained for pressurized, protected animals, and supported by the results obtained with cyanide 


\section{RADIO-PROTLCIIVE ACTION OF CERTAIN AMINES}

pretreatment, is afforded by the hypothesis, that the mechanism of radiochemical protection in vivo is partly due to relative anoxaemia, causing steeper gradients in fall-offin oxygen tension in tissues - an effect annulled by pressurization, and partly due to removal of oxygen and oxidizing radicals in cells due to pharmacological alterations in oxidative metabolism, which follows a common pattern for different protective agents and which is quantitatively related to the degree of cellular toxicity induced. The results obtained by Bacq et al. ${ }^{19}$ using sodium fluoracetate (a competitive inhibitor of the enzyme aconitase in the tricarboxylic acid cycle, which causes accumulation of citrate, and protects mice against irradiation), also seems best explained by its effect on oxidative metabolism, rather than by competition for free radicals by citrate.

\section{ADDENDUM}

Since the above experiments were conducted, our attention was drawn to an internal report of Salerno et al. ${ }^{17}$ in which oxygen respired at 5 atmospheres absolute pressure ( $60 \mathrm{lb}$ per sq. in.) completely reversed the protective action of cysteamine $(100 \mathrm{mg} / \mathrm{kg})$ in rats irradiated with $820 \mathrm{r}$ X-rays. We have extended our experiments to cover this degree of pressurization with oxygen, but a residual protection results for the disulphide cystamine $(-\mathrm{S}-\mathrm{S})$ at $60 \mathrm{lb}$. per sq. in., which is practically the same as for $45 \mathrm{lb}$. per sq. in., in agreement with the trend of the curve shown in Figure 4.

The addition of cyanide pretreatment to pressurization with oxygen, results in a much more substantial reduction in the protection of cystamine (and 5-hydroxytryptamine) but a residual protection exists, even at $60 \mathrm{lb}$. per sq. in. pressure. The full results of these experiments will be published shortly.

\section{REFERENCES}

${ }^{1}$ Loiseleur, J. and Latarjet, R. Bull. Soc. Chim. biol., Paris 24 (1942) 172

${ }^{2}$ Gray, L. H. Progress in Radiobiology: Oliver and Boyd, Edinburgh, 1956

${ }^{3}$ Pihl, A. and Eldjarn, L. Progress in Radiobiology: Oliver and Boyd, Edinburgh, 1957

${ }^{4}$ Fischer, P. Arch. int. Physiol. 64 (1956) 130

${ }^{5}$ Cater, D. B., Phillips, A. F. and Silver, I. A. Proc. roy. Soc. B 146 (1957) 382

${ }^{6}$ Scott, O. C. A. Progress in Radiobiology: Oliver and Boyd, Edinburgh, 1956

${ }^{7}$ Bace, Z. M., Cypers, Y., Evrard, E. and Soetens, R. C.R. Soc. Biol., Paris 149 (1955) 2014

${ }^{8}$ PATt, H. M. Physiol. Rev. 33 (1953) 35

${ }^{9}$ Devik, F. and Lotre, F. Acta radiol., Stockh. 44 (1955) 243

${ }^{10}$ Devik, F. Progress in Radiobiology: Oliver and Boyd, Edinburgh, 1956

${ }^{11}$ Crabtree, H. G. and Cramer, W. Proc. roy. Soc. B 113 (1933) 238

${ }^{12}$ Bace, Z. M., Herve, A., Lecomte, J. and Fischer, P. Science 111 (1950) 356

${ }^{13}$ Dowdy, A. H., Bennett, L. R. and Chastain, S. M. Radiology 55 (1950) 879

${ }^{14}$ Mottram, J. C. Brit. J. Radiol. N.S. 8 (1935) 32

${ }^{15}$ Hall, B. V. Fed. Proc. 11 (1952) 63

${ }^{16}$ Smith, D. E., PAtt, H. M. and Tyree, E. B. publication of the Biological and Medical Division, Argonne National Laboratory (1950) Report No. 4401, 72

${ }^{17}$ Salerno, P. R., Uyeki, E. and Friedell, H. L. publication of the W'estern Reserve L'niversity (1955) A.E.M.R. Project W31-109-eng-78, No. 4924

${ }^{18}$ Lefort, M. J. Chim. phys. 47 (1950) 179

${ }^{19}$ Bace, Z. M., Fischer, P., Herve, A., Liebece, C. and Liebece-Hutter, S. Nature, Lond. 182 (1958) 175 


\title{
EFFEGTS OF RESPIRED OXYGEN-RADIO-PROTEGTIVE AGTION OF CERTAIN AMINES- $(b)$ RAT LYMPHOGYTES (in vivo)
}

\author{
Ruth Moore and H. A. S. van den Brenk \\ Radiobiological Research Unit, Cancer Institute Board, \\ Melbourne
}

RAT LyMPHOCYTES, in vivo and in vitro, have been used as a radiobiological indicator for the study of quantitative effects in non-dividing but radiosensitive cells $1,2,3,4$. The ratio of degenerating to normal cells at a predetermined time after irradiation can be used as a measure of radiation damage. Clearly observable pyknotic changes are visible within a few hours of irradiation, the time of onset of pyknosis varying from cell to cell.

Using explanted rat lymph nodes, Trowell ${ }^{3}$ demonstrated that an increase in oxygen in the irradiated medium caused an increase in radio-sensitivity, which, at 100 per cent oxygen tension, was twelve times that for the anoxic state. Patt et al. ${ }^{5}$ showed that cysteine had a protective action on irradiated rabbit thymocytes in vitro in the presence of oxygen.

The experiments described below were designed to determine the influence in vivo on the irradiation of rat lymphocytes of:

(1) two radio-protective agents, cystamine and 5-hydroxytryptamine (5-OHT)

(2) changes in respired oxygen pressure

(3) the effect of respired oxygen tensions on the chemical protection.

\section{MATERIALS AND METHODS}

The rats used were from a Canberra black stock, weighing between 60 and $70 \mathrm{~g}$.

Cystamine and 5-hydroxytryptamine in aqueous solution were injected intraperitoneally 7 minutes before irradiation. The rats were irradiated with $400 \mathrm{r}$ X-rays, whole-body dose, in a specially-designed pressure tank, described in the previous paper.

At a fixed time after irradiation, the rats were killed by cervical fracture, and two lumbar and one sacral lymph nodes were dissected out. Each node was used to prepare a film using the technique of Trowell ${ }^{2}$. The time between killing the rats and fixing the films was from 7 to 10 minutes.

Each slide was coded to eliminate subjective error, and 500 small lymphocytes were counted and scored for each film. Previous experiments carried out had shown that when nodes were fixed 5 hours after treatment, pyknotic cells present were mainly in the later stages of degeneration, and the presence of a considerable number of chromatin fragments made accurate counts 


\section{RAIOIO-PROTIECIVE ACTION OF CIRTAIN AMINES}

difficult. Consequently, counts were made from films fixed 3 hours after irradiation.

\section{RESULTS}

The results of cell counts are shown in Table 1. They show that for rat lymphocrtes in vivo there is no significant difference between irradiation of the animal

Table 1. Effect of 5-hydroxytryptamine $\left(0.25 \times 10^{-5}\right.$ moles $)$ and cystamine $\left(0.33 \times 10^{-4}\right.$ moles $)$ on the pyknotic count of lymph nodes 3 hours after irradiation ( $400 \mathrm{r}$ whole-body dose) in zizo. Eflect of increased respired oxygen tension on the radio-protective action.

The figures represent the means and the standard deviations. Figures in parenthesis indicate the number of nodes examined.

Both 5-hydroxytryptamine and cystamine significantly reduce the percentage of pyknotic lymphocytes after irradiation in both air and oxygen $(P \leqslant 0.01$ in all cases).

\begin{tabular}{|c|c|c|}
\hline Treatment & Pyknosis (per cent) & Significance \\
\hline $\begin{array}{l}\text { 5-hydroxytryptamine only } \\
\text { Cystamine only }\end{array}$ & $\begin{array}{l}2 \cdot 0 \pm 1 \cdot 30(15) \\
4 \cdot 2 \pm 2 \cdot 67(15)\end{array}$ & \\
\hline $\begin{array}{l}\text { Irradiation in air } \\
\text { Irradiation in oxygen* }\end{array}$ & $\begin{array}{l}21 \cdot 9 \pm 5 \cdot 96(15) \\
20 \cdot 3 \pm 5 \cdot 42(28)\end{array}$ & $\begin{aligned} t & =0 \cdot 310 \\
P & \geqslant 0 \cdot 05\end{aligned}$ \\
\hline $\begin{array}{l}\text { 5-hydroxytryptamine (Irradiated in air) } \\
\text { 5-hydroxytryptamine (Irradiated in oxygen*) }\end{array}$ & $\begin{array}{l}13 \cdot 1 \pm 4 \cdot 93(29) \\
16 \cdot 3 \pm 6 \cdot 14(29)\end{array}$ & $\begin{aligned} t & =2 \cdot 22 \\
P & \leqslant 0 \cdot 05\end{aligned}$ \\
\hline $\begin{array}{l}\text { Cystamine (Irradiated in air) } \\
\text { Cystamine (Irradiated in oxygen*) }\end{array}$ & $\begin{array}{l}16 \cdot 4 \pm 6 \cdot 08(30) \\
13 \cdot 8 \pm 4 \cdot 79(28)\end{array}$ & $\begin{aligned} t & =1.82 \\
P & \geqslant 0.05\end{aligned}$ \\
\hline
\end{tabular}

* Oxygen respired at 4 atmospheres absolute pressure.

in pure oxygen at 4 atmospheres absolute pressure and irradiation carried out in air at atmospheric pressure; both cystamine and 5-OHT in the doses used, give significant protection against irradiation of rat lymphocytes in vivo, whether the animal is irradiated in air at atmospheric pressure or in pure oxygen at 4 atmospheres absolute pressure; whilst oxygen at 4 atmospheres pressure significantly reduces the protective effect of 5-OHT, compared with irradiation in air, no such significant difference was obtained for cystamine.

The 'oxygen effect', even in the presence of 5-OHT protection is small. However, a series of initial experiments gave results which indicated the trend outlined, and subsequently the experiments were repeated independently, and confirmed the original findings.

Throughout the examination of the prepared material, the histological descriptions of Trowell have been confirmed, and similar quantitative variations in counts (standard errors) have been obtained. However, the more detailed descriptions of pyknosis given by Schrek $^{6}$, using phase contrast, have been recognized in fixed stained material.

\section{DISCUSSION OF RESULTS}

Trowell ${ }^{3}$ found that the sensitivity of isolated lymph nodes was influenced by oxygen concentrations betwcen 0 and 100 per cent at atmospheric pressure, 


\section{RUTH MOORE AND H. A. S. VAN DEN BRENK}

but was not increased by an increase in pure oxygen tension from 1 to 2 atmospheres. His results show a twelvefold increase in radio-sensitivity from 0 to 100 per cent oxygen. However, this increase is largely dependent on the physical gradients which prevailed from the outside to the inside of the nodes. The figures he gives for oxygen tensions are those at the surface. For lymph nodes in vitro the tension decreases in proportion to the distance from the surface of the node ${ }^{1}$ and at oxygen tensions of less than 1 atmosphere, the centres of the larger nodes are anoxic and often necrotic. Owing to variations in the size of the explants it is impossible to assess the 'oxygen effect' factor.

In the experiments described, for intact rats breathing air, the oxygen tension in the tissue fluid of a well-vascularized organ such as a lymph node would be much more uniform. Also, the actual available oxygen in the presence of haemoglobin would be much larger than for tissue fluid, and this factor must be taken into consideration in evaluating the extent of a given rise in gaseous oxygen pressure, in equilibrium with the particular fluid. A significant change in radio-sensitivity in vivo would only be expected, for lymph nodes, under conditions of severe anoxia.

Both cystamine and 5-OHT exert a protective effect in vivo. No information is available concerning their effect in vitro. In the case of 5-OHT, increasing the respired oxygen tension to 4 atmospheres significantly reduces radioprotection. This result has not been found for the oxidized protective substance cystamine $(\mathrm{S}-\mathrm{S})$.

These results closely agree with the findings described for lethality of protected rats respiring oxygen at various partial pressures. It will be noted that the protective effect of both amines is small for this radio-biological indicator in comparison with whole-body effects. For mouse spleen and thymus, irradiated in vivo ${ }^{7}$ the protective action of cysteamine is also slight. It is difficult to escape the conclusion that the radio-protection afforded by these substances is less in well-vascularized organs and may be largely due to an upset in intracellular oxygen tension-partly the result of cellular anoxia due to anoxaemia, and partly due to a histotoxic anoxia.

\section{REFERENCES}

${ }^{1}$ Trowell, O. A. Exp. Cell Res. 3 (1951) 79

${ }^{2}$ Trowell, O. A. J. Path. Bact. 64 (1952) 687

${ }^{3}$ Trowell, O. A. Brit. J. Radiol. N.S. 26 (1953) 302

${ }^{4}$ Trowell, O. A., Corp, M. J. and Lush, W. R. Radiation Res. 7 (1957) 120

${ }^{5}$ Patt, H. M., Blackford, Margaret E. and Staube, R. L. Proc. Soc. exp. Biol., N.Y. 80 (1952) 92

${ }^{6}$ Schrek, R. Radiology 65 (1955) 912

${ }^{7}$ Gerebtzoff, M. A. and Bace, Z. M. Experientia 10 (1954) 341 


\title{
THE LIFE-SPAN OF MUTAGENS PRODUCED IN CELLS BY IRRADIATION
}

\author{
W. D. JACKSON \\ Botany Department, University of Tasmania, Hobart
}

INTRODUCTION

Ti1e target theory as put forward by Lea ${ }^{1}$ assumes direct action between the incident radiation and the cellular components. In chromosome breakage it is assumed that each break is produced by a particular particle. A basic assumption is that the initial chemical agents which are produced at ionization centres have a very short half-life and a short mean free path.

On the basis of an unqualified target theory we would expect irradiation to produce effects quite different from those produced by chemical mutagens. Instead, practically all investigations have shown a surprising similarity. Such similarity might be expected if irradiation were indirect in action through the agency of a chemical phase, with production of mutagenic substances or radicals which have a relatively long mean free path and half-life.

There is altogether much evidence which suggests such an indirect mode of action although there would seem to be certain results which are still adequately explained by the target theory based on direct action.

Evidence for an indirect action has come through study of the oxygen effect, where high oxygen tension gives enhanced damage with low ion density irradiation. A change in oxygen concentration from atmospheric to near zero concentrations causes a reduction of damage by a factor of two to three in a wide variety of material and in a number of responses such as (1) chromosome breakage, (2) mitotic rate, (3) growth, (4) survival or mean lethal dose, (5) skin reactions, (6) lethal mutations.

Fractionation of the dose into a number of smaller doses separated in time reduces the effect of irradiation. Decreasing the dose rate or intensity also has this effect. It seems reasonably certain that damage also increases proportionately with the linear ion density of the irradiation although the effects generally pass through a maximum with respect to types of irradiation ranked in increasing order of ion density. This is presumably due to the opposing effects of linear ion density and total path length per unit volume.

Some experimentation with these combined variables has been made. For example, experiments of Gray and Scholes ${ }^{2}$ show that the dose-rate effect is only observable with low linear ion densities. Similarly, experiments by Thoday and Read ${ }^{3}$, Giles et al. ${ }^{4}$, Swanson ${ }^{5}$ and Bender ${ }^{6}$ show that the oxygen enhancement is only observable at low ion density. Kirby-Smith and Dolphin ${ }^{7}$ have reported experiments on varying the dose rate at two levels of oxygen tension. Here no change was found in dose-rate effect at low 
oxygen levels but a marked effect at high oxygen levels was observed. If we consider these experiments as a group we find some difficulty in using the target theory as a functional hypothesis and it seems that the mechanism is better explained by some process which approaches target theory behaviour only under certain limiting conditions.

Further evidence for the form of the required working hypothesis is found in the patterns of chromosome breakage. Kotval and Gray ${ }^{8}$ concluded that about half of the breaks caused by $\alpha$-particles are caused by particles which do not traverse the chromatid. Camara ${ }^{9}$ and Jackson and Barber ${ }^{10}$ have demonstrated marked non-random distributions of simple breaks in chromosome arms. Frequency of breaks per unit length in different regions of the chromosome may show a fifty-fold variation. Such differences seem to be explained readily by assuming either that near misses are more effective in certain regions, or that many more ionizations are required in some regions before breakage occurs. Both these arguments suggest a cumulative indirect action. The remarkable similarity between the distribution of breaks produced spontaneously and those produced by X-rays, is further evidence in this direction.

The distribution of breaks between cells also shows evidence of cumulative, rather than direct action. On the basis of the target theory a Poissonian distribution is expected. However, the analysis of Jackson and Barber ${ }^{10}$ shows that the distribution of breaks after irradiation, like the distributions after treatment with alkylating mutagens or after spontaneous breakage, shows pronounced over-dispersion. There are marked tails of multiple events, the variance increasing as some power of the mean. All the distributions are fitted extremely well by the negative binomial distribution.

This is strong evidence for cumulative action in irradiation. Breakage appears to result from the cumulative action of a number of primary events scattered in space and in time, each of which contributes by the diffusion and collective action of active compounds or radicals. On this basis a suitable model leading to a negative binomial distribution can be constructed whereby cumulative contribution is obtained by incorporating a contagion factor in the probability equation. If diffusion is restricted by, say, the reduction in the mean free path, or when the mean number of events occurring in a given space and time is small, then collective contribution becomes negligible and damage occurs only in the local region of each primary event. Under these conditions, the contagion disappears and the model function approaches the Poissonian limit of the target theory. Such an hypothesis has at least the ability to explain direct and indirect action depending on the conditions.

There are two further lines of evidence pointing to indirect action. They are: (1) the fact that variation in dose rate, by fractionation or intensity, has no effect in the absence of oxygen, (2) the fact that the presence of oxygen increases the frequency of damage after $\mathrm{X}$ irradiation but has no influence on damage by high intensity radiation such as that by $\alpha$-rays. Both these effects can be explained on the basis of radio-chemical reactions known to occur in water. This evidence points clearly to the presence of an intermediate step between ionization and chromosome breakage.

It has been shown by Giles and Beatty ${ }^{11}, \operatorname{Read}^{12}$ and others, that in 
actively metabolizing material the oxygen tension is only effective in altering the irradiation damage if present during irradiation. It might be inferred from this that oxygen acts only by increasing the original yield of mutagen at the ionization sites. If this were so it would presumably act as a simple multiplying factor to the dose as has been suggested by Read ${ }^{13}$. The consistent values of between two and three for the oxygen enhancement mentioned before seem sufficient basis for this. However, there is increasing evidence which will be reviewed later, to show that oxygen, not only increases the primary yield of mutagens but by altering the biological protective system and by propagating chain reactions involving the original products also increases the effective half-life of the mutagens.

The influence of oxygen on the life-span of mutagens can be demonstrated by changes in the physiological conditions.

Since the demonstration ${ }^{14,15}$ that protection against inactivation of enzymes by irradiation can be obtained by relatively small quantities of biological reducing agents such as thiourea, similar protection by a range of such agents has been shown in a variety of organisms. Reviews of the literature have been given by Gray ${ }^{16}, \mathrm{Patt}^{17}$ and Hollaender ${ }^{18}$. Protection against chromosome breakage has been demonstrated by Mikaelsen ${ }^{19}$, Riley $^{20}$ and others. This form of protection operates by limiting the lifespan of the mutagenic products and thus differs from the protection obtained by reducing the oxygen concentration. Linked with this is the evidence from numerous experiments which indicates that the final breakage pattern is determined by modification of the results of the initial breakage by oxygen. This is possible either by causing more breakage or by altering the amounts of restitution and reunion between broken chromosome ends. Both these principles have been claimed to be effective. Giles and his co-workers ${ }^{4}$ have advocated the hypothesis of differential breakage while Schwartz ${ }^{21}$ and Baker and von Halle ${ }^{22}$ have proposed the differential reunion mechanism. However, it seems that these experiments find a more likely explanation along the general lines of an hypothesis suggested by Thoday ${ }^{23}$ and Gray ${ }^{24}$. This supposes that irradiation causes a spectrum of damage to the chromosomes, producing both actual and potential breaks in proportions altered by ion density and oxygen. The fate of the potential breaks is determined by consequent physiological conditions in which oxygen again plays an important part in transforming latent breaks into actual breaks.

If oxygen also influences breakage by determining the fate of potential breaks it should be possible to separate experimentally this sccondary cumulative effect from the direct effect of irradiation and from the increase to the immediate production of mutagen resulting from the presence of oxygen at the seat of ion formation. In particular, further exploration of these effects is possible by examining the oxygen effect under conditions of dormancy where the enzymes of the protective systems are hardly functional. The irradiation of seed has demonstrated that the oxygen effect is more pronounced in seeds than it is in actively metabolizing tissues. In addition, oxygen alone produces damage similar to that of X-rays.

Gustafsson ${ }^{25}$ observed that the frequency of aberrations in the first mitotic divisions in barley after irradiation of the dry seed was doubled (from 16 per cent to 33 per cent) by storage for two months after irradiation. He also 


\section{W. D. JACKSON}

showed $^{26}$ that germination and growth was decreased by storage after irradiation. Nichols ${ }^{27}$ showed that aged seed had the same symptoms of damage as irradiated seed and that aged seed was strongly affected by post-irradiation storage. Jackson ${ }^{28}$ reported similar damage in aged seed treated with oxygen and in irradiated seed. Nilan ${ }^{29}$ showed that low doses of irradiation producing undetectable effects when the seeds were germinated immediately, caused greatly increased effects when stored for four months especially when stored in oxygen. Yagyu and Morris ${ }^{30}$ have studied the post-storage effect in air after irradiation with $\mathrm{X}$-rays and thermal neutrons, both producing qualitatively similar results. Sire and Nilan ${ }^{31}$ found that pre- and post-treatment with oxygen increased X-ray damage in Crepis seeds, the frequency of micro-acentrics being increased disproportionately by post-storage. A non-random distribution of breaks between chromosome arms was found. This was not influenced by pre- or post-storage.

The following experiments were aimed at partitioning the total effect of irradiation on the basis of mechanism.

It was thought that by comparing the effect of the irradiation of dry seed in nitrogen with that in oxygen-nitrogen mixtures, a partition of the total effect into direct and indirect action of irradiation could be obtained. By comparison with the breakage due to oxygen alone, that part of the total breakage due to the direct effect of oxygen as distinct from irradiationoxygen effects could be determined. The remaining fraction is the total indirect effect or oxygen-irradiation interaction. This effect of oxygen could be divided further into that portion due to the increase in the primary yield at ionization centres and that portion resulting from a longer effective life-span of the mutagen. The latter partition could be obtained by comparing effects after post-storage in various oxygen concentrations with those after post-storage in nitrogen or those with no post-storage.

Attempts have also been made to extract mutagenic substances from dormant seeds.

\section{MATERIALS AND METHODS}

Various stocks of seeds of Allium cepa var. Br. Spanish, of different ages, were examined for chromosome breakage. Stocks were examined when fresh and re-examined after two and four years. This seed was used for comparison with fresh seed of the same strain in irradiation experiments using soft $\mathrm{X}$-rays. The irradiation was produced by a Coolidge type tube operating at a peak of $22.4 \mathrm{kV}$ at $55 \mathrm{~mA}$, giving an intensity of $50 \mathrm{r} \mathrm{sec}^{-1}$ at $10 \mathrm{~cm}$ from the target. The seed was irradiated in thin-glass phials in various mixtures of oxygen and nitrogen. The dose was measured by a thimble-type Victoreen meter placed in the phials. Target distance was kept constant and dose was varied by changing the duration of the exposure. To prevent overheating of the tube the dose was given in fractions of eight seconds with 10 seconds between fractions. Various doses from $0.8 \mathrm{kr}$ to $6.4 \mathrm{kr}$ were used, most of the experiments being done at low doses of 1.2 and $2.4 \mathrm{kr}$. The temperature at the time of irradiation and during storage was $18 \pm 1^{\circ} \mathrm{C}$.

The dry seed was stored before, during and after irradiation in various oxygen-nitrogen mixtures $(0: 100,20: 80,100: 0)$, in sealed thin-glass phials. The period of storage before irradiation was two weeks. Its purpose was to 
allow the gas tensions in the embryos to reach an equilibrium with the surrounding mixture of gases. Post-storage was tested by comparing seed germinated immediately after irradiation with seed held in the original phials for a further two weeks before germination. In one set of experiments post-storage was extended to one month after irradiation. As controls stock seed was compared with seed stored for two weeks and four weeks in 0,20 , and 100 per cent mixtures of oxygen in nitrogen.

All material was examined by germinating in petri dishes at $23 \mathrm{C}$ and fixing at the peak of the first mitotic divisions in the radicle. Squash preparations were made from seedlings selected at random and scored for number of acentric chromosome fragments per cell. The remaining sced was left in the petri dishes for comparisons of rates of growth.

In a further preliminary experiment fresh seed and two-year-old seed was irradiated with a dose of $4.8 \mathrm{kr}$ in air and in nitrogen after pre-storage for two weeks. Following irradiation the seed was leached using two cc of water in small closed-system cyclic extractors with an atmosphere of air. Fifty fresh seeds previously irradiated in air with $0.8 \mathrm{kr}$ of $\mathrm{X}$ irradiation were placed in the base of each extractor where they inbibed the lcachate. The extractions were carried out for seven days at 3 to $5 \mathrm{C}$, after which the seeds were germinated at $23 \mathrm{C}$ in the leachate and examined as above. Controls were run in which unirradiated fresh and aged seed was substituted for the corresponding irradiated seed in the leaching column.

\section{RESULTS}

Ageing of the seed causes an approximately exponential increase in spontaneous breakage. The percentage of aberrant cells in seed stored in air at

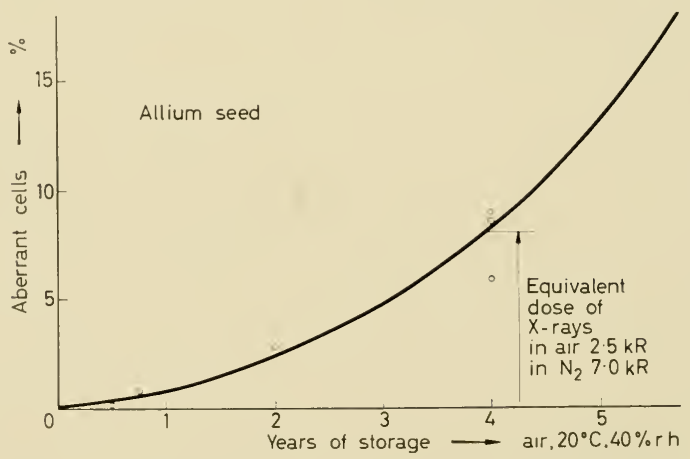

Figure 1. Frequency of cells with chromosome aberrations in seed stored in air for various periods, showing the exponential increase in damage with age

room temperature for periods of up to four years is shown in Figure 1 . The approximate equivalent dose of $\mathrm{X}$ irradiation, which must be given to fresh seed to produce the same level of damage as that found in four-year-old seed, 


\section{W. D. JACKSON}

was $2.5 \mathrm{kr}$. When fresh seed was irradiated in an atmosphere of nitrogen, following 14 days' storage in that gas, much less damage resulted. It was estimated graphically that a dose of about $7 \cdot 0 \mathrm{kr}$ would be required to produce the same damage as the dose of $2.5 \mathrm{kr}$ in air or the four years' storage in air.

It appears likely that oxygen is involved in the ageing process. It has long been known as one of the principal factors in seed storage ${ }^{32,33}$. It has also been shown by Conger and Fairchild ${ }^{32}$ that oxygen causes breakage in dormant pollen grains. The results of storage of fresh seed for four weeks in atmospheres of nitrogen, 20 per cent oxygen in nitrogen, and in pure oxygen, are shown in Figure 2. The damage is scored as number of acentric fragments per cell. It is seen that pure oxygen causes appreciable damage in four

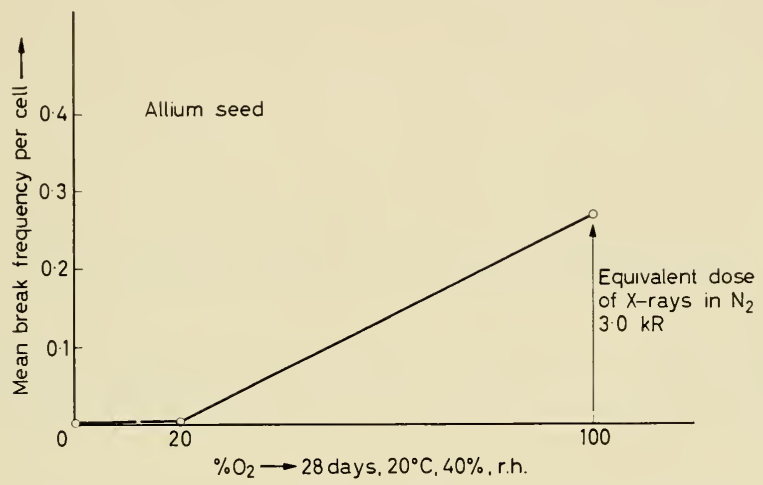

Figure 2. Frequency of chromosome breaks per cell in seed stored for four weeks in oxygen-nitrogen mixtures, showing the exponential increase in damage with oxygen concentration

weeks. The estimated equivalent dose of X-rays given in nitrogen is approximately $3 \mathrm{kr}$ so that one month's storage in pure oxygen is roughly equivalent to two years' storage in air.

The influence of oxygen combined with a small dose of $\mathrm{X}$ irradiation on fresh seed is shown in Figure 3. A dose of $1 \cdot 2 \mathrm{kr}$ given to seed in a nitrogen atmosphere after 14 days' storage in that gas causes the average of one fragment in 10 cells. The damage is approximately eight-fold in pure oxygen, and about three-fold in air. Utilizing the result obtained in the control series we may deduct a small part from the total effect at high oxygen tensions, due to the direct effect of oxygen, and we may regard the damage caused in pure nitrogen as the direct effect of irradiation. This partition of the damage into its relative parts is shown in Figure 4 . The shaded area represents the contribution to the total damage by the interaction of oxygen with the irradiation. This contribution rises more rapidly at low oxygen concentrations, although it increases throughout the range of oxygen concentration.

When the seed is held in the phials for a further 14 days of post-storage 
after irradiation, breakage increases. 'These results are plotted in Figure 5, with the results of the experiments without post-storage for comparison. The increase at low oxygen concentration is marked. As before, this total

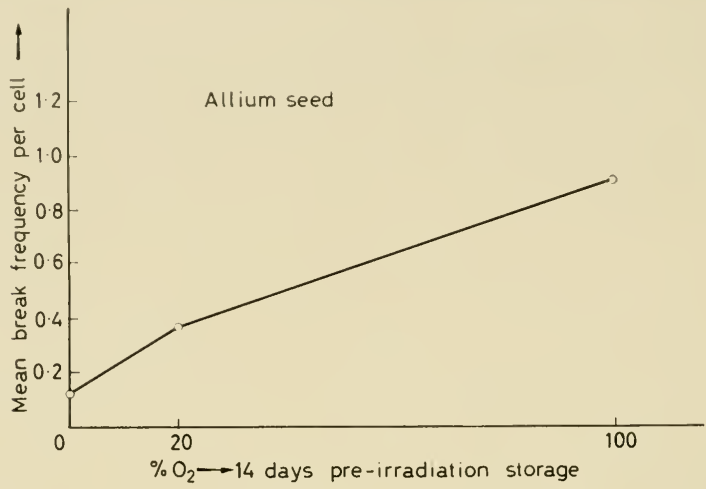

Figure 3. Frequency of chromosome breaks per cell in seed germinated immediately after irradiation in various oxygen-nitrogen mixtures and pre-storage for two weeks in these atmospheres (1.2 kr X irradiation)

effect may be partitioned into its various components and this is shown in Figure 6. The direct effect of irradiation and the direct effect of oxygen can be deducted. This leaves a large component made up of the interaction

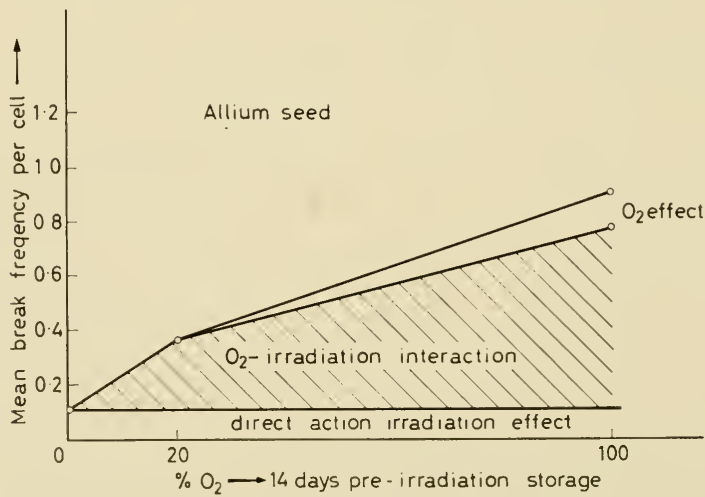

Figure 4. Partition of the total irradiation-oxygen damage shown in Figure 3

between irradiation and oxygen previously shown in Figure 4 and a poststorage oxygen effect (shaded area in Figure 6), which is again zero in nitrogen but which rises to full effect in 20 per cent oxygen concentration. 


\section{W. D. JACKSON}

Some information of the amount of post-storage damage with increasing time of post-storage has been obtained. Figure 7 shows the total damage,

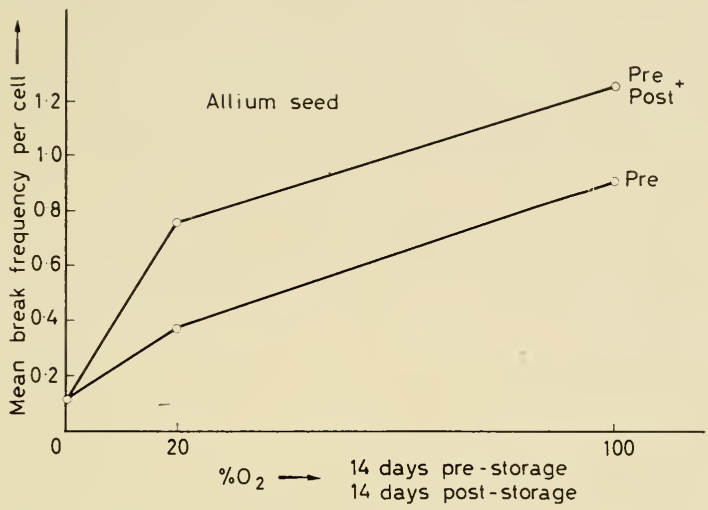

Figure 5. Frequency of chromosome breaks per cell in seed after fourteen day's' post-irradiation storage, irradiation and pre-storage in various oxygen-nitrogen mixtures ( $1 \cdot 2 \mathrm{kr} \mathrm{X}$ irradiation)

expressed as the proportion of damaged cells, after various intervals of poststorage in air. From this it would appear that little increase is obtained after 10 to 14 days. The total damage expressed as mean number of chromosome

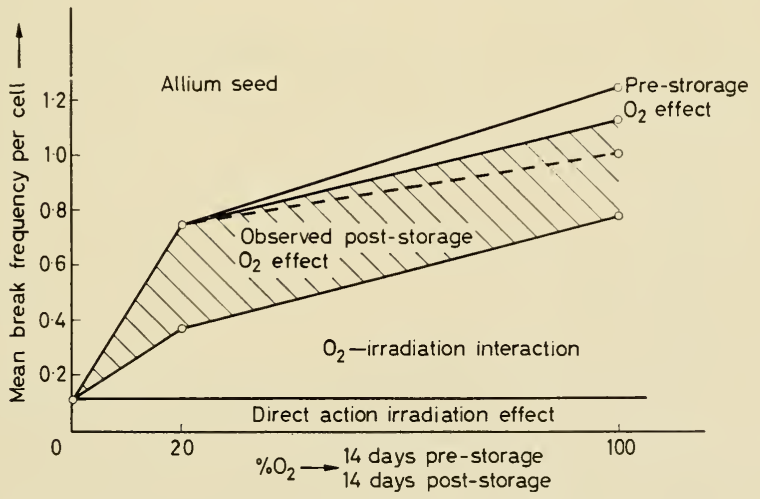

Figure 6. Partition of the total irradiation-oxygen damage shown in Figure 5

breaks after no post-storage and after two and four weeks' post-storage in nitrogen, 20 per cent oxygen in nitrogen, and pure oxygen is shown in Figure 8. Again, the total damage in 20 per cent oxygen increases rapidly 
after irradiation, approaching a limit after two weeks' post-storage. In 100 per cent oxygen the total damage continues to increase even after four wecks of post-storage, while in nitrogen no post-storage effect is shown.

Standard errors are not shown on the figures. These increase with oxygen

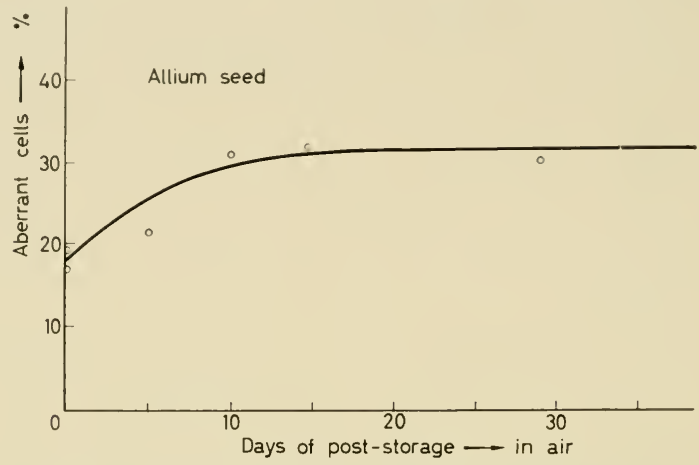

Figure 7. The effect of increasing the post-storage period in air on irradiation damage measured by frequency of cells with chromosome aberrations, showing the continued breakage in the two weeks following irradiation $(2 \cdot 4 \mathrm{kr} \mathrm{X}$ irradiation)

concentration. Treatments with oxygen show a large variance both within and between seeds. In general, the variance increases with the mean

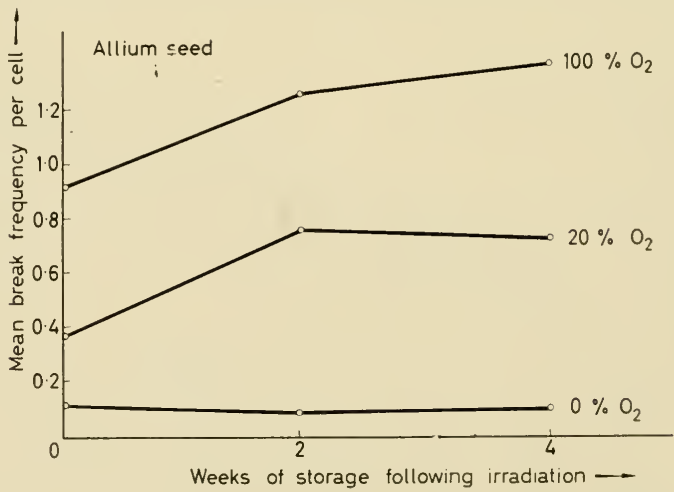

Figure 8. The effect of post-storage in various oxygen-nitrogen mixtures for two and four weeks after irradiation, showing that the increased breakage is dependent on oxygen concentration $(1 \cdot 2 \mathrm{kr}$ $\mathrm{X}$ irradiation)

breakage but at a faster rate so that the ratio of the variance to the mean increases in the series nitrogen, 20 per cent oxygen, 100 per cent oxygen and 


\section{W. D. JACKSON}

also in the series storage without irradiation, storage with irradiation, and storage with irradiation and additional post-storage. These trends are shown in Table 1.

Table 1. Chromosome breaks induced in pre- and post-irradiation storage in various oxygen-nitrogen mixtures-Mean and standard error of chromosome breaks per cell $(\bar{x} \pm$ S.E. $)$, and mean index of dispersion for these chromosome breaks $(V x / \bar{x} \pm$ S.E. $)$ Comparisons are shown of the Fits between the Sum Data, the Sum Poisson and Sum Negative Binomial fitted individually to the distributions for each root

\begin{tabular}{|c|c|c|c|c|c|c|c|c|c|c|}
\hline & $\begin{array}{c}\text { Storage } \\
\text { atmosphere }\end{array}$ & & \multicolumn{8}{|c|}{ Chromosome breaks per cell } \\
\hline $\begin{array}{c}\text { Pre- } \\
\text { irradiation }\end{array}$ & $\begin{array}{c}1 \cdot 2 \mathrm{kr} \\
\text { Irradiation }\end{array}$ & $\begin{array}{l}\text { Post- } \\
\text { irradiation }\end{array}$ & $\bar{x}$ & S.E. & $V x / \bar{x}$ & S.E. & cells & Fit & $\chi^{2}$ & $P$ \\
\hline $\mathrm{N}_{2}$ & - & - & $0 \cdot 06$ & 0.06 & $1 \cdot 1$ & $0 \cdot 7$ & 123 & $\begin{array}{l}\text { Poiss. } \\
\text { N. Bin }\end{array}$ & $\begin{array}{l}0.37 \\
0.02\end{array}$ & $\begin{array}{r}70.55 \\
20.85\end{array}$ \\
\hline $\mathrm{N}_{2}$ & $\mathrm{~N}_{2}$ & - & $0 \cdot 19$ & 0.08 & $1 \cdot 2$ & 0.9 & 109 & $\begin{array}{l}\text { Poiss. } \\
\text { N. Bin }\end{array}$ & $\begin{array}{l}0.03 \\
1 \cdot 56\end{array}$ & $\begin{array}{r}30.85 \\
5 \quad 0.50\end{array}$ \\
\hline $\mathrm{N}_{2}$ & $\mathrm{~N}_{2}$ & $\mathrm{~N}_{2}$ & $0 \cdot 22$ & $0 \cdot 10$ & $1 \cdot 2$ & $0 \cdot 2$ & 68 & $\begin{array}{l}\text { Poiss. } \\
\text { N. Bin }\end{array}$ & $\begin{array}{l}2 \cdot 06 \\
0 \cdot 41\end{array}$ & $\begin{array}{l}0.40 \\
0.85\end{array}$ \\
\hline air & air & 一 & 0.37 & 0.03 & $1 \cdot 2$ & $0 \cdot 1$ & 239 & $\begin{array}{l}\text { Poiss. } \\
\text { N. Bin }\end{array}$ & $\begin{array}{r}8 \cdot 23 \\
4 \cdot 58\end{array}$ & $\begin{array}{l}30.02 \\
3 \quad 0.20\end{array}$ \\
\hline air & air & air & 0.75 & $0 \cdot 28$ & $2 \cdot 1$ & $1 \cdot 8$ & 73 & $\begin{array}{l}\text { Poiss. } \\
\text { N. Bin }\end{array}$ & $\begin{array}{l}5 \cdot 37 \\
0.91\end{array}$ & $\begin{array}{l}0.15 \\
0.90\end{array}$ \\
\hline $\mathrm{O}_{2}$ & - & - & $0 \cdot 14$ & $0 \cdot 04$ & $1 \cdot 6$ & $1 \cdot 2$ & 83 & $\begin{array}{l}\text { Poiss. } \\
\text { N. Bin }\end{array}$ & $\begin{array}{r}0.49 \\
0.05\end{array}$ & $\begin{array}{r}0.50 \\
0.98\end{array}$ \\
\hline $\mathrm{O}_{2}$ & $\mathrm{O}_{2}$ & - & 0.91 & 0.37 & $3 \cdot 2$ & $1 \cdot 8$ & 113 & $\begin{array}{l}\text { Poiss. } \\
\text { N. Bin. }\end{array}$ & $\begin{array}{r}46 \cdot 15 \\
2 \cdot 07\end{array}$ & $\begin{array}{r}0.001 \\
7 \quad 0.92\end{array}$ \\
\hline $\mathrm{O}_{2}$ & $\mathrm{O}_{2}$ & $\mathrm{O}_{2}$ & $1 \cdot 26$ & 0.54 & $3 \cdot 4$ & $0 \cdot 7$ & 132 & $\begin{array}{l}\text { Poiss. } \\
\text { N. Bin. }\end{array}$ & $\begin{array}{r}96 \cdot 05 \\
7 \cdot 21\end{array}$ & $\begin{array}{r}0.001 \\
0.40\end{array}$ \\
\hline
\end{tabular}

The leaching experiment, although merely a preliminary to a larger experiment, is interesting in the light of the above evidence. However, because of the lack of statistical control and the inefficient design, the results must be viewed with caution. The results of the leaching experiment are shown in Figure 9. The leachate from unirradiated fresh seed slowed germination of the test seed but produced no increase in the breakage of the chromosomes. However, the leachate from irradiated fresh seed increased chromosome breakage in the test seeds by a factor of 2.5 (significant at the 0.005 level). The leachate from unirradiated aged seed produced a high, but variable amount of breakage in the test seed. The mean breakage level 
was about that produced by leachates from irradiated fresh seed. When irradiated aged seed was used to obtain the leachate, breakage in the test seed increased approximately three-fold over the unirradiated aged seed

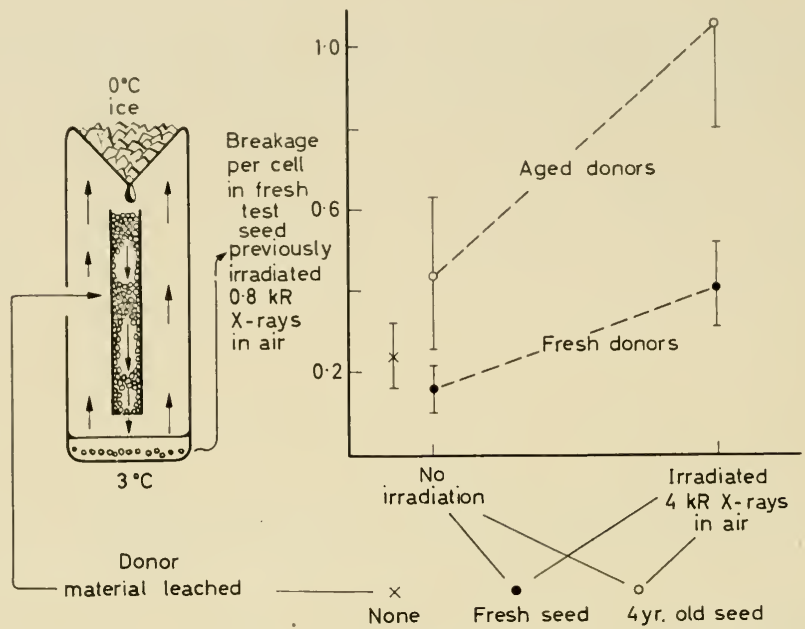

Figure 9. The effect of leachates from aged and fresh seed, irradiated and nonirradiated, on the chromosome breakage induced in fresh test seed by a small sensitizing dose of irradiation

trials. Because of the large variance the probability of obtaining this difference by chance was $0 \cdot 01$.

The spontaneous breakage in aged seed used in the leaching experiment measured in a pooled sample from 10 root tips was 0.57 acentric chromosome fragments per cell. The agent producing chromosome breakage appears to be quite independent of the germination inhibitor. There is no significant difference in germination of seed soaked in leachates from irradiated and unirradiated donor seeds, although there is a significant increase in the germination of seed soaked in leachate from old seed, as compared with leachates from fresh seed. Thus although old seed contributes compounds causing increased breakage, it apparently contributes less germination inhibitor. The effect of irradiation would seem to be merely additive to the effects of ageing. There was no significant change in the type of aberrations produced or in the 'stickiness' of the chromosomes. A slightly increased frequency of metaphases with undercondensed nucleic acid was noticed in treatments with leachates from aged seed.

\section{DISCUSSION OF RESULTS}

The early conceptions of radiation damage to chromosomes were based largely on the physical principles ${ }^{1}$. Final damage was considered to result from the separate events of breakage and reunion of the chromosome threads. 


\section{W. D. JACKSON}

The last decade has seen the replacement of this concept by the view that chemical and physiological principles are deeply involved with the physical phenomena. In particular it was shown that radiation sensitivity varied widely both in organisms and in individual cells, depending on development and on physiological conditions ${ }^{35}$. The discovery of the modifying effect of oxygen was an important step. Following Thoday and Read's finding ${ }^{36}$ that oxygen increased radiation damage in bean roots, the oxygen effect was shown to hold in a variety of material ${ }^{4}$ and was subsequently found to be an important factor not only in chromosome breakage, but in many other forms of radiation damage.

Two opposed views arose as to the influence of oxygen. Giles and his co-workers ${ }^{4}$ assumed that oxygen increased the initial breakage of chromosomes, while a number of workers $21,22,37,38$, took the view that oxygen altered the reunion process rather than the breakage mechanism. Direct experimental evidence for or against these views is difficult to obtain because an unknown number of original breaks restitute the original structure, or reunite to form structures which are indistinguishable from the original. Thus, if the proportion of breaks entering these restitution processes changes, then the apparent breakage also changes.

Experiments by Giles and Riley ${ }^{39}$, Giles $^{40}$ and Read ${ }^{41}$ showed that the oxygen effect in actively metabolizing tissue was only obtained if the oxygen was present at the time of irradiation. From this it seemed likely that oxygen was involved in some direct chemical step which could be assumed between ionization and breakage. It was also known that the effect of oxygen is altered by the type of radiation used. Thoday and $\operatorname{Read}^{3}$ showed that the significant oxygen effect obtained with X-rays could not be obtained using $\alpha$ irradiation. Later Giles et al. ${ }^{4}$ showed that the oxygen enhancement with neutron irradiation was intermediate between that obtained with $\mathrm{X}$ and $\alpha$ irradiation. Gray ${ }^{16}$ and $\operatorname{Read}^{13}$ pointed out the similarities between these effects and the known effects of dissolved oxygen in the radio-chemical decomposition of water ${ }^{42}$. Consequently, Gray and Read, elaborating the proposals of Weiss ${ }^{43}$, have developed a physical-chemical mechanism for radiation damage. On the basis of this mechanism the chromosome aberrations have the following sources:

(1) direct ionization of the chromatin thread,

(2) indirect effect of $\mathrm{H}$ and $\mathrm{OH}$ radicals formed both in and outside 'target' areas by ionization of water,

(3) a similar but more widespread indirect effect produced by $\mathrm{HO}_{2}$ and $\mathrm{H}_{2} \mathrm{O}_{2}$.

The direct ionization of the chromosome material, being strictly direct action, would follow target theory expectations. The mean free path of $\mathrm{H}$ and $\mathrm{OH}$ radicals would be small, as shown by Weiss and Lea, so that although extra target effects are present these are expected to be limited. The contribution by the third source of $\mathrm{HO}_{2}, \mathrm{H}_{2} \mathrm{O}_{2}$ and other powerful oxidants is expected to be considerable as these compounds may have a long mean free path. With radiation giving a high density of ions per unit path length, these substances are formed in watery mediums even in anaerobic conditions. However, $\mathrm{H}_{2} \mathrm{O}_{2}$ and $\mathrm{HO}_{2}$ are only formed with radiations of low linear ion density such as $\mathrm{X}$ and $\gamma$ irradiation when oxygen is present. 
Giles and his co-workers ${ }^{44}$ assumed that the simplest and most direct explanations of the oxygen effect on chromosome breakage was by indirect increase to the primary breakage along the lines of the above argument. As evidence against theories that oxygen might alter the radio-sensitivity of the cells, or that it might modify the chromosomes to make them more easily broken, or that the oxygen might alter the rate of restitution as opposed to visible reunions, they point out that with these theorics the oxygen effect would not be limited to low ion density irradiation. They also draw attention to the experiments of Conger and Fairchild ${ }^{34}$ and Gerschman et al. ${ }^{45}$ from which it is evident that under suitable conditions oxygen alone can cause chromosome breakage and other effects indistinguishable from those produced by irradiation. As direct evidence they quote the experiments of Riley, Giles and Beatty ${ }^{46}$ with microspores of Tradescantia which indicate that the restitution times in oxygen and nitrogen are substantially similar.

The evidence favouring the theory that oxygen influences the restitution of breaks has been summarized by Swanson ${ }^{5}$. Experiments using the pollen grain division in Tradescantia where both chromosome and chromatid breaks are observed show the following results with irradiation of increasing ion density:

(1) total breakage increases and the oxygen effect decreases,

(2) chromosome breakage increases and the oxygen effect for these breaks increases,

(3) chromatid breakage decreases and the oxygen effect for these breaks decreases,

(4) exchanges increase and the oxygen effect for these decreases slightly.

The fact that oxygen concentration alters the relative numbers as well as the absolute numbers of these different aberrations and the fact that numbers of chromosome and chromatid breaks seemed to compensate one another, lead Swanson to suppose that some of the chromosome (iso-chromatid) breaks are converted by incomplete restitution to chromatid breaks. This incomplete restitution was thought to occur with increased frequency at low oxygen tension explaining the relationship between ion density, oxygen effect and the ratio of chromosome and chromatid breaks. Further evidence for this hypothesis has come from the study of the loss of ring $\mathrm{X}$ chromosomes in Drosophila $22,47$.

As Swanson ${ }^{5}$ points out, there is some contradictory evidence in experiments with high ion density irradiation. The results for $\alpha$-rays obtained by Thoday and Read ${ }^{3}$ and the results of Giles, Beatty and Riley ${ }^{4}$ for neutron irradiation do not show the expected shifts in aberration frequencics. An analysis of the degree of sister union in chromosome breaks and the non-sister union in chromatid breaks by Conger ${ }^{48}$ shows that the differential yield of chromosome breaks with different oxygen concentrations cannot be explained by an alteration in the fusibility of broken ends. Exchange breaks show a marked influence of oxygen but in the opposite direction to that expected if oxygen increases breakage by affecting fusion.

A view which offered some compromise between the breakage hypothesis and the reunion hypothesis for the oxygen enhancement of radiation damage was put forward by Thoday ${ }^{23}$ and Gray ${ }^{49}$. They suggested that the initial radiation damage to chromosomes varied in character and was modified 
by oxygen. In addition to actual breaks they considered that potential or latent breaks were formed, whose fate was determined by the physiological conditions of the cell. Lüning ${ }^{50}$ and Swanson ${ }^{5}$ adopted and extended this scheme to include a spectrum of chromosome damage. They postulated that the important effects of oxygen were to convert potential breaks into actual breaks and to alter the rate of fusion of broken ends. Although this concept brought the opposed views into a common orbit it did not settle the question of the relevant parts played by oxygen in breakage and reunion, a question which underlies basic knowledge of radiation damage to chromosomes.

Much recent research in this field has been directed at separating breakage and reunion by fractionation in various conditions of oxygen availability. As well as experiments in which the oxygen tension has been varied directly, trials where the effect of oxygen has been suppressed indirectly by 'protective' agents have been made. Other experiments have been conducted in which the oxygen effect was enhanced by physiological states of lowered respiration. These include, conditions of rest (such as in the seeds used in the present work), near zero temperatures (at which oxygen is more soluble and oxidase systems inefficient), and treatments of cells with respiratory inhibitors.

With $\mathrm{X}$ and $\gamma$ irradiation, and to a lesser extent with neutrons, the partial protection obtained by irradiation in a vacuum or in an inert gas can be obtained by treatments with strong reducing agents such as hydrosulphites $19,51,46,20,52$. This protective effect is expected from reducing agents capable of lowering the concentration of dissolved oxygen. However, reducing agents of biochemical nature which are relatively ineffectual in removing molecular oxygen are known to protect biological materials from damage by irradiation. Of these, glutathione, cysteine, 2,3-dimercaptopropanol (BAL), thiourea and ethanol have proved effective in lessening chromosome breakage by $\mathrm{X}$ and $\gamma$ irradiation $51,38,52,20$.

Wolff and co-workers have used this protective effect to investigate the breakage and reunion hypothesis in fractionation experiments. By changing the separation interval between two or more dose fractions, an interval can be found, above which the fractions act independently, and below which the open breaks induced by the first fraction interact with those of the second to increase the number of exchange, or two-event aberrations. Wolff ${ }^{38}$, working with Vicia faba, found that BAL shortened this interval in addition to decreasing the number of aberrations. He assumed that BAL hastened the reunion of breaks, thus decreasing the period for which the ends are open. This effect could be obtained by varying the dose rate ${ }^{38}$. Here the intensity required to produce a significant alteration in the number of exchanges was increased in the presence of BAL. From these experiments Wolff assumed that much of the increased breakage in the presence of oxygen was caused by an increase of reunion over restitution. However, detailed experiments with Atwood ${ }^{53}$ led to a change in this hypothesis for it was found that the reduced breakage due to $\mathrm{BAL}$, although correlated with the reduction of the period where breaks remained open, was not affected by this phenomenon. It was found that the reduction of the open period was also dependent on dose, so that with large doses the ends remained open for longer periods. Doses given in the absence of BAL caused an extension of the open 
period produced by subsequent doses given in the presence of BAL. It was proposed that irradiation produces a delay in reunion of breaks by the destruction of some metalolic activity. This activity could be protected by $\mathrm{BAL}$ so that the recovery time was reduced.

In contrast to these experiments using reducing agents, Wolff and Luippold ${ }^{54,55}$ and Cohn ${ }^{56,57,58}$ have tried respiratory inhibitors in fractionation experiments. These experiments extend the original findings of Zirkle ${ }^{59,60}$, King and Schneiderman ${ }^{61}$, King et al. ${ }^{62}$, Schneiderman and King ${ }^{63}$ and Haas et al ${ }^{64}$ in which carbon monoxide and carbon dioxide were both found to increase the breakage induced by irradiation if oxygen was also present, although these gases had no effect in the absence of oxygen. Haas et al. ${ }^{64}$ also showed that both carbon monoxide and carbon dioxide increase the effect of irradiation at slow dose rates to equal the effect at high dose rates. In the fractionation experiments of Wolff and Luippold, and Cohn, it was shown that respiratory inhibitors like carbon monoxide, cyanide, dinitrophenol, and low temperatures have the opposite effect to that produced by $\mathrm{BAL}$ or other anoxic conditions. Respiratory inhibitors extend the 'open period' of the breaks beyond normal, whereas BAL and anoxic conditions reduce the 'open period'. They conclude from this that an active oxidative metabolism, probably that providing high-energy phosphate bonds, is required to get reunion of the broken ends. This oxidative metabolism is in some way inhibited by irradiation, a similar effect being produced by compounds which interfere with the cytochrome system. BAL and other reducing agents enable a faster recovery after inhibition, or in some way protect the oxidative metabolism from irradiation damage.

It was shown by Wolff and Atwood ${ }^{53}$ that the breaks which rejoin quickly after irradiation are capable of uniting with breaks which remain 'open' for long periods. It was also shown that there was a period of greater or less duration within which there was no rejoining. On the basis of these facts it was considered unlikely that qualitative differences between the breaks themselves could account for the observed difference in reunion times. Wolff and Luippold ${ }^{55}$, Abrahamson ${ }^{65}$ and Cohn ${ }^{56}$ claim that qualitative differences between the breaks do exist. The general argument put forward was that certain breaks closed quickly because they were closed by ionic bonds. The breaks which remained 'open' for long periods were thought to be closed by covalent bonds with high-energy requirements. This difference was not observed in fractionation experiments by Cohn ${ }^{58}$ in which carbon monoxide produced equal delay in both types of breaks. It would thus seem that there is little qualitative difference between breaks which unite quickly and those which unite slowly.

The investigation of the oxygen effect under conditions of metabolic rest provides another uscful avenue to test the breakage-reunion hypothesis. The present set of experiments was designed to exploit this method using dormant seed. The results of these, and experiments using similar states of rest, enable interesting comparisons to be made with the other methods of modifying the normal metabolic state.

Storage in oxygen causes chromosome breakage in dry seed (Figures 1 and 2) and this breakage appears to be identical in form and distribution with that induced by irradiation. These observations agree with the general results of 
ageing in seed ${ }^{\mathbf{1 0}}$, and it seems as if this ageing effect can, as far as chromosome breakage is concerned, be attributed to oxygen. Similar effects of oxygen in breaking chromosomes are known from the experiments of Conger and Fairchild ${ }^{34}$ using pollen. Again chromosome breakage due to ageing pollen has been reported. The type of compound involved is not known, but it is likely that peroxy compounds similar to $\mathrm{H}_{2} \mathrm{O}_{2}$ and $\mathrm{HO}_{2}$ are involved. Fetner $^{66}$ and Brinkman and Lamberts ${ }^{67}$ have reported damage by ozone and the remarkable efficiency of this gas in inactivating oxidase enzymes has been shown by Todd ${ }^{68}$. The fact that oxygen is itself effective in causing breakage would indicate that its effect in irradiation produced breakage is on breakage rather than on reunion. The remarkable similarity in the pattern of breakage shown by Jackson and Barber ${ }^{10}$ is additional evidence for this idea.

A knowledge of the breakage produced by oxygen alone, and the breakage induced by a given X-ray dose in the absence of oxygen, allows the total effect of irradiation in various synthetic atmospheres to be partitioned into its component parts (Figure 4). When this is done it is seen that in conditions of metabolic rest the component due to the interaction of oxygen with irradiation accounts for much of the damage. This component is greater in dormant cells than in non-resting cells. An analysis of the distribution of breaks caused by these separate components provides additional information on the type of process operating in each component as well as evidence of the effect of oxygen on breakage and reunion. The proportion of various aberration types remains remarkably constant. In this material the absence of chromatid breaks and the very low rate of non-sister reunion is a feature of all components. Since these types show no change in frequency and the proportion of sister unions to open breaks apparently remains constant, these results would support the thesis of Giles and Conger that oxygen exerts its effect by altering breakage rather than reunion. In addition, an analysis of the distribution of breaks between cells shows that while the damage produced in the absence of oxygen has a Poissonian distribution, the distribution produced by irradiation with oxygen, and by treatments with oxygen alone, are significantly over-dispersed. This would indicate that the mechanism of radiation damage approximates direct action in the absence of oxygen but is distinctly cumulative in action in the presence of oxygen. Since the breakage due to oxygen alone is produced by a cumulative action the inference is again, that the effect of oxygen in irradiation experiments is directed through the breakage mechanism.

The post-storage experiments confirm the previous findings $25,27,29,31,30$ that storage of irradiated seed in atmospheres containing oxygen increases radiation damage. The present experiments show, in addition, the dependence of this process on oxygen concentration and length of storage. A partition of the damage into its component elements (Figure 6) shows the magnitude of this post-storage effect and its importance at low levels of oxygen concentration. An analysis of the breakage distribution shows that the amount of over-dispersion increases with post-storage and with oxygen concentration. Even when the contribution to the dispersion produced by oxygen alone is removed, it can be shown that the post-storage effect introduces additional over-dispersion. 
The continued increase in breakage during the first 10 days following irradiation has important implications. It demonstrates conclusively that either mutagenic substances having a long half-life are able to exist after irradiation, or that some auto-propagative reactions, which are able to supply these compounds, are set in motion by the irradiation. Either or both these conditions are of course possible. Since these processes require oxygen it seems likely that they are similar to the mechanisms already proposed by $W^{\prime}$ ciss $^{43}$, Read ${ }^{12,13}$, and Gray ${ }^{49}$.

The leaching experiments indicate that the presence of such mutagenic substances can be demonstrated directly by this method. If these active compounds can be identified with the irradiation-oxygen interaction then it seems that leaching may provide a method of isolating the active compounds $(c f$. Scarascia and Scarascia-Venezian ${ }^{69}$ and D'Amato and Hoffmann-Ostenhof ${ }^{70}$ ).

If post-irradiation effects occur in states of metabolic rest it is likely that they also operate to a limited extent in states of unrest. The only suppressing influences here are active protective systems and if these are temporarily saturated or inactivated by the irradiation there seems no reason why delayed breakage should not be important in general. This immediately raises the question as to whether the oxygen effect is not merely the expression of this continued form of breakage. Such an effect would explain the mechanisms of latent breaks advanced by Thoday ${ }^{47}$, Gray ${ }^{48}$, Lüning ${ }^{49}$ and Swanson ${ }^{5}$. This continued opening of latent breaks due to the prolonged production of mutagen could conceivably account for the so-called 'open period' and its dependence on dose and metabolic rate. The correlation between breakage and delay in reunion at different oxygen tensions would be explained. The life-span of these mutagenic substances or their continued production would depend upon factors modifying the metabolic rate. In anoxic conditions the production of mutagens is limited because in low oxygen concentrations the balance of the reactions shifts away from the production of peroxy compounds. A similar reduction in the effect would be obtained if the active oxidative mutagens are removed by suitable reducing agents such as cysteine. These agents would decrease the apparent mean free path of the mutagens. On the other hand, if the enzyme systems removing these oxidative products are inhibited by carbon monoxide or other metabolic poisons, then the life span of these radiation products is increased. From this it will be seen that the results of the fractionation and intensity experiments using reducing agents such as BAL, and metabolic inhibitors such as carbon monoxide, can be explained by continued breakage. While the argument that the reunion process is dependent on the metabolic rate is sound, and it is certain that reunion accounts for some of the oxygen effect, it seems likely that most of the oxygen effect is attributable to delayed breakage. It is certain that reunion cannot explain the increased breakage in post-storage experiments.

\section{CONCLUSIONS}

An analysis of chromosome breakage in Allium cepa after treatment of the dry seed by doses of $\mathrm{I} \cdot 2 \mathrm{kr}$ of $\mathrm{X}$ irradiation combined with pre- and postirradiation storage shows the following:

(1) oxygen appears to be a most important factor in the process of ageing. Chromosome breakage increases exponentially with storage time in air, 
W. D. JACKSON

(2) storage in various oxygen-nitrogen mixtures shows that oxygen causes breakage in dry seed as it does in pollen. Breakage increases exponentially with oxygen concentration. A dose of $1.5 \mathrm{kr}$ of soft $\mathrm{X}$ irradiation given in the absence of oxygen produces approximately the same damage as 14 days' storage in pure oxygen,

(3) the effect of $1 \cdot 2 \mathrm{kr}$ of $\mathrm{X}$ irradiation on seed pre-stored for 14 days in various oxygen-nitrogen mixtures, and also that stored for an additional 14 days' post-storage in these mixtures, has been partitioned into a direct irradiation component, a direct oxygen component, an oxygen-irradiation component, and an oxygen irradiation post-storage component. The interaction-components account for more than two-thirds of the damage,

(4) breakage continues during the post-storage period if oxygen is present. Other experiments showed that the total number of deletions rises rapidly in the early post-storage period and approaches a constant value after about 10 days' post-storage in air. In oxygen the breakage continues at an increased rate. Substances which can be leached from both old seed and from fresh seed previously irradiated in air, can cause a significant increase in chromosome breakage in seed which has previously been given a small sensitizing dose of irradiation. The effect of oxygen in increasing radiation damage is thought to arise from extended breakage or opening of 'latent' breaks by the combined presence of oxidative mutagens with long mean free paths.

My original experiments on post-storage effects were extended by $\mathrm{Mr} . R$. Crowden as an honours project under my supervision. His results are incorporated in his honours thesis (University of Tasmania, 1954). I have availed myself of this work and have incorporated his results with those from my later experiments. I wish to acknowledge the use of this data and to thank Professor Barber for his helpful suggestions with the manuscript.

\section{REFERENCES}

${ }^{1}$ LeA, D. E. Actions of Radiations on Living Cells 2nd edn: Cambridge University Press, London, 1955

${ }^{2}$ Gray, L. H. and Scholes, M. Brit. J. Radiol. N.S. 24 (1951) 82

${ }^{3}$ Thoday, J. M. and Read, J. Nature, Lond. 163 (1949) 133

${ }^{4}$ Giles, N. H., Beatty, A. V. and Riley, H. P. Genetics 37 (1952) 641

${ }^{5}$ Swanson, C. P. J. cell. comp. Physiol. 45 Supplement 2 (1955) 285; Genetics 40 (1955) 193

${ }^{6}$ Bender, M. A. Genetics 43 (1958) 122

${ }^{7}$ Kirby-Smith, J. S. and Dolphin, G. W. Nature, Lond. 182 (1958) 270

${ }^{8}$ Kotval, J. P. and Gray, L. H. J. Genet. 48 Supplement 2 (1947) 135

${ }^{9}$ Camara, A. Agron. lusit. 3 (1941) 341

${ }^{10}$ Jackson, W. D. and Barber, H. N. Heredity 12 (1958) 1

${ }^{11}$ Giles, N. H. and Beatty, A. V. Science 112 (1950) 643

12 Read, J. Brit. J. Radiol. N.S. 24 (1951) 635

${ }^{13}$ ReAd, J. Brit. J. appl. Phys. 2 (1951) 337

${ }^{14}$ Dale, W. M. Biochem. J. 36 (1942) 80

${ }^{15}$ Barron, E. S. G. and Dickman, S. J. gen. Physiol. 32 (1949) 595

${ }^{16}$ Gray, L. H. Progr. Biophys. 2 (1951) 240

${ }^{17}$ Patt, H. M. Physiol. Rev. 33 (1953) 35

${ }^{18}$ Hollaender, A. ed. Radiation Biology vol. 1: McGraw Hill, New York, 1954

${ }^{19}$ Mikaelsen, K. Science 116 (1952) 172

${ }^{20}$ Riley, H. P. Genetics 42 (1957) 593

${ }^{21}$ Schwartz, D. Proc. nat. Acad. Sci., Wash. 38 (1952) 489 
22 Baker, W. K. and von Halle, F. S. Proc. nat. Acad. Sci., I'ash. 39 (1953) 152

23 Troday, J. M. Heredity 6 Supplement (1953) 299

${ }^{24}$ Gray, L. H. Heredity 6 Supplement (1953) 311

25 Gustafsson, A. Hereditas, Lund 22 (1936) 281

${ }^{26}$ Gustafsson, A. Hereditas, Lund 30 (1944) 165

27 Nicrior.s, C. Amer. J. Bot. 29 (1942) 755

${ }^{28} \mathrm{~J}$ Ackson, W. D. Communication to the First Australasian Conference on Radiation Biology Melbourne, 1955

29 Nilan, R. Genetics 40 (1955) 588

${ }^{30}$ Yagru, P. and Morris, R. Genetics 42 (1957) 222

31.Sire, M. W. and Nilan, R. A. Genetics 42 (1957) 395

${ }^{32}$ Guillaumin, A. C.R. Acad. Sci., Paris 187 (1928) 571

${ }^{33}$ Barton, L. V. and Crocker, W. Twenty Years of Seed Research at the Boyce Thompson Institute for Plant Research: Faber and Faber, London, 1948

${ }^{34}$ Conger, A. D. and Fairchild, L. M. Proc. nat. Acad. Sci., Wash. 38 (1952) 289

35 Sparrow, A. H. and Rubin, B. A. Survey biol. Progr. 2 (1952) 1.

${ }^{36}$ Thoday, J. M. and REAd, J. Nature, Lond. 160 (1947) 608

${ }^{37}$ Swanson, C. P. and Schwartz, D. Proc. nat. Acad. Sci., Wash. 39 (1953) 1241

${ }^{38}$ Wolff, S. Nature, Lond. 173 (1954) 501; Genetics 39 (1954) 356

${ }^{39}$ Giles, N. H. and Riley, H. P. Proc. nat. Acad. Sci., Wash. 36 (1950) 337

${ }^{40}$ Giles, N. H. Symposium on Radio-biology (Oberlin 1950) ed. Nickson, J. : John Wiley and Son, Inc., New York, 1952, p 267

${ }^{41}$ Read, J. Brit. J. Radiol. N.S. 25 (1952) 89

42 Bonet-Maury, P. and Lefort, M. Nature, Lond. 162 (1948) 381

${ }^{43}$ Werss, J. Brit. J. Radiol. N.S. 1 Supplement (1947) 56

${ }^{44}$ Giles, N. H. J. cell. comp. Physiol. 45 Supplement 2 (1955) 271

${ }^{45}$ Gerschman, R., Gilbert, D. L., Nye, S. W., Dwyer, P. and Fenn, W. O. Science 119 (1954) 623

${ }^{46}$ Riley, H. P., Giles, N. H. and Beatty, A. V. Amer. J. Bot. 39 (1952) 592

${ }^{47}$ Baker, W. K. and von Halle, E. S. J.cell. comp. Physiol. 45 Supplement 2 (1955) 299

${ }^{18}$ Conger, A. D. J. cell. comp. Physiol. 45 Supplement 2 (1955) 309

${ }^{19}$ Gray, L. H. Brit. J. Radiol. N.S. 26 (1953) 609

${ }^{50}$ Lüning, K. G. Hereditas, Lund 40 (1954) 295

${ }^{51}$ Mikaelsen, K. Proceedings of the Ninth International Congress of Genetics: Caryologia 6 Supplement (195t) 1100

${ }^{52}$ Riley, H. P. Amer. J. Bot. 42 (1955) 765

${ }^{53}$ Wolff, S. and Atwood, K. C. Proc. nat. Acad. Sci., Wash. 40 (1954) 187

${ }^{54}$ Wolff, S. and Luippold, H. E. Science 122 (1955) 231

55 Wolff, S. and Luippold, H. E. Proc. nat. Acad. Sci., Wash. 42 (1956) 510

${ }^{56}$ Cohn, N. S. Genetics 41 (1956) 639

${ }^{57}$ Cohn, N. S. Genetics 42 (1957) 366

${ }^{58}$ Cohn, N. S. Genetics 43 (1958) 362

${ }^{5}{ }^{9}$ Irkle, R. E. J. cell. comp. Physiol. 16 (1940) 301

${ }^{60}$ Zirkle, R. E. J. cell. comp. Physiol. 17 (1941) 65

${ }^{61}$ King, E. D. and Schneiderman, H. A. Proc. nat. Acad. Sci., Wash. 38 (1952) 809

${ }^{6}$ King, E. D., Schneiderman, H. A. and Sax, K. Proc.nat. Acad. Sci., Wash. 38 (1952) 34

${ }^{63}$ Schneiderman, H. A. and King, E. D. Proc. nat. Acad. Sci., Wash. 39 (1953) 834

${ }^{64}$ Haas, F. L., Dudgeon, E., Clayton, F. E. and Stone, W. S. Genetics 39 (1954) 453

${ }^{65}$ Abrahiamson, S. Genetics 41 (1956) 631

${ }^{66}$ Fetner, R. H. Nature, Lond. 181 (1958) 504

${ }^{67}$ Brinkman, R. and Lamberts, H. B. Nature, Lond. 181 (1958) 1202

${ }^{68}$ Todd, G. W. Physiol. Plant. 11 (1958) 457

69 Scarascia, G. T. and Scarascia-Venezian, M. E. Caryologia 6 (1954) 247

${ }^{70}$ D'Amato, F. and Hoffmann-Ostenhof, O. Adianc. Genet. 8 (1956) 1 


\title{
RADIO-ACTIVE FISSION-PRODUCTS IN THE HUMAN FOOD CHAIN
}

\author{
J. F. Loutit \\ Medical Research Council Radiobiological Research Unit, \\ Atomic Energy Research Establishment, Harwell, England
}

IT is Now of course common knowledge that small amounts of fission-products from nuclear fission are widely distributed around the earth and in the atmosphere. Most of these radio-active materials result from the testing of nuclear weapons; but, as the accident in 1957 at Windscale showed, a contribution also comes from reactors and their associated plant. There are two fundamental differences-firstly, in the case of weapons there is instantaneous fission so that, for each, the fission-products are a more or less predictable mixture of the short, medium and long-lived nucleides. In the reactor, on the other hand, the process of fission has been going on for days, weeks or months. Thus the composition of the mixture varies with time: the short-lived nucleides will have largely decayed and the longer the charge has been exposed to the neutron flux, the greater the accumulation of the more long-lived products. Secondly, in the explosion of weapons there is a deliberate release not only of energy but of all by-products: whereas in civil practice every effort is made to contain the radio-active materials, so that in normal operations there is an escape only of unavoidable traces of radioactive material. On a world-wide basis we are concerned more with the deposition of products from weapons. The hazards from reactors and their associated plant are confined to the local and moderately remote areas.

I shall be concerned mostly with the fission-products from weapons and the world-wide fall-out. Furthermore, my remarks will be chiefly concerned with the landmass that I know, the United Kingdom; the global problem has been considered and reported on recently by the United Nations Scientific Committee.

At the Atomic Energy Research Establishment at Harwell, the Health Physics Division has for many years been recording the radio-activity in the atmosphere, in rainfall and on the ground resulting from explosion of nuclear weapons. In the earlier years these explosions were mainly of weapons of kiloton size exploded in Nevada. Later there were contributions from the U.S.S.R. and from the British tests in Australia. Weapons of this size throw up debris to a varying height but this seldom exceeds about 40,000 to 50,000 feet, the region of the so-called tropopause between the lower troposphere and the overlying stratosphere. Stewart and his colleagues at Harwell ${ }^{1}$ find that the radio-active fission-products from such explosions are deposited relatively rapidly, the half-time of deposition being about three weeks. During this time of course they are carried round the globe with the prevailing air-currents. 
In 1954 , we entered a new phase, the age of megaton weapons with their vastly greater power. These throw their debris to much greater heights and much of the material is injected into the stratosphere from which the rate of deposition is very much slower than from the troposphere. The half-time of deposition may be as long as ten years, though the prevailing opinion seems to be that this estimate is unduly long. In some ways this injection into the stratosphere can be considered as a safety-factor in that the shorter lived fission-products decay in the stratosphere and do not reach us in their radio-active state. On the other hand, because the yield of the weapon is so very much larger, very much greater quantities of long-lived radio-active materials are injected into the stratospheric 'bank', whence they are paid out slowly into the troposphere.

Two of the longest-lived fission-products are ${ }^{90}$ strontium and ${ }^{137}$ caesium. Unhappily, of course, the oxides of both are readily soluble in water and biological fluids, so that when they contaminate food-stuffs they are readily taken into the body. The oxides of rather less long-lived fission-products, like cerium and some of the rare earths, are not soluble even in digestive fluids; thereforc only minute traces of these, relative to strontium and caesium, are absorbed.

In the United Kingdom, Stewart finds a very definite correlation between the deposition of fission-products and rainfall ${ }^{2}$. Data are available for a number of years from a station at Milford Haven on the Welsh coast. More recently another half a dozen stations have been set up. Table 1 shows Stewart's results from rainfall normalized for each station against a value of 100 at Milford Haven, where the actual precipitation is about 37 inches per year, considerably greater than the average for the whole country. There is an eight-fold range between Felixstowe on the East Coast and the high ground of Mount Snowdon in Wales. The total deposition of ${ }^{90} \mathrm{Sr}$ is also normalized to 100 at Milford Haven.

Table 1. Normalized ${ }^{90} \mathrm{Sr}$ deposition and rainfall-1957 to 1958

\begin{tabular}{lcccccc}
\hline Station & Felixstowe & Abingdon & Kinloss & $\begin{array}{c}\text { Milford } \\
\text { Haven }\end{array}$ & Liverpool & $\begin{array}{c}\text { Mount } \\
\text { Snowdon }\end{array}$ \\
Rainfall & 60 & 68 & 81 & 100 & 97 & 429 \\
Deposition & 51 & 56 & 87 & 100 & 105 & 355 \\
\hline
\end{tabular}

Stewart's other notable finding is that the concentration of ${ }^{90} \mathrm{Sr}$ in rainwater varies anything up to six-fold between autumn and spring. His explanation is that there is a general atmospheric circulation. The airmass in the stratosphere tends to move toward the Pole in the autumn; it concentrates as a heavy blanket over the Pole during the long winter night and enters the troposphere with the beginning of spring; it moves towards the Equator, and en route the contained radio-activity is washed out in rain, particularly in latitudes 50 to $60 \mathrm{~N}$. By the time this air reaches the Equator it has lost its radio-activity; in the Tropics, even though the rainfall is high, the contamination on the ground is low. The same phenomenon is seen, but to a less marked extent, in the Southern Hemisphere. 


\section{J. F. LOUTIT}

It is when the fission-products reach the troposphere that the biologist becomes involved. Figure $I$ in the paper of Bryant, Chamberlain et al..$^{3,4}$, shows the chain in which we are interested. ${ }^{90} \mathrm{Sr}$ can be inhaled directly from the air and be absorbed through the lung. From the average concentration of ${ }^{90} \mathrm{Sr}$ in air, it can be calculated, however, that the hazard from this route of entry is less by several orders of magnitude than from the gut. In this connexion let us first consider rainwater which has been shown to be the main vehicle whereby the radio-activity is deposited-Stewart's recent data indicate 2 to $7 \mu \mu \mathrm{C}{ }^{90} \mathrm{Sr}$ per litre of rainwater, depending on the season in the United Kingdom. If rainwater were used directly as drinking water, this would constitute a significant fraction of the average daily intake of ${ }^{90} \mathrm{Sr}$, now estimated to be about 5 to $6 \mu \mu \mathrm{C}$ per day ${ }^{5}$. However, in the United Kingdom drinking water is obtained from reservoirs, rivers and bores. The rainwater in contact with the earth has every opportunity to be purified by the absorption of fission-products on to clay-minerals and by exchange of fission-products with other ions in the soil. Thus drinking waters are in fact from 10 to 100 times less radio-active than rainwater. The main contamination at the present time is of food. Radio-activity in rain is deposited directly on to food-stuffs such as cereals and vegetables, which constitute an important part of the diets of man and domestic animals. It also falls on to grass which is the most efficient trap. It is true that the next shower of rain may wash off a considerable proportion of the radio-activity, but in turn it deposits a new consignment. Whereas man derives his vegetable food from perhaps a square foot or so of ground a day, grazing animals, such as the cow and sheep, browse off areas anything up to a thousand times greater. These ruminants are thus great accumulators, but also, as far as human diet is concerned, filters.

The rain also of course falls directly on to soil, or is washed off vegetation into soil, from which all plants derive their macro-nutrients and a large part of their micro-nutrients. It has been known for some time that many trace elements, which we now know to include strontium and caesium, can be absorbed directly from the leaves. Due to Scott Russell and his colleagues we are becoming increasingly aware that the entry of these materials into plants is not only a matter of foliar uptake and absorption from the true soil by the feeding roots, but that there is a third mechanism which Scott Russell has called 'stem-base absorption'. This is of particular importance in the case of pasture grasses, especially those which are not well maintained. This will be discussed in more detail later.

From the animal biologist's point of view, the cow derives its nutrients in large part from grass; the strontium, being a chemical analogue of calcium, is metabolized by the cow in much the same way as calcium, and some of it appears in the milk. Under normal conditions in the United Kingdom, milk provides at least 50 per cent of the dietary calcium for the human population. Caesium, being an alkali metal, is treated metabolically in some ways as potassium. Thus it is generally distributed in soft tissues, but the biological turnover appears to vary quite widely between species, being some two weeks in the rat, some four months in man.

Since 1954 the Health Physics and Chemical Divisions of the Atomic Energy Research Establishment at Harwell have put an increasing effort 
into the analysis of the various itcms of the human food chain for ${ }^{90} \mathrm{Sr}$. Reports have been issued periodically by Bryant, Chamberlain and their colleagues. This effort in what might be called 'biological monitoring' has had as a by-product a better understanding of certain aspects of plant and animal physiology. In 1957, because of the increasing importance of this work and because of the physiological implications, there was a redistribution of effort. By agreement between the Atomic Energy Authority, the Agricultural Research Council and the Medical Research Council, the Atomic Energy Research Establishment will continue to be responsible for the monitoring of the atmosphere, of rainfall and water supplies and for the assay of human bones. The Agricultural Research Council is taking over the responsibility for the monitoring of materials in the food chain and for interpretation of the data within their sphere. The Medical Research Council is responsible for the interpretation of the results as they affect the human population.

To retrace the past, Bryant and his colleagues found in $1956^{3}$ that the accumulated deposition of ${ }^{90} \mathrm{Sr}$ in soil varied from about 2000 to 10,000 $\mu \mu \mathrm{C} / \mathrm{m}^{2}$. The variation is of course due to the variation of rainfall. As useful information in plant and animal physiology had been obtained from comparison of strontium to calcium ratios in tissues with that in precursors (e.g., bone to diet or plant to nutrient), it was perhaps natural for Bryant et al. to express their results in a similar fashion in strontium-units $\left(\mu \mu \mathrm{C}{ }^{90} \mathrm{Sr} / \mathrm{g}\right.$ calcium). This gave figures of $0 \cdot 15$ to 800 S.U. - a range of about 5000 - for the different soils. However, it is extremely doubtful if these figures have any meaning, since in many soils the calcium is largely unavailable to the plant. The grass from the same sites in terms of $\mu \mu \mathrm{C} / \mathrm{m}^{2}$ was some hundred times less radio-active than soil and was in the range of 15 to 150 for the accumulated growth. It is acceptable to express the radio-activity of grass in terms of strontium-units when it is being considered as diet for animals and the observed variation is 25 to $2000 \mathrm{~S}$.U. The higher figures of strontium-units were found in hill pasture, on acid soils with lime deficiency. It is notable of course that such soils are not only deficient in calcium but other nutrients as well and the total growth under these conditions is poor. Nevertheless, sheep are put out to graze on these natural highland pastures and consequently ingest a relatively high concentration of ${ }^{90} \mathrm{Sr} / \mathrm{kg}$ of diet. This is reflected in the bones of these sheep which were some twenty times as radio-active in terms of ${ }^{90} \mathrm{Sr} / \mathrm{g} \mathrm{Ca}$ as sheep from lowland pasture. The figures for sheep bone of 150 S.U. and thereabouts have led to expressions of anxiety in the press and Parliament. However, there is no reason to suppose that such levels or even levels many times greater will be deleterious to the sheep with their relatively short economic life. The generally accepted permissible levels for man in radiological occupations is equivalent to 1000 S.U. and it has been suggested that for domestic animals with their much shorter expectation of life the permissible dose might be some ten times greater. What is important about these levels of 100 and more strontiumunits is to predict what will be the future state of affairs.

In summary-do the present levels reflect the accumulated deposit of the last few years or the annual rate of deposit? If the value in sheep bone is a function of the accumulated deposit, since there is much ${ }^{90} \mathrm{Sr}$ in the 


\section{J. F. LOUTIT}

stratospheric bank still to be deposited, the position is rightly of concern now. If, on the other hand, these values in sheep bone are chiefly a function of the rate of deposit, which we know from Stewart's observations has been relatively constant in the last few years at between 2 to $3 \mathrm{mC} / \mathrm{km}^{2}$ per year, one should now begin to see some signs of equilibrium. Recent ${ }^{6}$ observations suggest that such an equilibrium in sheep bone is being attained. The same phenomenon, however, can be seen more readily and quickly as a result of the analyses of milk. Bryant and his colleagues have since 1954 been analysing the dried milk from a factory in Frome, Somerset. There is only one observation for 1954 but many for 1955, 1956 and 1957. Their report ${ }^{4}$ shows that, while there is a considerable scatter in the figures in any individual year, the mean or median is practically constant for those three years in spite of the fact that the accumulated fall-out of ${ }^{90} \mathrm{Sr}$ has risen seven-fold in that time.

The same report gives the figures for the analyses of human bones derived from autopsies made in 1956 . The activity of ${ }^{90} \mathrm{Sr}$ in strontium-units was, as one would expect, a function of age, the maximum concentration being in the first few years of life. The activity in the bones of still-births was in the region of $0.4 \mathrm{~S}$.U., rising to about 0.8 at the age of two years and falling off thereafter to much lower levels. The maximum in the first year or so of life merely indicates that the child population has only been exposed significantly to ingestion of fall-out for about two years. One would expect that with the passage of time the peak would shift. There is evidence of this given in a later report ${ }^{7}$. A plateau now seems to extend between the ages of a few months and three years. The mean and median values for stillbirths are still about the same-at $0.5 \mathrm{~S}$.U. The median level in the age group of 0 to 5 years was increased over the figure for 1956; but as the population sampled was known to be different, being predominantly the population in the west and wetter parts of the country, this is not surprising, nor are the few individual values which are higher than the highest for 1956 . As far as one can interpret the data therefore, the rate of deposition of ${ }^{90} \mathrm{Sr}$ has been constant for three years; the concentration of ${ }^{90} \mathrm{Sr}$ in milk has been constant for the same length of time; and allowing for the difference in human population sampled, the radio-activity of recently deposited bone is also reasonably constant.

${ }^{137}$ Caesium has not received the same amount of attention so far as ${ }^{90} \mathrm{Sr}$, but the analyses of Booker ${ }^{8}$ at the Atomic Energy Research Establishment show that the levels of ${ }^{137} \mathrm{Cs}$ in the dried milk from Frome have also been approximately constant during this time. Since caesium has a much faster turnover in the mammalian body than strontium, one can usefully investigate the caesium content of the adult, who should within a relatively short space of time come into equilibrium with his environment. As ${ }^{137} \mathrm{Cs}$ is a nucleide which emits $\gamma$-rays, the body content can be assayed by measuring the total output of $\gamma$ radiation with a whole-body counter, and with the appropriate discriminator one can identify the specific $\gamma$-rays of ${ }^{13}{ }^{7} \mathrm{Cs}$. Rundo's measurements at Harwell ${ }^{9}$ on the same individuals over the last year or so show that there is little alteration in total body content of ${ }^{137} \mathrm{Cs}$. The contamination of both milk and the human subject thus seem to be at present dependent also on rate of fall-out. 
At this stage it would be worth while to take note of the recent experimental work in the laboratory and field aimed at clucidating some of the factors which have hitherto been obscure. If we start at the beginning of the chain-the soil-this is an extremely complex factor. Soils vary in their texture and in their constituent clay-minerals. They vary as to $\mathrm{pH}$, content of organic matter and content of inorganic ions. When strontium and calcium are under discussion, it is possible to analyse the total content in the soil of these elements by completely breaking down the soil by drastic chemical treatment, for instance by fusion with soda and elution of calcium and strontium carbonates. However, this does not give any indication of the amount of calcium or strontium available to the plant. A number of milder extracting agents, such as normal ammonium acetate, have been used in an attempt to assay the so-called 'available' calcium and strontium. However, the correlation between what the chemist sees as available calcium and what the plant sees is poor.

Russell, Schofield and Newbould ${ }^{10}$ of Oxford reported a new concept to the Second Geneva Conference on the Peaceful Uses of Atomic Energy. They consider that an 'equilibrium soil solution' would be one in which the ionic concentration would remain constant irrespective of the ratio of soil to solution. This should be the solution that the roots of the plants take up. To determine the constitution of this equilibrium soil solution would be a formidable proposition. Instead, they added ${ }^{89} \mathrm{Sr}$ and ${ }^{45} \mathrm{Ca}$ to soil and determined the equilibrium distribution of the tagged ions between soil and solution to derive a soil/solution factor. They also grew plants in such a soil and determined a plant/soil factor. For eight different soils with a wide range of 'extractable' calcium, they found a close correlation between the soil/solution factor and the plant/soil factor. This suggests that the concept of the equilibrium soil solution is valid for most conditions. In practice, by determining a soil/solution factor one should be able to predict what would be the plant/soil factor. Under most conditions the plant does not discriminate markedly between calcium and strontium. Previous work by Squire and Russell ${ }^{11}$ suggests that what a plant is mainly concerned with is the total concentration of calcium and strontium in the nutrient solution.

Another experiment is in progress at the Agricultural Research Council's Field Station at Compton. Middleton and Squire ${ }^{12}$ have 18 drain pipes filled with five different sorts of soil, well-packed and weathered. The surface of each cylinder has been contaminated with one millicurie of ${ }^{90} \mathrm{Sr}$. Some cylinders have been kept bare; others are growing crops such as rye-grass. Cores of soil are periodically taken to determine the rate of leaching through the profile of the soil, and the crops, where present, are periodically harvested. So far in one year from 0.3 to 0.9 per cent, depending on the soil type, of the ${ }^{90} \mathrm{Sr}$ originally applied has been absorbed by the crop. From each type of soil the uptake of calcium by the rye-grass has been relatively constant, but the uptake of ${ }^{90} \mathrm{Sr}$ has varied with the soil. Low ratios of ${ }^{90} \mathrm{Sr}$ to calcium are associated with those soils with a high exchangeable content of calcium. Addition of calcium carbonate to a soil initially low in exchangeable calcium has markedly reduced the uptake of ${ }^{90} \mathrm{Sr}$. In the soils themselves, after 19 months the major part of the radio-activity has not penetrated more than two inches down the soil profile. 


\section{J. F. LOUTIT}

A second experiment has been concerned with, as it were, the comparative physiology of different species of plants. Rye-grass, clover and lucerne have been grown in deep boxes. In some boxes a layer of ${ }^{89} \mathrm{Sr}$ has been placed one inch below the surface. In other boxes the ${ }^{89} \mathrm{Sr}$ has been placed at the six-inch or twelve-inch level. These boxes have been sampled on three occasions. The young growing plants, of course, all take up ${ }^{89} \mathrm{Sr}$ from the one-inch layer but on the third occasion when the plants were all well established, rye-grass still took up much more ${ }^{89} \mathrm{Sr}$ from the one-inch layer than from the other two. In the case of clover the uptake was much the same from all three layers, but by lucerne, known to be a deep feeder, the uptake from the twelve-inch layer was greater than from the other two. This shows us that the pasture grasses, like rye-grass, are especially likely to take up fall-out strontium in unploughed permanent pasture, because the ${ }^{90} \mathrm{Sr}$ moves extremely slowly through the soil and remains concentrated in the top inch or two. Ploughing of pastures would help to redistribute the strontium through the soil profile and to dilute it. The pasture could then be reconstituted by reseeding. The practice of turning over leys every three to five years is already recommended as good agricultural practice.

However, we have seen that not all contamination comes from the soil through the roots. Middleton ${ }^{13}$ has already published some of his observations on the accumulation of ${ }^{89} \mathrm{Sr}$ and ${ }^{137} \mathrm{Cs}$ in the edible parts of agricultural crops. Boxes containing the various species at different stages of growth have been contaminated with a fine spray of soluble salts of these nucleides. This necessitates a specially designed spraying chamber. After spraying, the crops were dried off and later exposed to wind and rain. Much of the radioactivity was lost by being washed off with rain or in other ways such as the decay of the older leaves. Some of the ${ }^{89} \mathrm{Sr}$ was absorbed by the leaves and remained in situ. Little, if any, entered the vessels so that there was little translocation to developing edible parts of the plants. ${ }^{137} \mathrm{Cs}$ was also absorbed through the leaves but this did enter the circulation and some appeared subsequently in edible parts of the plant-young leaves and fruit, roots and tubers.

Laboratory experiments such as these are being carried out and have been reported in other parts of the world. What is perhaps unique are some of the experiments planned and carried out in the field in Great Britain.

Milbourn, Ellis and Russell ${ }^{14}$ have used plots of land roughly one acre in area in various parts of the country, each with a different soil type. The areas have been sprayed with ${ }^{89} \mathrm{Sr}-$ special precautions being taken to prevent contamination of the staff undertaking the spraying operation. The sprayed area has then been cultivated by one or other of three different methods, shallow scuffling with a rotary cultivator, ploughing to the conventional depth of six or seven inches, or deep ploughing to twelve inches. In some cases a cultivated and sown area has also been sprayed with ${ }^{89} \mathrm{Sr}$ or an established pasture has been contaminated. The contaminated and subsequently cultivated plots were sown with crops-rye-grass, cereals and root or fodder crops. In the case of rye-grass the uptake was by far the greatest when pre-sown areas were contaminated just before the seed germinated. Next in general order were those areas first contaminated and then cultivated with rotary cultivators. As might be expected the uptake 
was greater when the soil was low in available calcium. In the areas sown with cereal crops the uptake was notable only on one soil with little readily extractable calcium. On all soils the uptake into the plant was almost exclusively into the straw or chaff, or both; extremely little entered the grain. The root or fodder crops varied according to the conditions; kale and sugar beet took up significant amounts of strontium from several soils. The effect of emplacement by the various forms of cultivation was very small in the decper rooted species. It is notable that when stabilized pasture had been contaminated the level of ${ }^{89} \mathrm{Sr}$ in the tissues formed subsequently, was up to five times higher than in grass sown on contaminated ground.

This brings us back to predictions about the future. Russell ${ }^{15}$ has just published his appreciation of this problem. He has taken the results of the field experiments and noted the uptake by rye-grass according to the calcium status of the soil. Figures are available for the fraction of total cultivated agricultural soils in Britain, according to the extractable calcium in the soil. Britain is fortunately placed and half the cultivated area has more than 15 mequiv. of calcium per $100 \mathrm{~g}$ of soil. Only a few per cent have less than 5 mequiv. Combining the data obtained from the field experiment with appropriate weights for the fraction of total cultivated area corresponding to each particular soil type, he thus derived a national mean for ${ }^{90} \mathrm{Sr}$ in $\mu \mu \mathrm{C} / \mathrm{g}$ calcium. This calculation leads to the conclusion that there should now be $\mathrm{l} \cdot \mathrm{l} \mathrm{S} . \mathrm{U}$. in plants per $\mathrm{mC} / \mathrm{km}^{2}$ of ${ }^{90} \mathrm{Sr}$ deposited on agricultural land. However, the observed results in pasture grasses and correspondingly in milk are 8 to 14 times greater than would be expected on this basis. On the other hand, annual crops have values approximately of this amount. Russell notes that established pastures, particularly uncultivated hill grazings, have not only a root system penetrating the true soil and an aerial leaf system, but each plant has a crown which can mechanically trap particulate matter. In this area between the true aerial leaves and the roots there is a mat consisting of organic matter and decayed leaves infiltrated with surface roots. Thus fall-out which is not directly trapped by the aerial leaves is deposited in this mat and material which is first deposited on the leaves can be later washed off into the mat. There is thus an intermediate reservoir between the aerial parts and the true soil. The capacity of the plant to absorb micronutrients, such as strontium, from this mat is likely to be high, and under natural conditions the strontium will not be diluted here with calcium as in soil, however calcium deficient. While this reservoir is being filled the plant will absorb ${ }^{90} \mathrm{Sr}$ according to the total deposited; but when it is filled there should be an equilibrium between the intake from the atmosphere and aerial parts of the plants and the output to the true soil below; thus the plant will then absorb from it according to the rate of deposition. It is likely that this reservoir will take several years to attain this equilibrium, especially where the layer of mat is substantial. If this hypothesis should be proved correct, some of the calculations of others based on levels obtained now or in the immediate past and on the past trends, may be unduly pessimistic.

If one regards the uptake at equilibrium from the mat and from the aerial parts of the plant as both dependent on rate of fall-out and only the uptake from the true soil to be dependent on accumulated fall-out, then given a constant rate of fall-out as over the last few years continuing in the future 


\section{J. F. LOUTIT}

(which is one of the assumptions made by the United Nations Scientific Committee) - an equilibrium will be reached for cumulative fall-out at 12 times the present level, but the contamination of lowland pastures in the United Kingdom will have risen only three to four times. For annual crops the contamination is likely to be intermediate between 12 and four at about seven times the present level. For hill pastures the final equilibrium should exceed the present levels by smaller factors even than three to four. It is to be expected that the levels in milk will, as before, closely follow the levels in the corresponding pastures.

Russell rightly points out that differences in agricultural conditions may cause a very large variation in the relative magnitudes of the factors which cause the contamination of the plants. Conditions in the United Kingdom determine the uptake there, but not necessarily elsewhere. Thus, while milk in Frome, Somerset, has been relatively constant in radio-activity of ${ }^{90} \mathrm{Sr}$ since 1955, the reported values for milk in New York, U.S.A., have risen steadily. In the United Kingdom, particularly the southern part, permanent grazings contribute largely to the cow's normal diet. In the U.S.A. cattle are fed largely on annual crops.

From these predictions of the future values of foodstuffs at equilibrium one could calculate the future contamination of the average Briton. The average diet is known from the statistics of the Ministry of Agriculture, Fisheries and Food. About half of the dietary calcium comes from milk and milk products; over 20 per cent comes from mineral chalk added to flour; and the miscellaneous remainder is mainly from vegetable sources. Bryant et al. ${ }^{5}$, we have already noted, have made a retrospective survey of the levels recently obtaining in a British diet and the following is a summarized version of their Table IV:

\begin{tabular}{|c|c|c|c|}
\hline & \multicolumn{2}{|c|}{ Daily Intake } & \multirow[b]{2}{*}{${ }^{90} \mathrm{Sr} \mu \mu \mathrm{C}$} \\
\hline & $\mu \mu \mathrm{C}{ }^{90} \mathrm{Sr} / \mathrm{g} \mathrm{Ca}$ & $\mathrm{Ca} \mathrm{mg}$ & \\
\hline Milk, etc. & $5 \cdot 45$ & 667 & $3 \cdot 64$ \\
\hline Flour, etc. & $2 \cdot 0$ & $332 *$ & $0 \cdot 66$ \\
\hline Vegetable, etc. & $15 \cdot 0$ & 115 & $1 \cdot 73$ \\
\hline Meat & $14 \cdot 8$ & 27 & $0 \cdot 40$ \\
\hline \multirow[t]{2}{*}{ Rest } & $3 \cdot 8$ & 58 & $0 \cdot 22$ \\
\hline & & 1199 & $6 \cdot 65$ \\
\hline
\end{tabular}

* $200 \mathrm{mg}$ Ca from chalk.

Applying Russell's factors one gets:

\begin{tabular}{|c|c|c|c|}
\hline & $\mathrm{Ca} \mathrm{mg}$ & Factor & ${ }^{90} \mathrm{Sr} \mu \mu \mathrm{C}$ \\
\hline Milk, etc. & 667 & $x$ & $14 \cdot 56$ \\
\hline Flour, etc. & 332 & $\times \quad 12$ & $7 \cdot 82$ \\
\hline Vegetable, etc. & 115 & $\times \quad 12$ & $20 \cdot 76$ \\
\hline Meat & 27 & $x$ & $1 \cdot 60$ \\
\hline \multirow[t]{2}{*}{ Rest } & 58 & $\times \quad$ ?8 & $1 \cdot 76$ \\
\hline & 1199 & & $46 \cdot 50$ \\
\hline
\end{tabular}




\section{RADIO-ACTINE FISSION-PRODUCTS IN THE HUMAN FOOD CHAIN}

So that with an Observed Ratio $\left({ }^{90} \mathrm{Sr} \mathrm{Ca}\right.$, bone: ${ }^{00} \mathrm{Sr} / \mathrm{Ca}$, diet) of 0.25 one would expect bone to be about $10 \mathrm{~S}$.U. The present work of the joint survey being carried out by the Agricultural Research Council, Medical Research Council Joint Committee, with help from the Atomic Energy Authority and others, is designed to affirm the preliminary survey of Bryant et al., to identify conditions in special areas of high rainfall and low productivity, and especially to validate the predictions.

\section{REFERENCES}

${ }^{1}$ Stewart, N. G., Crooks, R. N. and Fisiler, E. M. R. A.E.R.E. HP/R 2017 (1957)

${ }^{2}$ Stewart, N. G., Osmond, R. G. D., Crooks, R. N. and Fisher, E. M. R. A.E.R.E. HP/R 2354 (1957)

${ }^{3}$ Bryant, F. J., Cilamberlain, A. C., Morgan, A. and Spicer, G. S. J. Nuclear Energy' 6 (1957) 22

${ }^{4}$ Bryant, F. J., Chamberlain, A. C., Morgan, A. and Spicer, G. S. A.E.R.E. $H P / R 2353$ (1957)

${ }^{5}$ Bryant, F. J., Chamberlain, A. C., Spicer, G. S. and Webb, M. S. W. Brit. med. J. $i$ (1958) 1371

${ }^{6}$ Bryant, F. J., Morgan, A. and Spicer, G. S. A.E.R.E. HP/R 2730 (1958)

${ }^{7}$ Bryant, F. J., Henderson, E. H., Spicer, G. S. and Webb, M. S. W. A.E.R.E. C/R 2583 (1958)

${ }^{8}$ Booker, D. V. A.E.R.E. HP/R 2183 (1958)

${ }^{9}$ Rundo, J. Second Conference on the Peaceful Uses of Atomic Energy Paper P/1467 Geneva, 1958

${ }^{10}$ Russell, R. S., Schofield, R. K. and Newbould, P. Second International Conference on the Peaceful Uses of Atomic Energy Paper P/287 Geneva, 1958

11 Squire, H. and Russell, R. S. J.exp. Bot. 9 (1958) 262

12 Middleton, L. J. and Squire, H. Communication to the Food Chain Conference, Harwell, 1958

${ }^{13}$ Middleton, L. J. Nature, Lond. 181 (1958) 1300

${ }^{14}$ Milbourn, G. M., Ellis, F. B. and Russell, R. S. Communication to the Food Chain Conference, Harwell, 1958

15 Russell, R. S. Nature, Lond. 182 (1958) 834

\section{DISGUSSION}

Dr. DAvis: You mentioned in passing the use of ${ }^{89} \mathrm{Sr}$ to give a measure of the age of strontium activity. Could you tell us a little more about the use of the ratio in practice and give us some idea of the absolute levels of ${ }^{89} \mathrm{Sr}$ normally encountered in biological materials?

DR. LoutrT: Let us assume that one looks at the assays of grass or milk for a representative year in England. The ${ }^{89} \mathrm{Sr} /{ }^{90} \mathrm{Sr}$ ratio starts low in January: the cattle are on stored feed, collected the previous summer. In the spring the ratio rises as the cattle are put out to grass onto which perhaps there is a fresh deposit of fission-products from a recent series of tests in Nevada (tropospheric fall-out). The ratio falls off as the summer and time proceeds. In the autumn perhaps there is a megaton test by the U.S.S.R. and the ratio rises again (stratospheric and tropospheric fall-out). When the cattle go indoors for winter quarters the levels fall again. In the local circumstance at Windscale, the levels of ${ }^{89} \mathrm{Sr}$ in milk rose in some cases some 30 -fold compared with ${ }^{90} \mathrm{Sr}$ - evidence of recent fission.

Dr. Green: Could you claborate the fission-product situation in relation to crops such as rice and alfalfa grass? 


\section{DISCUSSION}

DR. LoutrT: Alfalfa is, as far as I know the same as lucerne, and therefore one would expect that caesium which gets into the vascular system, would be translocated down from the aerial parts to the deep roots 24 inches down or however far they go. Your first question was related to rice which is a special Oriental problem. Diet in the Orient is mainly of vegetable origin and the main source of calcium is the plant not the animal. For most vegetation in the East the general metabolism is probably not very different from that which we have investigated in the United Kingdom. But rice is peculiar. It grows in paddy fields. We predict that here the situation may be similar to the conditions in, shall we say, the Welsh hills or the Scottish Highlands which in our country have been the object of popular concern, and which Russell has investigated. If one looks at the sheep which have grazed the Welsh hills, the activity in their bones over 1954 to 1957 has gone up linearly apparently in relation to the cumulative fall-out. This is in contrast to the milk figures, and therefore, presumably, the bones of cows on lowland pastures. Now our prediction is that these sheep bones will similarly level off. As Welsh and Highland pasture is of extremely poor growth on extremely unfertile ground, the material deposited on the aerial parts is washed down into the crown of the grass, and is taken up again into the new leaves as they spring up, so that there is a recycling of the fall-out above ground. Also the surface level and the true soil are separated by a mat of varying degrees of thickness; it may be 2 inches on fairly good ground, or it may be 6 inches on extremely poor ground, and this mat ultimately forms peat and, I presume, coal. It is a product of the decayed unploughed permanent vegetation. It represents the accumulation of centuries. In this mat are all the surface roots of the grass plant. The mat is extremely deficient in all the essential elements, so that we have an enormous reservoir in which the fall-out is accumulating. On good pasture the layer of mat is only a fraction of an inch thick. Until this mat reservoir is saturated with ${ }^{90} \mathrm{Sr}$ and comes into equilibrium with the soil below, one would predict that the bone level of sheep feeding on this ground, would rise linearly with the cumulative fall-out. It appears to take only about a year to fill this reservoir in lowland pasture; it might take 4,5 or 6 years to fill this reservoir in the heavily matted areas, and there is an indication from the 1958 results that this levelling off is, in fact, now occurring in the Welsh hills. If that is so, then in the Welsh hills, instead of there being a rise by a factor of five for cumulative fall-out in 1967, there may, in fact, only be a rise by another factor of two over the present values. That is-sheep in the Welsh hills have already got much nearer their peak than animals in lowland conditions. Similar conditions may apply with rice. But here, instead of a layer of mat, there is a layer of mud on the bottom of the flooded paddy field, and this mud layer may be acting as a reservoir, and giving artificially high figures at the present time for rice. This is only a hypothesis; until it is tested one does not know what the right answer is.

Dr. George: May I ask you, from the very interesting results you have been recounting this morning, could I tempt you to hazard a guess as to the order of magnitude of the radiation dosage to bone marrow in man received from fall-out, the relative contributions from the $\gamma$ radiation of the material on the ground and from ${ }^{90} \mathrm{Sr}$ ?

Dr. LoutiT: I have not done the calculation, and I would not like to put it into any quantitative form-but there is an appreciation of the problem in a little work from Sweden recently, by Nelson and others, and I think one could derive from that book the dose to bone marrow from various concentrations of ${ }^{90} \mathrm{Sr}$ in the bone. From the present levels of ${ }^{90} \mathrm{Sr}$ in the bone, from predicted levels of ${ }^{90} \mathrm{Sr}$ in the bone, and the calculations there, I think you could get the answer, but I would not like to do it out of my head.

MR. JACKson: The figures you gave for Britain point to a pretty pessimistic view for Australia, I would say, just knowing the two factors which are really important. It 


\section{RADIO-AC:TIVE FISSION-PRODUCTS IN THE HUMAN FOOD CHAIN}

would seem that if you got a variation of about seven-fold for uptake on various soils, I would think, just gucssing, that you would have about a ten-fold increase in resiclual acrial loam if you consider the lower ratios, which we have compared with those in Britain. So we have a ten-fold increase in the aerial residual, and we have a seven-fold increase in the root crops, because of poorer soil. It does not look too good, even though we are better off in that we have lower levels of fall-out.

DR. Lourit: It is this sort of thing that I had in mind when I started off by saying that anything that I said was only relevant to Britain. I think that we there, by means of the combination of field survey and experiment, have been able to get down to this sort of calculation. The only thing that I can suggest for local conditions is, that you make some sort of experimental appreciation, as well as carrying on the survey observations, and then you will also have a calculation that can be applied to local conditions.

Professor Titterton: Could I just comment on that, Mr. Chairman? The integral experiment has been done, differential experiments have not been done, but the numbers which I gave yesterday (Paper 16), which are typical, naturally, of the growing areas in Australia, for things such as cabbages, milk, soil samples and sheep bones, show quite clearly that the ratios are in the right dircction. There is certainly no factor of 10-there might be a few per cent one way or the other. But our levels in food-stuffs, in milk, compare very well with the expected levels you would get from an actual fall-out. So I think you can rest assured that a factor of 10 is not going to turn up. It may be 20 per cent, or something like that. 


\title{
INJURY AND RECOVERY IN NEUTRON-IRRADIATED ANIMALS*
}

\author{
Howard H. Vogel, Jr., Donn L. Jordan and Samuel Lesher \\ Biological and Medical Research Division, Argonne National Laboratory, \\ Lemont, Illinois, U.S.A.
}

INTRODUCTION

DURING the past several years a programme has been carried on at Argonne National Laboratory, near Chicago, Illinois, in which the biological effects of fission neutrons and of ${ }^{60} \mathrm{Co} \gamma$-rays have been studied and compared in a wide variety of organisms ${ }^{1}$. All exposures have been carried out in a special yamma-neutron radiation chamber ${ }^{2}$. This exposure facility has been used in various experiments over the past six years, first, at the heavy-water reactor, CP-3', and, more recently, at Argonne's present research reactor, CP-5. The fast neutron flux was obtained by Zirkle's method ${ }^{3}$ of using the thermal column of a reactor in conjunction with a sheet of uranium to convert the thermal flux to one of fission neutrons. Pure $\gamma$ radiation was obtained from eighteen ${ }^{60} \mathrm{Co}$ sources mounted on a turret as part of the chamber.

MORTALITY MODES: INTESTINAL AND HAEMATOLOGICAL SYNDROMES

Evidence has been presented ${ }^{4}$ that exposure to these two radiations appears to produce death in mice by different mechanisms. A characteristic early mortality mode is observed after irradiation of mice with fission neutrons ${ }^{5}$. Recent histological and cytological studies of the duodenum of neutronirradiated mice indicate that this early four to ten-day mortality is correlated with severe damage and partial denudation of the intestinal mucosa ${ }^{6}$. On the other hand, mice irradiated with ${ }^{60} \mathrm{Co} \gamma$-rays, within the acute lethal dose range, do not usually die from this intestinal syndrome. Although their intestinal cells show damage following irradiation, recovery is rapid, and the mucosal lining appears in good condition three to four days after exposure to $\gamma$-rays (up to $1000 \mathrm{rad}$, single, whole-body dose). Mice dying after $\mathrm{X}$ or $\gamma$ irradiation, within the acute lethal dose range, usually show a high mortality peak near the end of the second week after exposure, with a characteristic haematological syndrome.

The intestinal syndrome, in neutron-irradiated mice, seems to reach a peak between three and a half and six days following exposure. The duodenum of mice exposed to a single dose (350 rad) of fission neutrons is severely damaged with complete destruction of the crypts and the subsequent extensive loss of the epithelial lining of the villi. Less than half of such irradiated animals live beyond the six-day period. Irradiation with this

* This work was performed under the auspices of the United States Atomic Energy Commission. 


\section{INJURY AND RECONERY IN NEUTRON-IRRADIATED ANIMALS}

dose of fission neutrons produces a high percentage of irreparable chromosome breaks and leads to a prolonged delay in cell division (at least 22 hours) ${ }^{6}$. A comparison of duodenal damage and recovery rate suggests a relative biological effectiveness (R.B.E.) of greater than six when comparing the effects of neutrons and $\gamma$-rays on intestinal sensitivity.

A section of duodenum from a mouse irradiated with fission neutrons is illustrated in Figure 1. The intestine was removed four days after the single

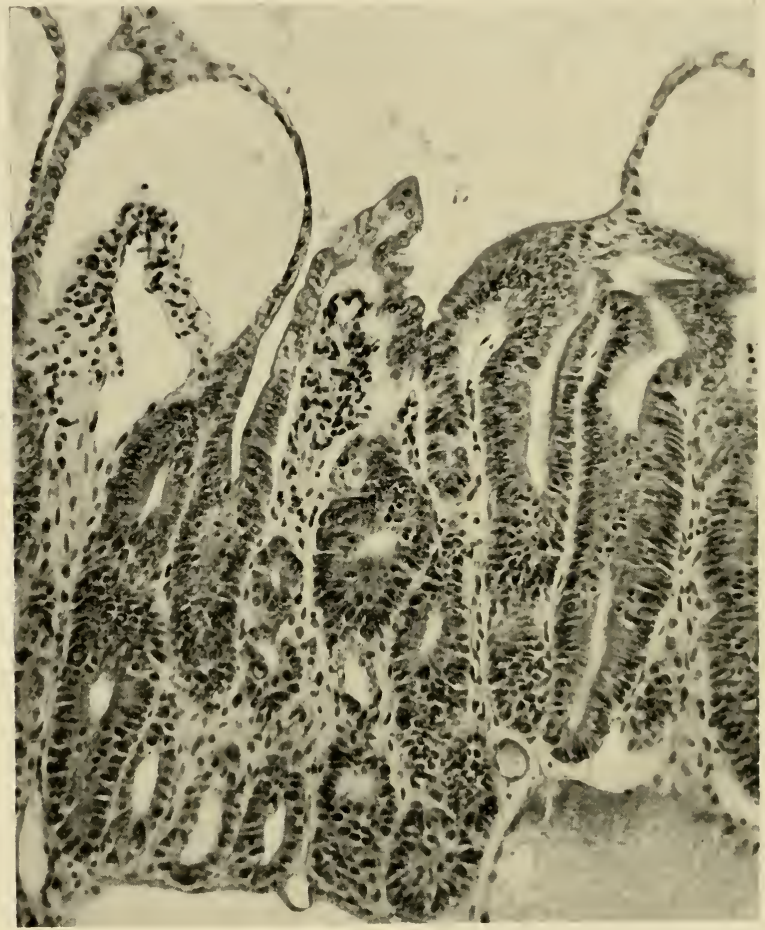

Figure 1. Cross-section of mouse duodenum 94 hours after $350 \mathrm{rad}$ fission neutrons (single whole-body irradiation) $\times 100$. (Reduced by one-half when reproduced.)

neutron exposure $(350 \mathrm{rad})$. This photograph shows the results of typical destruction of the crypts and the extensive loss of the epithelial covering of the duodenal villi at this time. Note the reduced size of the villi, the enlarged cells, chromatin masses, and severe damage and denuding of the mucosa. This mouse would undoubtedly have died from bacteraemia and septicaemia within a day or two. 
RADIATION PROTECTION EXPERIMENTS

Comparative Effects of Single, Postirradiation Intravenous Injection of Bone-Marrow Cells in Mice Irradiated with Lethal Doses of Fission

Neutrons and ${ }^{60} \mathrm{Co} \gamma$-Rays

CF No. 1 female mice, six to eight weeks of age, were exposed to a single dose of fission neutrons or of ${ }^{60} \mathrm{Co} \gamma$-rays sufficiently high so that $95-100$ per cent would die within 30 days. The exposures were carried out in the gamma-neutron radiation chamber ${ }^{2}$ at the CP-5 research reactor. Ninetyfour mice were exposed to $360 \mathrm{rad}$ of fission neutrons in $100 \mathrm{~min}$ with the

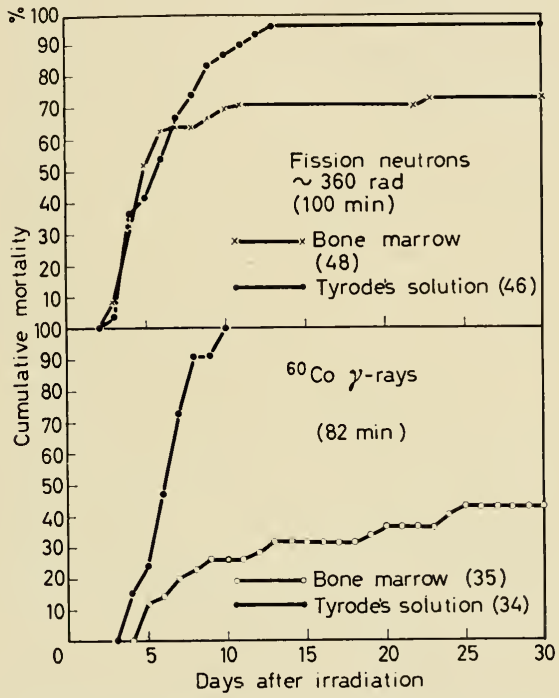

Figure 2. Comparative effects of single, postirradiation intravenous injection of homologous bone marrow cells in mice irradiated with lethal doses of fission neutrons and ${ }^{60}$ Co $\gamma$-rays $(1082 \mathrm{r}$ )

reactor operating at $1000 \mathrm{~kW} ; 69$ additional mice were exposed to a single dose of $1082 \mathrm{r}$ of ${ }^{60} \mathrm{Co} \gamma$-rays delivered at an intensity of $13 \cdot 3 \mathrm{r} / \mathrm{min}$. Each series of irradiated mice was then subdivided into two groups, the first receiving an intravenous injection via the tail vein of 0.2 c.c. bone-marrow cells in Tyrode's solution, the second half receiving 0.2 c.c. of Tyrode's solution only. All injections were completed within a few hours following irradiation.

The bone-marrow cells were obtained from the femora of other CF No. 1 female mice of approximately the same age as the irradiated animals. The donor mice were sacrificed with ether and both femurs were dissected free. The head of each femur was then cut off and the cells were washed out of the marrow cavity into a small glass dish with a small amount of sterile 
Tyrode's solution, by means of a hypodermic needle. For every irradiated mouse which reccived a bone-marrow injection, one donor mouse was sacrificed, and each bone-marrow injection contained the equivalent of the cellular contents from two femurs.

The results of this cxperiment are illustrated in Figure 2. It is clcar from the cumulative mortality indicated for the $\gamma$-irradiated mice that the singlc intravenous injection of bone-marrow cells gave definite protection. All of the 34 irradiated controls died within 10 days after exposure. In contrast, only 15 of the 35 mice ( 43 per cent) which received bone-marrow cells died during the 30-day period following irradiation. The protective action of these cells following irradiation with fission neutrons is much less evident. For seven or eight days after exposure, no protection by the marrow cells is seen. However, there is evidence of marrow protection in the neutronirradiated mice after the first week and the 30-day lethality is decreased.

It scems probable that bone-marrow cells failed to protect neutronirradiated mice during the first week after exposure because these animals were dying as a result of intestinal damage against which the bone-marrow cells were ineffective. In contrast, $\mathrm{X}$ - or $\gamma$-irradiated mice are well protected by bone-marrow cells because their haematopoietic systems are stimulated to prevent death from the usual 'haematological syndrome'.

\section{The Synergistic Action of Intravenous Bone-Marrow Cells and Streptomycin in Protecting Neutron-Irradiated Mice}

Since it has been demonstrated that an antibiotic such as streptomycin can protect neutron-irradiated mice for at least 10 days after exposure ${ }^{7}$ it seemed possible that a combination of marrow cells and streptomycin might result in better protection than either agent alone. It was thought that the antibiotic would keep some of the irradiated mice alive beyond the period of the intestinal syndrome, and that the bone-marrow cells could then assume their protective role in helping to prevent the later deaths associated with the destruction of the blood-forming elements.

Approximately 130 CF No. 1 female mice were irradiated with $350 \mathrm{rad}$ of fission neutrons at the CP-5 research reactor. The reactor was operated at $2000 \mathrm{~kW}$, twice the power of the first experiment, so that the second exposure was carried out in $46 \mathrm{~min}$, at a dose rate of $7.5 \mathrm{rad} / \mathrm{min}$.

The irradiated mice were divided into four equal groups as follows:

Group I (32 mice) received a single intravenous injection of bone-marrow cells $(0 \cdot 2$ c.c. in Tyrode's solution) within a few hours after exposure.

Group II (32 mice) received a single intravenous injection of bone-marrow cells and, in addition, received daily subcutaneous injections of streptomycin ( $5 \mathrm{mg}$ in 0.5 c.c. physiological saline) for the first 12 days after irradiation.

Group III (32 mice) received a single intravenous injection of Tyrode's solution $(0 \cdot 2$ c.c.) and daily streptomycin injections, as above.

Group IV (30 mice) received a single intravenous injection of Tyrode's solution plus daily subcutaneous injections of 0.5 c.c. physiological saline solution.

A fifth group of 32 mice served as unirradiated controls. 
HOWARD H. VOGEL, JR., DONN L. JORDAN AND SAMUEL LESHER

The results of this experiment (Figure 3) tend to support the hypothesis. Although daily streptomycin therapy alone (Group III) protected the irradiated mice for at least nine days, protection was not evident thereafter; the 30 -day mortality figure ( 75 per cent) was not greatly reduced from that of the saline-injected irradiated mice of Group IV (87 per cent). A single bone-marrow injection (Group I) reduced the 30-day mortality to only 25 per cent. Most of these deaths occurred during the first eight days after exposure, during the period of intestinal damage. When both agents were

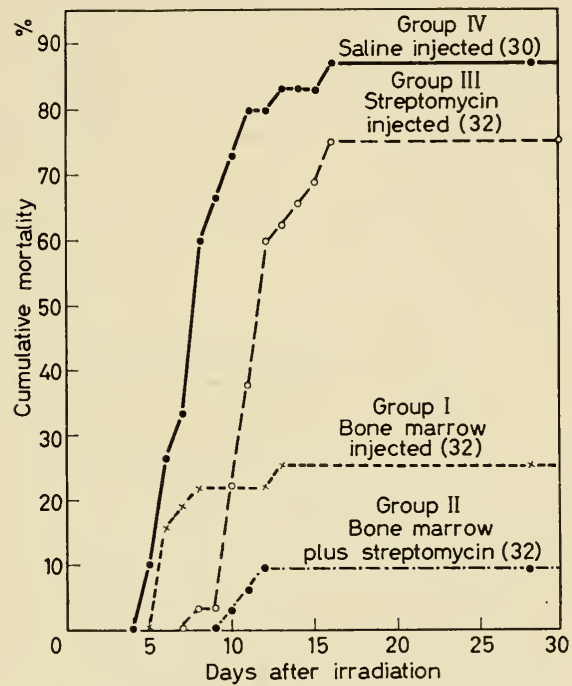

Figure 3. Comparative protective effects of postirradiation treatment with $(a)$ streptomycin, $(b)$ homologous bonemarrow cells, and (c) both agents combined. CF No. 1 female mice irradiated with single dose of $350 \mathrm{rad}$ of fission neutrons at the CP-5 research reactor. Duration of exposure: 46 minutes.

combined (Group II), a synergistic protective action was observed; only three mice of the 32 irradiated (9 per cent) died within the 30-day period, in contrast to approximately 90 per cent in Group IV, which received neither therapeutic agent.

The CF No. 1 mouse used in these experiments, and obtained commercially from Carworth Farms, is not a pure inbred line. Several skin transplants have been attempted between individual mice of this strain and invariably the homotransplants showed destruction within a two-week period. However, the CF No. 1 mice protected by the bone marrow and streptomycin technique did not show a significant delayed death (Figure 4). This 'homologous disease' often reported after homologous and heterologous marrow transplants, 


\section{INJURY ANI) RECONERY IN NEUTRON-IRRADIATED ANIMALS}

60 to 100 days after transplantation, presumably is an immune reaction between graft and host.

Several protective experiments of this same kind have been carried out

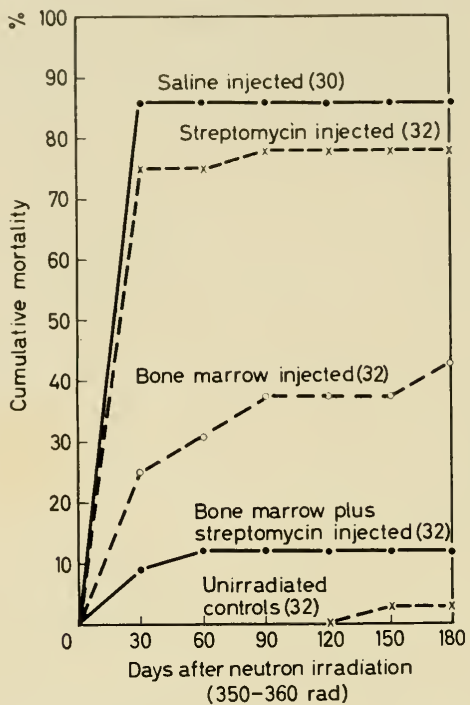

Figure 4. Survival of similarly treated groups of mice as illustrated in Figure 3 , for a period up to six months after exposure to neutrons. Note that the mice protected by the bone-marrow cells do not show significant delayed or 'homologous' deaths (60-90 days) from immune reactions between host and graft.

Table 1. Summary of data for neutron-irradiated mice

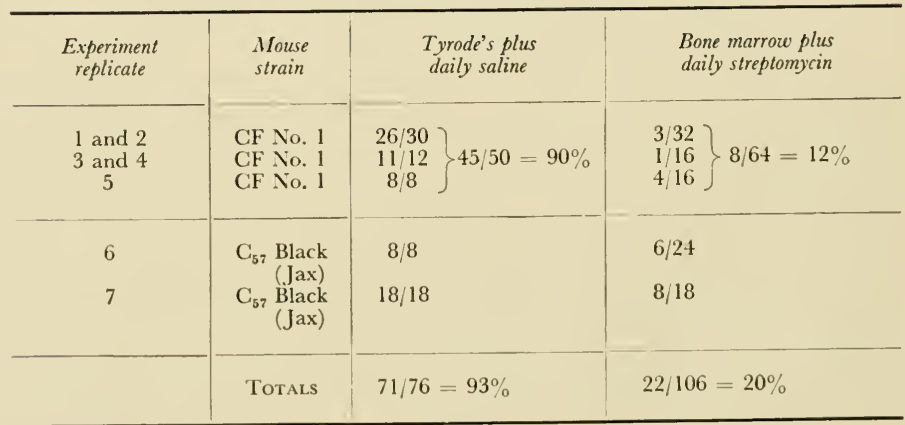


HOWARD H. VOGEL, JR., DONN L. JORDAN AND SAMUEL LESHER

using the C57 black mouse, an inbred strain, from the Roscoe B. Jackson Memorial Laboratory in Bar Harbor, Maine. The results of these tests, using daily streptomycin and isologous bone-marrow cells, are summarized in Table 1 .

\section{Combination of the Amino Acid, Cysteine with Bone Marrow and Streptomycin Treatment}

Previous work from this laboratory has indicated that pretreatment of neutron-irradiated mice with the amino acid, cysteine, effectively reduced the radiation dose by approximately seven to eight per cent ${ }^{8}$. It seemed

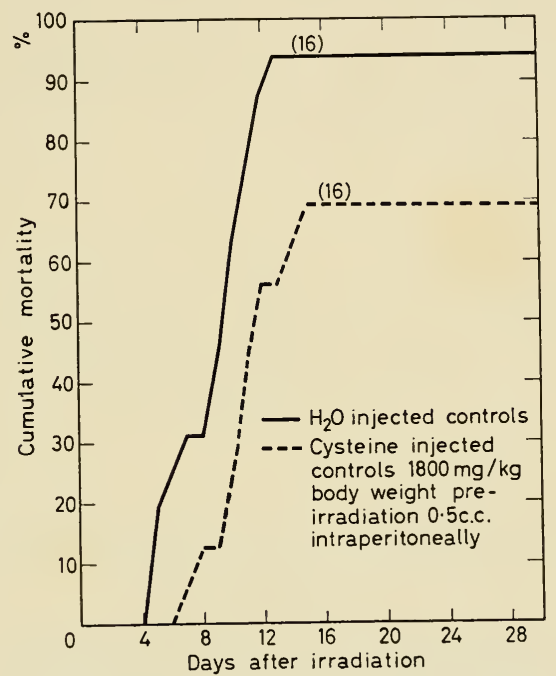

Figure 5. The protective effect of cysteine, injected intraperitoneally into neutron-irradiated mice.

probable, therefore, that a combination of this agent with the bone marrow and streptomycin therapy described above might produce even better protection. Consequently, experiments could be carried out in the 'supralethal' neutron dose range.

A preliminary experiment was completed to test the effectiveness of cysteine given intraperitoneally instead of intravenously as in our former work with this sulph-hydryl-containing amino $\mathrm{acid}^{8}$. Since the bone-marrow cells are most effective when injected into a vein after irradiation, it was hoped that the intraperitoneal route could be used for the cysteine injection prior to neutron exposure. The results of this experiment, shown in Figure 5, indicated that the cysteine was effective by this route. However, it was necessary to give higher doses than when the intravenous route was utilized: mice given 0.5 c.c. of a 10 per cent cysteine solution $(\mathrm{pH} 7-8,1800 \mathrm{mg} / \mathrm{kg}$ 


\section{INJURY ANI RECOVERY IN NEUTRON-IRRIDIATEI) ANINALS}

body weight) showed the same type of dose reduction we had previously reported ${ }^{8}$.

The three treatments were therefore combined, cysteine being injected intraperitoncally into mice before neutron exposure; these irradiated animals were then given 0.2 c.c. of bone-marrow cells from other $\mathrm{CF}$ No. 1 female mice into a tail rein within a few hours after irradiation. The bone marrow technique was the same as that described above. The mice were also

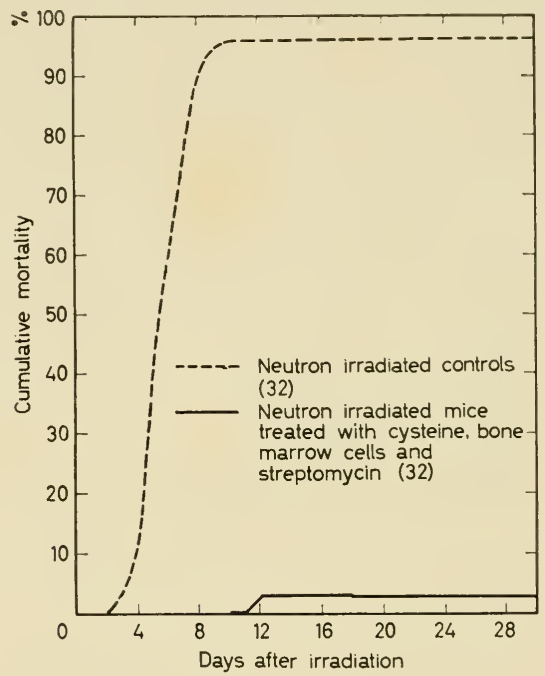

Figure 6. Comparative mortality, in the acute 30-day period following single exposure, between neutronirradiated control mice and neutron-irradiated mice treated with a combination of cysteine (before exposure) and bone-marrow cells and streptomycin (after exposure).

injected daily with a dose of 0.5 c.c. streptomycin, given subcutaneously, for a ten-day period after exposure.

Other neutron-irradiated mice received an injection of water as a preirradiation control for the cysteine. These animals also received $0 \cdot 2$ c.c. Tyrode's solution (the bone marrow vehicle) and daily injections of 0.5 c.c. saline solution instead of streptomycin. This group constituted the neutronirradiated, 'nontreated' controls.

The data from this experiment are summarized in Figure 6. It is clear that we are dealing with so-called supralethal doses of fission neutrons: only one of the control mice survived the exposure. In contrast, only one of the 32 mice treated with the triple technique died within the acute 30 -day period. It is interesting to point out that both in the experimental and in the control 
groups, all the mortality in the acute period took place within 10-12 days after exposure.

Further experiments have been carried out recently at still higher doses of fission neutrons: we have been able to protect neutron-irradiated mice which have received doses as high as $400 \mathrm{rad}$.

In Figure 7 the body weight data are illustrated for the various groups of mice. It is clear that there is a sharp decline in body weight for at least four days following exposure, but in the treated animals there is a definite recovery as shown by the average body weights, usually beginning between the sixth and seventh days after exposure. This is evidence, we believe, that

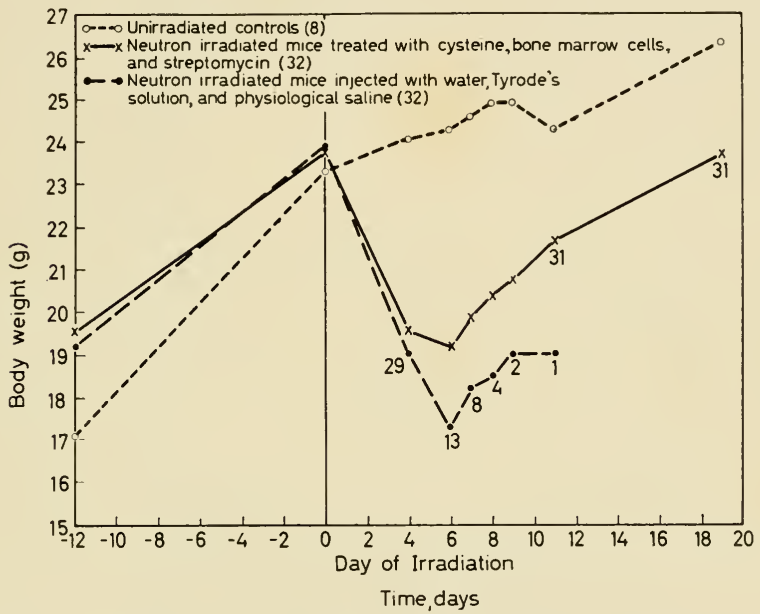

Figure 7. Body weight comparisons between unirradiated control mice, neutron-irradiated controls, and neutron-irradiated mice 'protected' with combined cysteine, bone-marrow cells, and streptomycin techniques. The numbers below the lines indicate the number of mice alive at that particular day.

the administered bone-marrow cells have been transplanted successfully into the host's blood-forming system and are stimulating haematopoietic recovery.

If one looks at the cumulative mortality curve for untreated neutronirradiated mice (Figure 6), it is evident that at this time, one week after exposure, more than 80 per cent of the mice are dead. This is undoubtedly the reason that bone-marrow cells alone are not very effective in mice exposed to lethal doses of fission neutrons. The antibiotic streptomycin helps to protect the mice from fatal bacteraemia and septicaemia during the 10 -day period following exposure ${ }^{7,9}$. By this time the bone marrow, ineffective against the intestinal syndrome, has taken over its protection of the mouse haematological system. The cysteine helps the entire protective process by reducing the total effective radiation dose by approximately 10 per cent. 
'RECOVIRY' AFTER FISSION NELTRON IRRADIATION: PAIRED EQUAL DOSES WITH VARYING TIME INTERVALS

Many investigators have utilized a paired-dose technique to study radiation recovery in animals exposed to $X$ - or $\gamma$-rays. There are, however, few such fractionation studies following exposure to fission neutrons.

Mice (female CF No. 1 of 20 to $25 \mathrm{~g}$ body weight) have been irradiated with equal paired doses of both ${ }^{60} \mathrm{Co} \gamma$-rays and fission neutrons in order to

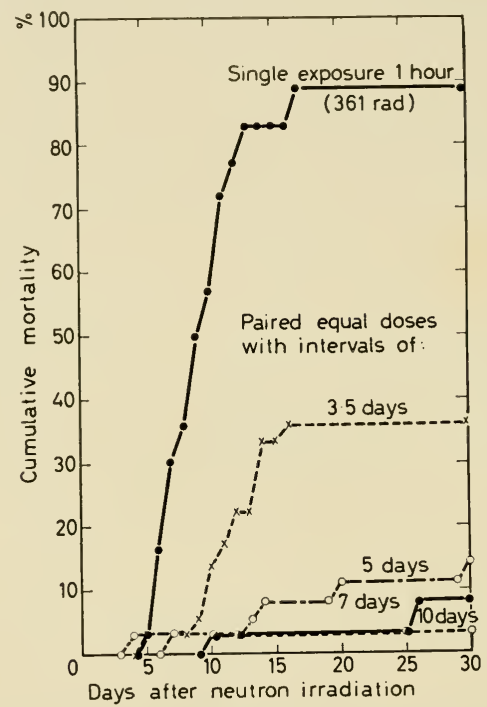

Figure 8. Acute 30-day mortality in CF No. 1 female mice irradiated with a single exposure of fission neutrons (361 rad in 1 hour), and compared with similar mice irradiated with paired equal doses with 3-5-, 5-, 7-, and 10-day intervals between the paired doses. It is evident that there is recovery after paired exposure to fission neutrons.

study and compare the recovery rates following exposure to these two radiations.

Several experiments have now been carried out which show clearly that there is definite recovery after exposure to fission neutrons, when 30-day mortality of mice is used as a criterion. This type of experiment is illustrated in Figure 8. Five groups of 36 mice were irradiated with neutrons. Group 1 received a single dose of $361 \mathrm{rad}$ in 1 hour. Thirty-two of 36 , or 89 per cent, of these mice died in the 30 -day period following exposure. The remaining four groups of mice were exposed to one-half the dose received by the first group (30-minute rather than 60-minute exposure), and were then exposed 
to a second 30-minute irradiation after a time interval of $3 \cdot 5,5,7$, or 10 days, respectively. After these time intervals, the 30 -day mortality figures were 36 per cent, 14 per cent, 8 per cent, and 3 per cent as compared to approximately 90 per cent when the single dose was administered. There is, therefore, definite recovery following fractionation of the fission-neutron

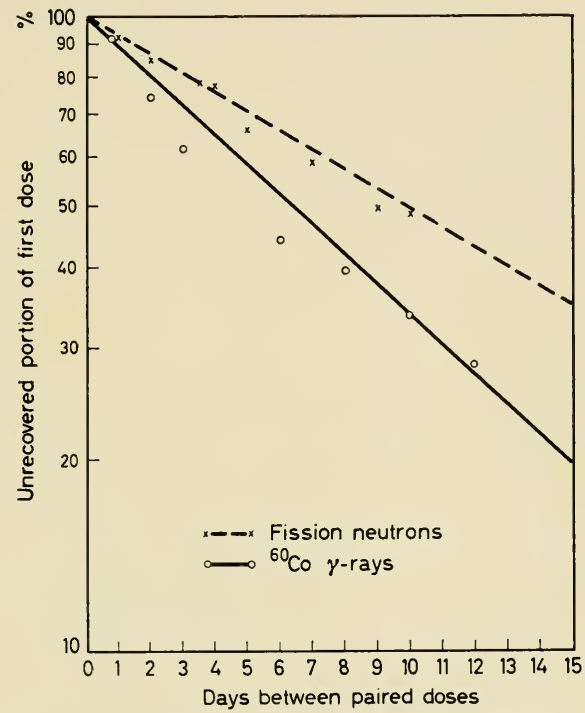

Figure 9. Comparative recovery rates in mice exposed to equal paired doses of ${ }^{60} \mathrm{Co} \gamma$-rays and of fission neutrons, with intervals between the exposures varying from 1 to 12 days. The graph illustrates the unrecovered portion of the first exposure (\%) plotted against the time between the paired doses (semi-log plot).

dose. It would also appear from the data that the amount of recovery was related to the time interval between the equal paired doses.

A comparison of such paired-dose experiments following both ${ }^{60} \mathrm{Co} \gamma$-rays and fission neutrons has been made. Several interesting facts are evident:

(1) The relationship between the lethal dose required to kill 50 per cent of the mice in the 30 -day period $\left(\mathrm{LD}_{5030}\right)$, and the time between doses, at least in the range of 1 to 10 day intervals, seems to be a linear one on a $\log -\log$ plot, whether the radiation is fission neutrons or $\gamma$-rays from ${ }^{60} \mathrm{Co}$.

(2) There is evident recovery after fractionation of either dose of radiation.

(3) The recovery rate, as judged by the slopes of the lines, does not appear to be identical.

This latter point is emphasized in Figure 9 in which the residual or ' unrecovered' portion of the first dose (in percentage) is plotted against the time interval in days between equal paired doses. 


\section{INJURY AND RECOVERY IN NEUTRON-IRRADIATED ANIMAIS}

These data suggest that the recovery rate after irradiation by fission neutrons is slower than that after $\gamma$ irradiation. When the data are plotted on semi-log paper as in Figure 9, a linear fit is scen. This suggests that the relationship between the unrecovered portion and the time between doses is exponential, at least when the time interval is of the order of 1 to 10 days.

It is seen from this figure that 50 per cent of the $\gamma$-ray dose is recovered when the time interval between doses is approximately six days. The

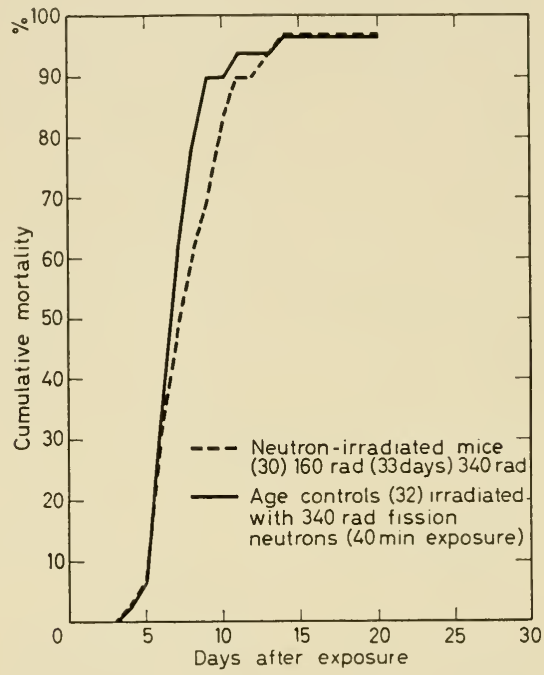

Figure 10. Cumulative mortality of CF No. 1 female mice irradiated with $160 \mathrm{rad}$ (approximately one-half the $\mathrm{LD}_{50 / 30}$ dose), and, 33 days later, exposed to a second dose of $340 \mathrm{rad}$. Compared with age controls irradiated with a single dose of $340 \mathrm{rad}$ fission neutrons.

comparative half-recovery time after fission-neutron irradiation would be about 10 days.

The same split-dose technique has been used in recent experiments in which the time between the two equal doses of fission neutrons has been extended to one or two months.

In Figure 10 are compared the cumulative mortality data for two groups of mice cxposed to fission neutrons. Group A (30 mice) received one exposure of $160 \mathrm{rad}$, followed 33 days later by a second exposure of $340 \mathrm{rad}$ at the same rate. These should be compared with the mortality data of 32 mice irradiated only once with 340 rad. (The second exposures for the two groups were carried out simultaneously in the same irradiation cages.) In each group only one mouse survived the acute period $\left(\mathrm{LD}_{97}{ }_{30}\right)$. There is 
HOWARD H. VOGEL, JR., DONN L. JORDAN AND SAMUEL LESHER

no evidence from this experiment that there is any residual or unrecovered portion left from the first $160 \mathrm{rad}$ of fission neutrons after the interval of 33 days, as measured by this technique.

In Figure 11 are summarized the mortality data from a similar exposure to split doses of fission neutrons, carried out at the CP-5 research reactor, with an interval of two months between exposures. It is clear from these data that mice exposed to $100 \mathrm{rad}$ or $185 \mathrm{rad} 60$ days prior to a second exposure of $300 \mathrm{rad}$ of fission neutrons, showed no increase in 30-day mortality when

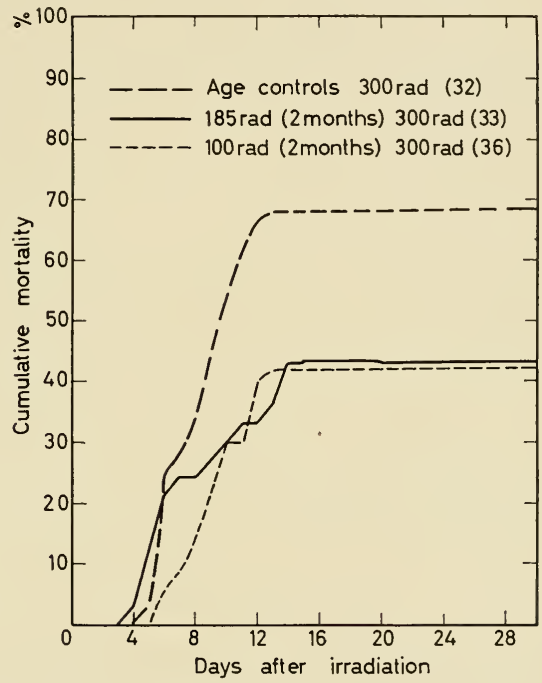

Figure 11. Cumulative mortality of CF No. 1 female mice irradiated with 300 rad fission neutrons, 2 months after a preliminary exposure of $100 \mathrm{rad}$ or of $185 \mathrm{rad}$ of neutrons. Compare with age control group which were irradiated only once with 300 rad.

compared with a group of age controls simultaneously exposed to a single dose of $300 \mathrm{rad}$. There is even an indication, since the mortality in both split-dose groups is lower than that in the age controls, that the first dose of neutrons might be slightly 'beneficial' as measured by 30-day mortality. At any rate, we may conclude that 60 days after a first neutron dose (from 30 per cent to 60 per cent of the $\mathrm{LD}_{5030}$, single, whole-body exposure), there seems to be no residuum as measured by the 30 -day acute mortality criterion.

In this paper, we have limited our consideration of recovery data to neutron-irradiated mice. However, parallel experiments have recently been reported describing recovery in the four-day chick embryo, when irradiated with paired doses of fission neutrons with only two to three hours between exposures $^{10}$. Daniels and Vogel ${ }^{11}$ have also reported complete recovery in 
the giant amoeba, Pelomyxa illinoisensis, when unirradiated protoplasm was micro-injected into a neutron-irradiated cell. Further studies in recovery after fission neutron irradiation are now in progress.

The authors wish to express their sincere appreciation to Richard R. Barhorst and Nicholas Bink for their excellent technical assistance in this work. We also wish to thank Atlee Tracy and Jane Glaser for aid in the photographic work and Dr. Robert Straube for advice in the cysteine experiment. These individuals are all members of the Biological and Medical Research Division of Argonne National Laboratory.

\section{REFERENCES}

${ }^{1}$ Clark, J. W., Jordan, D. L. and Vogel, H. H., Jr. Amer. J. Roentgenol. 77 (1957) 524

${ }^{2}$ Yogel, H. H. Jr., Blomgren, R. A. and Bohlin, N. J. G. Nucleonics 11, No. 3 (1953) 28

${ }^{3}$ Zirkle, R. E., Raper, J. R., Riley, E. F., Jr. and Stapleton, G. E. U.S. Atomic Energy Commission Report AECD-2328, 1945

${ }^{4}$ Vogel, H. H., Jr., Clark, J. W. and Jordan, D. L. Radiology 68 (1957) 386

${ }^{5}$ Vogel, H. H., Jr., Clark, J. W. and Jordan, D. L. Radiation Res. 6 (1957) 460

${ }^{6}$ Lesher, S. and Voger, H. H., JR. Radiation Res. 9 (1958) 560

${ }^{7}$ Hammond, C., Vogel, H. H., JR., Glark, J. W., Cooper, D. B. and Miller, C. P. Radiation Res. 2 (1955) 354

${ }^{8}$ Patt, H. M., Clark, J. W. and Vogel, H. H., Jr. Proc. Soc. exp. Biol., N.Y. 84 (1953) 189

${ }^{9}$ Vogel, H. H., Jr., Clark, J. W., Hammond, C. W., Cooper, D. B. and Miller, C. P. Proc. Soc. exp. Biol., N.Y. 87 (1954) 114

${ }^{10}$ Vogel, H. H., JR. publication of the Biological and Medical Research Division, Argonne National Laboratory (1959) -in the press

${ }^{11}$ Daniels, E. W. and Vogel, H. H., JR. Radiation Res. (1959)-in the press

\section{DISGUSSION}

Professor White: From the fact that there were no deaths from this second immunological reaction, would you conclude that the fission neutrons were more effective in knocking out the normal immunological mechanism of the animal than $\mathrm{X}$ irradiation, for example?

DR. Vogel: That is a very interesting point, and I am not sure of it. There is a tendency, I think, from these data, to conclude that neutrons may be more effective. The only reason I say that, is, that after similar $\gamma$ irradiation, one does get some secondary homologous deaths, and so far I have six neutron experiments running and the animals are still there and we have not had a significant secondary death. I think it is a very important point to follow up.

DR. LOUTIT: If I can go further-you showed some results with $\mathrm{C} 57$ black mice which were given combined treatment. Now, the bone marrow for those C57 blacks, is that isologous C57?

DR. Vogel: Yes.

Dr. Loutit: But even so, even with that isologous marrow, the deaths in this case were substantial for one reason or another?

Dr. Vogel: That is so. As you know, Dr. Loutit, these experiments do vary from time to time, with technique and other factors. But I was interested by the fact that the results from C57 black mice were not as good as those from the CF No. 1 strain. 


\section{DISCUSSION}

Dr. George: I did not quite catch how you gave marrow to the mice, did you give it in one shot, or two or three?

Dr. Vogel: It was given in a single shot within a few hours after radiation, intravenously through a tail vein. The contents of both femurs, from another mouse, in Tyrode's solution were given in each shot.

Dr. GRAY: Is it not true that cysteine gives better protection against $\gamma$-rays than fission neutrons?

Dr. Vogel: Yes, on the whole as I recall it, for $\gamma$-rays it is down by about 15 per cent, for neutrons by about 8 per cent.

Dr. Gray: That is a two to one drop in mortality?

Dr. Vogel: No, this refers to dose. This would be the effective dose reduction-15 per cent for the $\gamma$-rays and about 8 per cent for the fission neutrons.

Dr. Loutit: Have you any observations on the bacteraemia of these mice treated with bone marrow?

Dr. Vogel: No, but this would be a productive course of investigation. 


\title{
IMMUNOLOGICAL STUDIES ON LETHALLY AND SUB-LETHALLY IRRADIATED ANIMALS*
}

\author{
G. J. V. Nossal and Lois Larkin \\ II'alter and Eliza Hall Institute, Royal Melbourne Hospital, \\ Melbourne Victoria
}

WhOLE-BODY IRRADIATION profoundly depresses the immune response ${ }^{1}$. This phenomenon has been recognized by many workers as a useful tool in the investigation of problems connected with the cellular aspects of immunity. After large doses of whole-body irradiation, an animal is immunologically neutral for some time, and can act as a host for immunologically competent cells. The behaviour of these transferred cells can then be studied in a variety of circumstances, and it is this type of experiment which will be reported in the present paper.

In recent years there has been great interest in the cellular aspects of immunity inspired by experimental findings in several fields. First there is the work, of which Dr. Loutit is one of the pioneers, on the saving of lethally irradiated animals with isologous, homologous and heterologous bone marrow. The resulting chimaeras and the immunological reactions taking place during the recovery phase have been the subject of intensive study in many laboratories. Then there is a finding by Simonsen ${ }^{2}$ which has most interesting implications. He finds that when adult fowl leukocytes are injected into chick embryos, they lodge in the embryo spleen, proliferate extensively, and appear to make antibodies to the antigens of the host embryo, resulting in erythroblastosis foetalis, with the appearance of Coombs-type antibodies, and eventual death of the embryos owing to haemolytic anaemia. Moreover, when these cells, now proliferating in the host spleen, are transferred to further embryos, the same pattern is repeated, and this type of passage can be carried on indefinitely. This suggests that antibody-producing cells can replicate functionally for an indefinite period in a series of embryonic host spleens.

Stimulated by these and other findings, Sir Macfarlane Burnet ${ }^{3}$ has postulated an entirely new concept of antibody formation, called the clonal selection theory. This theory has provided the background to much of the work to be reported, and therefore will be discussed in some detail.

In its simplest form, the hypothesis states that the information necessary for the production of any conceivable antibody globulin resides in a normal unstimulated adult animal. This information exists in the form of clones of mesenchymal cells, each of which is designed to form one type of patterned globulin or antibody. It is postulated that the ancestors of antibody-forming cells, during embryonic development, randomize and stabilize into definite clones of cells. As soon as stabilization is achieved, each cell can form one,

* This work was supported by a grant from the National Health and Medical Research Council, Canberra. 


\section{G. J. V. NOSSAL AND LOIS LARKIN}

and only one sort of antibody molecule. Antigenic stimulation in adult life is followed by preferential multiplication of the cells of the clone capable of responding to that antigen, and by increased synthetic activity. This results in the outpouring of more of the relevant globulin, which we can now detect by classical immunological techniques, and call the specific antibody. When the same antigen is introduced a second time, there are far more cells of the relevant clone ready to respond, and a typical secondary response ensues. If a cell were confronted with its corresponding antigen while it was still immature, it is postulated that a hypersensitivity reaction would follow, and that the cell would die. By this means, the injection of large amounts of an antigen during embryonic life could lead to the elimination of all the cells of the clone capable of responding to it. Thus there would be a permanent impairment of the antibody response to this antigen; in other words, immunological tolerance would result.

The idea of a clonal mechanism of immunological memory has been accepted in principle by Lederberg ${ }^{4}$ as a plausible genetic approach. However, he has put forward a somewhat different concept, in which mesenchymal cells are considered to be totipotent as regards antibody formation, but can be genetically stabilized by contact with an antigen, resulting in clonal expansion when the relevant antigen is injected a second time. This is essentially a post-adaptive approach, in contrast to the preadaptive approach of Burnet's formulation.

\section{EXPERIMENTAL}

In order to obtain experimental evidence bearing on these hypotheses, we undertook studies on the transfer of immunologically competent cells to host animals under a variety of conditions. The techniques involved are simple. Spleens derived from immunized or non-immunized animals were processed to give single-cell suspensions, and stimulated with a purified flagellar antigen from Salmonella bacteria by incubation at $37^{\circ} \mathrm{C}$ for $30 \mathrm{~min}$. Excess antigen was then washed away, and the cells injected intraperitoneally into recipient animals.

Figure 1 indicates what happens when cells from an immunized rat are secondarily stimulated in vitro, and injected into normal rats, either adult or one-week old. It can be seen that in both situations, the transferred cells make antibody, but in the case of the adult rats, the serum antibody titres do not rise to such high levels, but begin to fall after about 7 days. This is due to immunological rejection of the injected cells by the normal defence mechanism of the host. On the other hand, the one-week-old rats, which are incapable of rejecting the graft because they are immunologically immature, harbour the transferred cells much longer, and the serum antibody titres of the host animals therefore continue to rise for about two weeks.

The controls in these experiments received injections of a cell-free homogenate of the same spleen. The antibody produced by the adult controls was probably due to persistent antigen present in the cells, which caused a primary type of response.

Figure 2 gives the result of a similar experiment using sub-lethally irradiated recipient rats. These rats received $500 \mathrm{r}$ of whole-body irradiation on the day before cell transfer. Control rats, injected with antigen after irradiation, made 
little or no antibody. The rats injected with spleen cells secondarily stimulated in vitro developed antibody in their serum, and the curve of antibody

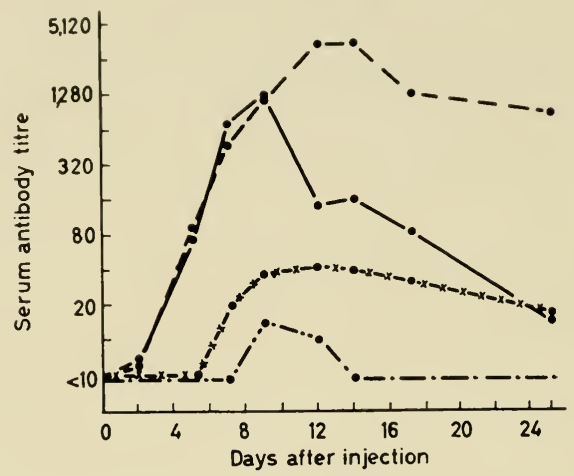

Figure 1. Transfer of immune spleen cells to normal recipients: - - adult rats - whole cells; week-old rats-whole cells;..--- week-old ratscontrols; $-\times-\times-\bullet$ adult rats-controls

production is essentially similar to the curve seen in the immunologically immature animals.

The next experiments were designed to show whether the process of

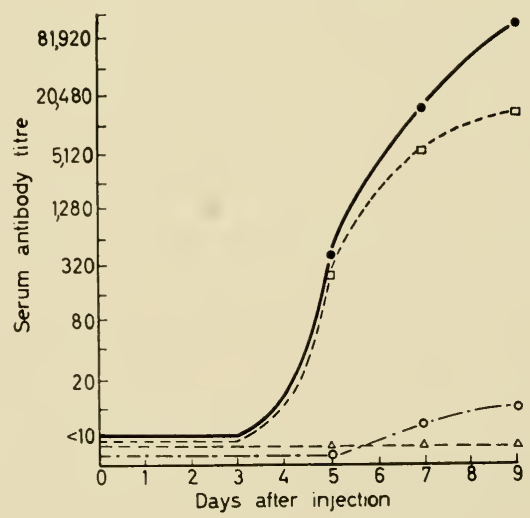

Figure 2. Transfer of immune spleen cells to sub-lethally irradiated recipients: $0-\cdot-0$-weck-old ratscontrol; $\square--\square$ 2-week-old rats-whole cell; $\triangle--\Delta$ adult rats-control; - - adult rats-whole cell

antibody production could be initiated by normal cells stimulated in vitro, and transferred to X-irradiated recipients. It can be seen (Figure 3) that adult 


\section{G. J. V. NOSSAL AND LOIS LARKIN}

recipients were adequate hosts for the antibody-producing cells, and antibody developed in their serum. However, in the neonatal recipients, the transferred cells did not make antibody. Apparently the environment of the neonatal animal is inimical to the initiation of a primary antibody response, although as was seen earlier, there is nothing in the environment inimical to antibody production per se. These results are in agreement with findings described by Dixon and Weigle ${ }^{5}$. Similar results were obtained when nonirradiated neonatal rats were used as recipients. However, when a large number of normal spleen cells was injected into the neonatal recipients either before, with, or some days after the stimulated spleen cells, some antibody

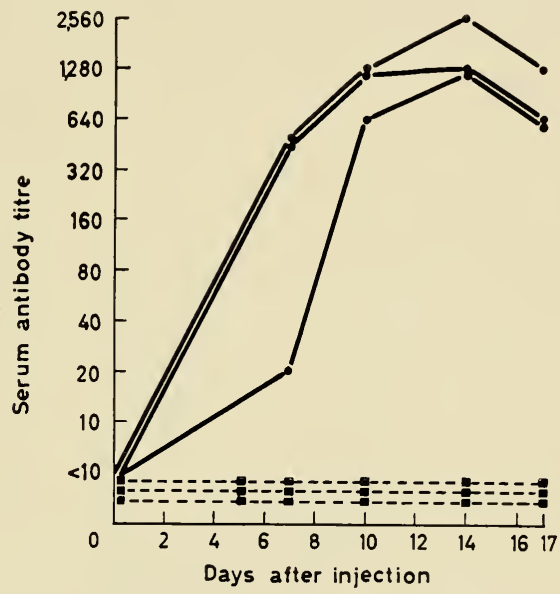

Figure 3. Transfer of normal spleen cells stimulated in vitro: - adult irradiated recipients; neonatal irradiated recipients

production did result. Conversely, when neonatal spleen cells were transferred to $\mathrm{X}$-irradiated adult recipients, after suitable stimulation in vitro, some antibody production resulted ${ }^{6}$.

The full implications of this work are not clear as yet, but it appears that for the first step in the chain of events leading to antibody formation to take place, the cells concerned must be placed in a suitable environment, such as is provided by an adult animal. If this first step has already been taken, then the process of antibody production can continue quite satisfactorily even in the environment of the neonatal animal, and, to a lesser extent, in tissue culture. The nature of this essential environmental factor is still entirely obscure, and is being investigated further at the moment.

The next question to interest us was the possibility of isolating a 'clone' of antibody-producing cells in the immunologically neutral environment of the neonatal rat or the $\mathrm{X}$-irradiated adult rat. The experimental procedure was as follows: recipients were inoculated intraperitoneally with stimulated 
spleen cells. A considerable proportion of these found their way to the spleen of the recipient animal, and differentiated there into antibodyproducing cells. The recipients were killed two weeks later, their spleens were removed, restimulated in vitro, and injected into further recipient animals, and so forth. The basic plan of these experiments was rather similar to that of the experiments by Simonsen, cited earlier.

Figure $t$ demonstrates the effect of passage of stimulated spleen cells through a series of neonatal rats, antigenic stimulation in vitro preceding each passage. The controls, given cither antigen alone, or unstimulated adult

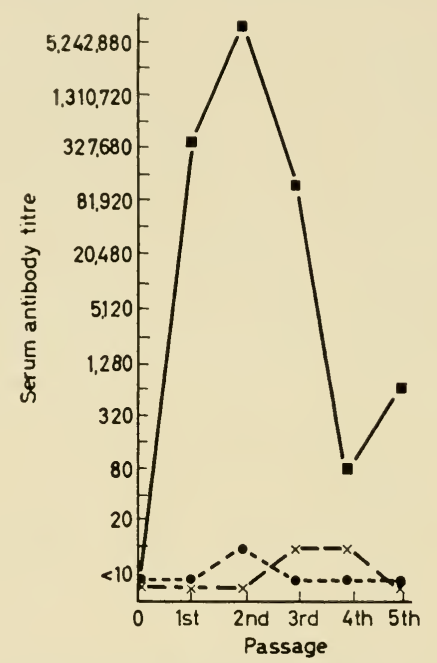

Figure 4. Serial transfer of immune splecn cells to neonatal recipients: $\mathbf{-}$ immune spleen; $-\ldots$ normal spleen; $x-x$ antigen alone

spleen cells, elaborated virtually no antibody. The recipients of immunized spleen cells developed high titres of antibody for the first three passages, but then the titres fell off rather sharply. However, some immunologically competent cells were still present even after five passages. In Figure 5 the results of serial passage through sub-lethally irradiated adults are depicted. Here, the results were not quite so easy to interpret, because the control animals did have a partial response to the injection of antigen alone, and on passage developed quite high titres. However, it can be seen that serial passage of cells from immune donors to $\mathrm{X}$-irradiated recipients is followed by persistent antibody-forming activity for at least six passages. Here, also, the difference between neonatal and adult environment is evident. The adult animal can support the initiation of the primary response, as evidenced by the good titres obtained on first and subsequent passages of normal spleen 


\section{G. J. V. NOSSAL AND LOIS LARKIN}

cells stimulated in vitro. The neonatal animals were able to support secondarily stimulated cells only.

These experiments have not been quite as conclusive as was hoped. We have not been able to isolate a population of cells with abnormally high antibody-producing potential which might represent a pure clone. However, we have demonstrated that given adequate antigenic stimulation, antibodyforming cells or their descendants can be serially passaged through a number of hosts, with continued functional integrity. A more sophisticated approach will have to be used if a clone is to be isolated.

The final series of experiments is concerned with a rather different problem related to immunological tolerance. When animals are given large doses of whole-body irradiation, this is followed by necrosis of a large proportion of the mesenchymal cells. Subsequently, there is a phase of intense proliferation

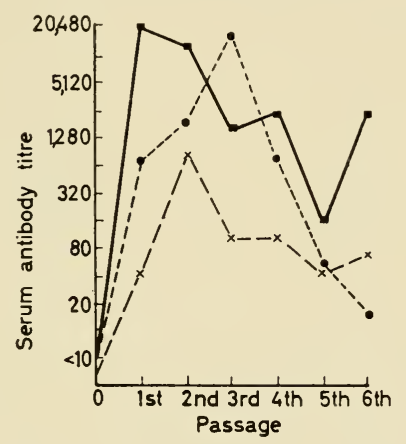

Figure 5. Serial transfer of immune spleen cells to adult sub-lethally irradiated recipients: $\mathbf{-}$ immune donor;

- normal donor; $\times-x$ antigen alone

and differentiation of cells, be it the animal's own cells, or the cells of a bonemarrow graft. We thought it might be possible that during this recovery phase the mesenchymal cells might go through a stage of functional immaturity, corresponding to the stage represented by embryonic mesenchymal cells. If this were the case, then the cells should be capable of being made tolerant to a suitable antigen injected along with them. Dr. Loutit and collaborators ${ }^{7}$ have shown that tolerance does in fact develop in lethally irradiated mice to the tissues of the saving homograft in a large proportion of cases. However, this problem differs little from the question of whether immunological tolerance to an unrelated antigen can be induced.

Numerous workers have demonstrated that immature animals can be made tolerant to foreign erythrocytes, provided that sufficiently large doses are given $8,9,10$. Accordingly, we lethally irradiated inbred $\mathrm{C} 3 \mathrm{H}$ mice with $850 \mathrm{r}$ of whole-body irradiation, and saved them with a bone-marrow isograft. The next day, and thereafter twice weekly for four weeks, the mice received large doses of rat erythrocytes intraperitoneally. At the end of the 
injection course the animals were bled, and the serum rat-erythrocyte agglutinin titres are shown in Table 1. Instead of becoming tolerant, the mice developed high antibody titres. We also attempted to save irradiated mice with embryonic tissues in the form of whole-embryo emulsion. About 20 per cent of the mice which were given 750 to $850 \mathrm{r}$ followed with a whole-embryo homograft, survived for at least 3 months. When these mice were given a course of injections of foreign erythrocytes in an attempt to make them tolerant, the majority developed antibody. This could mean either that transfer to the adult environment favoured rapid maturation of the embryonic cells, allowing these to make antibody; or else that the lethally irradiated animals' own cells recovered rapidly enough to give an adequate

Table 1. Antibody production in lethally irradiated mice

\begin{tabular}{c|c}
\hline $\begin{array}{c}\text { Bone-marrow grafted mice } \\
\text { Serum titre }\end{array}$ & Normal mice \\
& Serum titre \\
10,000 & \\
10,000 & 10,000 \\
10,000 & 10,000 \\
10,000 & 10,000 \\
10,000 & 10,000 \\
600 & 10,000 \\
& 10,000 \\
\hline
\end{tabular}

immune response. Considering our previous results on the transfer of normal neonatal spleen cells stimulated in vitro to $\mathrm{X}$-irradiated adult recipients, and the results of others, we consider the former hypothesis the more likely. In any case, it is clear that tolerance to foreign erythrocytes cannot be induced under these circumstances.

This paper has covered a lot of ground, and has made brief reference to several different experimental projects. The final interpretation of much of the work awaits further experimentation. However, it is clear that far more factors influence the production of antibodies than is generally realized. The initiation of the process can only take place in adult animals, or in an environment packed with adult cells. Conversely, immature cells can make antibody when transferred to an adult environment. Antibody-producing cells can be serially passaged several times and continue to function, but there is no evidence that specific antibody-forming clone can be isolated in this way. Therefore, there is still no experimental proof of Burnet's clonal selection hypothesis, or of its modifications. However, a cellular immunological memory has been shown to exist, and numerous techniques have been worked out for investigating the genetic implications of this phenomenon. The use of whole-body irradiation in depressing the immune response has been a most valuable tool, and we feel that this branch of radiation biology will be a productive one for many years to come.

The authors wish to express their sincere thanks to Sir Macfarlane Burnet for his interest in this work and to the staff of the Peter.MacCallum Cancer Clinic, especially Miss Betty Rose, for performing the irradiations. 


\section{DISCUSSION}

REFERENCES

${ }^{1}$ Taliaferro, W. H. and Taliaferro, Lucy E. J. Immunol. 16 (1951) 181

${ }^{2}$ Simonsen, M. Acta path. microbiol. scand. 40 (1957) 480

${ }^{3}$ Burnet, F. M. Aust. J. Sci. 20 (1957) 67

${ }^{4}$ Lederberg, J. J. cell. comp. Physiol., Supplement to Vol. 52 -in press

${ }^{5}$ Dixon, F. J. and Weigle, W. O. J. exp. Med. 105 (1957) 75

${ }^{6}$ Nossal, G. J. V. Immunology, 1959-in press

${ }^{7}$ Barnes, D. W. H., Ford, C. E., Ilbery, P. L. T. and Loutit, J. F. Transplantation Bull. 5 (1958) 101

${ }^{8}$ Simonsen, M. Acta path. microbiol. scand. 39 (1956) 21

${ }^{9}$ Nossal, G. J. V. Aust. J. exp. Biol. med. Sci. 36 (1958) 235

${ }^{10}$ Medawar, P. B. et al., Proc. roy. Soc. B 146 (1956) 1

\section{DISGUSSION}

DR. LoutrT: I was intrigued by this idea of the effect of the adult's environment on immature cells. This made me wonder whether the experiments have been controlled by introducing the immature cells into the immature normal or immature irradiated animals to see if they responded in exactly the same way as they do in the adult, or in a different way.

DR. Nossal: Yes, we have performed this control, and introduction of immature into immature normal, and immature into immature $\mathrm{X}$-irradiated never caused the formation of antibody.

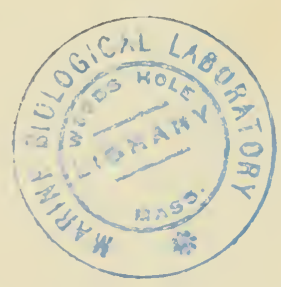




\title{
SHORT-TERM STUDIES OF THE EFFECT OF RADIOIODINE THERAPY FOR THYROTOXICOSIS ON THE THYROIDAL, IODIDE CLEARANCE RATE
}

\author{
I. D. Thomas, T. H. Oddie and F. F. Rundle \\ Unit of Clinical Investigation, Royal North Shore Hospital, \\ Sydney, N.S.W.
}

IODINE uptake studies of patients who have received radioiodine therapy for thyrotoxicosis give results which frequently cannot clearly be correlated with the patient's clinical status. It has been concluded by some that thyroidal iodine uptake behaves capriciously after the administration of therapeutic radioiodine, the corollary being that uptake studies are of little value in the follow-up of these patients. The discrepancy between the clinical picture and the uptake is not surprising, since the uptake rate is related to one aspect of thyroid function, that is, thyroid hormone formation, while clinical assessment depends on an estimation of metabolic processes, which in turn reflect the level of circulating thyroid hormone. Some of this hormone is already formed before therapy is given, while some may be released from the thyroid by the breakdown of tissue following therapy.

It has been shown that by using a precise method of measuring thyroidal iodide clearance rate ${ }^{1}$, it is possible to predict with reasonable accuracy the patient's response (in terms of this clearance rate), to a given dose of radioiodine $^{2}$. It has further been shown that the achievement of a normal thyroidal iodide clearance rate will eventually be followed by a normal state of the patient, judged by other means ${ }^{3}$. These studies have hitherto utilized assessment of the iodide clearance rate at least two months after therapy, this minimum interval being required because of the technical difficulties involved in using small tracer doses against the high background of a therapeutic dose.

Using methods described elsewhere ${ }^{4}$ the present studies have followed the variations in iodide clearance rate (iodine uptake), in sixteen thyrotoxic patients during the first month after radioiodine therapy, estimations of clearance rate being made 5 days, 13 days and 28 days after the giving of the dose.

The time at which the greatest lowering of uptake occurred and the level of this uptake in relation to the usual diagnostic ranges have been noted. The observations have been grouped according to whether a second therapeutic dose proved necessary on follow-up.

\section{RESULTS}

Requiring further therapy (9 patients)

Time of lowest observed uptake

$\begin{array}{cl}5 \text { days: } & 1 \text { patient } \\ 13 \text { days: } & 7 \text { patients } \\ 28 \text { days: } & 1 \text { patient }\end{array}$


Uptake rate at lowest observed point

Hyperthyroid range: 5 patients

Euthyroid range: 4 patients

Uptake rate at 28 days

Hyperthyroid range: 8 patients

Euthyroid range: 1 patient

Not requiring further therapy (7 patients)

Time of lowest observed uptake

13 days: 3 patients

28 days: 4 patients

Uptake rate at lowest observed point

Hyperthyroid range: 1 patient

Euthyroid range: 4 patients

Hypothyroid range: 2 patients

Uptake rate at 28 days

Hyperthyroid range: 1 patient

Euthyroid range: 4 patients

Hypothyroid range: 2 patients

\section{DISCUSSION OF RESULTS}

The results suggest that the mode of response in the first 28 days may be of value in determining whether the patient will obtain a satisfactory therapeutic response to the dose he has received.

Of the nine patients who required retreatment the uptake rate at 28 days was rising and was in the hyperthyroid range in eight patients. In only one patient was there no clear indication from the uptake studies that retreatment would be necessary. Of the seven patients who did not require retreatment only one had a high uptake at 28 days.

The number of patients so far studied is small; wider experience may lead to different conclusions, but it appears reasonable to hope that observations of the type described may enable a programme of therapy to be advanced by at least one month. With therapy given at an earlier point on a rising slope, the theoretically necessary dose is smaller and this offers a way of reducing the radiation to which the patient is exposed.

\section{REFERENCES}

${ }^{1}$ Oddie, T. H., Meschan, I. and Wortham, J. J. clin. Invest. 34 (1955) 106

${ }^{2}$ Oddie, T. H., Rundle, F. F. and Meschan, I. Int. F. appl. Radiation 5 (1959) 77

${ }^{3}$ Thomas, I. D., Oddie, T. H. and Rundle, F. F. Unpublished data

${ }^{4}$ Oddie, T. H., Thomas, I. D., Myhill, J. and Fitzsimons, E. To be published

\section{DISCUSSION}

Dr. LoutiT: There was one other point that I picked up that you did not mention; in the first group in the slide the doses were in the region of 10,20, 40 millicuries; in the second group they were all low doses of the order of 1 to 4 millicuries. Is there any significance in these differences in doses of radioiodine? 


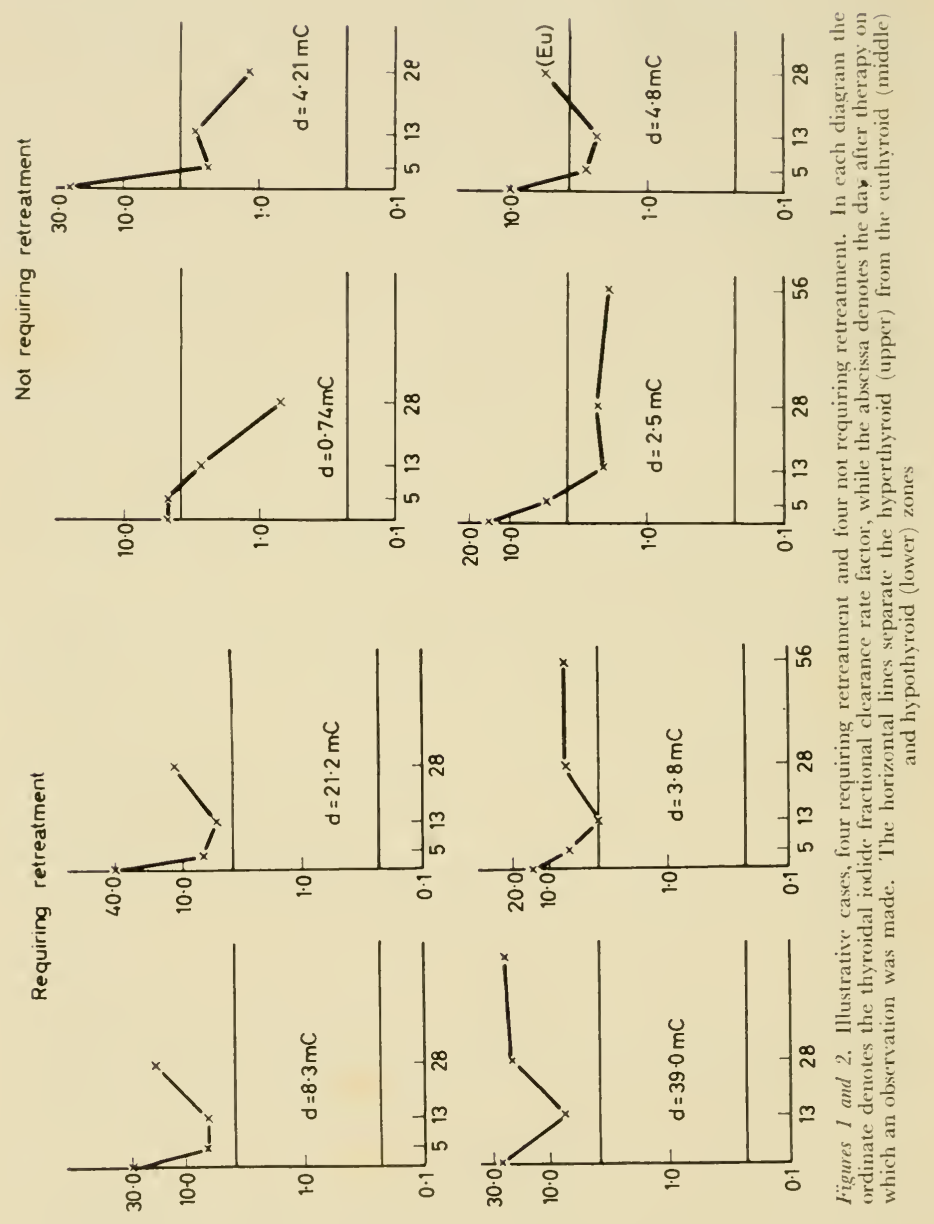




\section{DISCUSSION}

Dr. Thomas: The actual difference if you see the complete data does not fall into those groups. Some people who have a large dose do well and some people who have small doses do well. That depends on the individual response of the patient to radiation. Speaking generally, if a patient has a high iodide clearance rate he will require a big dose, particularly if our previous experience has shown that he is resistant to radiation.

Mr. TIRRELL: Is there any numerical relationship between the basal metabolic rate over that period and the values given there, or does it fluctuate from patient to patient?

DR. Thomas: Well the basal metabolic rate if measured by a reliable technique would correspond more with the clinical assessment of the patient, and that might still be very high. We have had patients who are clearly very toxic in this period in which we have a normal uptake rate, and we have stayed our hand and not given further treatment then because we maintain that if the thyroid is sufficiently damaged at that point not to be producing more thyroid hormone, the patient must eventually catch up and that is in fact what happens. The basal metabolic rate at that early stage would still be high, corresponding with the clinical status of the patient. 


\title{
EFFECT OF $\mathrm{X}$ IRRADIATION ON THE MOUSE FOETUS
}

\author{
A. S. Fraser and R. J. Hall \\ Commonwealth Scientific and Industrial Research Organization, \\ Animal Genetics Section, Zoology School, University of Sydney
}

IRRADIATION during foetal development can produce permanent modifications of the structure of the resultant organism, which, because they mimic the effects of mutants, have been termed phenocopies. Various authors have shown that the frequency and type of abnormality are closely related to the time of exposure, and this gave rise to the concept of 'sensitive or critical periods', in which each sequence of development was thought to pass through one or more phases when it was sensitive to irradiation. Russell ${ }^{1}$ in an extensive series of experiments identified the sensitive periods of a number of developmental sequences in the mouse. Most of her researches were concerned with fairly macroscopic aspects of structure, and we, therefore, decided to extend these researches, concentrating on any effects on the coat and skin. The primary aim was to compare the sensitive periods of macroscopic characters, with those for as small a structure as could easily be scored. The facial whiskers are such a structure. They are large, and therefore, easily scored, yet are formed by a very small living structure, the skin follicle $^{2}$. The same data are of interest in considering patterns of radiosensitivity. This is the primary aim of the present paper.

Pregnant mice, dated by the vaginal plug method, were irradiated with $\mathrm{X}$-rays, generated at $85 \mathrm{kV}$, at a rate of 43 roentgens per minute. Three doses were used: 250,300 and 350 roentgens. The mice were scored (i) as dead or alive, (ii) as showing external morphological abnormalities, and (iii) for presence or absence of the three secondary groups of facial whiskers. The frequencies of mice, scored at birth, which were dead or alive, normal or abnormal, are given in Table 1. Presence or absence of facial whiskers are not included in these classifications.

The incidence of phenocopies of external morphology are, from these data,

Table 1. Frequencies of mice, scored at birth, which were dead or alive, normal or abnormal

\begin{tabular}{|c|c|c|c|c|}
\hline$X$-ray dose & Alive & Dead & Alive & Dead \\
\hline $250 \mathrm{r}$ & $95 \cdot 4$ & $4 \cdot 6$ & - & - \\
\hline $300 \mathrm{r}$ & $68 \cdot 2$ & $8 \cdot 2$ & $11 \cdot 1$ & $12 \cdot 5$ \\
\hline $350 \mathrm{r}$ & $55 \cdot 1$ & $6 \cdot 7$ & $5 \cdot 5$ & $32 \cdot 7$ \\
\hline
\end{tabular}


0 per cent, $23 \cdot 5$ per cent and $38 \cdot 2$ per cent respectively for the three doses of $\mathrm{X}$ irradiation. Clearly, they show a marked threshold of sensitivity in the range 250-300 r. However, this conclusion cannot be accepted without considerable reservation, since no account is taken of undiagnosed phenocopies, and of mice which are affected by $\mathrm{X}$ irradiation to such an extent that they die and are resorbed before birth.

Considering first the problem of undiagnosed phenocopies, there is an increase in the frequency of dead, apparently normal mice with increase in dose of X-rays. The frequency of mice, dead at birth, in our control stocks is about $4 \cdot 0$. The increased incidence of such normal dead mice is then 0.6 per cent, $4 \cdot 2$ per cent, and 2.7 per cent at the three levels of treatment. Are such mice dead because they are phenocopies, or because of some unrelated effects of $\mathrm{X}$ irradiation?

It can be argued that they are undiagnosed phenocopies from the relation of their frequency to age at irradiation. This follows the same pattern as the frequency of recognizable phenocopies in having a peak of incidence at 10 to 12 days. This is shown in Tables 2 and 3.

Table 2. Frequencies of abnormal mice, related to age at irradiation

\begin{tabular}{ccc}
\hline & & Level of irradiation \\
Age at irradiation, days & $300 \mathrm{r}$ & $350 \mathrm{r}$ \\
\hline & & \\
\hline & 7 & 0 \\
10 & 11 & 21 \\
11 & 44 & 46 \\
12 & 24 & 100 \\
13 & 46 & 67 \\
14 & 8 & 32 \\
& 0 & 16 \\
\hline
\end{tabular}

Table 3. Percentage of mice born dead, related to age at irradiation-data from Russell ${ }^{1}$ are shown in parentheses

\begin{tabular}{ccccc}
\hline $\begin{array}{c}\text { Age at } \\
\text { irradiation, } \\
\text { days }\end{array}$ & 200 $\mathrm{r}$ & $250 \mathrm{r}$ & $300 \mathrm{r}$ & $350 \mathrm{r}$ \\
\hline & & & & \\
8 & $(12)$ & $(100) 44$ & 23 & 56 \\
9 & $(50)$ & $(100) 66$ & 26 & 48 \\
10 & $(61)$ & $(92) 0$ & 28 & 53 \\
11 & $(7)$ & $(40)-$ & 36 & 82 \\
12 & $(0)$ & $(-)-$ & 14 & 36 \\
13 & - & $(-)-$ & 6 & 8 \\
14 & & & & \\
\hline
\end{tabular}

It is therefore plausible to consider that the frequencies of phenocopies should be corrected to values of 0.6 per cent, $27 \cdot 7$ per cent and 40.9 per cent, including the frequencies of mice born dead, but apparently normal, which are in excess of the control frequencies of such mice. 
Not all diagnosed phenocopies are born dead. At 300 r 47 per cent are alive at birth, and at $350 \mathrm{r}, 1+$ per cent are alive at birth. If we assume that the same proportions of undiagnosed phenocopies are alive at birth, then $2 \cdot 0$ per cent and 0.3 per cent of the live, apparently normal mice of the $300 \mathrm{r}$ and $350 \mathrm{r}$ groups are undiagnosed phenocopies. The radio-sensitivity on this basis is 0.6 per cent, 29.7 per cent, and $41 \cdot 2$ per cent at 250,300 and $350 \mathrm{r}$ respectively. Clearly these corrections, which, in any case, involve several assumptions, do not affect the general conclusion, namely, that radio-sensitivity to phenocopy formation has a threshold at approximately $250 \mathrm{r}$.

Another set of corrections are of more importance. These are for mice affected by radiation which die and are resorbed before birth. No data are available from direct observation, and it is necessary to base the corrections on the reduction of litter size. The mean litter sizes are shown in Table 4.

Table 4. Mean litter size at birth

\begin{tabular}{|c|c|c|c|}
\hline \multirow{2}{*}{$\begin{array}{c}\text { Age at } \\
\text { irradiation, } \\
\text { days }\end{array}$} & \multicolumn{3}{|c|}{ Level of irradiation } \\
\hline & $250 \mathrm{r}$ & $300 \mathrm{r}$ & $350 \mathrm{r}$ \\
\hline 8 & $5 \cdot 1$ & $2 \cdot 6$ & $1 \cdot 2$ \\
\hline 9 & $3 \cdot 6$ & $1 \cdot 5$ & 1.4 \\
\hline 10 & $5 \cdot 4$ & $2 \cdot 1$ & $1 \cdot 6$ \\
\hline 11 & $4 \cdot 5$ & $3 \cdot 2$ & $1 \cdot 9$ \\
\hline 12 & - & $4 \cdot 0$ & $3 \cdot 5$ \\
\hline 13 & - & $4 \cdot 7$ & $5 \cdot 4$ \\
\hline 14 & - & $4 \cdot 8$ & $6 \cdot 0$ \\
\hline
\end{tabular}

The average litter size of control stocks is $7 \cdot 1$, and it is clear that even $250 \mathrm{r}$ produces a significant decrease of litter size. This may be due to an effect on the dam, rather than induction of abnormalities in the foetuses. The frequency of females which, although fertilized, produce no progeny at term is greater than would be expected from a simple effect on individual foetuses. It is not possible from our data to separate the two effects, and therefore any corrections of radio-sensitivities based on reduction of litter size are likely to be over-estimated since they will include the effect on dams. The mean litter sizes, over all ages, are $5 \cdot 0,3 \cdot 5$ and $3 \cdot 0$ respectively for the 250, 300 and $350 \mathrm{r}$ groups. Assuming that the differences between the actual litter sizes in irradiated groups, compared to that in controls, are due to lethal phenocopies which are resorbed, then the corrected relation of phenocopy incidence to level of irradiation is $29 \cdot 4$ per cent, $64 \cdot 8$ per cent and $88 \cdot 6$ per cent. These values do not show a threshold effect, indicating a sigmoid relationship, (see Figure 1). Russell ${ }^{3}$ determined the effects of levels of radiation in the range 25-100 $\mathrm{r}$. Her precision of diagnosis is certainly greater than ours, involving as it does, dissection of the mice. However her values are unlikely to be greater than ours by a factor of more than two to three. The main reason for presenting her data in Figure 1, is to show how it follows a sigmoid function. Its different position, i.e., an inflexion at about $100 \mathrm{r}$, whereas our data indicate an inflexion at $300 \mathrm{r}$, is due to greater 


\section{A. S. FR.ASER AND R. J. HALL}

precision in diagnosis of morphological defects, and a greater incidence of resorption in our stocks than in hers; lethality is far greater in our stocks.

The data are of interest in considering the problems of radio-sensitivity. The first consideration of our data indicates a marked threshold effect. Extension of our analysis to include undiagnosed phenocopies sufficiently modifies the data to make this conclusion suspect. If we then consider Russell's results ${ }^{3}$ at low levels of irradiation it becomes clear that radiosensitivity in phenocopy induction is a sigmoid function with an inflexion at about $250 \mathrm{r}$. The induction of phenocopies is unlikely to be a major problem sociologically, but the data emphasize a general danger, namely that data based on the usual hundred or so animals cannot have an accuracy

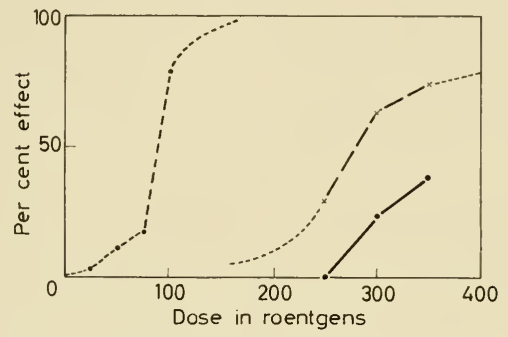

Figure 1. Relationship of frequency of phenocopies to level of irradiation-in our data without corrections for undiagnosed or resorbed phenocopies, $(\cdot-\cdot)$; in our data after correction, $(\times-\cdots \times)$; in Russell's data ${ }^{3}(\cdot--\cdot)$

of more than $0 \cdot 1$ to $1 \cdot 0$ per cent. Consequently, a sigmoid relationship of dose to effect would be interpreted as a threshold.

This does not constitute a sociological danger unless effects with occurrences of less than the order of accuracy of the experiment are important. In problems such as the causation of cancer and genetic damage by irradiation this is patently true, and consequently experiments with accuracies far greater than the usual experiment are required before valid distinctions can be made between threshold functions and inflected sigmoid functions.

\section{REFERENCES}

${ }^{1}$ Russell, L. B. J. exp. Zool. 114 (1950) 545

${ }^{2}$ Fraser, A. S. and Hall, R. J. Aust. J. sci. Res., B 11 (1958) 425

${ }^{3}$ Russell, L. B. Proc. Soc. exp. Biol., N.Y. 95 (1957) 174

\section{DISCUSSION}

Dr. Craig: Have you tried experimenting with different selected environments to see if there are any differences as to when these particular phenocopies become observable? For example, suppose the environment is different in any particular case, would you still get the irradiation sensitive period maximal at 10 to 12 days or might it be repressed as maximal at some other time, e.g., at the five- to six-day period or the 
eight- to nine-day period, where the rate of development is changed owing to environmental circumstances?

Dr. Fraser: Yes, I think this would be very interesting in terms of the growth of the organism. Our way of going into this is not so much to change the environment, since there is quite a sufficient fluctuation of growth rate in mice. Instead we plan to irradiate and then remove the foetus two to three days after exposure, when we could make accurate measurements on its growth rate at that time of exposure, and determine whether we were getting any fluctuation of sensitive period by this means. This would cover your suggestion. 


\title{
THE SPECTRUM OF SENSITIVITY OF DROSOPHILA GERM CELL STAGES TO X IRRADIATION
}

\author{
Irwin I. Oster* \\ Indiana University $\dagger$, Bloomington, Indiana, U.S.A.
}

VARIOUs external and internal conditions are known to affect the sensitivity of chromosomes to ionizing and non-ionizing radiations. Although it has been shown in experiments on many plants and animals that the condensed state of the chromosomes, such as that found during late prophase, metaphase, and anaphase of mitosis and meiosis, is the most susceptible to damage by radiation, the recent findings of Auerbach ${ }^{1}$, Khishin ${ }^{2}$, Lüning 3 , 4, 5, 6 and Oster ${ }^{7}$, demonstrating the extreme radio-sensitivity of the spermatid stage whose chromosomes are less spiralized than those of spermatozoa in Drosophila, indicate that this is far from an absolutely valid generalization. Similarly, notwithstanding the fact that it has been found that lowering the oxygen tension (for instance by the physical exclusion of oxygen or the addition of reducing substances such as sulphite ions) generally reduces radiation-induced damage caused by X-rays in a whole array of organisms ranging from bacteria and higher plants to Drosophila and the mouse, recent work has indicated that the degree of response of different cell stages varies considerably ${ }^{8,9}$. Because of these discrepancies, which are no doubt in part due to differences in the physiological environment and metabolism of the different organisms studied, it is often difficult to draw any general conclusions with regard to the processes involved in the production of radiation damage from experiments carried out on heterogeneous groups of plants and animals. In addition, it is known that this heterogeneity exists even at the level of the cell stages which have been treated and studied. Thus it would appear that further work of a more systematic nature along these lines is indicated. While there is no a priori reason to believe that one or even similar mechanisms underlie the sensitivity of all cell stages and organisms to radiation, it seems reasonable to suppose that elucidation of the variation in the sensitivity of different cell stages of one cell type under a variety of conditions may help to shed light on the basis for the differences in radiosensitivity amongst different organisms.

For such a determination of the spectrum of sensitivity of one type of cell it would be preferable to use an organism in which genic and chromosomal aberrations can be readily analysed and in which techniques are available for treating sharply defined stages of mitosis and/or meiosis with X-rays under a variety of conditions. We have found that the fruit fly, Drosophila

\footnotetext{
* Present address: Division of Chemotherapy, The Institute for Cancer Research, 7701 Burholme Avenue, Philadelphia 11, Pennsylvania, U.S.A.

$\dagger$ This is Zoology Department contribution No. 663. New observations here reported were made with the aid of a grant to Dr. H. J. Muller and associates from the United States Atomic Energy Commission Contract AT(11-1)-195.
} 
melanogaster, is most suited for such experiments since not only can heritable variations induced in it be casily detected and analysed but techniques have been worked out for ensuring that one is treating and testing cells which represent homogeneous samples of distinct stages of mitosis or meiosis. Since there are firm grounds for supposing that the same conditions as affect somatic cells will affect those in meiosis and since the latter are ideal for the analysis of induced heritable nuclear changes, the experiments to be reported below have been carried out on the reproductive cells. While it was recognized soon after Muller's demonstration of X-ray mutagenesis in 1927 that mature germ cells of both male and female fruit flies are much more radio-sensitive than immature germ cells ${ }^{10}$ it took more than 20 years before it was shown that there are various gradations of sensitivity amongst the different pre-meiotic and post-meiotic stages. This work, carried out independently by several investigators and which will be referred to in connection with our more recent work, was made possible by the claboration of more refined breeding techniques which ensure the sampling of cells which represent homogeneous groups at the time of treatment.

\section{PROCEDURE}

In the work which involved the treatment of male germ cells of Drosophila melanogaster the following scheme was used. (Although this technique has already been described ${ }^{9}$, its applicability to work on mutation in general and its ease of employment warrants our showing it again in order to familiarize additional workers with its operation.) The treated chromosomes are represented by asterisks:

$$
\begin{aligned}
& \begin{array}{lllll}
\mathrm{P}_{1} & \mathrm{y} & \mathrm{B} & \\
& * * * * * * * * * * * * * * * & * * & * * * * *
\end{array}
\end{aligned}
$$

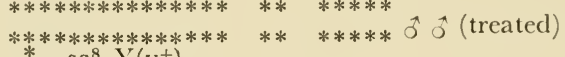

$$
\begin{aligned}
& \text { * } \mathrm{sc}^{8} \cdot \mathrm{Y}\left(\mathrm{y}^{+}\right) \\
& \text {(non-yellow, Bar eyes) }
\end{aligned}
$$

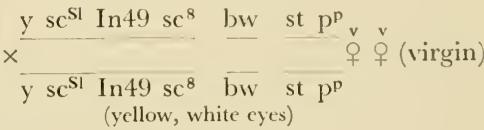

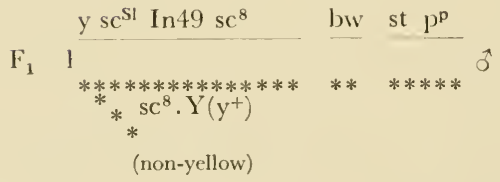

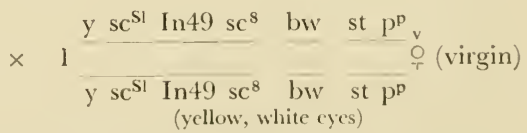

$\mathrm{F}_{2}$ absence of independent assortment between bw and $\mathrm{st}, \mathrm{p}^{\mathrm{p}}=$ autosomal translocation. 
IRIVIN I. OSTER

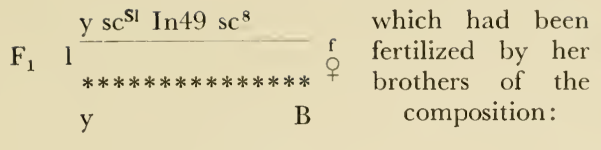

(yellow, Bar eyes)

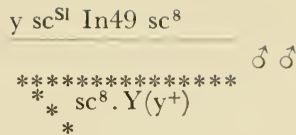

(non-yellow)

$\mathrm{F}_{2}$ absence of non-yellow, Bar eyed males $=$ sex-linked recessive lethal mutation of paternal origin.

The use of Bar eyes (B) to mark the irradiated sex-chromosomes makes the detection of sex-linked recessive lethals fairly easy. The scoring of translocations is simplified by using the easily discernible markers, brown (bw) located on chromosome II, scarlet (st), and the peach allelomorph of pink $\left(p^{p}\right)$ which are both located on chromosome III. The eyes of flies heterozygous for these markers appear brick-red in colour while the eyes of those homozygous for brown and scarlet are white. These two classes present a strong contrast with either of the recombinants, namely, brown, or scarlet with the peach allelomorph of pink, which look brown or orange, respectively. In order to facilitate the work further, the $F_{1}$ males and females can be allowed to mate with each other for at least two days before being separated; this permits one to carry out the tests for lethals by placing one such inseminated female in a vial rather than having to collect new males with which to mate them as is usually done. When the $F_{1}$ flies are separated they should be counted to determine the frequency of any exceptional males which will appear yellow in contrast to the normal class of males expected. The latter have non-yellow bodies since they carry the normal dominant allelomorph $\left(\mathrm{y}^{+}\right)$of yellow in the $\mathrm{sc}^{8}$ insertion of their $\mathrm{Y}$ chromosome. The yellow males represent cases of loss of the whole or part of the X or Y chromosome. The translocation tests can be carried out by mating one $\mathrm{F}_{1}$ non-yellow male with one virgin female similar to his mother per vial. As these stocks had been also chosen for their high fertility the amount of sterility resulting from these time-saving procedures is practically negligible (i.e. less than 5 per cent). The $F_{1}$ fertilized females are tested for lethals (i.e. a mutation affecting some vital process(es) resulting in the death of the individual prior to maturity) by examining the $\mathrm{F}_{2}$ offspring for the absence of Bar (B) males which would indicate that a lethal has been induced in the paternal $\mathrm{X}$ chromosome; the $\mathrm{F}_{1}$ males are tested for translocations (i.e. a chromosomal disarrangement involving the breakage of two non-homologous chromosomes and their subsequent reunion in a new order) between autosomes II and III by being backcrossed to y $\mathrm{sc}^{\mathrm{Sl}}$ In $49 \mathrm{sc}^{8}$; bw; st $\mathrm{p}^{\mathrm{p}}$ virgin females and examining the $\mathrm{F}_{2}$ offspring for the absence of independent assortment between brown (bw) on the one hand and the scarlet (st), peach $\left(\mathrm{p}^{\mathrm{p}}\right)$ combination on the other hand, since the former is not linked with the latter in normal flies. All the $\mathrm{F}_{2}$ cultures which do not yield an adequate number of flies to enable one to determine whether or not a lethal or translocation is present can be retested by repeating the $F_{1}$ cross with the $F_{2}$ generation.

For the experiments on female germ cells, a modified scheme, based on 
stocks previously described ${ }^{11}$, was synthesized and used. The treated chromosomes are represented by asterisks:

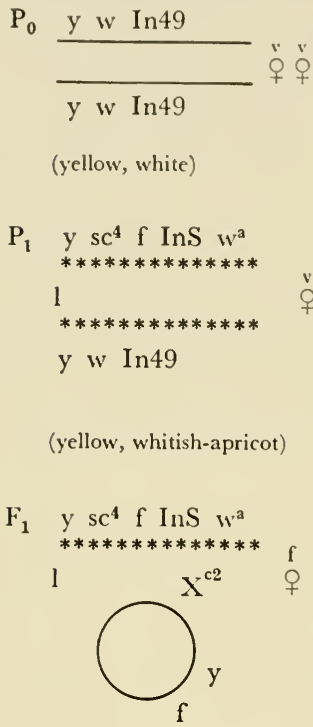

(yellow, forked)

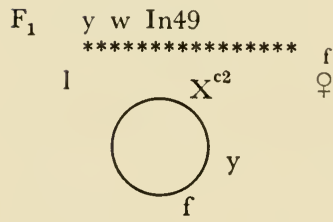

(yellow)

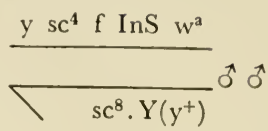

(non-yellow, apricot, forked)
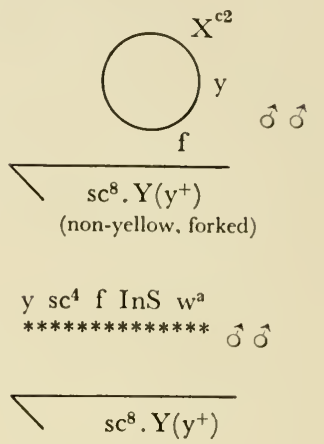

(non-yellow, apricot, forked)

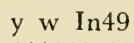

or:
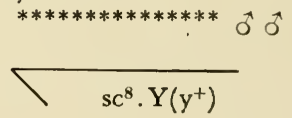

(non-yellow, white)

$\mathrm{F}_{2}$ absence of non-yellow, apricot-eyed, forked or non-yellow white-eyed, males $=$ sex-linked recessive lethal mutation of maternal origin.

Here again, our scheme relies on easily discernible markers, yellow-body colour (y), white eyes ( $w)$, apricot eyes $\left(w^{a}\right)$, and forked bristles (f). The yellow whitish-apricot treated $P_{1}$ females should be collected as virgins. To detect sex-linked lethals, $F_{1}$ females and males can be shaken over into fresh vials at the end of their hatching period and left in this way for 2 to 3 days in order to ensure that they mate with their brothers. After this period the flies can be counted from each vial separately. The females should be separated from the males (which can then be discarded after they have been counted and it has been noted that both classes of males are present; the 
absence of either one or both indicates the presence of pre-existing lethals) and divided into two groups according to the marker, forked (f), thereby distinguishing the lethal tests of the two maternally-derived chromosomes. They can then be placed individually into vials since they have already been fertilized. The two classes of $\mathrm{F}_{1}$ flies arising from each treated or control female should each be kept separately (by placing a rubber band around the groups of vials) in order to enable one to detect lethals of common origin arising spontaneously during early cleavage and/or in young germ cells. In the $F_{1}$, the frequency of non-yellow females, $s c^{8} . Y\left(y^{+}\right) / y s^{4} f \operatorname{InS~w} w^{a} / y$ w In 49 , and yellow males, $\mathrm{X}^{\mathrm{c} 2}$, $\mathrm{y} \mathrm{f}$, will indicate the rate of non-disjunction occurring spontaneously and induced by the treatment. Examination of the $\mathrm{F}_{2}$ generation for the absence of $\mathrm{sc}^{8} . \mathrm{Y}\left(\mathrm{y}^{+}\right) / \mathrm{y} \mathrm{sc}^{4} \mathrm{f} \mathrm{InS} \mathrm{w}^{\mathrm{a}}$ or $\mathrm{sc}^{8} . \mathrm{Y}\left(\mathrm{y}^{+}\right) / \mathrm{y} \mathrm{w}$ In $49 \mathrm{f}$ males, depending on which chromosome is being scored, and at least $10 \mathrm{sc}^{8} . \mathrm{Y}\left(\mathrm{y}^{+}\right) / \mathrm{X}^{\mathrm{c} 2}$, $\mathrm{y}$ f males will then indicate the presence of a sex-linked lethal mutation of maternal origin. This scoring is relatively simple since it involves the recognition of light-eyed males amongst red-eyed males. Please note that the light-eyed flies must be non-yellow in body colour and any yellow flies which might appear merely represent cases of non-disjunction and should not be considered in deciding whether or not a lethal is present. Even though this scheme does not allow for the retesting of individuals where there is some doubt as to the presence of a lethal due to an insufficient yield of flies of all classes, in practice, it has been found that such cases are very rare because the stocks for this scheme had been selected for good fertility and viability.

Large numbers of homogeneous samples of reproductive cells for treatment can be obtained by irradiating accurately determined stages of the life-cycle which contain a preponderance of one type of germ cell and the utilization of only this one stage at a time for genetic analyses by the use of short mating periods following the maturation of the cells. Thus spermatogonia or oogonia can be treated in third instar larvae, immature oocytes in freshly eclosed females, mature oocytes in 96-hour-old females, spermatids in 48-hourold pupae, mature sperm in adult males and/or in inseminated females. When testing immature cells for the presence of mutations it is advisable to take only a few offspring for analysis from each treated parent in order to reduce the error resulting from the sampling of mutations which have multiplied by cell division after their origination in one cell. All the stages were exposed to X-rays delivered at a rate of $160 \mathrm{r} /$ minute $(135 \mathrm{kV}, 20 \mathrm{~m} \mathrm{~A}, 1 \mathrm{~mm}$ aluminium filtration) or $400 \mathrm{r} /$ minute $(175 \mathrm{kV}, 20 \mathrm{~mA}, 1 \mathrm{~mm}$ aluminium filtration) in leucite chambers in nitrogen, air, or oxygen, depending on the experiment. These differences in intensity had previously been found by us to have no detectable effect on the yield of mutations obtained while Clark ${ }^{12}$ has reported a higher frequency of induced changes following an exposure of Drosophila to X-rays delivered at the rate of $2000 \mathrm{r} /$ minute than following an equivalent exposure delivered at the rate of $100 \mathrm{r} /$ minute. The flies were treated and bred at a temperature of $25 \pm 1{ }^{\circ} \mathrm{C}$.

\section{RESULTS AND DISCUSSION}

Radio-sensitivity of the male germ line

Previously it had been reported that the spermatid stages of Drosophila 
melanogaster are much more susceptible to the mutagenic effects of X-rays than mature spermatozoa ejaculated by the male on the first day after irradiation, with the latter being somewhat more sensitive than sperm released on the second day following treatment $1,2,3,4,5,6,13$, while the work of Bonnier and Lïning ${ }^{14}$, and Abrahamson ${ }^{15}$ has indicated that spermatozoa in the seminal receptacles and spermathecae of females are also more susceptible than mature spermatozoa treated in the male. Following our demonstration in 1956 that the spermatid stages are even more radiosensitive than sperm in the female ${ }^{7}$, we have carried out additional tests on the different stages and Table 1 summarizes our results.

Table 1. Results of X irradiation of different cell stages in the male Drosophila melanogaster

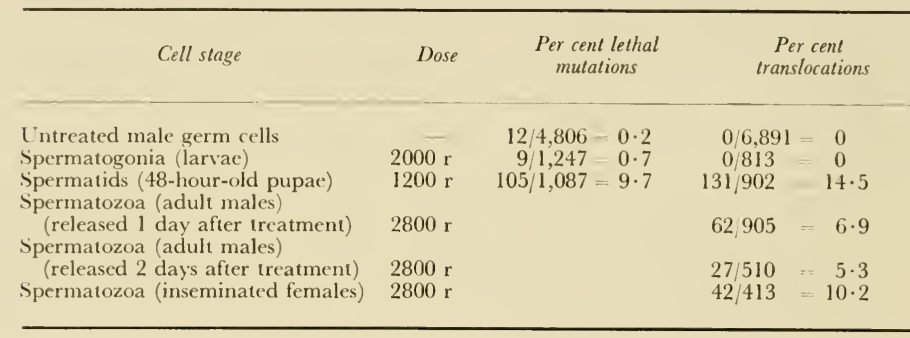

Thus it can readily be seen that although the spermatid stages received less than one-half as much radiation as the spermatozoa in the female they yielded one-half again as many translocations. According to our results there does not seem to be too large a difference between the radio-resistance of spermatozoa released one day after treatment and those released two days following treatment. This finding agrees with the results of Nordbach ${ }^{\mathbf{1 6}}$, who has failed to obtain consistent differences amongst the rates of induced changes in sperm released during the first and second days following treatment with X-rays. The cause for this variation has not yet been determined. Arranging the male germ cells in order of decreasing sensitivity to the mutagenic effects of X-rays we have, spermatids, spermatozoa in the female, sperm released one day after treatment, sperm released two days after treatment, and spermatogonia. Although we have not irradiated spermatocytes Khishin has found them to be somewhat more sensitive than spermatogonia and less sensitive than mature spermatozoa 2 .

It is interesting to note that although it has been thought that there is something in the physico-chemical nature of condensed chromosomes which makes them most sensitive to $\mathrm{X}$-rays, our results demonstrating the greater sensitivity of spermatids as compared to spermatozoa, the latter's chromosomes being even more spiralized than those of the former, seem to indicate that some other factor(s) is responsible, in part at least, for the heightened sensitivity of spermatids. A previous attempt to find the cause for this heightened sensitivity of the spermatid stage to the mutagenic action of radiation by the utilization of stocks containing either rod-shaped or ringshaped sex chromosomes which yielded substantially similar frequencies of recessive lethal mutations, had indicated that this is not due merely to 
a separation of broken chromosomes favouring the disarrangement of pieces during spermiogenesis. If this had been the case, it would have been expected that the recovered rate of recessive lethals from irradiated spermatids would have been lower in the case of a ring-shaped chromosome due to the loss by twisted restitutions, of those mutations associated with structural changes by the shuffling of the chromosomes during the elongation of the spermatid to form the spermatozoon ${ }^{7}$. We shall reconsider the probable mechanism(s) involved in the differential sensitivity of the various stages of spermiogenesis in the section on the effects of variation of oxygen tension on the radio-sensitivity of the male and female germ lines.

\section{Radio-sensilivity of the female germ line}

As was mentioned previously, although it was already noted as early as $1928^{17}, 10,18$ that in the female of Drosophila melanogaster mature germ cells are more sensitive to $\mathrm{X}$-rays than immature germ cells, King's extensive histological studies of oogenesis, which indicated that the development of an egg in an ovariole can be subdivided into at least 14 distinct stages, raised the question whether these diverse stages also exhibit different sensitivities ${ }^{19}$. Soon afterwards he showed that susceptibility to radiation-induced chromosome breakage as measured by dominant lethality, $\mathrm{X}$ chromosome loss, and induced recessive lethal mutations does indeed vary strikingly during oogenesis ${ }^{20}$. In view of this it was decided to try to obtain additional quantitative data on the sensitivity of three stages of oogenesis which differ markedly from each other with regard to their morphological characteristics. These included oogonia, stage 7 oocytes which show a Feulgen-positive nucleolus or karyosome lying in a reticulate nucleoplasm surrounded by a nuclear membrane, and stage 14 oocytes which show a Feulgen-positive karyosphere lying free in the ooplasm, the nuclear membrane having disappeared. The chromosomes of stage 14 oocy tes are in first meiotic metaphase and hence are in a condensed condition ${ }^{21}$. In addition, since it had been shown by Muller in $1946^{22}$ and later by Hildreth and Carson ${ }^{23}$ and Schalet ${ }^{24}$ that an inordinately high percentage of all spontaneous mutations occur during the early cleavage stages of the developing egg in Drosophila it was decided to investigate the response of such early embryos to the mutagenic action of X-rays.

Non-treated females serving as controls yielded the offspring for the

Table 2. Results of $\mathbf{X}$ irradiation of different cell stages in the female Drosophila melanogaster

\begin{tabular}{lcc}
\multicolumn{1}{c}{ Cell stage } & Dose & Per cent lethal mutations \\
& & \\
\hline Untreated female germ cells & - & $49 / 11,630=0 \cdot 4$ \\
Early cleavage stages & $800 \mathrm{r}$ & $21 / 345=6 \cdot 1$ \\
Oogonia & $2400 \mathrm{r}$ & $33 / 2,056=1 \cdot 6$ \\
Stage 7 oocytes & $1600 \mathrm{r}$ & $28 / 1056=2 \cdot 7$ \\
Stage 14 oocytes & $1600 \mathrm{r}$ & $8 / 149=5 \cdot 4$ \\
\hline
\end{tabular}

determination of the spontaneous mutation rate of our stocks. Table 2 gives the results obtained by us.

Thus in the female germ line, the chromosomes are most susceptible to the 
induction of lethal mutations by $\mathrm{X}$-rays in early cleavage stages, less susceptible in stage 14 oocytes, still less susceptible in stage 7 oocytes, and even still less susceptible in oogonia. These results indicate that the high radiosensitivity of the early mitotic stages parallels the high frequency with which spontaneous changes occur in them, the induced rate during these early cleavage stages being similar to that of the most sensitive stage hitherto known, i.e. spermatids. Whether this is due to the fact that these cells have one of the highest rates of division known ( 10 minutes per cycle as compared to 20 minutes for bacteria and 5 minutes for some viruses) is not yet quite certain. This is so because although it may very well be that mutations can occur most readily either spontaneously or after treatment with a mutagen during the process of chromosome synthesis by an error in gene duplication, the fact that X-rays can induce whole-body mutations with an extremely high frequency (i.e. in both strands of a single chromosome) after treatment of spermatids and spermatozoa indicates that mistakes in gene-copying are not solely responsible for the origination of mutations. In this connection it should also be mentioned that unlike the evidence found for the chromosomes of some plants ${ }^{25}$, increasing the oxygen tension above that present in air did not enhance the spontaneous mutation rate during the highly mutable early cleavage stages of Drosophila in experiments carried out by us.

Considering the germ cells in both sexes of Drosophila on the basis of their induced rates of heritable changes we have the following order of decreasing sensitivity to X-rays: (1) spermatids and early cleavage stages, (2) spermatozoa in the female, (3) spermatozoa released one day after treatment, spermatozoa released two days after treatment, and stage 14 oocytes, (4) stage 7 oocytes, and (5) spermatogonia and oogonia.

The data also indicate that the most sensitive stages, spermatids and early cleavage stages, are 12 times more susceptible than the least sensitive stage, oogonia, to having lethal mutations induced in them. The rates obtained from spermatogonia have not been used for this comparison since the frequency of lethals detected in these cells is even lower than their relative degree of sensitivity would lead us to suspect. This is due to the fact that some of the mutations produced in spermatogonia are weeded out during meiosis (i.e. by germinal selection) because the $\mathrm{X}$ chromosome in the male is only present in one dose. Thus induced changes in it are not covered by their unchanged counterparts in the homologous chromosome as occurs in the female of Drosophila which has two X chromosomes.

Effects of variation of oxygen tension on the radio-sensitivity of the male and female germ lines

In view of the fact that the work of Read on growth inhibition of Vicia faba roots, Giles and Beatty ${ }^{26}$ on chromosome interchanges in Tradescantia microspores, Hollaender, Baker and Anderson ${ }^{27}$ on sex-linked mutations and translocations in Drosophila melanogaster and D. virilis, respectively, and Baker and Edington ${ }^{28}$ on translocations in Drosophila virilis, had given a rather similar pattern of results when X-rays were applied in combination with different oxygen tensions, it has been generally assumed that the amount of X-ray induced damage rises steeply as the oxygen supply is increased from 0 per cent to 21 per cent of an atmosphere (i.e. the amount present in air) 


\section{IRWIN I. OSTER}

but tends to level off after that. However, it should be pointed out that this may not necessarily be a universal principle because not only was the work mentioned above carried out on samples of cells heterogeneous with regard to meiotic and mitotic stage but other work, such as that of Glass ${ }^{29}$ on Drosophila, Hornsey ${ }^{30}$ on chicken fibroblasts, and Trowell ${ }^{31}$ on rat lymphocytes, had yielded quantitatively different results. It should be particularly emphasized that the above cited work on Drosophila was carried out at a time when the latest techniques were unavailable; thus account could not be taken of those differences in the developmental stages of sperm treated and subsequently analysed which have been shown to exert such a great influence on the magnitude of the response elicited by different treatments ${ }^{32}$.

This enhancement of X-ray mutagenesis by oxygen is presumably brought about by the formation of highly mutagenic radicals resulting from the ionization of water molecules and their subsequent reactions with oxygen. Reinvestigating this effect on homogeneous samples of germ cells we obtained the results shown in Table 3.

Table 3. Results of $\mathrm{X}$ irradiation of homogeneous samples of Drosophila melanogaster germ cells in different atmospheres

\begin{tabular}{|c|c|c|c|c|}
\hline \multirow[t]{2}{*}{ Cell stage } & \multirow[t]{2}{*}{ Dose } & \multicolumn{3}{|c|}{ Per cent lethal mutations in } \\
\hline & & $\mathrm{N}_{2}$ & Air & $\mathrm{O}_{2}$ \\
\hline Spermatids (48-hour-old pupae) & $1200 \mathrm{r}$ & $\frac{127}{4421}=2 \cdot 9$ & $\frac{105}{1087}=9 \cdot 7$ & $\frac{91}{788}=11 \cdot 5$ \\
\hline Spermatozoa (96-hour-old pupae) & $1440 \mathrm{r}$ & $\frac{116}{3826}=3 \cdot 0$ & $\frac{145}{2987}=4 \cdot 9$ & $\frac{274}{3646}=7 \cdot 5$ \\
\hline Stage 7 oocytes & $1600 \mathrm{r}$ & $\frac{17}{1516}=1 \cdot 1$ & $\frac{16}{572}=2 \cdot 8$ & \\
\hline
\end{tabular}

These data demonstrate that the response of particular stages of germ cell development to variations of the oxygen tension differs considerably. Decreasing the oxygen tension below that present in air has a relatively greater effect on the radio-sensitivity of spermatids as compared to spermatozoa in the male and stage 7 oocytes, while increasing it above that present in air has a relatively lesser effect on spermatids as compared with spermatozoa. Spermatozoa X-rayed in inseminated females respond to variations in oxygen tension in the same manner as spermatozoa in 96-hour-old pupae. These findings originally led us to speculate that the high sensitivity of spermatids to X-rays under normal aerobic conditions may be due to more intracellular and/or intercellular oxygen being normally present (or available) in these cells ${ }^{8,9}$. On this interpretation decreasing their supply of oxygen by placing them in nitrogen would considerably reduce their susceptibility to X-ray induced damage while increasing their oxygen supply would have comparatively little effect since a large amount is already present. However, it was noted that this is probably not the only factor responsible for the differential radio-sensitivity and that other mechanisms may also be involved here since it was found that spermatozoa treated in pure oxygen are not as sensitive to the same dose of X-rays as spermatids treated in air. 
In view of this consideration it may very well be that some other factor(s) is operating during the spermatid stage causing it to be more susceptible to $\mathrm{X}$-rays. It has been suggested ${ }^{33,34}$, on the basis of electron-microscope studies by $\mathrm{Ris}^{35}$ which seem to indicate that the chromosomes during the spermatid stages show a decrease in the amount of the protein surrounding them, that the lack of this 'protective' protein coat increases the radiosensitivity of the nucleic acid of spermatid chromosomes. In addition, histochemical studies have indicated that spermatids have mainly histonetype proteins, while in spermatozoa the histones have been replaced by protamines $^{36}$. These latter compounds, by virtue of their greater number of basic $\mathrm{NH}_{2}$ groups which can neutralize some of the mutagenic radicals produced by X-rays, could afford protection for spermatozoa during irradiation thereby making them less sensitive to $\mathrm{X}$-rays than spermatidis.

As a matter of fact this phenomenon may also be involved in the extreme radio-sensitivity of the early cleavage stages in that during such a period of extremely rapid duplication of the genetic material (i.e. nucleic acid), there is insufficient time for the building up of the normal quantities of the protein components of the chromosomes, hence the genes are more likely to be injured by $\mathrm{X}$ irradiation. Further histochemical and electron-microscope work will be needed to verify this suggestion.

\section{Effect of variations of other conditions on the radio-sensitivity of the male germ line}

Abrahamson and Telfer $^{37}$ had shown that when spermatozoa obtained under a variety of conditions were irradiated in the seminal receptacles and spermathecae of females no significant differences in sex-linked lethal mutation and translocation rates among the different series were obtained. These experiments included sperm which had been aged in the female prior to irradiation, sperm not aged, sperm aged following irradiation, sperm from aged males, and sperm from non-aged males. Although it is conceivable that the age of the sperm might have an influence on its sensitivity to X-rays, Abrahamson's results are not altogether surprising in view of the fact that ageing of sperm in Drosophila per se has no effect on its viability, thus indicating its relative stability. On the other hand, Dubovsky ${ }^{38}$ and Strömnaes ${ }^{39}$ had claimed that sperm from different wild-type stocks often yielded different rates of sex-linked and dominant lethals, respectively, following an exposure to X-rays. Such results can be interpreted on the basis of either a heterogeneity of germ cells sampled caused by different degrees of sperm utilization amongst the different stocks or the pre-existence of different frequencies of detrimentals amongst the different stocks. The latter together with induced detrimentals would act synergistically giving rise to completely lethal chromosomes with different frequencies amongst the stocks. That either or both of these interpretations are probably correct was borne out by our results which indicated that sperm obtained from males of different origin gave sensibly equal frequencies of autosomal translocations when they were irradiated in the female. These results are shown in Table 4. Translocations were used to demonstrate this since their rate of spontaneous origin is negligible, hence induced frequencies are not easily confused with variable numbers of pre-existing cases such as may exist for lethals amongst different stocks. 
Table 4. Results of the irradiation in the female of sperm obtained from males of different origin

\begin{tabular}{|c|c|c|}
\hline & Males & Per cent translocations \\
\hline \multirow{3}{*}{ (Females) } & B ô & $74 / 1547=4 \cdot 8$ \\
\hline & bw; st $\mathrm{p}^{\mathrm{p}}=$ Oregon- $\mathrm{R}$ 。 & $68 / 1528=4 \cdot 5$ \\
\hline & Samarkand $\delta$ & $92 / 2114=4 \cdot 4$ \\
\hline
\end{tabular}

On the other hand, it is possible that different physiological environments in the seminal receptacles and spermathecae may result in different rates of induced chromosome breakage in the spermatozoa stored in these organs. Also variations in the ooplasm caused by different genotypes, environmental influences on the females or both may result in different rates of chromosome reunion. There should be ample opportunity for this to occur since it is known that chromosomes broken in spermatozoa undergo reunion only after fertilization ${ }^{40}$. To test this, sperm were $\mathrm{X}$-rayed in females of different genotype and phenotype and in various physiological conditions. Three different wild-type stocks were selected. One of them in particular (i.e. the Canton-S females) appeared to be more sensitive to the radiation-induced necrosis following $\mathrm{X}$ irradiation of adults than the other two strains. The lozenge stock was chosen since, unlike ordinary females which have both spermathecae and seminal receptacles, this mutant besides having abnormally shaped eyes lacks spermathecae for storing spermatozoa. The spermathecae are a pair of mushroom-shaped organs $70 \mu$ wide and $40 \mu$ high, connected to the uterus by a slender duct $145 \mu$ long and $20 \mu$ in diameter. In fertilized females the lumen is filled with a concentrically coiled mass of spermatozoa. The seminal receptacle is a compactly coiled tube applied to the anterior end of the uterus, below the common oviduct. The tube is long ( 1.5 to $2.7 \mathrm{~mm})$ and its diameter is $2 \cdot 5$ to $4 \cdot 5 \mu$ at its proximal portion and 12 to $19 \mu$ at its distal part. In virgin females the receptacle contains a liquid, appearing in sections as a reticular coagulum; after fertilization the lumen is filled with spermatozoa, arranged longitudinally with their heads toward the tip of the tube. It is possible that absence of one of these structures may influence X-ray mutagenesis, for instance, by causing more crowding of the sperm in the structure which is present. Starvation and desiccation for 12 hours prior to irradiation in one group and in another followed by an exposure to a 100 per cent oxygen atmosphere for one hour after irradiation were also tried in order to attempt to influence X-ray mutagenesis by altering the physiological condition of the female. The results shown in Table 5 were obtained.

Thus these variations, even if they do alter the milieu of the sperm in inseminated females, are without effect on the mutagenic efficacy of X-rays on mature male germ cells. These results can also be used as an indication that if some pre-, simultaneous, or post-treatment is found to alter the induced mutation rate of sperm exposed in females then it is at least not mediated through such an indirect effect as starvation of the females, our results having shown that such physiological changes do not have an appreciable effect on X-ray mutagenesis in sperm of inseminated females. 
Table 5. Per cent translocations following irradiation (with $1600 \mathrm{r}$ ) of sperm (y sc $\mathrm{si}^{81} \operatorname{In} 49 \mathrm{sc}^{8}$; bw; st $\mathrm{pl}^{\mathrm{l}}$ ) in inseminated females of diflerent genotypes and under different conditions

\begin{tabular}{|c|c|}
\hline Females & Per cent translocations \\
\hline Canton-S $:\llcorner$ & $54 / 1275=4 \cdot 2$ \\
\hline Samarkand $\stackrel{1}{q} \swarrow$ & $49 / 1025=4 \cdot 8$ \\
\hline Oregon-R $\stackrel{\&}{+} \swarrow$ & $14 / 399=3.5$ \\
\hline Lozenge $\stackrel{1}{+} \swarrow$ & $50 / 944=5 \cdot 3$ \\
\hline Oregon- $R \stackrel{\&}{q}$ (starved and desiccated) $\swarrow$ & $50 / 1027=4 \cdot 9$ \\
\hline Orcgon-R $\stackrel{f}{q}$ (starved and desiccated) $\swarrow+\mathrm{O}_{2}$ & $33 / 710=4.6$ \\
\hline
\end{tabular}

Returning for a moment to the effects of more drastic changes and their effects on mutagenesis, I would like to discuss the extensive work of Sobels ${ }^{41,42,43,44,45}$ and Clark ${ }^{12}$. Sobels found, by careful breeding to ensure the sampling of germ cells to be homogeneous at the time of treatment, that exposure of Drosophila to such catalase- and cytochrome-inhibiting substances as sodium azide and potassium cyanide prior to or following $\mathrm{X}$ irradiation potentiates $\mathrm{X}$-ray mutagenesis $\mathbf{4 1 , 4 2 , 4 3 , 4 4 , 4 5}$. Clark also obtained an enhancement after injecting flies with sodium azide prior to treatment with an intense dose of X-rays (i.e. $2000 \mathrm{r} /$ minute). Sobels reported that posttreatment of Drosophila males with cyanide significantly enhances the rate of sex-linked lethals induced by X-rays delivered at a high intensity (i.e. $2200 \mathrm{r}$ minute), but not at a low intensity (i.e. $590 \mathrm{r} /$ minute). His work seemed to indicate that the enhancement of X-ray induced damage was greater in spermatids which had been either pre-treated or post-treated than in spermatozoa which had been treated similarly and was interpreted as showing that substances favouring the accumulation of peroxides enhance $\mathrm{X}$-ray mutagenesis.

However, since cyanide and azide are non-specific enzyme poisons the results do not indicate whether this potentiation of $\mathrm{X}$-ray mutagenesis is mediated by an inhibition of the catalase or cytochrome systems or both. While Sobels had reasoned that it is probably catalase which is inhibited it had not been ruled out that the cytochrome system was not involved, since Wolsky ${ }^{46}$, using carbon monoxide which is a fairly specific inhibitor of cytochrome oxidase in the dark, had shown that cytochromes function in the pupae of Drosophila. To decide this question, inseminated females were pre- and post-treated and pupae containing spermatids were pre-treated with carbon monoxide in the dark and irradiated. The different groups of inseminated females were exposed for 5 minutes with carbon monoxide and the pupae were exposed for one hour. During these treatments it was noted that Drosophila is relatively insensitive to the poisonous effects of carbon monoxide. Genetic analyses of their offspring yielded the results shown in Table 6 .

Therefore Sobel's assumption that part of the mutagenic effect of X-rays is mediated by the formation of peroxide radicals, most of which are ordinarily decomposed by catalase, is borne out by our results showing that 


\section{IRWIN I. OSTER}

Table 6. Results following irradiation alone and combined with carbon monoxide pre- or post-treatments of male Drosophila melanogaster germ cells

\begin{tabular}{lccc}
\hline \multicolumn{1}{c}{ Cell stage } & Treatment & $\begin{array}{c}\text { Per cent lethal } \\
\text { mutations }\end{array}$ & $\begin{array}{c}\text { Per cent } \\
\text { translocations }\end{array}$ \\
\hline Spermatozoa in females & $1600 \mathrm{r}$ & $\frac{139}{2840}=4 \cdot 9$ & $\frac{162}{4813}=3 \cdot 4$ \\
Spermatozoa in females & $\mathrm{CO}+1600 \mathrm{r}$ & $\frac{70}{1611}=4 \cdot 3$ & $\frac{101}{3152}=3 \cdot 2$ \\
Spermatozoa in females & $1600 \mathrm{r}+\mathrm{CO}$ & $\frac{97}{1964}=4 \cdot 9$ & $\frac{70}{2614}=2 \cdot 7$ \\
Spermatids & & & $\frac{76}{496}=15 \cdot 3$ \\
Spermatids & $1600 \mathrm{r}$ & $\frac{171}{1171}=14 \cdot 6$ \\
\hline
\end{tabular}

inhibition of the cytochrome system appears to have no effect during X-ray mutagenesis in Drosophila. On the other hand, although it has been found that potassium cyanide, sodium azide, and carbon monoxide are not by themselves mutagenic, some recent results by Clark $^{\mathbf{4 7}}$ have shown that combinations of either of the first two mentioned compounds with carbon monoxide cause a rise in the lethal mutation rate in Drosophila. It would be of interest to determine the effect of such combination treatments on the formation of chromosomal disarrangements.

I wish to thank Professor $H$. J. Muller for his constant interest during the course of this work. I should also like to express my sincere appreciation to Mrs. Astrid Cicak, who supervised and carried out the work with the help of Mrs. Louise Petoe, Elizabeth Ehrlich, Mae V. Bay, and Joyce Stafford. They are to be especially commended for their careful and untiring efforts in executing many of the technical portions of these experiments.

\section{REFERENCES}

${ }^{1}$ Auerbach, C. Z. indukt. Abstamm.- u. VererLehre 86 (1954) 113

${ }^{2}$ Khishin, A. F. E. Z. indukt. Abstamm.- u. VererLehre 87 (1955) 97

${ }^{3}$ LünING, K. G. Hereditas, Lund 38 (1952) 91

${ }^{4}$ LüNING, K. G. Hereditas, Lund 38 (1952) 321

${ }^{5}$ Lüning, K. G. Acta zool., Stockh. 33 (1952) 193

${ }^{6}$ Lüning, K. G. Studies on X-ray Induced Mutations in Various Stages of Spermiogenesis in Drosophila melanogaster A. Bonnier's Press, Stockholm, 1952

${ }^{7}$ Oster, I. I. Proceedings of the Fifth International Conference on Radiobiology Stockholm, 1956, p. 475

${ }^{8}$ Oster, I. I. Rec. Genet. Soc. Amer. 26 (1957) 387

${ }^{9}$ Oster, I. I. Genen en Phaenen 3 (1958) 53

${ }^{10}$ Muller, H. J. Amer. Nat. 64 (1930) 220

11 Oster, I. I. Drosophila Inform. Serv. 29 (1955) 154

${ }^{12}$ Cllark, A. M. Nature, Lond. 177 (1956) 787

${ }^{13}$ Baker, W. K. and von Halle, E. S. Proc. nat. Acad. Sci., Wash. 39 (1953) 152 
14Bonnier, G. and Lüning, K. G. Hereditas, Lund 39 (1953) 193

15 Abrailamson, S. and Telfer, J. D. Genetics 39 (1954) 955

16 Nordbacin, K. Drosophila Inform. Serw. 29 (1955) 150

${ }^{17}$ Multer, H. J. Communication to the Fifth International Cicnetics Congress, Berlin, 1927-published in V'erhandlungen des $V$. Internationalen Kiongresses für Vererbungswissenschaft Berlin, 1927; Z. indukt. Abstamm.- u. VererLehre (1928) Supplement 1

${ }^{16}$ Muller, H. J., Valencia, R. M. and Valencia, J. I. Rec. Genet. Soc. Amer. 18 (1949) 106; Genetics 35 (1950) 126

${ }^{19}$ King, R. C., Rubinson, A. C. and Smith, R. F. Growth 20 (1956) 121

${ }^{20}$ King, R. C., Darrow, J. B. and Kaye, N. W. Genetics 41 (1956) 890

21 Sonnenblick, B. P. Biology of Drosophila (Ed. M. Demerec): John Wiley and Sons, New York, 1950

22 Muller, H. J. Rec. Genet. Soc. Amer. 14 (1946) 55; Genetics 31 (1946) 225

${ }^{23}$ Hildreth, P. E. and Carson, G. L. Proc. nat. Acad. Sci., Wash. 43 (1957) 175

${ }^{24}$ Schalet, A. Rec. Genet. Soc. Amer. 26 (1957) 393

${ }^{25}$ Conger, A. D. and Fairchild, L. M. Proc. nat. Acad. Sci., Wash. 38 (1952) 289

${ }^{26}$ Giles, N. H. and BeAtty, A. V. Science 112 (1950) 643

${ }^{27}$ Hollaender, A., Baker, W. K. and Anderson, E. H. Symposia on Quantitative Biology 16 (1951) 315

${ }^{28}$ Baker, W. K. and Edington, C. Genetics 37 (1952) 665

${ }^{29}$ GLAss, B. Brookhaven Symposia in Biology 8 (1955) 148

${ }^{30}$ Hornsey, S. Brit. J. Radiol. N.S. 26 (1953) 646

${ }^{31}$ Trowell, O. A. Brit. J. Radiol. N.S. 26 (1953) 302

${ }^{32}$ Muller, H. J., Herskowitz, I. H., Abrahamson, S. and Oster, I. I. Genetics 39 (1954) 741

${ }^{33}$ Auerbach, C. personal communication

34 Prokofyeva-Belgovskaya, A. A. personal communication

${ }^{35}$ DAss, C. M. S. and Ris, H. J. biophys. biochem. Cytology 4 (1958) 129

${ }^{36}$ Felix, K., Fischer, H. and Krekels, A. Progress in Biophysics and Biophysical Chemistry 6 (1956) 1

${ }^{37}$ Abrahamson, S. and Telfer, J. D. Genetics 41 (1956) 677

${ }^{38}$ Dubovsky, N. V. C.R. Acad. Sci. U.R.S.S. 4 (1935) 95

${ }^{39}$ Strömnaes, O. Hereditas, Lund 37 (1940) 533

${ }^{40}$ Muller, H. J. J. Genet. 40 (1940) 1

${ }^{41}$ Sobels, F. H. Proceedings of the First International Photobiological Congress Amsterdam, 1954 , p. 332

${ }^{42}$ Sobels, F. H. Z. indukt. Abstamm.- u. VererLehre 86 (1955) 399

${ }^{43}$ Sobels, F. H. Experientia 12 (1956) 318

4 Sobels, F. H. Z. indukt. Abstamm.- u. VererLehre 87 (1956) 743

${ }^{45}$ Sobels, F. H. Proceedings of the Fifth International Conference on Radiobiology Stockholm, 1956, p. 449

${ }^{46}$ Wolsky, A. A. Nature, Lond. 139 (1937) 1069

${ }^{47}$ Clark, A. M. Nature, Lond. 181 (1958) 500

\section{DISGUSSION}

Dr. Clarke: Is there any information available on the effects of carbon monoxide or azide on neutron induced spectrum in Drosophila, whether used before or after treatment?

Dr. OSTER: No- I am trying to get a neutron source which has a very small gamma contamination to investigate this question.

Professor White: I should just like to comment that from the recent work of Gall at the University of Minnesota it would appear that the chromosomes in the spermatid 
nucleus, or at any rate in a particular stage of the spermatid, are in a very unique morphological condition, as was determined by electro-micrograph, from which it appears that the chromosomes at a particular stage are almost like membranes. There is a very complicated kind of honey-comb appearance as if many membranes were present, but had fused together in places. This kind of appearance is, I think, almost unique to the spermatid, and it may, of course, have some relationship to the proteins of the chromosomes, but it may also be in part responsible for the high radio-sensitivity. This work was done on grasshopper spermatid, and I think it might be very desirable that it should be repeated on Drosophila spermatid to see if the structure was the same there.

DR. Loutit : Can Dr. Oster tell us anything of the metabolic activity of the spermatid versus the spermatozoa or the spermatogonia. I understand that with regard to bacteria there is a suggestion that, as it were, the resting stage is less mutable than the stage which is actively metabolized. Would the stages in spermatozoa development be variable in their metabolic activities?

DR. OsTER: I think that there is not very much direct evidence concerning the metabolic activity of the different stages of spermatogenesis. However, from our general knowledge of the process of gametogenesis and from genetical experiments we can infer that the spermatid has a more active metabolism than the spermatozoon. This conclusion is based on the following: 1. While the major portion of the genetical material is not functioning in the spermatozoon and probably not in the spermatid, as I mentioned earlier, the chromosomes of the spermatid are in the process of undergoing chemical changes in their protein composition. 2. The major portion of the metabolic activity of a spermatozoon is concerned with providing energy for movement while the metabolic activity of the spermatid is concerned with a whole host of processessince during this period of transformation from the spherical spermatid to the conical spermatozoon very drastic changes occur in its nuclear and cytoplasmic constitution. It is certain that the differences in morphology which exist amongst the various stages of male gamete development are associated with metabolic activities which differ both quantitatively and qualitatively.

In this connection it is worth mentioning some facts derived from studies on the Cecropis silkworm, Platysamia cecropia. Experiments by Schneiderman, Ketchel, and Williams involving the effects of temperature, metabolic inhibitors, oxygen tension, and carbon monoxide on the in vitro spermatogenesis of male germ cells of the silkworm have indicated that the differentiation of the gametes is an aerobic process. They also found that cytochrome oxidase, which is already saturated at an ambient oxygen tension of only 5 per cent is the terminal oxidase involved in the maturation of the sex cells. However, because this enzyme is so readily saturated by substrate and because it is present only in relatively minute quantities in spermatids (as compared to spermatozoa where it is very abundant), there is a good possibility that this small amount of terminal oxidase is insufficient to cope with the amount of oxygen which is constantly diffusing to the spermatids via the highly permeable tracheal system. This, naturally, would lead to the existence of a higher partial pressure of oxygen in spermatids than in spermatozoa. Since the spermatids of Drosophila are undergoing similar biochemical and structural changes during their differentiation into spermatozoa it seems very likely that a situation identical to the one in the silkworm is present in the fruit fly. Evidence that the cytochrome system is also functioning in the pupae of Drosophila was obtained by Wolsky in experiments with carbon monoxide which is a fairly specific inhibitor of cytochrome oxidase in the dark. Thus these experiments, also, suggest the existence of metabolic differences amongst the different stages and, as I mentioned in my paper, these may bear some relationships to the differential radio-sensitirito ivbich we have described. 


\title{
THE GENETIC BASIS OF X-RAY INDUCED SOMATIG DAMAGE
}

\author{
IRWIN I. OSTER* \\ Indiana University, $\uparrow$ Bloomington, Indiana, U.S.A.
}

THE exposure of individuals to ionizing radiation, besides resulting in damage to various organ systems such as the blood-forming tissues, the gonads, and the gastro-intestinal tract, has been found to lead to an acceleration of the so-called 'natural' processes of ageing ${ }^{1}$. Although it has been shown that many of the former immediate effects of radiation can be traced back to induced chromosomal aberrations, a genetic basis for shortening of the life-span, if any does indeed exist, has not been demonstrated. A breakthrough for an attack on this problem occurred when it was found that male larvae of Drosophila melanogaster are more susceptible to killing by X-rays than females $^{2}$. As was pointed out, this difference in radio-sensitivity may have a genetic basis in that males, having only one $\mathrm{X}$ chromosome and one relatively inert (as considered from a genetic stand-point) $\mathrm{Y}$ chromosome, would more often suffer the deleterious effects of loss of its one $\mathrm{X}$ chromosome following its breakage by radiation than females, which have two $\mathrm{X}$ chromosomes. It should be pointed out, however, that chromosome breakage caused by radiation can kill somatic cells and/or their descendent-cells by either one or a combination of two main processes. One method is by the formation of chromosome bridges by dicentric isochromatids resulting from the union of centromere-bearing sister chromatid fragments. Such nuclei which are joined together by a permanent chromosome bridge will subsequently give rise to abnormal polypolar figures and giant cells. As was shown by Muller and Pontecorvo in $1940^{3,4}$, this process appears to be the principal cause of death in early Drosophila zygotes derived from irradiated spermatozoa. The other process occurs when such dicentrics fail to form permanent bridges. In this case the daughter nuclei which arise succeed in isolating themselves while the parts of the broken chromosome are often left outside of them where they degenerate. Such hypoploid cells are usually so deranged that they die; when they are not so abnormal as to die they are likely to be seriously impaired in their functioning. In diploid animals this derangement frequently results from the hypoploidy per se but the degree of impairment would be increased in those cases in which the homologous member of the affected pair of chromosomes has inherited or has had induced in it a cell-damaging gene mutation. In order to determine whether either one or both of these processes plays a role in the long-term effects of X-rays, experiments involving the response to $\mathrm{X}$ irradiation of individuals differing in their chromosomal constitution were undertaken.

* Present address: Division of Chemotherapy, The Institute for Cancer Research, 7701 Burholme Avenue, Philadelphia 11, Pennsylvania, U.S.A.

$\dagger$ This is Zoology Department contribution No. 663. New observations here reported were made with the aid of a grant to Dr. H.J. Muller and associates from the United States Atomic Energy Commission Contract AT(11-1)-195. 
It should be noted that Drosophila is ideally suited for this work because the appropriate stocks can be readily synthesized and because exposure of the larval stages, having the various developmental and physiological processes associated with growth and differentiation crowded into a relatively short period of time, tends to accelerate the appearance of induced damage. In a sense then, death resulting shortly before or after hatching from the pupa case which takes place 4 to 5 days following irradiation, represents a shortening of the life-span comparable to that observed in longer-lived higher forms.

\section{MATERIALS AND METHODS}

For all the experiments to be reported hybrid third instar Drosophila melanogaster larvae from crosses of two unrelated stocks were used. This avoided the use of individuals already homozygous for deleterious genes. The treated individuals were exposed to $1280 \mathrm{r}(135 \mathrm{kV} ; 20 \mathrm{~mA} ; 1 \mathrm{~mm} \mathrm{Al} \mathrm{filtration;}$ $160 \mathrm{r} / \mathrm{min}$ ) when their outer surfaces were fairly dry. Unirradiated but similarly handled larvae served as controls. By the use of suitably marked stocks which facilitated the separation of the sexes it was possible to segregate large numbers of male and female larvae. The males or females to be compared resembled each other genotypically and phenotypically but differed in chromosomal morphology. The following is the general type of scheme which was used in order to obtain easily recognizable individuals of both sexes. The particular scheme shown below was employed to obtain ringshaped chromosome- and rod-shaped chromosome-bearing individuals.

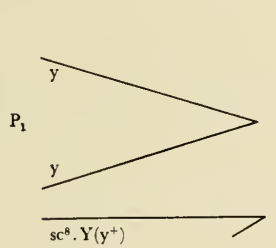

(black mouth-parts)

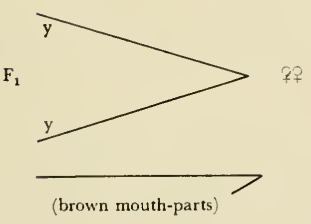

y

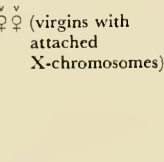

attached
$\mathrm{X}$-chromosomes

(brown mouth-parts)

or

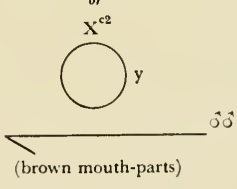

y

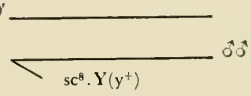

(black mouth-parts)

or

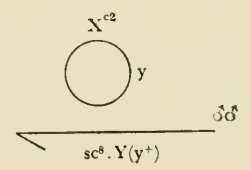

(black mouth-parts) 
These were employed on the basis of the fact that ring-shaped chromosomes which are broken lead more often than ordinary rod-shaped chromosomes to the formation of chromosome bridges by the dicentric isochromatids resulting from the union of centric sister-chromatid fragments and/or hypoploid cells lacking a chromosome or part of it, resulting from the failure of the dicentrics to form a permanent bridge followed by the formation of daughter nuclei lacking the sections of the broken chromosomes which had been left outside them.

RESULTS AND DISCUSSION

The results shown in Table 1 were obtained:

Table 1

\begin{tabular}{ccccc}
\hline $\begin{array}{c}\text { Genotype } \\
\text { of male }\end{array}$ & Treatment & $\begin{array}{c}\text { Number of } \\
\text { larvae }\end{array}$ & $\begin{array}{c}\text { Number of } \\
\text { imagoes hatching }\end{array}$ & $\begin{array}{c}\text { Per cent } \\
\text { mortality }\end{array}$ \\
rod-X & control & 375 & 348 & $7 \cdot 2$ \\
rod-X & $1280 \mathrm{r}$ & 523 & 320 & $38 \cdot 8$ \\
ring-X & control & 368 & 329 & $10 \cdot 6$ \\
ring-X & $1280 \mathrm{r}$ & 661 & 276 & $58 \cdot 2$ \\
\hline
\end{tabular}

The majority of the individuals which survived and reached adulthood after being irradiated as third instar larvae showed extreme wing abnormalities, lack of many bristles, and marked weakness which was presumably due to damage to the musculature. Mortality, in those cases in which it occurred during the pre-imaginal stages, occurred most frequently amongst late pupae and very rarely during the late larval and early pupal instars. It can readily be seen that male larvae bearing a ring-X chromosome were much more susceptible to the deleterious effects of X-rays than male larvae containing a normal rod-X chromosome. In addition, it was noted that the ring-containing survivors were also less viable than their rod-bearing counterparts. Such results can be interpreted on the basis of the fact that ring- $\mathrm{X}$ chromosomes are lost more often following irradiation. This would be especially deleterious in the case of males since they contain only one such chromosome per cell. These results demonstrate that this X-ray induced shortening of the life-span has a genetic basis and they complement the data obtained previously by which it was shown that male larvae having one $\mathrm{X}$ chromosome are more susceptible to $\mathrm{X}$-ray induced somatic damage than females having two $\mathrm{X}$ chromosomes.

On the other hand, it was shown that female larvae heterozygous for a ring$\mathrm{X}$ chromosome do not have a higher $\mathrm{X}$-ray induced mortality than females homozygous for two ordinary rod-X chromosomes. This finding as well as the previously observed difference between males and females supports the view that death has been caused by hypoploidy following breakage rather than by bridge formation. If the latter had been true, females (two X chromosomes) and males (one $\mathrm{X}$, one $\mathrm{Y}$ chromosome) would have been found to be equally sensitive to $\mathrm{X}$-rays, since a $\mathrm{Y}$ chromosome in the male is expected 


\section{IRWIN I. OSTER}

to break and form bridges about as often as an $\mathrm{X}$ chromosome in either male or female, while females heterozygous for a more breakable ring- $\mathrm{X}$ chromosome would have been found to be more radio-sensitive than females with two rod-X chromosomes.

It is planned that this type of analysis will be extended to include the effects of other mutagenic agents on individuals of diverse chromosomal make-up and the effects of radiation on specially-constructed stocks of females whose $\mathrm{X}$ chromosomes are permanently attached to each other. If our interpretation is correct, these should behave more like males than normal females having two detached $\mathrm{X}$ chromosomes following an exposure to $\mathrm{X}$-rays.

I wish to thank Professor H.J. Muller for the many stimulating discussions which we had during the course of this w'ork. I should also like to express my appreciation to Mrs. Astrid Cicak who helped with many of the technical aspects of the experiments.

\section{REFERENCES}

${ }^{1}$ United Nations Scientific Committee on the Effects of Atomic Radiation Report to the General Assembly, Official Records: Thirteenth Session Supplement No. 17 (A/3838), New York, 1958, p. 22

${ }^{2}$ Oster, I. I. and Cicak, A. Drosophila Inform. Serv. 32 (1958) 143

${ }^{3}$ Pontecorvo, G. and Muller, H. J. Rec. Genet. Soc. Amer. 9 (1940) 165; Genetics 26 (1941) 165

${ }^{4}$ Muller, H. J. and Pontecorvo, G. Rec. Genet. Soc. Amer. 10 (1941) 157; Genetics 27 (1942) 157

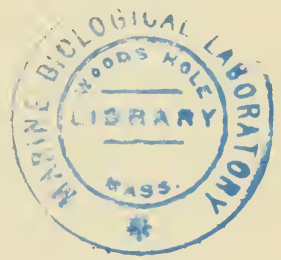




\title{
IMPERFECTIONS INDUCED IN SOLIDS BY FAST-PARTICLE IRRADIATION
}

\author{
P. G. Klemens
}

\begin{abstract}
Division of Physics, Commonwealth Scientific and Industrial Research Organization, University Grounds, Sydney
\end{abstract}

\section{INTRODUCTION}

WHEN solids are irradiated with fast particles, stable and metastable changes are induced in them. These changes vary widely with the nature of the solid and the character of the incident radiation. We shall be mainly concerned with radiation damage due to atomic displacements, caused either by the direct action of the incident particle, or by the action of other displacements.

This is not the only type of change, for there are also possible changes due to electronic excitations, except in metals, where excited electronic states are short-lived. However, the difference between a change due to electronic excitation and one due to displacements is not always clear-cut; for example, bond rupture may occur, followed by an atomic rearrangement, the energy for the movement of atoms being supplied by thermal vibrations.

Some instances of changes due to displacements in solids have been known for some time, for example from the study of radio-active minerals ${ }^{1}$. The introduction of nuclear reactors has given a great impetus to research in this field. The reason is partly that radiation damage may, in some cases, affect important physical properties of the solid components of reactors, and partly that reactors have made available a strong source of fast and penetrating particles, which can be used to study, for more fundamental purposes, the nature of radiation damage and consequent changes in physical properties. It should be noted that neutrons are not the only source of radiation damage: beams of high-energy electrons, protons, deuterons and alpha particles are all being used; however, where high dosage or uniform penetration of thick specimens is required, the nuclear reactor has obvious advantages.

THE NATURE OF RADIATION DAMAGE

Let us first look, in a qualitative way, at the physical processes of radiation damage. A charged particle, or even a neutral atom, travelling through a solid, will lose energy by electron excitation. Competing with this process will be energy loss by collision with the atoms. If sufficient energy is transferred to an atom, it will break away from its lattice site and move through the crystal, itself dissipating its kinetic energy by the above processes. If the energy imparted to an atom bound in the crystal lattice is below a certain threshold $E_{d}$, it will only excite lattice vibrations. Typical values of $E_{d}$ are about $25 \mathrm{eV}^{\prime}$, but the existence of a sharp threshold is of course an oversimplification. 


\section{P. G. KLEMENS}

The energy loss by electronic excitation will far outweigh the loss by collision with the crystal atoms if the moving particle or atom has a velocity which is comparable or higher than electronic velocities. At lower energies, collision processes will predominate. As a rough approximation, electronic excitation ceases below a limiting energy $E_{t}$ given by:

$$
E_{t}=M_{i} E_{0} / 8 m
$$

where $M_{i}$ is the mass of the moving particle or atom, $m$ the electronic mass, and $E_{0}$ an electronic energy: in insulators $E_{0}$ is the first ionization energy (band gap), in metals it is the upper energy of the conduction electrons (Fermi energy). In both cases $E_{0}$ is typically of the order of, say, $5 \mathrm{eV}$, so that $E_{t}$ is several $\mathrm{keV}$, except for incident electrons.

While electronic excitations may be neglected below $E_{t}$, collisions occur also above $E_{t}$, though relatively rarely, and must be considered. The maximum energy transferred at a single collision is :

$$
\Delta E=E \frac{4 M_{i} M_{0}}{\left(M_{i}+M M_{0}\right)^{2}}
$$

where $E$ is the energy of the moving particle and $M_{0}$ the mass of the crystal atom.

It is possible to calculate the total number of displaced atoms, using the known cross-sections for electron excitation and collision processes, and following the degradation of energy of the incident fast particle, and of each atom knocked from its lattice site. Such calculations were published by Seitz ${ }^{2}$, and subsequently refined-see, for example, the reviews of Kinchin and Pease ${ }^{3}$ and Seitz and Koehler ${ }^{4}$.

The total number of displaced atoms may exceed considerably the number of those displaced directly by the incident particle. Each primary displaced atom, starting off with a lower energy, will lose relatively less energy by electronic excitation, and since its mass equals the mass of a crystal atom, it will more readily transfer energy in excess of $E_{d}$ to crystal atoms and thus cause further displacements. These displaced atoms will in turn displace others, and so on. The total number of displacements in such a cascade arising from a primary displacement is typically of the order of $E_{t} / 3 E_{d}$. With $M_{0} \sim 10^{4} \mathrm{~m}$, typical numbers may range from 50 to 100 .

The neutron is particularly efficient in creating displacements, as it does not lose energy by electronic excitation, but only by collision. The energy transfer to a knocked-on atom is of the order of $10^{4}$ to $10^{5} \mathrm{eV}$, and each primary displacement produces a cascade as discussed above.

On the other hand, a fast electron would lose most of its energy by electronic excitation, since $E_{t}$ is low, and in one of the rare collisions with crystal atoms only a small fraction of its energy is transferred (2), so that only some of these collisions will give rise to displacements, and fewer still to secondary displacements. Indeed it is possible to adjust the bombardment voltage so that only primary displacements can be created.

Electromagnetic radiation primarily produces ionization effects (electronic excitation). However, if the radiation is sufficiently hard (gamma rays) it can produce Compton electrons which, in turn, may be sufficiently energetic to cause occasional displacements. 
In the case of irracliation by heavy particles or neutrons, one would not expect the displacements to be evenly distributed in space. While a charged particle or a displaced atom has energy in excess of $E$, and loses energy by electronic excitation, it moves some distance through the crystal, but it creates most of its displacements when its energy has fallen below $E_{t}$, that is at the end of its range, when the particle and its progeny have a short mean free path. Most of the displacements, therefore, occur in small volumes at the end of the range or where energetic primary displacements occurred, though there are also some isolated displacements, mainly early displacements just above the threshold energy $E_{d}$. Thus there should be displacement clusters, each containing say 50 to 100 displacements in a small region, superimposed on a background of isolated displacements. Evidence for this arrangement of displacements was obtained from low-temperature thermal conductivity measurements by Berman, Simon, Klemens and Fry ${ }^{5}$, to be discussed under the heading 'Thermal Conductivity' (p. 278).

We must also consider the heat liberated by processes which do not cause displacements. If sufficient heat is liberated in a small region, there will be local melting, followed by solidification after the heat has been conducted away. While displacements give rise to vacancies and interstitials only, or their aggregates, melting and solidification may produce more complex imperfections, such as dislocations. To determine the extent of the molten region and its rate of cooling, the macroscopic equations of heat conduction are sometimes used; however, this procedure is valid only if the characteristic dimensions are larger than the mean free path of the microscopic carriers of heat (electrons in metals, lattice waves in insulators).

It was pointed out by Seitz ${ }^{2}$ that the electronic excitation energy liberated by a fast particle in the early part of its range will produce a heated region of cylindrical shape, the 'thermal spike'. In the case of metals, the energy given to the electrons will be distributed among all electrons in a given region almost instantaneously, raising their temperature, while the lattice temperature will initially lag behind. The hot electrons will move outwards a distance $l$, their mean free path for interacting with lattice waves; the time required to move this distance is also the time required to establish thermal equilibrium with the lattice (typically of the order of $10^{-13} \mathrm{sec}$ ). After this time, the energy has been shared with the lattice and is distributed throughout a cylindrical region of radius $l$, so that the average energy increase of an atom in that region is :

$$
\bar{E}=\frac{\mathrm{d} E}{\mathrm{~d} z} \frac{\mathrm{l}}{\pi l^{2} n}
$$

where $n$ is the number of atoms per unit volume, and $\mathrm{d} E / \mathrm{d} z$ is the energy loss of the fast particle per unit path length. It is the magnitude of $\bar{E}$ which determines whether there is any melting; the subsequent outward flow of heat may be described, without serious error, in terms of macroscopic conduction theory.

In the case of copper $\left(l \sim 4 \times 10^{-6} \mathrm{~cm}\right)$, bombarded by $1 \mathrm{MeV}$ electrons $\left(\mathrm{d} E / \mathrm{d} z \sim 10^{7} \mathrm{eV} / \mathrm{cm}\right)$ or by $1 \mathrm{MeV}$ protons $\left(\mathrm{d} E / \mathrm{d} z \sim 10^{9} \mathrm{eV} / \mathrm{cm}\right), \bar{E}$ is only $2.5 \times 10^{-6}$ and $2.5 \times 10^{-4} \mathrm{eV}$ respectively, leading to quite insignificant temperature changes $\left(1\right.$ degree $\sim 10^{-4} \mathrm{eV}^{\mathrm{V}}$ ). In materials of shorter electron 


\section{P. G. KLEMENS}

mean free path, howcver, especially if the incident particle is heavy, it is possible to get values of $\bar{E}$ up to $10^{-2}$ or $10^{-1} \mathrm{eV}$, so that local melting may occur.

The situation is different in insulators, where local heating produces an outward flow of lattice waves, whose mean free path $l$ is of the order of $10^{-7}$ $\mathrm{cm}$ in typical cases. Substituting into (3), this would give values for $\bar{E}$ of the order of $10^{-3} \mathrm{eV}$ for an incident electron, and $10^{-1}$ for a proton, so that massive particles can produce local melting.

While local melting along the track is probably an unusual occurrence in metals and alloys, it is also possible to have spikes of spherical symmetry. Once the energy of a particle has fallen below $E_{t}$ (say, $10^{5} \mathrm{eV}$ ), it does not travel appreciably, and passes most of its energy, either directly or through its progeny, to the lattice by collisions. This energy is distributed instantaneously within a volume $l^{3}$, and even in a metal, where it is shared among $10^{6}$ to $10^{7}$ atoms, local melting is possible. Such a spike occurs in the region of a displacement cluster, and it was termed 'displacement spike' by Brinkman ${ }^{6}$.

So far it has been tacitly assumed that all irradiation damage remains locked in the lattice, but this is not invariably so. A displaced atom leaves behind a vacancy and lodges itself in an interstitial position. However, either the vacancy, or the interstitial, or both, may be mobile and recombine by diffusion. Such recombination processes are favoured by the fact that a large fraction of the displaced atoms are displaced with energy only slightly above $E_{d}$, and do not travel far before being stopped, so that the resulting interstitialcy-vacancy pair is initially of small separation.

The mobility of these defects is a function of temperature and of the type of material. In some cases, notably in non-metals, prolonged annealing is necessary to remove the damage, in other cases, including many metals, annealing is very pronounced even at room temperatures. In the latter cases it is necessary to irradiate the specimen at low temperatures to retain all radiation damage: in the case of copper even at liquid helium temperatures.

There is a rough relationship between ease of annealing and ductility. Plastic deformation may be pictured in terms of the motion of dislocations. This motion will, in general, be impeded by obstacles, including other dislocations, and the motion of dislocations is then no longer conservative, but involves the creation and annihilation of vacancies, or possibly interstitials. The details of these interaction processes are not yet fully understood, but it seems that the ability of point defects to diffuse plays a role in the deformation process. Good ductility implies a high mobility of these defects, and this implies easy annealing of at least part of the radiation damage; hence the difference between metals and insulators in their ease of annealing.

It should be remembered that even in materials which do not anneal at the temperature of irradiation, some self-annealing may occur during irradiation because of the temperature increase in the thermal spikes.

A different type of change occurs in polymers. Here the primary effect is one of the breaking and reforming of bonds between randomly orientated chains. This is an electronic effect, which can be produced by all types of radiation. The effect of this is to produce increased cross-linking, and a 
stiffening of the network, with a profound effect on plastic properties. However, a polymer contains some crystalline regions, and the effect of the bond changes of any actual displacement is to reduce the crystallinity?

\section{CIIANGES IN PIIYSICAL PROPERTIES}

The structural imperfections induced in solids by irradiation, as well as those produced by other means, affect many of the physical properties. Some properties will only suffer small changes, the relative change being comparable to the fractional volume (on an atomic scale) which is damaged: such properties include density, lattice spacing, elastic constants and specific heat. Other properties are very sensitive to small concentrations of imperfections. The various conduction properties, for example, depend upon the mean free paths of the carriers of heat or electricity, and these are structure sensitive, particularly at low temperatures. In the case of semi-conductors, the number of carriers, too, is influenced very strongly. Various mechanical properties depend upon the number of mobile imperfections, their sources, sinks and mobilities, and are, therefore, also structure sensitive.

There have been many investigations of the effects of irradiation of various materials on their physical properties, including their crystal structure as deduced from diffraction. They are too numerous even to catalogue here, but have been reviewed, for example, by Dienes ${ }^{8}$, Glen ${ }^{9}$, Kinchin and Pease $^{3}$ and by Seitz and Koehler ${ }^{4}$.

Imperfections in solids and their effect on physical properties constitute a large and important part of solid-state physics. These imperfections may be produced not only by irradiation, but also by the introduction of impurities, by plastic deformation and by quenching, and they may be removed or rearranged by heat treatment. In each case it is necessary to identify the imperfections, determine their concentrations, trace out possible genetic relationships between them, and determine quantitatively the effect of each imperfection on various physical properties. It is usually not possible to do so unambiguously, but by measuring and correlating several physical properties and by making use of theory (which, unfortunately, can usually be relied upon only to an order of magnitude), it is sometimes possible to arrive at a self-consistent picture. It is obviously of advantage to use irradiation studies in conjunction with other investigations, (a) because it is possible to vary the concentration of radiation-induced imperfections in a controlled manner, even if their absolute concentrations are uncertain, (b) because one can estimate theoretically at least the order of magnitude of these concentrations more reliably than in the case of quenching or deformation, and (c) because the principal imperfections differ from those produced by other methods, being mainly vacancies and interstitials in equal concentration.

The difficulties in the interpretation of the imperfections and of their effect on physical properties may be illustrated by the case of copper, a material to which much attention has been paid.

In a pure metal the most convenient indicator of crystal imperfections is the increase of electrical resistivity caused by them, though this increase occurs to varying degree for all imperfections, and therefore does not identify them. However, the resistivity is reduced to its original value by annealing, since this removes the imperfections. The minimum temperature required 


\section{P. G. KLEMENS}

to remove a particular imperfection depends upon the nature of the imperfection, and by noting corresponding changes in the resistance as the annealing temperature is increased, it is possible to identify a number of recovery stages, and to correlate the changes in resistance (and in other properties, if they are also measured) with whatever imperfection has been removed. In copper, five (or possibly six) such recovery stages have been observed, and the problem is to identify the imperfections corresponding to each stage. All but the last two stages occur at or below room temperature, and can only be observed if deformation or irradiation is carried out at low temperatures, otherwise annealing proceeds during the damaging process ${ }^{10}, 11,12$.

In recent years great attention has been paid to the first annealing stage, occurring at about $30^{\circ} \mathrm{K}$ for materials which have been irradiated at or near liquid helium temperatures. It is now believed that this stage corresponds to the removal of interstitial atoms, which are highly mobile except at the lowest temperatures. Thus, in this temperature region, there is no annealing of copper which was plastically deformed at helium temperatures ${ }^{13}$, when one would not expect interstitials; however, it does occur after deuteron irradiation $^{14}$. The quantitative interpretation is, however, somewhat uncertain.

The group under Koehler (University of Illinois), using high-energy deuterons, has related changes in the electrical resistance to changes in density and lattice spacing during that first recovery stage ${ }^{12,15}$. Their results generally support the interpretation of stage $I$ in terms of the removal of vacancy interstitial pairs, and allows an estimate of the electrical resistivity due to such pairs.

There is little uncertainty in the theoretical value of the electrical resistivity due to vacancies in copper, for it arises mainly from their charge defect $^{16,17}$, and is about $1 \mu \mathrm{ohm}-\mathrm{cm}$ per atomic per cent. The resistivity of interstitials, however, is governed largely by the lattice distortion around them, and is much more difficult to calculate. Estimates of this resistance range from $1 \cdot 5 \mu \mathrm{ohm}-\mathrm{cm}$ (Potter and Dexter ${ }^{18}$ ) to $10 \mu \mathrm{ohm}-\mathrm{cm}$ (Overhauser and Gorman ${ }^{19}$ ) per atomic per cent. From the relation between the electrical resistivity increase and the lattice expansion, Simmons and Balluffi estimate the resistivity of vacancy-interstitial pairs (Frenkel defects) to be about $4 \mu \mathrm{ohm}-\mathrm{cm}$ per atomic per cent, but the number of defects thus deduced is only about one-sixth of the concentration calculated from the displacement theory.

Corbett, Denney, Fiske and Walker ${ }^{20}$ bombarded copper with fast electrons at liquid helium temperatures and studied changes in electrical resistivity, as well as annealing behaviour. In this case there are single displacements only, and very few displacement clusters or spikes, so that the interpretation should be simple, and calculations of the number of displacements relatively reliable. They found that 90 per cent of the resistance increase disappeared during stage I, confirming that interstitials combine with vacancies. However, they found the apparent change of resistivity to be only $1 \cdot 5 \mu \mathrm{ohm}-\mathrm{cm}$ per atomic per cent of Frenkel defects.

Blewitt's group at Oak Ridge have now facilities for neutron irradiation at liquid helium temperatures ${ }^{21}$. Blewitt, Coltman, Klabunde and Noggle ${ }^{22}$ concluded from the annealing kinetics and the sensitivity of annealing rates 
to impurities of neutron-irradiated copper that the removal of interstitials during stage $\mathbf{I}$ is not a simple process of point defect diffusion.

These considerations illustrate the complexity of the problem. It is almost certain that our ideas on this subject will undergo some change before attaining finality.

THERMAL CONDUCTIVITY: EFFECT OF IRRADIATION

Another physical property which is very sensitive to radiation damage is the thermal conductivity. This is particularly so for non-metals, where the thermal conduction is due to the transport of energy by lattice waves. The thermal conductivity is then given by:

$$
\kappa=\frac{1}{3} \int S(\omega) v l(\omega) \mathrm{d} \omega
$$

where $S(\omega) \mathrm{d} \omega$ is the contribution of waves of frequency $\omega, \mathrm{d} \omega$ to the specific heat per unit volume, and $l(\omega)$ is the mean free path of lattice waves. Lattice waves are scattered by the anharmonicities of the lattice forces, by lattice imperfections and by the crystal boundaries. The temperature dependence of the conductivity is governed by the temperature and frequency variation of $l(\omega)$, and since different imperfections scatter with different frequency variations, it is possible to identify the dominant imperfections from their thermal resistance $23,24,25$. It is, however, necessary to study the thermal conductivity over a wide range of temperatures, usually from liquid helium to liquid air temperatures.

The sensitivity of the conductivity to lattice imperfections and the possibility of identifying them lends interest to thermal conductivity studies of irradiated solids. This applies, of course, only to lattice thermal conductivities: the electronic thermal conductivities of metals only yield the same information as the electrical resistivities ${ }^{24}$. In the case of alloys, however, it is possible to separate out the lattice component of thermal conductivity, and this can yield information about lattice imperfections ${ }^{24,26}$. While this technique could, no doubt, be applied to irradiation damage in alloys, no such investigation has yet been published.

The first measurements of the effect of irradiation on the thermal conductivity were made on neutron-irradiated quartz $z^{5,23,27}$. Measurements were made of the thermal conductivity of the original crystal, and of the same crystal after three successive doses of neutron irradiation. From the temperature variation of the additional thermal resistance it was deduced that at least two types of imperfections were present: isolated point defects and more extensive regions of damage. The latter would, of course, be expected from the theory of radiation damage, as displacements should be clustered near the end of the range of a knocked-on atom.

Berman also studied the annealing behaviour of this thermal resistance. No change occurred at annealing temperatures lower than $300^{\circ} \mathrm{C}$; this, together with the proportionality of the resistance to exposure, indicates that no recovery took place during irradiation.

It is very noticeable that the thermal conductivity curves of the heavily irradiated specimen approach that of fused silica, and Klemens suggested that the regions of extensive damage are vitreous inclusions. In a localized 


\section{P. G. KLEMENS}

displacement cascade an appreciable fraction of the bonds is broken, some by the displacements, some by the heat liberated in the displacement spike, and when the material settles down again it goes into the metastable vitreous state.

Similar thermal conductivity studies have been undertaken by Berman, Foster and Rosenberg ${ }^{28}$ on neutron-irradiated sapphire and diamond, and it seems that these results should be interpreted in a similar way. At Oak Ridge, Cohen (private communication) has studied potassium chloride crystals after gamma and neutron irradiation. After gamma irradiation only single-point defects appeared: this is reasonable for the Compton electrons could only produce single displacements. After neutron irradiation, more complicated imperfections appear, but the detailed interpretation is still uncertain. The effect of neutron irradiation on the thermal conductivity of fused silica was also studied by her-see below.

That large-scale defects in irradiated quartz should be vitreous inclusions is confirmed by the fact that very intense neutron irradiation turns quartz into an amorphous material $29,30,31$. There is, however, a small difference in density between fused silica and the irradiation-produced glass, the latter being about 2 per cent denser. This suggests a less open and, therefore, less disordered structure, so that the irradiation-produced glass should have a higher thermal conductivity, particularly at low temperatures ${ }^{32}$, a prediction recently confirmed by Cohen.

Vitrification due to heavy neutron bombardment does not occur in all insulators ${ }^{33}$, but presumably only in glass-forming substances, or possibly also in those which just fail to satisfy the usual criterion of vitrificability ${ }^{34}$. Certain radio-active minerals occur in an amorphous state, the metamict state, due to radiation damage by alpha particles produced within them ${ }^{3}$, and Primak pointed out the essential similarity between these two phenomena. Metamictization probably occurs only as a result of heavy particle or neutron bombardment, when displacement clusters or spikes are formed.

Wittels and Sherrill ${ }^{29}$ observed density changes in quartz on neutron bombardment. Very curiously, the rate of density change increases quite markedly before decreasing again on approaching saturation, instead of gradually decreasing with dosage, as would be expected for simple saturation. Klemens ${ }^{32}$ suggested that this is due to the vitreous inclusions: each inclusion will tend to expand, but will be constrained by the surrounding crystal, so that the system is under internal stress. After further irradiation, when the density of inclusions is higher, they will interact elastically, stresses will be relieved by plastic flow, and the delayed expansion will occur. On this model any change of lattice parameters would be essentially unrelated to changes in hydrostatic densities, and the accelerated change of the latter should not be accompanied by a similarly accelerated change of the former; however, X-ray lines should be broadened and skewed because of the inhomogeneous strain.

Further extensive measurements by Wittels ${ }^{35}$ did not confirm this theory, for although there was appreciable broadening and skewing of the lines, and there were good indications of the presence of vitreous inclusions from diffuse rings in Laue photographs, there was also a real shift of the lines, and the change in lattice spacings not only paralleled the change in hydrostatic 
density, but even exceeded it for heavier exposures. It thus appears that the lattice is expanded mainly by the isolated point defects, and becomes less rigid as the defect concentration is increased.

Cohen (reference 36 and private communication) measured the thermal conductivity of fused quartz before and after neutron irradiation. As predicted by Klemens, ${ }^{32}$ the thermal conductivity increased on neutron irradiation, due to the destruction of short-range order. After prolonged neutron irradiation, the thermal conductivity curve reached a terminal form, showing that the effects of irradiation saturate. On annealing, the original (vitreous silica) curve was recovered. When crystalline quartz was irradiated and subsequently annealed, the conductivity curve approached that of the unirradiated crystal, as previously found by Berman ${ }^{27}$. However, on prolonged irradiation, a saturation curve was reached, identical with the saturation curve of irradiated quartz. When the material was now annealed it reverted, not to the form of the original crystal, but to the form of unirradiated glass; in other words, the heavily irradiated crystal had become completely amorphous, losing all memory of its original crystalline form.

\section{REFERENCES}

${ }^{1}$ Hamberg, A. Geol. Fören. Stockh. Förh. 36 (1914) 31

${ }^{2}$ Seitz, F. Disc. Faraday Soc. 5 (1949) 271

${ }^{3}$ Kinchin, G. H. and Pease, R. S. Rep. Progr. Phys. 18 (1955) 1

${ }^{4}$ Sertz, F. and Koenler, J. S. Solid State Physics, Vol. 2: Academic Press Inc., New York, 1956, p. 307

${ }^{5}$ Berman, R., Simon, F. E., Klemens, P. G. and Fry, T. M. Nature, Lond. 166 (1950) 277

${ }^{6}$ Brinkman, J. A. J. appl. Phys. 25 (1954) 961

${ }^{7}$ Charlesby, A. Effects of Radiation on Materials (Ed. Harwood et al.): Reinhold, New York, 1958, chapter 10

${ }^{8}$ Dienes, G. J. Ann. Rev. Nucl. Sci. 2 (1953) 187

${ }^{9}$ Glen, J. W. Advanc. Phys. 4 (1955) 381

${ }^{10}$ Seeger, A. Handbuch d. Physik, Vol. 7/1: Springer, Berlin, 1956, p. 383

${ }^{11}$ Van Bueren, H. G. Influence of Lattice Defects on the Electrical Properties of Cold-worked Metals (thesis) Leiden, 1956

${ }^{12}$ Koenler, J. S., Henderson, J. W. and Bredt, J. H. The Thermal Annealing of Imperfections in the Voble Metals: University of Illinois Technical Report, 1956

${ }^{13}$ Blewitt, T. H., Coltman, R. R. and Redman, J. K. Report on the Conference on Defects in Crystalline Solids, The Physical Society, London, 1955, p. 372

${ }^{14}$ Cooper, H. G., Koenler, J. S. and Marx, J. Phys. Rev. 97 (1955) 599

${ }^{15}$ Simmons, R. O. and Balluffi, R. W. Phys. Rev. 109 (1958) 335

${ }^{16}$ Jongenburger, P. Appl. sci. Res., Hague B3 (1953) 237

${ }^{17}$ Jongenburger, P. Nature, Lond. 175 (1955) 546

18 Potter, R. J. and Dexter, D. L. Phys. Rev. 108 (1957) 677

${ }^{19}$ Overilauser, A. W. and Gorman, R. L. Phys. Rer. 102 (1956) 676

${ }^{20}$ Corbett, J. W., Denney, J. M., Fiske, M. D. and Walker, R. M. Phys. Rev. 108 (1957) 954

${ }^{21}$ Coltman, R. R. and Brewitt, T. H. Proceedings of the Cryogenic Engineering Conference University of Colorado, Boulder, 1956, p. 110

${ }^{22}$ Blewitt, T. H., Coltman, R. R., Klabunde, C. E. and Noggle, T. S. J. appl. Phys. 28 (1957) 639

${ }^{23}$ Klemens, P. G. Proc, roy'. Soc. A 208 (1951) 108 


\section{DISCUSSION}

${ }^{24}$ Klemens, P. G. Handbuch d. Physik, Vol. 14: Springer, Berlin, 1956, p. 198

${ }^{25}$ Klemens, P. G. Solid State Physics, Vol. 7: Academic Press Inc., New York, 1958, p. 1

${ }^{26}$ Kemp, W. R. G., Klemens, P. G., Tainsh, R. J. and White, G. K. Acta Metallurgica 5 (1957) 303

${ }^{27}$ Berman, R. Proc. roy. Soc. A 208 (1951) 90

${ }^{28}$ Berman, R., Foster, E. L. and Rosenberg, H. M. Report on the Conference on Defects in Crystalline Solids The Physical Society, London, 1955

${ }^{29}$ Wittels, M. C. and Sherrill, F. A. Phys. Rev. 93 (1954) 1117

${ }^{30}$ Primak, W., Fuchs, L. H. and Day, P. Phys. Rev. 91 (1953) 551

${ }^{31}$ Primak, W., Fuchs, L. H. and Day, P. J. Amer. ceram. Soc. 38 (1955) 135

${ }^{32}$ Klemens, P. G. Phil. Mag. 1 (1956) 938

${ }^{33}$ Primak, W. Phys. Rev. 95 (1954) 837

${ }^{34}$ Stevels, J. M. Progress in the Theory of the Physical Properties of Glass: Elsevier, Amsterdam, 1948

${ }^{35}$ Wittels, M. C. Phil. Mag. 2 (1957) 1445

${ }^{36}$ Cohen, A. F. J. appl. Phys. 29 (1958) 591

\section{DISGUSSION}

DR. SEgAL: Dr. Klemens has discussed the irradiation damage in the temperature range between liquid helium and room temperatures. I wonder if he could tell us whether any work has been done at very high temperatures, say, up to about $3000^{\circ} \mathrm{C}$.

DR. KLEMENS: I am not aware of any studies of irradiation effects, in which the material was kept at very high temperatures during irradiation, although such studies may have been carried out in connection with the development of reactors working at high temperatures. In most substances annealing takes place at high temperatures and it is more profitable to irradiate at low temperatures and subsequently increase the temperature, studying the annealing behaviour. From such knowledge one can deduce the behaviour during irradiation at high temperatures.

DR. GREen: I wonder if Dr. Klemens would agree that the reason why very little irradiation-damage work has been done on complex compounds and biological chemicals is that the experimental techniques necessary to find out what has happened are somewhat complex? Would he also agree that we now have a seemingly useful tool, the electron paramagnetic resonance method, which is particularly suitable for compounds of biological significance, so that much information may be derived in this manner in the future?

DR. KLemens: Yes, this is certainly so. I have recently seen an illustration of the power of the paramagnetic resonance method at Oak Ridge, where this technique is used to study the effects of neutron irradiation on crystalline and vitreous silica, thus providing further information on the problem which I have discussed in my paper. 


\title{
RADIOBIOLOGICAL MECHANISM AT THE CELLULAR LEVEL: Lines of investigation which have been opened up by the recent technical developments
}

\author{
L. H. Gray \\ British Empire Cancer Campaign Research Unit in Radiobiology, \\ Mount Vernon Hospital, Northwood, England
}

WE HAVE to confess that though the action of $\mathrm{X}$-rays on living cells has been studied for more than sixty years we are still extremely ignorant of the mechanisms involved.

The formation of ions and excited molecules represents a gross local disturbance from the molecular standpoint. We can confidently assert from our knowledge of the physical processes involved that some 300,000 such disturbances occur in a cell 10 microns in diameter exposed to 100 rads of $\gamma$ radiation, but with a few exceptions confined to studies with seeds, these disturbances have not been directly observed in living cells. Radiobiologists have hitherto had to rely entirely on the cell as its own indicator of the changes initiated in it by ionizing radiation. Since the initial disturbances are approximately randomly distributed over all cell functions, and the materials which serve these functions are undergoing continuing synthesis, it is to be expected that the great majority will escape detection. Aberrant molecules may either be rejected or, if built into the permanent structure, may cause so slight a disturbance of function as to escape our comparatively crude methods of analysis. The forms of radiobiological damage known to us at present, therefore, do not constitute a representative cross-section of the 'built-in' defects, still less of all defects sustained by the irradiated cell, but are a highly selected group. The basis of selection is immediately evident when we consider some of the better known forms of radiobiological damage.

\section{Damage to the Genome-Sub-microscopic}

The uniqueness of every element of the genome of a haploid cell makes almost any kind of error in this material detectable by the highly developed techniques of genetic analysis. The linear dose dependence and absence of doserate dependence so frequently obscrved point to gene mutation as being initiated monotopically, i.e. as a single event process. After many years of doubt it now appears to have been established for Neurospora by the work of Giles and de Serres ${ }^{1}$ and for Drosophila by Muller and Oster ${ }^{2}$, that ionizing radiation may induce mutation back to the wild type at a locus which had previously undergone mutation under the influence of radiation. This does 


\section{H. GRAY}

not, of course, imply that when a mutation occurs at a given locus the energy supplied by the ionizing radiation itself induces a switch between alternative molecular configurations. It is equally possible, and rather more in keeping with the phenomenon of multiplicity reactivation in viruses, to assume that in the case of both forward and back mutation a molecular configuration which has been rendered defective by irradiation, may be replaced at the time of the gene reduplication by one of a limited number of possible alternative configurations representing the alleles at the locus in question. The nature of the original defect remains to be discovered.

\section{Damage to the Genome-Visible}

Structural damage to chromosomes has a three-fold chance of detection, namely by genetic analysis, by microscopic observation at metaphase and anaphase, and by the fact that it generally impairs the proliferative capacity of the cell. Accordingly, it is one of the best documented forms of radiobiological damage. Other organelles may be damaged as frequently as chromosomes, but escape notice for want of visual or functional methods of detection. In fact, mitochondrial damage may be prominent at an early stage in irradiated cells. Thus, Ludford ${ }^{3}$ reports that $40 \mathrm{~min}$ after a mouse adenocarcinoma 27 had been exposed in vivo to mixed $\beta$ and $\gamma$ radiation, the mitochondria of almost every cell were either granular or vesicular, and in some cells were reduced in numbers. The dose is, unfortunately, not known but was probably between 500 and $1500 \mathrm{rad}$. At this time the chromosomes of the very few cells which were in division were showing signs of stickiness and clumping. Chromosome structural damage would only have become microscopically visible very much later, after the period of mitotic inhibition, which lasted more than a day in these cells under the particular conditions of irradiation used by Ludford. Despite the earlier appearance of the mitochondrial damage, we can be much less certain of its relation to primary disturbances than in the case of chromosome structural damage. At the levels of dose with which we are concerned, neither form of damage would be visible in cells in which metabolism had been in abeyance between irradiation and the time of observation. Both may therefore, in principle, be regarded as a manifestation of the response of the cell to injuries outside the organelles concerned. In the case of chromosome structural damage, however, dose and dose-rate relations observed with radiations of differing LET, as well as the agreement between the observed distribution of aberrations between the cells of an irradiated population with that expected for random events, indicates that each observed aberration has been initiated by a monotopic event. These relations also indicate that aberrations which involve two chromatids are only formed when events are initiated either by one ionizing particle, or by two, at adjacent sites in each of the two threads. Finally, the very beautiful micro-beam experiments of Bloom, Zirkle, and Uretz ${ }^{4}$ have shown that the probability of producing a chromosome aberration by the passage of a proton through other organelles, or through the cytoplasm at several microns distant from a chromosome, is negligible compared with a probability that an aberration will be initiated by a proton which passes through, or in the immediate vicinity of, the site at which the aberration subsequently appears. 
These lines of evidence appear to constitute firm grounds for an attempt to trace the actual sequence of changes which connects the initiating eventbe it ionization, excitation, or an attack by a free radical-and the olsserved chromatid lesion. No corresponding cvidence exists as yet in the case of mitochondrial damage.

\section{Carcinogenesis}

Transformation to malignancy is an inherently detcctable type of change, and the rate of growth of most malignant cells is such that if this change occurred in a single cell early in the life of a mouse, the fact of the occurrence would be declared clinically. A rough calculation of the number of basal layer cells in the skin of a mouse shows that if the probability of conversion from the normal to the fully malignant state in one step were even as low as $10^{-10} / \mathrm{rad}$, half the population of mice exposed to $100 \mathrm{rad}$ would develop epitheliomas. As this is not observed, we must conclude either that the probability of transformation is lower than $10^{-10} / \mathrm{rad}$, or that the transformation to malignancy is not a one step process. Independent evidence strongly favours the latter alternative. A single application of one of the more active chemical carcinogens will give rise to skin cancer in mice if followed by repeated applications of a 'promoting' agent such as croton oil. If croton oil is applied repeatedly to irradiated mouse skin, tumours appear after $\beta$-ray doses down to $700 \mathrm{r}^{5}$, and possibly down to $300 \mathrm{r}$ (Schubickpersonal communication). When small areas of mouse or rat skin were exposed to $\beta$ radiation only ${ }^{6}$, no tumours were produced unless the dose was such (12,000 rad in a single exposure, or 4,600 rad in two fractions 2 months apart) as to produce actual tissue breakdown. The appearance of malignant cells was regarded as an end product of repeated cycles of tissue breakdown and repair. On this view the role of irradiation is unspecific. It may be, however, that when radiation is used alone as a carcinogen, it has both to initiate specific cellular transformation and also to serve as a 'promoter', and that, in the case of skin cancer, promotion is achieved by way of regenerative hyperplasia. Similarly, in the case of the induction of lymphomas, ovarian tumours, and pituitary tumours, it may be that the important roles played by hormonal imbalance, or by haemopoietic insufficiency, are concerned with promotion. If this view is correct, then the characteristics of any specific transformation which may be involved might be more readily revealed by experiments in which tissue which had been exposed to moderate doses of radiation was then subjected to the action of an independent 'promoting' agent.

\section{Stimulation of Visual Receptors}

Perhaps the most immediate indication of molecular disturbances induced by ionizing radiation known to us at present is provided by the retinal response in mammals and amphibia, and related response in lower organisms. The subject has been reviewed by Lipetz, who himself contributed many of the important original observations 7,8 . The X-ray threshold for stimulation of the frog retina is of the order of $1 \mathrm{rad}$ delivered, for example, as a $5 \mathrm{sec}$ exposure to $0.2 \mathrm{rad} / \mathrm{sec}$. This is estimated to correspond to between 0.5 and 150 times as much energy absorbed by the visual purple as the minimum for visible light stimulation. Baylor and $\mathrm{Smith}^{9}$, have examined the response of a 


\section{H. GRAY}

crustacean, viz. the large water flea, Dahpnia magna, to $\mathrm{X}$ radiation. When exposed to $\mathrm{X}$ radiation at dose rates exceeding $150 \mathrm{r} / \mathrm{min}$, the Daphnids instantly responded by swimming downwards and away from a source of red light, by means of which they were being examined. On interrupting the irradiation, the Daphnids instantly reversed these two trends in their direction of movement. The change in behaviour pattern is thus initiated by a total dose of only a few rads, provided this is delivered at $150 \mathrm{rad} / \mathrm{min}$. Such behaviour can be produced by high temperature, high $\mathrm{pH}$, or low pressure. The possibility that the effect of irradiation was mediated through one of these agents was excluded, but in the course of the investigation it was found that the swimming pattern varied systematically when dyes of graded Redox potential were added to the water. Compounds with potentials, relative to the hydrogen electrode, of less than +0.045 (Brilliant cresyl blue) simulated irradiation, and six compounds with potentials from +0.062 (Thionine) to +0.275 (Catechol) produced the converse behaviour. The authors suggested that response to irradiation may be due to a radiation-induced reversible reduction of the eye pigment in the nauplius eye, but the alternative of an induced fluorescence or chemiluminescence in the substances of the eye pigment, or its immediate environment, cannot be said as yet to have been ruled out.

The optic nerve is stimulated by an appropriate chemical agent in a very small number out of a large array of identical pigment molecules. If the required chemical change is one which can be effected by ionizing radiation - and reversible reduction is a well established radiation-induced transformation in methylene blue and many other molecules ${ }^{10}, 11$ - it must be expected that this change will occur in a small proportion of the molecules exposed to a dose of a few rads.

Other interesting examples of immediate changes in behaviour patterns of animals in response to the onset of irradiation at dose rates of a few hundred $\mathrm{r} / \mathrm{min}$ have been described by Hug ${ }^{12,13}$.

In the examples cited above, detection of the primary radiation disturbance at the molecular level has rested either on the uniqueness of the molecules in question or on the existence within the cell of a mechanism which responds to a change in a very small proportion of a large array of identical molecules. The mere loss in effectiveness of a small proportion of identical molecules serving the same function would not be expected to be detectable, and this has often proved to be the case. Some striking examples have been quoted elsewhere ${ }^{14}$ and include the inability of radiation at dose levels less than about $100,000 \mathrm{r}$ to interfere with the emission of light by luminous bacteria ${ }^{15}$ with adaptive enzyme formation ${ }^{16}$, or with the ability of bacteria to support virus growth ${ }^{17}$. The possibility, of course, exists that an altered molecule might disturb biological function not by its loss, but by reason of a positive toxicity. It might act as an anti-metabolite in relation to its own proper function, or it might be endowed with more general toxicity. In this latter connection the formation of organic peroxides calls for special consideration since peroxides are formed by the irradiation of almost any organic material in the presence of oxygen. The experiments of Dewey and Boag ${ }^{18}$ indicate that all the oxygen present in a bacillus at the beginning 
of irradiation in a medium containing $15 \mu \mathrm{M} / 1$. of dissolved oxygen, is consumed radiochemically after the cell has been exposed to a dose of around 3,000 to $5,000 \mathrm{rad}$. The concentration of oxygen within the bacillus is unknown, but assuming it to be comparable with that outside the cell, the total organic peroxide formation may well amount to $1.5 \mu \mathrm{M} / 1$. - or higher in the case of cells exposed to larger doses under conditions of continuous aeration. Although some organic peroxides are known to be mutagenic, and particular peroxides such as cumene hydroperoxide and disuccinoyl monoperoxide are biologically active towards micro-organisms, viruses, and transforming principle at extremely low concentrations ${ }^{19}$, attempts to implicate peroxides in particular types of biological damage induced by ionizing radiation have generally been inconclusive or negative ${ }^{20}$. This is probably because most cells are adequately protected by their catalase content. In an interesting investigation with a haemin-deficient strain of Escherichia coli, recently reported by Adler and Stapleton ${ }^{21}$, it has been shown that, in the absence of catalase, E. coli exhibited a progressive loss of colony-forming ability after irradiation, which closely resembles the 'after effect' of radiation originally reported by Alper ${ }^{22}$. In this case, the total effect on the irradiated aerobic cell appears as a sum of three components, viz. (a) damage which is independent of peroxide formation, $(b)$ damage which is dependent on the absorption of oxygen but not on the effects of peroxides acting after the end of irradiation, and $(c)$ on an 'after effect' which can be simulated by the treatment of the irradiated (but not the unirradiated) cell by chemical hydrogen peroxide or hydrogen peroxide resulting from the exposure of the medium to the given dose level.

At the outset of this Conference Sir Macfarlane Burnet enunciated four questions concerned with genetic damage and carcinogenesis, to which he hoped answers would be forthcoming. Two of these questions were: 'Can what is determined of the genetic effects of radiation in the laboratory be pushed down to the very small levels found in Nature?' and 'How does the effect of ionizing radiation vary with its strength?'

We find ourselves in a dilemma because any conceivable experiment which we might set up to obtain answers to these questions, by use of laboratory animals, still leaves a very large gap in dose rate and over-all time of irradiation to be bridged by extrapolation, and we have no theory of radiobiological damage so well founded that it can be used with complete confidence to bridge that gap. While acknowledging that we cannot at present answer Sir Macfarlane's questions, it is perhaps worth noting that there are certain circumstances in which it is possible to extrapolate with confidence to as low a dose or as low a dose rate as we please on the basis not of a theory, but of a physical fact, namely that ionizing particles deliver their energy to matter in quanta of considerable magnitude. It follows ( $c f$. Paper 1$)$ that for a cell (or element of tissue) of any size, there is a dose $D_{s}$ which we may call a single particle dose, and which has the following significance. If a large number of such cells or elements of tissue are exposed to this dose, an average of one particle will cross each volume element. The actual numbers will be distributed in accordance with the Poisson formula, so that about one-third will not be traversed by any ionizing particles at all, about one-third would be traversed by a single particle, one-sixth would be traversed by two parti- 


\section{H. GRAY}

cles, one-twentieth by three particles, and so on. The proportion of the cells which are traversed by two particles relative to the proportion traversed by one particle, falls rapidly as the dose is reduced below $D_{\varepsilon}$. For example, when exposed to $\frac{1}{3} D_{s}$ the proportions traversed by one, two, and three

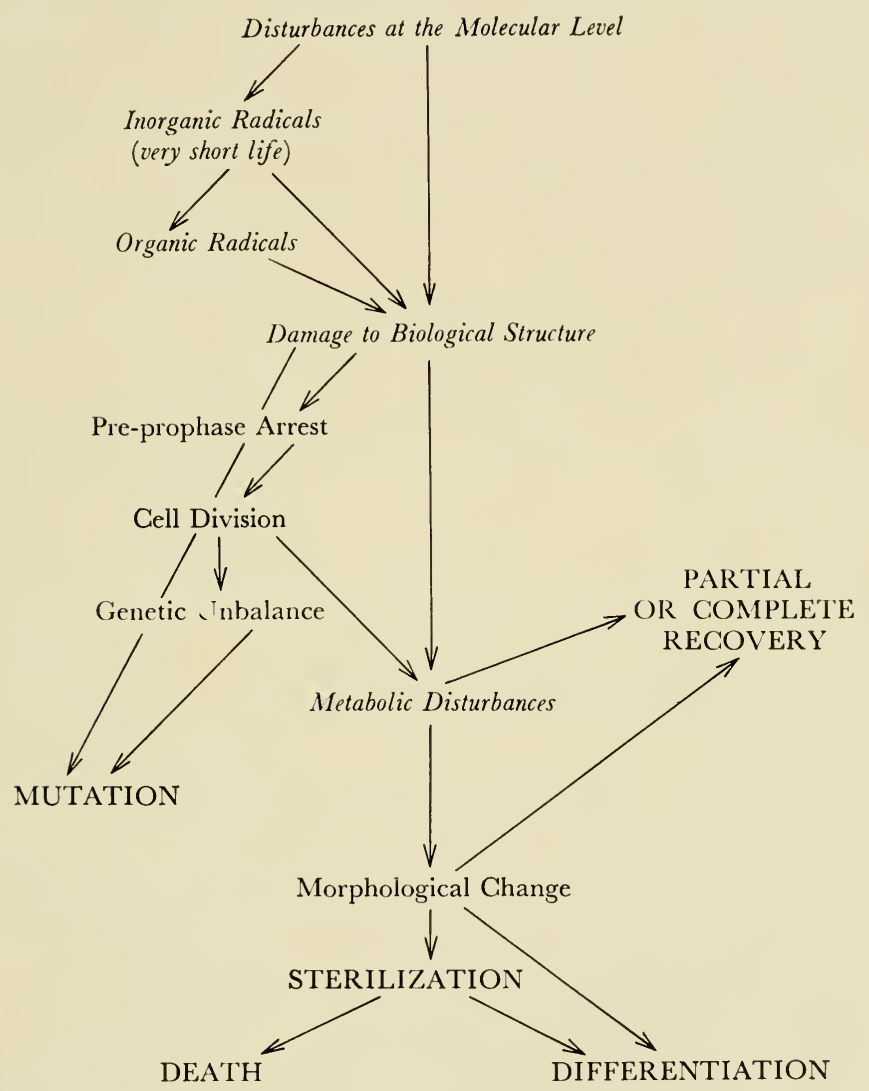

Figure 1. Stages in the development of radiobiological damage

particles are as $1: 0 \cdot 17: 0 \cdot 02$. If, therefore, a particular biological response is due to the combined effect of two or more particles, this will be clearly revealed by experiments within the dose range $\frac{1}{3} D_{s}$ to $3 D_{s}$ as a lack of proportionality between dose and effect. Conversely, if proportionality is found experimentally at this dose level, it may confidently be inferred at all lower dose levels, because lowering the dose only affects the proportion of 
RADHOBLOLOGICAL NECHANISM AT THE CELLULAR I.VEE,

cells in which something happens, not the event itself. The energy delivered to those cells which are affected is determined solely by the size of the cell and the quality of radiation. Since dose rate (or intensity) can only have meaning in relation to effects produced by more than one particle, situations which satisfy the critcria for single particle action neccssarily satisfy the criteria for dose-rate independence. We already have the information necessary for an approximatc calculation of the dose of radiation $D_{z}$ of given quality $(\gamma, \mathbf{X}$, neutron, or $\alpha$ radiation) corresponding to a given volume of tissue, which must, of course, be taken as the volume within which irradiation-induced disturbances may contribute to the biological response. In special circumstances this volume may be larger than the cell itself-as when an irradiated cell is exposed to an 'after-effect' due to toxic products produced in the surrounding medium. In many cases such extraneous influence can be excluded on experimental grounds, and the volume to be considered is the volume of the cell. It may even be possible on experimental grounds to narrow the volume further to that of a cell constituent, or organelle such as the nucleus, with a corresponding increase in the magnitude of $D_{s}$.

It is believed that $D_{s}$ has been reached experimentally in the study of the induction of lysogeny in $E$. coli by $\mathrm{X}$ radiation, in which linearity was established down to less than $1 \mathrm{r}^{23}$, and for the induction of chromosome structural damage by $\alpha$ radiation in which linearity was established down to $4 \mathrm{rad}^{24}$.

Figure 1 attempts to put together the meagre information at present available into a scheme representing salient features in the development of radiobiological damage. End results are shown as capitals and observable intermediate stages in ordinary type. Stages which are essentially conjectural are shown in italics, and it is perhaps the most significant thing about the Figure that the italics predominate. They fall broadly into a group concerned with primary physical and chemical processes, and a group concerned with metabolism.

The remainder of this discussion will be concerned with the possibility of obtaining information about the former group by direct experiment.

Since we must accept that, in general, within the living cell all the species with which we are concerned-ions, free electrons, and free radicals-will be short-lived, the optimal conditions for detection are likely to be achieved by compressing the total dose into the shortest possible time, and by using pulsed methods of detection. The combination of a source which delivers large doses in single pulses and pulsed detection methods not only increases the chance of successful detection by increasing the instantaneous concentration of the species concerned, but also introduces the possibility of measuring lifetimes directly. It may be useful to discuss practical possibilities and limitations by reference to the techniques being developed in our laboratory by my collcague Dr. J. W. Boag.

\section{Electron Pulse Generator}

Technical aspects of our high current clectron pulse generator have been reported at the Second International Conference on the Peaceful Uses of Atomic Energy by Miller and Boag ${ }^{25}$. This instrument, which was designed in the Research Department of Messrs. Metropolitan Vickers Electrical Co. 


\section{H. GRAY}

Ltd., employs the axial component of the electric field associated with $10 \mathrm{~cm}$ radio waves travelling along a loaded cylindrical wave guide to accelerate bunches of electrons to an energy of around 1.5 MeV. Radio-frequency power from a $2 \mathrm{MW}$ magnetron is supplied in pulses of approximately $2 \mu \mathrm{sec}$ duration, as in the $4 \mathrm{MeV}$ travelling wave accelerators in use as a source of $\mathrm{X}$ radiation in a number of Radiotherapy Departments ${ }^{26,27}$. Our accelerator differs from the clinical instruments in the construction of the waveguide, which is designed for maximum current at 1 to $1.5 \mathrm{MeV}$, and does not employ feedback of unused power from the output end of the waveguide. This has important advantages for single pulse operation and does not necessarily waste any appreciable amount of power. Figure 2 shows the

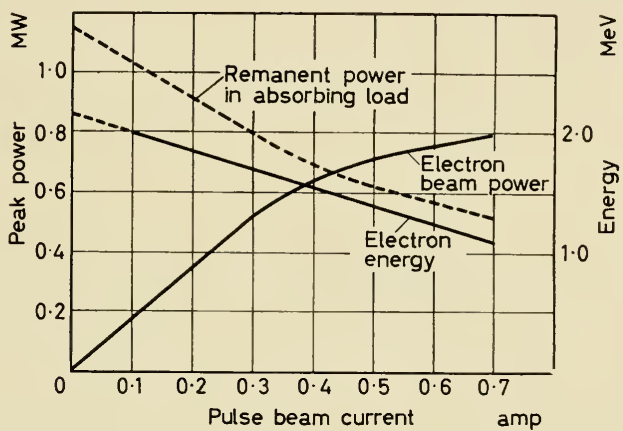

Figure 2. Performance of high current accelerator-input power approximately $1.8 \mathrm{MW}$

(Reproduced by kind permission of C. W. Miller and J. W. Boag)

current voltage and power characteristics of our instrument when the power input is $1.8 \mathrm{MW}$. It is evident that up to $0.7 \mathrm{~A}$ of electron current may be obtained during the $2 \mu \mathrm{sec}$ pulse. Under these conditions the ratio of electron beam power to input power is 0.43 , which is slightly less than the ratio usually obtained in the $4 \mathrm{MeV}$ instruments which employ feedback. Improved injection appears to be the key to any further increase in beam current. A study of the problem of optimum power conversion by Saxon 28 indicates that it should be possible to achieve a ratio of 0.8 to 0.9 in a practical waveguide which does not employ feedback.

As supplied by the makers, the machine operates with repetitive pulses at frequencies of up to 500 pulses per second. For studies of the kinetics of irradiated chemical and biological systems reproducible single pulses are required. These cannot readily be obtained from the standard modulator which employs resonant charging of the pulse forming network. To obtain single pulses, the pulse forming network is therefore trickle charged to $20 \mathrm{kV}$ from a low power D.C. rectifier set, the discharge being effected through the usual hydrogen thyratron, to which a single triggering pulse can be applied.

For certain experiments it was desired to obtain a pair of similar pulses separated by an interval which could be varied from a few microseconds upwards. Since the shorter intervals allow no time for recharging the pulse 
forming network, a second identical network was provided which could be trickle charged from the same $20 \mathrm{kV}$ power pack and discharged independently through the pulse transformer by means of a separate hydrogen thyratron. Trigger pulses at the desired spacing applied to the two hydrogen thyratrons then give twin output pulses of identical size and form, but variable spacing. The changeover from repetitive pulses to single or twin pulses is effected by a single switch on the master oscillator pancl, and this rapid changeover is very convenient since it is usually necessary to run briefly on repetitive pulses in order to degas the guide immediately prior to single or twin pulses. During this degassing the gun filament is off and the gun itself is disconnected from the pulse transformer by a servo operated switch in order to eliminate dark current.

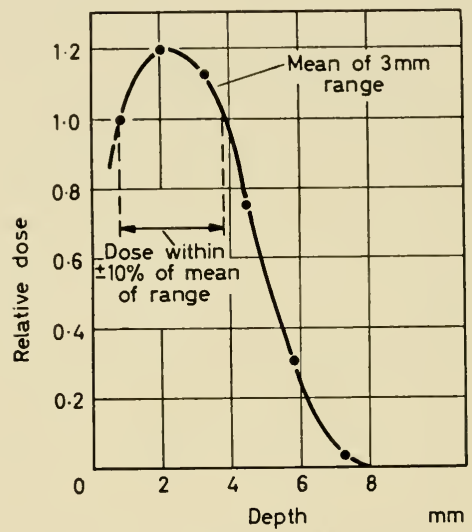

Figure 3. Depth dose for $1.4 \mathrm{MeV}^{\prime}$ electrons in Perspex

(Reproduced by kind permission of C.W. Miller and J.W. Boag)

Any chosen number of pulses between 2 and 99 can also be delivered by means of a twin-Dekatron pulse selector which stops the master oscillator when the chosen number of pulses has been delivered.

A magnetic holding field is provided by low voltage high current solenoids surrounding the accelerating structure. These provide an axial magnetic field which is 600 gauss near the input and tapers to a low value at the output end of the machine. With this arrangement 50 per cent of the total electron current of $0.7 \mathrm{~A}\left(\right.$ at $\left.1.1 \mathrm{MeV}^{\mathrm{V}}\right)$ emerges through a thin aluminium window within an $8 \mathrm{~mm}$ diameter circle. Scattering in the window and in the air spreads the beam rapidly and the radial current distribution at any distance $z$ along the axis may be represented very closely by a Gaussian curve. Measurements of the radial distribution of dose rate at different distances from the window have been made by irradiating small pieces of Perspex arranged across the beam, and measuring the induced u.v. absorption relative to a control. This technique has been calibrated calorimetrically ${ }^{29}$ and yields rapid and reproducible estimates of dose. A typical depth dose curve 


\section{H. GRAY}

taken by irradiating a stack of thin slips of Perspex in a broad beam is shown in Figure 3. It can be seen that when the machine is operated at $1.5 \mathrm{MeV}$ a layer of Perspex $3 \mathrm{~mm}$ thick, or about $0.4 \mathrm{~g} / \mathrm{cm}^{2}$ of any similar material, lying about the peak of the curve, received a dose lying within \pm 10 per cent of the mean. The maximum dose which can be delivered in a single pulse close to the window, when using the electron beam without external focusing, is of the order of $10^{5} \mathrm{rad}$ and the mass of material receiving this dose is about $0 \cdot 25 \mathrm{~g}$. This corresponds to a maximum dose rate during the $2 \mu \mathrm{sec}$ pulse of some $5 \times 10^{10} \mathrm{rad} / \mathrm{sec}$. For certain purposes it is desirable to have an even more concentrated electron beam and auxiliary quadrupole focusing magnets have therefore been constructed, following a design due to M. C. Crowley-Milling. Two permanent magnet quadrupole lenses, each of which brings the beam to a sharp line focus, are combined at the appropriate spacing to give a reasonably good point focus. With this arrangement, about 50 per cent of the beam current can be made to pass through a circle of $2 \mathrm{~mm}$ diameter at the exit window and the dose in a single pulse at this point is then of the order of $10^{6} \mathrm{rad}$ to a mass of about $0.01 \mathrm{~g}$.

\section{Analytical Systems}

\section{Light and u.v. spectroscopy}

Spectrographic examination of the living cell is rendered difficult by the large amount of unspecific scattering which usually results from differences in refractive index between the cell and the medium in which it is suspended. Nevertheless, certain pigment molecules having relatively high molecular extinction coefficients have been extensively studied in yeast, bacteria, and ascites tumour cells. Quantitative studies of the proportion of each member of the cytochrome enzyme chain which is in the oxidized and reduced state at a given time, have been carried out by the use of the very beautiful double beam method of Britton Chance ${ }^{30}$. It is evident that by means of single microsecond pulses it is quite possible to irradiate the cell when the cytochrome system is in known intermediate Redox conditions between those corresponding to aeration and to complete anoxia. It is not impossible that molecular species generated by the action of ionizing radiation might be studied spectroscopically by methods similar to those employed by Britton Chance, and that short-lived species might be studied by flash spectroscopy.

So far, our own experience of flash spectroscopy is limited to a preliminary investigation of the kinetics of the oxidation of ferrous sulphate, about which a good deal is already known from the analysis of steady states. For this purpose, Dr. Boag ${ }^{31}$ has developed a light source which goes a long way to fulfilling most of the desirable characteristics, namely that the duration of the flash should be of the order of a few microseconds, that the spectrum should be continuous extending well into the u.v., that the source should have high intrinsic brilliance for efficient utilization of the light in an optical system, and adequate output for photographic recording of a spectrum with a single flash. In Boag's design an energy of about $1 \mathrm{~J}$ is stored in a titanite (specific inductive capacity s.i.c. 1,000) capacitor, charged to $12 \mathrm{kV}$. When connected through a trigger spark gap in air to uranium electrodes in a water filled metal envelope with a quartz window, an underwater spark is formed which lasts about $10 \mu \mathrm{sec}$ and gives a strong continuous spectrum. 
R.IDHOBIOLOGICAL MECHANISM NT THE CLLLLLAR LEVEL,

The duration of the spark could probably be reduced to as little as 1 to 2 usec. Preliminary studies* of the kinetics of the ferrous sulphate oxidation reveal, as expected, a large part of the total yield of ferric iron to have occurred during the post-irradiation period. The maximum dose available at the time in a single pulse from the accelerator used for these studies was $3,000 \mathrm{rad}$. It was evident that considerably larger doses were desirable for an extensive study of the kinetics of radiation-induced reactions in solutions. The work is being continued with the larger pulses available from the electron pulse generator described above.

When electrons of energy greater than about $0.4 \mathrm{MeV}$ enter water, they generate the so-called Cerenkov radiation. This radiation extends as a continuous spectrum throughout the visible and u.v. and is emitted in a forward direction at an angle to the direction of movement of the electron which depends on the electron energy. This light has been ingeniously used by Boag to look for evidence of radicals formed by the decomposition of water. For this purpose the quadrupole focusing magnets referred to earlier were employed so as to concentrate the electron beam proceeding from the accelerator into a fine pencil before it emerged through the aluminium window. Cerenkov radiation is rather weak, and with the optical arrangement employed about 50 pulses were needed in order to obtain adequate blackening in a Hilger Intermediate Spectograph (E486). A spectrum has been observed which consisted of groups of absorption bands extending throughout the visible and u.v. to $2300 \AA$ at least. The spacing of individual maxima was some $50 \mathrm{~cm}^{-1}$ while groups of bands were separated by about $500 \mathrm{~cm}^{-1}$. The spectrum has not been identified.

\section{Electron spin resonance spectroscopy}

Free radicals were discussed more than 30 years ago as possible intermediates in gas-phase photochemical reactions, and the existence of a free radical is generally considered to have been first convincingly demonstrated by Paneth and Hofeditz ${ }^{32}$ in the course of their study of the decomposition of tetramethyl lead. A little later free radicals were recognized to play an important role as intermediates in ordinary temperature liquid-phase reactions. In 1944 Weiss $^{33}$ put forward the view that radiation-induced reactions in aqueous solution proceed from the initial formation of the two radicals $\mathrm{H} \cdot$ and $\mathrm{OH} \cdot$, and from that time the radiation chemistry of liquid systems has been written almost entirely in terms of free-radical reactions. Few, however, of the free radicals which have been postulated have actually been identified independently by physical means.

The possibility of such identification resides in the fact that a free radical is intrinsically paramagnetic by virtue of the magnetic moment of the unpaired electrons which correspond physically with the chemical free valency. In the absence of any other quantized magnetic moments with which the moment of the free electron may be coupled, a single unpaired electron has a magnetic moment of $\sqrt{ } / 3$ Bohr magnetons. Thus, since the molar susceptibility $\chi_{\mathbf{M}}=\chi M_{\rho}$ is given by:

$$
\chi_{\mathrm{M}}=N\left(\alpha_{\mathrm{O}}+\mu_{\mathrm{M}}^{2} / 3 k T\right)
$$

* Carricd out in collaboration with Professor Rotblat, using electron pulses from the St. Bartholomew's Hospital $15 \mathrm{MeV}$ Linear Accelerator. 


\section{H. GRAY}

where $M=$ molecular weight, $\rho=$ density, $N=$ Avogadro's number, the paramagnetic term $\mu_{\mathrm{M}}^{2} / 3 k T$ for a material consisting entirely of free radicals would be $1260 \times 10^{-6} \mathrm{c}$.g.s. units at $20^{\circ} \mathrm{C}$. Since the diamagnetic term $\alpha_{\mathrm{O}}$ for most organic materials is not more than 10 per cent of this, paramagnetism is a characteristic property of free radicals. The Theorell balance is said to be capable of measuring a $10^{-3}$ molar concentration of radicals in a $0.02 \mathrm{ml}$. sample with 10 per cent accuracy ${ }^{34}$. If, therefore, all the free radicals formed by radiation in a given material were permanent, and the yield of free radicals was of the order of 1 per $30 \mathrm{eV}$, then exposure to dose levels of the order of 1 megarad would, in the absence of any other change in the magnetic conditions of the sample, produce sufficient paramagnetism to be measured by the Theorell balance. In fact the conditions for such a measurement are not likely often to be fulfilled, even in non-living materials, so other methods of detection have to be employed. The method of electron spin resonance spectroscopy offers considerable promise.

Though first applied to the detection of radicals by Zavoisky ${ }^{35}$ in 1945, some 10 years elapsed before this technique was pressed into the service of radiation chemistry. In 1954 and 1955 papers appeared by Combrisson and Uebersfeld $^{36}$ and by Gordy, Ard, and Shields ${ }^{37}$, on paramagnetism induced by irradiation of organic materials. The latter paper in particular, which was concerned with electron spin resonance studies of $\mathrm{X}$ irradiated amino acids and proteins, marks the beginning of a development in radiation chemistry which is of the greatest interest to radiobiologists.

Detection of radicals by electron spin resonance depends on the fact that the two orientations of a free electron in a magnetic field $H$, namely with and against the field, differ in energy by an amount $E=g \beta H$, so that if an electron which is precessing undisturbed around the direction of a uniform magnetic field $H$ is exposed to an electromagnetic field of frequency $v$ such that $h \nu=$ $g \beta H$, transitions to the higher energy state will occur as a result of resonant absorption of energy from the electro-magnetic wave. On introducing numerical values for the spectroscopic splitting factor, $g=2 \cdot 0023$, and for $\beta$ (the value of the Bohr magneton) $=0.92710^{-20} \mathrm{erg} /$ gauss, it becomes evident that resonant absorption will occur when a $3 \mathrm{~cm}$ wave passes through a material containing free radicals situated in a magnetic field of about 3600 gauss.

In general, there may be some interaction, and therefore some coupling, between the spin magnetic moment of the electron, its orbital magnetic moment, and the nuclear magnetic moment, if any, of the nuclei with which the unpaired electron is associated. The latter interaction gives rise to hyperfine structure of the energy levels whereby a particular type of free radical may be recognized. The absorption spectrum of the radical is usually presented as a function of magnetic field at fixed frequency, or as the first differential of this function.

This method of measuring free radicals is not only very much more sensitive than the Theorell balance and similar methods, but has a number of features of particular interest to radiobiologists. Chief of these are perhaps: (1) That it is applicable to the study of radicals formed in living cells, suspended if necessary in an aqueous medium.

(2) Quantitative work is not in general confused either by the diamagnetism 


\section{RADIOBIOI,OGICAL MECHANISM AT THE CELLULAR LIVLL}

of the bulk of the specimen or the paramagnetism of elements such as iron, manganese, and oxygen.

(3) That in favourable circumstances some information can be obtained about the nature of the free radicals as well as about the numbers present.

(t) The method offers a possibility in principle of examining the kinetics of radical reactions in living systems at short intervals of time after irradiation.

The fraction of the energy of a resonant electromagnetic wave which is removed by even a millimolar concentration of radicals in a $100 \mathrm{mg}$ specimen, is exceedingly small, and the art of the spectroscopist consists in achieving such stability of operation that when the incident and absorbed waves are balanced in some kind of null disposition, the difference between them stands out above the 'background noise' and may be amplified and recorded. Instrumentation has been dealt with comprehensively by a number of authors, including Gordy, Smith, and Trambarulo ${ }^{38}$ and Ingram $^{39}$.

We have not considered our own electron spin resonance spectrometer, which has been built in the laboratory at comparatively low cost, to be in any way remarkable. It uses $3.2 \mathrm{~cm}$ waves $(9375 \mathrm{Mc})$ generated by a $723 \mathrm{~A} / \mathrm{B}$ Klystron and employs a superheterodyne detection system. The main Klystron is stabilized by an automatic frequency correction circuit in which the sample cavity itself is used as a standard of reference. The local oscillator operates with a frequency $60 \mathrm{Mc}$ different from the main oscillator, and this difference in frequency is amplified and passed to a phase sensitive detector modulated to $180 \mathrm{c} / \mathrm{sec}$, and thence to a pen recorder. The magnet at present in use is very small and inexpensive. A steady field of some 3300 gauss is produced by permanent magnets behind the pole pieces. These are initially magnetized in situ, and the magnetizing coils are then used to vary the field by \pm 300 gauss. The pole diameter is only $2 \cdot 5 \mathrm{in}$. and the gap $1 \mathrm{in}$., but by the use of Rose shims the field variation on the central plane near the axis is kept below 1 part in $10^{4}$ over a region $5 \mathrm{~mm}$ in diameter. The sample is usually smaller than this.

To the radiobiologist the important figure of merit of any equipment would be the smallest number of radicals in a specimen of given size which can be estimated with a given accuracy. Such figures are to be found in the literature but they are not always very meaningful. Since the number of spins which have contributed to a given signal is proportional to the area of an absorption spectrum, sensitivity depends on the shape of the spectrum, being greatest when most of the absorption lies within one or two sharp peaks as is the case with the stable free radical diphenyl picrichydrazyl (DPPH) and with irradiated glycine, and least for a broad structureless band such as is obtained by irradiating seeds. Indeed, it is probable that many of the radicals formed by the irradiation of biological materials escape detection altogether.

The performance of different types of equipment may be compared on the basis of the signal noise ratio for a standard paramagnetic substance such as a manganese salt which gives a six line spectrum, or DPPH which gives a single sharp peak. Commoner et al. ${ }^{40}$ quote their limit of detection as 0.04 
ml. of a $10^{-5}$ molar aqueous solution of $\mathrm{Mn}^{++}$, i.e. $2 \cdot 4 \times 10^{14}$ spins. Conger and Randolph ${ }^{41}$ quote $3 \times 10^{13}$ radicals of DPPH as giving the 'minimum detectable signal'. The corresponding figure quoted by Hirshon and Fraenkel ${ }^{42}$ is $10^{13}$ radicals. Our own equipment gives about $10: 1$ signal/ noise ratio with $10^{15}$ radicals of DPPH. Figures of this kind can at present be taken only as rough order of magnitude estimates. The theoretical limit of sensitivity has been computed by Fraenkel ${ }^{43}$ as $10^{10}$ spins $\left(2 \cdot 10^{-14}\right.$ moles $)$ at a concentration of $10^{-8}$ to $10^{-10}$ moles $/ 1$.

Perhaps the best indication of the useful levels of sensitivity so far achieved is given by the minimum dose for which quantitative results have been reported by different workers, viz. barley seeds $50 \mathrm{kr}^{44}$, wheat germ (150 $\mathrm{mg}$ sample) $10 \mathrm{kr}^{41}$, and glycine $2 \mathrm{kr}^{44}$. The many problems associated with the use of quantitative electron spin resonance spectroscopy for evaluating radical yields in irradiated materials have been discussed informatively by Zimmer, Ehrenberg, and Ehrenberg ${ }^{44}$, Zimmer ${ }^{45}$, and Livingston ${ }^{46}$.

As mentioned above, radicals only show hyperfine structure when the unpaired electron is associated to some degree with nuclei which have a magnetic moment. As far as biological materials are concerned, this excludes ${ }^{12} \mathrm{C},{ }^{16} \mathrm{O},{ }^{31} \mathrm{P}$, and ${ }^{32} \mathrm{~S}$, and leaves only ${ }^{1} \mathrm{H}$ and ${ }^{14} \mathrm{~N}$ among the major constituents of tissue. However, the nuclei ${ }^{2} \mathrm{H},{ }^{13} \mathrm{C}(0.5$ per cent abundance), ${ }^{17} \mathrm{O}$, and ${ }^{33} \mathrm{~S}$ ( 1 per cent abundance) have magnetic moment, and these isotopes may prove useful. Smaller and Avery ${ }^{47}$ have used the differences between the spectra which result from irradiation of normal and of deuterated yeast to good effect in analysing radicals formed in the water and in the organic constituents of the cell. It should be noted, however, that while biological systems are not in general greatly disturbed by growth in up to 20 per cent heavy water, a sharp toxicity often sets in at about the 40 per cent level ${ }^{48}$. It is also to be noted that Laser has reported ${ }^{49}$ that when $E$. coli $B$. is irradiated in $\mathrm{D}_{2} \mathrm{O}$ the ratio of aerobic to anaerobic sensitivity is increased from the usual $2 \cdot 5: 1$ to about $8: 1$.

It is in some ways unfortunate that oxygen, which is a paramagnetic molecule and a bi-radical, does not give an observable spectrum except in the gas phase at low pressures ${ }^{50,51,52}$. The coupling of the electron spin to the molecular axis of oxygen produces a complicated set of magnetic energy levels that depend on the rotational state of the molecule. Since the perturbations caused by collisions are not sufficiently strong to break down the coupling but do broaden the rotational levels, no spectrum is observed at high pressures or in solution ${ }^{43}$.

One of the most exciting things about the communication from Gordy et al. in 1955, to which reference has been made above ${ }^{37}$, was that all the amino acids which had been examined gave rise on examination to paramagnetic centres with distinguishable spectra. The second was that proteins did not show the expected superposition of spectra corresponding to the component amino acids. Some of the sulphur-containing proteins showed no peaks corresponding to many of the constituent amino acids, but instead, a rather simple spectrum closely resembling that of irradiated cystine, suggesting that though the atoms originally ionized and excited must have been distributed in a random manner among all the amino acids, the free radicals appear preferentially in the cystine. This internal 'protection' 
by sulphur groups accords with Eldjarn's interpretation of some aspects of cysteamine protection ${ }^{53}$.

As a result of the systcmatic study of irradiated amino acids and proteins by the group at Duke University, it is believed that the observed spectra can now be interpreted with much greater assurance ${ }^{54}$, but the subject of electron spin resonance spectroscopy is still at a stage when quite divergent interpretations are possible. Blumenfeld and Kalmanson ${ }^{55}$, for example, make the interesting suggestion that the very small signal which they observed in irradiated native protein, as compared with that from irradiated denatured protein, is due to the existence of conduction bands in the native protein. As in other branches of spectroscopy, confident interpretation of spectra is a goal which will be approached asymptotically.

In the meantime much can be learnt from the study of the influence of physical factors on the strength of signals of unknown origin. Some very beautiful examples are provided in the field of photosynthesis through the study of the paramagnetism of chloroplasts as a function of time and intensity of illumination ${ }^{40}$. In radiobiology an interesting set of correlations has been established between the sensitivity of seeds to radiation and factors such as their water content at the time of irradiation, storage time, and the oxygen content of the water in which they are germinated. When the electron spin resonance signal from irradiated seed is examined, the signal strength is found to depend on water content over the same range as that which influences radio-sensitivity. The signal decays with time, and an inter-relation exists between water and oxygen as in their effects on radio-sensitivity ${ }^{\mathbf{4 1 , 4 1}}$. Remembering that some of the criteria of radiobiological damage almost certainly reflect chromosomal lesions, whereas the broad signal obtained from the irradiated seed may well be a superposition of signals from a great variety of organic radicals, we should not necessarily expect complete correspondence, and it would not have been surprising if no correspondence had been found at all. The results, therefore, suggest that irradiated seedsand irradiated spores which Powers et al. ${ }^{56}$ have found to exhibit a most interesting temperature-oxygen interdependence-merit further study by electron spin resonance spectroscopy.

Seeds are the materials of choice for current investigations because of the slow rate of change of electron spin resonance signal with time in these 'near dry' systems, and the same may be true of spores. Even in barley seed, however, some important resonances may have decayed during the period of irradiation. Conger and Randolph ${ }^{41}$ estimate a decay in wheat germ of 15 per cent in the first $45 \mathrm{~min}$. Zimmer et al. ${ }^{44}$ estimate a decay of 50 per cent in the first hour in grass seed. Higher dose rates than those employed in these investigations would have been advantageous.

Present indications are that although the radio-sensitivity of systems of low water content is very interesting, it is essentially different in a number of important respects from that of cells which compose most mammalian and plant tissucs. The goal as far as the radiobiological application of electron spin resonance spectroscopy is concerned, must remain the examination of the common cell types. For this purpose it will almost certainly be necessary to deliver the total dose in a single pulse of very short duration. As mentioned earlier, this facility is already available for pulse lengths down to $2 \mu \mathrm{sec}$. 


\section{H. GRAY}

Shorter pulses could probably be delivered without difficulty at the same dose rate, i.e. at a proportionate sacrifice of the upper limit of total dose. The spectrometer under construction for this work in our laboratory will have an air-core magnet, since it would be very difficult with conventional spectrometer design, to expose the specimen in the waveguide in the electron beam which had to traverse the gap between the poles across the transverse magnetic field. The tolerance in radial variation in magnetic field is so tight that it is doubtful whether the electron beam could be made to enter down the axis of the poles.

The irradiation of specimens in situ in the waveguide, and the recording of transient electron spin resonance signals, will no doubt pose many problems, both in instrumentation and interpretation, but we are of opinion that a determined attempt should be made to explore this unknown territory.

\section{REFERENCES}

${ }^{1}$ Giles, N. H. Jr., de Serres, F. J. and Partridge, C. W. H. Ann. N.Y. Acad. Sci. 59 (1955) 536

${ }^{2}$ Muller, H. J. and Oster, I. I. Advances in Radiobiology (Ed. G. Hevesy, A. Forssberg, and J. D. Abbott): Oliver and Boyd, London, 1957, p. 407

${ }^{3}$ Ludford, R. I. 10th Scientific Report of the Imperial Cancer Research Fund: Taylor and Francis, London, 1932, p. 125

${ }^{4}$ Bloom, W., Zirkle, R. E. and Uretz, R. B. Ann. N.Y. Acad. Sci. 59 (1955) 503

${ }^{5}$ Shubick, P., Goldfarb, A. R., Richie, A. C. and Lisco, H. Nature, Lond. 171 (1953) 934

${ }^{6}$ Glucksmann, A. F. Path. Bact. 63 (1951) 176

${ }^{7}$ Lipetz, L. E. Radiation Res. 2 (1955) 306

${ }^{8}$ Lipetz, L. E. Brit. 7 .Ophthal. 39 (1955) 577

${ }^{9}$ BAylor, E. R. and Smith, F. F. Radiation Res. 8 (1958) 466

${ }^{10}$ DAy, M. J. and Stein, G. Radiation Res. 6 (1957) 666

${ }^{11}$ Collinson, E. and Swallow, A. J. Chem. Rev. 56 (1956) 471

${ }^{12} \mathrm{Hug}$, O. Radiation Res. 9 (1958) 131

${ }^{13}$ Hug, O. Strahlentherapie 106 (1958) 155

${ }^{14} \mathrm{Gray}$, L. H. Radiation Res. Supplement 1 (1959) 73

${ }^{15}$ Hug, O. and Wolf, I. Progress in Radiobiology (Ed. J. S. Mitchell, B. E. Holmes and C. L. Smith): Oliver and Boyd, London, 1955, p. 23

${ }^{16}$ Baron, L. S., Spiegelmann, S. and Quastler, H. F. gen. Physiol. 36 (1953) 631

${ }^{17}$ Rouver, M. and Latarjet, R. Ann. Inst. Pasteur 72 (1946) 89

${ }^{18}$ Dewey, D. L. and BoAg, J. W. Nature, Lond. 183 (1959) 1450

${ }^{19}$ Latarjet, R. Ciba Foundation Symposium on Ionizing Radiations and Cell Metabolism (Ed. G. E. W. Wolstenholme and C. H. O’Connor): Churchill, London, 1956, p. 275

${ }^{20}$ Kimball, R. F. Ann. N.Y. Acad. Sci. 59 (1955) 638

${ }^{21}$ Adler, H. I. and Stapleton, G. E. Radiation Res. 9 (1958) 84

${ }^{22}$ Alper, Tikvah Brit. 7. Radiol. N.S. 27 (1954) 50

${ }^{23}$ Marcovich, M. H. Proceedings of the First Conference on the Peaceful Uses of Atomic Energy, 11, Geneva, 1955

${ }^{24}$ Kotval, J. P. and Gray, L. H. 7. Genet. 48 (1947) 135

${ }^{25}$ Miller, C. W. and Boag, J. W. Proceedings of the Second International Conference on the Peaceful Uses of Atomic Energy, Geneva, 1958

${ }^{26}$ Miller, C. W. Engineering, Lond. 80 (1955) 340 and 374; reprinted-Metropolitan Vickers Electrical Co. Ltd. Research Series, No. 19 
RADIOBIOLOGICAI, MECHANISM AT THI CELLULAR LEVEL

27 Milci:R, C. W. and Howard-I'Landers, P. Metropolitan Vickers Electrical Co. Ltd. Gazette (1953) December

${ }^{28}$ Saxon, G. Proc. phys. Soc. Lond. B 67 (1954) 705

${ }^{29}$ Bong, J. W.. Dolpiin, G. W. and Rotblat, J. Radiation Res. 9 (1958) 587

${ }^{30}$ Chince, B. Rel'. sci. Instrum. 22 (1951) 619

${ }^{31}$ BoAg, J. W. Mineria med., Paris (1957) 109

32 Paneth, F. and Hofeditz, W. Ber. disch. chem. Gires. 62 (1929) 1335

${ }^{33}$ WEIss, J. Nature, Lond. 153 (1944) 748

${ }^{34}$ Waluing, C. Free Radicals in Solution: John Wiley, New York, 1957

${ }^{35}$ Zavoisky, E. J. Phys., Moscow 9 (1945) 211

${ }^{36}$ Combrisson, J. and Uebersfeld, J. C. R. Acad. Sci., Paris 238 (1954) 1397

${ }^{37}$ Gordr. W., Ard, W. B. and Shields, H. Proc. nat. Acad. Sci., Wash., 41 (1955) 983

${ }^{38}$ Gordy, W., Smith, W. V. and Trambarulo, R. Microwave Spectroscopy: John Wiley, New York, 1953

${ }^{39}$ Ingram, D. J. E. Spectroscopy at Radio and Microwaze Frequencies: Butterworths, London, 1955

${ }^{40}$ Commoner, B., Heise, J. J. and Townsend, J. Proc. nat. Acad. Sci., Wash. 42 (1956) 710

${ }^{4}$ Conger, A. D., Randolph, M. L., Sheppard, C. W. and Luippold, H. J. Radiation Res. 9 (1958) 525

${ }^{42}$ Hirshon, J. M. and Fraenkel, G. K. Rev. sci. Instrum. 26 (1955) 34

${ }^{43}$ Fraenkel, G. K. Ann. N.Y. Acad. Sci. 67 (1957) 546

${ }^{44}$ Zimmer, K. G., Ehrenberg, L. and Ehrenberg, A. Strahlentherapie 103 (1957) 1

${ }^{45}$ Zimmer, K. G. Radiation Res. Supplement 1 (1959) 463

${ }^{46}$ Livingston, R. Radiation Res. Supplement 1 (1959) 463

47 Smaller, B. and Avery, E. C. Nature, Lond. 183 (1959) 539

${ }^{48}$ Bennet, E. L., Calvin, M., Holm-Hanson, O., Hughes, A. M., Lonberg-Holm, K. K., Moses, V. and Tolbert, B. M. Proceedings of the Second International Conference on the Peaceful Uses of Atomic Energy, Geneva, 1958

${ }^{49}$ LASER, H. Radiation Res. 9 (1958) 142

${ }^{50}$ Beringer, R. and Castle, J. G. JR. Phys. Rev. 75 (1949) 1963

${ }^{51}$ Beringer, R. and Castle, J. G. Jr. Phys. Rev. 81 (1951) 82

52 Tinkham, M. and Strandberg, M. W. P. Phys. Rev. 97 (1955) 937, 951; Phys. Rev. 99 (1955) 537

${ }^{53}$ Eldjarn, L., Pihl, A. and Shapiro, B. Proceedings of the First International Conference on the Peaceful Uses of Atomic Energy, 11, Geneva, 1955, p. 335

${ }^{54}$ SHIELDS, H. and GORDY, W. Electron spin resonance studies of radiation damage to amino acids: Duke Microwave Laboratory publication, 1958

${ }^{55}$ Blumenfeld, L. A. and Kalmanson, A. E. Proceedings of the Second International Conference on the Peaceful Uses of Atomic Energy, Geneva, 1958

${ }^{56}$ Powers, E. L., Webb, R. B. and Ehret, C. F. Cap. Cell. Res.-in the Press

\section{DISGUSSION}

DR. MARTIN: If one alters the pulse length, presumably all that happens is that a change in the slope of these oxygen and nitrogen curves occurs?

Dr. GraY: A lengthening of the pulse would prolong the time during which the cell is devoid of oxygen but would not change the fraction of the dose given under anaerobic conditions until the length of the pulse became comparable with the time requircd for a significant amount of fresh oxygen to reach the requircd site. We cannot conveniently change the length of our pulses, but we can give two pulses separated by a variable interval. The use of double pulses would probably be a 


\section{DISCUSSION}

convenient way of investigating the point you have in mind and might give results which are easier to interpret.

DR. WATson: At the beginning of this lecture you referred to the question raised by Sir Macfarlane Burnet concerning the linearity of dose response relations. Dr. Gray gave three examples, of which the first was a virus. I think it is true to say that not all viruses are inactivated in the way Dr. Gray indicated. The second was induction of the lysogenic state in bacteria, and the third was the induction of chromosome structural damage. Now, there is a common feature in all these-they are organized structures-and it would be unfair to argue from them to the general case of any cells. Is that correct?

Dr. Gray: I have not discussed which forms of radiobiological damage are or are not likely to show a linear dose response relation. My purpose was to indicate conditions under which an extrapolation can usefully be made if it had already been demonstrated experimentally that the dose response relation was linear down to the lowest doses investigated. Have I answered your question or not?

Dr. WAtson: That is perfectly clear. I was just going to point out that in fact these three are special types of structure as opposed to an ordinary cell, and that there is, in fact, no evidence of any kind which would suggest linear relations within an ordinary cell-a complete cell.

Dr. Gray: The chromosome structural damage and the induction of lysogeny to which I referred were both initiated in cells, namely, microspores and bacteria respectively. These examples of what I believe to be established linear dose relationships came to mind. I do not generalize to other types of cell, though it is my belief that these examples are not in fact unique.

DR. LoutiT: I should like to ask Dr. Gray in this connection whether Homer has nodded or not. On the board he warns us, very rightly, against too facile interpretation of linear log graphs, and then as one of his examples of biological response to a single physical event he showed Marcovich's data of which the ordinate was in logs. He was unable to show the abscissa, but that is also in logs.

DR. GRAY: I am sorry about that.

DR. LoutiT: In fact, my statistician has replotted this on a linear scale and the points are highly significantly not linear.

Dr. GraY: Is the relation not linear at the $1 \mathrm{r}$ level?

Dr. Loutit : It is not linear at the low dose level. There is a definite curvature like a two-headed curve just at the point where we are interested in it.

Dr. Gray: Well, this one is evidently not a very good example. I am sorry. I will withdraw this example pending further examination of Marcovich's data.

Note added later: Marcovich presented his data as a $\log / \log$ plot. This is a satisfactory way of testing for linearity since if strict proportionality exists between two variables, the $\log / \log$ plot will be a straight line. It is not quite as satisfactory as a simple plot of one variable against the other because lack of strict proportionality between the variables may leave the $\log / \log$ plot linear, and the lack of proportionality must be detected by the fact that the straight line is not at $45^{\circ}$ to the axes. The $\log / \log$ plot is not open to the objection which I raised against a linear log plot, which inevitably presents the appearance of a threshold when the variables are linearly related.

I have re-examined Marcovich's data, and cannot find, from a statistical examination of the average of the results obtained in all experiments, any indication of departure from proportionality between the dose and the number of bacteria in which the lysogenic transformation was induced. 
R.ADIOBIOLOGICAL MECHANISM AT THE CELLULAR LEVEL

MR. JACKson: I was considering the possibility that when a cell is irradiated two chain reactions are initiated, one involving inorganic radicals and another involving organic molecules leading to a production of organic peroxides, so that the response to a small pulse might be influenced by a preceding exposure to a large pulse. Could this be investigated by means of your Generator?

Dr. GraY: Yes, I think it could. We have many things we should like to do. I think this might be illuminating. 


\section{INDEX}

Italicized page numbers indicate that the subject is referred to on subsequent pages.

Acetic acid, radiation synthesis of, 109

Adrenalin, radio-protective action of, 184

Alanine, radiation synthesis of, 109

Alfalfa-see lucerne.

Allium cepa, irradiation of seeds, 190

$\alpha$-rays, sensitivity of cells to, oxygen effect on, 165

Amino acids, irradiation of, 295

radiation synthesis of, 109

Anaemia, 236

following injection of isotopic material, 56

Annealing, radiation induced, 275

Aspartic acid, radiation synthesis of, 109

Atomic Bomb Casualty Commission, 16

Atomic weapon tests, in Australia, 132, 138

Christmas Island, 132

Marshall Islands, 132

U.S.A., 139

ATP, 175

Atropine, inhibitive action of on radioprotective agents, 174

Australian Atomic Weapons Safety Committee, 127, 138

Autografts - see grafts.

Auxin, radio-protective action of, 173

Azide, enhancement of X-ray damage by, 162,264

BAL, radio-protective action of, 203

$\mathrm{BAS}$, inhibitive action of on radio-protective agents, 175

Bacteria, irradiation of, 153, 285

Benzene, irradiation of in chlorine, 106

$\beta$-rays, dose of and attempted replacement of bone marrow in the rabbit, 59

effect of on porphyrin compounds, 95 simple organic compounds, 89

skin carcinogenesis, 284

synthesis of organic compounds by, 105

Blood, effects of irradiation on, 37, 95

$\mathrm{BOL}$, inhibitive action of on radio-protective agents, 175

Bone, caesium levels, 213

radiation damage to, 153

strontium levels, I43, 213

uptake of calcium and strontium, 119, I43

Bone marrow, radiation damage to, 153 uptake of ${ }^{198} \mathrm{Au}$ by, 58

Bone-marrow dose, annual mean, 15

assesment of in diagnostic radiology, 30

Bone-marrow grafting, protective action of, $47,56,69,74,223,236$

secondary radiation disease following, 48 , 73

${ }^{137}$ Caesium, as source of irradiation, 37, 111 in human food chain, 213
Calcium, absorption and excretion of, 118 levels in bone, 119 plasma, 120

metabolism of, 119

Calcium-strontium ratios, in human food chain, 217

growing child and adult, 123

infants, 123

soils and pastures, 214

still-births, 121

Cancer-see tumours.

Carcinogenesis, 284

Catalase, 85, 286

Catalysis, radiation, 107

Cavity theory of ionization, 2

Cells, irradiation of, $5,37,76,152,190,253$, 282

Cheese-cloth method of airborne fall-out collection, 128

Cholesterol, irradiation of, 106

Christmas Island Tests, 132

Chromosome aberrations, radiation induced, 9,282

effect of oxygen tension on, $76,152,190$ 253

in germ cell stages of Drosophila melanogaster, 253

in leukaemia, 17, 20

in seeds of Allium cepa, 190

in Tradescantia microspores, 9

Clonal selection theory, 236

Clover, uptake of radio-active isotopes by, 215

${ }^{60}$ Cobalt, as source of irradiation, 19, 39, 73, 163,221

Co-enzyme A, 6

Contamination, radioactive,

build up on ground, 136, 138, 212,

in laboratories, 147

on soils, and pasture, 212

ingestion and inhalation of, 148

Copper, irradiation of, 273, 275

Cow, uptake of radio-active iodine, 142

isotopes, 118

strontium, 210

Cyanide, and radio-sensitivity, 79, 157, 161, 180,264

Cystamine, radio-protective action of, 181, 187

Cysteamine, radio-protective action of, 85, $169,172,179,189,296$

Cysteine, radio-protective action of, 169 $179,203,227$

Cytochrome oxidase, 86, 161, 264

Daphnids, radiation induced behaviour of, 285 


\section{INDEX}

$\delta$-rays, $t$

Displacement spike, 275

I) $\times \mathrm{A}, 6,23,15^{2}$ ?

1).N', and radio-sensitivity, 163

1)P'Pll, irradiation of, $29 \cdot 4$

1)rosophila melanogaster, radio-sensitivity of germ cell stages of, 153, 253, 282

Farthed and insulated screen methods of fallout collection, 134

Ehrlich ascites tumour, 76,155

Enzyme molecules, irradiation of, 5 ,

Eusinophil counts, effect of irradiation on, 40

Erythrocyte cells, inoculi, 241

radiation damage to, 153

Escherichia coli, 85, 152, 286

Ethylene, polymerization of by irradiation, 107

Fall-out,

airborne, 136, 138

dating of from continuous change in $\beta$-ray energy distribution, 133

detection of, 127

ground accumulation of, 136, 138, 212

in rainwater, $128,138,210$

measurement of in Australia, 129, 138

methods of collection of, 134,138

Fast neutrons, and incidence of leukaemia, 19

dose, II' value, 2

imperfections induced in solids by, 272

injury and recovery in animals irradiated with, 221

Ferrous sulphate, irradiation of, 165

Fertility, 172, 248

Fission-products, in human food chain, 209 in radio-active fall-out, 127,138 human uptake of, 117

Fluoride, and radio-sensitivity, 162

Foetus, as material for grafts, 73, 237, 242 effects of irradiation on, 16, 153, 248 uptake of calcium and strontium by, 119

Formic acid, radiation synthesis of, 109

Fowl, irradiation of plasma in, 95 leukocyte transplants, 236

Gallus domesticus, plasma, irradiation of, 95 $\gamma$-rays, and incidence of leukaemia, 19

chromosomal structural damage induced by, 162

effect of on simple organic compounds, 89 dose following heterografting, 73

dose from fall-out in Australia, 141

dose, $\mathrm{J} V$ value, 2

dose from and attempted replacement of bone marrow in the rabbit, 59

injury and recovery after irradiation by, 221

synthesis of organic compounds by, 106

Germ-cell stages, irradiation of, 253

Glomerular clearance of calcium and strontium, 120

Glutamic acid, radiation synthesis of, 109

Glutathione, radio-protective action of, 159 , 179
Glycine, radiation synthesis of, 109, 294

Glycolic acid, radiation synthesis of, 109

${ }^{19 \times}$ ( sold, colloidal, as source of irradiation, 57

uptake by liver, bone marrow, spleen, 58

Grafts,

heterografts, secondary radiation disease following, 73

homograft survival following irradiation, 68

of bone marrow following irradiation, 47 , $56,69,74,223$

immunological studies, 236

of skin following irradiation, 68

of speen cells following irradiation, 47, 74, 237

Growth, inhibition of, radiation induced, 8

Gummed-paper method of fall-out collection, 128, 135, 141

Haemin, irradiation of, 95

Haemoglobin count, effects of irradiation on, 40,63

Haemopoietic tissue, as graft material, 15, 47, 221

effects of irradiation on, $26,47,73,153$, 284

Hair, radiation damage to, 153

Heterografts-see grafts.

Histamine, radio-protective action of, 173, 175,184

Homografts-see grafts.

Hydrocarbons, radiolysis of, 87

Hydrogen iodide, from scavenging with iodine, 89

Hydroxybutyric acid, radiation synthesis of, 109

5-hydroxytryptamine, radio-protective action of, $169,179,187$

Immunological, memory, 237

neutrality, 236

response, 68,73

depression of, 236

Index 1, 1a, 37

Industrial synthesis of organic compounds, 105

International Commission on Radiological Protection (1.C.R.P.), 31, 118, 142, 148

International Commission on Radiological Units and Measurements (I.C.R.U.), 1

Intestine, absorption of strontium and calcium by, 119

effects of irradiation on, 62, 221

${ }^{131}$ Iodine, measurements in fall-out in Australia, 142

scavenging with, 89,104

therapy for thyrotoxicosis, 244

lodoacetate, and radio-sensitivity, 161

Ionizing radiation-see irradiation.

Irradiation,

action of on porphyrin compounds, 95 simple organic compounds, 87

damage, nature of, 272

depression of immune response by, 236 


\section{INDEX}

Irradiation-continued

dose, 1

assessment of to bone marrow, 15, 30 gonads, 15

rate, 6

effect of on graft survival, $56,68,73$

mouse foetus, 248

thermal conductivity, 278

thymus function, 26

thyroidal iodide clearance rate, 244

from fall-out in Australia, 127, 141

germ cell mutagens produced by, 190, 253, 268

hazards in laboratories, 147

imperfections produced in solids by, 272 injury and recovery, 221

leukaemia induced by, 15

quality in radiology, 30

synthesis of organic compounds, 103

therapy for ankylosing spondylitis, 16, 30 enlarged thymus, 26

leukaemia, 47

thyrotoxicosis, 244

Kidney, differentiation of between calcium and strontium, 120

Lactic acid, plasma, 179

radiation synthesis of, 109

Laboratory design and practice, 147

Lens, radiation damage to, 153, 159

Leukaemia, chromosomal changes in, 17, 20 distribution with age, 17

induced by ionizing radiation, $15,26,30$, 56

in the mouse, $18,26,47$

treated by irradiation, 47

Leukocyte count, depression of following irradiation, $26,37,62$

Liver, effect of irradiation on, 62 grafting following irradiation, 74 uptake of ${ }^{198} \mathrm{Au}$ by, 58

LSD, inhibitive action on radio-protective agents, 175

Lucerne, uptake of radio-active isotopes by, 215,219

Lymphocyte levels, depression of following irradiation, $26,37,153,187$

Lymphocytosis stimulating factor (L.S.F.), 26

Lymphoid tissue, effects of irradiation on, $26,30,37,47,56$

Maralinga Tests, 132,138

Marshall Islands Tests, 132

Meiosis, 190, 253

Metabolism, of calcium and strontium, 119

Methylene blue, protective action of, 185 , 285

Microspores, irradiation of, 9, 153

Milk, calcium-strontium levels, 123

radio-active caesium in, 213 strontium in, 143, 212

Mitochondria, radiation damage to, 5, 283

Mitosis, 76, 153, 190, 253, 283

Monocyte levels, following irradiation, 37
Monte Bello Islands Tests, 138

Morphine, inhibitive action of on radio-protective agents, 174

Mouse, foetus, irradiation of, 248

heterografts and secondary radiation disease, 73 ,

homograft, survival, 68,237

leukaemia, radiation induced, 15

treated, 47

radio-protective actions of amines in, oxygen influence on, 169, 179

radio-sensitivity of Ehrlich ascites tumour cells, oxygen influence on, 76

thymus function, effects of radiation on, 26

Mutagens, germ cell, 190, 253

Nevada Tests, 139

Neutrophil counts, following irradiation, 40

Nitric oxide, role of in initiating radiobiological damge, 166

scavenging with, 166

Oleic acid, irradiation of, 106

Organic compounds, action of ionizing radiations on, 87,95

synthesis of by ionizing radiations, 103

Oxygen, and irradiation dose effect, 76,152 , $179,187,190,253,285$

Paramecium, radiation damage to, 153

Pastures, radio-active contamination of, 212

Pentane, radiolysis of, 87,91

Perfluoro-compounds, irradiation of, 106

Peritoneal cavity, irradiation of tumour cells in, 81,159

Perspex, irradiation of, 167, 290

Phage, irradiation of, 153

Phenocopies, incidence of following $\mathrm{X}$ irradiation of mouse foetus, 248

${ }^{32}$ Phosphorus, as source of irradiation, 56 uptake of by bone, 57

Photon, 1

Photosynthesis, 296

Plasma, calcium-strontium levels, 121

lactate and pyruvate, 179

porphyrins, irradiation of, 95

Platelet counts, following irradiation, 40

${ }^{239}$ Plutonium, contamination levels in laboratories, 148

Polymerization, by irradiation, 107

Polymers, effect of radiation on, 166, 275

Porphyrins, irradiation of, 95

Promezathine, and radio-protective action of histamine, 175

Proteins, irradiation of, 296

Pyknosis, 187

Pyruvate, plasma, 179

Quartz, irradiation of, 278

Rabbit, bone marrow replacement in 56 skin graft in, 68

Rad, definition of, 1

Radiation-see irradiation. 


\section{INDEX}

Radiologists, blood counts of, 43 incidence of leukacmia in, 16 ;

Radio-protection, 169, 179, 190, 221

Radiolysis, 87, 95, 105 of water, 165

Radium, isotopic, levels of in laboratories, 149

Rainfall, radio-activity in, 127, 138, 210

Rat, immunological studies in, 236 radio-protection in, $169,179,187$

R.B.l., definition of, 7

Reserpine, and release of radio-protective agents, 173

Resistivity, electrical, effect of radiation on, 277

Retina, response of to ionizing radiation, 284

Rice, uptake of radio-activity by, 219

Roots, irradiation of, 6, 153

Rye-grass, uptake of radio-activity by, 215

Scavengers, use of, $88,104,166$

Secondary radiation disease, 48,73

Seeds, irradiation of, 153, 190, 297

Sheep, uptake of fission-products by, 211 radioiodine by, 142

Skin, carcinogenesis of, 284 grafting following irradiation, 68 local irradiation of, 153, 172

Soils, radio-active contamination of, 212

Spectroscopy, electron spin resonance, 292 flash, 291

light, 291

u.v., 291

Spleen, cell inoculi following $\mathrm{X}$ irradiation, 237

grafting following irradiation, 47,74

radiation damage to, 153

radio-protective action of cysteamine in, 189

uptake of ${ }^{198} \mathrm{Au}$ by, 58

Split-dose techniques, 288

effects of, 163,191, 230

Strcptomycin, protective action of in neutron-irradiated mice, 152, 224

Strontium, metabolism of, 119

radio-active, uptake by man and beast, 117

${ }^{90}$ Strontium, as source of irradiation, 95

in human food chain, 209

rainfall, 210

soil and pastures, 143, 211

levels in bone, 143, 213

measurement of in fall-out in Australia, 143

pcrmissible contamination, levels of in laboratories, 149

Succinic acid, radiation synthesis of, 109

Synthesis, biological, following irradiation, 95
Synthesis-continued

of organic compounds by irradiation, 87 , 103

urea, 110

radiation, definition of, 103

Target theory, 109

Thermal conductivity, effect of radiation on, 278

${ }^{232}$ Thorium, levels of in laboratories, 148

Thyroid, build-up of ${ }^{131} 1$ by, 142,244

iodide clearance rate, 244

Thymus, effect of whole-body irradiation on function of, 26

extracts, 26

leukaemia induced by radiation treatment for enlarged, $16,26,30$

radio-protective action of cysteamine in, 189

Tolerance, radiation, 68, 73, 222, 236

Toluene, irradiation of in chlorine, 106

Tradescantia microspores, irradiation of, 8, 163

Transplants-see grafts.

Tritium $\left({ }^{3} \mathrm{H}\right)$, as source of irradiation, 105

Trypsin, 166

Tryptamine, radio-protective action of, 172

1-tryptophan, radio-protective action of, 172

Tumours, mammalian, 76, 153, 284

UNO Scientific Committee on the Effects of Atomic Radiation, 15, 30, 143

Urea, radiation synthesis of, 110

Vicia faba roots, irradiation of, 6,155

Virus, irradiation of, 285

Virus theory of leukaemia induction, 22

White cell counts, following irradiation, 40 , 43

X-rays, and homograft survival, 68 incidence of leukaemia, 15, 30 treatment of leukaemia, 47

behaviour of Daphnids under, 284

cell mutagens produced by, 162, 193, 253

dose, diagnostic assessment of, 30

IV value, 2

$D_{s}$ value, 288

following spleen cell transfer, 237

effect of on mouse foetus, 248 retina, 284

induced damage, oxygen effect on, 76, 153 methods of protection from, $169,179,187$ synthesis of organic compounds by, 110

Yeast, irradiation of, 6,153

${ }^{90}$ Yttrium, as source of irradiation, 95 


